Article

\title{
The Weevil Fauna Preserved in Burmese Amber-Snapshot of a Unique, Extinct Lineage (Coleoptera: Curculionoidea)
}

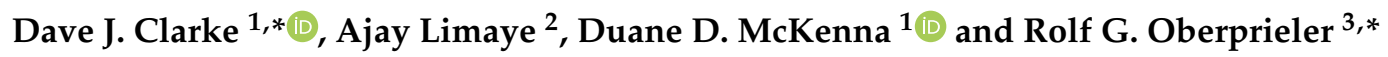 \\ 1 Department of Biological Sciences, University of Memphis, 3700 Walker Ave, Memphis, TN 38152, USA; \\ dmckenna@memphis.edu \\ 2 National Computational Infrastructure, Australian National University, 143 Ward Road, Acton, \\ Canberra, A.C.T. 2601, Australia; Ajay.Limaye@anu.edu.au \\ 3 CSIRO, Australian National Insect Collection, G.P.O. Box 1700, Canberra, A.C.T. 2601, Australia \\ * Correspondence: djclarke@memphis.edu (D.J.C.); rolf.oberprieler@csiro.au (R.G.O.); \\ Tel.: +1-773-573-2000 (D.J.C.) \\ http://zoobank.org/urn:lsid:zoobank.org:pub: 9DAC77A0-D2F8-432D-B0DB-782B9F122C8D \\ Received: 15 November 2018; Accepted: 10 December 2018; Published: 20 December 2018

\begin{abstract}
Only a few weevils have been described from Burmese amber, and although most have been misclassified, they show unusual and specialised characters unknown in extant weevils. In this paper, we present the results of a study of a much larger and more diverse selection of Burmese amber weevils. We prepared all amber blocks to maximise visibility of structures and examined these with high-magnification light microscopy as well as CT scanning (selected specimens). We redescribe most previously described taxa and describe 52 new species in 26 new genera, accompanied by photographs. We compare critical characters of these weevils with those of extant taxa and outline the effects of distortion on their preservation and interpretation. We conclude that only two weevil families are thus far represented in Burmese amber, Nemonychidae and a newly recognised family, Mesophyletidae, which appears closely related to Attelabidae but cannot be accommodated in this family. The geniculate antennae and long rostrum with exodont mandibles of most Mesophyletidae indicate that they were highly specialised phytophages of early angiosperms preserved in the amber, likely ovipositing in flowers or seeds. This weevil fauna appears to represent an extinct mid-Cretaceous ecosystem and fills a critical gap in the fossil record of weevils.
\end{abstract}

Keywords: Curculionoidea; Mesophyletidae; Cretaceous; taxonomy; morphology; CT scanning; amber preparation; angiosperm associations

\section{Introduction}

The beetle superfamily Curculionoidea (weevils) comprises one of the largest diversifications of phytophagous insects and the largest in beetles, and with more than 62,000 species in about 5800 genera $[1,2]$ it is one of the most diverse groups of metazoans. Weevils occur worldwide in all terrestrial habitats with vegetation and feed on all plant parts, some also on fungi associated with decaying plant material [3-5]. An elongated snout, or rostrum, with terminally positioned mouthparts is the quintessential feature of weevils and likely one of several 'key innovations' to which the astonishing taxonomic diversity of the group can be attributed. Weevils have been the subject of numerous recent and ongoing [6] phylogenetic and evolutionary studies, their evolutionary success generally ascribed to their intimate and complex ecological associations with plants (reviewed by [2,7]), and these inferences and insights are increasingly reliant on discoveries and robust interpretations of extinct forms (fossils). 
The first phylogenetic classification system for weevils was devised by G. Kuschel [1], who identified six major lineages (families). This classification differs from non-phylogenetic systems, which generally recognise a larger number of families and subfamilies, e.g., [8-11], but is now consistently reflected in the results of most modern phylogenetic analyses based on morphological or molecular data (e.g., [5,12-15]). The most recent higher-level classification of weevils [6] recognises eight extant families (Cimberididae, Nemonychidae, Anthribidae, Belidae, Attelabidae, Caridae, Brentidae and Curculionidae), raising the previous nemonychid subfamily Cimberidinae to family level. Differences among phylogenetic studies now seem to involve the placement of individual taxa rather than the basal branching patterns [2,13,16] (but see [6]). While few of these eight lineages have identifiable synapomorphies, their morphological definitions are robust, allowing for fossils to be reliably assigned to family group taxa provided sufficient characters are visible and interpretable.

Achieving a robust and densely taxon-sampled phylogeny is crucial for deciphering the complex evolutionary history of weevils $[15,17]$, but such attempts are equally reliant on a robust evaluation of morphological characters-the process of 'painstaking character analysis' [2]—as they are on phylogenomics and the promise these new data bring to fleshing out the weevil phylogeny $[6,18]$. This will provide the greatest chance of successfully incorporating the relatively rich fossil record of weevils into the bigger picture of weevil evolution as well as accurately testing evolutionary hypotheses involving morphological features and life history traits at scales appropriate to the questions being addressed.

The oldest definitive weevil fossils are known from the Upper Jurassic Daohugou and Karatau Lagerstätten in the Northern Hemisphere [19] and the Talbragar Fish Bed of Australia in the Southern Hemisphere (spanning 164-151 Ma in age) [16]. More Lagerstätten yielding weevils are known from the Lower Cretaceous period, the most productive ones being the Yixian Formation in China, the Pedrera de Rubies Formation in Spain and the Crato Formation in Brazil, of Barremian to Aptian age (129-113 Ma), but the number and diversity of weevils from these deposits is much smaller than that of Karatau. Weevil fossils are considerably rarer still in the Upper Cretaceous, few specimens only having been described from the Cenomanian and Turonian stages (100-90 Ma), in French and New Jersey amber and from the kimberlite diatreme at Orapa in Botswana. From the later Upper Cretaceous stages (Coniacian to Maastrichtian) weevil fossils are almost completely unknown, except for a very few poorly preserved specimens. Although weevil fossils are thus known from just before and just after the evolutionarily critical boundary period between the Lower and the Upper Cretaceous, these are far too few and not well enough preserved (most are compression fossils) to allow an assessment of the nature and characteristics of the weevil fauna that existed when the angiosperms began their great radiation [13]. This is changing now that more and more weevils are being recovered from Burmese amber [19], which, dated as $99 \mathrm{Ma}$ [20], was formed just at this time and has also yielded a number of angiosperm fossils that paint a portrait of the flora among which these mid-Cretaceous weevils lived. Moreover, the often exquisite preservation of the Burmese amber weevils allows a much better assessment of their adaptations to this flora than would be possible from compression fossils.

The weevil fossils from the Upper Jurassic and early Lower Cretaceous periods seemingly all represent Cimberididae and/or Nemonychidae, although the identity of groups such as Baissorhynchini remains somewhat uncertain [16]. Anthribidae, Belidae and Caridae are not yet authentically documented from the Mesozoic era and Attelabidae are known only by a single specimen preserved in New Jersey amber $[14,16]$, whereas fossils assigned to Brentidae and Curculionidae are known from the Lower-Cretaceous (Aptian) Crato Formation in Brazil and the early Upper-Cretaceous (Turonian) kimberlite diatreme at Orapa, Botswana [16]. The rich weevil fauna preserved in Burmese amber is also of critical importance in this respect, as it can potentially contribute more authentic early records of several weevil families from the middle of the Cretaceous period.

Burmese amber, known as burmite, is found mainly in the Hukawng Valley in Kachin State, northern Myanmar, although it is also known from several other sites in northern and central Myanmar [21,22]. Most commercially available burmite with inclusions originates from the Noije 
Bum mine near the Tanai township in the Hukawng Valley, and zircons from matrix sediments associated with amber from this mine have been U-Pb-dated as $98.79 \pm 0.62 \mathrm{Ma}$ in age [20]. This date therefore only applies to amber from this mine. Burmite has been mined for many centuries, but the significance of its rich animal and plant inclusions, specifically arthropods, only became recognised two decades ago $[23,24]$. Since then, Burmese amber has yielded an extraordinary number and diversity of insects and other arthropods (e.g., [25], including several extinct ordinal-level taxa, the earliest known representatives of many extant taxa [26] and the greatest diversity of Coleoptera recorded for any Cretaceous amber deposit [27]. Surprisingly, however, few weevils have been described from Burmese amber until now.

The first specimen in burmite to be described as a weevil was named Cryphalites rugosissimus and interpreted as a species of Scolytinae [28]. Its description and illustration are far too poor to ascertain its true identity, but a colour photograph published later supports the assessment that it is not a weevil but likely a colydiine zopherid [23]. The first definite weevil described from burmite is Mesophyletis calhouni Poinar, 2006, an unusual species in possessing geniculate antennae with loosely articulated clubs, exodont mandibles, serrulate tibiae with modified spurs, elongate-slender tarsi with very deeply bilobed third tarsites, and claws with bizarre dentition. Its generic name expresses the difficulty of placing it in any extant family, and a monotypic subfamily, Mesophyletinae, was erected for it, in a family called Eccoptarthridae [29]. Eleven further genera and species were described subsequently in isolated publications, in five different families: Burmonyx zigrasi Davis \& Engel, 2014, Aepyceratus hyperochus Poinar, Brown \& Legalov, 2017 and Burmomacer kirejtshuki Legalov, 2018 in Nemonychidae; Burmocorynus jarzembowskii Legalov, 2018 in Belidae; Mekorhamphus gyralommus Poinar, Brown \& Legalov, 2016 and Habropezus plaisiommus Poinar, Brown \& Legalov, 2016 in Caridae (as 'Ithyceridae'); Anchineus dolichobothris Poinar \& Brown, 2009 in Curculionidae; Burmorhinus georgei Legalov, 2018 in Curculionidae: Erirhininae; Palaeocryptorhynchus burmanus Poinar, 2009 in Curculionidae: Cryptorhynchinae; Microborus inertus Cognato \& Grimaldi, 2009 in Curculionidae: Scolytinae and Palaeotylus femoralis Poinar, Vega \& Legalov, 2018 in Platypodidae. However, very few of these family assignments are credible, because relevant family apomorphies were either not suitably demonstrated or actually misinterpreted. Many of these new taxa are similar to Mesophyletis in having geniculate antennae with loosely articulated clubs and are equally difficult to classify. Most intriguing are the species placed in extant subfamilies of Curculionidae, because dated phylogenetic analyses of weevils indicate these subfamilies to be younger than the middle of the Cretaceous $[6,13,14,30]$. None of these burmite weevil fossils have been re-examined and had their identities and/or provenance verified, which is of key importance for ongoing evolutionary studies of weevils, particularly for divergence time estimation, and some have unfortunately been used uncritically in divergence dating analyses (e.g., [31,32]), with likely significant impacts on resulting evolutionary scenarios [6].

The aim of the present contribution is to document the significant morphological and taxonomic diversity of weevils preserved in Burmese amber. We examine, reinterpret and in many cases redescribe 10 of the 13 Burmese amber fossils previously described as weevils, and we describe and illustrate 52 new species in 26 new genera, the majority belonging to a newly recognised family, Mesophyletidae, characterised by geniculate antennae with loosely articulated 4-segmented clubs and usually exodont and uniquely functioning mandibles, among other characters. A summary of all weevil taxa now known from Burmese amber is presented in an Appendix A. Integral to our goals is synthesising the main morphological characters useful to properly describe and classify weevil fossils and those that are also typically visible in amber fossils, with the intent of providing a crucial resource for future workers seeking to describe weevil fossils. We also touch on other character systems that are critical in the higher classification of weevils but only rarely visible in fossils, and we provide a general classification of morphological artefacts observable in Burmese amber weevils (and applicable to all amber inclusions) resulting from various kinds of degradative processes during and after entrapment and eventual preservation. This is coupled with an overview of the kinds of obscurities present in Burmese amber 
weevil fossils and their impact on observational accuracy. In a second paper we will conduct a phylogenetic analysis of the genera we identify herein, as well as of the family Mesophyletidae.

\section{Materials and Methods}

\subsection{Materials}

The study is based on 95 inclusions (93 examined by us) in as many amber pieces, deposited in the following collections:

$\begin{array}{ll}\text { AMNH } & \text { American Museum of Natural History, New York, U.S.A. } \\ \text { ANIC } & \text { Australian National Insect Collection, Canberra, Australia } \\ \text { CNUB } & \text { Capital Normal University, Beijing, China } \\ \text { FMNH } & \text { Field Museum of Natural History, Chicago, Illinois, U.S.A. } \\ \text { GPIH } & \begin{array}{l}\text { Geological-Palaeontological Institute and Museum, University of Hamburg, } \\ \text { Hamburg, Germany }\end{array} \\ \text { ISEA } & \begin{array}{l}\text { Institute of Systematics and Ecology of Animals, Novosibirsk, Russia } \\ \text { NIGP }\end{array} \\ \text { Nanjing Institute of Geology and Palaeontology, Chinese Academy of Sciences, } \\ \text { PaCO }\end{array}$

We obtained on loan for this study 56 specimens from Professor Bo Wang (NIGP), one from Professor Ren Dong (CNUB), one from Carsten Gröhn (GPIH) and four from private collectors in China, communicated by Yu-Lingzi Zhou (ANIC). One other specimen was purchased online by one of us (R.G.O.; in ANIC), and of another specimen housed in NIGP we received several high-quality images from Chenyang Cai (NIGP) that enabled us to describe the species (Nugatorhinus chenyangi) without having studied the specimen in person. The types of all new species described from these specimens will be deposited in these institutions after study, and the type locality for all of them is the Noije Bum Summit mine, located in the Hukawng Valley, Kachin State, Myanmar.

We also studied the type specimens of all hitherto described species of weevils preserved in Burmese amber, except those of Mesophyletis calhouni and Palaeotylus femoralis. We received the type specimens of Burmonyx zigrasi and Microborus inertus on loan from David Grimaldi (AMNH) and those of Mekorhamphus gyralommus, Burmorhinus georgei, Burmomacer kirejtshuki and Burmocorynus jarzembowskii from Andrei Legalov (ISEA). The types of Aepyceratus hyperochus, Anchineus dolichobothris, Habropezus plaisiommus (holotype and paratype) and Palaeocryptorhynchus burmanus were made available to us for study at Oregon State University. We were unfortunately unsuccessful in obtaining the holotype of Mesophyletis calhouni for study. This specimen was deposited in the amber collection of Ron Buckley, Sumter Ridge, Florence, KY, U.S.A., but in reply to our request to examine or borrow the specimen from Mr. Buckley, we were advised that it had been sold to Deniz Eren in Turkey. Our repeated requests to her to borrow the specimen remained unanswered, and thus it is effectively unavailable for scientific study and verification of the characters of the species. We also did not study the holotype of Paleotylus femoralis, as the description of this species was only published very recently, when our manuscript was already complete; besides, it is amply clear from the photographs and characters of the specimen that it is not a platypodine weevil (see below).

We received another nine specimens from the AMNH and nine more from the FMNH (Shuhei Yamamoto) when this study was already well underway. We examined these to gain a more comprehensive understanding of the diversity of taxa and characters of the Burmese amber weevil fauna, but their amber blocks need to be cut down for a proper study of the specimens, which is planned for a follow-up paper. One of the FMNH specimens evidently belongs in Mesophyletis, thus allowing us to redescribe at least this genus. 


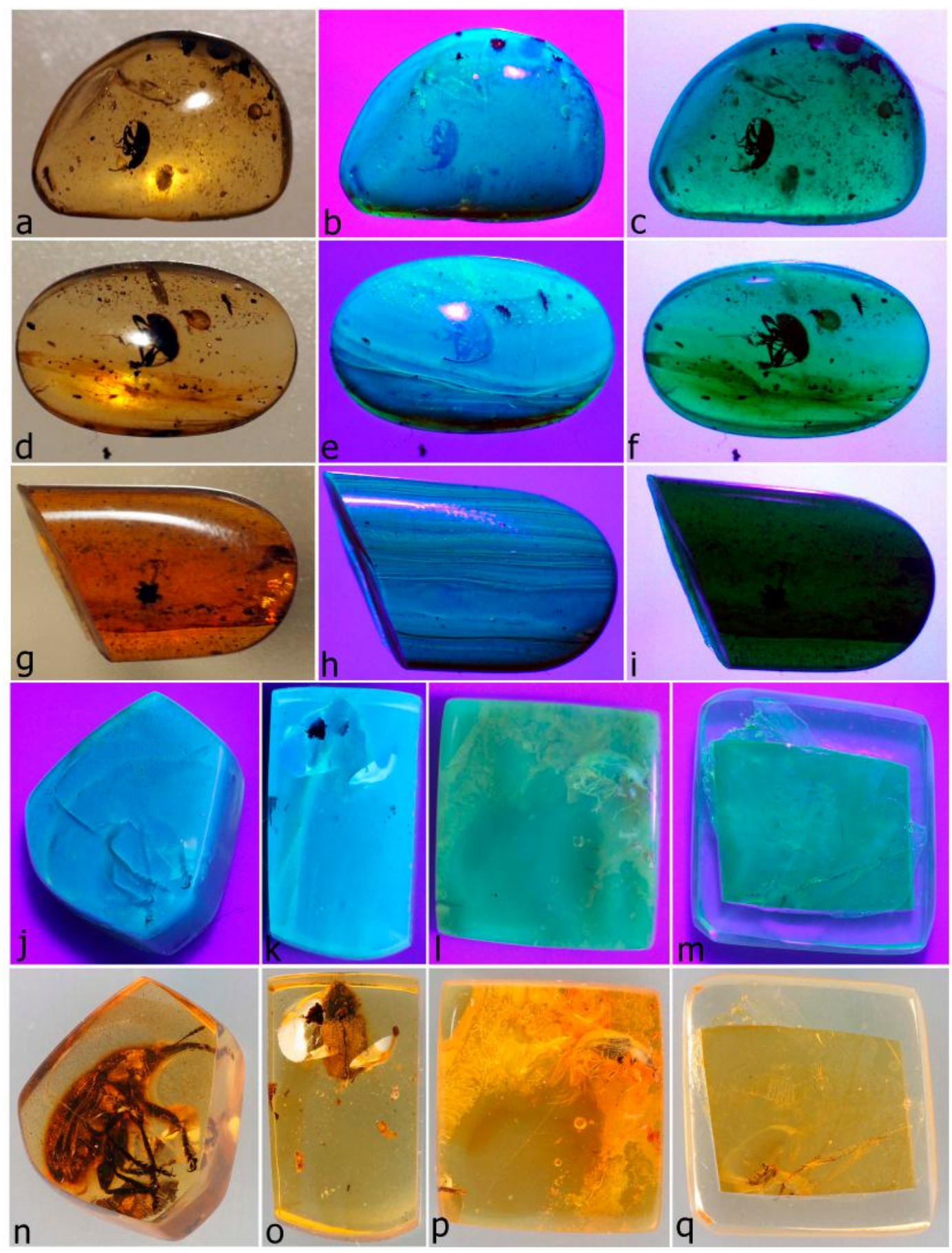

Figure 1. Amber in white light (a,d,g,n-q), incident near-ultraviolet (UVA) $(\mathbf{b}, \mathbf{e}, \mathbf{h}, \mathbf{j}-\mathbf{m})$ and reflected UVA light (c,f,i). Amber piece containing specimen of Bowangius sp. 2 (a-c); amber piece containing specimen of Mekorhamphus beatae (d-f); Burmese amber offcut ( $\mathbf{g}-\mathbf{i})$; amber piece containing specimen of Opeatorhynchus comans (j,n); amber piece containing holotype of Mekorhamphus gyralommus (k,o); Baltic amber piece containing a specimen of Baltocar sp. (1,p); amber piece containing holotype of Microborus inertus (m,q).

We checked the authenticity of all amber blocks available for study under ultraviolet light. Burmese amber is known to fluoresce in UV light, producing a pale milky blue colour when photographed $[33,34]$. The peak light absorbance of Burmese amber occurs at a wavelength of $380 \mathrm{~nm}$ [35], which is near the upper end of the range of UVA (near-ultraviolet) light (315-400 nm). As most commercially available UV lamps ('black lights') emit light in this range, they can be used 
conveniently to test Burmese amber. We used a $3 \mathrm{~W} 365 \mathrm{~nm}$ LED UV torch (TECH LIGHT) with a zoom lens and a $395 \mathrm{~nm}$ LED torch (SCORPION MASTER) for this purpose. The amber pieces illuminated with incident light from these torches appeared milky yellowish to bluish to the eye, but the images produced by a camera are pale bluish in colour. We photographed the specimens with an Olympus E-M1 digital camera, without using a flash. The amber pieces were placed on a non-reflective glass plate about $100 \mathrm{~mm}$ above the table surface, photographed first under white room light (Figure 1a,d,g,n,o), then under incident UV light (Figure 1b,e,h,j-m) and finally with UV light reflected from the table surface beneath the glass plate (Figure $1 \mathrm{c}, \mathrm{f}, \mathrm{i})$. The amber produced the characteristic pale milky (opaque) blue colour only under incident light, whereas under reflected light it also fluoresced in blue but remained translucent. All amber pieces we tested with incident UV light in this way fluoresced in the characteristic milky blue colour, except those of Dominican amber, Baltic amber (Figure 11,p) and Microborus inertus (Figure 1m,q), which all remained a dull yellowish-green under UV light, depending on the strength of the light, never fluorescing milky blue. As the Microborus amber piece is embedded in a thin block of artificial resin, we also tested a known burmite specimen (enclosing a staphylinid beetle) embedded in resin (and more deeply so, $2.0 \mathrm{~mm}$ ), and this glowed in the same characteristic blue as our Burmese amber weevil specimens did, indicating that the resin does not interfere with the fluorescence of the amber.

\subsection{Specimen Preparation}

After initial inspection and photography, almost all amber pieces were further cut or ground down in places to remove bubbles and impurities in the amber, correct planes or curvatures that obscured or distorted critical features of the specimens or just reduce the thickness of the surrounding amber and improve the visibility of important characters. The best shape to study the specimens from all angles generally proved to be a rectangular block (cuboid) aligned with the dorsal, ventral, lateral, cephalic, and caudal sides of the specimen. The results of such trimming were often astonishing, rendering a specimen almost impossible to study (Figure 2a-c,e,j) into one revealing most of its critical structures (Figure 2d,f-i,k). Coarser cutting was done using a Dremel 200 or 4000 rotary tool, at low speed, fitted with a Dremel 545 Diamond Wheel $(22.2 \times 0.62 \mathrm{~mm})$ for most cuts, or with a EZ545 blade $(38.1 \times 0.62 \mathrm{~mm}$ ) when cutting larger pieces (we also used a $\sim 1 \mathrm{~mm}$ blade), and mounted to a Dremel Workstation 220 in horizontal position so that the cutting could be viewed under a microscope. The edge and surfaces of these cutting wheels are impregnated with diamond and can be used both for cutting and for initial coarse grinding needs (other abrasives will also work for coarse grinding). Finer cutting was done by hand using an adjustable jeweller's saw (3" throat depth) fitted with a \#7/0 gauge blade (smallest blade size available for this saw). Surfaces were ground down (with or without prior cutting) using emery paper of 240 or 400 grit and subsequently smoothened using wet/dry emery paper of 800, 1200, 2000, 3000, 5000 and 7000 grit, usually under water and under the microscope at low magnifications. For final polishing we used either acrylic polishing paste (as used for polishing artificial resin; Vosschemie) or Dremel 421 polishing compound. A few inclusions had been cut or ground into during the original preparation; the resulting cavities were cleaned and then filled with clear polyester casting resin (Diggers Casting and Embedding Resin, Recochem Inc., Australia, http: //www.recochem.com.au/files/downloads/Cons_Casting_Embedding_Resin_PDS_Apr11.pdf, and Castin' $^{\prime}$ raft $^{\circledR}$ liquid plastic) so as to seal and properly preserve the specimens. All this work was undertaken under a microscope, generally a Leica EZ4 and a Wild M3C instrument with Leica/Wild Planapo $1.0 \times$ objectives. 


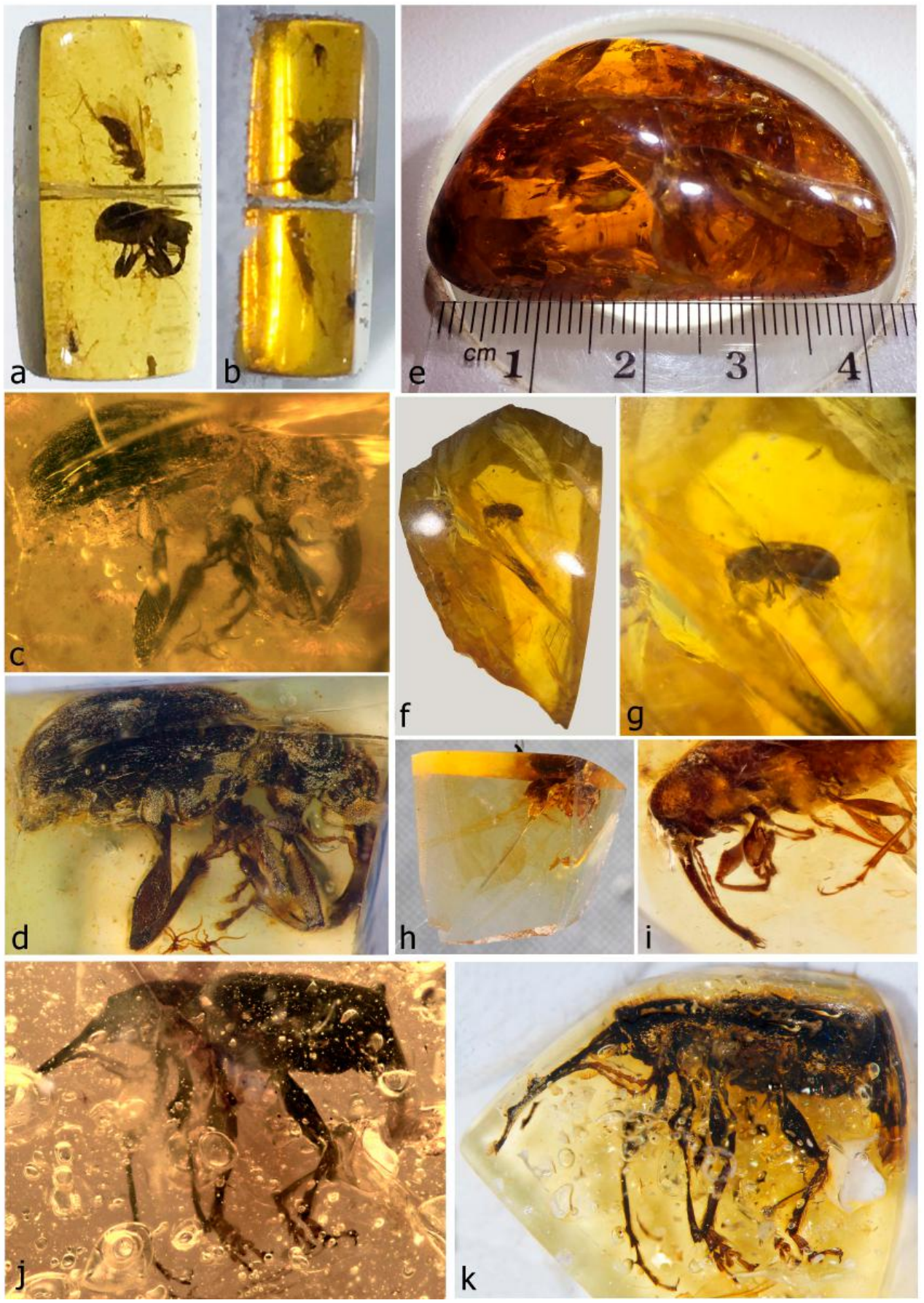

Figure 2. Block trimming to reveal inclusions in amber blocks and remove obstructions obscuring inclusions. Amber block containing holotype of Compsopsaros reneae showing sawcut between specimen and a second inclusion obscuring dorsal side (a); same, caudal view (b); same, lateral view of specimen prior to trimming (c); same, lateral view of specimen after removing most amber from side (d); original large amber piece containing holotype of Burmonyx zigrasi (e); resulting wedge containing specimen cut out of block, prior to final trimming (f); detail of specimen (g); final trimmed block (h); close-up of specimen in final block (i); amber piece containing holotype of Cyrtocis gibbus prior to trimming (j); block after trimming with specimen now largely free of bubbles and cracks (k).

\subsection{Specimen Study}

As typical for amber inclusions, critical structures and morphological characters were often not or only imperfectly visible in the amber pieces as received. This could be due to poor preservation 
of the specimen (compression, distortion or decomposition) or to impurities in the amber, such as bubbles of varying sizes and opacity, pieces of dark foreign matter (sometimes of a metallic nature), flow lines or shearing planes or cracks in the amber (sometimes visible by different colours of the amber) (Figure 3a) or a general cloudiness of the amber, which sometimes appeared as a greenish haze around the specimen (Figure 3h). It could also be due simply to the thickness of even relatively clear amber (without debris or obscurities) surrounding the specimen, which can cause it to appear blurred (especially at higher magnifications) due to the varying internal structure of the amber, the resulting varying optical clarity and available viewing angles. This alone, combined with potentially inadequate magnification and viewing techniques (dry vs. immersed in a liquid, the latter far superior), is likely an important factor in the omission or misinterpretation of several features in previously described amber weevil fossils and one for which different viewing techniques cannot compensate. Larger air bubbles can impede the view of some specimens due to the reflection of light from the inner bubble surfaces. Similarly, turbid (milky) impurities in the amber can restrict the visibility of specimens, and larger impurities and shearing planes close to the specimen sometimes can make it difficult to isolate structures (e.g., in Myanmarus caviventris; Figure 3g). A thin, continuous or fragmented film of air partially or substantially covers several specimens directly over the integument (Figure $3 c, f)$, similar to the familiar Verlumung in Baltic amber but never of the same opaque, white, emulsion-like nature (Figure 3d). These layers may stem from gases released by the insect body or from slight movements (particularly of appendages) after embedding in the amber, and they were particularly troublesome in the study of the specimens as they completely obscure the underlying features and are not removable by cutting down the amber, as larger obstructions further away from the specimen often are. Additional difficulties in assessing the characters of the specimens arose from the lenticular or cabochon shape of most amber pieces as received. While this usually allowed a good view of the specimen from two sides (the flat sides of the lens), characters on the other four sides were often impossible to study due to the distortions created by the narrowly rounded edges of the lens and to the thickness of the amber along the sides. Many of these difficulties and obstructions could be overcome by trimming the amber block down into a cuboid aligned with the sides of the specimen, and sometimes difficulties associated with block curvature could be compensated for, in part, by viewing the specimen immersed in a liquid. Large bubbles approaching or reaching the specimen could sometimes be opened from the outside, cleaned out under ethanol using a very fine brush and then filled with clear polyester resin. Essentially, it proved impossible to properly study any specimen without trimming down the amber block as far as possible. The difficulty of handling very small amber pieces can be overcome by embedding them in a larger block of clear artificial resin, a method employed routinely at the AMNH [36] (this can be done with or without the aid of a vacuum pump). Such embedding also provides added protection for the specimen. Mounting small and fragile amber pieces between cover slips [37] will also stabilise them but has the significant disadvantage of precluding adequate views of the entire specimen.

All specimens were first photographed as received, and further photographs were taken after cutting down and repolishing the amber block, especially of critical structures and characters. Photographs were mainly taken using a Leica DFC500 camera attached to a Leica M205 microscope, with the specimens immersed in mineral oil (of similar refractive index as the amber) to eliminate light reflections. The required viewing angle was obtained either by supporting the amber block in a bed of small glass beads in the oil or, when these reflected too much light, by tilting the container (a small glass beaker) with the amber block resting on its bottom. Multiple photographs taken at different focus levels were combined into single images using the software Leica Application Suite V4.3, and the images were enhanced (for brightness, contrast and sharpness) and cropped as necessary using the Adobe Photoshop CS6 software.

For study and illumination of the specimens under the microscope, a cold-light (LED) illuminator with two goose-neck arms proved to be best, generally with the light from one arm reflected up from the surface beneath the amber from one side and that from the other arm directed onto the specimen from the other side. Manipulating the tips of the arms allowed for fine adjustment of the direction and 
intensity of both lights so as to correctly illuminate the structures of interest. Such fine light adjustment was not possible during photography, however.

After initial study and photography, several specimens were scanned at the National Laboratory for X-ray Micro-Computed Tomography (CT Lab) of the Australian National University in Canberra (https://ctlab.anu.edu.au/capabilities/micro-ct.php) to reveal surface structures obscured by deposits or amber impurities too close to the specimens to be removable by grinding down the amber. The instrument used was a high-resolution micro-CT system (ANU4) with a double helical trajectory spanning $100 \mathrm{~mm}$ in height, a camera length of $315.4 \mathrm{~mm}$ and a detector resolution of $3 \mathrm{k} \times 3 \mathrm{k}$. The X-rays were generated by a Hama-L source, set at $80 \mathrm{kV}$ and 55-60 $\mu \mathrm{A}$ beam current. The sample distance was $12 \mathrm{~mm}$ for small to medium-sized specimens and $13.2 \mathrm{~mm}$ for larger ones, and the field-of-view (FOV) dimensions were $13.5 \mathrm{~mm}$ width by $26.1-28.0 \mathrm{~mm}$ length for the smaller specimens and $14.8 \times 21.2 \mathrm{~mm}$ for the larger ones, giving a voxel size of $5.3 \mu \mathrm{m}$ for small to medium-sized specimens and $5.9 \mu \mathrm{m}$ for the larger ones. Scanning time varied from $23 \mathrm{~h}$ for the larger to $32 \mathrm{~h}$ for the smaller specimens. Similar-sized specimens (amber blocks) were scanned together in a single tube of suitable diameter. The resulting 3D datasets were explored and rendered using the Volume Exploration and Presentation Tool of the open-source scientific visualisation software Drishti v2.6.4 [38], designed at the National Computational Infrastructure's VizLab (https://github.com/nci/drishti). Drishti is a graphics, hardware-based, direct-volume rendering application for real-time exploration and presentation of volumetric data. It comprises a series of modules (Import, Render and Paint) and allows researchers to colour, render, cut, slice, explore and animate a dataset and then prepare images and videos for presentation and publication. The NetCDF files generated by the $\mathrm{CT}$ scanner were first imported into Drishti using the Import module, in which the amber pieces scanned in the same tube were digitally separated from each other. The individual data sets were read at low (8-bit) resolution, and contrast was incremented with the help of histograms and slides were filtered. The information thus generated is written as *.pvl.nc (xml) files, which were read in the module Render to generate volumetric images, using the transfer function to adjust a gradient of density until the specimen was visible and the image suitably cropped around it. The transfer function of Render was then used in high-resolution mode to tune visualisation as well as lighting and shading effects. For most of the specimens, it was necessary to combine different transfer functions. Images of different views and video clips (Videos S1-S7) were saved for each specimen where possible.

The quality of images obtained from CT scanning varied significantly between specimens. Ironically, specimens well visible under a light microscope apart from small obscuring structures could often not be visualised satisfactorily from CT scans, whereas specimens very poorly visible under a light microscope, such as Calyptocis brevirostris and Petalotarsus oxycorynoides, yielded far better pictures and details from CT scans compared with photographs taken under a light microscope. The main reason for poor results from CT scanning was the lack of density contrast between the amber matrix and the specimen. This was especially true for finer structures such as appendages and setae. Sometimes different body parts also had different densities, so that the CT scans would reveal a different structure or layer of the specimen than is visible under the light microscope. For example, in Petalotarsus orycorynoides the CT scans revealed a severely cracked deeper integument layer than is visible externally and also showed the long single gular suture of the specimen much better than is visible via light microscopy. The lack of visibility and/or resolution of fine details (such as setae) in the CT scans was also due to the voxel size chosen for the scanning $(5.3-5.9 \mu \mathrm{m})$ being too large, especially for small specimens. It is likely that a smaller voxel size $(1-2 \mu \mathrm{m})$ would yield better and finer pictures of small structures, such as setae and teeth on the tarsal claws (e.g., in Calyptocis brevirostris), but it increases the scanning time and thus the costs. These structures are nevertheless clearly visible in photographs. 

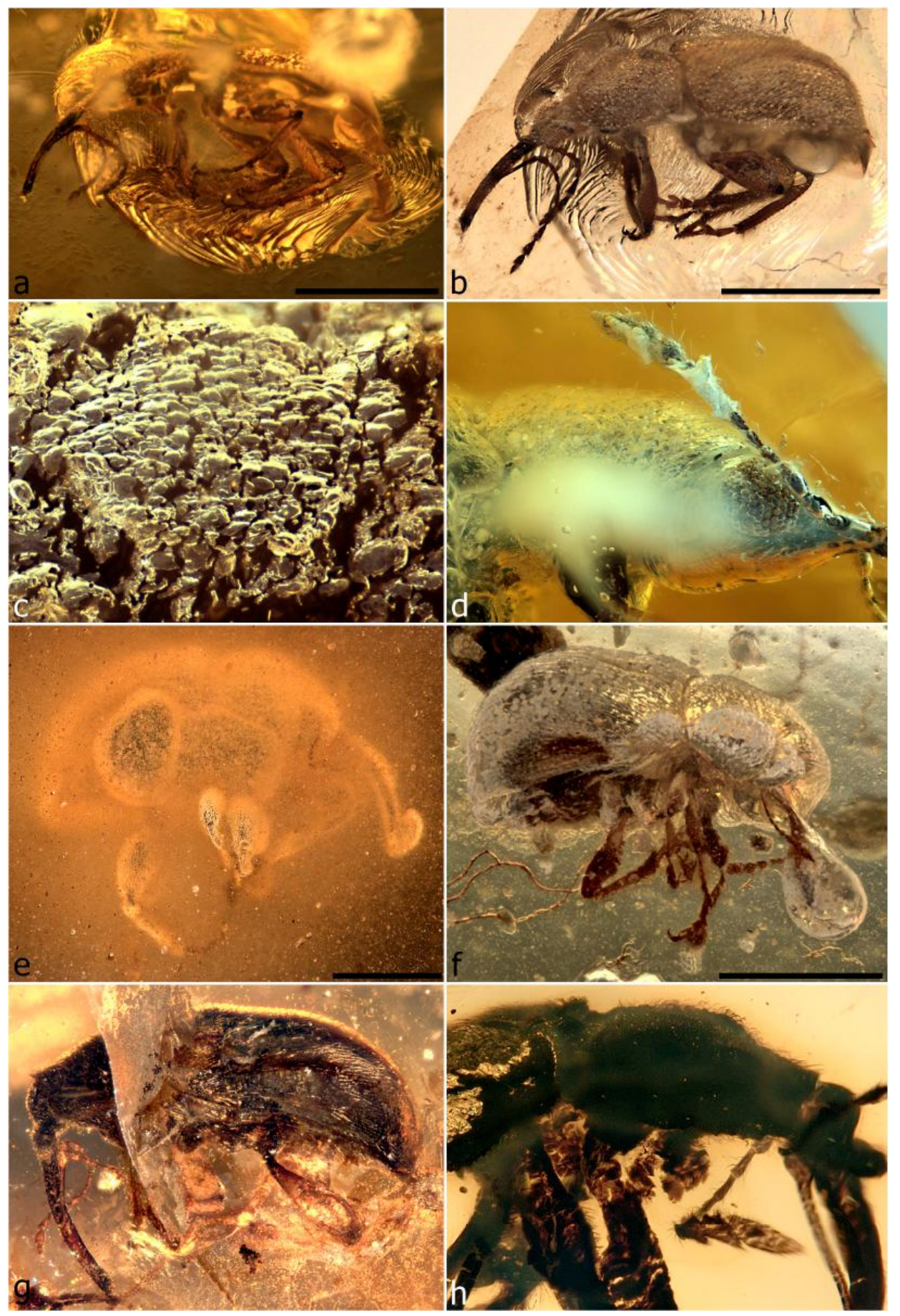

Figure 3. Obstructions in amber pieces obscuring critical taxonomic features of inclusions. Habropezus tenuicornis obscured by bubbles, flow lines and shearing plane (a); same, left side exposed after removal of excess amber and some bubbles and flow lines (reflection of shearing plane on right side of specimen reduced by different lighting) (b); Calyptocis brevirostris, irregular film of air obscuring elytra (c); Baltocar sp., white Verlumung obscuring right side of prothorax and structure of notosternal suture (d); Gnomus brevis, hazy cloud of organic particles shrouding specimen (e); Gnomus spinipes, imprint of specimen in amber after specimen pulled away from surrounding amber (f); Myanmarus caviventris, large fracture plane obscuring middle of left side and fine film of debris obscuring ventroposterior aspect (g); Mekorhamphus sp., badly distorted and compressed specimen with milky greenish film around thorax (h). Scale bars: $1.0 \mathrm{~mm}(\mathrm{a}, \mathrm{b}, \mathrm{e}, \mathrm{f})$. 


\subsection{Measurements}

All dimensions were measured using a graticule inserted into an ocular of the microscope. Length given is the standard length (SL) for weevils, measured in lateral view from the apex of the pronotum to the apex of the elytra. Due to distortions or obscurities in some specimens, it was not always possible to measure the length or other dimensions accurately.

\section{Results}

\subsection{Effects of Decomposition and Distortion on the Interpretation of Morphological Characters}

As in all insect fossils, the distortion and deformation of body parts can also be a significant source of misinterpretation of morphological characters of weevils preserved in Burmese amber. These processes can create seemingly authentic-looking structures and pose the risk of misinterpreting artefacts resulting from decomposition and deformation as legitimate taxonomic characters. One advantage of having examined so many specimens in our study is that of encountering a wide range of preservation quality, from near-perfect to very poor and resulting in unclassifiable specimens, and thus being able to compare the same structures in well and poorly preserved specimens. This has allowed the reliable identification of aberrations and of characters likely affected by these processes and, in most cases, their associated causes.

These processes, particularly decomposition, can have a significant effect on the structures of inclusions, in some cases completely destroying them, modifying them beyond recognition or generally preventing proper evaluation of some characters by affecting their natural positions in relation to other structures.

\subsubsection{Decomposition and Erosion}

Decomposition of inclusions may have occurred before a specimen was embedded and can continue in the amber after entrapment. Several fossils in our study are significantly modified by decomposition (usually in association with deformation), in some cases making it difficult or impossible to classify the specimen, depending on the characters affected. Of chief concern is when decomposition is minimal and seemingly affects only certain structures, in particular when the appendages have partially decomposed and some structures are potentially modified and/or missing. An example is the structure of the outer edge of the tibiae having seemingly lost the serrulation or crenulation due to decomposition. In the poorly preserved holotype of Bowangius glabratus, the protibiae are clearly carinate but the meso- and metatibiae serrulate, a combination otherwise rare and known mainly from other poorly preserved specimens. The legs of the holotype are clearly partially decomposed and the teeth of the protibiae may have been lost as a result. In the holotype of Anchineus dolichobothris, by contrast, remnant denticles are discernible on the protibiae but not on the others (which are all costate/carinate). In the Habropezus plaisiommus holotype, the basal half of the protibiae is carinate but the distal half distinctly serrulate (but the teeth irregularly separated), suggesting that the teeth on the basal half and some on the distal half have been lost. A complication in the interpretation of such inconsistencies is that some structures may also be affected by wear in life. In Mekorhamphus gracilipes and Periosocerus crenulatus, the protibiae and the meso- and metatibiae, respectively, are weakly crenulate, this being particularly difficult to see in the holotype of $M$. gracilipes and also on the other tibiae of this specimen.

\subsubsection{Depression, Compression and Crumpling Deformations}

As tree resin is deformable by changes in pressure and possibly heat during fossilisation, well preserved mummified inclusions may become modified subsequent to entrapment, even if decomposition was minimal. A common type of deformation is depression (dorsoventral flattening). In extreme cases the entire specimen is significantly affected, ranging from mild (e.g., the holotypes of Mekorhamphus gyralommus and Periosocerus deplanatus) to severe (e.g., Cetionyx ursinus, the whole 
body substantially compressed and the dorsal surface of the elytra concave) to uneven (e.g., Anchineus dolichobothris and Ocriocis binodosus, depression and crumpling affecting certain parts but not others). Localised depressions can considerably alter structures and make it difficult to interpret them. For example, in the holotype of Habropezus plaisiommus the rostrum is depressed and, as a result, the antennal insertions, mandible articulations and lateral structures are displaced ventrad and not properly visible. Depression can create the appearance of flattened structures or accentuate naturally flattened structures, such as tarsi and antennae (e.g., Cyrtocis gibbus). It can also cause the collapse of body cavities, e.g., of the ventrites into the abdominal cavity in Habropezus plasiommus, Anchineus dolichobothris, Palaeocryptorhynchus burmanus and Cetionyx batiatus. Localised depressions can cause artificial concavities in structures, such as the concave ventrites of Bowangius cyclops, and can also potentially alter the junctions of structures, such as by causing the separation of two sclerites at a suture, e.g., partly open coxal cavities. Depression of leg segments is evidently much rarer than compression but is evident in the holotype of Cyrtocis gibbus. Depression can also produce artefactual novel characters (see below).

Compression is lateral deformation and seemingly more common than depression. Examples are the compression of the elytra and abdomen of Cyrtocis gibbus and Bowangius tanaops, in which the elytra appear too narrow in dorsal view. The head and rostrum are frequently compressed, potentially creating artificial grooves or ridges along natural lines of weakness. The rostrum of Rhadinomycter perplexus, and potentially the head and prothorax, are distinctly compressed, and at least the rostrum in the basal part is deformed by compression. When leg segments become compressed, it can be difficult to interpret dorsal structures such as ridges, as the compression creates a sharp edge that can hide the presence of a true ridge or make the femur appear falsely carinate or costate.

In extreme cases, a specimen has become crumpled as a result of both depression and compression, the entire body collapsed and folded in on itself, as in Bowangius glabratus, Bowangius sp. 4, Ocriocis binodosus and Compsopsarus sp. In most cases these specimens are unclassifiable, but sometimes sufficient characters remain clearly visible so that it is still possible to make a genus and, in some cases, species assignments.

\subsubsection{Distortion}

Distortion is a kind of deformation in which the natural form and symmetry of the specimen is altered due to forces such as twisting or stretching in the amber. It can cause a general asymmetry of the body or localised asymmetry or asymmetrical placement of structures about the body axis. For example, in Rhadinomycter perplexus the left eye and antennal insertion are more anteriorly positioned than the right ones, and a similar altered form and position of the eyes occurs in the specimen of Rhynchitomimus chalybeus and several others. Distortion can also asymmetrically affect the junctions of structures (e.g., sutures) by pulling them apart. In Myanmarus caviventris and a few others, for example, the notosternal suture is slightly open on one side but fully closed on the other (as it is in congeners), further demonstrating the need to have a complete view of a specimen in order to check for these kinds of asymmetrical deformations and not misinterpret critical characters.

\subsubsection{Eruption of Internal Materials}

A common artefact in Burmese amber weevils is the occurrence of cuticular structures formed by the release of substances, apparently usually gases, from inside the body cavity. Such eruptions can create tubercle-like structures or protuberances, including structures resembling spines. In Cyrtocis gibbus the right elytron has a number of spine-like protuberances that are not present on the left, and the rostrum has two large asymmetrical humps. After block repreparation we could clearly determine that these processes are all associated with gas bubbles that erupted through the body wall and created these artificial structures. The holotypes of Habropezus plaisiommus and Leptopezus rastellipes also have notable examples of expulsion, but these are more obviously identifiable as mere eruptions because 
they have locally damaged the specimen (right profemur in H. plaisiommus; abdomen and legs in L. rastellipes) but not produced natural-looking false structures.

\subsubsection{Inauthentic Characters}

Any of the above processes can also have the effect of producing structures that appear to be characters of the specimen but, on closer inspection, are revealed to be artefacts because they are not present symmetrically. Usually this becomes apparent only after the amber block is trimmed and the entire specimen and details of its preservation become visible. For example, in the holotype of Burmonyx zigrasi a curved carina is evident on the upper side of the right profemur, but no trace of such a character is visible on the left one. Similarly, in Acalyptopygus elongatus the right side of ventrite 5 has a distinct notch, but this is absent from the left side. In the description of Anchineus dolichobothris, the claw bases are shown to have two apical processes between them, but these are artefacts resulting from the apex having split due to depression. A similar condition occurs in Burmocorynus longus. Trapped air layers over the surface of a specimen can also create surficial artefacts that can make the surface appear differently coloured or patterned. The specimen of Compsopsarus reneae has several patches of such surface layers, in places seemingly divided into scale-like chambers, and this artefact may also occur in the holotype of Mesphyletis calhouni (see there). These layers are nearly always not bilaterally symmetrical.

\subsubsection{Exaggeration of Structures}

Some stuctures or characters may become exaggerated (e.g., enlarged) by the processes of deformation and distortion. This is most frequently evident on the elytra, in which compression can amplify the distinctness of interstriae and the depth of striae. Usually (but not always) this artefact can also be identified by asymmetry between the two elytra.

\subsubsection{Identification of Artefacts}

In paired structures and body parts all these possible artefacts can usually be identied by determining whether they occur on both sides of the body, but this is not always possible, e.g., when the other side is obscured or differently deformed. It is also useful to check multiple conspecific specimens, or closely similar ones, as we have been able to do in several cases, but usually there will not be material available to do so (always an issue with isolated descriptions).

Trimming down the amber block is usually also essential for the accurate recognition of taxonomically valuable characters, as this often reveals whether a putative character is a legitimate one or merely an artefact of preservation. As a clear example, cutting the holotype of Burmonyx zigrasi out of its large original block revealed that what was drawn in the original publication as a wing is merely a crack in the amber.

\subsection{Morphological Characters}

In the description and classification of the Burmese amber weevils, as of all fossils, accurate identification and correct interpretation of morphological characters in comparison with those of relevant extant taxa is critical. Unfortunately this is often not included in published descriptions, leading to incorrect or doubtful assignment of fossils to higher taxa and subsequent untenable scenarios of evolutionary ages, distributions and biotic associations of taxa. Proper assessment of morphological characters is also hamstrung in studies of isolated specimens, as critical structures are often obscured or distorted. Only longer series of specimens can compensate for this, potentially revealing structures that are obscured in some specimens. From our studies of 93 specimens, the following assessment of the salient characters of the Burmese amber weevils was possible. 


\subsubsection{Mouthparts}

Although all mouthparts are important in the classification of weevils, usually only the labrum and the mandibles are sufficiently preserved and discernible in amber inclusions to be of general use in the assignment of specimens to higher taxa.

A distinct ('free') labrum occurs in weevils only in the basal ('lower') families Cimberididae, Nemonychidae (Figure 4a) and Anthribidae (Figure 4b). In Belidae, Attelabidae (Figure 4g), Caridae (Figure 4c), Brentidae and Curculionidae the apex of the rostrum is dorsally formed by a short epistome, which is firmly fused to the rostrum, without a transverse suture delimiting it posteriorly, and often hardly distinguishable. In Attelabidae the epistome is often apically spinose (Figure $4 \mathrm{~g}$ ), and in some Curculionidae (e.g., Meriphus Erichson, Eugnomini) it is also large and elongated beyond the mandibles (Figure 4j). In the Burmese amber weevils of this study, a distinct labrum is only discernible in Burmonyx zigrasi, Burmomacer kirejtshuki and Guillermorhinus longitarsis (Figure 4e,f), whereas all other specimens have an epistome (Figure $4 \mathrm{~d}, \mathrm{~m}$ ).

The shape of the mandibles differs widely in weevils, although the more basal families have fairly characteristic types. In Cimberididae and Nemonychidae the mandibles are typically long, narrow and falcate, with no or only few inner teeth (Figure 4a), and similar but broader and flatter mandibles occur in most Anthribidae (Figure $4 \mathrm{~b}$ ). In these families the mandibles also typically have a large setiferous groove or depression on the outside. In Belidae and Caridae the mandibles are generally small and strongly dentate apically or on the inside, without external setae (Figure 4c). This type also occurs in some Burmite specimens (Figure 4d). In Attelabidae the mandibles are typically exodont with two large outer teeth, the basal one often double (two cusps above each other) and the apical one aligned with a similar internal one to form a stout, anvil-shaped apex (Figure 4g). Exodont mandibles also occur in other weevils, e.g., in curculionine and eugnomine Curculionidae, and they generally have a different action (cutting rather than crushing) and hence a different shape (flattened), as well as a different socket and articulation plane. In Attelabidae their socket is elongate, narrow and in an apicolateral position (Figure $4 \mathrm{~h}$ ), allowing the mandibles to open widely and cut during the opening action, in a horizontal plane (Figure 4g). Similarly flat and sharply exodont, horizontal mandibles occur in several Eugnomini, e.g., Meriphus, but with an outwardly sickle-shaped apex (Figure 4j,n). In the curculionine genus Ergania Pascoe, the mandibles are also exodont and flattened but not anvil-shaped (Figure 4j), and their narrow socket and articulation plane are oblique (Figure 4p), the cutting or slicing action evidently occurring during a slanting, upward stroke. In other genera of the tribe Curculionini, the articulation plane is completely vertical and the mandibles are simplified into a single triangular tooth. Similar vertical mandibles also occur in a few other weevil taxa, e.g., the oxycorynine genus Rhopalotria Chevrolat and some species of the brentid genus Antliarhinus Schoenherr.

In the Burmese amber weevils, the flattened, exodont anvil shape of mandibles is particularly common, but it differs significantly from the attelabid type both in shape and in orientation and action. These mandibles typically have three small, triangular teeth on the outside and three on the inside, the two proximal ones being much larger and often recurved (especially the larger basal tooth) and the small apical ones together forming a narrow 'anvil' or ' $\mathrm{T}$ ' (Figure $4 \mathrm{k}, 1$ ). The mandibles also close in a horizontal plane but open into an obligue to vertical one (Figure 4o), their narrow sockets apparently curved in apical view and allowing the mandibles to rotate from a horizontal into a vertical position as they open, so that the large inner teeth face upwards and the smaller outer ones downwards in the open position (Figure 4o). This extraordinary orientation and movement of the mandibles appears unique to Burmese amber weevils, not having been recorded for any extant ones. It seems to enable the mandibles to cut a semicircular or, if the weevil rotated the rostrum by $180^{\circ}$, a circular groove into plant tissues, similar to that cut by a hole saw. However, narrower, horizontally articulating exodont mandibles occur in some taxa (Figure $4 \mathrm{~m}$ ), and the full range of mandible shape and articulation in these weevils is in need of closer study under higher magnifications or with other imaging techniques, such as higher-resolution CT scanning. 

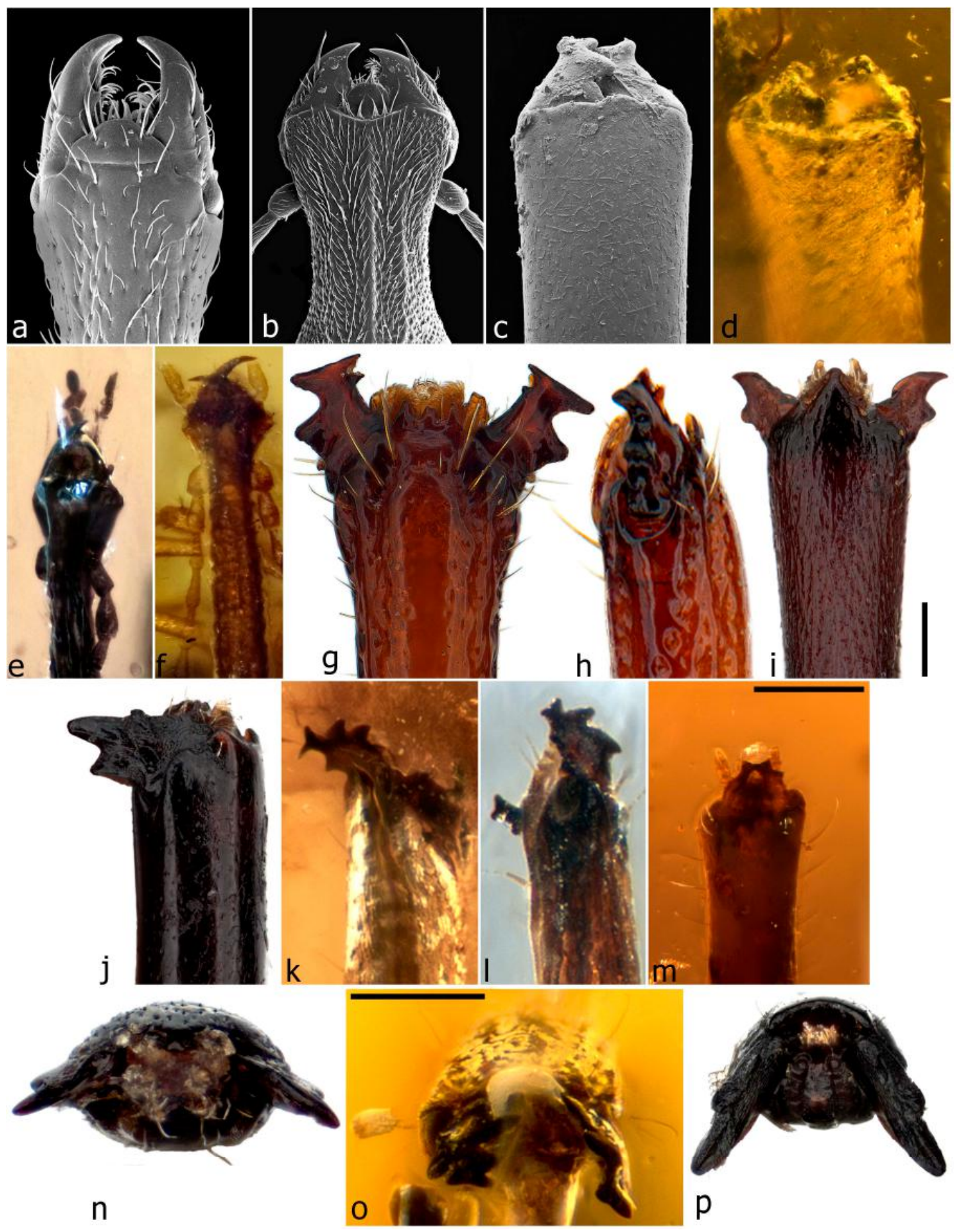

Figure 4. Apical part of rostrum showing mouthpart structures relevant to the classification of Burmese amber weevils. Basiliorhinus araucariae (Nemonychidae), dorsal view (a); Telala sp. (Anthribidae), dorsal view (b); Car cf. condensatus (Caridae), dorsal view (c); Petalotarsus sp. (Mesophyletidae), dorsal view (d); Guillermorhinus longitarsis (Nemonychidae), dorsal view (e); Burmonyx zigrasi (Nemonychidae), dorsal view (f); Rhodocyrtus cribripennis (Attelabidae), dorsal view (g); Rhodocyrtus cribripennis (Attelabidae), lateral view (h); Meriphus fullo (Curculionidae: Eugnomini), dorsal view (i); Ergania gibba (Curculionidae: Curculionini), dorsolateral view (j); Acalyptopygus brevicornis (Mesophyletidae), dorsolateral view (k); Louwiocis megalops (Mesophyletidae), lateral view (1); Elwoodius conicops (Mesophyletidae), dorsal view (m); Meriphus fullo (Curculionidae: Eugnomini), apical view (n); Habropezus kimpulleni (Mesophyletidae), apical view (o); Ergania gibba (Curculionidae: Curculionini), apical view (p). Scale bars: $0.1 \mathrm{~mm}(\mathrm{o}) ; 0.2 \mathrm{~mm}(\mathrm{i}, \mathrm{m})$. 


\subsubsection{Antennae}

Several characters of the antennae are important in the classification of weevil fossils, namely the shape of the antenna overall (straight or geniculate), the length of the basal segments (scape and first funicle segments) relative to each other, the shape of the club (the segments loosely articulated or compact) and the insertion on the rostrum (in a lateral or ventral position).

In the more primitive weevil families the antenna is straight, in that the scape is short and the pedicel (the first funicle segment) inserts into it in an apical position, its long axis aligning with that of the scape (Figure 5a). The term orthocerous ('straight-horned') is used to described weevils with this type of antenna (it applies to the weevil, not to the antenna). In some genera of these families, in particular in Belidae and Caridae, the scape is slightly elongate (usually as long as the first two or three funicle segments) and its articulation with the scape more flexible (Figure 5j). This type of antenna is here termed subgeniculate, and it also occurs in several Burmese amber weevils (Figure $5 b, c$ ). In the large family Curculionidae, the scape is typically about as long as the entire funicle and the latter is held at about a right angle to the scape (Figure $5 d$ ). This type of antennae is referred to as geniculate ('elbowed'), and weevils possessing it are termed gonatocerous. In the geniculate antenna of Curculionidae, the insertion of the pedicel in the scape is shifted into a ventral position, which allows the funicle to rotate forwards beneath the scape, and the ventral position means that the articulation socket is not visible ('closed') in apical view (Figure 5e). Even though curculionid antennae vary widely in shape, the ventral insertion of pedicel into scape generally remains, even in secondarily straight antennae (e.g., Brachycerini [39]). Geniculate antennae also occur in one other group of extant weevils, the subfamily Nanophyinae of Brentidae, but in it the geniculation is different in that the insertion of the pedicel in the scape remains in a more or less apical position, rendering the articulation socket visible ('open') in apical view (Figure 5f). The weevil fauna preserved in Burmese amber is remarkable for being the only other group of weevils with conspicuously geniculate antennae (it is by far the dominant type of antenna in the group), and these geniculate antennae are also of the 'open' type as in Nanophyinae (Figure 5g,h), not the 'closed' one of Curculionidae. The difference in the articulation type between the geniculate antenna in Curculionidae and in Nanophyinae and Mesophyletidae indicates that such antennae have evolved independently at least three times in weevils.

The shape of the antennal club also differs between weevil families, in that the club segments are distinct from each other (loosely articulated) (Figure 5a,j) in the more basal families but fused together (non-articulating) in Curculionidae (Figure $5 \mathrm{~d}$ ) and in some subfamilies of Brentidae (Ithycerinae, Microcerinae and Apioninae). In the Burmese amber weevils, the clubs are nearly always loose (Figure 5b,c,g,h), the only exception being the genus Petalotarsus, in which they are subcompact (Figure 5i), the segments not articulating though not as tightly fused together as they are in Curculionidae. As in weevils in general, the clubs of Burmese amber weevils are also four-segmented (in addition to a seven-segmented funicle) but generally much more distinctly so, with the terminal segment clearly inserted in the third (Figure 5b) and often conspicuously thinner (e.g., Habropezus tenuicornis, Figure 78), its base not being merely a constriction of the third. Even in species with subcompact clubs (e.g., Petalotarsus oxycorynoides), the four segments are clearly discernible (Figure 5i). In extant weevils, similar distinctly four-segmented clubs occur in some Anthribidae (e.g., Euciodes Pascoe), Caridae (e.g., Car pini Lea, Figure 5j) and even Curculionidae (e.g., Trichodocerus Chevrolat), whereas in Nemonychidae, Belidae and Attelabidae (Figure 5a) the distal two segments are seemingly always firmly fused and the presence of the fourth, apical segment is usually detectable only by the ring of sparse, long, erect sensory setae that occurs in about the distal quarter of all club segments, including the fourth. Even in the compact clubs of Brentidae and Curculionidae, the four segments are usually well discernible (Figure 5d). 


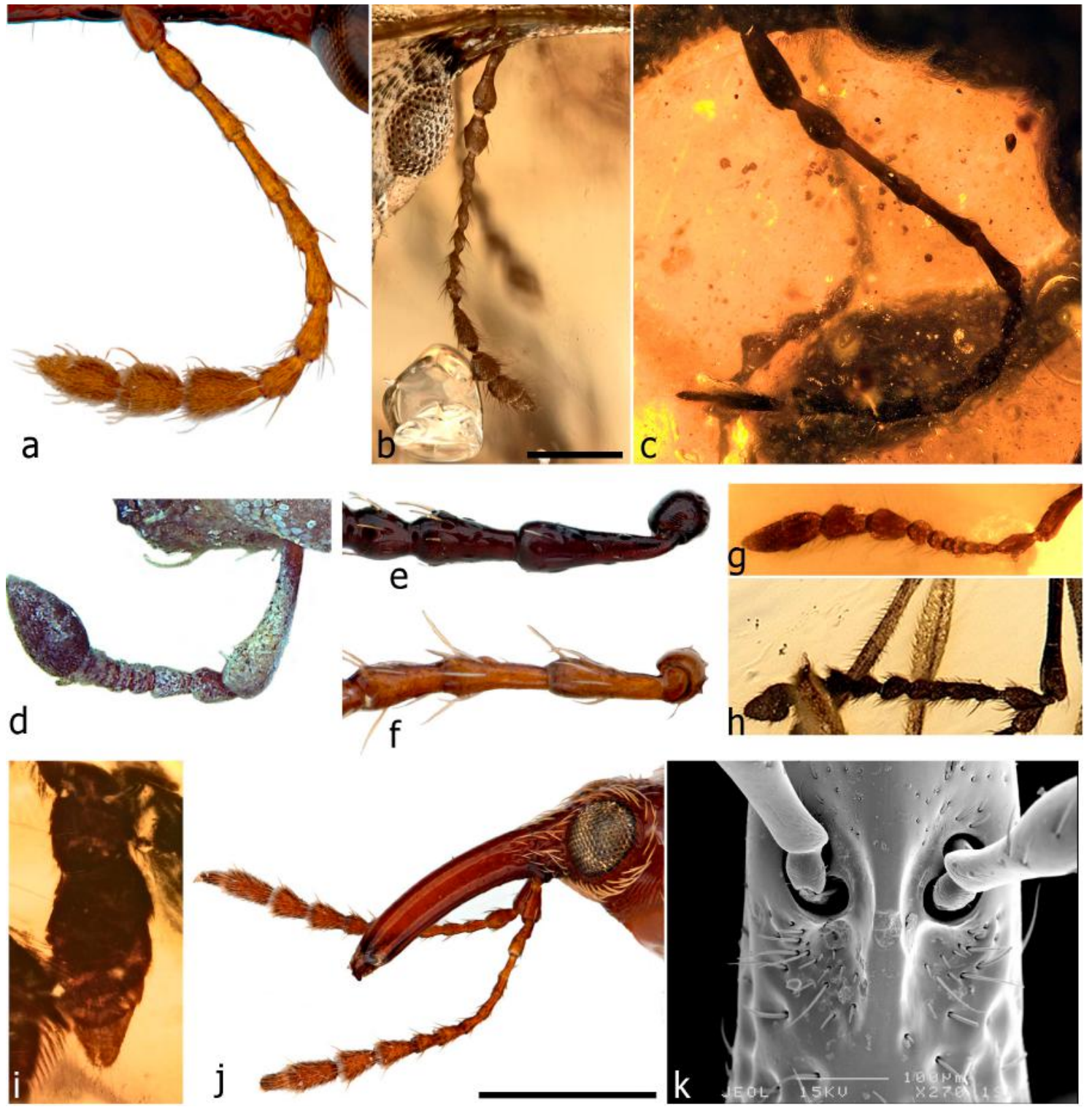

Figure 5. Structure of antennae in extant and Burmese amber weevils. Straight antenna, Rhodocyrtus cribripennis (Attelabidae), dorsolateral view (a); subgeniculate antenna, Acalyptopygus brevicornis (Mesophyletidae), dorsolateral view (b); subgeniculate antenna, Platychirus beloides (Mesophyletidae), dorsolateral view (c); geniculate antenna with compact club, Byrsops deformis (Curculionidae), dorsal view (d); ventral scape-pedicel articulation, Tournotaris granulipennis (Curculionidae), apical view (e); apical scape-pedicel articulation, Ctenomerus sp. (Nanophyinae), apical view (f); geniculate antenna, Bowangius cyclops (Mesophyletidae) (g); geniculate antenna, Habropezus crenulatus (Mesophyletidae), (h); subcompact antennal club, Petalotarsus oxycorynoides (Mesophyletidae) (i); ventrally inserted antennae, Car pini (Caridae), lateral view (j); reniform ventral antennal insertion sockets without scrobes, Car $c f$. condensatus (Caridae) (k). Scale bars: $0.2 \mathrm{~mm}$ (b); $0.5 \mathrm{~mm}$ (j).

The insertion of the antenna on the rostrum is typically in a lateral position (Figure $5 \mathrm{a}-\mathrm{c}$ ), and with geniculate antennae the socket opens posteriorly into a long groove (the scrobe) that runs along the side of the rostrum to about the eye and into which the scape recedes when the antenna is folded back against the head. With non-geniculate antennae there is no scrobe, and with subgeniculate ones there may at most be a shallow elongate depression on the side of the rostrum. In Caridae the antennal insertions are unusual and characteristic in that they are in a ventral position, the sockets being foveiform to reniform and no scrobes being present (Figure 5j,k). Such ventral antennal insertions 
do not occur in Burmese amber weevils, as known, the antennae always inserted laterally and the scapes usually folding back into a long scrobe.

The position of the antennal insertions in relation to the length of the rostrum is of less importance, as it depends primarily on the length of the scape. When the scape is short, the antennae are often inserted near the base of the rostrum, but when it is long (in geniculate antennae), the insertion has to be at least near the middle of the rostral length or is closer to the apex. In many weevils this position also differs between the sexes, the antennae generally inserted closer to the apex of the rostrum in males and nearer to the middle in females. This sexual dimorphism needs to be taken in consideration when delimiting species among weevil fossils (not only in amber inclusions but also in sedimentary compressions).

\subsubsection{Gular Sutures}

On the ventral side of the head, the development of the median sclerite, the gula, and its bordering sutures is important in the classification of families [16]. A distinct gula is only present in the families Cimberididae, Nemonychidae and Belidae, laterally bordered by a pair of sutures stretching from the base of the head forwards to the posterior tentorial pits. In Cimberididae the gula and its sutures are long and extend beneath the eyes to the base of the rostrum, the sutures converging anteriad (Figure 6a). In Nemonychidae they are vestigial and hidden under the anterior part of the prosternum, and in Anthribidaethey are absent. In Belidae the gula is generally smaller than in Cimberididae and its sutures are shorter, not extending anteriad to the rostrum but ending much further back (Figure 6b), and sometimes they meet anteriorly in a single tentorial pit beneath the posterior margin of the eyes. In Attelabidae the gula is lost towards the back of the head, and the gular sutures are united into a single suture that stretches from the back of the head forwards to beneath the eyes (Figure $6 \mathrm{c}$ ), where it usually joins the subgenal sutures on the underside of the rostrum (Figure 6d). In the three remaining families of extant weevils, Caridae, Brentidae and Curculionidae, the gula is also absent and a single gular suture remains, but it is short and ends in a more or less conspicuous tentorial pit beneath the posterior margin of the eyes (Figure 6d) or even further back. In Nanophyinae, however, in which the eyes and the posterior tentorial pit are placed further forward, the gular suture is also relatively long, sometimes extending shortly beyond the pit towards the base of the rostrum but not joining the subgenal sutures.

In the Burmese amber weevils, which nearly always have a porrect head, the underside is often well visible and shows a single, long gular suture (Figure 6f) as it occurs among extant weevils only in Attelabidae. Even when such a suture is not visible on the surface, it appears to be present underneath, as shown by CT scan images of the specimen of Petalotarsus oxycorynoides, which reveal a long gular suture in the denser inner layer of the cuticula (Figure $6 \mathrm{~d}$, in grey colour) but not on the less dense outer one (orange in Figure 6d). Failure to discern such a gular surface in a Burmese amber weevil therefore does not mean that it is not present.

\subsubsection{Coxal Cavities}

Important features of the pro- and mesocoxal cavities lie in their lateral closure. In most weevils the procoxal cavities are laterally (above the procoxae) closed by the juncture of the anterolateral part of the prosternum and the posteroventral part of the hypomeron (the hypomeral lobe), marked by the notosternal suture that typically extends more or less vertically for a short distance and then bends or curves anteriad towards the anterior prothoracic margin (Figure $7 \mathrm{a}, \mathrm{b}, \mathrm{h}$ ). When the anterior prosternal and the posterior hypomeral lobes meet along their entire length along the vertical part of the notosternal suture, the suture (and the procoxal cavity) is termed closed. In most Belidae and Rhynchitinae of Attelabidae, however, the horizontal branch of the notosternal suture is obsolete and the vertical branch opened up, forming a narrowly triangular cleft that exposes the procoxal trochantin (or pleurotrochantin) (Figure $7 c, d$ ). In the vast majority of Burmese amber weevils, the notosternal suture is closed (Figure 7e), but in a few specimens it is distinctly open (Figure 7f,g). 


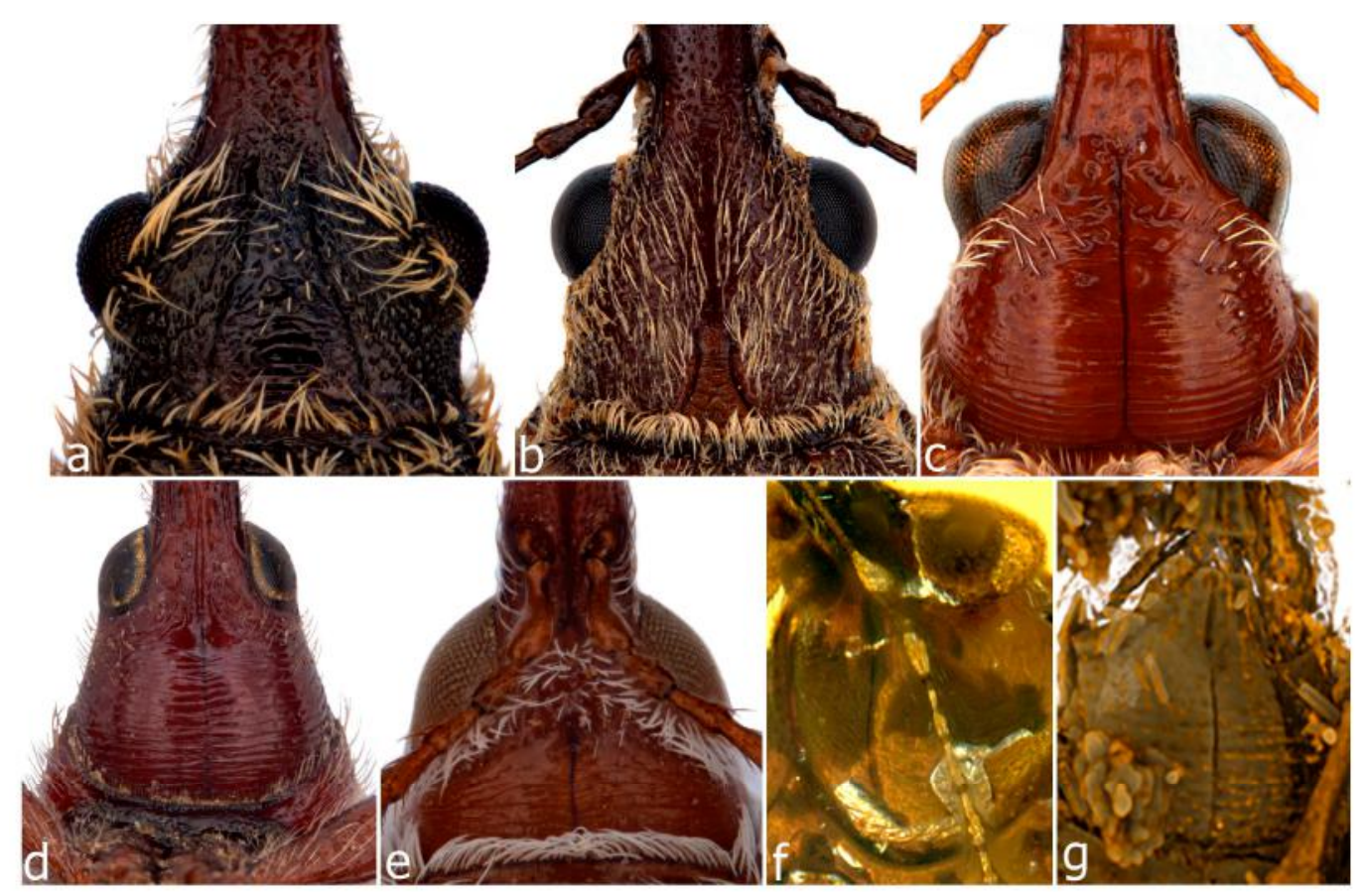

Figure 6. Gular sutures in extant and Burmese amber weevils. Long paired sutures, Cimberis elongata (Cimberididae) (a); short paired sutures, Hadrobelus undulatus (Belidae) (b); long single suture, Rhodocyrtus cribripennis (Attelabidae) (c); long single suture confluent with subgenal sutures, Merhynchites bicolor (Attelabidae) (d); short single suture, Car pini (Caridae) (e); long single suture, Elwoodius conicops (Mesophyletidae) (f); long single suture beneath surface, Petalotarsus oxycorynoides (Mesophyletidae) (g).

The position of the procoxal cavities (medially confluent or separate; in the middle of the prothorax or closer to the anterior or posterior margin) is also an important character but only on lower taxonomic levels (the generic mainly). In most weevils the procoxal cavities are medially confluent (the procoxae contiguous), separated cavities generally occurring in dorsoventrally flattened weevils or in those with a prosternal channel into which the rostrum recedes. The separation is caused by a median anterior prosternal and a median posterior hypomeral process (the latter originally paired) intruding between the cavities and meeting between them, but sometimes the processes do not quite meet and leave the cavities narrowly confluent in their middle. Procoxal cavities can only be termed separated when these processes are joined and completely separate the cavities, and separated procoxae do not always signify separated cavities as well. In the vast majority of Burmese amber weevils, the procoxal cavities are confluent (Figure 8a), distinctly separated ones occurring only in the genera Aepyceratus, Cetionyx, Burmocorynus and Petalotarsus (Figure 8b). In the descriptions of some Burmese amber weevils, the procoxae are said to be separated by a narrow septum, but this is in need of confirmation as it is usually difficult to properly discern the area between the procoxae, due to their position or to distortion or compression of the specimen, and bases of prosternal and hypomeral processes being visible does not necessarily mean that they meet between the procoxae and truly separate the coxal cavities. The typical shape of the body (high) and of the procoxae (deep and prominent) of most Burmese amber weevils suggests that the procoxal cavities are then always confluent; only in dorsoventrally flattened specimens can they be expected to be separate (if not discernible). 


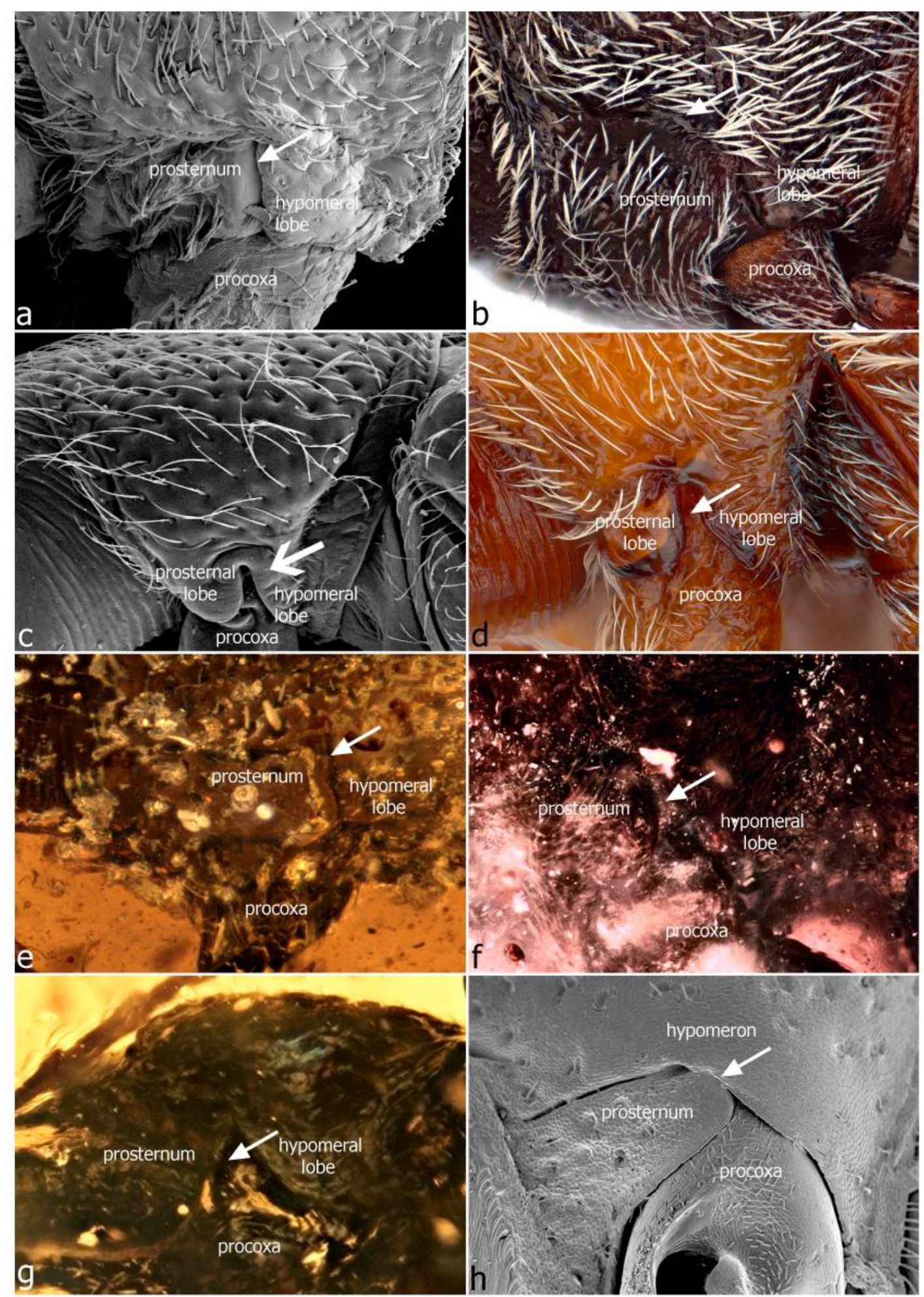

Figure 7. Procoxal cavities and notosternal sutures (arrows) in extant and Burmese amber weevils. Closed cavity, Car cf. condensatus (Caridae) (a); closed cavity, Notomacer araucariae (Nemonychidae) (b); open cavity, Metopum sp. (Attelabidae) (c); open cavity, Rhodocyrtus cribripennis (Attelabidae) (d); closed cavity, Electrocis dentitibialis (Mesophyletidae) (e); open cavity, Platychirus beloides (Mesophyletidae) (f); open cavity, Rhynchitomimus chalybeus (Mesophyletidae) (g); closed cavity, Rhopalotria slossonae (Belidae) (h). 

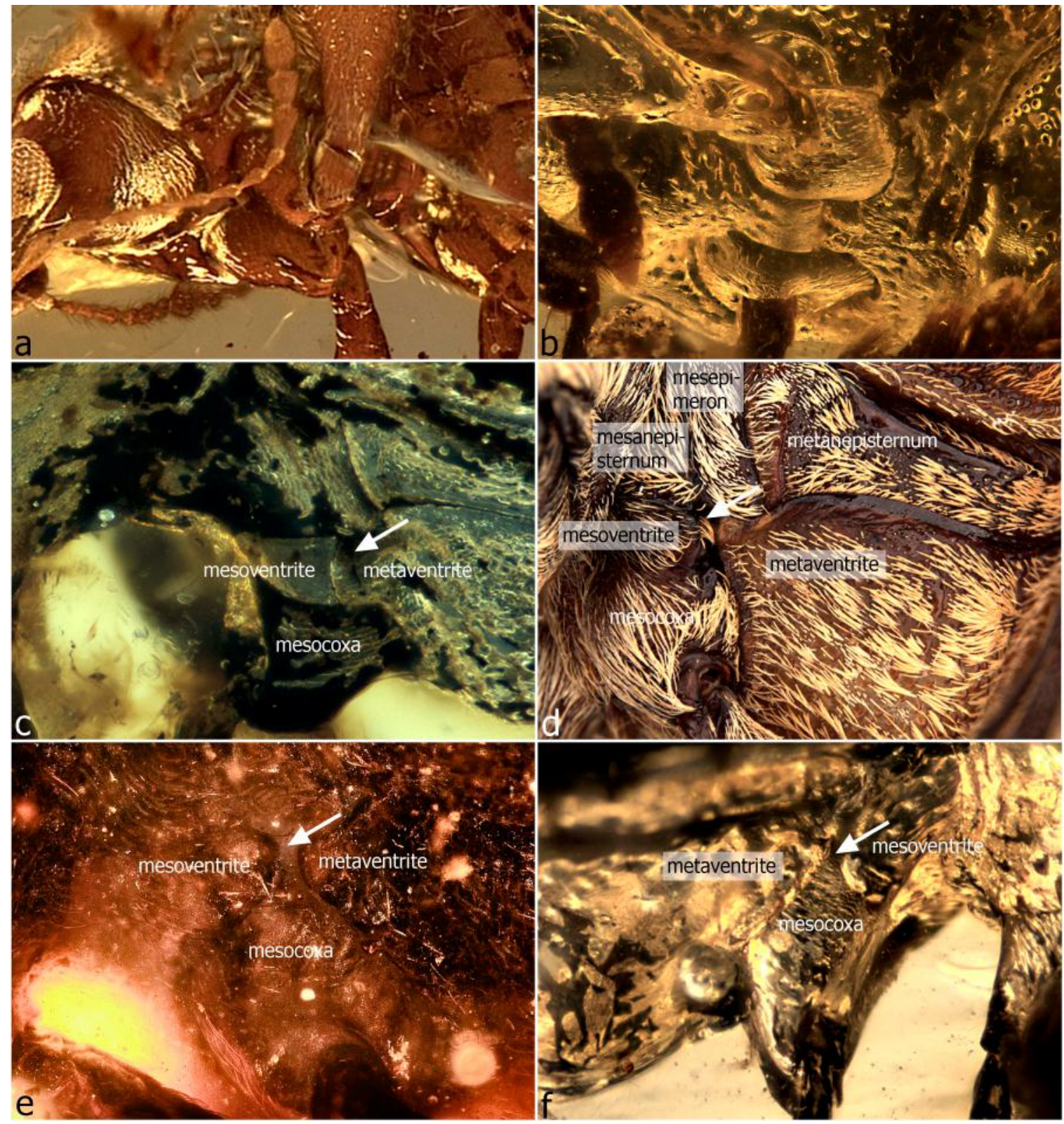

Figure 8. Procoxal and mesocoxal cavities in Burmese amber weevils. Confluent proxocal cavities (contiguous procoxae), Elwoodius conicops (Mesophyletidae) (a); separated proxocal cavities (procoxae), Petalotarsus oxycorynoides (Mesophyletidae) (b); closed mesocoxal cavity (suture arrowed), Acalyptopygus brevicornis (Mesophyletidae) (c); open mesocoxal cavity (suture arrowed), Hadrobelus undulatus (Belidae) (d); open mesocoxal cavity (suture arrowed), Platychirus beloides (Mesophyletidae) (e); open mesocoxal cavity (suture arrowed), Rhynchitomimus chalybeus (Mesophyletidae) (f).

The position of the procoxae along the longitudinal axis of the prothorax can also be of taxonomic importance. They are inserted between the anterior prosternum and the posterior hypomeron (the lateral portions of the prothorax that extend ventrad in weevils to close the procoxal cavities posteriorly), and they may be placed in the middle of the prothorax (prosternum and hypomeron being equally long, Figure $8 \mathrm{~b}$ ), closer to the anterior ventral prothoracic margin (the prosternum reduced in length) or closer to the posterior ventral prothoracic margin (the hypomeron reduced in length). In most Burmese amber weevils the prothorax is proclinate, the dorsum (pronotum) being much longer than the venter and the anterior lateral margins slanting backwards ventrad, so that the prosternum and/or hypomeron are very short (Figure 8a). 
The mesocoxal cavities in weevils are laterally typically broadly closed by the juncture of the mesoand metaventrites, marked by a more or less vertical suture above the mesocoxa. This condition occurs in most Burmese amber weevils too (Figure 8c). In most Belidae and rhynchitine Attelabidae, however, the lobes of the meso- and metaventrites do not quite meet above the mesocoxae, leaving a narrow gap and their cavities thus laterally open (Figure 8d) (without the mesanepisternum and/or mesepimeron closing the cavity). This condition occurs in a few Burmese amber specimens too (Figure 8e,f), and in the same taxa in which the procoxal cavities are likewise open. It also occurs in the extant genus Nemonyx Redtenbacher (Nemonychinae).

The transverse metacoxae laterally usually fit against the posterior part of the metanepisternum, thus completely separating the thoracic metaventrite from abdominal ventrite 1 . Only when the metacoxae are shortened (along their horizontal axis), as occurs in compact forms (e.g., Cryptoplini, some Cryptorhynchini and Entiminae), can metaventrite and ventrite 1 meet laterally below the metanepisternum (which is then often reduced or fused to the metaventrite). The metepimera are usually small and hidden under the elytra, but when they are exposed below the elytra, they also touch the lateral edge of the metacoxa. Exposed metepimera occur in a number of Belidae and Attelabidae (e.g., Rhodocyrtus) and also in some Curculionidae (e.g., Eugnomini). In Mesophyletidae as examined, the metacoxae always meet the metanepisternum, and metepimera are never exposed.

\subsubsection{Elytra and Scutellary Strioles}

The elytra in weevils are typically punctostriate, with the punctures aligned into ten longitudinal striae (Figure 9a,b) stretching from near the base of the elytra to the apex (Figure 9c). This condition also occurs in the vast majority of Burmese amber weevils (Figure 9d). In the more basal families Nemonychidae, Anthribidae, Belidae and Attelabidae, each elytron usually has an additional short striole behind the scutellar shield, stretching for only ca. $20 \%$ of the elytral length, next to the median suture (Figure 9a,b). The first two complete striae then often bend around this scutellary striole, so are not straight as the more lateral ones are. When the punctures are small and the elytra fairly densely setose, as in Nemonychidae, the scutellary strioles can be difficult to discern. The presence of scutellary strioles therefore is of critical importance in assigning a fossil to one of the above four families, although their absence does not necessarily exclude the specimen from them, as these strioles are lost in some extant members of all of them.

In the Burmese amber weevils studied, distinct scutellary strioles are only present in Burmonyx (though not as long as illustrated in the original description) and Guillermorhinus, and probably also in Burmomacer (not discernible). In all other specimens there are ten full striae where these are distinct and discernible, but in some specimens the striae are very faint and almost obsolete or covered by a vestiture of dense setae. As discernible, and as in Attelabidae and Caridae, the setae arise from the interstriae between the punctures and from the interstriae, not from the punctures, and they can be aligned into rows or irregularly scattered over the elytra.

The lateral edge of the elytra, beyond the 10th stria, can be inflexed to form an epipleural flange, which is often broader anteriorly and narrows more or less rapidly behind the abutment of the metacoxa onto the elytron. The upper margin of this flange, just beneath the 10th stria, can be produced into a costa or sharp carina, as occurs in Cimberididae, Nemonychidae, many Anthribidae, very weakly in some Belidae, Attelabidae and Caridae and also in some Curculionidae (e.g., Eugnomini). This condition is also present in many Burmese amber weevils, with the narrow posterior part of the flange often depressed to form a narrow groove. Most Burmese amber weevils also possess a distinct notch in the lateral margin just behind the base. In all specimens having this notch, an anterodorsal lobe or process of the metanepisternum fits into it. In association with the laterally folded ventrites fitting tightly against the inner elytral margins, this structural interaction between elytron and metanepisternum has been related to the locking of the elytra to the body in a resting position [40]. We are not certain that this structure has a locking function (it may actually serve an opposite function) and for reference prefer to simply call it an anterior marginal notch. 

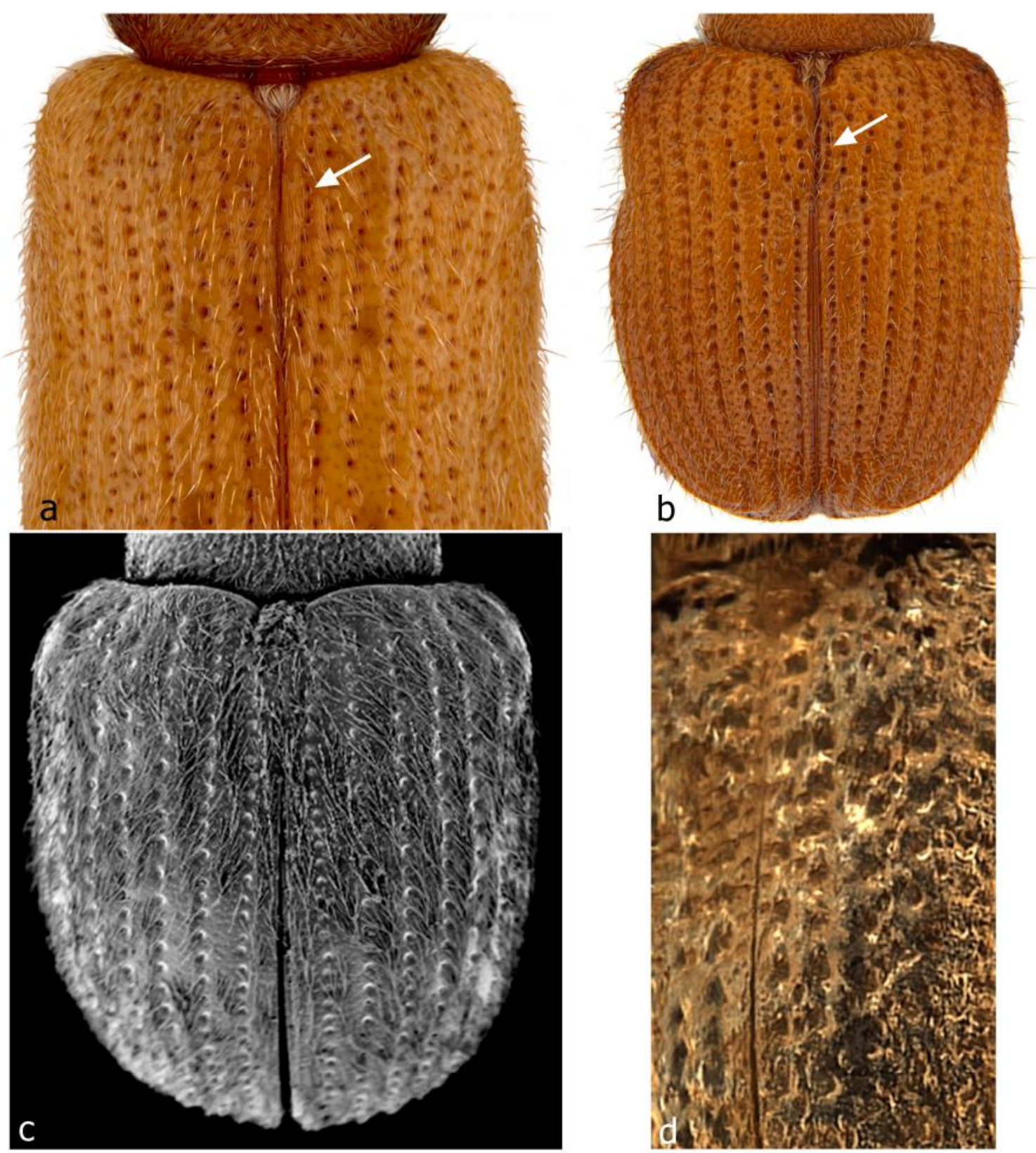

Figure 9. Elytral striae in extant and Burmese amber weevils. Scutellary strioles present (arrow), Aragomacer leai (Nemonychidae) (a); scutellary strioles present (arrow), Rhodocyrtus cribripennis (Attelabidae) (b); all striae complete (scutellary strioles absent), Car cf. condensatus (Caridae) (c); all striae complete (scutellary strioles absent), Louwiocis megalops (Mesophyletidae) (d).

\subsubsection{Tibiae}

In the families Belidae, Attelabidae and Caridae, the tibiae and femora often carry a conspicuous row of short black pegs along their outer edges. In Belidae such crenulations occur in the tribes Agnesiotidini and Belini of Belinae (but not in Pachyurini) and in most Oxycoryninae, in Attelabidae they occur in many Rhynchitinae (Figure 10a,b) and some Attelabinae, and in Caridae they are present in the genus Carodes Zimmerman (Figure 10c,d). In Belidae and Attelabidae these pegs are modified setae (Figure 10e), in several cases (especially in Belini) still ending in a stout seta, but in Agnesiotidini and Rhynchitinae setal remnants are only sometimes present in some pegs on the femora. In Carodes, by contrast, the pegs are formed from the integument above the setae, these remaining in their normal shape and conspicuously visible between the pegs (Figure 10d,f). 


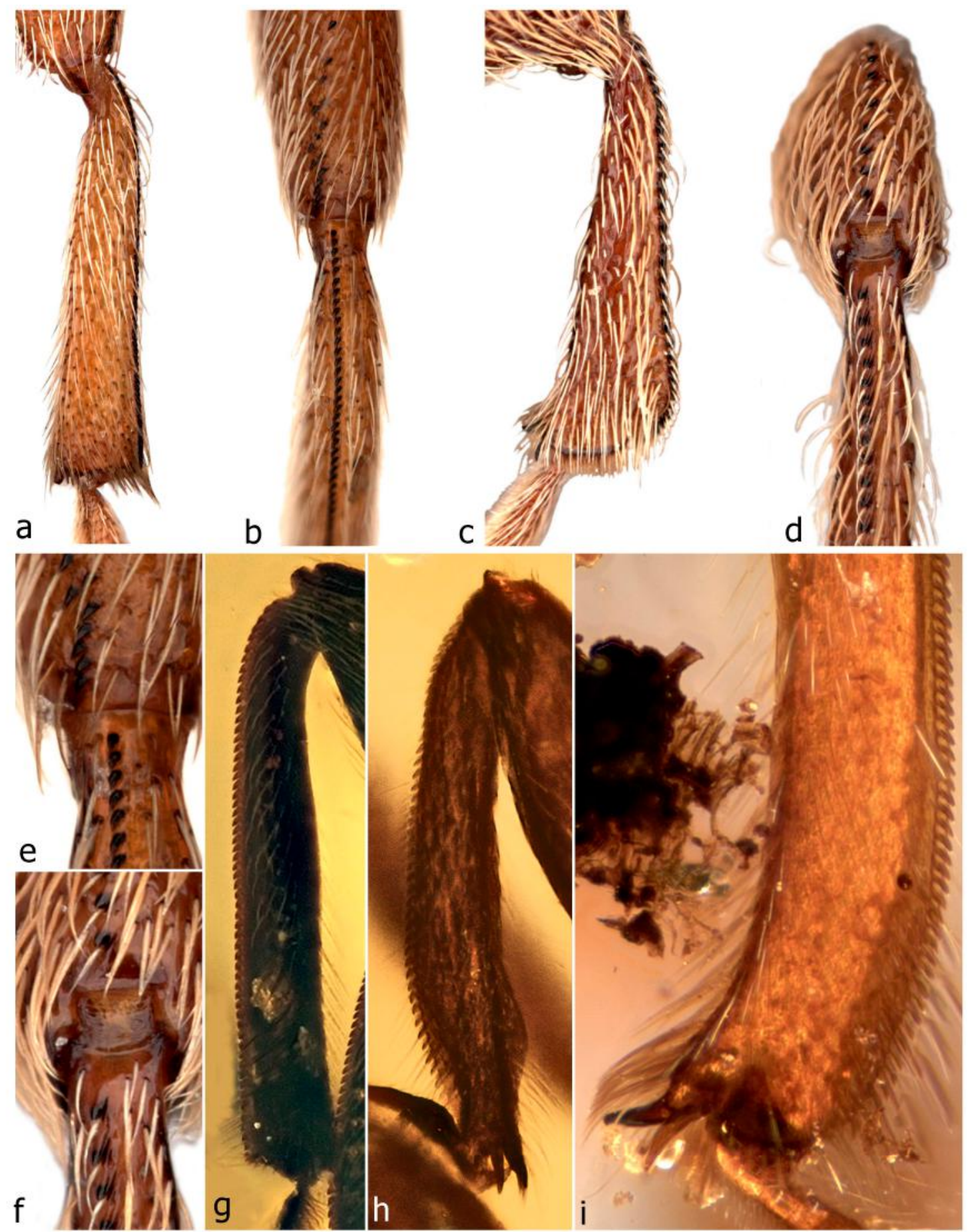

Figure 10. Tibial and femoral edges in extant and Burmese amber weevils. Serrulate metatibia and femur, Rhodocyrtus cribripennis (Attelabidae), lateral and outer view (a,b,e); serrulate metatibia and femur, Carodes revelatus (Caridae), lateral and outer view (c,d,f); crenulate metatibia, Mekorhamphus beatae (Mesophyletidae), lateral view (g); serrulate metatibia, Bowangius cyclops (Mesophyletidae), lateral view (h); pectinate metatibia, Elwoodius conicops (Mesophyletidae), lateral view (i).

Similar crenulations also occur in many Burmese amber weevils, but the pegs appear to be always embedded in a low, flat carina rather than directly in the integument and not derived from setae. When this carina is regularly finely notched and the pegs are rounded-curved and basally contiguous, the tibiae and femora are termed crenulate (Figure 10g), when it is toothed and the pegs are subtriangular and basally separated or subcontiguous, the tibiae are termed serrulate (Figure 10h), 
and when the pegs are longer, slender and subparallel, the tibiae are termed pectinate (Figure 10i). The difference between these types is not always clear, however, especially in small, poorly preserved or distorted specimens. In some specimens there appears to be only a smooth or finely scalloped carina present, not divided into distinct pegs. When such crenulations occur, they are present on the mesoand metatibiae and often also on the protibiae, and they may then occur on the femora as well, at least in the distal part. Although the tibial and femoral crenulations in Belidae, Attelabidae, Caridae and the Burmese amber weevils are very similar in appearance, they are evidently not homologous and have evolved (and probably been lost) several times.

The tibiae of most Burmese amber weevils carry the typical pair of apical spurs as it occurs in many weevils. These spurs are usually large and clearly discernible among the smaller setae fringing the apical surface of the tibiae, but occasionally they are smaller and difficult to discern. The distribution of the spurs between the three tibiae (the spur formula) is usually difficult to impossible to assess, as the spurs are rarely clearly visible on all three pairs of tibiae. In those specimens in which they are, the spur formula is generally 2-2-2, but it appears as if it may be 1-2-2 in some species. In Nugatorhinus and Petalotarsus, spurs are apparently consistently absent. In Elwoodius conicops and apparently Mesophyletis calhouni the inner spur on the meso- and metatibiae is fused to the tibia and broadened and flattened (Figure 111,m). A similar condition occurs in the extant Carodes revelatus (Caridae).

\subsubsection{Tarsi}

The tarsi of the Burmese amber weevils are characteristically long and the tarsites (tarsal segments) apically deeply excised to bilobed, not only tarsites 3 but also 2 and even 1 (Figure 11a-i). Tarsites 3 are often so deeply and narrowly bilobed that the two lobes become narrowly stalked (pedunculate) and basally connected only by a very short bridge (Figure 11c,d). They appear to become dislodged easily, i.e., during decomposition (Figure 11a); in the holotype of Echogomphus viridescens only one of the twelve lobes is still attached to the tarsus. This structure must have given the tarsi extreme flexibility and, together with the large, usually dentate claws and ventral pulvilli of dense, fine or stiff, sharp setae (Figure 11e), superb adhesion on smooth surfaces. In the genus Petalotarsus the tarsi are shorter and broader, apparently adapted to allow the robust and flattened weevils of this genus to tightly cling to the substrate on which they walked or sheltered. In Platychirus and Burmorhinus, tarsites 1 are much larger and broader than the others, similar to the condition in some extant members of Belidae (Figure 11j) and Caridae (Figure 11k). This probably also increased the adhesion ability of the tarsi, but as this enlargement of tarsites 1 is sexually dimorphic in Stenobelus Zimmerman [41], it may have played a role in mating or oviposition rather than in walking or feeding.

\subsubsection{Tarsal Claws}

The terminal tarsite (the onychium) in weevils generally carries an apical pair of claws, which are typically simple, i.e., smooth and evenly curved downwards and slightly divergent (Figure 12d). Modifications involve both the direction and the shape of the claws. They may become spread apart to align into a plane and point in opposite directions (termed divaricate; Figure 12c,i,g), or they may become pushed together to align parallel and point in the same direction, which can lead to various degrees of fusion (connate claws) until only a single claw remains. The shape may be altered by the development of an additional tooth on each claw, but the origin of this tooth differs and must be properly assessed; a simple description of claws as being 'toothed' or 'appendiculate' is misleading and not very meaningful. In addition, many claws have a long stout seta near the base, inserted in a ventral position slightly on the outside of the claw. This claw seta, here termed the ventrobasal seta, persists in many weevils and is sometimes characteristically modified, such as in the tribe Sitonini of Entiminae, in which it is long, flattened and slightly twisted and parallel to the claw on its outside. The presence of this seta is critical in understanding the dentition of tarsal claws. 


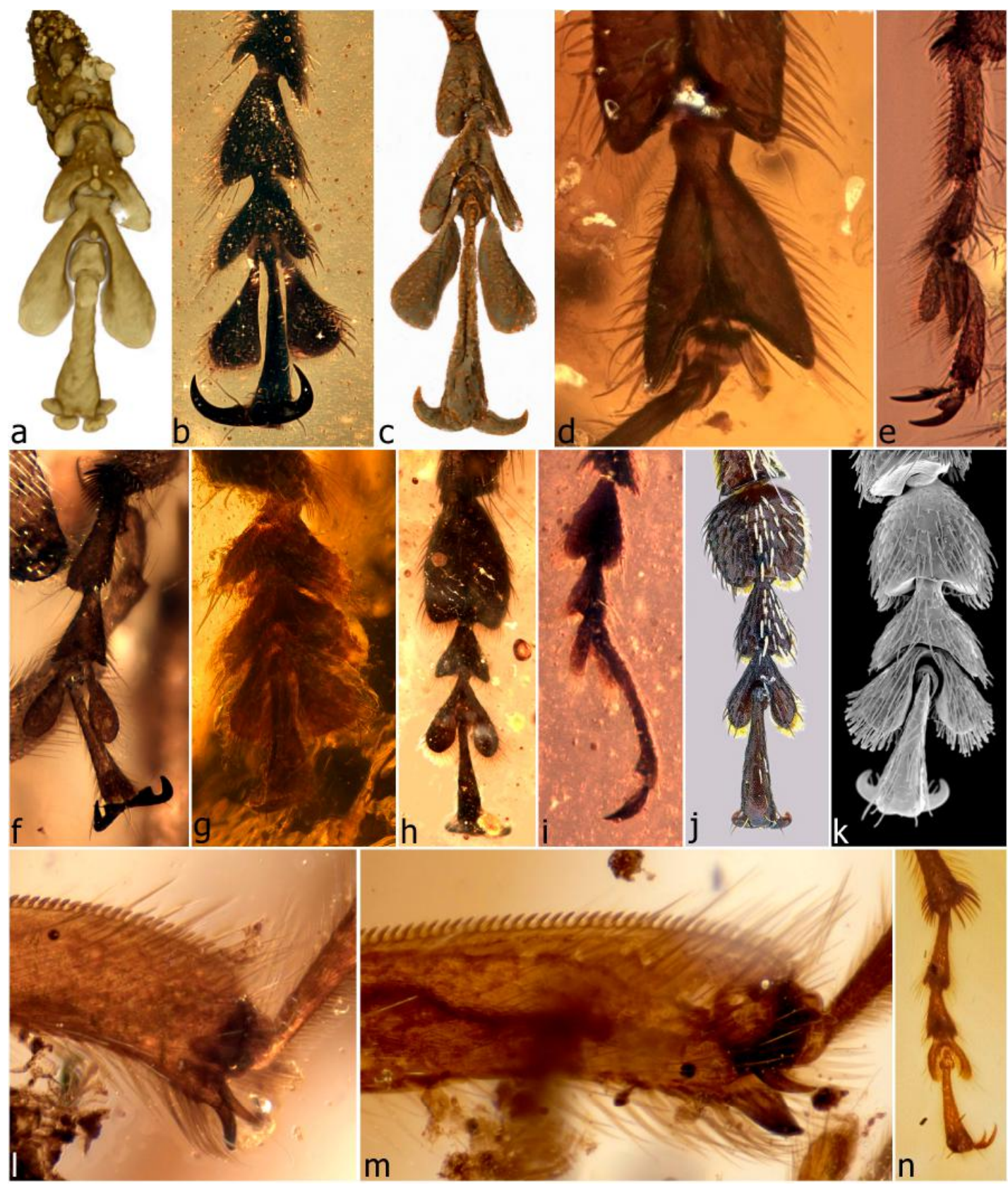

Figure 11. Tarsi in Mesophyletidae and some extant weevils. Calyptocis brevirostris, mesotarsus (CT scan) (a); Opeatorhynchus comans, protarsus (ventral view) (b); Cetionyx batiatus, protarsus (CT scan) (c); Echogomphus viridescens, protarsus (d); Habropezus incoxatirostris, protarsus, lateral view (e); Myanmarus caviventris, protarsus (f); Petalotarsus oxycorynoides, protarsus (g); Platychirus brevirostris, mesotarsus (h); Burmorhinus setosus, mesotarsus (i); Stenobelus testaceus (Belidae), protarsus (j); Car cf. condensatus (Caridae), metatarsus (k); Elwoodius conicops, mesotibial apex with fixed inner spur (1); Elwoodius conicops, metatibial apex with fixed inner spur (m); Burmonyx zigrasi (Nemonychidae), left metatarsus (dorsal view) (n).

A fundamental difference exists between claws that have a basal tooth on the underside (here termed dentate) and those that have a secondary tooth on the inside of the claw (termed bifid). The tooth of the dentate claw arises from an angled swelling of the ventral edge of the claw at the insertion of the ventrobasal seta (Figure 12a), whereas that of the bifid claw arises from a split on its inside (Figure 12b,e), not at the insertion of the ventrobasal seta, which is nearly always absent in bifid claws. When bifid claws become divaricate, the inner tooth is usually broadened and resembles 
that of the dentate claw (Figure 12c,f), but it is distinguishable by its position and the narrow angle of the separation from the claw and also by the absence of the ventrobasal seta. This claw is termed laminate, and it may differ between males and females of the same species [42]. The conclusion that these two types of toothed claws are not homologous is aptly confirmed by the Burmese amber species Myanmarus diversiunguis, whose front claws are dentate as well as bifid (Figure 121). We know of no such example among extant weevils.

The distribution of these claw types differs characteristically between the weevil families. Simple or basally slightly angled claws with a ventrobasal seta occur in Cimberididae, Caridae (Figure 12a), the brentid subfamilies Microcerinae (except ventrobasal seta absent in Gyllenhalia Aurivillius and Microcerus Schoenherr), Eurhynchinae, Nanophyinae (in Nanophyini claws connate with small ventrobasal seta; in Corimaliini free, divergent, without seta) and Brentinae and in most subfamilies of Curculionidae, in particular Brachycerinae, Erirhininae, Dryophthorinae, Cyclominae, Entiminae and Molytinae (though ventrobasal seta also absent in many genera and even within some genera, e.g., Brachycerus Olivier). In Belidae the claws are also simple or basally angled but always without a ventrobasal seta. Dentate claws with a ventrobasal seta occur in most Apioninae of Brentidae and in many taxa of the curculionid subfamily Curculioninae. Bifid or laminate claws (without ventrobasal seta) are characteristic of Nemonychidae (Nemonychinae and Rhinorhynchinae), Anthribidae (Anthribinae and Urodontinae) and Attelabidae (Rhynchitinae) as well as the monotypic brentid subfamily Ithycerinae (Figure 12e) (this exceptionally with a ventrobasal seta as well as 1-2 shorter ones above it) and in several tribes of Curculionidae (e.g., Anthonomini, Ceutorhynchini, Cleogonini). It thus appears that the ventrobasal seta is a plesiomorphic character that is dragged along throughout the weevils but has been lost numerous times, consistently in some taxa (Belidae) but irregularly in others (Brentidae and Curculionidae). In bifid claws (in Nemonychidae, Anthribidae and Rhynchitinae) it always seems to be absent, except for Ithycerus Schoenherr and some curculionid genera, e.g., Conotrachelus Dejean of Cleogonini.

The ventrobasal seta is also present in the vast majority of Burmese amber weevils (the Mesophyletidae), whose claws are mostly strongly dentate (Figure 12i,j) but sometimes only slightly angled (Figure 12h) to simple (Figure 12g). Among our sample, bifid claws only occur in Burmonyx, Guillermorhinus and Burmomacer (all Nemonychidae) as well as on the protarsi in Myanmarus diversiunguis, in which they are bifid and dentate (only dentate on the meso- and metatarsi). In their dentate, divaricate claws, the mesophyletids therefore differ significantly from all weevil families other than Brentidae and Curculionidae. Dentate claws (and bifid/laminate ones) appear associated with an arboreal life style as they are consistently absent in terricolous forms (unlike the ventrobasal seta, which also occurs in terricolous species), so they probably evolved convergently a number of times in different weevil groups. Those Mesophyletidae with dentate claws are therefore likely to have led a more specialised arboreal life than those with only simple or slightly swollen claws.

\subsubsection{Abdomen}

Structures of the abdomen relevant for classification concern the sclerotisation and exposure of tergite VII and/or VIII beyond the elytra to form a visible pygidium and the level of fusion of the ventrites. In extant weevils such a pygidium (formed by tergite VII) occurs characteristically in Anthribidae (Figure 13a,b), in most Attelabidae (Figure 13c) and in some Apioninae (fully exposed, partly exposed or covered) and also in several tribes of Curculionidae (Acalyptini, Ceutorhynchini, Curculionini, Ectemnorhinini, Mecinini, Metatygini, Microstylini, Trigonocolini, in males of some Derelomini and Tychiini). In males of Urodontinae (Anthribidae) tergite VIII is also exposed beyond VII [43], and in males of Ithycerus (Brentidae) tergite VIII is strongly sclerotised and pouch-like bent over to be visible from ventral view; in females it is hidden under tergite VII. An exposed pygidium formed by tergite VII also occurs in a number of Burmese amber weevils, in the genera Acalyptopygus (Figure 13d,e,g), Echogomphus (Figure 13h) and Calyptocis (Figure 13i,j). It has also been described for Mesophyletis, but this appears to be an error, as the apex of the abdomen is flexed down in the 
specimen and seems to just reveal a normal, sclerotised tergite VII that is covered by the elytra when the abdomen is in its normal position.
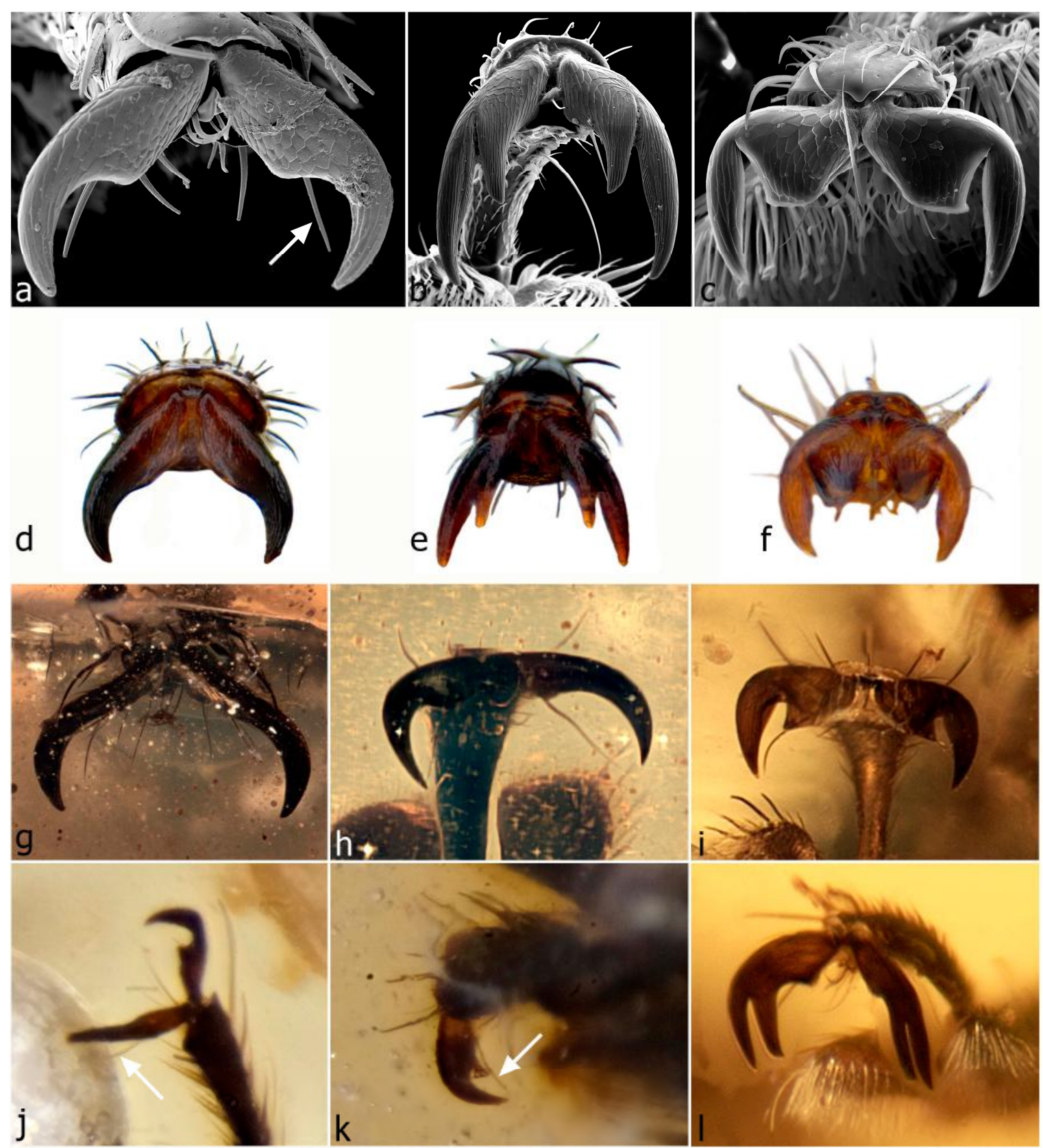

Figure 12. Tarsal claws in extant and Burmese amber weevils. Angulate, with ventrobasal seta (arrow), Car cf. condensatus (Caridae) (a); bifid, without ventrobasal seta, Telala sp. (Anthribidae) (b); laminate, without ventrobasal seta, Basiliorhinus araucariae (Nemonychidae) (c); simple, without ventrobasal seta, Hadrobelus undulatus (Belidae) (d); bifid, with ventrobasal seta, Ithycerus noveboracensis (Brentidae: Ithycerinae) (e); laminate, without ventrobasal seta, Rhodocyrtus cribripennis (Attelabidae) (f); simple, with ventrobasal seta, Cetionyx ursinus (Mesophyletidae) (g); angulate, with ventrobasal seta, Opeatorhynchus comans (Mesophyletidae) (h); dentate, with ventrobasal seta, Mekorhamphus gracilipes (Mesophyletidae) (i); dentate, with ventrobasal seta (arrow), Rhynchitomimus chalybeus (Mesophyletidae) (j); dentate, with ventrobasal seta (arrow), Calyptocis brevirostris (Mesophyletidae) (k); bifid and dentate, with ventrobasal seta, Myanmarus diversiunguis (Mesophyletidae) (1). 

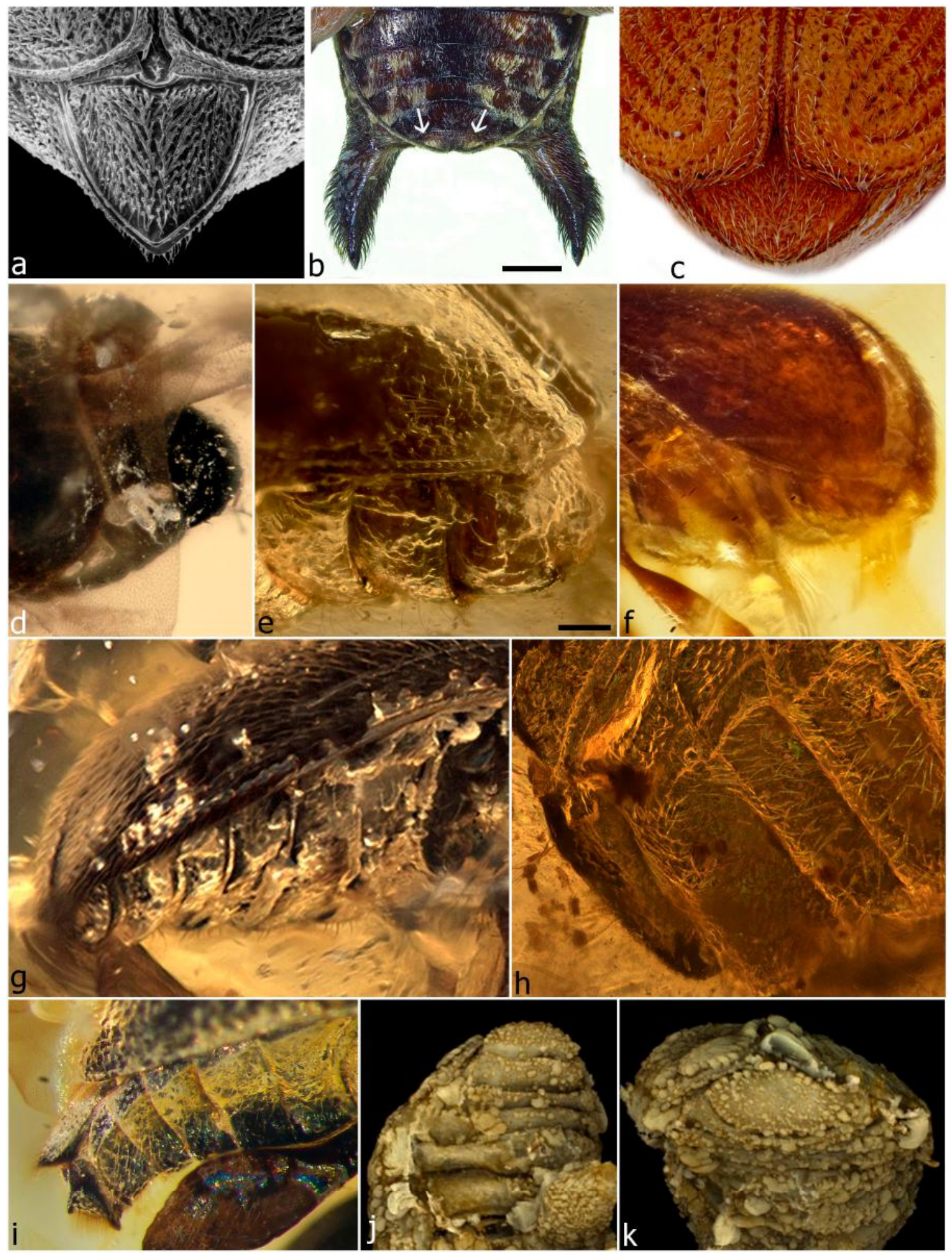

Figure 13. Pygidia and abdomens in extant and Burmese amber weevils. Araecerus fasciculatus, female (Anthribidae), caudal view (a); Telala sp. (Anthribidae), ventral view (arrows indicating long border with truncate ventrite 5) (b); Rhodocyrtus cribripennis (Attelabidae), caudal view (c); Acalyptopygus brevicornis (Mesophyletidae), dorsal view (d); A. lingziae, lateral view (e); Burmonyx zigrasi (Nemonychidae), caudolateral view (f); Acalyptopygus astriatus (Mesophyletidae), ventrolateral view (g); Echogomphus viridescens (Mesophyletidae), ventral view (h); Bowangius tanaops (Mesophyletidae), right lateral view (i); Calyptocis brevirostris (Mesophyletidae), ventral view (j); same, caudal view (k). Scale bars: $1.0 \mathrm{~mm}(\mathrm{~b}) ; 0.1 \mathrm{~mm}(\mathrm{e})$. 
A sclerotised apical tergite is also visible in Burmonyx zigrasi (Figure 13f) but does not form an exposed pygidium. In amber fossils in which the abdomen is so flexed down or the apex of the elytra is obscured, the shape of ventrite 5 can serve as an indicator of whether the pygidium is exposed, as an exposed pygidium abuts broadly onto this ventrite, so that its posterior margin is truncate, not rounded or angled. The triangular shape of ventrite 5 as depicted in the crude drawing of Mesophyletis calhouni indicates that a pygidium is not exposed in this species. In a few specimens of Bowangius, and possibly also in Anchineus dolichobothris, tergite VIII appears to be permanently exposed as well, in a vertical position between tergite VII and ventrite 5 (Figure 13i), suggesting that these specimens are males and that tergite VIII is exposed in some species of Mesophyletidae.

In extant weevils the ventrites are all free (separated from each other by an extendable membrane) in Cimberididae, Nemonychidae, Belinae of Belidae and Caridae, whereas in Oxycoryninae of Belidae, Attelabidae, Brentidae and Curculionidae ventrites 1 and 2 are braced or fused (not moveable against each other) and in Anthribidae ventrites 1 to 4 are so braced or fused [1]. In the Burmese amber weevils, five free ventrites occur only in the genera Burmonyx, Burmomacer and Guillermorhinus, whereas in all others as studied the basal two ventrites are fused, the suture between them thin though distinct, and only the three distal ventrites are free, separated by a more or less distinct membrane (Figure 13e,g,h) and usually slightly stepped (the anterior margin higher than the posterior margin of the preceding ventrite, Figure 13e). The difference between the suture separating ventrites 1 and 2 and those separating the other ventrites is usually readily visible (Figure 13g,i), except when the abdomen is obscured or distorted.

\subsection{Keys to Weevil Families and to Genera and Species of Burmese Weevils}

\subsubsection{Key to Families of Weevils}

Following recent changes to the family classification of extant weevils [6] and the addition of another family of extinct weevils here, a revised key to the families of Curculionoidea is required. The key below is intended to be applicable to fossils as well and therefore does not include characters of internal structures, genitalia and larvae. It does, however, rely on some key features that are not always readily observable in fossils (e.g., labrum, gular sutures, scutellary strioles, tarsal claws), but these are critical in distinguishing the extant families and without them such a key would become much more complex and fragmented. Additionally, in a group as large as weevils there are always exceptions, which cannot all be accommodated in a key such as this. If critical features as used in this key are not preserved or observable in fossils, their classification to families must be undertaken with great caution and possibly not attempted at all. Misclassifications can have grave consequences for evolutionary assessments of extinct taxa or faunas.

1 Labrum free, separated from frontoclypeus by a suture; antennae usually inserted apically, rostrum expanded in front of them; mandibles usually long, falcate to blade-like, with external

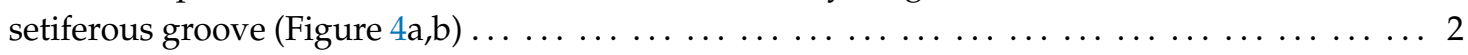

- Labrum absent (fused to frontoclypeus, without clypeolabral suture); antennae usually inserted medially to basally, rostrum not expanded in front of them; mandibles usually small, scoop-shaped with strong internal teeth or flat, exodont, without external setiferous groove

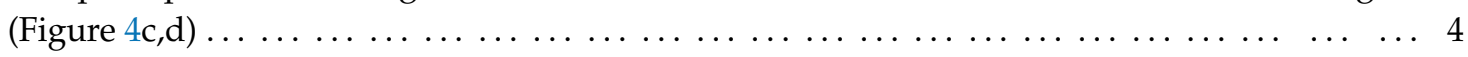

2(1) Prothorax with bracteate basal and lateral carinae (except Urodontinae); tibiae mostly without spurs; abdomen mostly with tergite VII vertical, exposed as pygidium (Figure 13a,b); ventrites

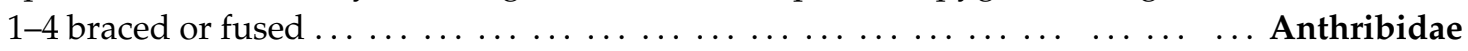

- Prothorax without bracteate carinae; all tibiae with a pair of spurs; abdomen with tergite VII horizontal, hidden under elytra; all ventrites free $\ldots \ldots \ldots \ldots \ldots \ldots \ldots \ldots \ldots$ 
3(2) Tarsal claws simple, with ventrobasal seta (Figure 12g); gular sutures paired, long, reaching between eyes (Figure 6a); elytra with punctation irregularly scattered, not aligned in striae ......

Cimberididae

- Tarsal claws bifid/laminate, without ventrobasal seta (Figure 12b,c); gular sutures paired, short, hidden under prosternal margin or vestigial; elytra with punctation aligned in striae, with scutellary striole (Figure 9a) (except irregular in Nemonyx) ............ Nemonychidae

4 (1) Antennae non-geniculate (straight), scape shorter than funicle $\ldots \ldots \ldots \ldots \ldots \ldots \ldots \ldots 5$

- Antennae geniculate, scape about as long as funicle $\ldots \ldots \ldots \ldots \ldots \ldots \ldots \ldots$

5(4) Gular sutures paired, short (Figure 6b); protibiae with apical grooming device in a broad shallow groove; tarsal claws simple, without ventrobasal seta . . . . . . . . . . . . . . . Belidae

- Gular suture single (Figure $6 c-g$ ); protibiae lacking grooming device; tarsal claws simple, dentate with ventrobasal seta or bifid/laminate without ventrobasal seta $\ldots \ldots \ldots \ldots \ldots \ldots \ldots$

6(5) Gular suture long, extending from base of head between eyes onto rostrum $\ldots \ldots \ldots \ldots$

- Gular suture short, extending from base of head to tentorial pit beneath posterior margin of eyes

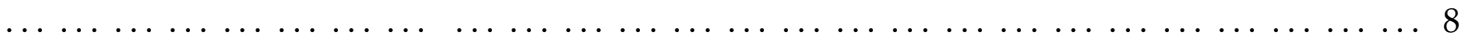

7(6) Tarsal claws bifid/laminate, without ventrobasal seta (simple in some Auletes and Attelabinae, in latter connate); elytra punctostriate, mostly with scutellary striole, or irregularly punctate (Figure 9b) .

Attelabidae

- Tarsal claws dentate, with ventrobasal seta; elytra punctostriate, always without scutellary striole (Figure $9 \mathrm{c}) \ldots \ldots \ldots \ldots \ldots \ldots \ldots$ Mesophyletidae: Aepyceratinae

8(6) Abdomen flat, all ventrites free, in lateral view at same level; first two ventrites not or slightly longer than 3 ; antennal insertions ventral (Figure $5 \mathrm{j}, \mathrm{k}) \ldots \ldots \ldots \ldots \ldots \ldots$ Caridae

- Abdominal segments in lateral view uneven, first two ventrites bulging downwards, fused; ventrites 1 and 2 distinctly longer than 3 ; antennal insertions lateral $\ldots \ldots \ldots \ldots \ldots \ldots$

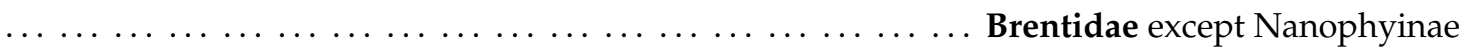

9(4) Geniculation of antennae (articulation of pedicel in scape) ventral, closed in apical view (Figure 5e); antennal clubs compact, segments pressed together (Figure $5 \mathrm{~d}$ ) $\ldots \ldots \ldots \ldots \ldots$

Curculionidae

- Geniculation of antennae (articulation of pedicel in scape) apical, open in apical view (Figure 5f);

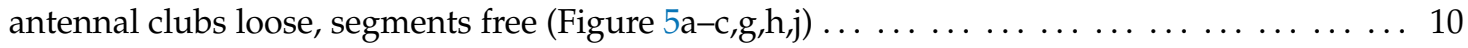

10(9) Basal margin of elytra crenulate; funicles 4- to 6-segmented; mandibles not exodont; interstriae 8 usually with crenulate carina; scutellar shield absent (not exposed); trochanters large, usually elongate, separating femur from coxa; tibiae without spurs; tarsal claws simple, usually connate (free, divergent in Corimaliini); ventrites 1 and 2 at lower level than $3-4 \ldots \ldots \ldots \ldots \ldots \ldots$

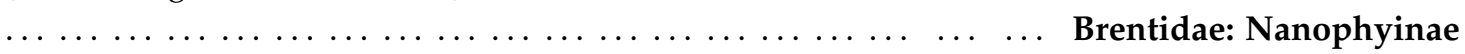

- Basal margin of elytral simple; funicles 7-segmented; mandibles usually strongly exodont; interstriae 8 never with crenulate carina; scutellar shield exposed; trochanters short, oblique, not separating femur from coxa; tibiae with spurs; tarsal claws always free, divaricate, simple, angulate or dentate; ventrites 1 and 2 at same level as $3-4 \ldots$.

Mesophyletidae: Mesophyletinae

\subsubsection{Key to the Genera and Species of Burmese Amber Weevils}

The genus Anchineus keys out in two different places because of the likelihood that it has serrulate tibiae (see treatment of Anchineus, below). The unnamed species of Mekorhamphus and Bowangius species 3 and 4 are excluded from the key, because they are too poorly preserved to accurately classify.

1 Labrum present; mandibles long (apically exposed in repose), simple, falcate; antennae non-geniculate (scape shorter than first funicular segment), inserted at apical quarter of rostral length; tarsal claws bifid; all ventrites free $\ldots \ldots \ldots \ldots \ldots \ldots \ldots \ldots \ldots$ 
- $\quad$ Labrum absent; mandibles short (may be exposed or concealed in repose), dentate internally and/or externally; antennae geniculate (scape about as long as funicle) or subgeniculate (scape longer than first funicular segment), inserted near middle or in posterior half of rostral length, or if antemedian then scapes much longer than first funicular segment; tarsal claws simple, basally angulate or dentate; ventrites 1 and 2 fused $\ldots \ldots \ldots \ldots \ldots \ldots$

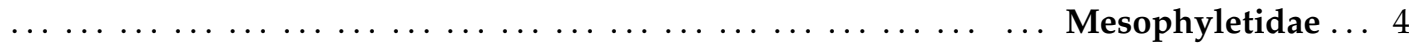

2 (1) Rostrum shorter than pronotum, $2.0 \times$ longer than wide in middle, dorsally with 2 grooves; anterolateral corners of postmentum not extended into long processes . . . . . . . . . . . .

Burmomacer kirejtshuki

- $\quad$ Rostrum longer than pronotum, >> $2.0 \times$ longer than wide in middle, dorsally with 4 grooves; anterolateral corners of postmentum extended into long processes $\ldots \ldots \ldots \ldots \ldots$

3 (2) Elytra coarsely punctostriate; striae distinct, coarse; tarsi with lobes of tarsite 3 broad, tarsites 5 narrow; claws strongly bifid, not basally angulate ............. Burmonyx zigrasi Elytra weakly punctostriate; striae indistinct, fine; tarsi with lobes of tarsite 3 digitate, tarsites 5 broad and flat; claws shortly bifid, preapical tooth small, basally angulate . . . . . . . . .

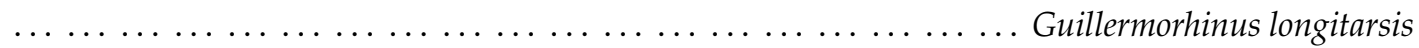

4(1) Antennae subgeniculate (scape longer than first funicular segment) $\ldots \ldots \ldots \ldots \ldots \ldots$

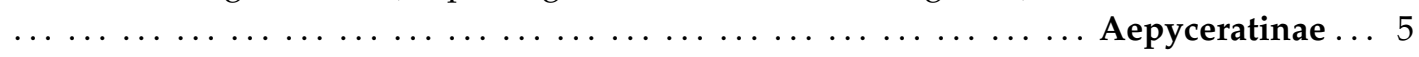
Antennae geniculate (scape about as long as entire funicle); if antennae not visible, rostrum

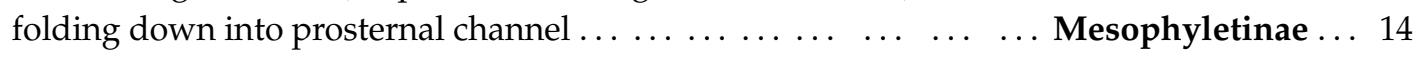

5 (4) Antennal insertions in middle of rostrum; antennae with scape only slightly $(1.2 \times)$ longer than first funicular segment, mandibles non-exodont $\ldots \ldots \ldots \ldots \ldots \ldots \ldots \ldots \ldots$ Antennal insertions behind middle of rostrum, in basal third; antennae with scape about twice as long as first funicular segment; mandibles exodont $\ldots \ldots \ldots \ldots \ldots \ldots \ldots$

6 (5) Pygidium exposed; vestiture even, without distinct setal patches ... ... Calyptocis brevirostris

- $\quad$ Pygidium hidden under elytra; vestiture with distinct patches of coloured setae ..........

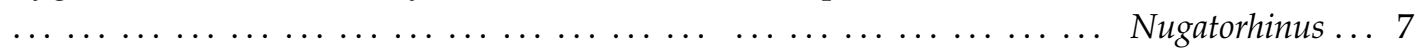

7 (6) Setal patches on body and legs orange-brown; rostrum shorter than pronotum; body length

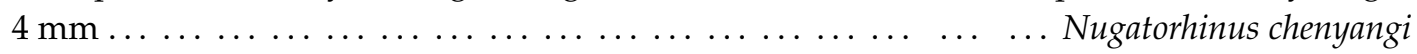
Setal patches on body and legs brilliant white; rostrum about as long as pronotum; body length $5 \mathrm{~mm} \ldots \ldots \ldots \ldots \ldots \ldots \ldots \ldots \ldots \ldots \ldots \ldots \ldots \ldots \ldots \ldots \ldots \ldots$ Nugathinus albomaculatus

8 (5) Body moderately flattened; elytral margins explanate; pronotum margined and weakly toothed at least basally, strongly inflexed ventrally; protibiae with elongate patch of dense subequally long setae (antennal cleaning brush); meso- and metatibiae with coarse teeth on distal half of inner margins ....................... Aepyceratus hyperochus

- $\quad$ Body more evenly convex; elytra and pronotum not margined as above; protibiae lacking brushes; meso- and metatibiae smooth along inner margins ... . . . . . . . . . 9

9 (8) Eyes finely facetted, nearly smooth; funicle segment 2 ca. twice longer than 1; pro- and mesocoxal cavities widely open laterally (with V-shaped suture) . . . . . . . . . . . 10 Eyes coarsely facetted; funicle segment 2 shorter than 1; pro- and mesocoxal cavities closed

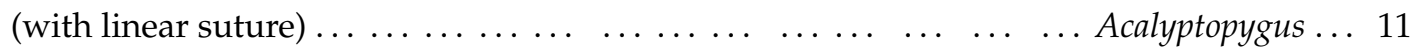

10 (9) Rostrum at least twice longer than pronotum, slender; tarsites 1 and 2 subequal in length and width; claws dentate (with large subtriangular basal tooth), with ventrobasal seta .........

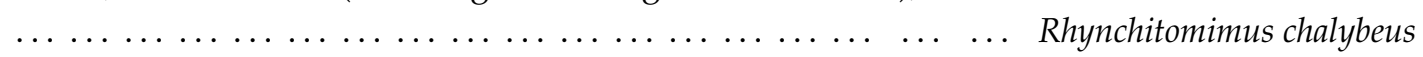


- $\quad$ Rostrum only slightly longer than pronotum, stout; tarsites 1 enlarged, much longer and wider than 2; claws simple, slightly basally angulate, without ventrobasal seta . . . . . . . .

11 (9) Elytra without striae ......................... Acalyptopygus astriatus

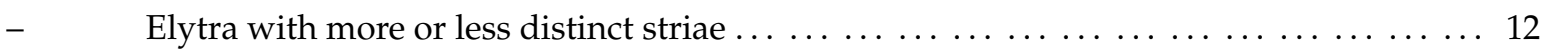

12 (11) Dorsum of head with dark median impunctate costa; scapes shorter than eye; funicle segments $2-7$ subequal . . . . . . . . . . . . . . . . . . . . . Acalyptopygus brevicornis

- $\quad$ Dorsum of head without costa; scapes as long as eyes; funicle segments 2-7 not all subequal

13 (12) Elytra distinctly punctostriate; funicle segments 2-4 subequal; body setae long, also with distinct erect setae throughout; metatibiae with single very long apical spur . . . . . . . . . . $\ldots \ldots \ldots \ldots \ldots \ldots \ldots \ldots \ldots \ldots \ldots \ldots \ldots \ldots \ldots \ldots \ldots \ldots \ldots$ Acalyptopygus elongatus

- $\quad$ Elytra weakly punctostriate; funicle segments 2-4 not subequal, 3 distinctly shorter than 2 or 4 ; body setae short, erect setae absent; metatibiae with two short spurs $\ldots \ldots \ldots \ldots \ldots \ldots$ $\ldots \ldots \ldots \ldots \ldots \ldots \ldots \ldots \ldots \ldots \ldots \ldots \ldots \ldots \ldots \ldots \ldots \ldots \ldots$ Acalyptopygus lingziae

14 (4) Tarsal claws simple (at most with angle or swelling at position of ventrobasal seta) . . . 15 Tarsal claws dentate (with distinct ventral tooth at position of ventrobasal seta) ... . . . 36

15 (14) Prothorax with prosternal channel for reception of rostrum, anterior lateral margins drawn out into ocular lobe; tarsi narrow, tarsites 3 deeply lobed but not pedunculate . . . . . . 16 Prothorax without prosternal channel, ocular lobes absent; tarsi very broad, flattened, tarsites

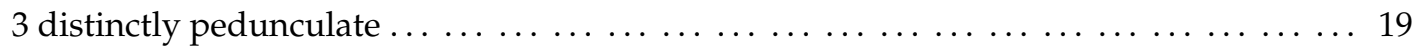

16 (15) Body squamose (with subcircular appressed scales); mesothorax with receptacle for apex of rostrum in repose $\ldots \ldots \ldots \ldots \ldots \ldots \ldots \ldots \ldots$ Palaeocryptorhynchus burmanus Body setose (setae erect); mesothorax without receptacle . . . . . . . . . . 17

17 (16) Mesoventrite in ventral view with forward-directed acute process (appearing as fin-like carina in lateral view); tibiae with 1 spur . . . . . . . . . . . . Rhadinomycter perplexus Mesoventrite without process; tibiae with 2 spurs . . . . . . . . . . . Burmorhinus . . 18

18 (17) Body elongate-slender (elytra ca. $2.0 \times$ longer than wide, pronotum slightly longer than wide); vestiture dense, on pronotum confusedly multidirectional; tibiae with inner apical tooth and 2 prominent tibial spurs; tarsites 5 shorter than $1-3 \ldots \ldots$ Burmorhinus georgei Body broader (elytra ca. $1.75 \times$ longer than wide, pronotum about as long as wide); vestiture sparser, on pronotum largely projecting anteromesad; tibiae without inner apical tooth, with 2 indistinct tibial spurs; tarsites 5 as long as $1-3 \ldots \ldots \ldots \ldots \ldots \ldots$. . . . . . . .

19 (15) Procoxae narrowly or widely separated by connected or nearly connected intercoxal processes of prosternum and hypomera (forming bridge between coxae; cavities separate or nearly so)

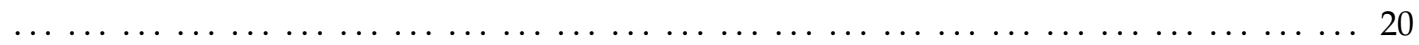

- $\quad$ Procoxae contiguous, intercoxal processes of prosternum and hypomera short, pointed, not connected between coxae (cavities broadly confluent) $\ldots \ldots \ldots \ldots \ldots \ldots \ldots$

20 (19) Antennal clubs distinctly subcompact (individual segments still visible); body generally elongate, usually somewhat flattened; prothorax much longer than wide; first funicular segment not distinctly shorter than second $\ldots \ldots \ldots \ldots \ldots \ldots \ldots \ldots \ldots \ldots \ldots \ldots$ Antennal clubs loose; body more robust; prothorax wider than long or subequal; first funicular

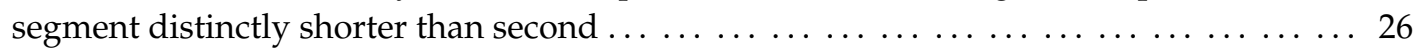

21 (20) Funicle and club segments flattened, the former distinctly widening towards club; prothorax not proclinate, anterior lateral margins vertical in lateral view; setae on protarsi extremely long (longer than width of tarsus) and wavy (possibly a male trait) $\ldots \ldots \ldots \ldots \ldots \ldots$ $\ldots \ldots \ldots \ldots \ldots \ldots \ldots \ldots \ldots \ldots \ldots \ldots \ldots \ldots \ldots \ldots \ldots \ldots \ldots \ldots$ Burmocorynus .. 22 
- $\quad$ Funicle and club segments rounded, the former not or weakly widening towards club; prothorax weakly to strongly proclinate, anterior lateral margins oblique in lateral view; setae on protarsi shorter than width of protarsi ................ . Petalotarsus ... 23

22 (21) Antennal clubs short, apical segment subequal to segment 3; apices of tibiae with long but weak fringing setae (coarser on metatibiae); meso- and metatibiae setose on only outer sides of distal half; mesotibiae with modified setae (robust, translucent spines) on inner edge of mesotibiae $\ldots \ldots \ldots \ldots \ldots \ldots \ldots \ldots \ldots \ldots \ldots \ldots \ldots \ldots \ldots \ldots \ldots \ldots \ldots \ldots$ Burmocorynus jarzembowskii

- $\quad$ Antennal clubs elongate, apical segment longer than segment 3; apices of tibiae with short and very coarse fringing setae; meso- and metatibiae setose on all sides of distal half; mesotibiae without modified setae on inner edge $\ldots \ldots \ldots \ldots \ldots \ldots \ldots \ldots$. . . . . Burmocorynus longus

$23(21) \quad$ Elytra with inner and outer stripes of whitish (or paler) setae $\ldots \ldots \ldots \ldots \ldots \ldots \ldots 24$

$-\quad$ Elytra without setal stripes $\ldots \ldots \ldots \ldots \ldots \ldots \ldots \ldots \ldots \ldots \ldots \ldots \ldots \ldots \ldots \ldots \ldots \ldots$
25

24 (23) Prothorax laterally deplanate; elytra with setal stripes distinct... Petalotarsus oxycorynoides

- $\quad$ Prothorax laterally rounded; elytra with setal stripes indistinct ... Petalotarsus curculionoides

25 (23) Eyes round, weakly protruding; body subcylindrical, especially prothorax; tarsites 2 triangular, apically subtruncate; tarsal claws basally angulate $\ldots \ldots \ldots \ldots$. . Petalotarsus cylindricus Eyes elongate, dorsoventrally compressed, distinctly protruding; body flattened, especially prothorax; tarsites 2 very deeply cleft, V-shaped, almost bilobed; tarsal claws simple ... ...

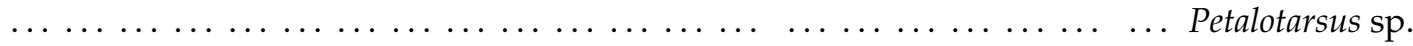

26 (20) Rostrum strongly curved; antennal insertions median; procoxae widely separated; apices of

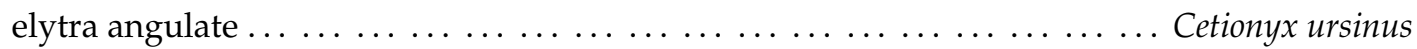

- $\quad$ Rostrum substraight, antennal insertions in basal third of rostral length; procoxae only

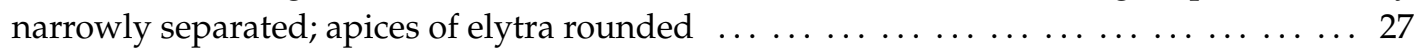

27 (26) Antennal clubs indistinct, not much wider than funicles; pronotum and elytra not close-fitting,

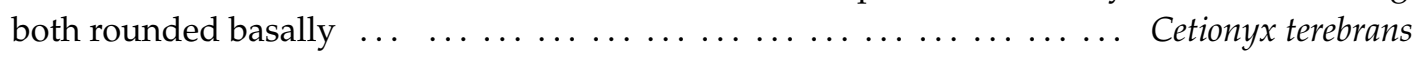
Antennal clubs distinctly wider than funicles; pronotum and elytra close-fitting . . . .....

28 (19) Tarsi very broad, flattened; tarsites 2 deeply bilobed, 3 strongly pedunculate, with bases very

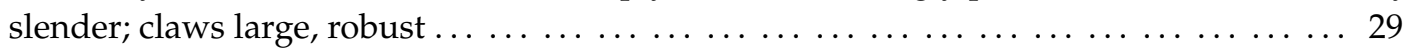

- $\quad$ Tarsi narrower; tarsites 2 apically truncate, slightly emarginate or apicolaterally angled; claws

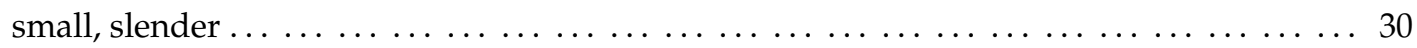

29 (28) Pygidium broadly exposed; vestiture with scattered green iridescent setae; meso- and metatibae each with 1 spur and long, inwardly projecting spike at apex $\ldots \ldots \ldots \ldots \ldots$

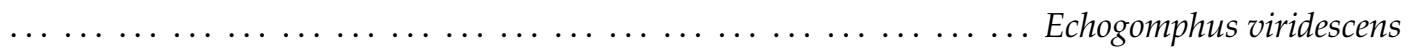

- $\quad$ Pygidium not exposed; vestiture without green iridescent setae; all tibiae with 2 short, distadly projecting spurs or none $\ldots \ldots \ldots \ldots \ldots \ldots \ldots \ldots \ldots$ Opeatorhynchus comans

30 (28) Body black, sparsely setose; ventrites 1 and 2 elongate, 3-4 each half as long as 1 or 2; ventrites

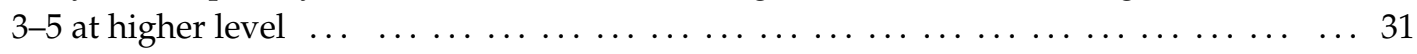

- $\quad$ Body testaceous, or paler; ventrites 1 and 2 not distinctly longer than others $\ldots \ldots \ldots \ldots 33$

31 (30) Inner tibial edge with 3-4 widely spaced denticles in distal half . . . . Electrocis dentitibialis

- $\quad$ Inner tibial edge smooth along distal half $\ldots \ldots \ldots \ldots \ldots \ldots \ldots \ldots \ldots \ldots \ldots \ldots$

32 (31) Elytral apices acutely rounded; outer edge of tibiae rounded, without tubercles ..........

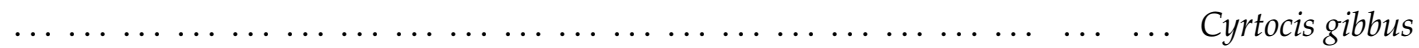
Elytral apices broadly rounded; outer edge of meso- and metatibiae with widely spaced flat tubercles... Ocriocis binodosus 
33 (30) Eyes conically protruding, facing forwards; outer edge of protibiae with small, sharp, widely spaced tubercles $\ldots \ldots \ldots \ldots \ldots \ldots \ldots \ldots \ldots \ldots \ldots \ldots \ldots \ldots \ldots \ldots \ldots \ldots \ldots \ldots$ Debbilirostris

- $\quad$ Eyes subspherical, barely protruding, lateral; protibiae without outer tubercles ... .... 34

34 (33) Lobes of tarsites 3 short and broad $\ldots \ldots \ldots \ldots \ldots \ldots \ldots \ldots$. . . . . . . . . . . . . . brevis

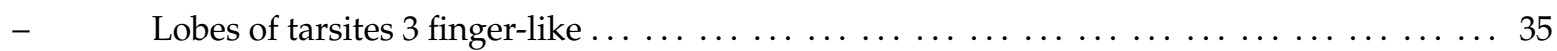

35 (34) Rostrum stout, nearly straight; tibial apices with 1 spur and a stout mucro directed perpendicular to tibial axis; elytra asetose $\ldots \ldots \ldots \ldots \ldots \ldots \ldots$ Gnomus sp.

- $\quad$ Rostrum long, curved; tibial apices with 2 spurs, no mucro; elytra setose ... Gnomus spinipes

36 (14) Head with pair of tubercles between eyes $\ldots \begin{array}{lllllllll} & \ldots & \ldots & \ldots & \ldots & \ldots & \ldots & \ldots & \ldots\end{array}$

$-\quad$ Head without tubercles between eyes $\ldots \ldots \ldots \ldots \ldots \ldots \ldots \ldots \ldots \ldots \ldots \ldots \ldots$
47

37 (36) Rostrum about as long as pronotum; tibiae carinate or costate on outside; ventrites straight, distinctly stepped, sutures not deeply incised ............. Compsopsarus . . 38

- $\quad$ Rostrum much longer than pronotum; meso- and metatibiae crenulate on outside; ventrites curved, subflatly aligned, sutures deeply incised between 2 and $5 \ldots \ldots \ldots \ldots \ldots$

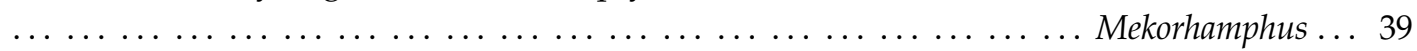

38 (37) Pronotum and elytra with loose whitish setal patches; sides of elytra in dorsal view rounded; pygidium exposed beyond elytral apices; ventrite 5 apically truncate $\ldots \ldots \ldots \ldots \ldots \ldots$

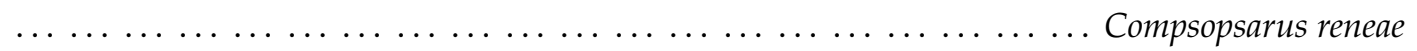

- $\quad$ Pronotum and elytra with uniform vestiture; sides of elytra in dorsal view distinctly emarginate; pygidum concealed by elytra; ventrite 5 elongate broadly triangular ... ...

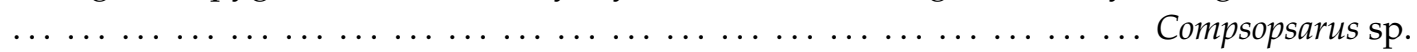

39 (37) Prothorax laterally with small dentiform process at anterior third of length; protibiae on outside distinctly curved in apical half, inner margin straight, width greater in distal half ...

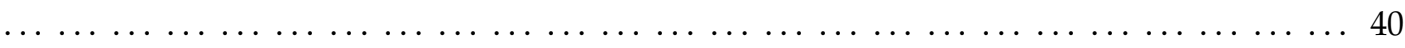

Prothorax laterally without dentiform process at anterior third of length; protibiae slender, outer and inner margins substraight, subequal in width $\ldots \ldots \ldots \ldots \ldots \ldots \ldots 41$

40 (39) Rostrum very long, $>2$. $\times$ longer than pronotum, slender; eyes slightly elongate; mesocoxae globular, moderately projecting, about as long as metaventrite; ventrite 5 as long as 3 and

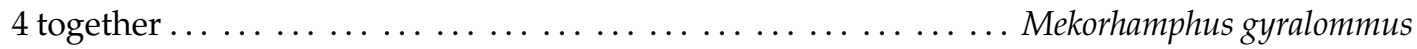

- $\quad$ Rostrum shorter, about $1.5 \times$ longer than pronotum, thicker; eyes round; mesocoxae subflat, elongate, longer than metaventrite; ventrite 5 very short, hidden $\ldots \ldots \ldots \ldots \ldots \ldots$

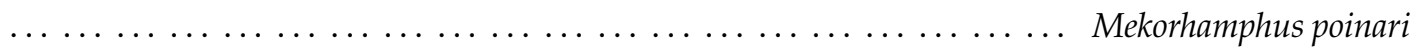

41 (39) Elytra sparsely covered in long, thin suberect setae; tarsites 2 bilobed (very deeply excised)

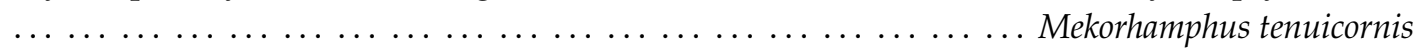

- $\quad$ Elytra without long, thin suberect setae; tarsites 2 shallowly excised, not bilobed $\ldots \quad \ldots 42$

42 (41) Ventrites weakly curved; sutures between ventrites straight at sides; tibiae distinctly crenulate along entire length; metatibiae apically truncate or only weakly notched dorso-apically; tarsi

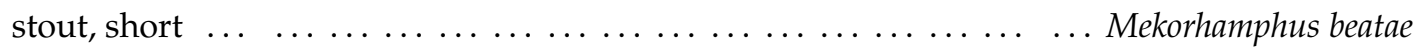

- $\quad$ Ventrites distinctly curved; sutures between ventrites kinked at sides; tibiae much less distinctly crenulate along entire length, most distinct in basal fifth; metatibiae distinctly

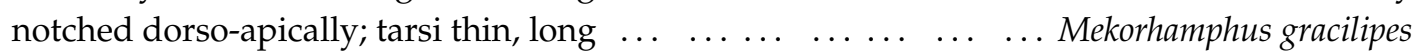

43 (36) Body moderately depressed; prothorax elongate, not proclinate, anterior lateral margins vertical in lateral view; prosternum elongate, about as long as procoxal cavity diameter; antennae thick, inserted in apical third (possibly a male trait); clubs short, with segments apically strongly oblique $\ldots \ldots \ldots \ldots \ldots \ldots \ldots \ldots \ldots \ldots$ Periosocerus $\ldots \ldots \ldots 4$ 
- $\quad$ Body robust, not depressed; prothorax transverse or elongate but variously proclinate, anterior lateral margins oblique in lateral view; prosternum short to very slender, shorter than procoxal cavity diameter; antennae slender, inserted closer to middle or in basal third of rostrum; clubs usually long to very long, with segments apically truncate to weakly oblique .........

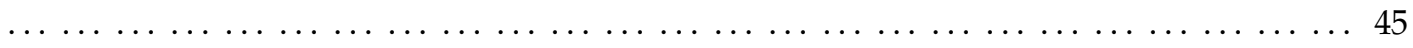

44 (43) Tibiae crenulate-serrulate, with thickend spur-like seta at outer apical margin; protarsi short and broad, ca. half as long as tibiae; antennal clubs elongate, almost as long as funicle ...... Periosocerus crenulatus

- $\quad$ Tibiae not crenulate or serrulate, outside rounded, without distinctly thicker seta at outer apical margin; protarsi elongate, more than half as long as tibiae; antennal clubs slightly longer than half length of funicle $\ldots \ldots \ldots \ldots \ldots \ldots \ldots \ldots$ Periosocerus deplanatus

45 (43) Tibiae carinate or rounded along outer edge, without any teeth forming a row . . . . . 46

- $\quad$ At least pro- or meso- and metatibiae crenulate or serrulate along outer edge $\quad \ldots \quad \ldots \quad \ldots \quad 48$

46 (45) Tibiae cylindrical, without crest or ridge on outer side; tarsites 3 broadly bilobed; mandibles horizontal; length $>3.0 \mathrm{~mm} \ldots \ldots \ldots \ldots \ldots \ldots \ldots \ldots \ldots \ldots \ldots \ldots$ Hukngius crassipes

- $\quad$ Tibiae crested or carinate on outer side; tarsites 3 digitate; mandibles vertical; length $<3.0 \mathrm{~mm}$

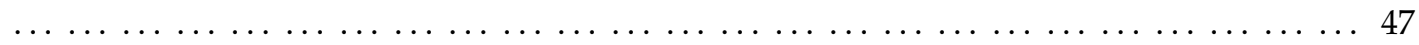

47 (46) Antennae inserted at or slightly in front of middle of rostrum; mandibles with indistinct teeth; scapes, first 2 funicle segments and last 2 club segments distinctly pale, depigmented; length $<2.0 \mathrm{~mm} \ldots \ldots \ldots \ldots \ldots \ldots \ldots \ldots \ldots \ldots \ldots \ldots \ldots \ldots \ldots \ldots \ldots$ Anchineus dolichobothris

- $\quad$ Antennae inserted just behind middle of rostrum; mandibles with sharp inner and outer teeth; antennae uniformly coloured; length $>2.0 \mathrm{~mm} \ldots \ldots \ldots \ldots$ Euryepomus lophomerus

48 (45) Meso- and metatibae distinctly crenulate or pectinate-carinate on outer side, teeth indistinctly separated $\ldots \ldots \ldots \ldots \ldots \ldots \ldots \ldots \ldots \ldots \ldots \ldots \ldots \ldots \ldots \ldots \ldots$

- $\quad$ Meso- and metatibae distinctly serrulate on outer side, teeth distinctly separated . . . . 55

49 (48) Body darkly pigmented, appendages distinctly paler; at least one ventrite impressed or with distinct concavity $\ldots \ldots \ldots \ldots \ldots \ldots \ldots \ldots \ldots \ldots \ldots \ldots \ldots \ldots \ldots \ldots$ Myanma $\ldots \ldots \ldots$ Body and legs not distinctly differently pigmented, ventrites not impressed or concave ...

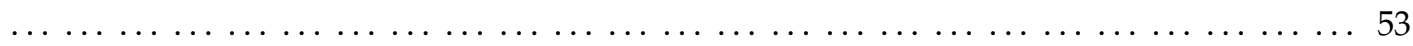

50 (49) Pronotum with sharp lateral tooth slightly in front of middle $\ldots \ldots \ldots \ldots \ldots \ldots$

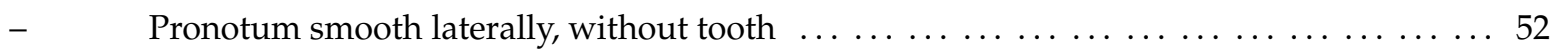

51 (50) Tibiae with two large flattened spurs; protarsal claws dentate, with large triangular tooth; metafemora subequal to others; ventrites 1-3 grooved with posterior angles elevated into blunt setose tubercles $\ldots \ldots \ldots \ldots \ldots \ldots \ldots \ldots \ldots \ldots \ldots \ldots \ldots$ Mymarus dentifer Tibiae with two normal spurs; protarsal claws deeply bifid and dentate; metafemora more swollen than others; ventrites 1-3 broadly shallowly impressed with posterior angles elevated into low, asetose tubercles . . . . . . . . . . . . . . . Myanmarus diversiunguis

52 (50) Elytral setae black but with whitish setae in loose patches; ventrites smooth except 5 with distinct concavity, setose on either side; outer side of meso- and metatibiae emarginate before apex; outer side of metafemora crenulate in distal third $\ldots \ldots \ldots \ldots \ldots \ldots \ldots \ldots$

\section{Myanmarus caviventris}

- $\quad$ Elytral setae whitish; ventrites shallowly concavely depressed on disc, 5 without concavity; outer side of meso- and metatibiae straight, not emarginate before apex; outer side of metafemora carinate in distal third $\ldots \ldots \ldots \ldots \ldots \ldots$. . . . . . . . . . . . . 
53 (49) Eyes distinctly conically protruding; meso- and metatibiae with strong carinate-pectinate ridge extending full length of tibia, and with large uneven apical spurs, the inner one fixed

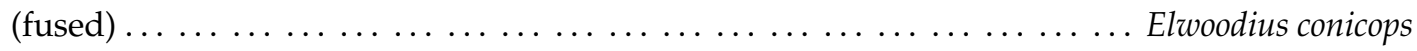
Eyes elongate, protruding, slanting backwards; meso- and metatibiae crenulate but not to

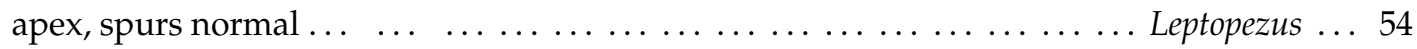

54 (53) Elytra distinctly punctostriate, interstriae broad and flat; rostrum much longer than pronotum, strongly curved (possibly a female trait), laterally with slender short setae in front of antennal insertions; outer edge of meso- and metafemora crenulate in distal third . . . . . . . . . . . Leptopezus rastellipes

- $\quad$ Elytral striae and interstriae indistinct; rostrum slightly longer than pronotum, moderately curved, thick basally, laterally with thick long setae in front of antennal insertions; outer edge of femora carinate in distal third $\ldots \ldots \ldots \ldots \ldots \ldots \ldots \ldots \ldots$ Leptopezus barbatus

55 (48) Tarsites 2 apically deeply excised, appearing almost bilobed; eyes flatly hemispherical ......

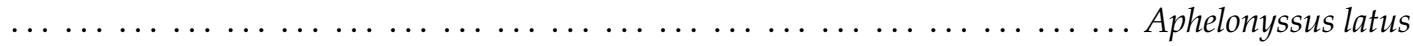

- $\quad$ Tarsites 2 apically truncate to weakly incised, entire; eyes protruding or hardly protruding

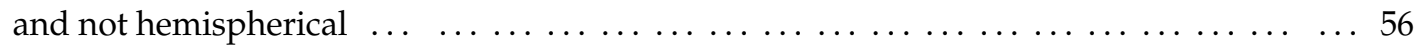

56 (48) Eyes vertically elongate, hardly prominent; outer edge of protibia carinate; mesotibiae distinctly bent inwards at apex $\ldots \ldots \ldots \ldots \ldots \ldots \ldots$ Louwiocis megalops Eyes round or compressed, variously prominent; outer edge of protibiae serrulate; mesotibiae straight to at most slightly curved inwards $\ldots \ldots \ldots \ldots \ldots \ldots \ldots \ldots \ldots$

57 (56) Tarsite 3 lobes digitate; mandibles with indistinct teeth; scapes, first 2 funicle segments and last 2 club segments distinctly pale, depigmented ............ Anchineus dolichobothris

- $\quad$ Tarsite 3 lobes broadly bilobed or pedunculate; mandibles with distinct inner and outer teeth;

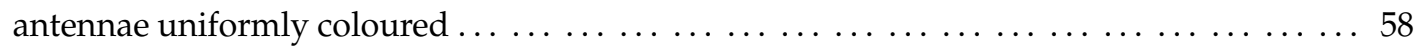

58 (57) Pro- and mesotibiae with long inner spur (probably fixed) and diminutive outer one, metatibiae with 2 subequal small spurs; tarsite 3 lobes strongly pedunculate; ventrites flatly

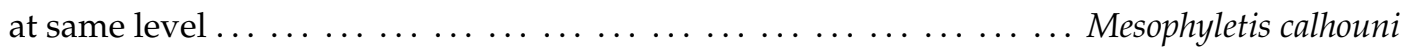

All tibiae with 2 subequal spurs; tarsite 3 lobes long but broader basally; ventrites not entirely

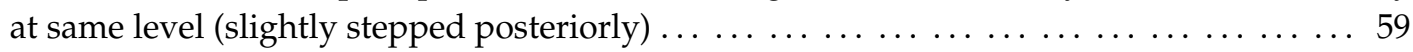

59 (58) Eyes moderately to distinctly depressed, flatly elongate; forehead flat to shallowly concave, broad, distance between eyes expanding posteriad ............ Habropezus ... 60 Eyes roundly protuberant or slightly elongate; forehead forming a narrow groove, distance between eyes subequal to rostral width, not increasing posteriad ........ Bowangius ... 63

60 (59) Rostrum in front of antennal insertions with row of distinct thick elongate setae; tibiae on outside at most sparsely serrulate, teeth widely spaced $\ldots \ldots \ldots \ldots \ldots \ldots \ldots \ldots 61$ Rostrum in front of antennal insertions without row of setae, at most a few near apex or setae indistinct; tibiae on outside closely serrulate or crenulate, teeth closely spaced . . . . . 62

61 (60) Rostrum bent downwards in middle (perhaps a distortion); protibiae carinate; meso- and metatibiae weakly serrulate, teeth minute and widely separated (probably setal sockets); tarsi slender, lobes of tarsites 3 long, slender at base ... ......... Habropezus incoxatirostris

- $\quad$ Rostrum evenly curved to nearly straight; all tibiae distinctly serrulate, teeth large, closely spaced; tarsi robust, lobes of tarsites 3 short, broad at base ......... Habropezus tenuicornis

62 (60) Outer sides of meso- and metafemora (and possibly profemora) with crenulate or serrulate ridge in distal third; tibiae with sparse fine setae in distal half, serrulate on outside, teeth distinctly separate, sharp; meso- and metatibae straight, not apically excised on outside, apically narrowly rounded $\ldots \ldots \ldots \ldots \ldots \ldots \ldots \ldots \ldots \ldots$ Habropezus plaisiommus Outer sides of femora rounded or carinate; tibiae with dense coarse setae in distal third, crenulate on outside, teeth contiguous, rounded; meso- and metatibae apically excised on outside, distinctly obliquely truncate apically $\ldots \ldots \ldots \ldots \ldots \ldots$ Habropezus kimpulleni 
63 (59) Body length $>5.0 \mathrm{~mm}$; elytra shining, without sculpture, setae very short, inconspicuous; protibiae carinate, others serrulate $\ldots \ldots \ldots \ldots \ldots \ldots$ Bowngius glabratus

- $\quad$ Body length $<3.0 \mathrm{~mm}$; elytra dull, rugosely sculptured, setae long distinct; all tibiae serrulate

.

$64(63) \quad$ Eyes elongate in lateral view, slightly compressed $\ldots \ldots \ldots \ldots \ldots \ldots \ldots \ldots \ldots$

$-\quad$ Eyes round in lateral view, hemispherical $\ldots \ldots \ldots \ldots \ldots \ldots \ldots \ldots \ldots \ldots \ldots$
65

65 (64) Rostrum substraight, on ventral side in front of eyes with row of several rounded teeth with intervening short setae on either side of gular suture; pronotal setae distinctly directed anteriad; procoxae closer to anterior prosternal margin . .......... Bowangius zhenuai

- $\quad$ Rostrum curved, flat on ventral side in front of eyes; pronotal setae directed anteromesad; procoxae closer to posterior hypomeral margin .............. Bowangius tanaops

66 (64) Pronotal setae distinctly directed anteriad; outer side of femora rounded, without carina or teeth; inner edge of metatibiae in apical third with rounded fin-like carina; tarsites 1 excised, 2 more deeply excised $\ldots \ldots \ldots \ldots \ldots \ldots \ldots \ldots \ldots \ldots \ldots \ldots \ldots \ldots$ Bownius cyclops

- $\quad$ Pronotal setae directed anteromesad; outer side of femora with carina in distal third to half; inner edge of metatibiae straight; tarsites 1 and 2 subtruncate to truncate $\ldots \quad \ldots \quad \ldots \quad \ldots 67$

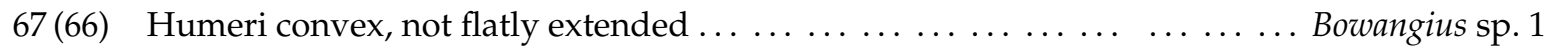

- Humeri flatly extended $\ldots \ldots \ldots \ldots \ldots \ldots \ldots \ldots \ldots \ldots \ldots \ldots \ldots \ldots \ldots \ldots$ Bowgius sp. 2

\subsection{Descriptions}

\section{Family NEMONYCHIDAE}

Following Kuschel [1], the usual concept of this family has included three subfamilies, Nemonychinae, Cimberidinae and Rhinorhynchinae (e.g., [9,44]). Although these three taxa share several characters, most of them are plesiomorphic and occur in other families too, and the three synapomorphies proposed for them $[1,44,45]$ are not particularly strong (one applying to the male terminalia, two to the larva). The only molecular phylogenetic analysis to date that included genera of all three subfamilies [13] did not recover them as a monophyletic family, finding Nemonychinae and Rhinorhynchinae more closely related to Anthribidae and Cimberidinae forming the sister taxon of this clade. A recent molecular analysis [6] based on a larger sample of DNA data (but fewer taxa) yielded a similar result, except that Cimberidinae formed the sister group of all other weevils, and as the nodal support for these relationships was maximal, the authors raised Cimberidinae to family level and restricted Nemonychidae to include only Rhinorhynchinae and Nemonychinae (though the latter was not represented in the analysis). In this narrower concept, Nemonychidae can be more easily characterised by possessing bifid or laminate tarsal claws, without a ventrobasal seta, and very short gular sutures, hidden under the prosternal margin to being obsolete. There are, however, several differences between Nemonychinae and Rhinorhynchinae [1], and their precise relationships require further study. In fossils (if well preserved), Cimberididae can be distinguished from Rhinorhynchinae by the lack of elytral striae, simple tarsal claws with a ventrobasal seta, apically lobed tarsites 2 , long gular sutures and, if visible, the lack of mesonotal stridulatory files.

Among the Burmese amber weevils known to us, none represent Cimberididae, but three species (Burmonyx zigrasi, Burmomacer kirejtshuki and Guillermorhinus longitarsis) are classifiable in Rhinorhynchinae due to their free labrum, distinct elytral striation and bifid claws.

\section{Subfamily Rhinorhynchinae}

With 19 genera and 57 species, this subfamily comprises the bulk of the extant fauna of Nemonychidae. Apart from the small genus Atopomacer Kuschel in Mexcio and the U.S.A., it is restricted to the Southern Hemisphere and particularly diverse in the Australo-Pacific region. It is divided into three tribes, Mecomacerini, Rhinorhynchini and Rhynchitomacrini, which differ in small features [45] mostly unobservable in fossils and may be easier characterised by their host plants, respectively Araucariaceae, Podocarpaceae and Nothofagaceae. All three nemonychid genera in 
Burmese amber, Burmonyx, Burmomacer and Guillermorhinus, possess the characters of Mecomacerini, i.e., apical maxillary palp segments as long as the scapes, a long prosternum in front of the procoxae (as long as the coxae) and a head deeply constricted behind the eyes. The apparent araucariaceous origin of the Burmese amber would support this assessment. A separate tribe was proposed for Burmomacer, based on its seemingly separated procoxal cavities [46]. Separated procoxal cavities do not occur in any extant nemonychid, not even in Brarus Kuschel, in which the prosternal and hypomeral intercoxal processes intrude more strongly between the procoxae but do not meet, thus separating the procoxae but not their cavities. Although at least the prosternal process is very broad and long in Burmomacer and clearly separates the procoxae, it is not possible to assess whether it also meets a hypomeral process and actually separates the procoxal cavities. Even if it does, this difference hardly warrants recognition of a different tribe, and we therefore treat Burmomacrini as a synonym of Mecomacerini (syn. n.). In its original description [46], the name Burmomacrini was malformed as Burmomaceratini; the stem of the name of the type genus is Burmomacr-, not Burmomacerat- (for details of the stem of names ending in -macer and the retention of the name Mecomacerini due to prevailing usage, see [11]).

A further alleged nemonychid tribe, Oropseini (originally misspelled as Oropsini), was proposed for the genus Oropsis Legalov \& Kirejtshuk, described from Lebanese amber [47]. However, its combination of characters as described (short but visible gular sutures, simple tarsal claws, striate elytra with short scutellary strioles) does not accord with either Nemonychidae or Cimberididae, and several other features visible in the photographs of the specimen (compact antennal clubs, elongate depressed eyes, low head, rough (rugose) elytral sculpture without distinctly visible striae, strongly elongated ventrite 1) also militate against its inclusion in either of these families. If it truly has a labrum as described, it cannot fit into any other currently recognised weevil family either, and it needs reexamination to ascertain whether it is a weevil at all. In particular, the segmentation of the tarsi, described as being pseudotetramerous (as "pseudoquadri segmented") but not visible in the published photographs, has to be verified. Another extinct genus described as a nemonychid and subsequently placed in Oropseini [47], Arra Peris, Davis \& Delclòs [48], has pentamerous rather than pseudotetramerous tarsi and evidently belongs in the tenebrionoid family Salpingidae.

Genus Burmonyx Davis \& Engel, 2014

Burmonyx Davis \& Engel, 2014: 129 [49] (type species, by original designation: Burmonyx zigrasi Davis \& Engel, 2014)

Redescription. Size. Length $2.33 \mathrm{~mm}$, width $0.96 \mathrm{~mm}$. Head short, transverse, globular, constricted behind eyes. Eyes large, lateral, strongly but flatly protruding, directed somewhat anteriad, coarsely facetted, dorsally separated by width of rostrum anteriorly but much further posteriorly; forehead flat, without tubercles between anterior margin of eyes; ventrally with anterolateral processes of postmentum. Rostrum about $1.5 \times$ longer than pronotum, slender, flattened, substraight, apically strongly expanded; antennal insertions in apical quarter, dorsolateral, without scrobes behind them; anterolateral corners of postmentum extended into long processes. Antennae non-geniculate, long; scapes short, globular, about half as long as funicle segment 1; funicles 7-segmented, segment 1 subequal in width to scape, segments 2-5 thinner, 6-7 broader, subequal; clubs large, much shorter than funicle, loosely articulated, 4 -segmented, segment 4 acute, shorter than 3. Mouthparts. Labrum present. Mandibles long, falcate, non-exodont, articulation horizontal. Maxillary palps prominent, elongate, projecting well beyond rostral apex, apparently 3-segmented. Labial palps elongate, slender, projecting well beyond rostral apex apparently 3-segmented. Thorax. Prothorax robust, not proclinate, anterior lateral margins vertical in lateral view. Pronotum convex, broad, only slightly narrower than elytra, laterally rounded, without tooth, disc flatter, posterior corners indistinct, fitting closely onto elytra; surface rugose, sparsely setose, setae reclinate, directed anteriad; notosternal sutures closed ventrally, not evidently continuing anteriad. Prosternum long, prosternal process apically slightly broader, shallowly excised, projecting obliquely ventrad over procoxae, not contacting hypomeral process (this not visible); procoxal cavities medially confluent, appearing separated anteriorly and 
between coxae, closer to posterior margin of hypomeron. Scutellar shield sparsely setose. Mesocoxal cavities closed laterally by meso- and metaventrite. Metanepisterna distinct, sparsely setose, without anterodorsal lobe. Metaventrite long, slightly convex. Elytra elongate, not basally lobed over base of pronotum, with broadly rounded humeri, posteriorly declivous, lateral margin sinuate to roundly emarginate in middle, anterior marginal notch absent, apically conjointly rounded, not exposing pygidium; sutural flanges narrow, equal; surface punctostriate, with scutellary striole (6-punctate on right elytron, 7-8-punctate on left), extending obliquely posteriad to about basal third of sutural length; interstriae flat, finely but distinctly punctosetose, setae short, thin, black, reclinate, directed caudad. Hindwings not visible. Legs. Procoxae small, globular, medially seemingly separated by intrusion of prosternal process but probably contiguous beneath this; mesocoxae subglobular, broadly separated; metacoxae flat, transversely elongate. Trochanters short, oblique. Femora long, weakly inflated, outer side rounded. Tibiae straight, compressed, outer side smooth, somewhat edged, with dense long stiff setae in distal half, apex obliquely truncate, with 2 spurs. Tarsi elongate, slender, almost as long as tibiae; tarsite 1 apically truncate, 2 shorter, subtriangular, 3 deeply bilobed, lobes broad, somewhat flattened, 5 long, apically expanded; claws divaricate, strongly bifid (inner tooth spiniform, almost as long as outer claw), without ventrobasal seta. Abdomen with all ventrites free, slightly stepped; 1-4 progressively shorter, 5 about as long as $3+4$, broadly rounded.

Derivation of name. The gender of the name Burmonyx was not specified by its authors and is not inferable from the name of the single species placed in the genus (a noun in genitive case). The suffix $-n y x$ in scientific names is normally derived from the masculine Greek noun onyx (G: onychos), a claw (e.g., in the comparable name Nemonyx, meaning 'divided claw'), but in Burmonyx it is said to be derived from the feminine Greek noun $n y x$ (G: $n y k t o s$ ) [49], the night (actually the goddess of the night), and thus the gender of Burmonyx must be taken to be feminine (Art. 30.1. of the International Code of Zoological Nomenclature) and the stem of the name to be Burmonyct-, not Burmonych-.

Remarks. Although the long, apically expanded rostrum, falcate mandibles, bifid claws and coarsely punctostriate elytra depicted in the original description of Burmonyx are consistent with a placement of the genus in Nemonychidae: Rhinorhynchinae as given [49], this assignment was unconvincing as the rostrum and antennae are not properly visible in the photographs provided and the alleged scutellary striole as indicated is too long for such a striole as it occurs in all extant weevils. Considering their possible misinterpretation of the scutellary striole (the optimal viewing angle being unavailable in the original block) and the similarity of the "appendiculate" claws of Burmonyx to the "divaricate bifid" ones described for Mesophyletis calhouni [29] (see there for further discussion), the authors conceded a "superficial resemblance" of Burmonyx to Mesophyletinae [49]. After cutting the specimen out of its large original amber block, we could ascertain that it indeed has a free labrum, falcate mandibles (see below) and non-geniculate antennae as well as scutellary strioles (but of normal length, not the one originally indicated, which is the inner edge of the left sutural stria) (Figure 14l). Together with the striate elytra and verified bifid tarsal claws, these features indicate that the placement of the genus in Nemonychidae is correct. The large right falcate mandible as drawn by the authors is in fact the right maxillary palp, which in the original block resembled a large mandible but was blurred by the thickness of the amber; the right mandible is tightly folded under the left one (Figure 14d,e). Whereas the insertion of the scape in the rostrum is correctly indicated in Figure 1 of the orginal description [49], most of the left antenna and the apical part of the rostrum were obscured in the original block and the actual length of the scape and funicle was therefore unclear. Burmonyx agrees with Guillermorhinus in having a long, thin rostrum and the anterolateral corners of the postmentum extended into long processes, but it differs from it in its coarsely punctostriate elytra, narrower tarsi (especially tarsites 5), broader lobes of tarsites 3 and more strongly bifid, not basally angulate tarsal claws. From Burmomacer it differs readily in its long rostrum, postmental extensions and the coarsely punctostriate elytra. It is represented by a single species. 
Burmonyx zigrasi Davis \& Engel, 2014 (Figure 14)

Burmonyx zigrasi Davis \& Engel, 2014: 129 [49]

Redescription. Size. Length $2.33 \mathrm{~mm}$ (excl. rostrum, not SL), width $0.96 \mathrm{~mm}$. Small, robust; orange-brown. Head broad, convex posteriorly; sparsely, shortly punctosetose, punctures umbilicate, setae directed anteriad. Eyes directed forwards, anterior margin much longer than posterior margin; coarsely facetted; without interfacettal setae. Rostrum dorsally carinate, with median, paramedian and dorsolateral carinae, these very sinuate, variously obsolete before apex; setose, with curved setae along most of length; ventrally with carinate edge extending from before antennal insertions to apex; with setae in space in front of insertions between dorso- and ventrolateral carina. Mandibular articulations lateral; dorso-apical rostral apex subsinuate, slightly emarginate in middle, slightly apicolaterally lobed. Antennae with club segments 1-3 distinctly obconical, subequal, 2 slightly wider than 1, 4 short, acute. Mouthparts. Labrum transverse, broadly convex; clypeolabral suture present but indistinct. Mandibles without internal teeth; articulation plane horizontal. Maxillary palps apparently 3-segmented (visible in dorsal view); terminal segment subfusiform, nearly $4 \times$ longer than penultimate one, this seemingly longer externally, segment 2 (?) seemingly subequal in length to and narrower than 3 (?). Labial palps with apical segment longer than penultimate one. Thorax. Prothorax with anterior margin extending seemingly evenly down sides to prosternum. Pronotum with white, subrecurved setae, basal margin not distinctly beaded. Prosternum transverse, much longer than hypomeron, about 3.0x longer than procoxae, minutely punctosetose like pronotum, setae whitish, anterior margin straight, prosternal process projecting subventrally, apically slightly bilobed. Mesothoracic sutures largely indistinct (mesoventrite and mesanepisterna possibly party fused); mesanepisterna and mesepimera sparsely setose. Metaventrite sparsely shallowly punctate; posterolaterally at same level as metacoxae; not protruding between meso- and metacoxae. Metanepisterna without anterodorsal lobe (dorsal edge straight). Elytra with 10 thin punctate striae; sutural interstriae more raised than others, setose distally near apex, forming slender, low carina. Elytral bases broadly arcuate, extending evenly across middle; subcarinate, continuous with anterior scutellar margin; not submarginally concave to receive basal pronotal margin; margin seemingly doubled, with carinate ridge delimiting basal margin, submarginally with secondary ridge appearing as dark arcuate line. Elytral sides with marginal groove gradually attenuating posteriad, becoming approximate with ventral edge of elytron near apex; without anterior marginal notch, dorsal edge forming distinct lateral carina upturned near humeri. Legs. Coxae small, indistinct. Tibiae sparsely setose, setae longer in distal half; apically with short flanges, with long, coarse, loose fringing setae. Tarsites 1 much longer than wide, subcylindrical, gradually expanding apicad, 2 slightly shorter, 3 lobate, lobes subflattened but concave along inner edges, cryptotarsite distinct, articulating with 3 basomedially, 5 about as long as $1+2$, slender, only very weakly curved. Protarsi slightly shorter, narrower than others; with lobes of tarsites 3 seemingly shorter than on other legs. Abdomen with terminal tergite sclerotised, visible above ventrite 5; setose. Ventrites moderately densely setose, sutures broadly arcuate. 


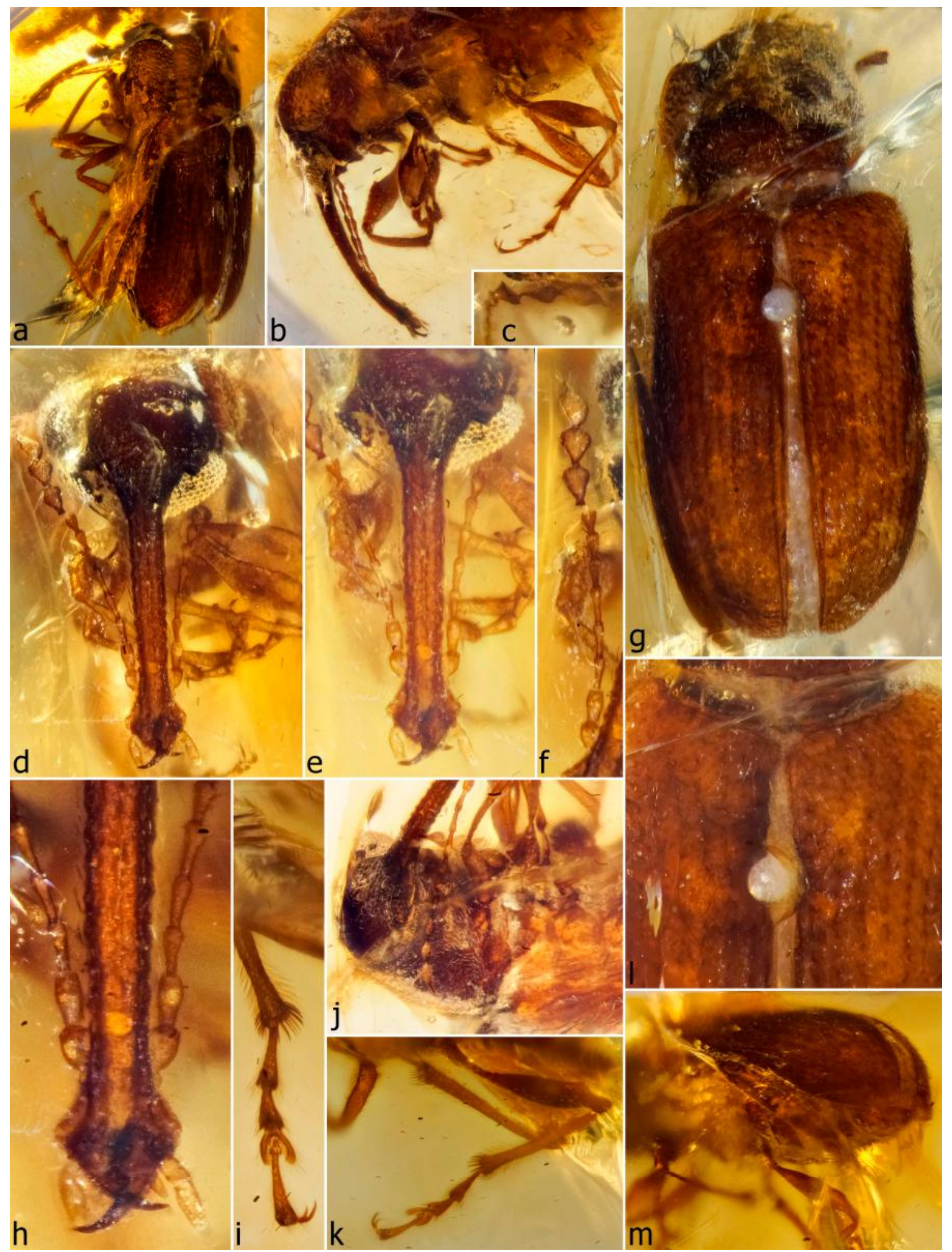

Figure 14. Burmonyx zigrasi, holotype. Habitus, left lateral (a); head and prothorax, left lateral (b); left antennal club, left lateral (c); head, dorsal (d); same, showing details of head and eyes (e); right antenna, dorsal (f); habitus, dorsal (g); detail of rostrum and mandibles, dorsal (h); left metatarsus, dorsal (i); head, prothorax and mesothorax showing closed coxal cavities, right lateroventral (j); left hindleg, anterior (outer) (k); detail of elytral striation showing scutellary striole, dorsal (1); elytral and abdominal apex, laterocaudal (m). 
Material examined. Holotype (AMNH JZC-Bu228): well preserved intact specimen, with mouthparts and appendages visible (right antennal club severed from funicle), prothorax and metaventrite distorted (or teratological; somewhat bulging, cuticle seemingly modified); re-prepared from much larger pebble-shaped amber piece from which the original description was prepared, now at end of flattened wedge $6.3 \times 6.9 \times 0.3-2.1 \mathrm{~mm}$, with two large flat faces and two oblique edge-faces exposing dorsal side and dorsum of head and rostrum; amber clear yellow, without any debris, with fracture running transversely through middle of inclusion near elytral bases, other less significant fractures in surrounding matrix.

Remarks. Even following extraction of this specimen from the original large amber piece, numerous details of it are partly or wholly obscured. These include the ventral side of the head and rostrum, the ventral prothorax (particularly the intercoxal and hypomeral areas) and much of the meso- and metathorax and ventrites. These details may become visible if the block were cut along the ventral side, but the existing fractures would necessitate stabilising the block with embedding resin prior to further cutting, ideally by the method described by Nascimbene and Silverstein [36]. Some distortion artefacts have created differences between the left and right sides of structures, particularly of the antennae, prothorax anterolaterally (the right side seemingly is the undistorted one) and metaventrite (unclear which side is less distorted). A bubble emanating from the elytral suture partly obscures the posterior endpoint of the scutellary strioles and locally distorts the sutural margins, probably facilitating the appearance of a long scutellary striole in the specimen. A distinct, curved, ridge-like structure on the upper side of the right profemur (Figure 14b) superficially seems unlikely to be a result of distortion, but it is seemingly absent on the left femur, thus casting doubt on the taxonomic value of this very distinctive feature. Contrary to the original drawing of the specimen [49], the left hindwing is not exposed behind the elytron; the structure drawn is merely a crack in the amber. Surface obscurities, mainly of the ventral side, may pose an additional difficulty when attempting to correctly identify further species or specimens of Burmonyx, as proportions of structures and other useful surface characteristics are obscured in places.

Perhaps the most noticeable differences between B. zigrasi and Guillermorhinus longitarsis are the much longer and coarser tibial fringing setae and very long spurs. Additional differences from $G$. longitarsis include the distinctly scalloped dorsal carinae of the rostrum, the longer scutellary strioles, the longer, slenderer funicle segments and the shorter apical club segments.

Genus Guillermorhinus Clarke \& Oberprieler, gen. n.

Type species: Guillermorhinus longitarsis Clarke \& Oberprieler, sp. n.

Description. Size. Length $2.1 \mathrm{~mm}$, width $0.93 \mathrm{~mm}$. Head porrect, short, largely not visible (retracted into prothorax). Eyes not visible, evidently small, directed somewhat forward, coarsely facetted, dorsally separated by width of rostrum anteriorly. Rostrum slightly longer than pronotum, slender, subflattened, weakly curved, apically expanded; antennal insertions in apical quarter, dorsolateral, with shallow scrobes indicated in front and behind them; anterolateral corners of postmentum extended into long processes (Figure 15f). Antennae non-geniculate, slightly longer than rostrum; scapes short, globular, subequal in length to funicle segment 1; funicles 7-segmented, segment 1 broader than scape, 2-7 thinner, shorter, subequal; clubs large, much shorter than funicle, loosely articulated, 4-segmented, apical segment short, acute, about as long as 3. Mouthparts. Labrum present. Mandibles long, falcate, non-exodont, articulation horizontal. Maxillary palps prominent, elongate, projecting well beyond rostral apex, apparently 3-segmented. Thorax. Prothorax narrower than elytra, proclinate, with anterior lateral margins oblique in lateral view. Pronotum laterally without tooth, posterior corners indistinct, fitting closely onto elytra; surface finely punctate, sparsely setose, setae reclinate, directed anteromesad; notosternal sutures closed ventrally, vertical, not evidently continuing anteriad. Prosternum long; procoxal cavities probably separated at least anteriorly but poorly visible (crumpled), closer to posterior hypomeral margin. Scutellar shield densely setose. Mesocoxal cavities closed laterally. Metanepisterna not visible. Metaventrite long, lightly convex. Elytra elongate, not basally lobed over base of pronotum, with broadly rounded humeri, posteriorly 
hardly declivous, lateral margin nearly straight, anterior marginal notch absent, apically closing evenly, conjointly rounded, not exposing pygidium; sutural flanges narrow, equal; surface weakly, shallowly punctostriate, with short scutellary striole, interstriae flat, finely punctosetose, setae short, thin, whitish, reclinate, directed caudad. Legs. Procoxae globular, not projecting, medially apparently separated by intrusion of prosternal process; mesocoxae globular, broadly separated; metacoxae flat, transversely elongate. Trochanters short, oblique. Femora long, weakly inflated at middle, outer side rounded. Tibiae straight, compressed, slightly widening distad, outer edge smooth, apices obliquely truncate, with 2 spurs. Tarsi elongate, slender, flattened, almost as long as tibiae; tarsites 1 and 2 subequal, widening distad, apically truncate, 3 deeply bilobed, lobes digitate, 5 long, apically expanded; claws divaricate, bifid, also with basal angulation, without ventrobasal seta. Abdomen with all ventrites free, slightly stepped; $1-5$ subequal, 5 about as long as $3+4$, broadly rounded.

Derivation of name. The name of the genus is composed of the first name of the eminent weevil specialist Guillermo ('Willy') Kuschel, to whom the Special Issue of Diversity in which this paper appears is dedicated, and the Greek noun rhis (G: rhinos), meaning nose or snout; its gender is masculine.

Remarks. Guillermorhinus agrees with Burmonyx in having the anterolateral corners of the postmentum extended into long processes (Figure 15f) but differs from it in its weakly, finely punctostriate elytra, broader, flat tarsites 5, narrow, digitate lobes of tarsites 3 and shortly bifid, basally angulate tarsal claws. It is also represented by a single species. Like Burmonyx, it differs from all extant genera of Rhinorhynchinae in its long postmental processes and narrow, finger-like lobes of tarsites 3. Its long terminal maxillary palp segments, long prosternum and deeply constricted head behind the eyes indicate that it belongs in the tribe Mecomacerini. From Burmomacer it also differs in its long rostrum and the postmental extensions.

Guillermorhinus longitarsis Clarke \& Oberprieler, sp. n. (Figure 15)

Description. Size. Length $2.1 \mathrm{~mm}$, width $0.93 \mathrm{~mm}$. Head largely invisible. Eyes evidently small. Rostrum subequal in width for most of length, expanded apically. Mouthparts. Mandibles prominent, long, slender, acutely pointed (overlapping and exposed in repose). Antennae with club segments 1-2 shortly obconical, subequal in length and width, 2 slightly wider than long, 3 subequal in width to 2 . Thorax. Pronotum finely punctosetose; with short, recurved, mesadly or anteromesadly directed setae. Prosternum moderately elongate, seemingly about as long as procoxae, anterior margin slightly emarginate. Mesoventrite short. Metaventrite long, flat. Elytra subparallel-sided, in dorsal view shallowly concave in front of middle; surface densely covered with short, acutely pointed setae directed caudad. Legs Metafemora more strongly inflated in middle than others; tibiae apically with short fringing setae; inner tooth of bifid claws curved. Abdomen with 5 subequal, free ventrites. Ovipositor elongate, weakly sclerotised (structural details not clearly visible).

Material examined. Holotype (NIGP154201), female: heavily distorted (depressed and crumpled) but otherwise largely intact and well visible specimen, with head mostly recessed into prothorax (this and eyes barely visible inside prothoracic cavity), prothorax and elytra collapsed and many thoracic details not visible or interpretable, rostrum, mouthparts, antennae and surface details well visible, right hindleg severed at trochantero-femoral joint, left metatibia fractured near base; near centre of short pyramidal block with rounded base, $5.0 \times 4.5 \times 2.8 \mathrm{~mm}$; amber clear but with yellow flow bands, free of fractures and organic debris, with few silvery diffuse bubbles.

Derivation of name. The species is named for its elongate legs, especially the tarsi. 


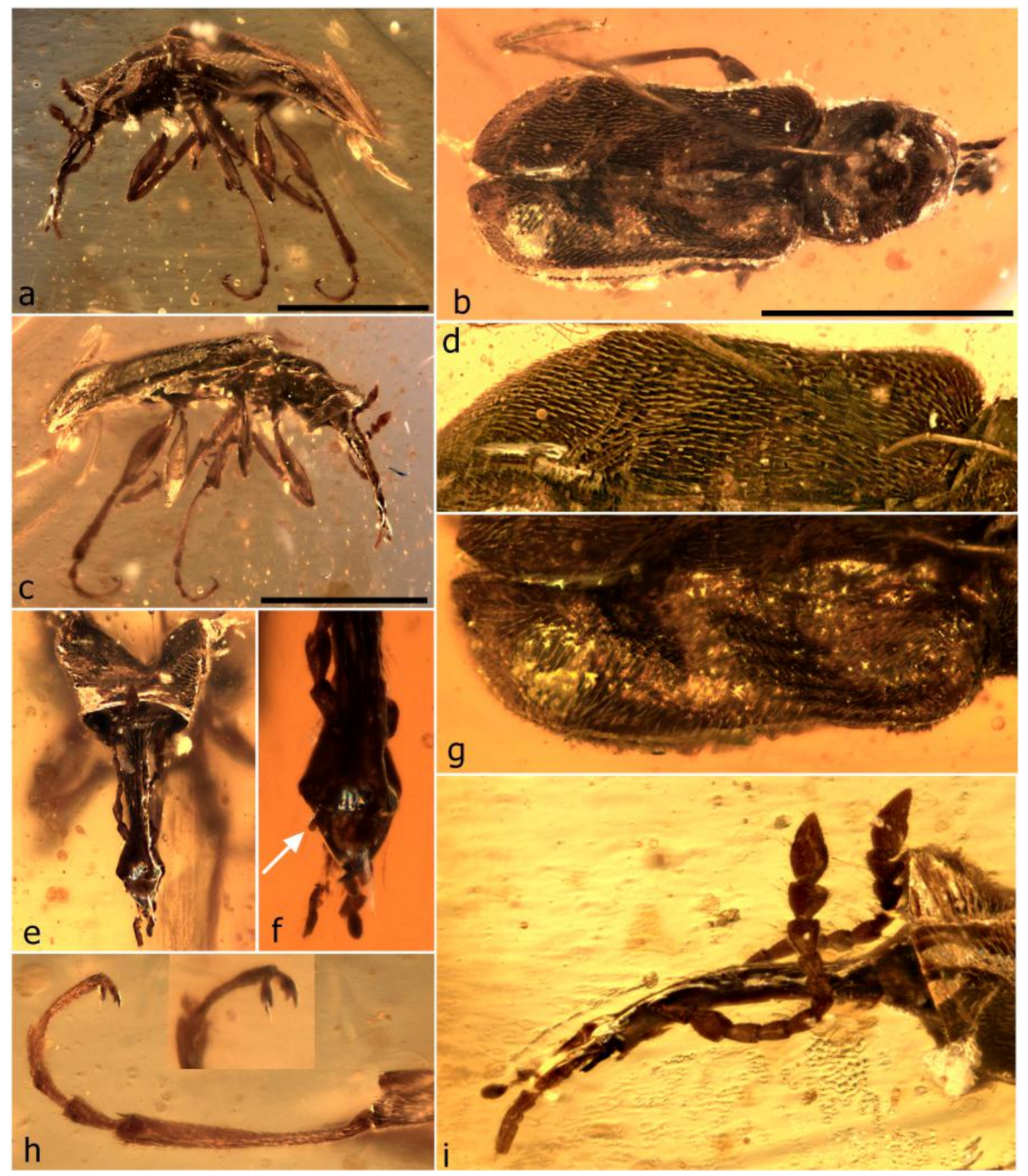

Figure 15. Guillermorhinus longitarsis sp. n., holotype. Habitus, left lateral (a); habitus, dorsal (b); habitus, right lateral (c); left elytron, dorsal (d); rostrum, dorsal (e); apex of rostrum and mandibles showing exposed postmental process (arrow), dorsal (f); right elytron showing faint striae, dorsal (g); left mestotibia and tarsus, insert showing detail of tarsal claw (h); head, rostrum and antenna, left lateral (i). Scale bars: $1.0 \mathrm{~mm}(\mathrm{a}-\mathrm{c})$.

Remarks. In addition to its remarkable and diagnostic claws, this species is characterised most readily by its very faintly and relatively finely punctostriate elytra. The elytra of Burmomacer kirejtshuki are seemingly coarsely punctostriate at the sides and fine on the disc, but the air layer covering most of the surface prevents a clear view of the surface and the more distinct lateral interstriae may be a result of compression at the sides. The postmental processes (Figure 15f,i) are more slender than those of Burmonyx zigrasi and very elongate, visible even in dorsal view as slight protrusions. The poor preservation of the holotype of G. longitarsis may make comparison with future specimens difficult, 
as neither body proportions and outlines nor other details useful for species distinctions may be readily comparable. Better views of the head, rostrum (especially the ventral side), thoracic venter and abdomen in additional specimens or species will hopefully aid in a more complete characterisation of the species and its affinities.

Genus Burmomacer Legalov, 2018

Burmomacer Legalov, 2018: 2 [46] (type species, by original designation: Burmomacer kirejtshuki Legalov, 2018)

Redescription. Size. Length $3.52 \mathrm{~mm}$, width $1.56 \mathrm{~mm}$. Head porrect, short, broad, constricted behind eyes. Eyes large, lateral, directed forwards, coarsely facetted, dorsally separated by slightly less than width of rostrum anteriorly but much further separated posteriorly; forehead flat, without tubercles between anterior margin of eyes. Rostrum short, subequal in length to pronotum, broad, robust, weakly curved, apically expanded; antennal insertions at apex, behind mandibular articulations, dorsolateral, without scrobes in front or behind them. Antennae non-geniculate, slightly longer than rostrum; scapes short, globular, slightly longer than funicle segment 1; funicles 7-segmented, segment 1 narrower than scape, 2-7 thinner, shorter, subequal; clubs large, almost as long as funicle, loosely articulated, 4-segmented, apical segment about as long as 3, acute. Mouthparts. Labrum present. Mandibles long, falcate, non-exodont, articulation horizontal. Maxillary palps prominent, elongate, projecting well beyond rostral apex, apparently 3-segmented. Thorax. Prothorax about as broad as elytra, not or only weakly proclinate, with anterior lateral margin slightly oblique in lateral view. Pronotum laterally without tooth, posterior corners distinct, angulate, fitting closely onto elytra; surface finely punctate, sparsely setose; notosternal sutures closed, curved anteriad; procoxal cavities broadly separated anteriorly and medially (possibly confluent posteriorly nearer hind margin of procoxae), situated nearer to posterior prothoracic margin. Scutellar shield densely setose. Mesocoxal cavities closed laterally by meso- and metaventrite. Metanepisterna distinct, sparsely setose, without anterodorsal lobe. Metaventrite long, lightly convex. Elytra elongate, not basally lobed over base of pronotum, with broadly rounded humeri, posteriorly hardly declivous, lateral margin nearly straight, anterior marginal notch absent, apically conjointly rounded, not exposing pygidium; sutural flanges not visible (only left apically); surface weakly, shallowly punctostriate, scutellary striole not visible, interstriae flat, finely punctosetose, setae short, thin, whitish, reclinate, directed caudad. Legs. Procoxae globular, not projecting, widely separated by broad prosternal process; mesocoxae globular, broadly separated; metacoxae flat, transversely elongate. Trochanters short, oblique. Femora long, subcylindrical, weakly inflated at middle, dorsally rounded. Tibiae straight, subcylindrical, slightly widening distad, outer edge smooth, apices obliquely truncate, with probably 2 spurs ( 2 on metatibiae, 1 discernible on mesotibiae). Tarsi elongate, slender, subcylindrical, almost as long as tibiae; tarsite 1 longer than 2, widening distad, apically subtruncate, 3 deeply bilobed, lobes short, narrow, 5 long, apically expanded; claws divaricate, strongly bifid (inner tooth spiniform, almost as long as outer claw), without ventrobasal seta. Abdomen with free ventrites, slightly stepped, 1 slightly longer than 2, 2-4 subequal, 5 subequal to $3+4$, broadly rounded, shortly notched at middle of posterior margin.

Remarks. The genus was not specifically described, only a reference given to the diagnosis of the tribe Burmomacrini. Its most unusual feature is the broad separation of the procoxae, but it cannot be ascertained whether the procoxal cavities are also completely separated, because the posterior part of the prosternum is not visible (hidden beneath the folded tarsi). It is thus not determinable whether the broad prosternal process meets a similar hypomeral one to fully separate the cavities. In the extant genus Brarus Kuschel the procoxae are also separated by a broad prosternal process, but this narrows rapidly posteriad and does not meet the opposing hypomeral process, leaving the coxal cavities shortly confluent in their middle. As the prosternal process in Burmomacer is longer and not narrowing, extending nearly to the posterior hypomeral margin, it is somewhat similar to that of Nemonyx, which extends to the posterior end of the procoxae but does not abut against any hypomeral process and thus leaves the coxal cavities broadly confluent posteriorly, almost open. Burmomacer differs from Burmonyx and Guillermorhinus in its much shorter, broader rostrum with only two grooves 
dorsally and in that the anterolateral corners of the postmentum are not extended into long processes. It agrees with Burmonyx in its similarly strongly bifid claws but has narrower lobes of tarsites 3 . It also appears to fit into the tribe Mecomacerini, but more details of its prosternal structure need to be known to ascertain this. It contains a single species as known.

Burmomacer kirejtshuki Legalov, 2018

Burmomacer kirejtshuki Legalov, 2018: 2 [46]

Material examined. Holotype (ISEA no. MA 2017/2): well preserved specimen missing only claws of right hindleg, otherwise intact, minimally depressed with elytra partly forced open, length $3.52 \mathrm{~mm}$, width $1.56 \mathrm{~mm}$, largely separated from surrounding amber, leaving most visible detail as an impression in amber matrix, well visible on all sides without surface obscurities; towards one end of rectangular cuboid $7.1 \times 1.8-2.5 \times 1.2-1.6 \mathrm{~mm}$, rounded off over head, with sides parallel to block faces; amber clear yellow-brown with diffuse tiny organic particles, free of fractures near specimen, with one large flat bubble obscuring basal pronotal and elytral areas.

Remarks. In view of the redescription of the genus above, the original description of the species is adequate for the moment. This species is similar to Burmonyx zigrasi in having bifid claws with long slender inner teeth but is much larger and has a shorter broader rostrum with only two dorsal grooves. The unusual preservation of the holotype makes it difficult to determine the true form of the specimen. It has clearly separated from the amber and partially decomposed in the resulting cavity, but some areas and appendages are evidently still intact and visible. The inside surface of the cavity has preserved a perfect impression of the original weevil surface, but the robustness and flatness of the specimen seems to be exaggerated.

Family MESOPHYLETIDAE Poinar, 2008 stat. $\mathbf{n}$.

Mesophyletinae Poinar, 2006: 879 [29] (not available; no type genus designated)

Mesophyletinae Poinar, 2008: 262 [50] (type genus: Mesophyletis Poinar, 2006)

Description. Head porrect, short, usually subglobular. Eyes moderately sized to very large in relation to head, hemispherical to subglobular to elongate conical to dorsoventrally flattened, usually strongly protruding and coarsely facetted, sometimes flatter and finely facetted; rarely with distinct interfacettal setae (Compsopsarus reneae). Rostrum slightly shorter to much longer than pronotum, subcylindrical, usually long and evenly thin, slightly downcurved, sometimes shorter and stouter, rarely flexible into a prosternal channel (Burmorhinus, Rhadinomycter); antennal insertions usually median, sometimes subbasal, rarely in apical third or quarter, behind them usually with long narrow scrobe extending to eye, in front of them usually with a lateral row of sparse, long erect setae. Gular suture (where discernible) single, long, extending from base of head onto underside of rostrum. Antennae subgeniculate to geniculate, of 'open' type (funicle inserted apically into scape); scapes usually about as long as entire funicle, at least slightly longer than funicle segment 1 ; funicles 7-segmented; clubs loosely articulated to subcompact, 4-segmented, apical segment usually distinctly inserted in or set off from penultimate one. Mouthparts. Labrum absent. Mandibles mostly strongly exodont and then often flattened, sometimes non-exodont, articulation horizontal to oblique. Maxillary palps (where discernible) 4-segmented, robust, short, not projecting beyond mandibles. Labial palps 3-segmented, inserted apically in prementum. Thorax. Prothorax usually proclinate, with anterior lateral margins oblique in lateral view, straight, rarely drawn out into ocular lobe. Pronotum subquadrate to transversely trapezoidal, rarely elongate, often narrowing apicad but apically not constricted or collared, laterally slightly to strongly rounded, posterior corners usually slightly produced, fitting closely onto elytra; notosternal sutures mostly closed, rarely open. Prosternum variable; procoxal cavities usually medially confluent, rarely separated. Mesocoxal cavities medially separated, laterally usually closed by meso- and metaventrite, rarely open (mesanepisternum and mesepimeron also not reaching coxa); metacoxal cavities elongate transverse, separated. Metanepisterna usually distinct, suture without sclerolepidia. Mesoventrite short, usually steeply declivous. Metaventrite longer, flat to slightly convex, often with rounded transverse weals 
before metacoxae. Elytra usually elongate, subparallel-sided, anterior margin straight to slightly arcuate or bisinuate, humeri broadly rounded; lateral edge (beyond stria 10) often inflexed into epipleural flange, without upper costa but with narrow posterior part (behind metacoxa) sometimes forming a narrow groove, lateral margin anteriorly sometimes notched to receive anterodorsal process of metanepisternum; apices usually individually rounded, sometimes exposing short pygidium; sutural flanges narrow, equal; surface distinctly to indistinctly punctostriate, with 10 striae but no scutellary striole; usually moderately setose, setae on striae between punctures and on interstriae, not in strial punctures, short, thin, sharp, suberect to reclinate, directed caudad. Legs. Procoxae mostly elongate and prominent, rarely globular, usually medially contiguous, rarely separated by prosternal and hypomeral processes meeting between them; mesocoxae globular, narrowly separated; metacoxae flat, transversely elongate, medially narrowly separated. Femora subcylindrical to flattened, inflated in distal half, dorsally rounded or with distal carina or crenulation, almost always unarmed. Tibiae subcylindrical to strongly flattened, outer edge often sharply crenulate to serrulate, sometimes rounded, distally usually expanded, sometimes slightly excised, and with dense, long, stiff setae, apex usually with 2 spurs, inner one sometimes fixed and broadened, rarely without spurs. Tarsi elongate, loose; tarsite 1 elongate to broadly triangular, apically often excised to even sublobate, 2 more narrowly triangular, apically usually deeply excised, sometimes bilobed, 3 deeply lobed, lobes long and stalked, often pedunculate, 5 elongate, basally narrow but distally broadened; claws divaricate, simple to basally angulate or dentate, nearly always with long ventrobasal seta. Abdomen with ventrites 1 and 2 fused, each longer than 3 and 4, 5 usually subtriangular but rectangular and apically truncate when last tergite (apparently VII) exposed as pygidium. Ovipositor with gonocoxites long, slender, with thin dorsal and ventral baculi (sclerotised rods), apically finely setose, with small cylindrical apical stylus with apical tuft of setae.

Remarks. This taxon was described as a subfamily of 'Eccoptarthridae', the family name then sometimes used for Caridae [9], although Poinar excluded the carids from his concept of Eccoptarthridae and restricted this family to the extinct genus Eccoptarthrus Arnoldi (an eobeline nemonychid) and Baissorhynchinae [29], which were probably Nemonychidae or Cimberididae as well [16]. A comparison between Mesophyletis and Eccoptarthrus was not made, but Poinar [29] placed the baissorhynchine genus Cretonanophyes Zherikhin in Mesophyletinae as it seemingly shared the diagnostic characters of Mesophyletis, namely geniculate antennae with loosely segmented clubs, elongate trochanters, tarsi with dentate claws and pedunculate tarsite 3 lobes and an exposed pygidium. He compared Mesophyletis with Caridae, Apioninae and Nanophyinae and could, correctly, not assign it to any of these taxa, but he did not make a comparison with Attelabidae, presumably because of their non-geniculate antennae.

With the much larger diversity of mesophyletid taxa now known and a much better assessment of their characters, it is evident that this group cannot be accommodated in any of the extant families without a significant widening of their concepts. The absence of a labrum readily distinguishes the mesophyletids from the 'lower' weevil families Cimberididae, Nemonychidae and Anthribidae. From Belidae they differ foremost in their geniculate antennae, long single gular suture and angulate to dentate tarsal claws with a ventrobasal seta, and although a few genera with subgeniculate antennae share features such as open coxal cavities and the antennal configuration with some Belidae, their protibiae also do not possess the apical antenna cleaner that is an autapomorphy for Belidae [1] (see Aepyceratinae below). With Attelabidae the mesophyletids share the long single gular suture, but they differ in many other important characters (geniculate or subgeniculate antennae, distinctly four-segmented clubs, consistent absence of scutellary strioles, divaricate dentate claws with ventrobasal seta, usually closed pro- and mesocoxal cavities), even in characters that are superficially similar (exodont mandibles, crenulate femora and tibiae), so that they cannot be included in this family. From the family Caridae the mesophyletids differ mainly in their long gular suture, their geniculate, laterally inserted antennae, fused ventrites 1 and 2 and (again) their differently exodont mandibles and crenulate femora and tibiae, so that they cannot be regarded as carids in the current 
concept of this family. The long single gular suture also distinguishes the Mesophyletidae from the 'higher' families Brentidae and Curculionidae, and from Brentidae other than Nanophyinae they further differ in their mostly geniculate antennae, from Nanophyinae also mainly in their short oblique trochanters, seven-segmented funicles and divaricate, mostly dentate tarsal claws (see key to families for other differences) and from Curculionidae additionally in their loose antennal clubs and differently (apically) geniculate antennae. Their unique combination of characters thus dictates the recognition of Mesophyletidae as a separate, ninth family of weevils that apparently became extinct without leaving any extant relatives. They are evidently most closely related to the 'middle' weevil families, specifically to Attelabidae and Caridae, although the similarly geniculate antennae and longer gular sutures of Nanophyinae may indicate a relationship to this subfamily too, despite the many differences between the two taxa. The precise relationships of Mesophyletidae to all these family taxa require further study.

The concept of Mesophyletidae is diffused to some degree by the few aberrant genera that have subgeniculate antennae and sometimes open pro- and mesocoxal cavities, but these have the same dentate tarsal claws, similarly exodont mandibles and single gular sutures (where discernible) and are therefore here included in Mesophyletidae as well, albeit in a different subfamily, Aepyceratinae.

Subfamily Aepyceratinae Poinar, Brown \& Legalov, 2017

Aepyceratinae Poinar, Brown \& Legalov, 2017: 75 [51] (type genus, by original designation: Aepyceratus Poinar, Brown \& Legalov, 2017)

Diagnosis. Head porrect, short. Eyes relatively small, hemispherical to subconical, slightly protruding, finely to coarsely facetted. Rostrum slightly longer or shorter than pronotum; antennal insertions subbasal to median, sometimes with weak short scrobe behind them. Gular suture single, long (where discernible). Antennae subgeniculate; scapes as long to twice as long as funicle segment 1 ; funicles 7-segmented; clubs loosely articulated, 4-segmented. Mouthparts. Labrum absent. Mandibles mostly exodont but sometimes non-exodont, articulation horizontal. Thorax. Pronotum subquadrate to transverse, laterally rounded, posterior corners usually extended, fitting closely onto elytra; notosternal sutures open or closed; procoxal cavities medially confluent; mesocoxal cavities open or closed. Elytra with broadly rounded humeri, apically individually rounded, in Acalyptopygus and Calyptocis exposing short pygidium; surface distinctly to indistinctly punctostriate, without scutellary striole. Legs. Procoxae subglobular to elongate, mostly prominent, medially contiguous; mesocoxae globular, narrowly separated; metacoxae flat, transversely elongate. Femora inflated in distal half, outside rounded; unarmed. Tibiae subcylindrical, outer edge rounded, apex with or without spurs. Tarsi elongate; tarsite 1 elongate to broadened, 3 deeply lobed; claws divaricate, dentate, with ventrobasal setae except in Platychirus. Abdomen with ventrites 1 and 2 fused, longer than $3+4$; last tergite exposed as pygidium in Acalyptopygus and Calyptocis.

Remarks. This taxon was described as a new subfamily of Nemonychidae in the mistaken observation that the type genus and species, Aepyceratus hyperochus, possesses a free labrum (along with non-geniculate antennae, free abdominal ventrites and tibial spurs) [51], but our examination of the type specimen confirmed that it has no labrum (as indeed evident in Figures 2C and 2D of Poinar et al. [51]). As non-geniculate antennae also occur in all other weevil families except Curculionidae, free ventrites also in Belinae and Caridae [1] and tibial spurs in all other families except Anthribidae, none of the other three characters specifically relates Aepyceratus to Nemonychidae (and Cimberididae). Moreover, Aepyceratus has ventrites 1 and 2 fused, not free (movable) as the remaining three, and subgeniculate antennae (the scape twice as long as funicle segment 1 ), unlike the condition in Nemonychidae. These features as well as its exodont mandibles and dentate tarsal claws strongly indicate that Aepyceratus and five other genera with subgeniculate antennae (Acalyptopygus, Calyptocis, Nugatorhinus, Platychirus, Rhynchitomimus) also belong in Mesophyletidae, in which they form a group that may for now be treated as a subfamily Aepyceratinae. Apart from the subgeniculate antennae there is no character in evidence to suggest that this subfamily constitutes a monophylum, and differences in the conditions of some characters (subbasal and median antennal insertions, exodont and non-exodont mandibles, open and closed pro- and mesocoxal cavities, presence and absence of 
tibial spurs, pygidium exposed or not) suggest that it may be a paraphyletic group with respect to the genera with geniculate antennae combined in the subfamily Mesophyletinae. A phylogenetic analysis is needed to test the concept of Aepyceratinae as here proposed.

Genus Aepyceratus Poinar, Brown \& Legalov, 2017

Aepyceratus Poinar, Brown \& Legalov, 2017: 75 [51] (type species, by original designation:

Aepyceratus hyperochus Poinar, Brown \& Legalov, 2017)

Redescription. Size. Length $6.9 \mathrm{~mm}$. Head short, transversely globular. Eyes large, flatly protuberant-subconical, lateral, finely facetted, dorsally separated by $1.5 \times$ basal width of rostrum anteriorly but much further separated posteriorly; forehead flat, without tubercles or ridges between eyes. Rostrum much longer than pronotum, weakly curved, subcylindrical (slightly flattened); antennal insertions subbasal, lateral, with faint scrobe indicated in front of them. Antennae subgeniculate, long; scapes oblong-fusiform, apically narrowed, about twice as long as funicle segment 1; funicles 7-segmented, segment 1 narrower than scape, 2 about $3.0 \times$ longer than 1 , 2-7 subequal, slender, apically slightly wider, 7 about $0.67 \times$ as long as 6; clubs large, long, loosely articulated, broader than funicle, 4 -segmented, apical segment acute, about as long as 3. Mouthparts. Labrum absent. Mandibles large, exodont and endodont, articulation horizontal. Thorax. Pronotum transversely convex, narrower anteriorly, without lateral tooth, posterior corners distinctly angulate, fitting closely onto elytra; surface densely tomentose; notosternal sutures open ventrally. Prosternum moderately long; procoxal cavities medially confluent, approximately in middle of prothorax. Scutellar shield densely tomentose. Mesocoxal cavities closed laterally. Metanepisterna distinct. Metaventrite elongate, nearly flat, slightly convex in front of metacoxae. Elytra elongate, basally excised to receive base of pronotum, with weakly rounded, subflat humeri, posteriorly declivous, lateral margins broadly explanate, apically weakly individually rounded, not exposing pygidium; surface not or faintly punctostriate, without scutellary striole, densely tomentose, setae confusedly multidirectional. Legs. Procoxae large, subglobular but expanded laterally, medially subcontiguous; mesocoxae large, subglobular, narrowly separated; metacoxae transversely elongate. Trochanters large, sublobate, not recessed into coxae. Femora long, distally inflated, outside rounded, inside excavate in distal half, receiving tibiae in repose. Tibiae distally expanded, outer edge rounded, densely setose, apices obliquely truncate, with 2 spurs, meso- and metatibiae distinctly upturned apicad. Tarsi slightly longer than tibiae; strongly flattened; tarsite 1 broad, apically exicsed, 2 shorter, strongly lobate, 3 very deeply, narrowly bilobed (subpedunculate), 5 long, apically expanded; claws divergent, strongly dentate, without ventrobasal seta (or this not visible). Abdomen with ventrites 1-5 progressively shorter, 1 and 2 at same level, fused, 3-5 articulated, each at slightly higher level; sutures between ventrites substraight.

Remarks. This presently monotypic genus known from the single specimen of Aepyceratus hyperochus is among the most distinctive of Burmese amber weevils, both in habitus and in characters. Although sharing a generally similar tarsal structure with Cetionyx, Burmocorynus, Opeatorhynchus and Petalotarsus (but differing in important details) and rostral and antennal characters with other genera of Aepyceratinae, its overall flattened shape and combination of characters sets it apart from all other Burmese amber weevils. Among these characters (all of which are unique among known Burmese amber weevils) are the distinctly tomentose dorsal vestiture (ventrally with long, more usual setae), the explanate, strongly inflexed elytral margins and ridged (including basally toothed) pronotal margins, the sublobate trochanters (edges not continuous with femoral edges) that are not recessed into the coxae (possibly what Poinar et al. [51], p. 76, meant by "trochanters not separating femora and coxae"), the distinct brush of dense short subequal setae along the distal inner sides of the protibiae (possibly a grooming device), the row of cuticular teeth along the inner sides of the meso- and metatibiae, the strong black erect tibial setae, the outwardly projecting cuticular spine on the outer apical angles of the tibiae and the structure of the tarsi (particularly the enlarged first tarsites, subpedunculate second tarsites and large flat basal tooth on the claws). Other notable differences include the much greater and posteriadly increasing interocular distance (larger than rostral width at base), similar to that of 
Debbia (Mesophyletinae), the laterally open procoxal cavities (shared with Rhynchitomimus, Platychirus and Nugatorhinus) and the laterally closed or possibly slightly open mesocoxal cavities (otherwise only in Nugatorhinus), the unusual configuration of the procoxae and surrounding prothoracic structures (as described) and the exodont but distinctly robust mandibles (not flattened, blade-like), in which the inner and outer sides are concave surfaces delimited by dorsal and ventral edges and the inner teeth are situated on dorsal and ventral edges of the inner side.

Aepyceratus hyperochus Poinar, Brown \& Legalov, 2017

Aepyceratus hyperochus Poinar, Brown \& Legalov, 2017: 76 [51]

Redescription. Size. Length $6.9 \mathrm{~mm}$ (excl. rostrum, not SL); moderately dorsoventrally flattened; dorsally subtomentose, covered in dense, multidirectional, subappressed, brownish and whitish setae. Head somewhat bulbous dorsally and ventrally; subtomentose, setae short; surface behind eyes rugose, sparsely setose; between eyes densely setose, setae whitish and brown, coarsely minutely punctate. Rostrum elongate, $2.9 \mathrm{~mm}$ long (Poinar et al., 2017); junction with head dorsally slightly concave; densely setose, with basal setae longer than distal ones; dorso-apically sparsely setose, shining; broadening apicad from about middle, apically ca. $2 \times$ broader than in middle. Apex dorsally broadly convex, laterally somewhat lobate; mandibular articulations shallow. Antennae. Scapes short, narrow basally at insertion, densely setose; clubs distinct, densely setose (tomentose), with longer setae apically, segments 1 and 2 obconical, 1 basally much thinner than 2, apically subequal, 2 slightly shorter than 1, 3 elongate, expanding apicad. Mouthparts. Mandibles with 2 large pointed external teeth (one basally, one apically); externally with dorso- and ventrolateral edges, the intervening surface slightly concave, without setae; internally with dorso- and ventromedial edges, the intervening surface slightly concave, with 3 smaller teeth, mesal and apical ones arising from dorsomedial edge and apical one arising from ventral edge, apically truncate, anvil-shaped with outer and inner angles formed by external and dorso-internal apical teeth, respectively. Thorax. Pronotum broadest at base, gradually narrowing anteriad, sides sinuate, outwardly curved until about apical third, then slightly concavely curved to anterior margin (appearing somewhat collared anterolaterally); sides forming lateral ridge (subcarinate) clearly demarcating pronotum from inflexed hypomeron, finely toothed in basal third; basal margin nearly straight, submarginally forming distinct lip separated from higher basal surface by narrow groove, lip thickest in middle third, fitting under inflexed basal elytral margins, medially with slight emargination to receive anterior margin of scutellar shield; setae mixed whitish/brownish, more whitish basally and laterally. Prosternum elongate, densely setose, setae longer than on pronotum, anterior margin slightly broadly emarginate, prosternal process abruptly convexly curved posteroventrad between inner apical margins of procoxae (not projecting between them), broadened apicad, not connected to hypomeral process, this apically subtruncate, vertically disjunct from hypomeral region by about procoxal length. Scutellar shield broadly transverse, anteriorly broadly rounded (fitting into emargination of pronotal margin), posterior margin medially pointed. Meso- and metaventrites densely setose, at most finely punctate; each with narrow intermesocoxal process. Mesocoxal cavities large. Elytra somewhat flattened; subrectangular; bases slightly sinuate, nearly straight; humeri weakly rounded, somewhat concavely extended; striae or interstriae absent or indistinct, sutural striae absent; surface finely punctate, punctation indistinct due to extremely dense short subappressed (tomentose) vestiture, setae confusedly multidirectional; explanate margin of sides dorsally densely setose as disc, with narrow band of whitish setae seemingly situated in a broad, stria-like channel along inner edge of margin and with seemingly evenly spaced sparse tufts of fine, curved setae; laterally with distinct and setose marginal groove (on inflexed portion, adjacent to edge contacting body). Elytral apices with small but distinct medial emargination (carinate explanate edge not continuing flushly from side to side). Legs generally short, robust; densely setose, covered in subtomentose vestiture, with different types of setae; setae generally shorter on forelegs. Procoxae apparently at most only narrowly separated behind prosternal process; very densely setose, especially posteriorly; setae golden, longer than dorsal setae. Trochanters robust, prominent, not recessed into coxae. Tibiae with long setae on inner faces, scattered elsewhere, apically denser near 
outer apical edge; protibiae subequal in width and depth for most of length, outer side near apex with several coarser blackish spine-like setae, also with longer whitish setae, inner side in distal half broadly concave, with area of dense subequal setae increasing in density apicad, apically with inner edge broadly convex, faintly produced to a subdued point, then concavely continuing along dorso-apical edge, with moderately dense setae partly obscuring outer spine, apical edge lined with coarser black setae; meso- and metatibiae with row of cuticular teeth along entire inner edge, teeth larger than on mesotibia, increasing in size apicad, each indistinctly separated by basal width of a tooth, with numerous distinctly coarse black semi-erect setae projecting almost perpendicularly to long axis of tibia (absent internally), with long whitish setae concentrated on inner faces, especially towards apex, metatibiae with 2 or 3 small cuticular teeth on outer apical edge. Tarsi strongly flattened, densely setose, with longer setae dorsally; ventrally with thick tenant setae forming dense setal pads; tarsites 1-3 progressively broader, 1 cordiform, progressively shorter from fore- to hindlegs, 2 strongly lobate, lobes slender and very narrow basally on meso- and metatarsi (subpedunculate), medial length less than half that of 1 , tarsite 3 with lobes elongate, about half as long as 5, strongly broadening apicad, continuous basally (not individually flexible), 4 (cryptotarsite) distinct, 5 somewhat flattened, ventrally setose, setae long and irregularly positioned and sized, ventroapically lobate, with pair of fine, curved setae projecting distad; claws with basal tooth large and explanate, inner edge almost flat, outer edge curved forming deep, curved notch between outer claw and tooth. Abdomen. Ventrites very densely setose, setae longer than elytral setae, distinctly patterned; ventrite 1 slightly longer than 2, 3 about $0.67 \times$ as long as 2,3 , and 4 with differently coloured setae, 4 slightly shorter than 3,5 subequal to or shorter than 4.

Material examined. Holotype (PACO, with curatorial \#B-C-50): exceptionally well preserved, intact specimen, not depressed, largely undistorted, well visible with exception of the ventral side partly obscured by thickness of amber and presumed plant debris, surface partly obscured by fragmented whitish coating; at corner of long irregular pyramidal block, with three large, mostly flat faces, one smaller flat face; with several pieces of possibly woody plant material obscuring clear view of ventral side; amber clear-brown, with minimal other debris (see also [51]).

Remarks. The holotype shows little sign of distortion associated with the preservation process, and aspects of the structure of the specimen seemingly related to dorsoventral flattening are symmetrical and do not appear to be aberrations. Nevertheless, we were unfortunately unable to borrow and further prepare the amber block, which would result in much clearer views of the ventral side of the inclusion and of several structures that are currently either not or insufficiently visible because of removable obscurities (debris, bubbles and amber). This includes the ventral side of the head (and thus the condition of the gular sutures) and ventral mouthparts and the ventral surface of (especially) the prothorax and the tarsal claws. Through our examination of the holotype, we could not confirm whether the basal teeth of the claws also possess a ventrobasal seta as we define herein. Only one of the visible claws has a seta visible in the correct general location, but as only the distal part of this seta could be viewed, we could not assess its insertion point. In all Mesophyletidae with dentate claws, the ventrobasal seta arises from the back face of and usually at or near the apex of the tooth and generally projects ventrad (and thus often appearing as an apical seta), and we therefore surmise that these setae are also present in A. hyperochus but simply obscured in the holotype in the current amber block in both possible viewing angles and by the enlarged basal teeth of the claws in this species (much larger and broader than in other genera).

Genus Platychirus Clarke \& Oberprieler, gen. $\mathbf{n}$.

Type species: Platychirus beloides Clarke \& Oberprieler, sp. $\mathrm{n}$.

Description. Size. Length ca. $5 \mathrm{~mm}$, width ca. $2 \mathrm{~mm}$. Head short, broad, transverse, subglobular. Eyes large, strongly protruding, lateral, finely facetted, dorsally without tubercles between them. Rostrum short, stout, cylindrical, antennal insertions lateral, subbasal, behind them without scrobes, in front of them without lateral row of setae. No gular suture visible. Antennae subgeniculate, long; scapes short but elongate, cylindrical, slightly thickening distad; funicles 7-segmented, longer 
than scape, segment 1 shorter than scape, medially inflated, 2 longer than 1 , segments 3 and 4 also elongate, 5-7 shorter; clubs 4-segmented, very loosely articulated (hardly differentiated from funicle), segment 4 narrow, elongate. Mouthparts. Labrum absent; mandibles narrow, elongate, exodont, articulation horizontal. Thorax. Prothorax proclinate, with anterior lateral margins oblique in lateral view. Pronotum short, broad, convex, rounded laterally, posterior corners rounded, not fitting closely onto elytra; surface finely punctate, sparsely setose, setae pale, directed anteriad; notosternal sutures widely open. Prosternum moderately long; procoxal cavities apparently medially confluent, in middle of prothorax. Scutellar shield not discernible. Mesocoxal cavities laterally narrowly open (mesoand metaventrite not meeting above coxae). Metanepisternal sutures distinct. Mesoventrite short, anteriorly sloping. Metaventrite long, convex. Elytra shortly elongate, with weakly, broadly rounded humeri, apically jointly truncate, only slightly individually rounded, not exposing pygidium; surface not punctostriate, finely setose. Legs. Procoxae short, globular, apparently medially contiguous; mesocoxae subglobular, narrowly separated; metacoxae flat, transversely elongate. Trochanters short, oblique. Femora short, thick, robust, subcylindrical, inflated through most of length, unarmed, outside rounded. Tibiae short, straight, robust, subcylindrical, outer edge rounded, apex truncate, without spurs; protibiae on inside without apical brush but a few black setae. Tarsi almost as long as tibiae; tarsite 1 long, very broad, flat, 2 triangular, insertion of 3 dorso-apical, 3 shortly bilobed, 5 as long as 1 , narrow between lobes but broadening apicad; claws divaricate, ventrally bluntly dentate, apparently without ventrobasal seta. Abdomen with ventrites 1 and 2 fused, each slightly longer than 3 .

Derivation of name. Platychirus is named for its broad flat first tarsites, the name formed from the Greek adjective platys, broad, and noun cheir (G: cheiros), a hand, and being masculine in gender.

Remarks. This genus has several characters of extant Belidae, in particular the broad, short head with large, round eyes, the lengths of the antennal segments (scape shortly elongate, funicle segment 1 short, the others elongate) and the open pro- and mesocoxal cavities, but it has no protibial brushes (antenna cleaners) and its mandibles are narrow, elongate, with a blunt, apical external tooth. Its remarkably broadened and flattened basal tarsites are also similar to those of some Belidae (e.g., Stenobelus [41]), but such tarsites occur in Car Blackburn (Caridae) as well. Despite these character agreements and the overall similarity of Platychirus to Belidae, the lack of protibial brushes, which are considered a synapomorphy for extant Belidae [1], and the elongate, exodont mandibles militate against assigning the genus to Belidae, and we consider it more plausible to group it together with the other Burmese amber genera with subgeniculate antennae and open coxal cavities in the subfamily Aepyceratinae of Mesophyletidae. In this group it is most similar to Rhynchitomimus, which has very similar antennae and also similar claws, although these carry a ventrobasal seta. If additional specimens of Platychirus are discovered, its taxonomic affinities may be able to become better understood. Platychirus is currently monotypic.

Platychirus beloides Clarke \& Oberprieler, sp. n. (Figure 16)

Description. Size. Length $5.12 \mathrm{~mm}$, width ca. $2.25 \mathrm{~mm}$. Head constricted behind eyes. Eyes subglobular, dorsally separated by about their width, forehead as broad as rostrum at base, flat. Rostrum as long as pronotum, slightly curved, abruptly thinner in front of antennal insertions, these subbasal; behind antennal insertions with sparse, short, erect setae dorsally and laterally, surface coarsely granulose. Antennae. Scapes reaching anterior margin of eye in repose; funicles much longer than scape, segment 1 half as long as scape, spindle-shaped, in middle as thick as scape, segment 2 ca. $1.5 \times$ longer than 1, thinner, slightly thicker apically, 3 similar but shorter, 4 similar but slightly shorter again, 5-7 shorter, bulbous at apex; clubs flat, basal segments broadening distad, segment 4 narrow, elongate. Mouthparts. Mandibles with 1 blunt apical external tooth. Maxillae and labium not discernible. Thorax. Pronotum short, roundly trapezoid, strongly convex, tumescent in basal half; surface minutely punctate, sparsely setose. Elytra shortly elongate, posteriorly sloping down and abruptly declivous apically; surface relatively densely very finely setose, setae black, recumbent, directed caudad. Legs. Metafemora not quite reaching posterior margin of ventrite 2 . Tibiae slightly shorter than femora, sparsely setose in apical half. Tarsi with tarsite 1 as long as $2+3$, apically slightly 
emarginate, 2 with apex slightly excised, 3 with lobes short, broad, broadly connected basally, 5 as long as 1; claws as for genus. Abdomen as for genus.

Material examined. Holotype (NIGP154202): very well preserved, intact specimen, not compressed or distorted, well visible under strong light; in rectangular block $7.2 \times 6.4 \mathrm{~mm}$, drop-shaped in cross-section, $5.8 \mathrm{~mm}$ thick across the weevil body; amber slightly cloudy with many small impurities, especially over back of elytra and oblique crack along left side of prothorax.

Derivation of name. The species name is an adjective formed for the genus name Belus and the suffix -oides, like, in reference to the similarity between the species and extant Belidae.

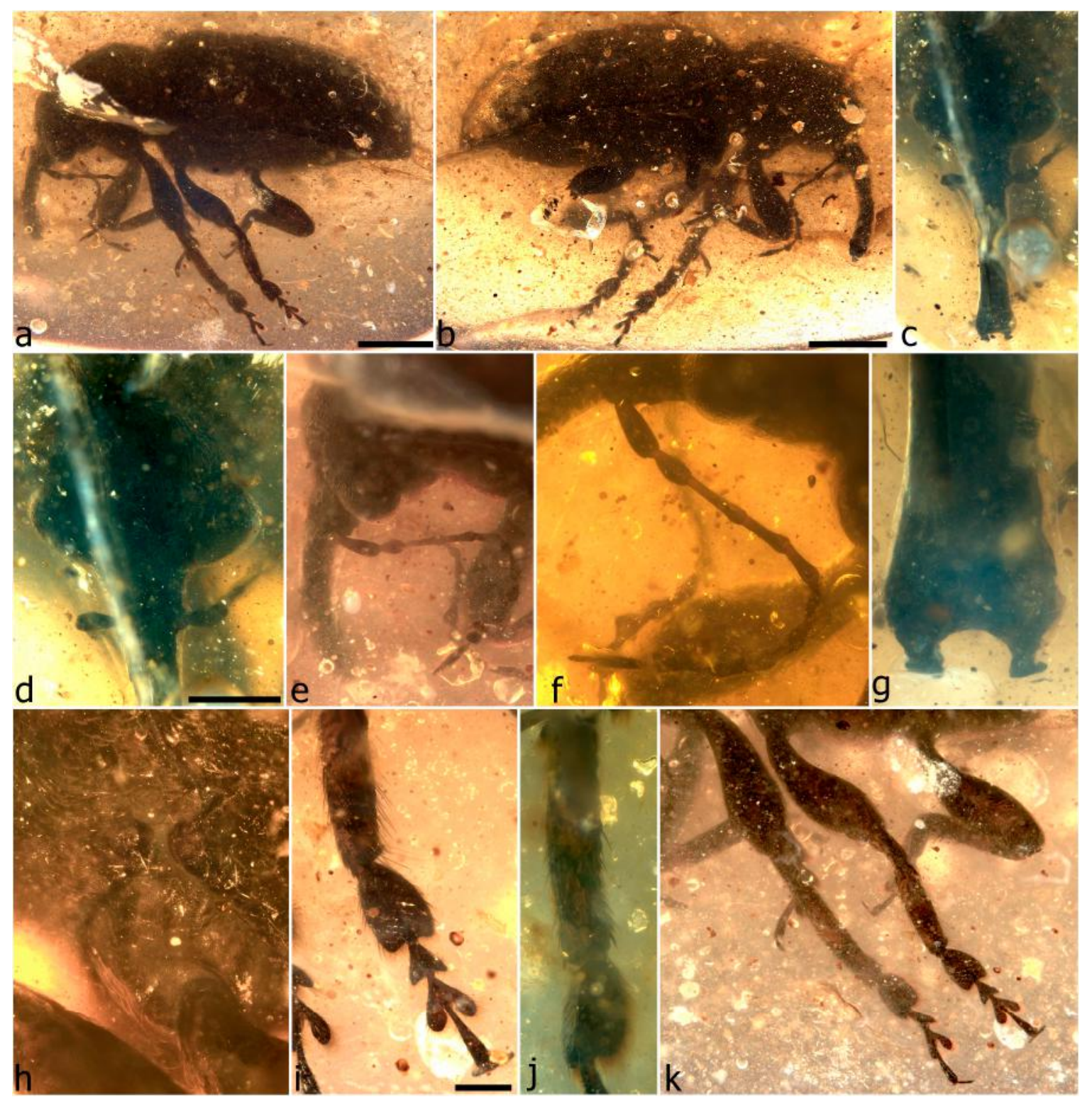

Figure 16. Platychirus beloides sp. n., holotype. Habitus, left lateral (a); habitus, right lateral (b); head, dorsal (c); eyes, dorsal (d); head and antenna, left lateral (e); detail of antenna and eyes, left lateral (f); apex of rostrum and mandibles, dorsal (g); open mesocoxal cavities (h); left mesotibiae, dorsal (i); left protibia, dorsal (j); left legs, dorsal (k). Scale bars: $1.0 \mathrm{~mm}(\mathrm{a}, \mathrm{b}) ; 0.5 \mathrm{~mm}$ (d); $0.2 \mathrm{~mm}$ (i).

Remarks. The species is very distinctive due to its rostrum being strongly constricted at the subbasally inserted antennae, its broadened first tarsites and its weakly dentate claws apparently without a ventrobasal seta. The constricted rostrum suggests that the single specimen known of it to date may be a female. 
Genus Rhynchitomimus Clarke \& Oberprieler, gen. $\mathbf{n}$.

Type species: Rhynchitomimus chalybeus Clarke \& Oberprieler, sp. n.

Description. Size. Length $2.94 \mathrm{~mm}$, width $1.2 \mathrm{~mm}$. Head long, broad, subglobular. Eyes large, lateral, strongly protruding, finely facetted, dorsally separated by slightly more than width of rostrum anteriorly but much further posteriorly; forehead weakly convex, without any tubercles. Rostrum very long (more than half body length), slender, subcylindrical, substraight; antennal insertions subbasal, lateral, with scrobes behind them, in front of them laterally without setae. Gular suture single, long. Antennae subgeniculate, long; scapes slender, cylindrical, apically slightly inflated, articulation with funicle segment 1 apical but open, free, about 3 times longer than funicle segment 1; funicles 7-segmented, segment 1 slightly roundedly obconical, basally thin and bent, apically subequal in width to scape, segments $2-6$ subequal, nearly twice longer than 1 , subcylindrical but 6 widened apically, 7 half as long, obconical shorter towards club; clubs large, loosely articulated, 4-segmented, without long sensory setae, apical segment acute, slightly shorter than 3 . Mouthparts. Labrum absent. Mandibles small, exodont and endodont, articulation horizontal. Thorax. Prothorax strongly proclinate, with anterior lateral margins oblique in lateral view. Pronotum convex, laterally rounded, without lateral tooth, posterior corners slightly angulate, fitting closely onto elytra; surface irregularly transversely rugose, sparsely setose, setae short, recurved anteriad and anteromesad; notosternal sutures widely open (forming open triangle), curved anteriad. Prosternum short, about as long as hypomeron; procoxal cavities medially confluent, in middle of prothorax. Scutellar shield transverse, glabrous. Mesocoxal cavities laterally widely open (forming open triangle). Metanepisterna distinct, glabrous, dorsal margin straight anteriorly, without lobe. Mesoventrite short, anteriorly sloping. Metaventrite longer, convex. Elytra elongate, basal margins extended into short broad lobe overlapping posterolateral angles of pronotum, with broad, obtusely rounded humeri, lateral margin weakly sinuate in middle, without anterior marginal notch; surface punctostriate, without scutellary striole but sutural stria slightly curved outwards at base, interstriae indistinct, rugose, very sparsely setose, setae long, thin, reclinate, directed caudad, uniformly coloured. Legs long slender. Coxae large, pro- and mesocoxae prominent, subconical; procoxae medially contiguous; mesocoxae nearly separated (process of meso- and metaventrites projecting between coxae but not contacting); metacoxae flat, transversely elongate. Trochanters short, oblique. Femora long, subcylindrical, strongly inflated in apical half, unarmed, outside rounded. Tibiae terete, nearly straight, not expanded distally, outer edge narrow but not carinate or crenulate, inner edge with sparse long stiff setae, apex subtruncate, with 2 spurs. Tarsi long, thin; tarsites 1 and 2 subequal in length, gradually widening apicad, apex subtruncate/lobed but extended beyond socket of following tarsite, 3 deeply bilobed, 5 longer than 3 , narrowly cylindrical at base but broadening apicad; claws large, slender divaricate, with broad sharp flat basal tooth and long stiff ventrobasal seta arising from underside of tooth. Abdomen not preserved (cut away).

Derivation of name. The name of the genus is composed of the generic name Rhynchites and the Greek noun mimos (G: mimou), an imitator or actor, in reference to the similarity of the genus with those of Rhynchitinae; the gender of the name is masculine.

Remarks. The subbasally inserted, subgeniculate antennae, widely open notosternal sutures, single long gular suture and large, protruding eyes of this genus are features of rhynchitine Attelabidae, but its elongate scapes (more than twice as long as funicle segment 1) and four-segmented clubs (without any long sensory setae) as well as the slender, divaricate and dentate tarsal claws bearing a long ventrobasal seta rule out a placement in Attelabidae. In all Rhynchitinae examined, the scapes are subequal in length to funicle segment 1 and the articulation between them is apical and narrow, and the tarsal claws are divergent but not divaricate, typically strongly bifid (rarely laminate) and always without a ventrobasal seta. Simple claws do occur in some species of Auletes [52] as well as in Baltocar, placed in Attelabidae: Sayrevilleinae [40], but at least in the latter again without a ventrobasal seta (no Auletini with simple claws examined). Baltocar also possesses scutellary strioles, which are absent in Rhynchitomimus but also in several extant Rhynchitinae. Given that elongate scapes, a single long 
gular suture, protruding eyes and tarsal claws with a ventrobasal seta occur widely in Mesophyletidae, it is evident that Rhynchitomimus belongs in this family too, in which its subgeniculate antennae place it in Aepyceratinae as here delineated. Open pro- and mesocoxal cavities also occur in Platychirus and partly in Aepyceratus and Nugatorhinus and must be interpreted as a convergence with those of Attelabidae. Rhynchitomimus currently includes only one species.

Rhynchitomimus chalybeus Clarke \& Oberprieler, sp. n. (Figures 17 and 18)

Description. Size. Length $2.94 \mathrm{~mm}$ (apex of abdomen cut off), width $1.2 \mathrm{~mm}$. Head porrect but flexible downwards, elongate from base of rostrum to near occipital foramen; vertex more finely punctate than pronotum; venter transversely strigate. Eyes bulbous, slightly dorsoventrally compressed, maximally separated dorsally by distance of one eye diameter. Rostrum subequal in width in basal half but widening apicad from middle, gradually curved dorsoventrad; scrobes receiving only basal half of scape in repose. Antennae subgeniculate; scapes slender, slightly longer than funicle segments $1+2$, reaching anterior margin of eye in repose, slender in basal 2/3 but inflated in apical $1 / 3$; funicles with segment 1 with narrow, bent stalk; clubs with segments elongate, subequal in length (2 slightly shorter), widening apicad, segment 4 distinct, slightly shorter than 3 . Mouthparts. Mandibles short, exodont, outside with 2 small acute teeth, inside with at least one apical internal tooth, apex broadly T-shaped. Palpi obscured by debris around apex of rostrum. Thorax. Pronotum irregularly transversely rugose, sparsely covered with very fine, short setae recurved anteriad; with slight anterior collar; sides broadly rounded, posterolateral corners slightly angulate. Scutellar shield subrectangular, with rounded corners, transverse. Mesoventrite small, depressed, strongly sloping to between mesocoxae. Mesanepisterna large, raised above mesoventrite, distal end rounded, overlapping mesocoxa. Mesepimera small, narrowly triangular. Metaventrite large, bulging, with precoxal groove tracking margin of metacoxal cavity. Metanepisterna long, broad, with anteroventral hook. Elytra with 10 complete indistinct striae of large open punctures; side with marginal groove subequal in width for entire length, dorsally delimited by thin, distinct keel, margin without anterior marginal notch. Legs. Metacoxae flat, slanting forwards laterally. Abdomen. Not preserved (cut away with amber).

Material examined. Holotype (CNUB, \#CNU-COL-MA-0444): very well preserved and well visible specimen, abdomen cut off at apex, much of legs cut away with amber (right protarsus from apex of tarsite 1, left middle leg at femorotibial joint, right mesotarsus and apical part of tibia, both hindlegs near trochanters), only moderately distorted; in wedge, $5.1 \times 2.0 \times 2.5 \mathrm{~mm}$, rounded at one end, with all sides visible; amber around specimen clear, colourless, rest yellow, with large mass of organic material obscuring the prosternum and venter of head, with few bubbles but without other major impurities; with section of amber broken out, exposing but not damaging part of abdomen, this and a cavity in right metafemur left from cutting away amber filled in with casting resin (see Section 2.2).

Derivation of name. The species is named for its bluish-black metallic coloration, from the Greek noun chalyps (G. chalybos) (hardened iron, steel); this metallic coloration is evident under different lightings.

Remarks. In addition to the unusual generic characters summarised above, the combination of the metallic and generally shining lustre with sparse, pale and generally inconspicuous setae, the very long, slender, substraight rostrum and legs (especially the protibiae) and the elongate elytra with weakly concave sides and coarsely rugose sculpture makes this one of the more distinctive species among our sample. The metallic blue cuticle is so far a unique feature in Burmese amber weevils. Several features of the mesothorax of the holotype are indicative of distortion (as seen more clearly in the head) and must be interpreted with caution. They may have resulted from the seemingly strongly depressed mesoventrite and include the form of the mesanepisterna (raised above the mesoventrite, overlapping the mesocoxae) and the medially confluent mesocoxal cavities, between which the pointed apices of the meso- and metaventral intercoxal processes do not touch (a unique feature among the studied specimens). These three features are likely not real or somewhat exaggerated character states, 
and better-preserved specimens are needed to assess them properly; such may also enable description of the ventrites and hindlegs, which are cut away in the holotype.

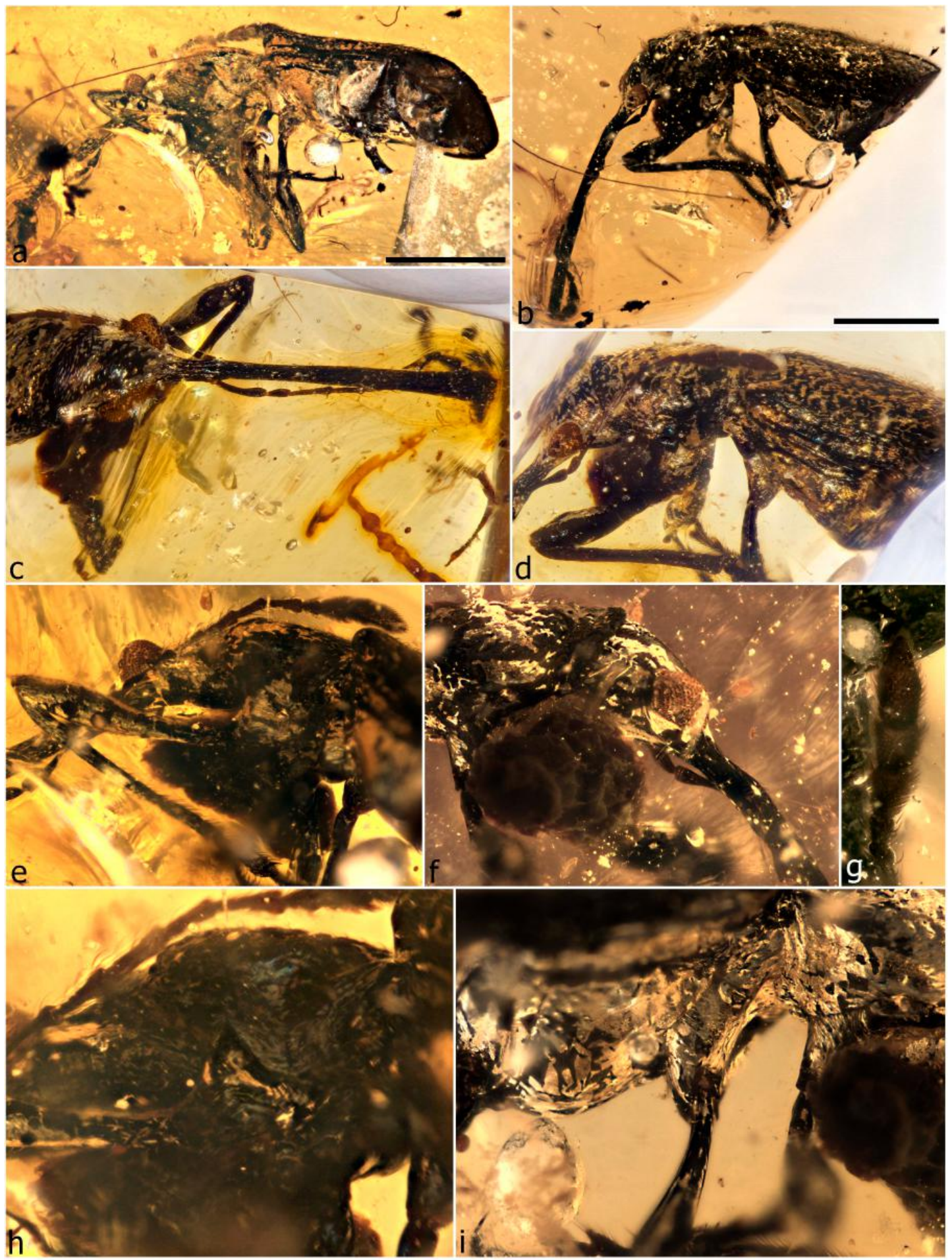

Figure 17. Rhynchitomimus chalybeus sp. n., holotype. Habitus, right lateral oblique (a); habitus, left lateral (b); head and antenna, dorsal (c); head, prothorax and pterothorax, left lateral (d); prothorax and antenna, left lateral oblique (e); head and prothorax (f); antennal club (g); prothorax showing widely open notosternal suture (h); meso- and metathorax and mesocoxa, right lateral (i). Scale bars: $1.0 \mathrm{~mm}$ $(\mathrm{a}, \mathrm{b})$. 

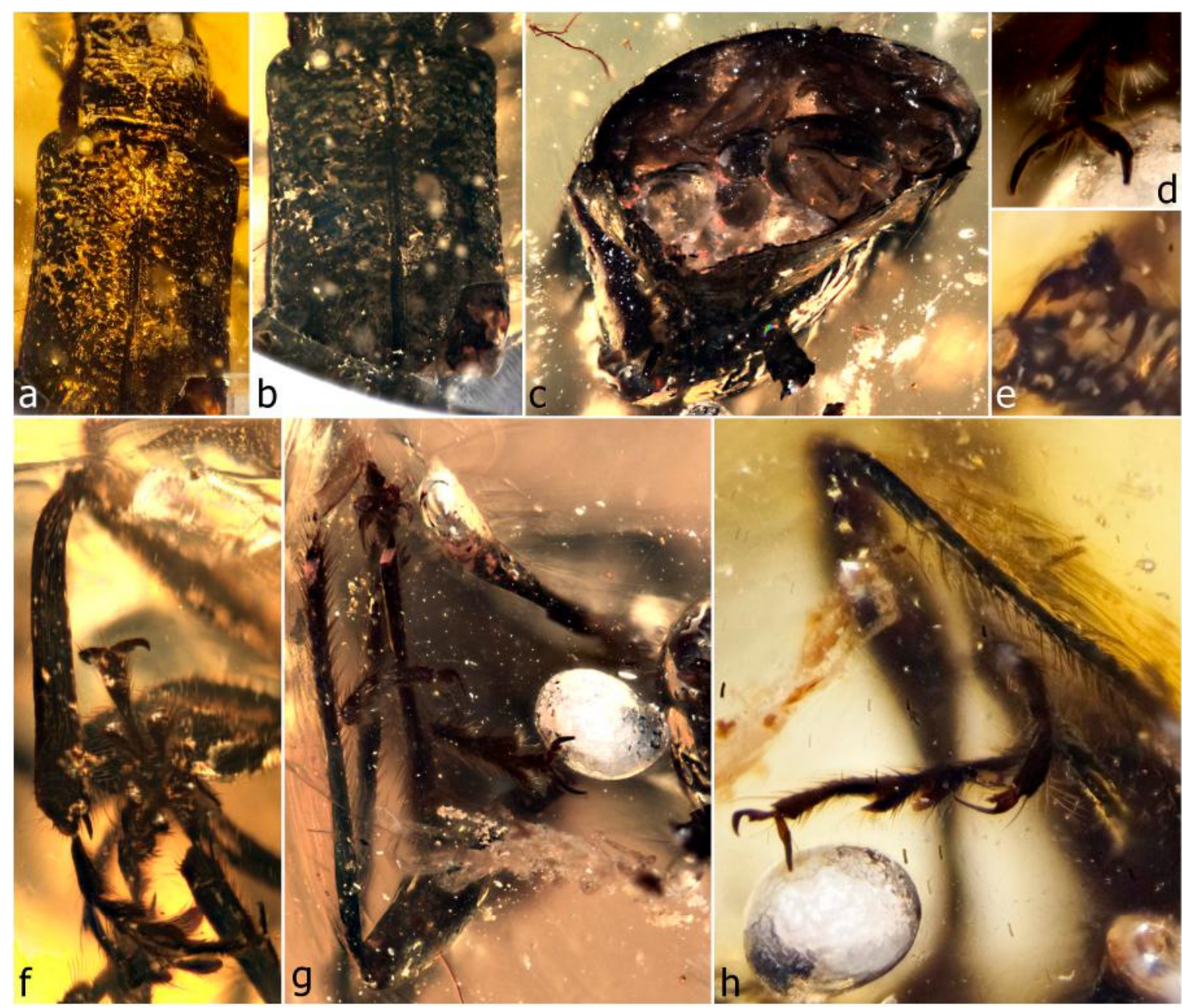

Figure 18. Rhynchitomimus chalybeus sp. n., holotype. Pronotum and elytra, dorsal (a); elytra (b); cut-away end of abdomen (c); tarsal claw, doso-apical (d); tarsal claw, apical (e); tibiae and details of legs $(\mathbf{f}-\mathbf{h})$.

Genus Nugatorhinus Clarke \& Oberprieler, gen. n.

Type species: Nugatorhinus chenyangi Clarke \& Oberprieler, sp. n.

Description. Size. Length $3.58-4.82 \mathrm{~mm}$, width $1.32-2.4 \mathrm{~mm}$. Head short, subquadratic transverse, slightly flattened. Eyes large, strongly protruding, coarsely facetted, dorsally separated by nearly width of rostrum anteriorly but further posteriorly; forehead flat, with a pair of low, transverse curved ridges between anterior margin of eyes and an elongate tuft or patch of coloured setae above eyes. Rostrum as long as or shorter than pronotum, stout, subcylindrical, substraight; antennal insertions lateral, without scrobes behind them, in front of them laterally with a few long erect setae. Apparently a single long gular suture present (not clearly discernible). Antennae subgeniculate, long; scapes stout, cylindrical, apically only slightly inflated, slightly longer than funicle segment 1 ; funicles 7-segmented, segment 1 subequal to scape, others thinner and progressively shorter towards club; clubs large, loosely articulated, flattened, 4-segmented, apical segment acute, about as long as 3. Mouthparts. Labrum absent. Mandibles small, non-exodont, articulation horizontal. Thorax. Prothorax proclinate or not. Pronotum slightly convex, laterally rounded, without tooth, posterior corners slightly extended, fitting closely onto elytra; surface coarsely tuberculate, sparsely setose, setae reclinate, directed anteromesad, disc with 2 pairs of patches of dense coloured setae, a small anterior one just before middle and a larger, elongate one just behind middle, laterally with patch of long coloured setae anteriorly and another posteriorly; notosternal sutures open ventrally but then 
closed, curved anteriad. Prosternum moderately long; procoxal cavities medially confluent, in middle of prothorax. Scutellar shield densely setose. Mesocoxal cavities closed or possible slightly open. Metanepisterna distinct, at least posteriorly densely setose. Mesoventrite short, anteriorly sloping. Metaventrite longer, flat or slightly convex. Elytra elongate, basally lobed over base of pronotum, with broadly rounded humeri, posteriorly declivous, lateral margin strongly sinuate to roundly emarginate in middle, apically individually rounded, not exposing pygidium; sutural flanges narrow, equal; surface punctostriate, without scutellary striole, interstriae convex, finely tuberculate, setose, setae long, thin, reclinate, directed caudad, interstriae 3 with row of 4 large, spaced, subcircular patches of dense setae, interstriae 7 with similar row of 3 setal patches placed slightly further back, interstriae 5 with 1 or 2 much smaller anterior setal patches, interstriae 9 with 4 or 5 similar patches, 1 or 2 anteriorly and 2-3 smaller ones at declivity. Legs. Procoxae large, prominent, medially contiguous; mesocoxae subglobular, narrowly separated; metacoxae flat, transversely elongate. Trochanters short, oblique. Femora long, subcylindrical, inflated in distal half, outside rounded, apically with patch of long coloured setae, inside excavate in distal half, receiving tibiae in repose, walls of groove at apex flatly tooth-like extended (meso- and metafemora). Tibiae straight, compressed, distally expanded, outer edge rounded, with dense long stiff setae in distal half, apex obliquely truncate, without spurs. Tarsi almost as long as tibiae; tarsite 1 apically excised, 2 shorter, triangular, apically excised, 3 deeply bilobed, 5 long, apically expanded; claws divaricate, dentate with ventrobasal seta at apex of tooth. Abdomen with ventrites 1 and 2 fused, each slightly longer than 3, 3 slightly longer than 4,5 as long as 3 , apically broadly rounded.

Derivation of name. Nugatorhinus is named for the funky patches of coloured setae that adorn its head and body, the name formed from the Latin noun nugator, a joker or jester (clown), and the Greek noun rhis (G: rhinos), a nose or snout, and being masculine in gender.

Remarks. Nugatorhinus is distinguishable from all other Burmese amber weevils by the large, dense, coloured setal patches on its head, body and legs, especially the large round to oval ones on the elytra. It is one of only six genera of Mesophyletidae with subgeniculate antennae, the scapes being elongate but only slightly longer than funicle segment 1 . From Aepyceratus, Platychirus, Rhynchitomimus and Acalyptopygus it also differs in having small, non-exodont mandibles, a thick, straight rostrum and a pair of crescentic ridges between the eyes, and from Calyptocis it is further distinguishable by not having an exposed pygidium. It currently includes two species.

Nugatorhinus chenyangi Clarke \& Oberprieler, sp. n. (Figures 19 and 20)

Description. Size. Length $3.58 \mathrm{~mm}$, width $1.32 \mathrm{~mm}$. Head slightly constricted behind eyes. Eyes hemispherical, forehead with a pair of elongate tufts of long, orange-brown setae above eyes. Rostrum shorter than pronotum, straight; basal 2/3 of length dorsally sparsely covered with long, orange-brown setae directed caudad; antennal insertions in middle of rostral length, in front of them with lateral row of a few long, erect setae, epistome flanked by 3 pairs of long, erect setae. Antennae. Funicles with segment 1 not inflated, 2 subequal in length but thinner, 3-7 progressively shorter towards club; clubs slightly flattened, with apical segment distinct, narrow, as long as 3. Mouthparts. Mandibles with 3 inner teeth. Maxillae and labium not discernible. Thorax. Prothorax proclinate, with anterior lateral margins oblique in lateral view. Pronotum elongate, $1.5 \times$ longer than broad in middle, laterally rounded; surface sparsely setose, setae long, thin, disc with dense orange-brown setal patches; notosternal sutures shortly, broadly open ventrally, then closed. Scutellar shield small, rounded, convex, covered with dense orange-brown setae. Mesocoxal cavities laterally possibly open (not clearly discernible). Metaventrite flat. Elytra narrowly elongate, posteriorly very gently declivous, lateral margin strongly sinuate; interstriae densely setose, setal patches orange-brown, interstriae 5 with 2 smaller anterior setal patches, interstriae 9 with a larger patch and 4 smaller ones spaced to near apex. Legs. Femora apically with patch of long orange-brown setae. Tibiae slightly flattened, basally strongly curved, with dense long stiff setae in distal half. Tarsi with tarsite 1 subcylindrical, 2 apically excised, 3 with lobes narrow, not pedunculate, 5 about as long as 1; claws as for genus. Abdomen as for genus. 
Material examined. Holotype (NIGP168266): extremely well preserved, intact specimen, not compressed or distorted, only a large clear bubble obscuring a small part of right side; in centre of rectangular block ca. $5.15 \times 3.6 \times 3.4 \mathrm{~mm}$; amber very clear, without major impurities.

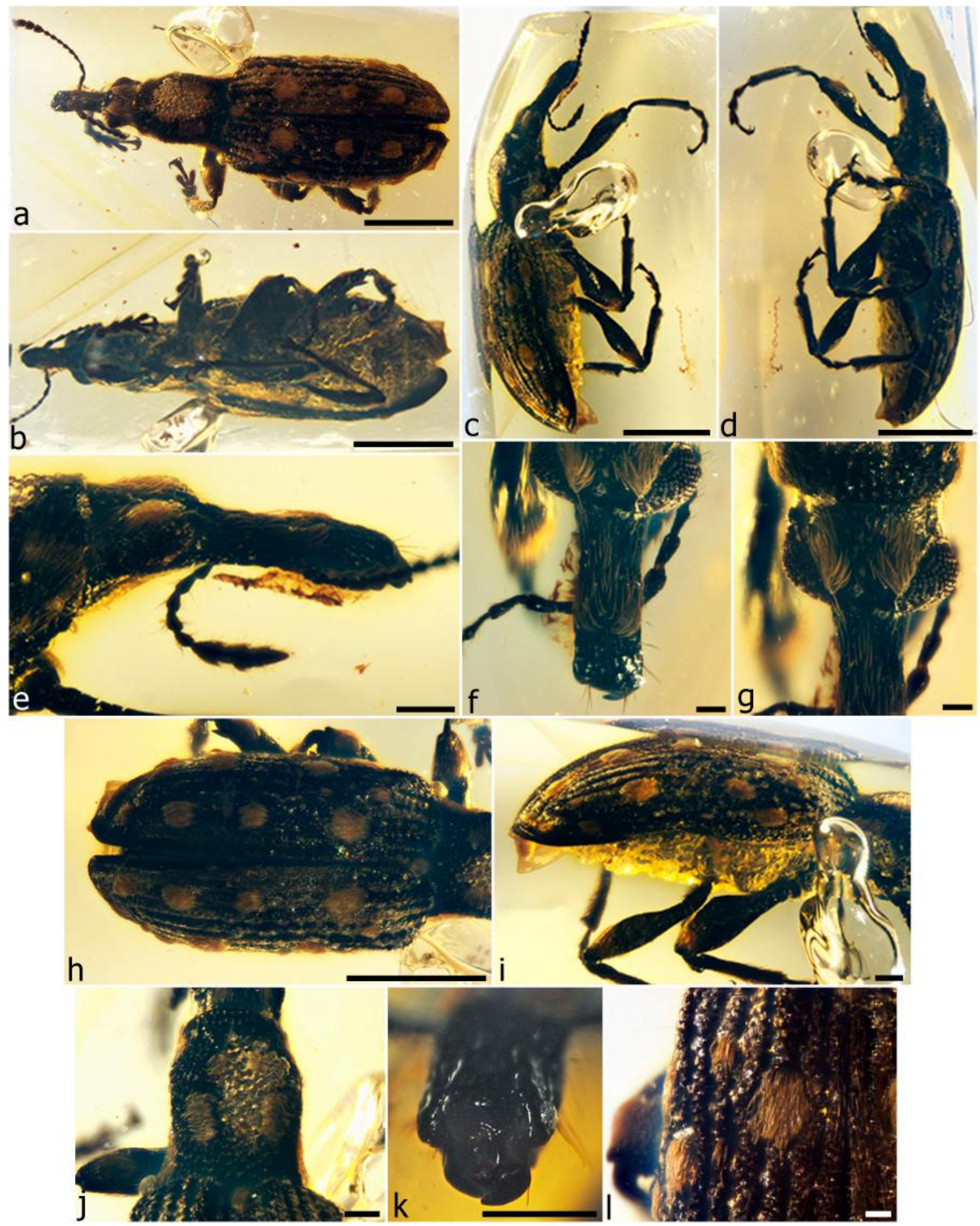

Figure 19. Nugatorhinus chenyangi sp. n., holotype. Habitus, dorsal (a); habitus, ventral (b); habitus, right lateral (c); habitus, left lateral (d); head and antenna, left lateral (e); rostrum, dorsal (f); head showing detail of setal tufts, dorsal (g); elytra, dorsal (h); elytra, lateral (i); pronotum, dorsal (j); apex of rostrum and mandibles $(\mathbf{k})$; detail of elytra showing setal tufts and deep striae (1). Scale bars: $1.0 \mathrm{~mm}$ $(\mathrm{a}-\mathrm{d}, \mathrm{h}) ; 0.2 \mathrm{~mm}(\mathrm{e}, \mathrm{i}, \mathrm{j}) ; 0.1 \mathrm{~mm}(\mathrm{f}, \mathrm{g}, \mathrm{k}, \mathrm{l})$. 


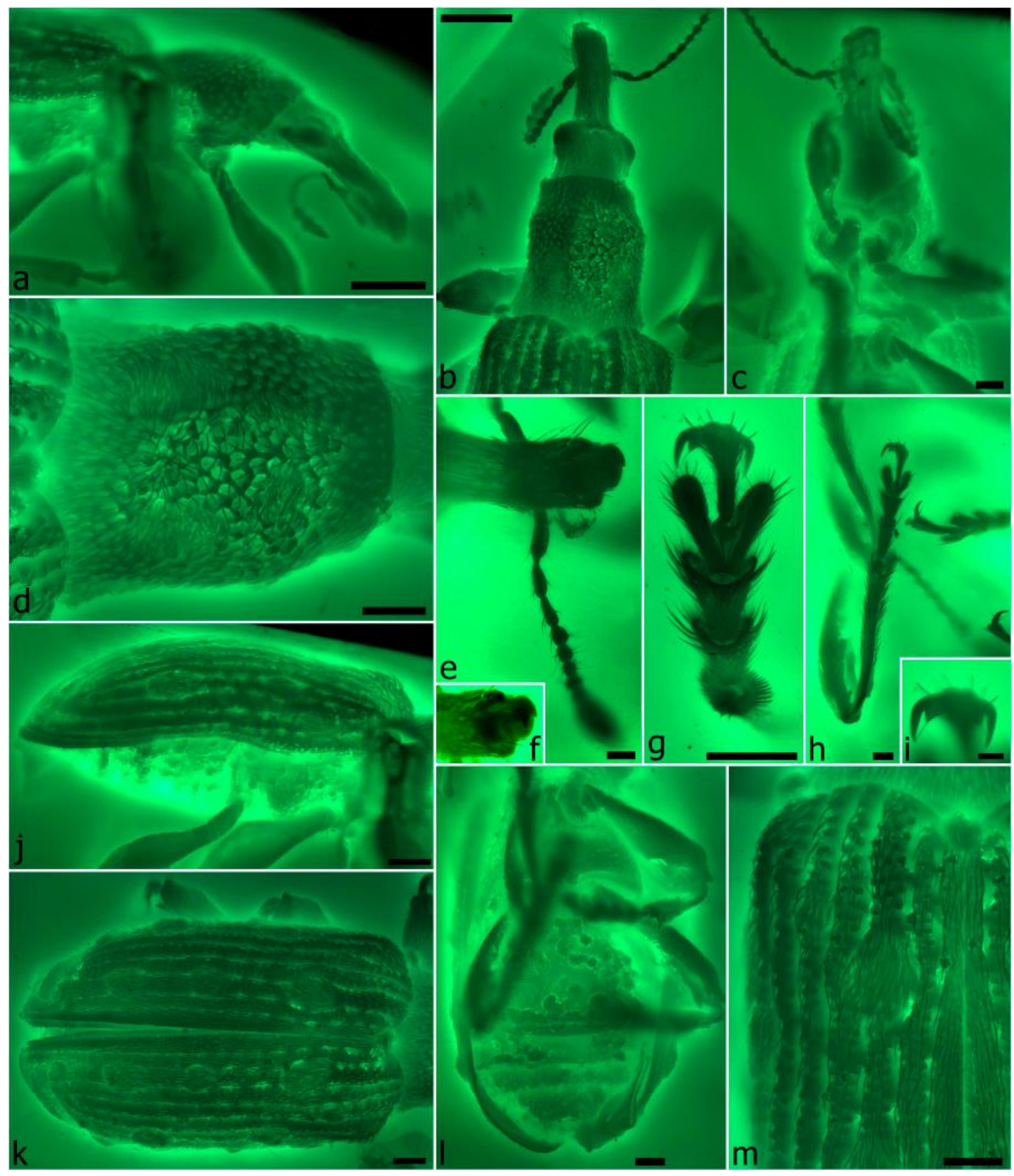

Figure 20. Nugatorhinus chenyangi sp. n., holotype. Images taken under fluorescent green light. Head and prothorax, right lateral (a); same, dorsal (b); same, ventral (c); pronotum, dorsal (d); rostrum and antenna, dorsal (e); apex of rostrum and mandibles, dorsal (f); tarsus, dorsal (g); right metatibia and tarsus, dorsal (h); tarsal claw, apical (i); elytra, right lateral (j); elytra, dorsal (k); ventrites (1); detail of left elytron (m). Scale bars: $0.5 \mathrm{~mm}(\mathrm{a}, \mathrm{b}) ; 0.2 \mathrm{~mm}(\mathrm{c}, \mathrm{d}, \mathrm{j}-\mathrm{m}) ; 0.1 \mathrm{~mm}(\mathrm{e}, \mathrm{g}, \mathrm{h}) ; 0.05 \mathrm{~mm}(\mathrm{i})$.

Derivation of name. The species is cordially named for Chenyang Cai (NIGP), who made a series of good photographs of the specimen available to us, from which we compiled the description. The dedication also recognises Chenyang's contributions to the study of beetle fossils, from Burmese amber and other Lagerstätten.

Remarks. Due to its conspicuous patches of orange-brown setae adorning its body, Nugatorhinus chenyangi is one of the most readily recognisable Burmese amber weevils. The single specimen so far known is remarkably well preserved and allows a complete characterisation of the species. The other 
known species, N. albomaculatus, has a similar arrangement of setal patches, but silvery white in colour, and a longer rostrum and larger body size.

Nugatorhinus albomaculatus Clarke \& Oberprieler, sp. n. (Figure 21)

Description. Size. Length $4.82 \mathrm{~mm}$, width $2.4 \mathrm{~mm}$. Head not constricted behind eyes. Eyes elongate, dorsoventrally flattened, slanting backwards, forehead with a pair of elongate patches of dense white setae above eyes. Rostrum about as long as pronotum, hardly curved; basal part dorsally not conspicuously setose, only few fine setae; antennal insertions slightly before middle of rostral length, in front of them with a few long, erect, lateral setae. Antennae. Scapes longer than funicle segment 1 ; funicles with segment 1 slightly inflated at apex, others not clearly visible; clubs with apical segment acute, longer than 3. Mouthparts. Mandibles with 2 visible inner teeth, apical one sharp, other blunter. Maxillae and labium not discernible. Thorax. Prothorax not evidently proclinate. Pronotum subquadratic, laterally straight; surface coarsely tuberculate, tubercles anteriorly elongate, confluent, forming short longitudinal ridges, very sparsely setose, setae small, thin, disc with dense white setal patches. Scutellar shield large, trapezoidal, convex, covered with dense white setae. Metanepisterna posteriorly with dense white setae. Metaventrite slightly convex. Elytra moderately elongate, posteriorly strongly declivous, lateral margin strongly roundly emarginate above metacoxae; interstriae sparsely setose, setal patches white, interstriae 5 with a small anterior patch, interstriae 9 with a larger and a small one anteriorly and 2 smaller ones at declivity. Legs. Femora apically with patch of dense white setae. Tibiae with median third of length girdled with silvery-white setae, distal third with dense, long, black, suberect setae; protibiae longer than others. Tarsi large, flat, protarsi only half as long as protibiae; tarsite 1 triangular, 2 apically deeply excised, 3 with lobes flat, 5 about as long as $1+2$; claws divaricate, apparently simple (not clearly discernible). Abdomen with ventrites 1 and 2 as for genus, rest not properly discernible.

Material examined. Holotype (NIGP154203): reasonably well preserved, intact specimen with compressed legs, left protarsus lying over apex of rostrum, poorly visible due to numerous small white bubbles on dorsal surface and a thick layer of small to minute bubbles below ventral surface, rostrum and legs protruding through it, also several small cracks along both sides; situated on right side of roundedly rectangular cuboid ca. $6.6 \times 4.9 \times 4.3 \mathrm{~mm}$ with rounded edges and corners, dorsal surface slightly convex; amber clear with few small impurities apart from the numerous bubbles.

Derivation of name. The species is named for its conspicuous silvery-white, dense, setal patches on especially the elytra, the name being an adjective.

Remarks. Nugatorhinus albomaculatus is also an easily recognisable Burmese amber weevil due to the conspicuous white setal patches on its body. Although the single specimen so far known is not very well preserved and many of its features are obscured by bubbles, it clearly represents the same genus as $N$. chenyangi, from which it differs not only in the white colour of its setal patches but also in having a longer rostrum, a larger body size and various other subtle characters. 


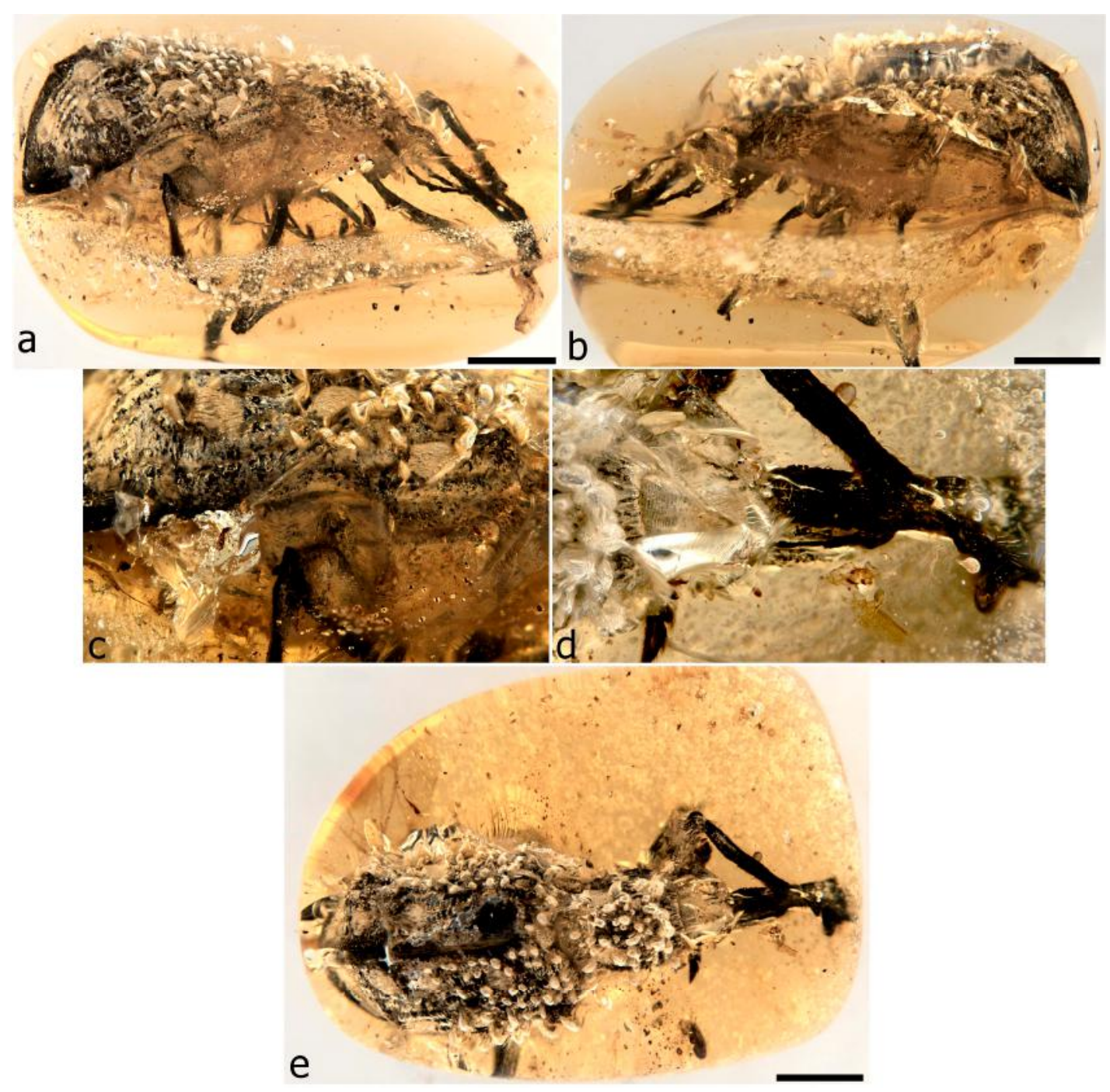

Figure 21. Nugatorhinus albomaculatus sp. n., holotype. Habitus, right lateral (a); habitus, left lateral (b); detail of elytra (c); head, dorsal (d); habitus, dorsal (e). Scale bars: $1.0 \mathrm{~mm}(\mathrm{a}, \mathrm{b}, \mathrm{e})$.

Genus Calyptocis Clarke\& Oberprieler, gen. $\mathbf{n}$.

Type species: Calyptocis brevirostris Clarke \& Oberprieler, sp. $\mathrm{n}$.

Description. Size. Length $5.6 \mathrm{~mm}$, width $3.19 \mathrm{~mm}$. Head porrect, short, not constricted behind eyes. Eyes relatively small, hemispherical but only slightly protruding, coarsely facetted, dorsally separated by about half basal rostral width anteriorly but further posteriorly; forehead flat, without tubercles above eyes. Gular suture single, long, from base of head to about base of rostrum. Rostrum subequal in length to pronotum, stout, subcylindrical, substraight; antennal insertions lateral, slightly antemedian, with scrobes behind them directed obliquely ventrad beneath eye. Antennae subgeniculate, long; scapes short, subcylindrical, slightly longer than funicle segment 1; funicles 7-segmented, segments 1-2 elongate, subequal in length, 3 slightly shorter, apically rounded, 4-7 progressively shorter, obconical; clubs large, loosely articulated, 4-segmented, apical segment long, acute, slightly longer than segment 3. Mouthparts. Labrum absent. Mandibles small, non-exodont, articulation horizontal. Maxillary palps robust but short, not projecting beyond mandibles, 4-segmented; segment 2 shorter and narrower than 1, 3 shorter than 2, 4 subequal in length to 3, obconical and narrower than 3. Labial palps attached apically to prementum, 3-segmented; segment 1 slightly longer and broader than 2, 3 subequal in length to and narrower than 2, obconical. Thorax. Prothorax strongly proclinate, with anterior lateral margins oblique in lateral view. Pronotum 
evenly convex, laterally rounded, without tooth, posterior corners not extended, fitting closely onto elytra; surface seemingly coarsely rugose; notosternal sutures closed. Prosternum moderately short; procoxal cavities medially confluent, slightly closer to anterior margin of prosternum. Mesocoxal cavities seemingly closed. Mesoventrite short, anteriorly strongly sloping down. Metaventrite longer, convex. Elytra short and broad, seemingly basally lobed over base of pronotum, with broadly rounded humeri, strongly sloping posteriorly, lateral margin strongly sinuate to roundly emarginate in middle, apically individually rounded, exposing short pygidium; surface indistinctly punctostriate, interstriae seemingly subflat, rugose or shallowly tuberculate. Legs. Procoxae globular, only slightly projecting, medially contiguous; mesocoxae globular, narrowly separated; metacoxae flat, transversely elongate. Trochanters short, oblique, apparently not recessed into coxae. Femora long, inflated in distal half but constricted before apex, outside rounded, on inside of constriction with large acute tooth shearing against basal curved part of tibia. Tibiae subcylindrical, widening apicad, pro- and mesotibiae straight, metatibiae curved backwards, outer edge rounded (not carinate or crenulate), all with dense erect setae in distal half, especially on posterior surface and possibly forming antennal cleaner on protibiae, apex subobliquely truncate, without spurs (or too small to discern). Tarsi elongate, about $0.67 \times$ as long as tibae, robust; tarsite 1 elongate-triangular, apically truncate to weakly lobed, 2 shorter and broader, apically slightly emarginated, 3 broader still, deeply emarginate with lobes broad, 4 forming distinct globular cryptotarsite recessed into base of 3, 5 slightly longer than 3 , strongly widening distad; claws divaricate, dentate, inner tooth small, acutely and inwardly curved, with long ventrobasal seta, almost reaching outer tip of claw. Abdomen with ventrites 1 and 2 subequal in length, 3-4 progressively shorter, 5 subequal to 3 and 4; last tergite exposed as distinctly cupular pygidium.

Derivation of name. The name of the genus is composed from the Greek adjective kalyptos (covered) and noun kis (G: kios) (weevil or beetle); its gender is masculine.

Remarks. The absence of a labrum, the subgeniculate lateral antennae (the scapes only slightly longer than funicle segment 1), the single long gular suture and the exposed pygidium conform with the characters of Attelabidae, but Calyptocis differs from this family in its distinctly dentate tarsal claws with a ventrobasal seta and must therefore also be placed in the subfamily Aepyceratinae of Mesophyletidae. In this subfamily it agrees with Acalyptopygus in having an exposed pygidium, but this genus differs in having strongly exodont mandibles and the scapes apically clavate and about twice as long as the first funicle segment. Calyptocis includes only one species.

Calyptocis brevirostris Clarke \& Oberprieler, sp. n. (Figures 22-24, Video S1)

Description. Size. Length $5.6 \mathrm{~mm}$, width $3.19 \mathrm{~mm}$. Head with dorsal outline continuing evenly from base of rostrum, without sinus; ventrally bulging. Rostrum short (but longer than exposed part of head), depth slightly increasing apicad, coarsely rugose. Thorax. Pronotum slightly longer than head, slightly narrower than elytra basally. Lateral pronotal margins broadly rounded; setation not visible. Prosternum thin, shorter than hypomeron. Scutellar shield prominent. Elytra punctostriate; striae thin, linear, interstriae broad, subflat; concave behind humeri.

Material examined. Holotype (NIGP154204): well preserved specimen, minimally distorted or compressed but most surface details including vestiture, surface sculpture and mouthparts obscured by nearly unbroken layer of bubbles and debris, missing part of left protarsus and left mesotarsal claw (cut away with amber) and left antenna; in block with two flat faces and one large curved face, $11 \times 7.9 \times$ $6.4 \mathrm{~mm}$; amber clear yellow-brown, with diffuse gritty impurities forming cloud surrounding much of specimen, obscuring especially ventral structures, with large cavity on flat side, two smaller cavities on curved side (above elytra) infilled with resin (see Section 2.2).

Derivation of name. The species is named for its short, stout rostrum, which resembles that of the extant Australian belid genera Pachybelus Zimmerman and Pachyura Hope.

Remarks. This species is unique among Burmese amber weevils in its large size and robust body, short rostrum, subgeniculate antennae and pygidium. Although the specimen is largely covered with a film of tiny bubbles that obscures many of its features, several critical ones are discernible, especially in the CT scans we had done (Figures 23 and 24, Video S1). 


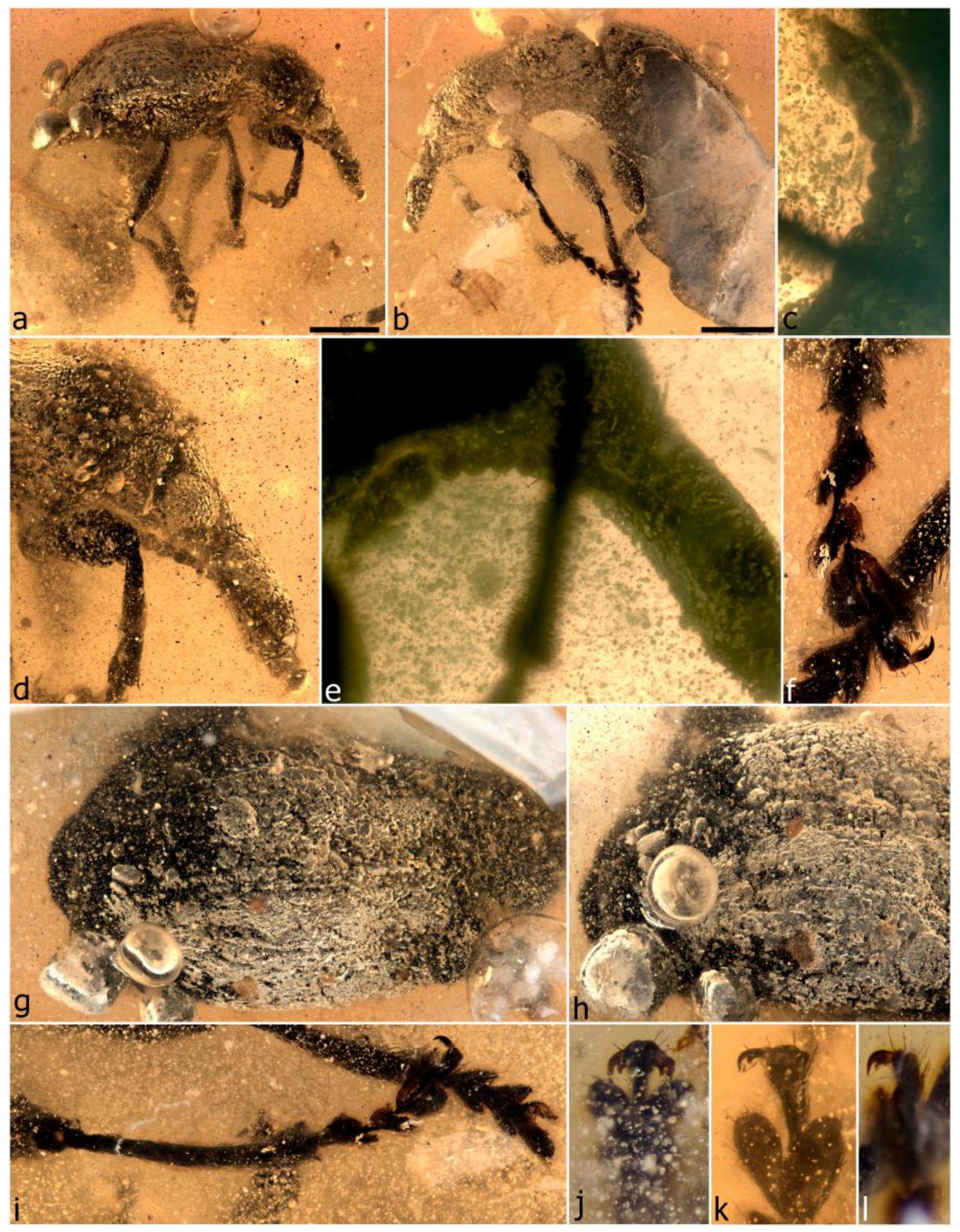

Figure 22. Calyptocis brevirostris sp. n., holotype. Habitus, right lateral (a); habitus, left lateral (b); detail of antenna, right lateral (c); head and prothorax, right lateral (d); rostrum and antenna, right lateral (e); protarsus (f); elytra, dorsal (g); elytra and pygidium, dorsoposterior $(\mathbf{h})$; forelegs (i); claw (j-l). Scale bars: $1.0 \mathrm{~mm}(\mathrm{a}, \mathrm{b})$. 


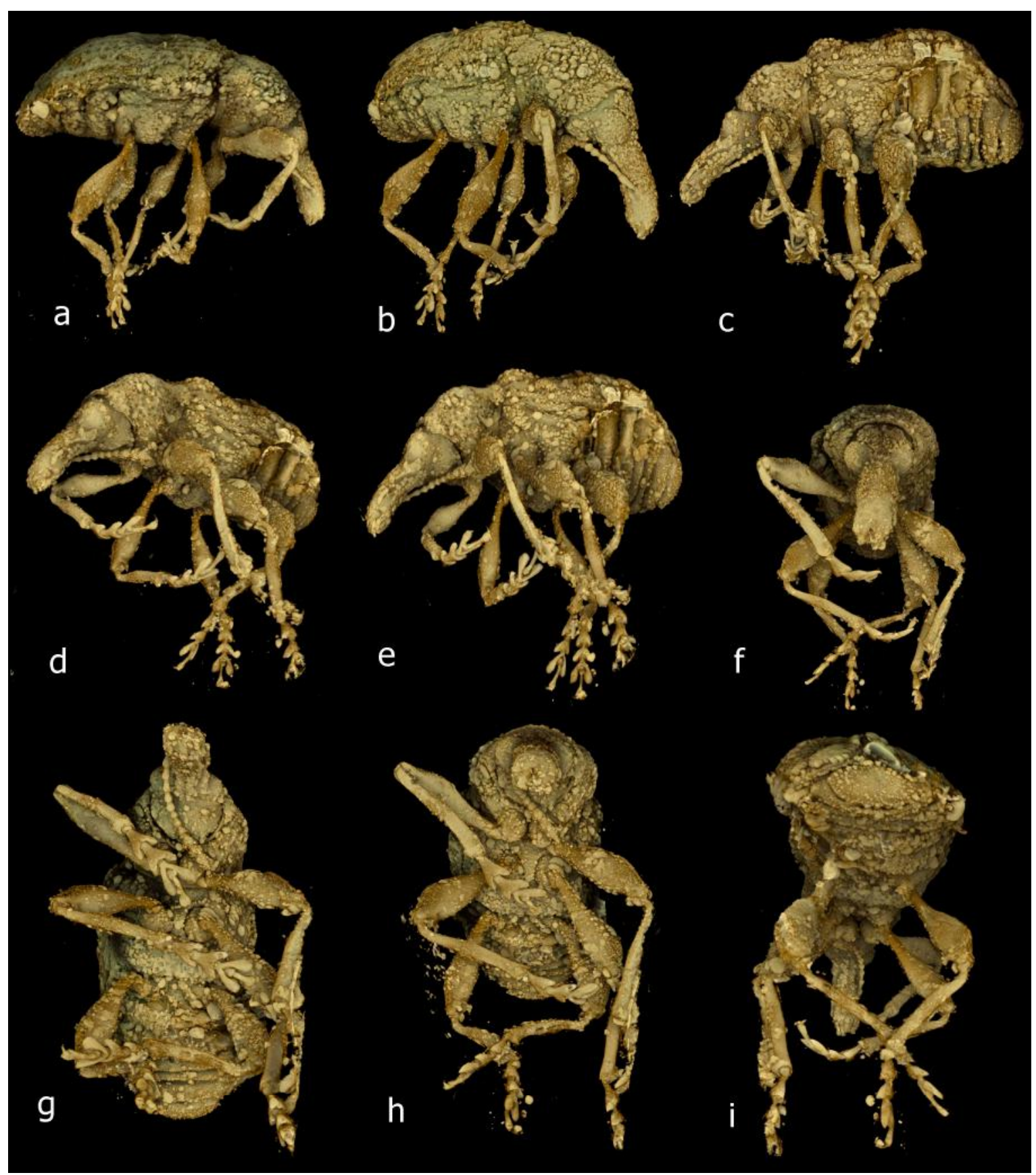

Figure 23. Calyptocis brevirostris sp. n., holotype. Habitus images extracted from micro-CT scanning reconstruction (see also Video S1). Right lateral (a); right lateral oblique (b); left ventral oblique (c); left lateral oblique (d); left lateral (e); frontal (f); ventral (g); frontal oblique (h); posterior oblique (i). 


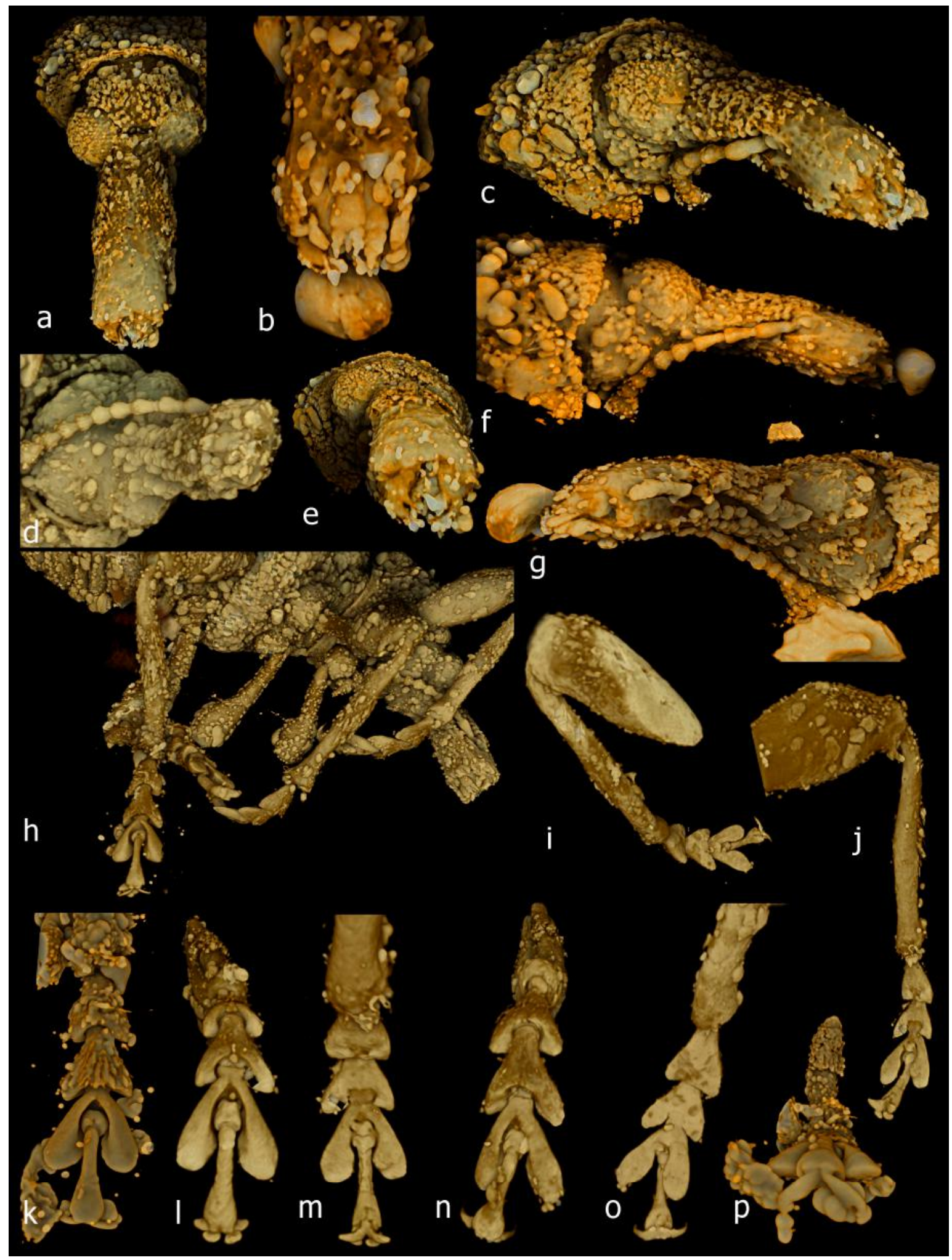

Figure 24. Calyptocis brevirostris sp. n., holotype. Morphological details extracted from micro-CT scanning reconstruction (see also Video S1). Head, dorsal (a); apical part of rostrum and mouthparts, ventral (b); head, right lateral oblique (c); head, ventral (d); head, frontal oblique (e); head, right lateral (f); head left lateral (g); head, thorax and legs, ventral oblique (h); legs (i,j); tarsi (k-p). 
Genus Acalyptopygus Clarke \& Oberprieler, gen. n.

Type species: Acalyptopygus brevicornis Clarke \& Oberprieler, sp. n.

Description. Size. Length 2.0-2.75 mm, width 0.8-1.1 mm. Head short, porrect, subconical, not constricted behind eyes. Eyes large, elongate, somewhat compressed, strongly protruding, coarsely facetted, dorsally separated by width of rostrum at base, forehead subtrapezoid, without tubercles. Rostrum as long as pronotum, stout, slightly downcurved, subcylindrical; antennal insertions lateral, in basal quarter to third of rostral length or less, behind them with short scrobes extending to eye, in front of them without lateral row of setae. Gular suture single, long, from base of head to base of rostrum. Antennae subgeniculate; scapes straight, subcylindrical, distally strongly clavate, twice longer than funicle segment 1 ; funicles nearly $3 \times$ longer than scape, 7 -segmented, segment 1 as thick as apex of scape, other segments half as thick as 1 , subequal; clubs long, very loosely articulated, especially segment 1, 4-segmented, segment 4 distinct, broad, long. Mouthparts. Labrum absent. Mandibles small, flat, horizontal, exodont, with T-shaped apex, articulation oblique. Maxillary palps 3-segmented, elongate, slender. Thorax. Prothorax slightly proclinate, with anterior lateral margins oblique in lateral view. Pronotum roundly subrectangular to trapezoidal, laterally broadly rounded, without tooth, weakly convex, punctate, sparsely setose, setae short, fine, suberect, pale, directed mesad to anteromesad; notosternal sutures closed. Prosternum moderately long; procoxal cavities medially confluent, in middle of prothorax or closer to anterior margin of prosternum. Scutellar shield small, sometimes indistinct. Mesocoxal cavities laterally closed (by meso- and metaventrite). Metanepisternal sutures distinct. Mesoventrite short, anteriorly strongly sloping. Metaventrite raised into transverse weals before metacoxae. Elytra elongate, bases tightly abutting pronotum but not extending over its base, with weak, broadly rounded humeri closely fitting with pronotal corners, posteriorly declivous, apically individually rounded, exposing pygidium in repose; sutural flanges apically visible, thin, equal; surface punctostriate, rarely astriate, without scutellary striole, sparsely setose, setae short, stout, acute, reclinate, directed caudad. Legs. Procoxae large, elongate, prominent, medially contiguous; mesocoxae subglobular, narrowly separated; metacoxae transversely elongate, reaching elytra. Trochanters short, oblique. Femora long, subcylindrical, strongly inflated in distal half, unarmed, outside rounded. Tibiae long, straight, flattened, outer edge rounded, apically with long dense setae, apex obliquely truncate, with 2 fine spurs (or 1 on metatibiae). Tarsi narrow, about $0.67 \times$ or more as long as tibiae; tarsite 1 elongate, apically weakly excised, 2 shorter, deeply excised, 3 deeply bilobed, 5 as long as $1+2$; claws divaricate, dentate with very narrow space between outer edge of basal tooth and inner edge of claw, with or without ventrobasal seta at apex of tooth. Abdomen with ventrites 1 to 2 fused, each slightly longer than 3 and 4, 4 shorter than 3, 5 longer than 4, with long, slightly curved apical margin fitting onto ventral margin of pygidium.

Derivation of name. The genus is named for its exposed pygidium, the name derived from the Greek adjective akalyptos, meaning uncovered, and noun pyge (G: pygos), rump or buttocks, and being masculine in gender.

Remarks. Acalyptopygus differs from the other genera placed in Aepyceratinae except Calyptocis foremost by its exposed pygidium, from Aepyceratus, Platychirus and Rhynchitomimus also by having closed pro- and mesocoxal cavities and from Nugatorhinus by its exodont mandibles and uniform vestiture, not featuring distinct coloured setal patches on the head, pronotum, elytra and legs. From Calyptocis it differs in its elongate, slender rostrum with exodont mandibles, long (at least twice longer than pedicel), apically strongly clavate scapes and very long clubs with a distinct and usually narrow apical segment. Uniquely among Aepyceratinae, Acalyptopygus is the only genus having the type of exodont mandibles typical of the majority of Mesophyletinae, being flattened with several large inner and outer teeth and horizontal in repose but opening into a vertical position via oblique articulation sockets. It currently includes four species. In A. brevicornis and A. lingziae the tarsal claws lack the ventrobasal seta that is so characteristic of and almost ubiquitous in Mesophyletidae. 
Acalyptopygus brevicornis Clarke \& Oberprieler, sp. n. (Figure 25)

Description. Size. Length $2.25 \mathrm{~mm}$, width $0.81 \mathrm{~mm}$. Dark blackish-brown; antennae and legs paler. Head subporrect; dorsally slightly convex, with median, slightly raised, flat, impunctate and glabous costa extending from base of rostrum to hind part of head; finely punctosetose, denser behind and between eyes. Eyes lateral, subelongate, dorsally separated by width of rostrum anteriorly, further posteriorly. Rostrum slightly downcurved, inserted in dorsal half of head, basally with dorsal outline continuing onto head, with weak sinus before eyes but ventral outline forming large sinus with strongly bulging head; dorsally and laterally without carinae; antennal insertions in basal quarter of rostral length, in front of them with deep scrobes extending to slightly below front margin of eye; mandibular articulations oblique. Antennae. Scapes ca. $2.0 \times$ longer than funicle segment 1, extending to below front margin of eye, apex truncate; funicles with segment 1 oval-shaped, 2 nearly $0.67 \times$ as long as 1 but much narrower, segments 2-7 subcylindrical, subequal; clubs with segments obconical, apically oblique, 1-3 subequal, obconical, 4 narrow, acute, slightly shorter than 3 . Mouthparts. Mandibles with 2 teeth on outside, a larger rounded basal and a smaller rounded apical one, and 3 teeth on inside, 2 large basal and a smaller rounded apical one with short slender apical part, apical teeth forming T. Maxillary palps with segments 1 and 2 subequal, 3 ca. $1.5 \times$ longer than 2 . Thorax. Prothorax with indistinct lateral edge. Pronotum widest just behind middle, narrowing anteriorly, only slightly narrower than elytra; not constricted anterolaterally; densely punctosetose, punctures small, distinct; base broadly sinuate, shortly lobate at middle, closely abutting bases of elytra and scutellar shield; corners slightly extended, closely fitting with humeri. Prosternum short, about as long as hypomeron. Scutellar shield at same level as elytral bases, subquadrate, with straight anterior margin, densely setose. Metaventrite punctate, setose. Elytra densely setose, setae short, obliquely subrecurved; surface rugose, weakly punctostriate, striae indistinct; interstriae basally and laterally slightly raised above striae, indistinct from striae on disc, without any prominent lateral striae; bases broadly rounded; humeri flat, weakly produced; marginal groove subequal in width along entire length. Legs. Procoxae conical; mesocoxae subglobular, very prominent. Tibiae sparsely setose, with longer denser setae in distal half; apically with long slender fringing setae and 2 spurs; protibiae slender, apically slightly expanded and with outer edge obliquely truncate, somewhat produced distad to form angulate lobe; mesotibiae with outer edge continuing as rounded apical flange, with small mucro; metatibiae with setation as on mesotibiae and outer edge produced to lobe as in protibiae, ventrally produced to acute point. Tarsi with tarsite 1 slightly widening apicad, 2 deeply excised, 3 broadly lobate, lobes subpedunculate, about half as long as 5, 5 slender; claws without ventrobasal seta. Abdomen. Ventrites 1 and 2 subflatly aligned, with indistinct suture between them, subequal in length, $3-5$ slightly stepped, 3 slightly shorter than 2, 4 slightly shorter than 3, 5 longer than 4 .

Material examined. Holotype (NIGP154205): exceptionally well preserved and well visible specimen, with left fore and middle legs cut off at femorotibial joint, mandibles and most aspects of antennae and legs visible (some obscured due to being folded beneath body), surface details also well visible through fragmented coating of whitish debris, left wing partly extended; in centre of cuboid $6.1 \times 2.2 \times 1.2 \mathrm{~mm}$, rounded off at one corner, with sides subparallel to flat faces of block and dorsal side parallel to curved edge; amber clear yellow, with few impurities but large fracture on right side of specimen and few other smaller fractures and minimal debris in vicinity of specimen.

Derivation of name. The species is named for its short antennae, especially the scapes, which are only $2 \times$ longer than funicle segments 1 but still reach the eyes in repose (antennae inserted subbasally). The name is a Latin adjective.

Remarks. The species differs from $A$. astriatus in the rugose elytra with indistinct striae and the weak sinus between rostrum and head in lateral view, and from A. elongatus and A. lingziae it is readily distinguishable by having the scapes shorter than the eyes and subequal funicle segments. A distinctive feature of the holotype is the broad, slightly raised, smooth and impunctate median costa on the head, a feature so far restricted to Acalyptopygus and shared at least with A. astriatus and possibly with A. lingziae. Another remarkable feature of the species is the heterogenous structure 
of the tibial apex, in the pro- and metatibiae produced into a distinct truncate outer flange (in the latter so developed that, in concert with the spurs, the apex appears claw-like in lateral view) but in the mesotibiae forming simple rounded flanges equipped on the inside with a short sharp mucro. This mesotibial mucro also occurs in A. elongatus and one undescribed species known to us. As in $A$. lingziae, the tarsal claws of $A$. brevicornis lack the ventrobasal seta.

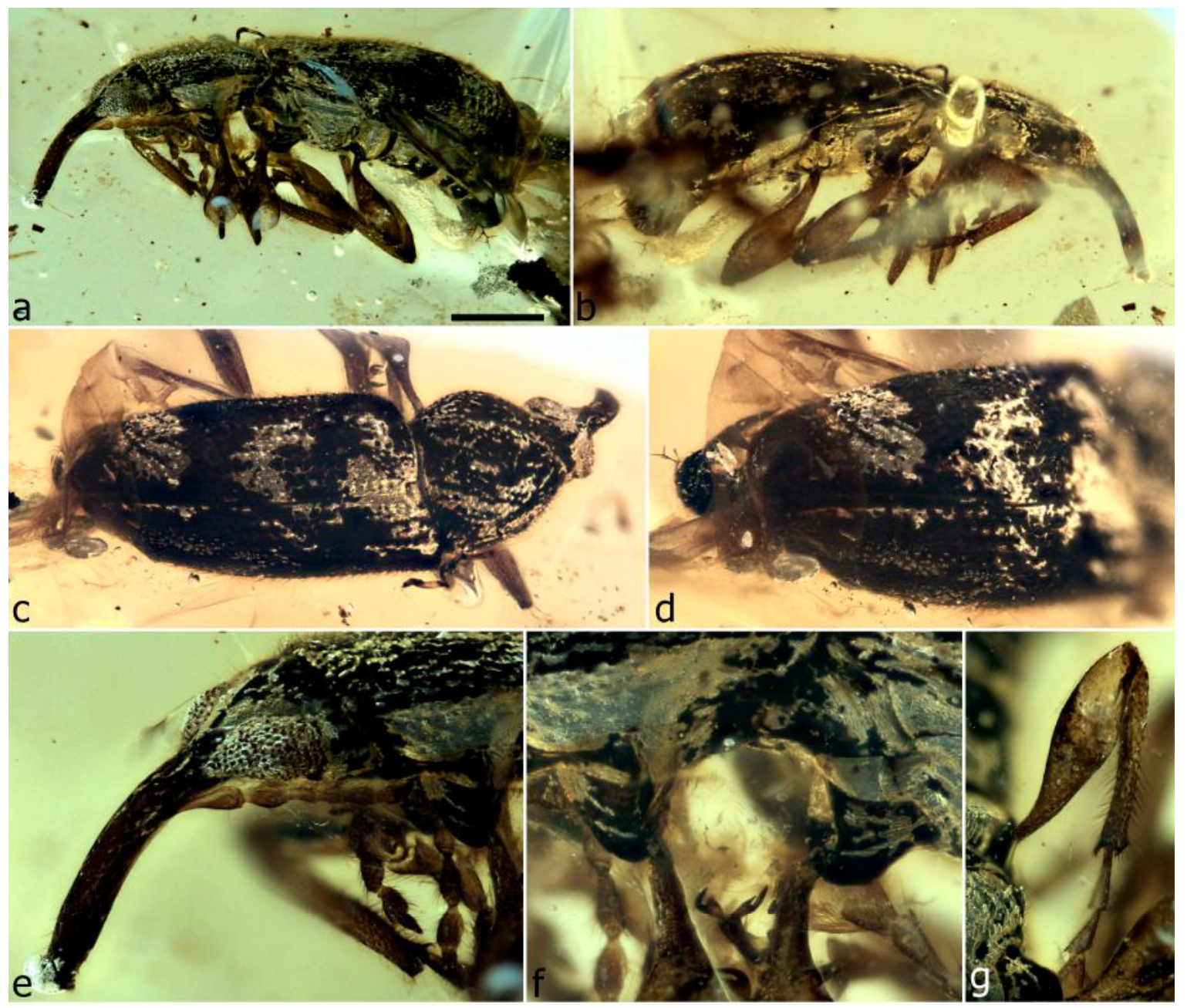

Figure 25. Acalyptopygus brevicornis sp. n., holotype. Habitus, left lateral (a); right lateral (b); dorsal (c); elytral apices and pygidium, dorsal (d); head and prothorax, showing median costa of forehead (e); pro- and mesocoxae, showing closed coxal cavities (f); left metatibia (g). Scale bars: $0.5 \mathrm{~mm}$ (a).

Acalyptopygus lingziae Clarke \& Oberprieler, sp. n. (Figure 26)

Description. Size. Length $2.75 \mathrm{~mm}$, width $1.1 \mathrm{~mm}$. Eyes only slightly slanting backwards, protruding, forehead between them narrowly triangular, apparently with dark median costa (head somewhat compressed). Rostrum distinctly downcurved, inserted in dorsal half of head but basally with dorsal outline not continuing onto head, forming a shallow sinus before eyes, ventral outline curved evenly onto that of head, not forming a conspicuous sinus. Antennae. Scapes as long as eye; funicles with segments 2 to 4 subequal, slightly shorter than 1 , subcylindrical, 5 slightly shorter and apically swollen, 6 shorter, swollen in middle and thicker, 7 longer, subapically swollen; clubs with segments 1 to 3 subequal in length. Thorax. Pronotum broadly roundly trapezoidal, laterally slightly expanded but not explanate, posterior corners distinctly narrowly extended to fit closely onto elytral humeri. Metaventrite longer than mesoventrite, distinctly raised into transverse weals. Elytra posteriorly strongly declivous, well exposing pygidium in repose; surface faintly punctostriate, 
without scutellary striole, vestiture not discernible. Legs. Tibiae with 2 relatively stout spurs. Tarsal claws without ventrobasal seta. Abdomen with ventrite 5 longer than each of 3 and 4 .

Material examined. Holotype (NIGP154206): very well preserved, intact specimen, not compressed or distorted, well visible but with thin layer of air over most of surface; in centre of elongate rectangular cuboid ca. $5.3 \times 2.7 \times 2.7 \mathrm{~mm}$; amber clear, with many small impurities and four large but clear bubbles on right side of specimen.

Derivation of name. The species is named after Yu-Lingzi Zhou, presently at ANIC, for obtaining specimens for this study and for her various help and discussions about this interesting extinct fauna.

Remarks. This species also differs from $A$. astriatus by possessing faint but broad elytral striae and a slight dorsal sinus between the head and the rostrum. From $A$. brevicornis it is distinguishable by its longer scapes (as long as the eye) and from A. elongatus by having two tibial spurs. With A. brevicornis it agrees in lacking the ventrobasal seta on the tarsal claws.

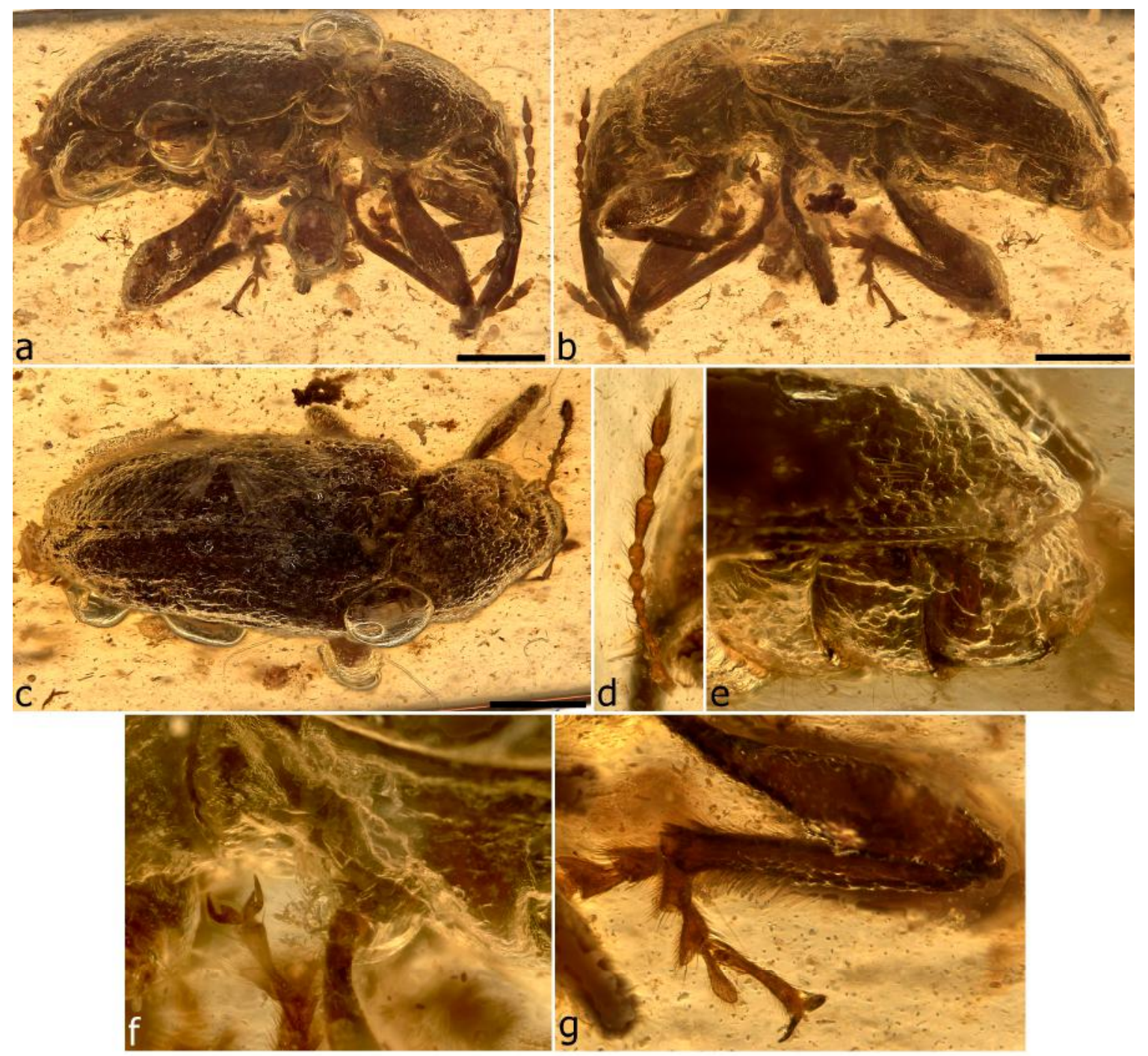

Figure 26. Acalyptopygus lingziae, holotype. Habitus, right (a); left (b); dorsal (c); antenna (d); elytral apices and ventrites 3-5 (e); thorax, left lateral (f); hindleg (g). Scale bars: $0.5 \mathrm{~mm}(\mathrm{a}-\mathrm{c})$. 
Acalyptopygus elongatus Clarke \& Oberprieler, sp. n. (Figure 27)

Description. Size. Length $1.99 \mathrm{~mm}$, width $0.82 \mathrm{~mm}$. Head setose, setae short, recurved, some erect; dorsally convex, dorsal outline nearly continuously curved from base of rostrum; ventrally less convex; between eyes separated by about a basal width of rostrum. Eyes lateral; moderately protuberant, subspherical, slightly elongate. Rostrum slightly longer than pronotum; moderately downcurved, inserted in dorsal half of head, basally with dorsal outline continuing onto head, without any sinus before eyes but ventral outline forming large sinus with strongly bulging head; dorsally and laterally without carinae; antennal insertions in basal quarter of rostral length; with scrobes behind them weakly delimited; mandibular articulations deep, oblique. Antennae. Scapes elongate, about as long as eye, reaching front margin of eye, apically truncate; funicles with segment 1 slightly longer than 2, broader, 2 ca. $2.0 \times$ longer than 3, 4-7 progressively slightly broader and longer. Mouthparts. Mandibles with 2 teeth on outer side, one forming long outer apical tooth; inner edge with 3 large subequal teeth; apically forming T, slightly emarginate at middle; articulation plane oblique. Right maxilla apically setose; maxillary palps 3-segmented, subtelescoped (2 within 1), segments progressively narrower; projecting obliquely ventrally. Labial palps short, apically and closely inserted, projecting obliquely. Thorax. Pronotum widest at about middle, slightly narrower than elytra; coarsely punctate; densely setose, setae long, reddish; sides rounded; somewhat constricted anteriorly; basal margin broadly lobate in middle, closely fitting to elytra, corners rounded. Scutellar shield small, at same level as elytra; densely setose. Metaventrite distinctly concave medially between narrow, very prominent transverse weals. Elytra distinctly punctostriate; setose, setae reddish, suberect-recumbent except for scattered long erect setae; striae ca. $2.0 \times$ wider than interstriae; interstriae prominent, interstria 8 forming rounded ridge, prominent in dorsal view, 7 and 8 confluent; anteriorly forming prominent slightly produced humeri; lateral margin sinuate; with marginal groove subequal in width along entire length, punctosetose, with anterior marginal notch. Legs. Mesocoxae globular, very prominent, longer than wide. Tibiae apically without distinct flanges, apex lined with long slender fringing setae, dorso-apical edge with several elongate thin setae; protibiae with 2 short spurs; mesotibiae with small mucro and 2 short spurs; metatibiae ventrally with single long, probably fixed spur and long, slender seta, ca. $2.0 \times$ longer than spur. Tarsi elongate, about as long as tibiae; tarsite 1 elongate, ca. $2.0 \times$ longer than 2, apically slightly excised, 2 similar, narrower than 1,3 deeply lobate, lobes subpedunculate, concave along inner side, ventrally with dense setal pads, cryptotarsite distinct, 5 about as long as $1+2$, setose dorsally and ventrally; claws with ventrobasal seta. Abdomen. Tergites VII and VIII strongly sclerotised, forming cupular pygidium with apparent inflexed median lip. Ventrites sparsely setose, denser laterally; sutures substraight; 1 and 2 subequal in length, $3-4$ subequal (4 very slightly shorter), 5 longer than 4 , with posterior edge broadly rounded to substraight.

Material examined. Holotype (NIGP154207): well preserved, undistorted and well visible specimen, with left protarsus missing tarsites 3-5, appendages and rostrum otherwise intact but legs folded under specimen and right antenna obscured by bubble, right maxilla projecting obliquely from rostral apex (displaced), pygidium dislodged and partly severed, one wing partly extended, with sparse coating of whitish debris partly obscuring surface details; in irregular rectangular block with large curved and large flat face and two smaller flat faces, $6.7 \times 1.9 \times 1.7 \mathrm{~mm}$; amber clear yellow, with flat bubbles and small fractures partly obscuring ventral side (mainly head and thorax).

Derivation of name. The species is named for its elongate shape, the name being an adjective.

Remarks. This is the smallest of the four known species of Acalyptopygus and unique in the genus in possessing a single elongate spur on the metatibiae. It is also distinguishable from A. astriatus by having distinct elytral striae, but it agrees with this species and differs from the other two in having a ventrobasal seta on the teeth of the tarsal claws. It agrees with A. brevicornis (and one undescribed species) in having a mesotibial mucro but has differently shaped pro- and metatibiae and scapes as long as the eyes. From A. lingziae it differs additionally in its conspicuous erect body setae and progressively longer, more uniform funicle segments. The holotype appears to be a female, as a pair of 
long, flat, basally contiguous processes with dense and quite long setae on the inner and apical edges is faintly discernible inside the cupular pygidium.

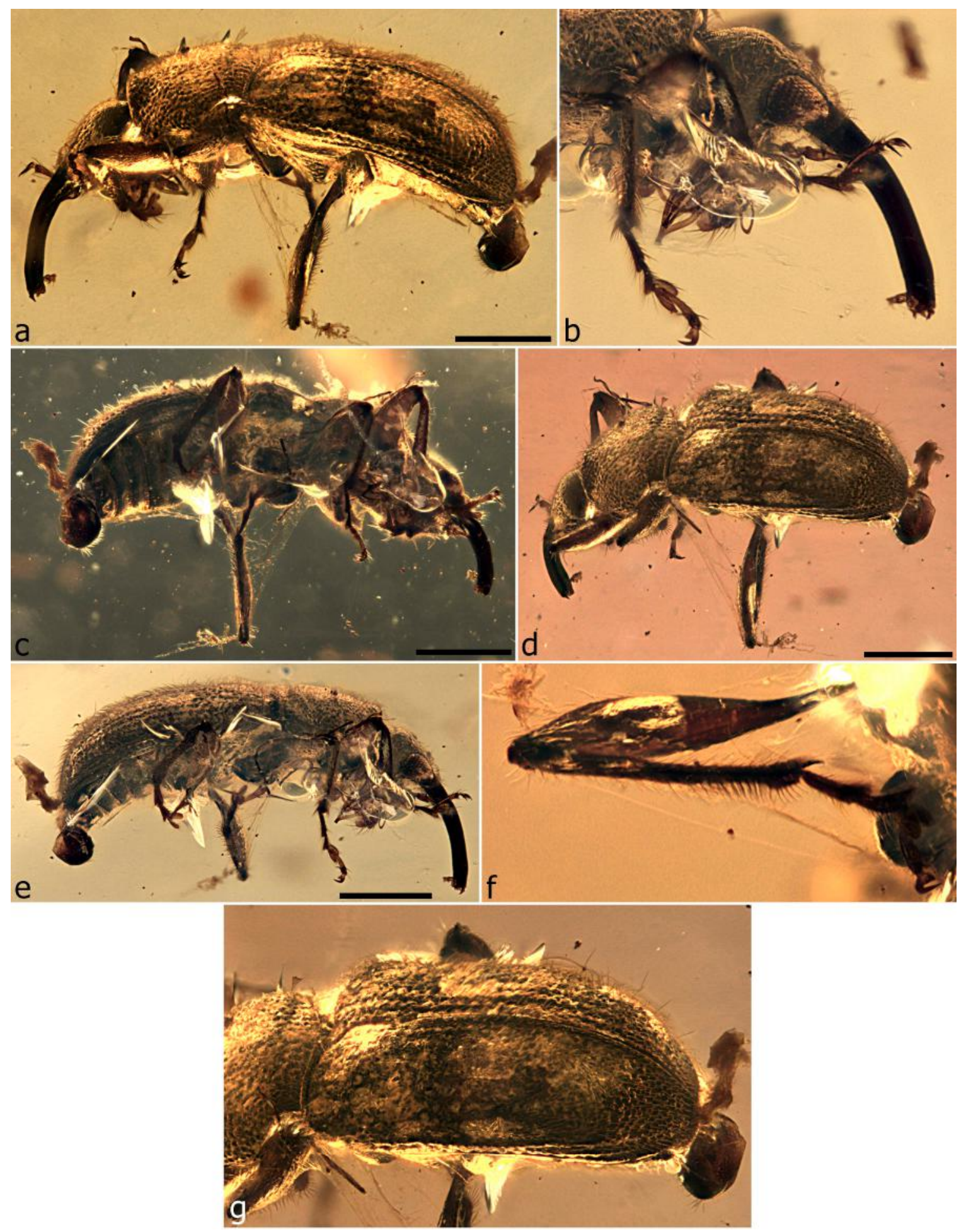

Figure 27. Acalyptopygus elongatus sp. n., holotype. Habitus, left lateral (a); head and anterior leg, left (b); habitus, right ventrolateral (c); habitus, left dorsolateral (d); habitus, right lateral (e); hindleg, ventral (f); pronotum and elytra (g). Scale bars: $0.5 \mathrm{~mm}(\mathrm{a}, \mathrm{c}-\mathrm{e})$. 
Acalyptopygus astriatus Clarke \& Oberprieler, sp. n. (Figure 28)

Description. Size. Length $2.20 \mathrm{~mm}$, width $0.95 \mathrm{~mm}$. Eyes slanting backwards, forehead between them trapezoidal, with narrow bare (black) median costa widening basad. Rostrum slightly downcurved, inserted in dorsal half of head, basally with dorsal outline continuing onto head, without any sinus before eyes, but ventral outline forming large sinus with strongly bulging head. Antennae. Scapes shorter than eye; funicles with segments 2 to 7 subequal, 7 slightly thicker; clubs with segment 1 elongate, spindle-shaped, 2 and 3 shorter and thicker. Mouthparts. Mandibles with 2 teeth on outer side, one forming long outer apical tooth, another sharper broader one at middle; inner edge with small basal tooth, 2 large subequal teeth at middle and a smaller apical one; apically forming $\mathrm{T}$, slightly emarginate at middle. Thorax. Pronotum roundly subrectangular, widest in middle of length, laterally roundly explanate (sides of prothorax steeply sloping down), posterior corners angulate but not extended to fit closely onto elytral humeri; surface finely granulose. Metaventrite short, indistinctly convex. Elytra posteriorly evenly declivous, only shortly exposing pygidium in repose; surface not punctostriate, sparsely irregularly punctosetose, intervals between punctures flat, dull. Legs. Tibiae with 2 long fine spurs. Tarsal claws with distinct ventrobasal seta. Abdomen with ventrite 5 as long as 3 .

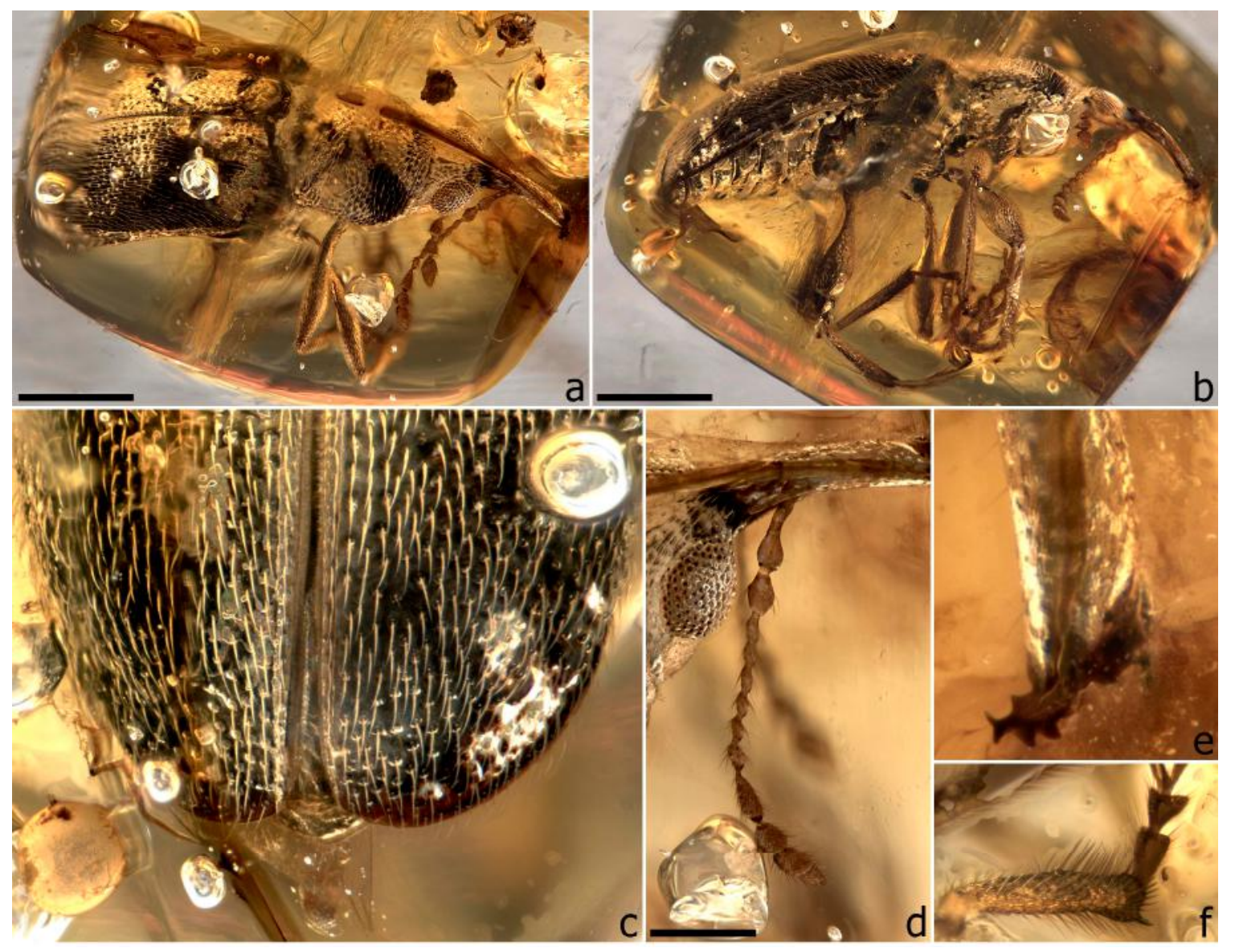

Figure 28. Acalyptopygus astriatus sp. n., holotype. Habitus, dorsal (a); habitus, right lateral (b); elytral declivity, showing no striae (c); head and right antenna, lateral oblique (d); apex of rostrum and right mandible, right lateral (e); left metatibia, tarsites 1-2 (f). Scale bars: $0.5 \mathrm{~mm}(\mathrm{a}, \mathrm{b}) ; 0.2 \mathrm{~mm}(\mathrm{~d})$.

Material examined. Holotype (NIGP154208): very well preserved, intact specimen, not compressed or distorted, well visible; on right side of rectangular cuboid $2.95 \times 2.6 \times 2.2 \mathrm{~mm}$ with rounded edges and corners; amber clear, with few large but clear bubbles at front on left side of specimen, and large vertical shearing plane across left side of specimen. 
Derivation of name. The species is named for the absence of striae on its elytra, the name being a Latin adjective.

Remarks. This species differs from all other Acalyptopygus species in its lack of elytral striae, the setiferous punctures being aligned into irregular rows. From A. brevicornis and A. lingziae, it is also distinguishable by the absence of a dorsal sinus between the rostrum and the head, the granulose pronotum and the unequal club segments, and from A. elongatus it further differs in having two metatibial spurs (a single long one in A. elongatus) but no sparse long erect body setae. As in A. elongatus, however, its tarsal claws possess a distinct ventrobasal seta.

\section{Subfamily Mesophyletinae Poinar, 2008}

Mesophyletinae Poinar, 2008: 262 [50] (type genus: Mesophyletis Poinar, 2006)

Anchineini Poinar \& Legalov, 2015: 558 [53] (type genus: Anchineus Poinar \& Brown, 2009) syn. n.

Mekorhamphini Poinar, Brown \& Legalov, 2016: 158 [54] (type genus: Mekorhamphus Poinar, Brown \& Legalov, 2016) syn. n.

Burmocorynini Legalov, 2018: 5 [46] (type genus: Burmocorynus Legalov, 2018) syn. $\mathbf{n}$.

Diagnosis. Head porrect, short. Eyes mostly large to very large, hemispherical to conical, mostly strongly protruding, coarsely facetted. Rostrum slightly to much longer than pronotum, usually long and thin, sometimes shorter and stouter, rarely flexible into a prosternal channel (Burmorhinus, Rhadinomycter); antennal insertions mostly subbasal to median, rarely in apical quarter, behind them with long narrow scrobe extending to eye. Gular suture single, long. Antennae geniculate of 'open' type; scapes about as long as funicle; funicles 7-segmented; clubs loosely articulated to subcompact, 3-4-segmented. Mouthparts. Labrum absent. Mandibles mostly exodont but sometimes non-exodont, articulation horizontal to oblique or quasivertical. Thorax. Pronotum subquadrate to trapezoidal, laterally rounded, posterior corners usually extended, fitting closely onto elytra; notosternal sutures closed; procoxal cavities usually medially confluent, rarely separated; mesocoxal cavities closed. Elytra with broadly rounded humeri, apically mostly individually rounded, rarely subtruncate, sometimes exposing short pygidium; surface distinctly to indistinctly punctostriate, without scutellary striole, usually densely setose. Legs. Procoxae mostly elongate and prominent, medially contiguous, rarely subglobular and medially separated; mesocoxae globular, narrowly separated; metacoxae flat, transversely elongate. Femora inflated in distal half, outside often carinate to crenulate in distal half, almost always unarmed. Tibiae subcylindrical to flattened, outer edge usually serrulate or crenulate, apex usually with 2 spurs. Tarsi long; tarsite 1 usually elongate triangular, 3 deeply lobed, lobes often pedunculate, claws divaricate, simple to angulate to dentate, with ventrobasal setae. Abdomen with ventrites 1 and 2 fused, longer than 3-4; last tergite sometimes exposed as pygidium.

Remarks. The subfamily Mesophyletinae comprises the bulk of the known mesophyletid genera and species and is characterised foremost by its geniculate antennae, by which it differs from Aepyceratinae as here delineated. Other conspicuous characters present in most taxa are the serrulate or crenulate tibiae and the strongly dentate tarsal claws. On the basis of the tarsal claws, the genera of Mesophyletinae may be divided into two groups, those with simple to basally slightly swollen or angulate tarsal claws and those with strongly dentate ones. The first group currently includes eleven genera (Burmocorynus, Burmorhinus, Cetionyx, Cyrtocis, Echogomphus, Electrocis, Debbia, Gnomus, Opeatorhynchus, Petalotarsus and Rhadinomycter) and the second fourteen (Anchineus, Aphelonyssus, Bowangius, Compsopsarus, Elwoodius, Euryepomus, Habropezus, Hukawngius, Leptopezus, Louwiocis, Mekorhamphus, Mesophyletis, Myanmarus and Periosocerus). Whether these two groups may constitute natural entities in some concept (not necessarily in the generic aggregations as above) and can be recognised as tribes will have to be determined from a comprehensive phylogenetic analysis of their relevant characters; they are here used merely as a convenient way of grouping the genera for identification purposes. In extant weevils toothed claws are often used as a generic character, e.g., to distinguish Storeus Schoenherr (dentate) from Emplesis Pascoe ('simple'), but such a distinction is frequently blurred by conditions of bluntly toothed and basally swollen claws. In Mesophyletidae the dentition of the claws is clearly significant at a higher level, and intermediary states are unknown 
(occur to some degree only in Gnomus), but whether it is suitable to characterise generic groups remains to be seen.

This subfamily subsumes the tribes Mesophyletini, Anchineini and Mekorhamphini as erected by Legalov and Poinar [53] and Poinar et al. [54]. These are not maintained here, as the differences between their type genera are trivial in comparison with the greater character disparities exhibited by the large, robust forms with simple or angulate tarsal claws, in particular the Burmocorynus-Cetionyx-Petalotarsus group but also a number of isolated smaller genera. If the provisional generic group with simple to angulate tarsal claws as here circumscribed can be found to be monophyletic, the tribal name Burmocorynini may be applied to it, but this is not evident at present and we therefore also subsume the tribe Burmocorynini into Mesophyletinae. A tribal classification of Mesophyletinae is premature at this stage and should only be considered when the characters of the group have been studied in more detail and in a phylogenetic context.

Genus Cetionyx Clarke \& Oberprieler, gen. $\mathbf{n}$.

Type species: Cetionyx batiatus Clarke \& Oberprieler, sp. $\mathrm{n}$.

Description. Size. Length $8.2-10.0 \mathrm{~mm}$, width $3.8-5.7 \mathrm{~mm}$. Head short, subconical, not or slightly constricted behind eyes. Eyes small, elongate, somewhat compressed, strongly protruding, coarsely facetted, dorsally separated by width of rostrum, further expanded posteriorly; forehead flat, without tubercles. Rostrum longer than pronotum, slender, cylindrical, slightly to strongly downcurved; antennal insertions lateral, in or behind middle of rostral length, behind them with scrobes extending to eye, in front of them without lateral row of setae. Gular suture not discernible. Antennae geniculate, long, very slender; scapes long, thin, cylindrical, apically slightly thickened; funicles shorter than scape, 7-segmented, segment 1 less than half as long as 2, 2-4 long, progressively shorter, 5-7 distinctly shorter; clubs long, weakly differentiated, loosely articulated, 4-segmented, segments subcyclindrical, apical segment bluntly triangular. Mouthparts. Labrum absent. Mandibles small, exodont, with at least 2 external teeth, articulation horizontal. Thorax. Prothorax slightly to strongly proclinate, with anterior lateral margins oblique to nearly vertical in lateral view. Pronotum roundly subrectangular to trapezoidal, laterally weakly to broadly rounded, without tooth; weakly convex, finely to coarsely punctate, sparsely to densely setose, setae short, fine, suberect, pale, directed mesad; notosternal sutures closed. Prosternum moderately long, prosternal process meeting hypomeral process or almost so; procoxal cavities narrowly to broadly separate or nearly so, in about middle of prothorax. Scutellar shield indistinct, small. Mesocoxal cavities laterally closed (by meso- and metaventrite). Metanepisterna distinct. Mesoventrite short, anteriorly strongly sloping. Metaventrite raised into transverse weals before metacoxae. Elytra shortly to moderately elongate, with weak, broadly rounded or sharply angulate humeri, posteriorly declivous, apically individually rounded, not exposing pygidium in repose; sutural flanges narrow, equal; surface weakly coarsely punctostriate, without scutellary striole, sparsely to densely setose, setae short, stout, reclinate, directed caudad. Legs. Front legs often longer than middle and hindlegs. Procoxae subglobular, prominent, medially narrowly to broadly separated; mesocoxae subglobular, broadly separated; metacoxae transversely elongate, reaching elytra. Trochanters short, oblique. Femora long, subcylindrical, inflated in distal half, unarmed, outer side rounded, inner side excavate in distal quarter, receiving tibiae in repose, walls of groove at apex flatly roundly extended. Tibiae long, straight, subcylindrical, outer edge rounded, apically with long dense setae, apex obliquely truncate, with 2 small spurs (sometimes absent on protibiae or possibly on metatibiae). Tarsi $0.67 \times$ or more as long as tibiae, broad, flat, densely setose, fringed with long setae; tarsite 1 elongate, apically deeply excised to lobate, 2 shorter, apically very deeply excised, 3 deeply bilobed, lobes strongly pedunculate, attachment with basal plate extremely slender in both dimensions, apically broad and flat, 5 slightly longer than $1+2$; claws divaricate, basally swollen to angulate (not dentate) with ventrobasal seta at apex of swelling or angle. Abdomen flat, ventrites 1 and 2 subequal, slightly longer than 3 and 4, 5 broadly rounded, subequal or longer than 4 . 
Derivation of name. The genus is named for its large tarsi and claws, latinised from the Greek adjective keteios (large, monstrous) and noun onyx (G: onychos), a claw or talon; the gender of the name is masculine.

Remarks. This genus includes the largest weevils known from Burmese amber, reaching more than $11 \mathrm{~mm}$ in body length and with a rostrum that can attain three-quarters of the body length, so another $8 \mathrm{~mm}$. Cetionyx is mainly characterised by its large, broad, shaggy tarsi with large claws, which are similar only to those of Opeatorhynchus and (less so) of Burmocorynus (and partly to those of Petalotarsus but longer and more loosely articulated), but also by its distinctive antennae, being very slender with a short funicle segment 1 (much shorter than segment 2 ) and indistinct clubs that are scarcely broader than the funicles. Cetionyx is readily distinguishable from Burmocorynus and Petalotarsus by its higher and broader body, long slender antennae and loosely articulated clubs. From Opeatorhynchus it is also distinguishable by its antennal structure (the short funicle segments 1 and indistinct clubs) as well as by its separated procoxae. It agrees with Opeatorhynchus in having the most strongly pedunculate lobes of tarsite 3 among our sample, the basal part extremely thin in both dorsal and lateral view, especially at the point of the very flexible attachment to a distinct basal plate. This basal structure of tarsites 3 differs from that of Burmocorynus, in which the basal connection of the lobes is broader and thicker in dorsal and lateral view. Among the material available for this study, Cetionyx is represented by three species. Unfortunately none of the specimens currently available are sufficiently well preserved to allow a detailed study and depiction of all characters. However, our CT reconstruction of C. batiatus (Video S2) gives a good impression of what these large Cretaceous weevils looked like and at least in this specimen demonstrably compensates for the lack of detail observable under light microscopy.

Cetionyx batiatus Clarke \& Oberprieler, sp. n. (Figures 29-31, Video S2)

Description. Size. Length $8.22 \mathrm{~mm}$, width $4.62 \mathrm{~mm}$. Head bulbous dorsally and ventrally; not constricted behind eyes (posteriorly); punctate, punctures small. Rostrum elongate, perhaps as long as entire body, inserted at front of head (with dorsal sinus); subcylindrical; moderately curved. Scrobes lateral, narrow, sharply delimited, reaching eyes. Antennae sparsely setose; scapes reaching to just below eye, apically slightly bent, articulation with pedicel oblique; funicles with segment 1 ca. half as long as 2, 2 elongate, subparallel, only slightly widening apicad, $3 \mathrm{ca} .0 .67 \times$ as long as 2, 3 and 4 subequal, 5 subequal in width, about $0.67 \times$ as long as 4,6 slightly shorter than 5, 6 and 7 subequal; clubs with segments 1 and 2 subequal, 4 distinct, broadly inserted in 3 . Thorax. Prothorax not or slightly proclinate, with anterior lateral margins seemingly nearly vertical in lateral view. Pronotum narrower than elytra; strongly transverse; densely and coarsely punctate; rugosely sculptured, with minute channels between punctures; sparsely setose, setae short, recurved, directed mesad to anteromesad; sides rounded, with slight anterior collar; basal pronotal margin broadly curved, closely fitting with elytra. Prosternum short, about $0.33 \times$ as long as procoxae, anterior margin broadly emarginate, prosternal process broadly pointed, contacting apex of hypomeral process (Figures 30e and 31e). Elytra broad, moderately strongly convex; striae and interstriae indistinct, striae thin, interstriae wide; sculptured as pronotum; sparsely setose (appearing almost glabrous), bases straight, subcarinate, slightly raised, medially continuous with anterior scutellar edge, tightly fitting with pronotum, forming broadly obtuse angle at elytral suture; humeri indistinct, cupulate, strongly concave to receive posterolateral angles of pronotum; sides broadly rounded, basally curved evenly to humeri, with marginal groove distinct, finely punctate, broadened anteriorly forming lateral ridge; anterior marginal notch present; apices individually rounded. Scutellar shield rectangularly rounded, glabrous, flush with elytral surface. Mesocoxal cavities widely separated by less than half of mesocoxal width; meso- and metaventral intercoxal processes broad, flat, abutting, separated by straight suture. Meso- and metaventrite coarsely punctate; with apparent discrimen. Legs. Tibiae long, slender; clothed with distally increasingly dense setae; tibiotarsal articulation surfaces oblique to concave; spur formula 0-2-2; protibiae elongate-slender, distinctly curved outward, apically expanded, inside longer than outside, in apical two-thirds with dense increasingly longer setae, anterior and posterior apical 
flanges densely setose, apical fringing setae not lining edges; meso- and metatibiae slightly curved outward, on inner side in apical half with distinct elongate patch of dense, long setae, basal- and distal-most setae longer than intervening ones, apically with narrowly rounded anterior flange, spurs closely situated, robust. Tarsi with tarsite 2 wider and shorter than 1, lobes of $3 \mathrm{ca}$. $0.67 \times$ as long as 5 , very narrow basally, protarsi elongate, ca. half as long as protibia, longer than meso- and metatarsi, metatarsi with tarsite 2 more distinctly Y-shaped than on other legs; claws of meso- and metatibae less basally angulate than those of protarsi. Abdomen Ventrites slightly stepped, finely setose, more finely punctate than meso- and metaventrites; ventrite 3 shorter than 2, 4 longer than 3, 5 elongate, ca. $1.5 \times$ longer than 4, apically broadly rounded, 4 and 5 with very short, fine, subappressed setae, impunctate; sutures straight or nearly so, not forming wide/deep gaps between ventrites.

Material examined. Holotype (NIGP154209): poorly preserved, partly decomposed but mostly visible specimen, with ventral parts of head and prothorax and ventrites partly collapsed and variously broken, rostrum distorted, apices of right femora, left metatarsal claws and apical part of rostrum cut away with amber, fore- and middle legs severed at trochanters; in high-domed irregular cabochon, $14.5 \times 11.5 \times 6.5 \mathrm{~mm}$, orientated with dorsal side subparallel to curved face; amber brownish-yellow, largely transparent but with gritty impurities and larger debris particles, with only small oblique fracture over elytra and pronotum.

Derivation of name. The species is named for its large, robust shape, reminiscent of an ancient Roman gladiator, after Batiatus, the owner of a gladiatorial school from which the Spartacus rebellion arose in 73 B.C.E.; the name is a noun in apposition.

Remarks. The poor preservation and partial distortion of the holotype made it difficult to assess many of the characters of this species under the light microscope, but fortunately the specimen became well visible from CT scanning, which allowed a more or less complete assessment of its structural details (Figures 30 and 31, Video S2), in particular those of the ventrites and the separation of the procoxal cavities (by narrow, adjoining intercoxal processes), which correlates with the much more broadly separated mesocoxae. All these areas are difficult to impossible to properly discern on the holotype under a light microscope. Cetionyx batiatus differs from C. ursinus mainly in its sparse, indistinct vestiture (appearing almost glabrous), straighter rostrum and rounded elytral apices and from $C$. terebrans in its more distinct antennal clubs (wider than the funicles), more closely fitting pronotum and elytra and the absence of spurs on the protibiae.

Cetionyx terebrans Clarke \& Oberprieler, sp. n. (Figure 32)

Description. Size. Length $10.00 \mathrm{~mm}$, width $3.8 \mathrm{~mm}$. Eyes small, distorted, seemingly flattened and pushed up. Rostrum ca $2 \times$ longer than pronotum, slender, only gently downcurved; antennal insertions just before basal third of length. Antennae. Funicles with segment 1 elongate, thin, distinctly shorter than 2, 2 and 3 subequal, 4 slightly shorter, 5-7 shorter, subequal; clubs long, segment 1 slightly longer than funicle segment 7 but similar, 2 thicker, obconical, 3 as long but narrower, 4 slightly shorter than 3. Mouthparts. Mandibles obliquely cut away, apparently scoop-shaped, not exodont; articulation horizontal. Maxillae and labium not discernible. Thorax. Prothorax slightly proclinate, with anterior lateral margins oblique in lateral view. Pronotum (poorly visible, obscured by while bubbly layer and cloudy amber) elongate, slightly convex, laterally hardly rounded, posterior corners rounded, not fitting closely onto elytra; surface not visible. Scutellar shield seemingly short and broad. Elytra (largely obscure, only basal half of left elytron properly visible), shortly elongate, laterally substraight, posteriorly gently declivous, apically rounded; surface weakly punctostriate, interstriae sparely setose, setae short, robust, reclinate (visible laterally). Legs. Front legs longer than middle and hindlegs. Procoxae slightly protruding and diverging, possibly separated, others and trochanters not properly visible; metacoxae appearing subglobular. Femora long, subcylindrical, slightly sinuate, profemora only slightly inflated in middle, meso- and metafemora more so. Tibiae densely setose in apical quarter, meso- and metatibiae apically broadened, bent inwards (possibly a preservation artefact); apex with 2 short, stout spurs (only one visible on protibiae). Tarsi about as long as tibiae; tarsite 1 elongate, broadly triangular, apically deeply excised, 2 slightly shorter, apically very deeply 
excised, 3 very deeply bilobed, lobes pedunculate, 5 very narrow between lobes of 3 , rapidly broadened beyond them; claws divaricate, basally swollen, with ventrobasal seta. Abdomen not visible.

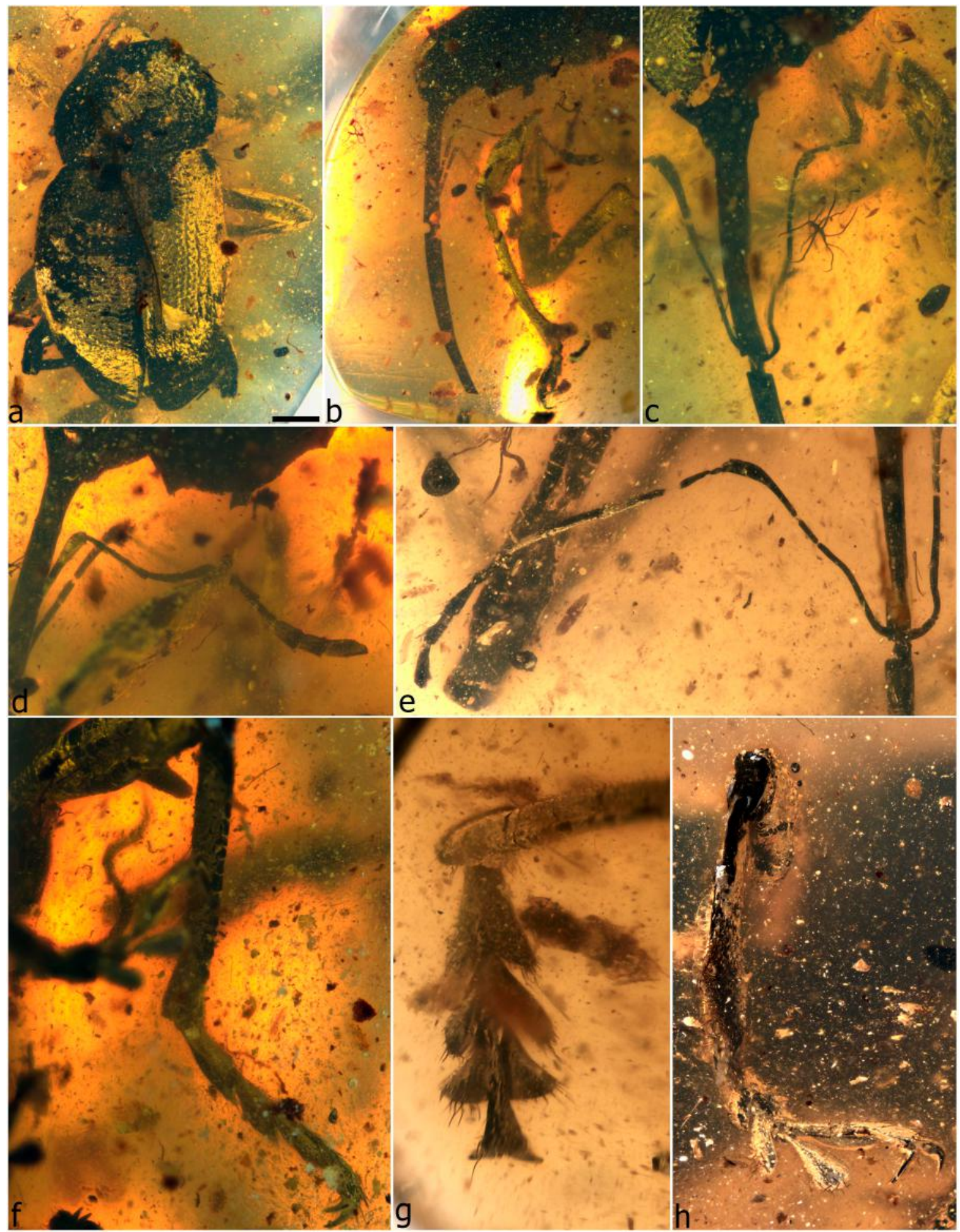

Figure 29. Cetionyx batiatus sp. n., holotype. Habitus, dorsal (a); head, left lateral (b); head and antenna, dorsal oblique (c); detail of left antenna, dorsal oblique (d); detail of right antenna, dorsal (e); mesotibia and -tarsus (f); mesotarsus, dorsal (g); mesotibia and -tarsus (h). Scale bar: $1.0 \mathrm{~mm}$ (a). 


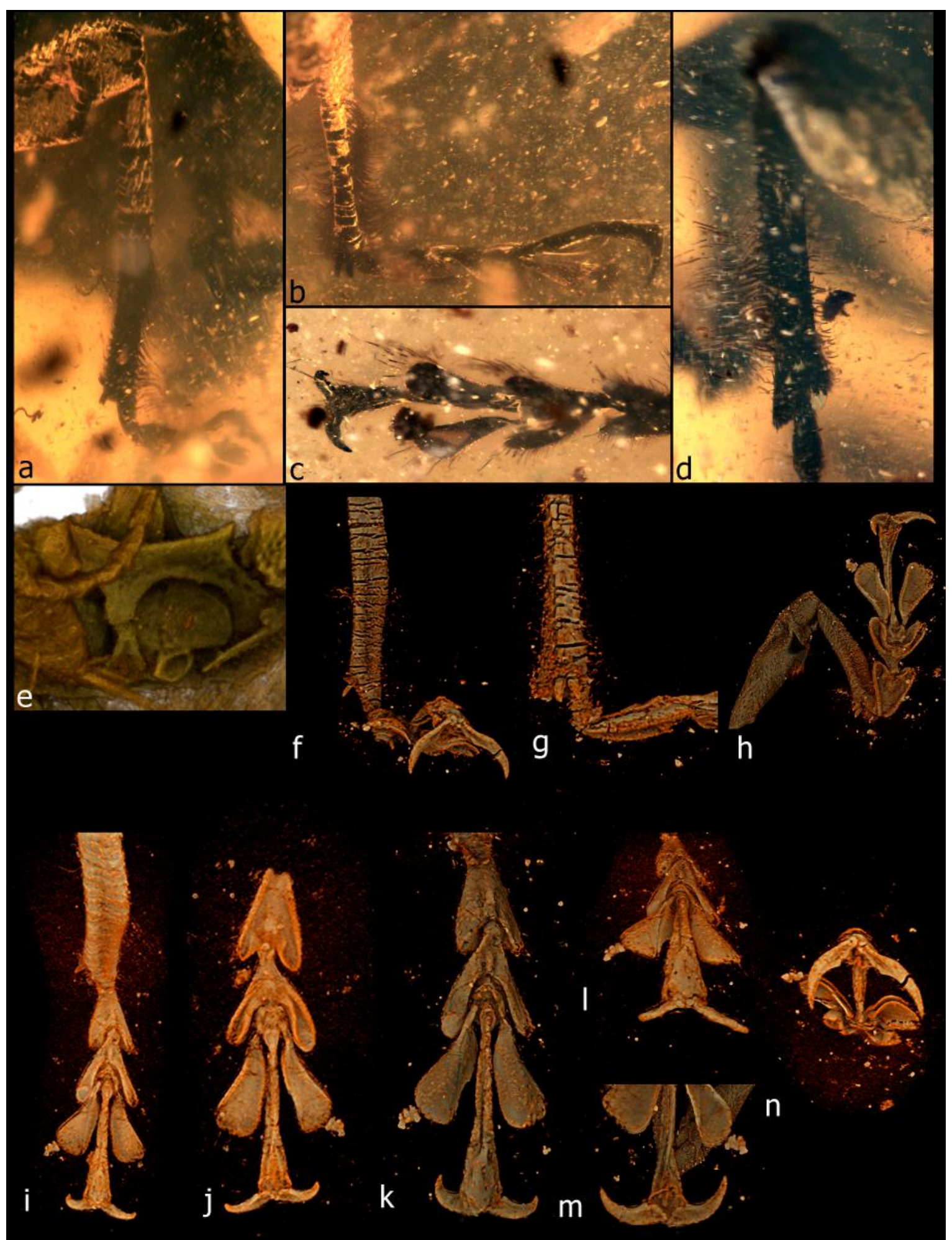

Figure 30. Cetionyx batiatus sp. n., holotype. Mesotibia showing spurs (a); mesotibia and -tarsus (b); protarsus (c); metatibia showing spurs (d); details of prothorax, ventral (e); micro-CT scan reconstructions showing details of tibiae and tarsi $(\mathbf{f}-\mathbf{n})$. See also Video S2. 


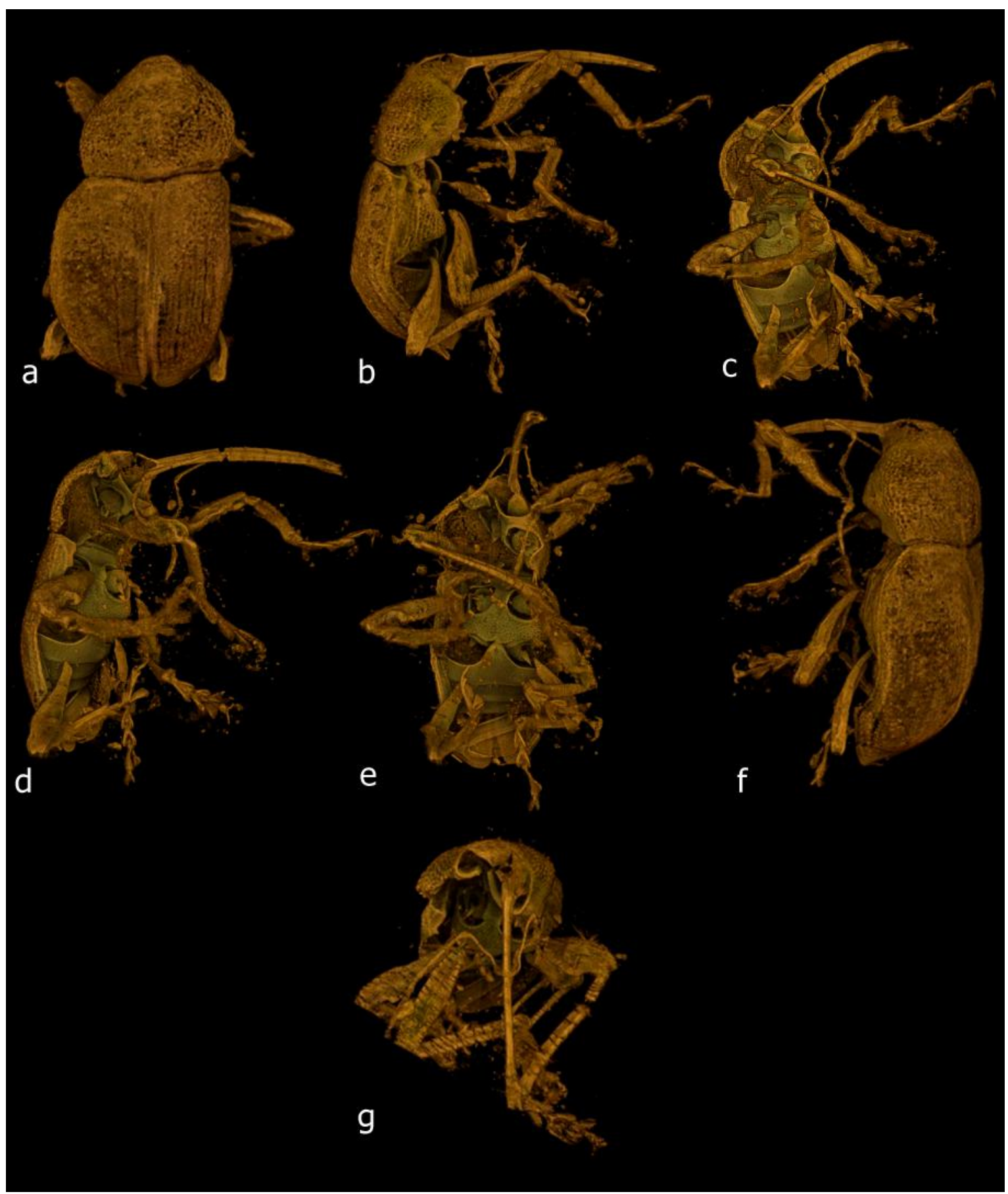

Figure 31. Cetionyx batiatus sp. n., holotype. Micro-CT scan images showing different views of the whole body, particularly useful for revealing obscured ventral details and the general effects of deformation and distortion on the shape and visibility of structures (a-g). See also Video S2. 


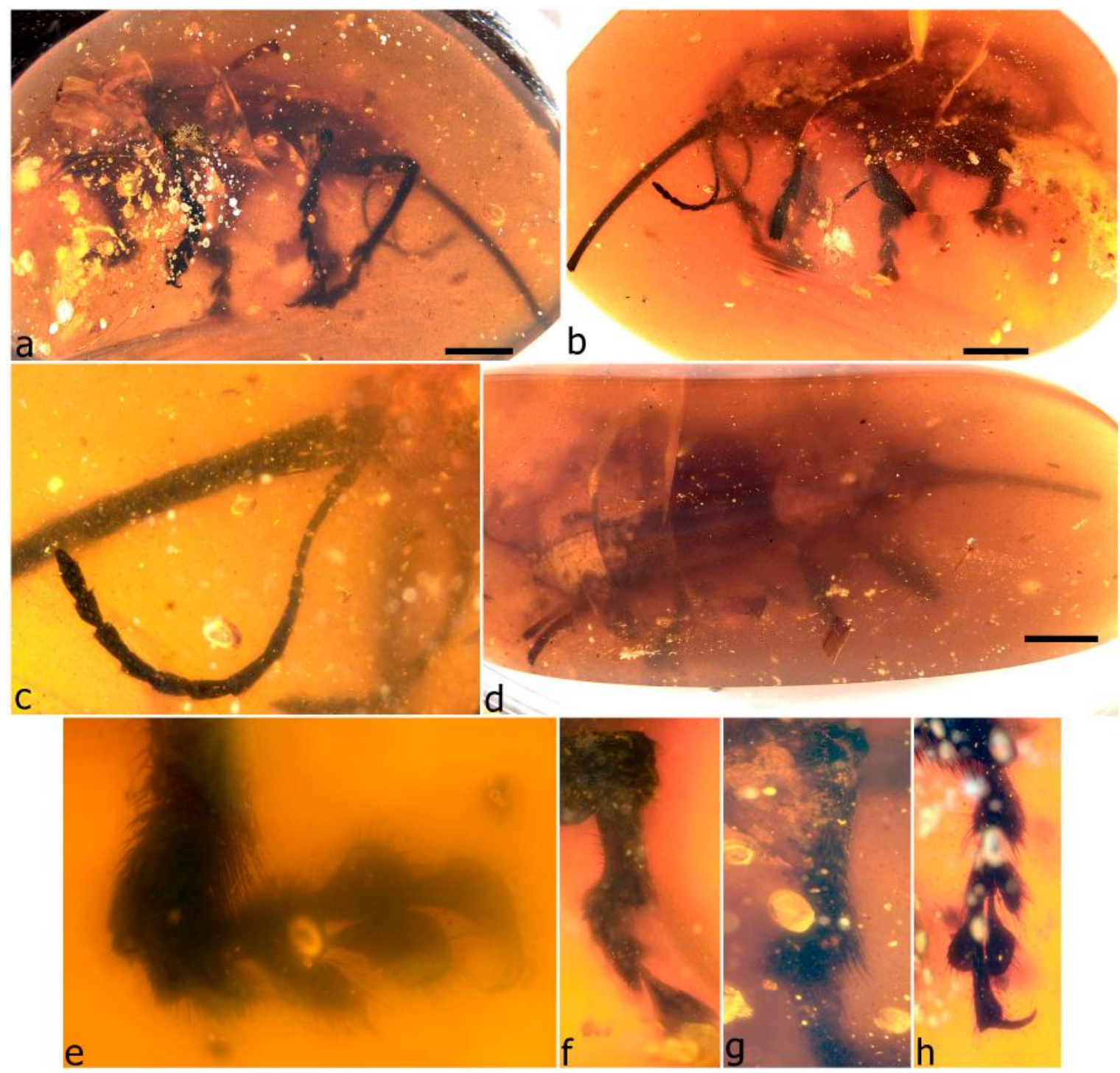

Figure 32. Cetionyx terebrans sp. n., holotype. Habitus, right lateral (a); left lateral (b); left antenna (c); habitus, dorsal (d); left metatarsus, dorsal (e); right mesotibia showing curvature (f); right mesotibia showing dorso-apical setal patch (g); right metatarsus, dorsal (h). Scale bars: $2.0 \mathrm{~mm}(\mathrm{a}, \mathrm{b}, \mathrm{d})$.

Material examined. Holotype (NIGP154210): well preserved, intact specimen, with slightly compressed legs and eyes, dorsal surface obscured by layer of white encrustation except over apical half of elytra, apex of rostrum slightly cut off on left side; at slight angle in middle of irregular block $8.7 \mathrm{~mm}$ thick with flat oval surfaces ca. $19.7 \times 14.2 \mathrm{~mm}$; amber dark orange-brown, slightly opaque, with 2 irregular transverse vertical cracks around specimen, a thin warped horizontal layer of bubbles and other debris at back, and various other small bubbles and impurities throughout.

Derivation of name. The species is named for its long, stout, straight rostrum, which is evidently suited to piercing plant material. The name is a Latin participle meaning 'the piercer' or 'the borer', treated as a noun in apposition.

Remarks. The single specimen of this species is the largest of all weevil fossils in Burmese amber studied by us. It differs from C. ursinus in having a stouter, almost straight rostrum, a narrower prothorax with less closely fitting pronotum and elytra, a sparser vestiture and differently elongate antennal segments. Cetionyx batiatus has a similarly straight rostrum but longer, thinner antennae, especially the clubs, and also a shorter, broader prothorax and no spurs on the protibiae. A more 
detailed comparison of these two species is prevented by the poor preservation of and visibility of both holotypes, but that of $C$. terebrans may also become better visible with CT scanning.

Cetionyx ursinus Clarke \& Oberprieler, sp. n. (Figure 33)

Description. Size. Length $9.71 \mathrm{~mm}$, width $5.69 \mathrm{~mm}$. Head punctate, ventrally bulbous. Eyes slightly protruding, seemingly longer than wide. Rostrum extremely long, subequal to body length, strongly curved, dorsally with longitudinal wavy carinae or ridges; setose, setae short, directed anteromesad. Antennae setose; scapes reaching front margin of eye, apical articulation with pedicel oblique; funicles with segments $1-4$ progressively gradually widening, $5-7$ progressively shorter towards club, 2 elongate, 3 and 4 subequal, ca. $0.67 \times$ as long as 2, 5 slightly more than half as long as 4, expanded apically, 6 ca. $0.67 \times$ as long as 5, 7 slightly shorter than 6; clubs with segments 1 and 2 subequal in length, obconical, 2 slightly wider than 1, 3 slightly shorter than 2, 4 broadly inserted into 3, about $0.67 \times$ as long as 3 . Mouthparts. Mandibles large, robust, flattened but thick, probably bilaterally asymmetrical, on outer side with 2 small triangular teeth, on inner side with one very large, somewhat dorsadly directed tooth with complex structure (possibly bicuspid), apex anvil-shaped with inner and outer teeth small, inner apex of left mandible appearing to form concave receptacle; articulation sockets seemingly oblique. Thorax. Prothorax strongly proclinate, with anterior lateral margins oblique in lateral view. Pronotum much broader than long, narrower than elytra, widest in front of base, more strongly narrowing anteriad; sides rounded. Prosternum about as long as procoxae, anterior margin broadly emarginate, prosternal process broadly rounded, separating procoxal cavities anteriorly but not posteriorly (not contacting hypomeral process). Pronotum densely and coarsely punctorugose; densely setose; anterior margin straight, posterior margin nearly straight, closely fitting to elytra. Meso- and metaventral intercoxal processes broad, separated by transverse suture. Metaventrite posterolaterally densely setose. Eytra. Bases straight, obtusely angulate, tightly fitting with pronotum, carinate from scutellar shield to junction with mesepimeron; humeri not strongly projecting, distinctly concave to receive basal pronotal corners; sides broadly curved, widest just before base, narrowing anteriad; lateral marginal groove distinct, broad anteriorly forming lateral ridge, from middle very narrow to elytral apex, region in groove densely setose, anterior marginal notch present; apices not meeting evenly at suture, individually bluntly angulate (apices together shallowly emarginate). Legs long, robust; densely setose, setae mostly subappressed; in distal third with longer setae on outer sides; forelegs distinctly longer than middle and hindlegs. Pro- and mesocoxae broadly separated, globular, not strongly projecting; metacoxae subglobular, reaching elytra. Tibiae on outer side of distal third with longer denser setae, at apex posteriorly well emarginate to allow basal tarsites to bend up; with pronounced inner (protibiae) and outer (meso- and metatibae) apical flanges lined with fringing setae, tarsal articulation surfaces oblique-concave, spur formula 0-2-2; protibiae with apical edge lined with short, spine-like fringing setae, longer setae near apex, seemingly without spurs; mesotibiae more robust and distinctly shorter than protibiae, apical edge with short dense fringing setae, spurs short, outer one distinctly longer and thicker than inner one; metatibiae along outer side in distal third with area of very dense and much longer setae, setae longer basally and apically, shorter in middle, spurs short. Meso- and metatarsi about $0.67 \times$ as long as protarsi; tarsite 1 strongly lobate apicolaterally, 2 very deeply excised, 3 distinctly pedunculate, lobes about $0.67 \times$ as long as 5 , each strongly broadened apicad, 5 about as long as $1+2$, curved ventrad. Abdomen. Ventrites slightly stepped; densely setose; 1 and 2 subequal in length, each longer than 3 and 4,1 with broad intercoxal process, 5 about as long as 4, broadly rounded; sutures straight, not forming wide/deep gaps between ventrites.

Material examined. Holotype (NIGP154211): poorly preserved, partly decomposed and poorly visible specimen (especially ventrally), heavily but symmetrically distorted, with elytra and pronotum depressed (caved in) forming broadly concave surface, right middle leg severed and missing, rostrum and other appendages intact, well visible though mandibles partly obscured by bubble; in irregular cuboid $16.5 \times 11.5 \times 9.0 \mathrm{~mm}$, with three curved faces; amber clear yellow-brown, cloudy due to granular or gritty impurities, with many larger impurities partly obscuring specimen, with small 
fracture over right protarsus and several conspicuous flow bands, a more conspicuous one separating most legs from rest of body.

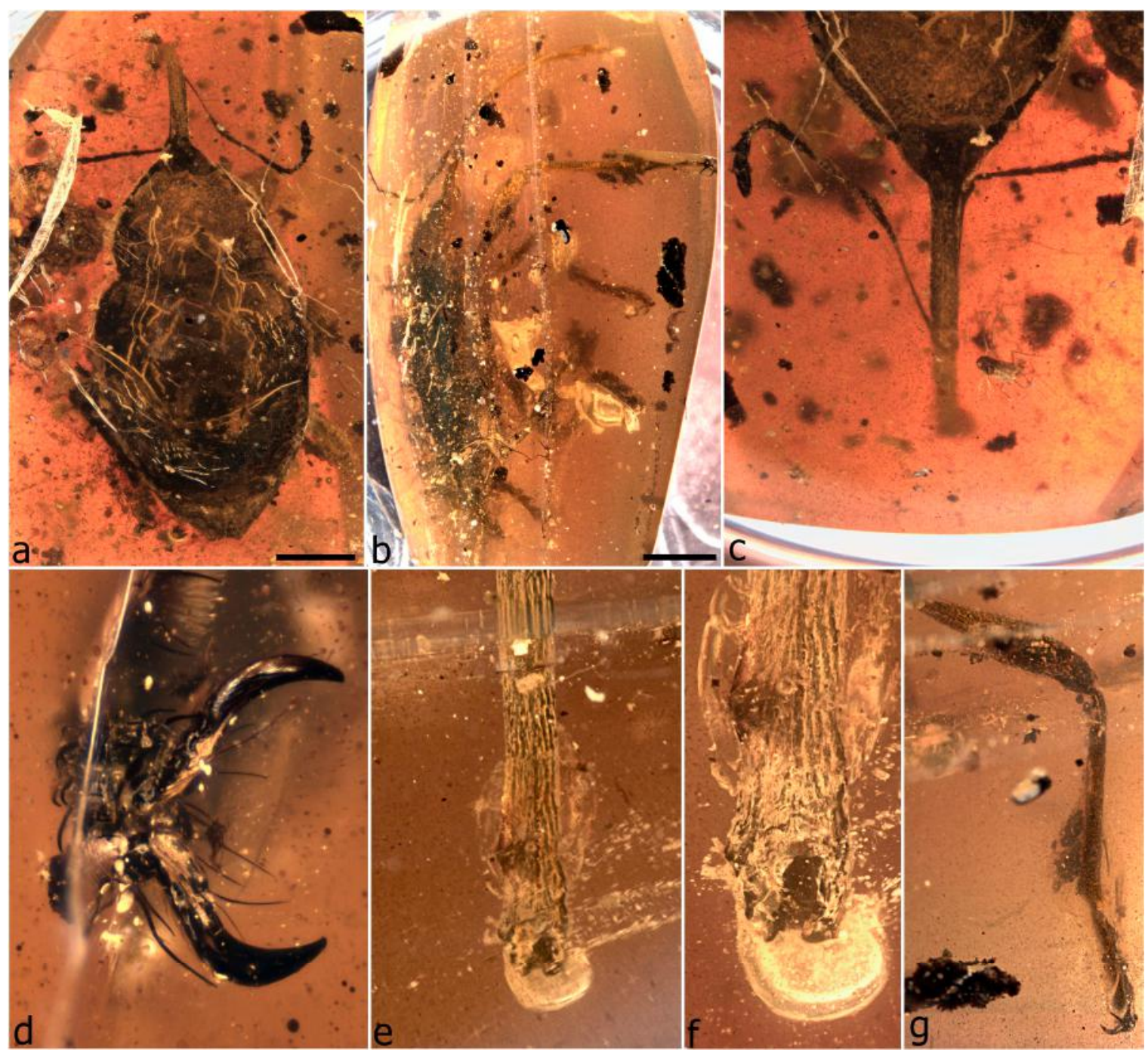

Figure 33. Cetionyx ursinus sp. n., holotype. Habitus, dorsal (a); habitus, right lateral (b); head and antennae, dorsal (c); protarsal claws (d); apical part of rostrum, dorsal (e); mandibles (f); right anterior leg (g). Scale bars: $2.0 \mathrm{~mm}(\mathrm{a}, \mathrm{b})$.

Derivation of name. The species is named for its bear-like appearance (from the Latin adjective ursinus, derived from the noun ursus, a bear), being very large with a dense brown vestiture, large shaggy tarsi and sharp claws.

Remarks. This species is almost as large as $C$. terebrans but not as robust. It differs from this species as well as from the slightly smaller $C$. batiatus mainly due to its longer, much more strongly curved rostrum, denser vestiture and distinctly angulate elytral apices. From the latter species it also differs in not having the procoxal cavities fully separated (the prosternal and hypomeral process not meeting). The long, thin, strongly curved rostrum of the single known specimen suggests that it is a female and able to drill holes into thick plant organs or tissues.

Genus Burmocorynus Legalov, 2018

Burmocorynus Legalov, 2018: 5 [46] (type species, by original designation: Burmocorynus jarzembowskii Legalov, 2018) 
Redescription. Size. Length $6.15-6.7 \mathrm{~mm}$, width $1.2-1.8 \mathrm{~mm}$. Head elongate, slightly flattened dorsally, strongly bulging ventrally, slightly constricted behind eyes. Eyes elongate, flatly protruding, evidently not facetted (surface smooth), dorsally separated by slightly more than width of rostrum anteriorly but slightly further separated posteriorly; forehead flat, without tubercles between eyes. Rostrum evidently at least as long as pronotum, cylindrical, substraight; antennal insertions lateral, with scrobes behind them, in front of them laterally with line of numerous long erect setae. Single long gular suture present. Antennae geniculate, long, flattened; scapes cylindrical, apically not or only slightly inflated, not reaching eyes; funicles 7-segmented, segments 1 and 2 subequal, elongate, obconical, 3-7 shorter, progressively wider towards club; clubs large, subcompact, flattened, 4 -segmented, segment 4 narrowly rounded, longer than 3. Mouthparts not visible. Thorax. Prothorax elongate, not proclinate, anterior lateral margins vertical in lateral view. Pronotum slightly convex, laterally rounded, without tooth, posterior corners truncate, fitting closely onto elytra; surface coarsely rugose, sparsely setose, setae reclinate, golden and black, directed anteromesad on disc; notosternal sutures closed, curved anteriad. Prosternum moderately long; procoxal cavities widely separated, in middle of prothorax. Scutellar shield elongate-rectangular, densely setose. Mesocoxal cavities closed laterally. Metanepisterna distinct, densely setose. Mesoventrite long, flat. Metaventrite longer, flat or slightly convex, raised into low transverse weals. Elytra elongate, basally lobed over base of pronotum, with narrowly truncate humeri, posteriorly weakly declivous, lateral margin nearly straight, apically individually rounded, not exposing pygidium, extending beyond apex of ventrite 5; sutural flanges narrow, equal; surface coarsely punctostriate, without scutellary striole, interstriae indistinct, subflat, coarsely rugose, setose, setae short, thin, reclinate, directed caudad. Legs. Proand mesocoxae subequal, longer than wide; procoxae large, globular, prominent, widely separated; mesocoxae globular, very widely separated; metacoxae subglobular, shortly transverse. Trochanters short, oblique. Femora long, subcylindrical, inflated in distal half, outside rounded. Tibiae substraight, compressed, distally expanded, outer edge rounded, with dense long stiff setae in distal half, apex strongly oblique, with 2 spurs. Tarsi almost as long as tibiae (metatarsi slightly more than half length of tibia); tarsite 1 apically deeply excised, 2 shorter, very deeply excised (almost bilobed), 3 deeply bilobed, lobes pedunculate but broadly connected basally, 5 as long as $1+2$, apically expanded, not flattened; claws divergent-divaricate, basally angulate with ventrobasal seta at apex of tooth. Abdomen with ventrites 1 and 2 each about as long as $3+4,3$ and 4 subequal, 5 about as long as $3+4$, apically narrowly rounded.

Remarks. The genus was not specifically described, only a reference given to the diagnosis of the tribe Burmocorynini. The tribe was placed in the family Belidae because of the alleged non-geniculate, basally inserted antennae, protibial grooves (the antennal cleaners of Belidae) and paired gular sutures of the single specimen, but none of these character interpretations is correct, as we could ascertain from our examination of the specimen (after trimming the amber block) as well as of another similar, evidently congeneric specimen we received too late for inclusion in this paper. The antennal insertions of the holotype of Burmocorynus jarzembowskii are not visible (cut off with the rostrum), and the seemingly short scapes are in fact the clavate apices of longer thinner ones, as is the case in our other specimen, which has clearly geniculate antennae. A very similar, elongate but larger specimen illustrated by Xia et al. [55], p. 115, with very similar eyes and tarsi, also has geniculate antennae and probably represents the same genus, and also the less well-preserved specimen here described as Burmocorynus longus has geniculate antennae. The protibiae of Burmocorynus jarzembowskii are apically dilated and densely setose as they are in Cetionyx and many other mesophyletids, but they do not have antennal cleaning brushes as they occur in Belidae, and there are no short paired gular sutures as alleged (as drawn in Figure 14, [46]). Burmocorynus therefore cannot be classified in Belidae but clearly belongs in Mesophyletidae and specifically in the vicinity of Cetionyx and Petalotarsus, with which it shares the separated procoxae and the large, loose tarsi with deeply lobed tarsites 2 and 3 . We will assess the relationships of these genera in more detail with the description of our additional specimen of Burmocorynus. The second part of the genus name (-corynus) is poorly chosen, as the taxon 
has nothing to do with the belid genus Oxycorynus and tribe Oxycorynini, to which it was related by its author. Burmocorynus presently comprises two species, but it is likely that our additional specimen and the one depicted by Xia et al. [55] represent different further species.

Burmocorynus jarzembowskii Legalov, 2018

Burmocorynus jarzembowskii Legalov, 2018: 5 [46]

Material examined. Holotype (ISEA no. MA 2018/1); length $6.7 \mathrm{~mm}$, width $1.78 \mathrm{~mm}$ : very well preserved and well visible specimen, with a fragmented film of organic material over body but surface still well visible, most of rostrum, antennal scapes and part of right funicle, apex of left profemur and right leg at femorotibial joint cut away with amber, missing outer claw of left protarsus; re-prepared from much larger discoidal amber piece from which the original description was prepared, now in elongate irregular cuboid $7.5 \times 3.0 \times 4.1 \mathrm{~mm}$ with end closest to head of specimen rounded; amber hazy brown with greenish hue (under microscope light), with diffuse microscopic particles, with 2 fractures over dorsal side of specimen, one larger one ventrally obscuring right side of prothorax.

Remarks. In view of the redescription of the genus above, the original description of the species is adequate for the moment. Additional characters warranting mention here (and not present in $B$. longus) include the unusual modified thick setae on the inner side of the mesotibiae, the dense long setae on the ventrites, the extension of the elytral apices beyond ventrite 5 and the pale setae on the sides of the pronotum and elytral interstriae.

Burmocorynus longus Clarke \& Oberprieler, sp. n. (Figure 34)

Description. Size. Length $6.15 \mathrm{~mm}$, width $1.91 \mathrm{~mm}$. Head. Antennal insertions median. Antennae. Scapes elongate, not extending to eye; funicles about as long as scape, segments 1-2 subcylindrical, subequal, 3-7 broadly subobconical, progressively longer and broader towards club, 6-7 slightly narrower than club; clubs with segment 1-2 broadly flatly obconical, 2 ca. half as long as $1,3 \mathrm{ca}$. half as long as 2, much narrower, $4 \mathrm{ca} .2 .5 \times$ longer than 3 , elongately narrowly flatly conical, broadly inserted into 3 . Mouthparts. Not preserved. Thorax. Pronotum elongate, longer than wide; basal pronotal margin sinuate, with weak median process. Prosternum elongate, longer than hypomeron. Elytra. Elytra punctostriate; sparsely setose, punctures not well defined; bases and humeri strongly concave to receive base of pronotum; bases widely obtuse, with notch in middle to receive median process of base of pronotum; margins with broad shallow anterior notch, with marginal groove gradually thickening anteriad but lacking lateral carina; apices individually rounded. Legs. Tibiae apically lined with coarse fringing setae, tarsal articulation surfaces suboblique, with 2 short spurs, shorter on protibiae; meso- and metatibiae with in distal half with denser, longer setae on outer and inner side. Tarsi broad, setae distinctly elongate, especially on protarsi; tarsite 1 elongate-triangular, acutely lobate, 2 broader, strongly lobate; 3 distinctly pedunculate, lobes $0.67 \times$ as long as 5,5 elongate, slender, slightly curved. Abdomen. Ventrites sparsely setose, 1 and 2 subequal in length, 3 and 4 successively slightly shorter, 5 about as long as $3+4$, narrowly rounded.

Material examined. Holotype (NIGP154212): poorly preserved, partly decomposed specimen, with most of head and thorax heavily distorted, appendages somewhat compressed, in places fragmented, head partly retracted into prothorax well visible, vestiture possibly partly abraded, apical part of rostrum and of right elytron cut away, appendages intact, with large crystalline mass erupting from elytral suture in about middle, causing local distortion of cuticle, hindwings partly extended; in centre of irregular block with three flat sides and one long curved side over dorsal side of specimen, $8.7 \times 2.5-4.0 \times 3.3 \mathrm{~mm}$; amber clear yellow with flowbands of greenish hue (under microscope light) and minimal impurities, with few discoidal fractures below head and prothorax.

Derivation of name. The species is named for its long, narrow shape, from the Latin adjective longus.

Remarks. Despite the substantial distortion of this specimen, particularly of the head and ventral side, sufficient detail can be seen in it to conclude that it belongs in Burmocorynus. Of key importance is the visibility of the procoxae, which are broadly separated by adjoining prosternal and hypomeral 
processes. The species agrees with $B$. jarzembowskii in its size and very elongate body, differing mainly by the characters given in the key. The surface of the body seems to have had much of the setae abraded, but in places pale setae are visible, and this species may have had a vestiture similar to that of B. jarzembowskii.

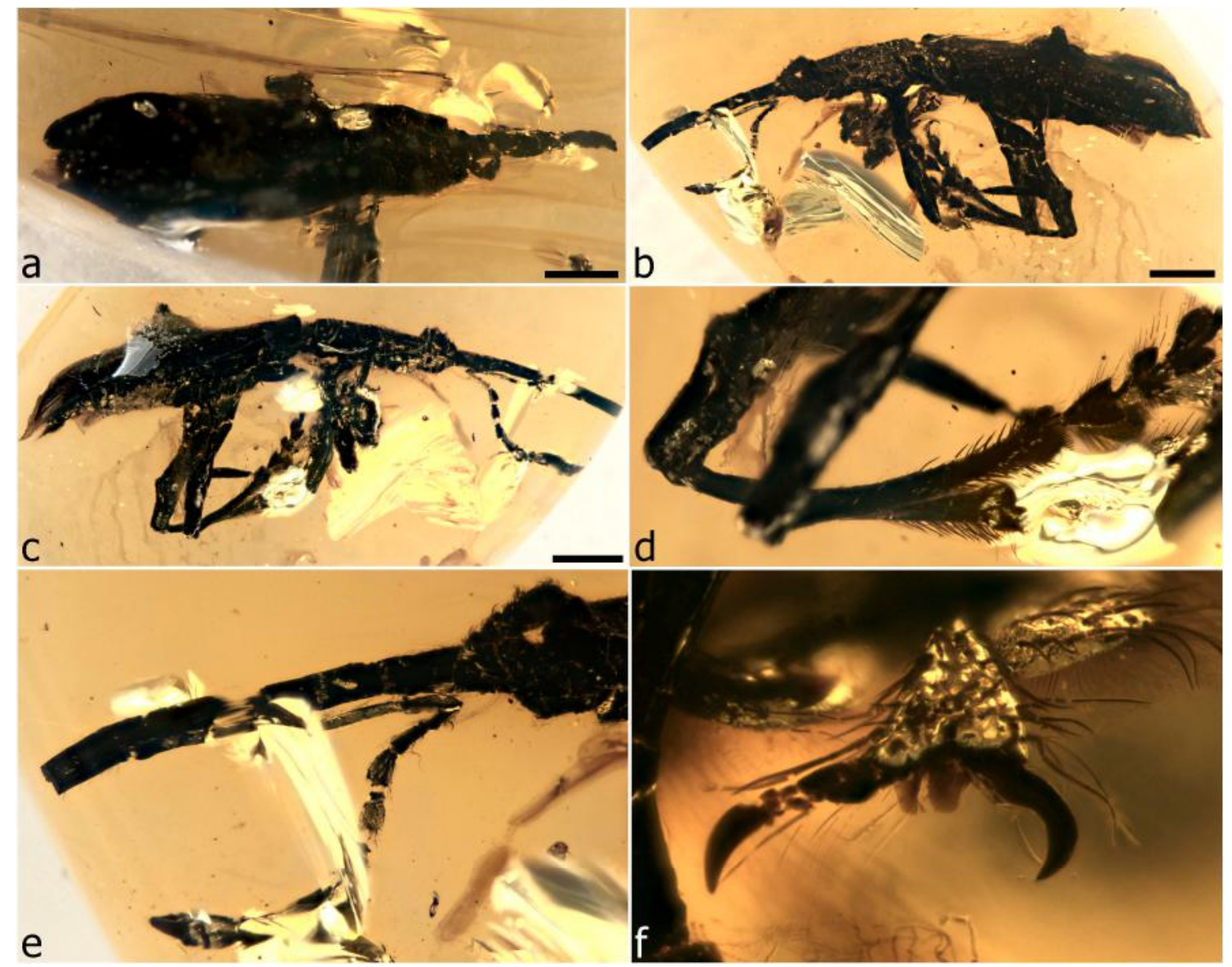

Figure 34. Burmocorynus longus sp. n., holotype. Habitus, dorsal (a); habitus, left lateral (b); habitus, right lateral (c); right metatibia and tarsites 1-3, showing pair of short spurs between coarse short rows of inner and outer apical fringing setae (d); head and left antenna, left lateral (e); left protibial claws, showing lobate ventral apex of claw segment (artefact) (f). Scale bars: $1 \mathrm{~mm}(\mathbf{a}-\mathbf{c})$.

\section{Genus Petalotarsus Clarke \& Oberprieler, gen. n.}

Type species: Petalotarsus oxycorynoides Clarke \& Oberprieler, sp. n.

Description. Size. Length 4.1-7.25 mm, width 1.7-2.2 mm. Head short, not or weakly constricted behind eyes. Eyes protruding, coarsely facetted, dorsally separated by about width of rostrum at base, without tubercles between them, forehead flat to slightly impressed. Rostrum as long as or slightly longer than pronotum, stout, cylindrical; antennal insertions lateral, in or near middle of rostral length, behind them with scrobes extending to eye, in front of them with or without lateral row of erect setae. Long single gular suture indicated. Antennae geniculate, robust; scapes elongate, cylindrical, distally inflated; funicles about as long as scape, 7-segmented, segment 1 elongate, thick, 2 about as long as 1, rest progressively shorter and thicker; clubs 4-segmented, subcompact but segments still distinct, progressively wider towards club, apical segment acute. Mouthparts. Labrum absent. Mandibles small, seemingly exodont with 1 blunt outer tooth, articulation horizontal. Thorax. Prothorax slightly to distinctly proclinate, with anterior lateral margins oblique in lateral view. Pronotum elongate, narrowly trapezoidal to rectangular, laterally rounded in dorsal view, usually deplanate but not carinate, without lateral tooth, posterior corners extended, fitting closely onto elytra; surface setose, 
setae short, acute, directed mesad to anteromesad; notosternal sutures closed. Prosternum moderately long; procoxal cavities separated, in middle of prothorax. Scutellar shield small. Mesocoxal cavities laterally closed (by meso- and metaventrite). Metanepisternal sutures distinct. Mesoventrite short, anteriorly sloping. Metaventrite longer, flat, not raised into weals before metacoxae. Elytra elongate, bases extended anteriad to fit over base of pronotum, with broadly rounded humeri, posteriorly gently declivous, apically individually rounded, not exposing pygidium; sutural flanges narrow, equal; surface punctostriate, without scutellary striole, sparsely setose, setae sometimes concentrated into longitudinal bands, directed caudad. Legs. Procoxae subglobular, not prominent, medially separated; mesocoxae subglobular, separated; metacoxae flat, transversely elongate. Trochanters short, oblique. Femora straight, subcylindrical, inflated in distal half, unarmed, outside rounded. Tibiae straight, subcylindrical, outer edge rounded to subcostate, distally strongly setose, apex truncate, with 1 or 2 spurs. Tarsi large and broad, almost as long as tibiae, strongly setose; tarsite 1 shortly triangular, apically excised, 2 shorter, apically deeply excised to bilobed, 3 deeply bilobed, lobes broad, subpedunculate, 5 about as long as $1+2$, apically broad; claws divaricate, basally swollen or angulate, with ventrobasal seta. Abdomen with ventrites 1 and 2 longer than each of 3 and 4 .

Derivation of name. The genus is named for its broad flat tarsi, the name derived from the Greek adjective petalos (broad, flat) and noun tarsos (G: tarsou), the flat of the foot, and being masculine in gender.

Remarks. This genus is remarkable among the Burmese amber weevil fauna in that its species have broadly separated procoxae, broad and flat tarsi and subcompact antennal clubs, and most also having a flattened body. Petalotarsus differs from the similar genus Burmocorynus mainly by the flatter body and the antennal structure (rounded segments, less robust funicles, clubs more distinctly differentiated from funicles) but also in the proclinate prothorax. Three of the five known specimens are distinguishable from Burmocorynus also by the distinctive pale setal stripes on the elytra, although this feature is evidently not always as distinct as in P. oxycorynoides and may be an unrecognised feature of the other species as well (their elytra not properly visible). Most of the included species, especially $P$. oxycorynoides, possess features related to the flattened form, including the elongate prothorax, broadly separated procoxae and mesocoxae, horizontal and flatly aligned mesoventrite, metaventrite and hypomera, flattened apically expanded tibiae, broad flat and short tarsi and long subflatly aligned ventrites. Like the other genera with large species, most of the available material of Petalotarsus is poorly preserved or visible, and better material of most included species is needed before a detailed comparison with Burmocorynus is possible. Currently none of the available specimens allow a clear view of the mandibles (or other mouthparts), and those of Burmocorynus have been cut away with the amber in all known specimens. Only the mandibles of the largest known Petalotarsus species are partly visible, and their short, seemingly triangular and non-exodont form (Figure 4d) indicates a possible difference between these genera and the more typical exodont form of the mandibles as known from other genera of this group (Opeatorhynchus, Cetionyx). Whereas the subcompact clubs may suggest an affinity of Petalotarsus with the family Curculionidae, the lack of any scales and the broadly divaricate, basally swollen or angulate tarsal claws with a long ventrobasal seta (as typical for Mesophyletidae) indicate that the genus belongs in this family as well, just representing seemingly specialised forms adapted to living in narrow spaces (as extant Curculionidae of a similar body shape do). Petalotarsus is currently represented by four species, three of which are described here.

Petalotarsus oxycorynoides Clarke \& Oberprieler, sp. n. (Figures 35-37, Video S3)

Description. Size. Length $7.01 \mathrm{~mm}$, width $1.72 \mathrm{~mm}$. Head subporrect, dorsally coarsely punctate in front of eyes; setose, setae directed anteriad; ventrally bulging behind eyes. Eyes large, prominent, slightly elongate, dorsolateral. Rostrum slightly shorter than pronotum; coarsely punctate basally; punctures well defined; antennal insertions median. Antennae. Scapes extending to front margin of eye, apically truncate; funicles with segment 2 nearly $2.0 \times$ longer than 3,3 globular, ca. half as long as 2, 4-6 longer, subequal in length, 7 slightly longer and wider than 6; clubs with segments 1-4 gradually shortening apically, apical one obconical, rounded at apex. Mouthparts. Mandibles 
visible but blurred. Thorax. Prothorax slightly proclinate, tightly fitting onto both mesoventrite and elytral humeri, posterolateral margin narrowly emarginate to receive lobe of mesothorax (see below). Pronotum laterally rounded, narrowing anteriad and basad, anterior margin broadly curved, basal margin subangulate at middle, tightly fitting to elytral bases; disc raised into central platform; surface punctosetose, punctures round, distinct, setae yellowish-white; notosternal sutures obliquely curved anteriad. Prosternum elongate, flattened, slightly longer than hypomeron, behind anterior margin with distinct slender groove tracking margin, medially forming broad $\mathrm{V}$, prosternal process very broad, ca. half as wide as procoxa, with semi-longitudinal rugose sculpturing, similar to ventral head sculpturing but finer; hypomeral process with median suture, this and prosternal process separated by sternellum-like structure comprising pair of indistinct sclerites, posterior margin broadly arcuate. Mesoventrite flat, at same level as metaventrite, elongate in front of mesocoxae; lateral part and inner anterior part of mesanepisterna forming anterolateral lobe fitting into prothorax. Mesanepisterna with row of irregular punctures tracking suture between mesoventrite and mesanepisterna. Metaventrite disc distinctly punctate, punctures deep; sparsely setose, setae short. Elytra. Disc with broad stripe of dense, subappressed, yellowish-white setae adjacent to suture, gradually fading posteriad, with another stripe just laterally of middle of disc; intervening setae brownish, sparser; intervening surface finely sculptured, impunctate; surface along suture subsmooth, laterally of outermost setal stripe with at least 4 visible striae, with tiny punctures; bases obtusely angulate, extended to fit over pronotum; humeri submarginally concave to receive pronotal corners; sides moderately densely setose, setae directed mesad, with marginal groove narrowing posteriad, dorsal edge forming distinct lateral carina, obsolete before humerus, with distinct anterior marginal notch. Legs. Coxae slightly longer than wide, globular, widely separated. Femora narrow basally, gradually inflated in distal half, distally narrowed ventrally, inside concave to receive tibiae in repose; sparsely setose. Tibiae flattened, dorso-apically with several elongate setae; protibiae apparently flattened (distorted?), thicker apically, sparsely setose, apically with large inner flange, fringing setae similar to others (not coarse); with at least 1 spur; mesoand metatibiae densely setose in distal half, apically with coarse fringing setae, shorter on outer apical edge; without (meso-) or with 1 spur (metatibiae). Tarsi with long setae apicolaterally, ventrally with dense pulvilli of whitish setae on tarsites 1-3; tarsite 1 narrower than 2, 5 shorter than median lengths of 1-3. Abdomen. Tergites weakly sclerotised. Ventrites densely setose, 1 and 2 at approximately same level, suture between them weakly angulate medially, fainter than others, 3-5 more distinctly stepped, sutures between them broadly arcuate, 1 slightly shorter than 2, densely setose medially, sparser laterally; $2-4$ progressively shorter; 5 about twice length of 4 , rounded posteriorly.

Material examined. Holotype (NIGP154213): poorly preserved, strongly distorted specimen, especially around head and prothorax, with elytra spread, apparently both hindwings extended (left seemingly separated), appendages and rostrum intact, distal half of rostrum and mandibles obscured by large bubble, other areas and some appendages pulled away from amber leaving an impression in surface; in drop-shaped slab, $17.1 \times 9.2 \times 4.2 \mathrm{~mm}$; amber clear yellow, unfractured, with few large debris masses near specimen.

Derivation of name. The species is named for its similarity to the belid genus Oxycorynus, which is also flattened with a laterally deplanate prothorax, the name being an adjective composed from Oxycorynus and the suffix -oides (similar).

Remarks. This species is similar to P. curculionoides in having interstriae 2 and 8 covered with dense yellowish setae, but they are more distinctive in this species and it is also larger and has the disc of the pronotum elevated and the sides more strongly deplanate. Other seemingly unique features as observed include the distinct row of short pale setae on the basal underside of mesotarsites 5 and the medial angulate emargination of the suture between ventrites 1 and 2. The CT scans (Figure 37c; Video S3) confirm the presence of a single long gular suture, but this is not so distinctly evident under a light microscope. 


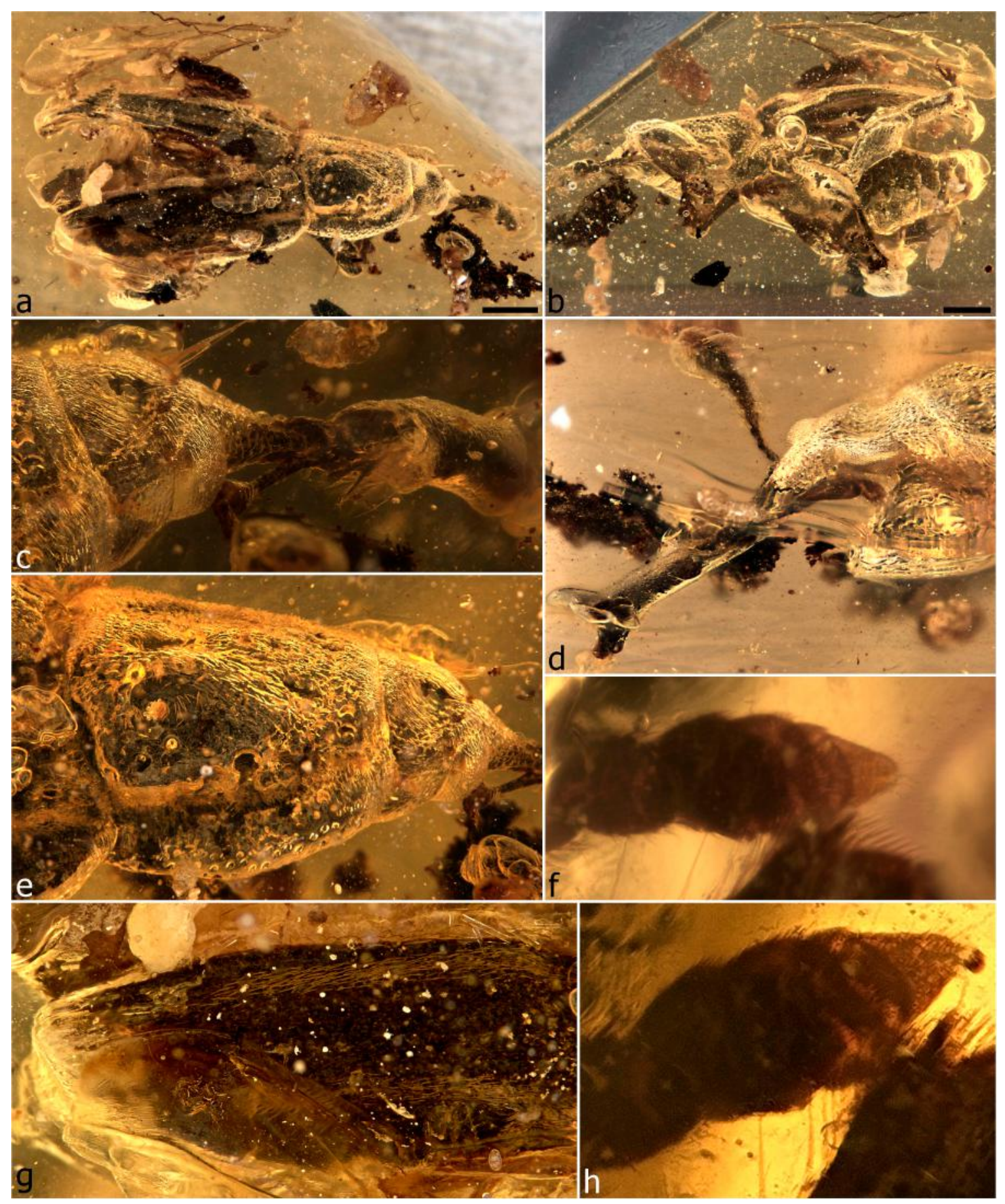

Figure 35. Petalotarsus oxycorynoides sp. n., holotype. Habitus, dorsal (a); habitus, left ventrolateral (b); head, right dorsolateral (c); head, left dorsolateral (d); prothorax, dorsal (e); antennal club (f); right elytron showing setal stripes, dorsal (g); antennal club enlarged (h). Scale bars: $1.0 \mathrm{~mm}(\mathrm{a}, \mathrm{b})$. 


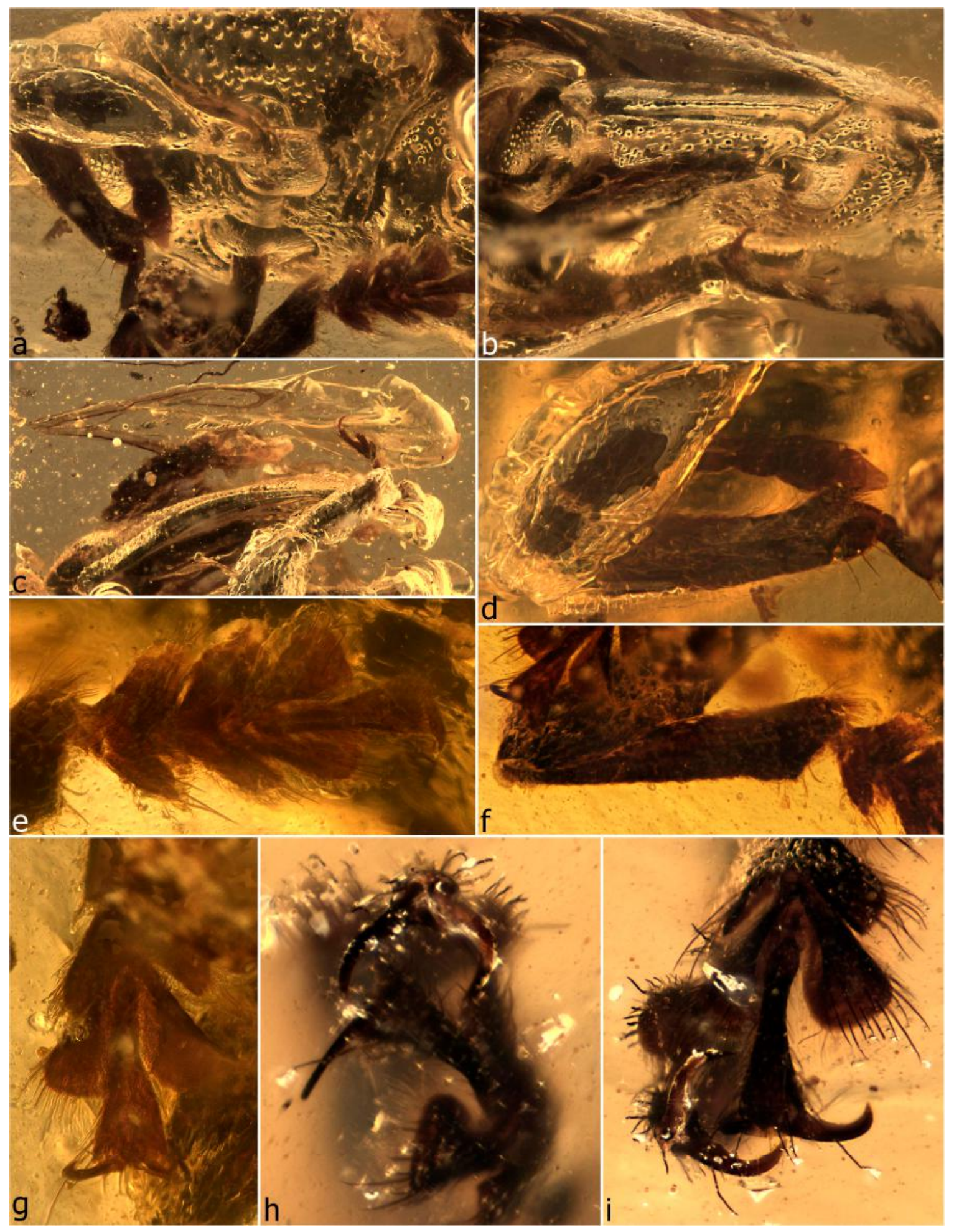

Figure 36. Petalotarsus oxycorynoides sp. n., holotype. Prothorax, ventrolateral (a); thorax, ventrolateral (b); edge of elytra, left hindleg and probable wing (c); left foreleg (d); right protarsus, dorsal (e); protibia (f); metatarsus, dorsal (g); right meso- and metatarsal claws (h,i). 

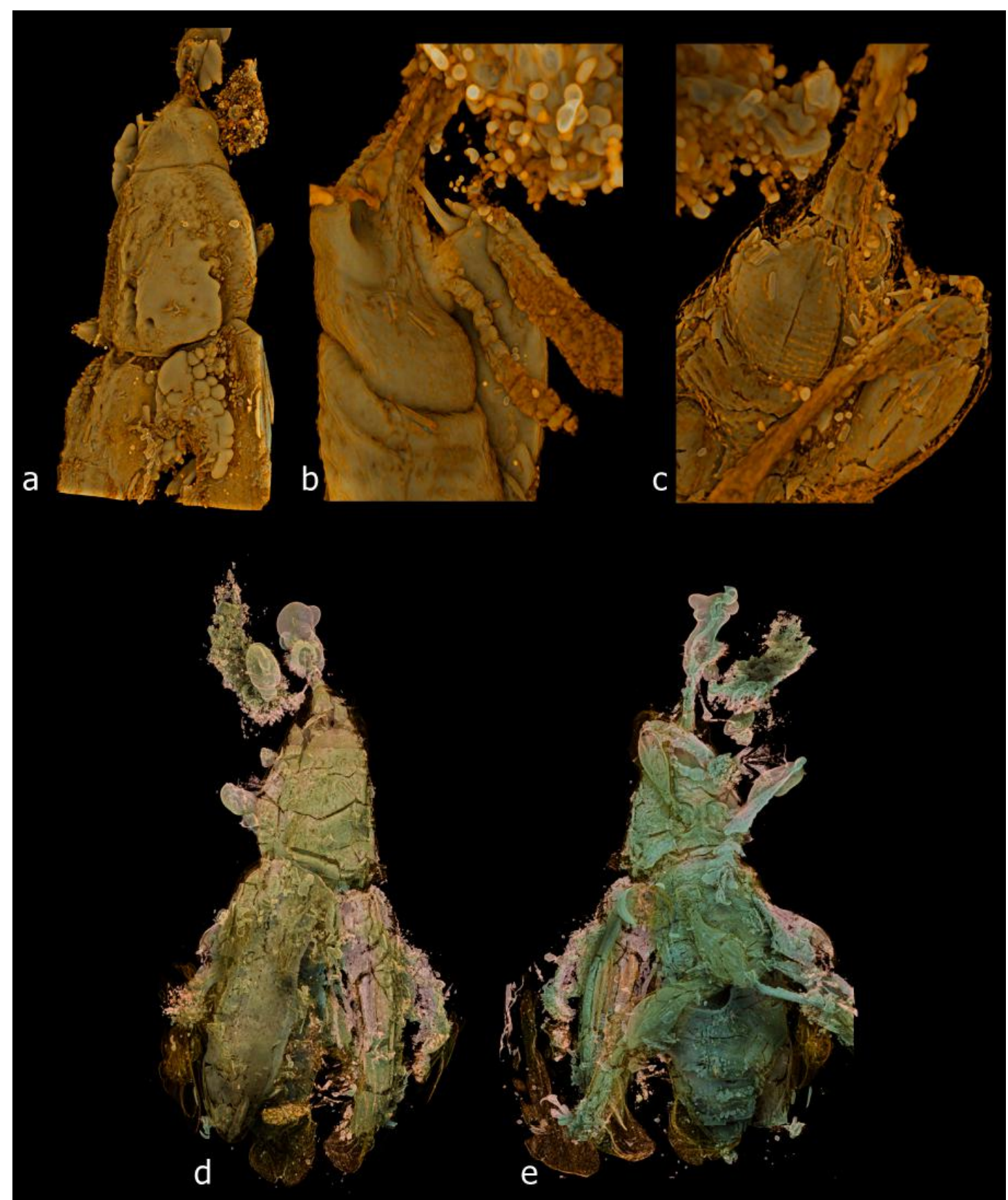

Figure 37. Petalotarsus oxycorynoides sp. n., holotype. Habitus and detail images extracted from micro-CT scanning reconstruction (see also Video S3). Head and pronotum, dorsal (a); same, lateral, showing antenna (b); same, ventral (c); habitus, dorsal (d); habitus, ventral (e).

Petalotarsus curculionoides Clarke \& Oberprieler, sp. n. (Figures 38 and 39)

Description. Size. Length 4.1-4.4 mm, width 1.6-1.7 mm. Head transverse, weakly constricted behind eyes. Eyes large, elongate, subglobular, somewhat compressed, strongly protruding, forehead between them flat, triangular. Rostrum as long as pronotum, slightly curved; antennal insertions in middle of rostral length, in front of them with lateral row of 7-10 long, erect setae. Antennae moderately long; scapes thin, gradually inflated in distal third; funicles with segment 1 elongate, thick, 2 slightly shorter and thinner, 3-5 progressively shorter and thicker, 6 and 7 as thick as club; clubs with segment 4 long, thin, narrowly obconical, longer than 3. Mouthparts. Mandibles obscured by fine debris, dentition evidently weak; tips of labial palps visible. Thorax. Prothorax slightly proclinate. 
Pronotum narrowly roundly trapezoidal, longer than broad at base, laterally explanate, slightly convex; surface punctorugose, sparsely setose, setae pale, directed mesad. Scutellar shield small, subquadatic. Elytra with 2 stripes of moderately dense setae along length of elytra, one on interstria 2, the other on interstria 8, other interstriae with few small setae directed caudad, fully developed. Legs. Procoxae subglobular, not prominent, medially separated by less than their width; mesocoxae separated by about their width. Femora long, strongly inflated in distal half, thickest in distal quarter. Tibiae shorter than femora, outer edge subcostate, distally strongly setose, apically flatly expanded, at apex with 2 small spurs (at least on metatibiae). Tarsi almost as long as tibiae, protarsi broader than meso- and metatarsi, strongly setose; tarsite 1 very shortly, broadly triangular, apically deeply excised, 2 shorter, deeply bilobed, 3 with lobes short and broad, subpedunculate, with dense pulvilli of silvery white setae, 5 short and broad; claws basally swollen with ventrobasal seta. Abdomen with ventrites 1 and 2 ca. $1.5 \times$ longer than each of 3 and 4, 5 narrowly semicircular.

Material examined. Holotype (NIGP154214; Figure 38), length $4.10 \mathrm{~mm}$, width $1.7 \mathrm{~mm}$ : well preserved, intact specimen, not compressed or distorted, mostly well visible except for left side of pronotum, with apex of left hindwing exposed; in centre of elongate rectangular cuboid $7.4 \times$ ca. $4.8 \times$ $3.7 \mathrm{~mm}$, dorsal surface convex; amber dark but clear, on left side of pronotum with large and small clear bubble, on right side with small white bubble over metathorax, with large transparent brown ring beneath rostrum, also a transverse vertical crack on left side of rostrum, few larger impurities. Paratype (NIGP154215; Figure 39), length $4.38 \mathrm{~mm}$, width $1.66 \mathrm{~mm}$ : poorly preserved, strongly distorted specimen covered by layer of bubbles and debris, with elytra separated from abdomen and from each other, exposing hindwings and membranous abdominal tergites, claw segment of right hindleg missing, left antenna and rostral apex not visible (obscured by bubbles); in rod-shaped block with three flat sides and one long curved side, tapered at one end, flat at other, $9.1 \times 1.5-4.0 \times 3.2 \mathrm{~mm}$; amber clear yellow, with diffuse microscopic particles and minimal debris.

Derivation of name. The species is named for the similarity of its compact antennal clubs to those of the family Curculionidae, the name being an adjective composed of the stem of the name Curculionidae and the suffix -oides (similar).

Remarks. This species is similar to P. oxycorynoides in having interstriae 2 and 8 conspicuously densely setose (though less distinct in the paratype), but it is smaller and less flattened and has an evenly, slightly convex pronotum (the disc not elevated) as well as somewhat narrower tarsi and spurs on the meso- and metatibiae. The two specimens available for study differ slightly from each other but are considered to be conspecific. The main differences are (states in paratype): shorter and basally broader elytra with straight sides, only curved posteriorly (longer and narrower elytra with sides more evenly curved from humerus to apex), distinct setal stripes (faint, indistinct, outer one much broader), distinct, coarse, subevenly aligned fringing setae, at least on the outer flanges of the tibial apices (only weak apical fringing setae) and broad tarsi (narrow, longer).

Petalotarsus cylindricus Clarke \& Oberprieler, sp. n. (Figure 40)

Description. Size. Length $5.3 \mathrm{~mm}$, width $1.9 \mathrm{~mm}$. Head subconical, not constricted behind eyes. Eyes medium-sized, round, slightly protruding, forehead between them slightly impressed. Rostrum $1.5 \times$ longer than pronotum, only very slightly curved; antennal insertions behind middle of rostral length, almost at basal third, in front of them seemingly without lateral row of setae. Antennae relatively short; scapes straight, apically clavate; funicles about as long as scape, segment 1 slightly inflated, 2 as long as 1 but thinner, 3-5 similar, 6-7 shorter; clubs short, with apical segment small, acute, about as long as 3. Mouthparts. Mandibles with 1 blunt tooth on outside. Thorax. Prothorax proclinate. Pronotum roundly rectangular, longer than broad at base, slightly convex, laterally not explanate; surface densely rugose, sparsely setose, setae very fine, thin, recumbent, directed anteromesad. Prosternum moderately long; procoxal cavities medially narrowly separated or confluent (not clearly discernible). Scutellar shield subquadratic, slightly convex. Metaventrite weakly tumescent before metacoxae. Elytra basally rounded (shallowly lobed); surface very sparsely setose, setae not clearly visible. Legs. Procoxae slightly elongate, prominent, medially narrowly separated; 
mesocoxae narrowly separated. Femora long, strongly inflated in distal half, thickest in distal quarter. Tibiae shorter than femora, outer edge rounded, at apex with 1 spur visible on mesotibiae (but possible 2 present), 2 spurs on metatibiae. Tarsi about $0.67 \times$ as long as tibiae; tarsite 1 apically slightly excised, 2 as long as 1, apically strongly excised, 3 with lobes short, 5 slightly shorter than $1+2$, broadening apicad; claws basally angulate, with ventrobasal seta at apex of angulation. Abdomen with ventrites 1 and 2 fused, longer than each of 3 and 4, 5 not visible.

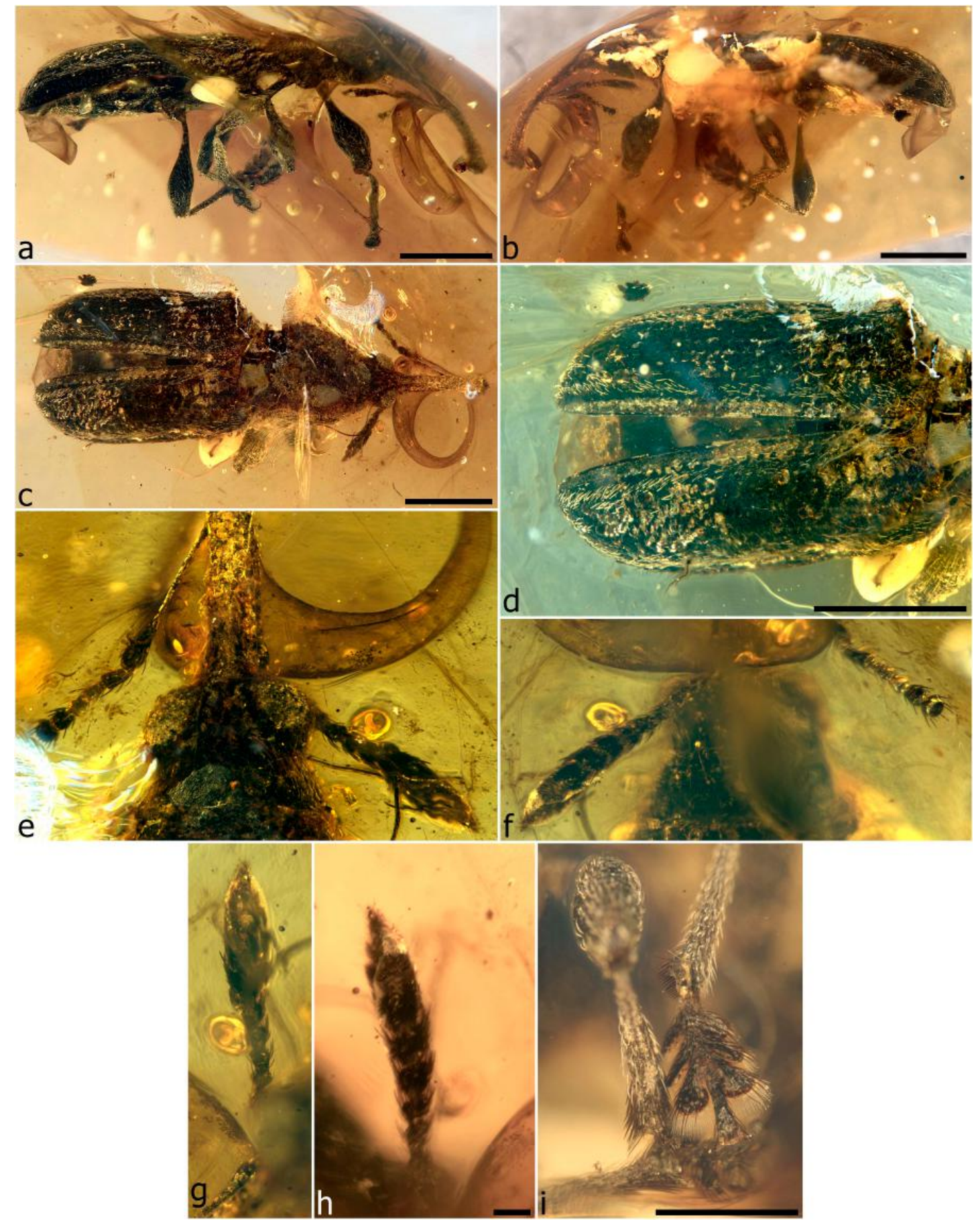

Figure 38. Petalotarsus curculionoides sp. n., holotype. Habitus, right lateral (a); habitus, left lateral (b); habitus, dorsal (c); elytra, dorsal (d); head, dorsal (e); antennae, ventral (f); right antenna (g); right antennal club detail (h); protarsus (i). Scale bars: $1.0 \mathrm{~mm}(\mathrm{a}-\mathrm{d}) ; 0.5 \mathrm{~mm}(\mathrm{i}) ; 0.1 \mathrm{~mm}(\mathrm{~h})$. 


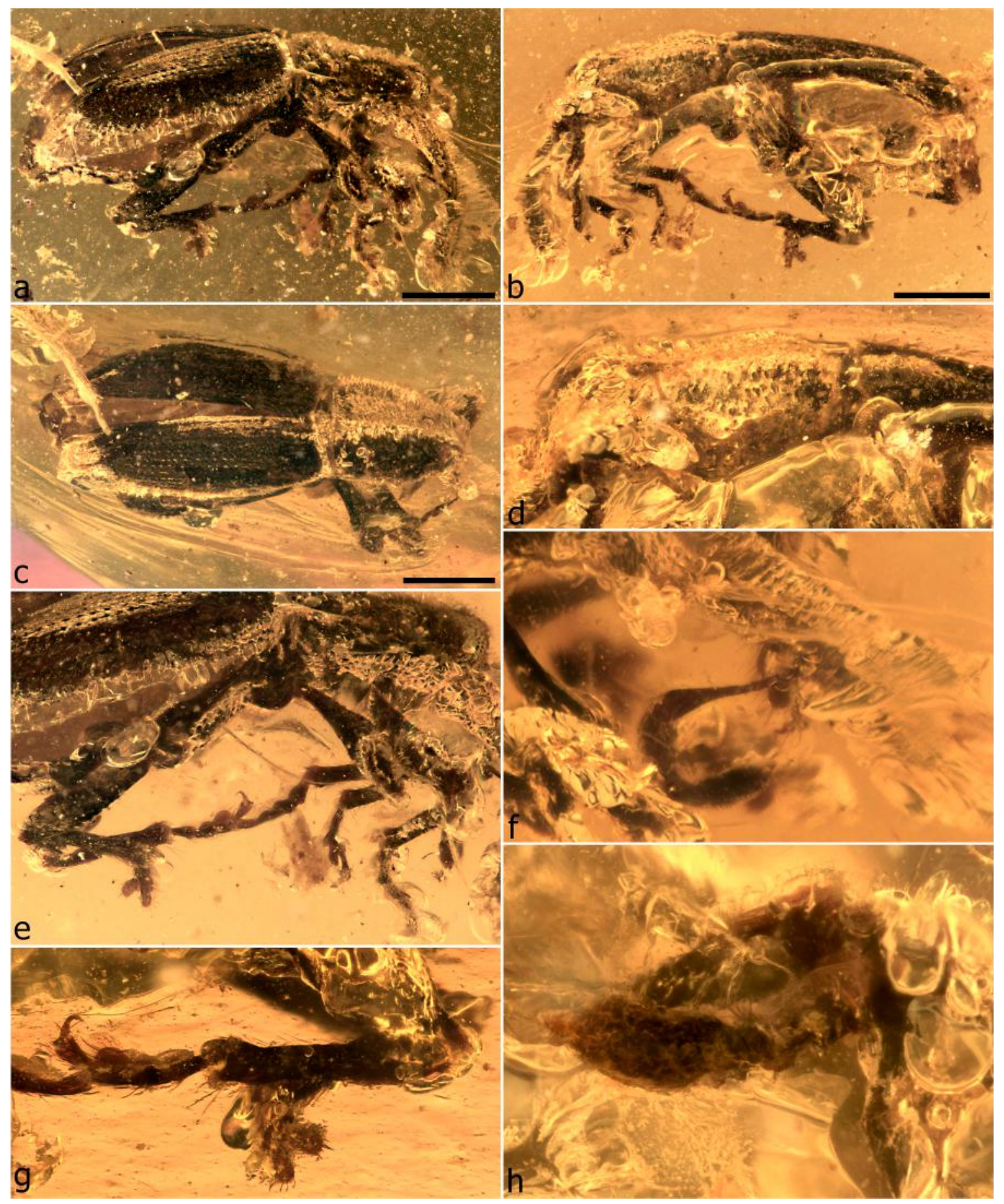

Figure 39. Petalotarsus curculionoides sp. n., paratype. Habitus, right lateral (a); habitus, left lateral (b); habitus, dorsal (c); head, prothorax and elytral humerus, left lateral (d); elytra and legs, right lateral (e); right antenna (f); left metatibia and -tarsus (g); antennal club (h). Scale bars: $1.0 \mathrm{~mm}(\mathrm{a}-\mathrm{c})$.

Material examined. Holotype (NIGP154216): reasonably well preserved, intact specimen, not compressed or distorted, not well visible; diagonally in centre of thin rectangular cuboid $7.5 \times 7.2 \times$ $3.5 \mathrm{~mm}$; amber dark, clear on left side of specimen but cloudy on right side, with large warped film posteriorly on ventral side, wrapping over middle and hindlegs, and with large crack along middle of elytra and right around specimen, with many small impurities especially on right side of specimen.

Derivation of name. The species is named for its cylindrical body shape, the name being a Latin adjective. 


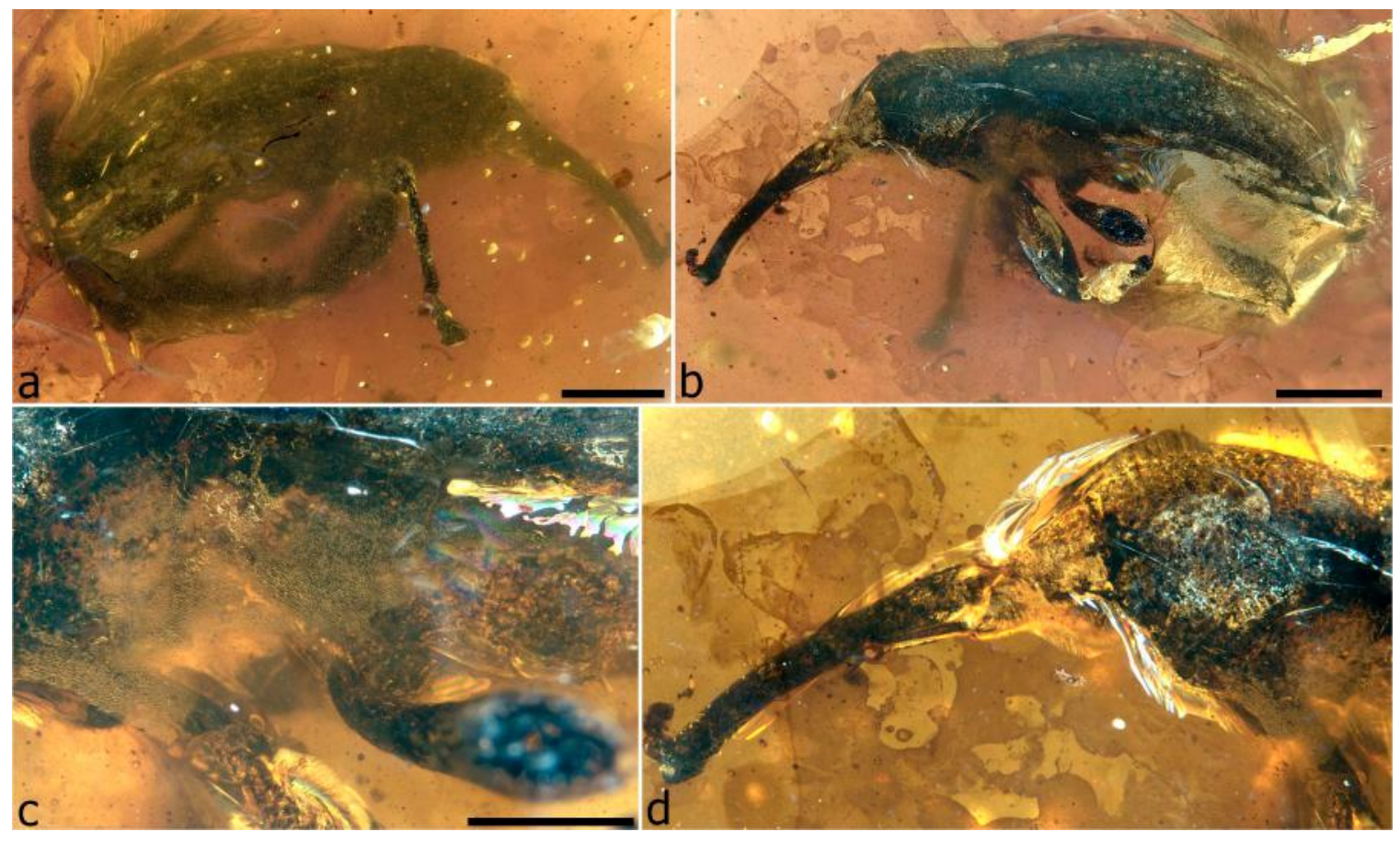

Figure 40. Petalotarsus cylindricus sp. n., holotype. Habitus, right lateral (a); left lateral (b); pro- and mesothorax, left lateral (c); head and prothorax, left lateral (d). Scale bars: $1.0 \mathrm{~mm}(\mathrm{a}, \mathrm{b})$; $0.5 \mathrm{~mm}$ (c).

Remarks. Petalotarsus cylindricus is atypical of the genus in that its body is not flattened and the tarsi are not as conspicuously flat and broad, and the procoxae are also not distinctly separated (possibly even contiguous), but the antennal clubs are evidently subcompact and no other significant differences from the other species of Petalotarsus are apparent. However, the single specimen is not well preserved and visible, and if CT scanning of it is attempted and successful and further differences become evident, or if further specimens are found, its status in Petalotarsus may need to be reassessed.

Petalotarsus sp. (Figure 41)

Material examined. One specimen (in private collection of Mr. Wei Ma, China), $7.25 \mathrm{~mm}$ long, $2.2 \mathrm{~mm}$ wide: very well preserved, intact, not compressed or distorted, reasonably well visible from left and dorsal sides, underside completely obscured by layer of white and black impurities and right side obscured by large dense cylinder cut along length; placed at angle in left side of lenticular block ca. $14.2 \times 11.0 \times 5.8 \mathrm{~mm}$; amber clear but much debris on right and underside of specimen, much of which can be removed by cutting away the long halfpipe (already half trimmed away) above specimen.

Remarks. This large specimen is quite well visible in dorsal view, but its other sides are obscured by dense debris and the curvature of the amber piece (a cabochon). For proper study and description of the specimen, the cabochon needs to be trimmed into a cuboid, which would also remove a lot (though not all) of the dense matter obscuring the right side of the specimen. We do not describe this species as the specimen is housed in a private collection, in which accessibility of a holotype to science cannot be guaranteed. We provisionally treat it as belonging in Petalotarsus, but in some characters it agrees better with Burmocorynus, having flattened funicles and clubs, the funicle segments widening towards the club and similar protarsi but with shorter setae. Its procoxal cavities are distinctly separated, as in Burmocorynus and Petalotarsus. 


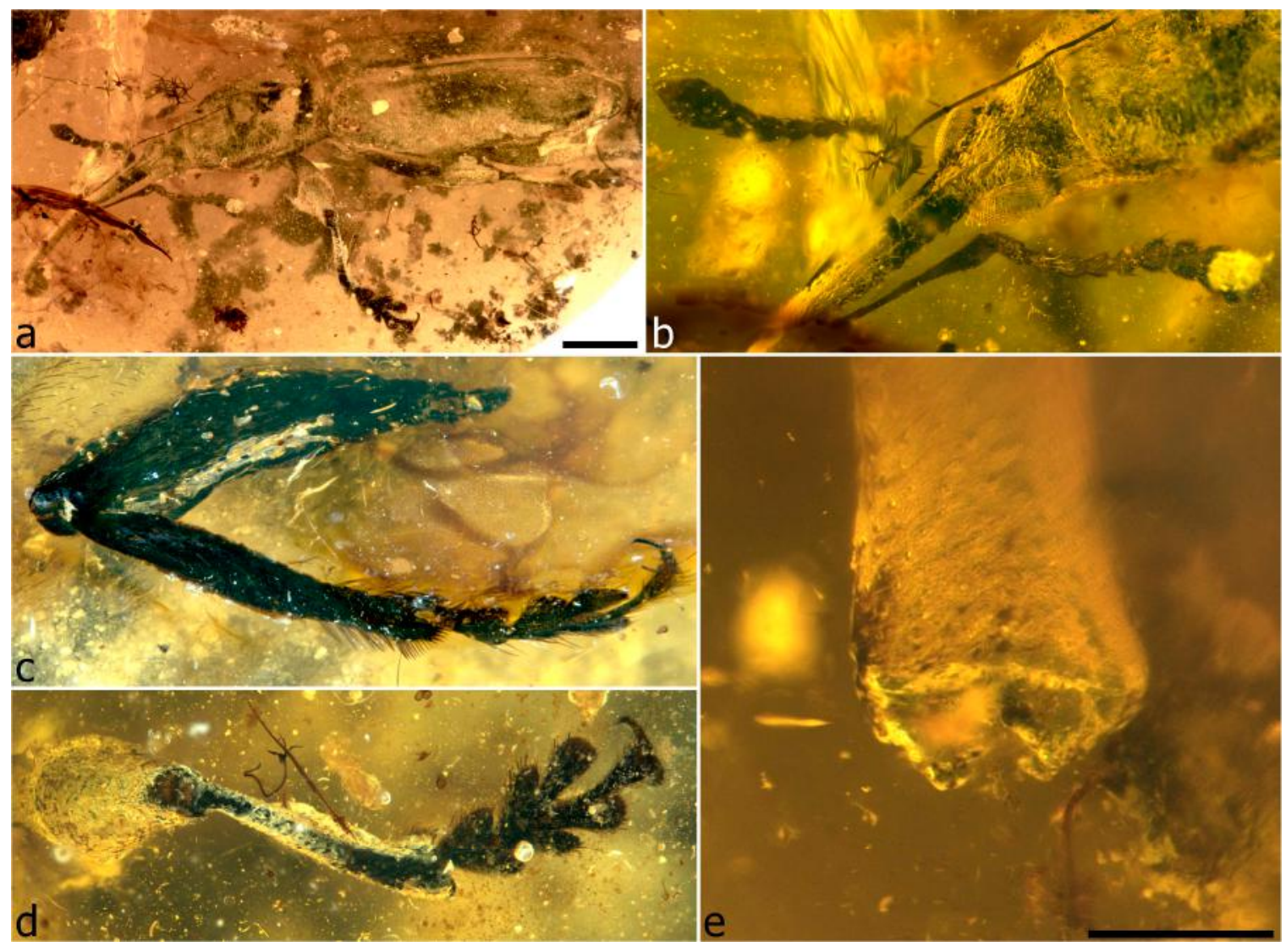

Figure 41. Petalotarsus sp. Habitus, left lateral (a); head and antennae, dorsal (b); right hindleg (c); left foreleg, dorsal (d); apex of rostrum and mandibles, dorsal (e). Scale bars: $1.0 \mathrm{~mm}$ (a); $0.2 \mathrm{~mm}(\mathrm{e})$.

Genus Opeatorhynchus Clarke \& Oberprieler, gen. n.

Type species: Opeatorhynchus comans Clarke \& Oberprieler, sp. n.

Description. Size. Length $5.68 \mathrm{~mm}$, width $2.06 \mathrm{~mm}$. Head short, porrect, not constricted behind eyes, dorsally continuous with rostrum, ventrally bulging. Eyes elongate, flatly protruding, coarsely facetted, dorsally separated by about width of rostrum at base, further separated posteriorly, without tubercles between them, forehead flat to slightly convex. Rostrum relatively short, slightly longer than pronotum, subcylindrical; antennal insertions lateral, in middle of rostral length, behind them with scrobes reaching eye, in front of them without lateral row of erect setae. Long single gular suture present. Antennae geniculate, long, slender; scapes elongate, reaching anterior margin of eye in repose, cylindrical, distally inflated; funicles about as long as scape, 7-segmented, segments progressively thicker towards club, segment 1 elongate, thick, 1-4 subequal in length, 5 shorter than 4 , 6 and 7 subequal, slightly longer than 5; clubs 4-segmented, loose, thicker than funicle, segment 4 large, broadly inserted into 3. Mouthparts. Labrum absent. Mandibles small, exodont with 2 large teeth on outer side, articulation oblique. Maxillary palps robust, slightly projecting from apex of rostrum, 3-segmented. Thorax. Prothorax slightly proclinate, with anterior lateral margins oblique in lateral view. Pronotum elongate, subrectangular, convex, laterally weakly rounded in dorsal view, without lateral tooth, posterior corners rounded, fitting closely into humeri; surface densely setose, partly obscuring integument, setae short, acute, directed mesad to anteromesad; notosternal sutures closed. Prosternum moderately long; procoxal cavities confluent, in middle of prothorax. Scutellar shield not visible. Mesocoxal cavities laterally closed (by meso- and metaventrite). Metanepisterna distinct, setose at least anteriorly. Mesoventrite short, anteriorly sloping. Metaventrite behind mesocoxae short, about half as long as mesocoxa, raised into slight weals before matacoxae. Elytra elongate, base extended to fit over pronotum, with narrow acute humeri, closely fitting to and not much broader than pronotal 
corners, posteriorly gently declivous, apically slightly individually rounded, not exposing pygidium; sutural flanges narrow, equal, broader apically; surface punctostriate, without scutellary striole, densely setose, partly obscuring integument, setae short, thin, sharp, reclined, directed caudad. Legs. Procoxae large, subglobular, prominent, contiguous; mesocoxae subglobular, separated; metacoxae flat, shortly transversely elongate. Trochanters short, oblique. Femora subcylindrical, gradually inflated in distal half, unarmed, outside rounded. Tibiae straight, subcylindrical, outer edge rounded, densely setose in distal half, apex obliquely truncate, with 2 spurs. Tarsi large and broad, almost as long as tibiae, strongly setose; tarsite 1 shortly triangular, apically excised, 2 shorter, narrowly bilobed, 3 deeply bilobed, lobes strongly pedunculate, attachment with basal plate extremely slender in both dimensions, 5 much longer than $1+2$, apically broad; claws divaricate, basally angulate, with ventrobasal seta. Abdomen with ventrites 1 and 2 longer than each of 3 and 4 .

Derivation of name. The genus is named for its awl-shaped body and rostrum in lateral view, the name formed from the Greek nouns opeas (G: opeatos), an awl, and rhynchos (G: rhyncheos), a snout, and being masculine in gender.

Remarks. This genus is distinguishable from other genera with broad tarsi and pedunculate lobes of tarsites 3 by the combination of the antennal structure, including the broad, very loosely articulated clubs, and the medially confluent procoxal cavities. It is most similar to Cetionyx, differing from it mainly in these characters. It is one of only three specimens in the group of genera including Burmocorynus, Petalotarsus, Cetionyx and Echogomphus in which the mandibles are relatively distinct, being exodont with two teeth on the outer edge.

Opeatorhynchus comans Clarke \& Oberprieler, sp. n. (Figures 42 and 43, Video S4)

Description. Size. Length $5.68 \mathrm{~mm}$, width $2.06 \mathrm{~mm}$. Large, robust, densely setose; especially on ventrites. Head coarsely punctate, punctures small; setose. Eyes with deep narrow groove tracking posterior margin (possibly an artefact). Rostrum slightly downcurved, setose from base to antennal insertions, apicodorsally with 2 elongate setae. Mandibular articulations deep, about as long as mandible length. Antennae. Scapes reaching slightly below front margin of eye, apically truncate; funicles with segments 1-7 subequal, 2-4 slightly expanded apically, 6-7 slightly thicker; clubs with segments subequal in width, 1 slightly longer than 2, 2-3 subequal in length, 4 slightly shorter than and broadly inserted onto 3, paler than rest of antenna, apically narrowly rounded. Mouthparts. Mandibles on inner and outer edges with 2 teeth, basal ones much larger than apical ones, these forming apical T. Maxillary palps with basal segment short, broad, apical segment elongate, tapering. Thorax. Pronotum widest just before middle, densely, coarsely punctate, punctures larger than on head; setose, setae mixed dark and paler brownish, on sides distinctly patterned with browner setae mixed with seemingly golden setae. Pronotum strongly convex, sides rounded; posterior angles rounded; base tightly fitting to elytra. Prosternum elongate, about as long as procoxae, anterior margin substraight in middle, prosternal process short, acute; hypomeron well-developed, about as long as prosternum. Mesothorax distinctly, coarsely punctate. Metaventrite coarsely punctate, densely setose, especially posterolaterally; punctures large, dense, distinct. Elytra with striae much narrower than interstriae, punctures distinct, shallow; densely setose, denser just before humeri, setae laterally forming paler thick stripe; interstriae broad, flat; bases subsinuate, forming obtuse angle, carinate to junction with mesepimeron, humeri distinctly cupulate, receiving posterior pronotal corners; lateral marginal groove very narrow in apical half, abruptly broadened anteriorly to humerus, dorsally forming epipleural carina, area inside groove densely setose; lateral margin with anterior notch. Legs long, slender, densely setose. Procoxae large, projecting, subconical, elongate, contiguous; mesocoxae narrowly separated, large, globular, prominent; metacoxae very large, prominent, subglobular (not distinctly transverse), longer than ventrite 1 . Tibiae straight, apically expanded; tarsal articulation surfaces concave, with pronounced apical flanges, inner and outer edges lined with coarse fringing setae, dorso-apical edge well emarginate to allow basal tarsites to bend up, with 5-6 elongate slender setae; protibiae with outer side slightly elongately concave, lined with dense setae, with 2 short thin indistinct apical spurs; meso- and metatibiae very densely setose in apical half, on outer side situated 
in broad emargination, this more distinct on metatibiae, with 2 larger spurs. Tarsi elongate, flattened, (protarsus) at least $0.67 \times$ as long as protibia; tarsite 1 triangular, apically excised, of protarsi longer than of mesotarsi, 2 slightly narrower than 1, shortly bilobed, lobes narrow, lobes of 3 ca. $0.67 \times$ as long as 5, 4 distinct, recessed into basal plate of 3, 5 long, exceeding 3 by third its length, very slender and strongly widening apicad, curved dorsoventrally. Abdomen. Tergites (III-VI) weakly sclerotised, seemingly glabrous; VII large, VIII small, both strongly sclerotised and densely setose, setae apically on each longer than rest; VII basally on either side of middle with orange, distinctly transversely irregularly strigose wing-binding patch, also with parasclerite. Ventrites slightly stepped (not at same level), 3-5 free, at progressively slightly higher levels, densely setose, setae fine, long and erect; punctate/rugosely sculptured; sutures straight; ventrite 1 slightly shorter than 2,3 ca. $0.67 \times$ as long as 2, 4 very slightly shorter than 3, 5 shorter than 4, broadly shallowly impressed, with transverse line of long dark setae at apex, appearing as posterolateral tufts on either side of impressed margin.

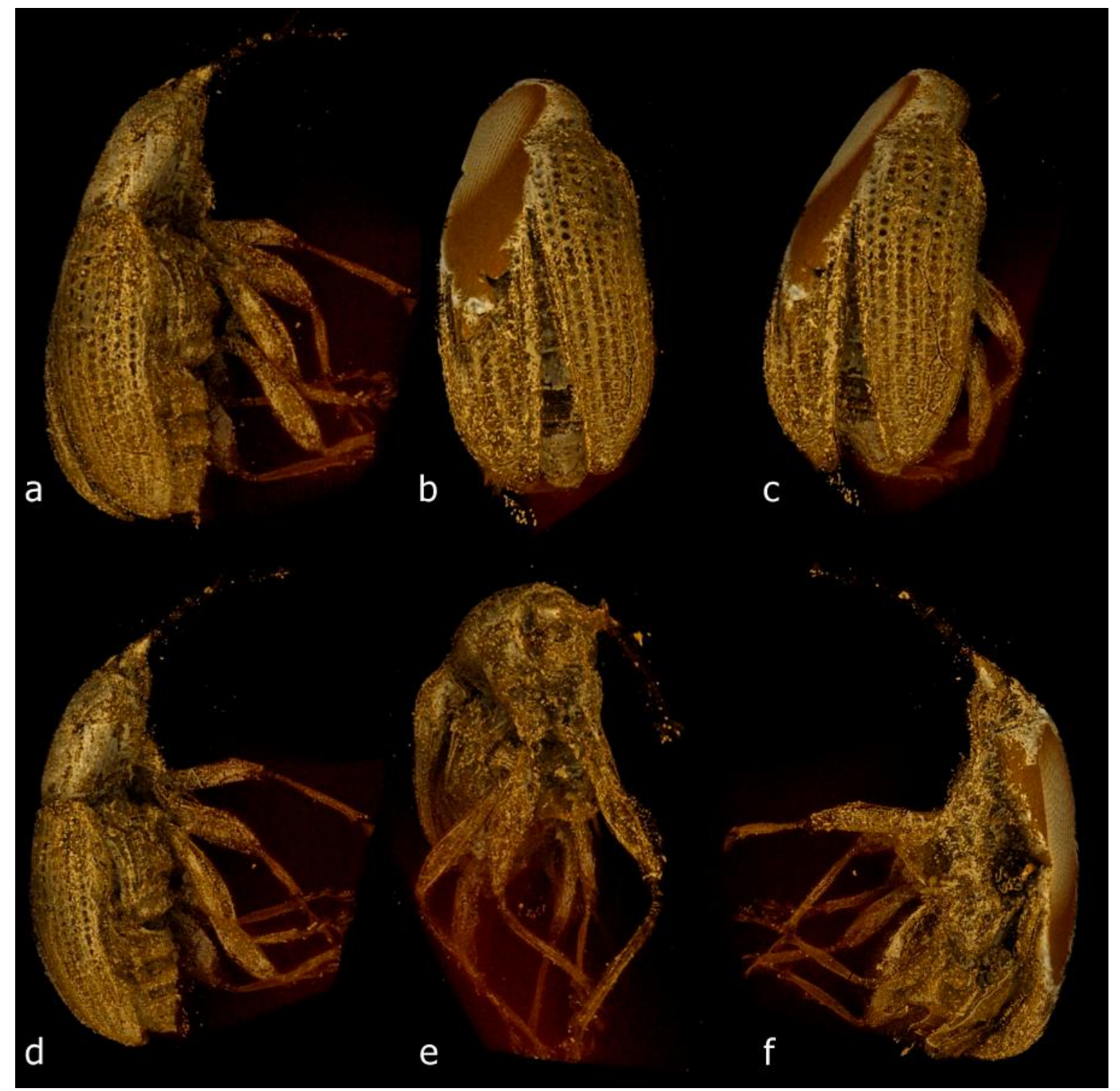

Figure 42. Opeatorhynchus comans sp. n., holotype. Habitus images extracted from a micro-CT scanning reconstruction (see also Video S4). Right lateral oblique (a); dorsal (b); right dorsolateral (c); right lateral (d); frontoventral (e); left lateral (f). 


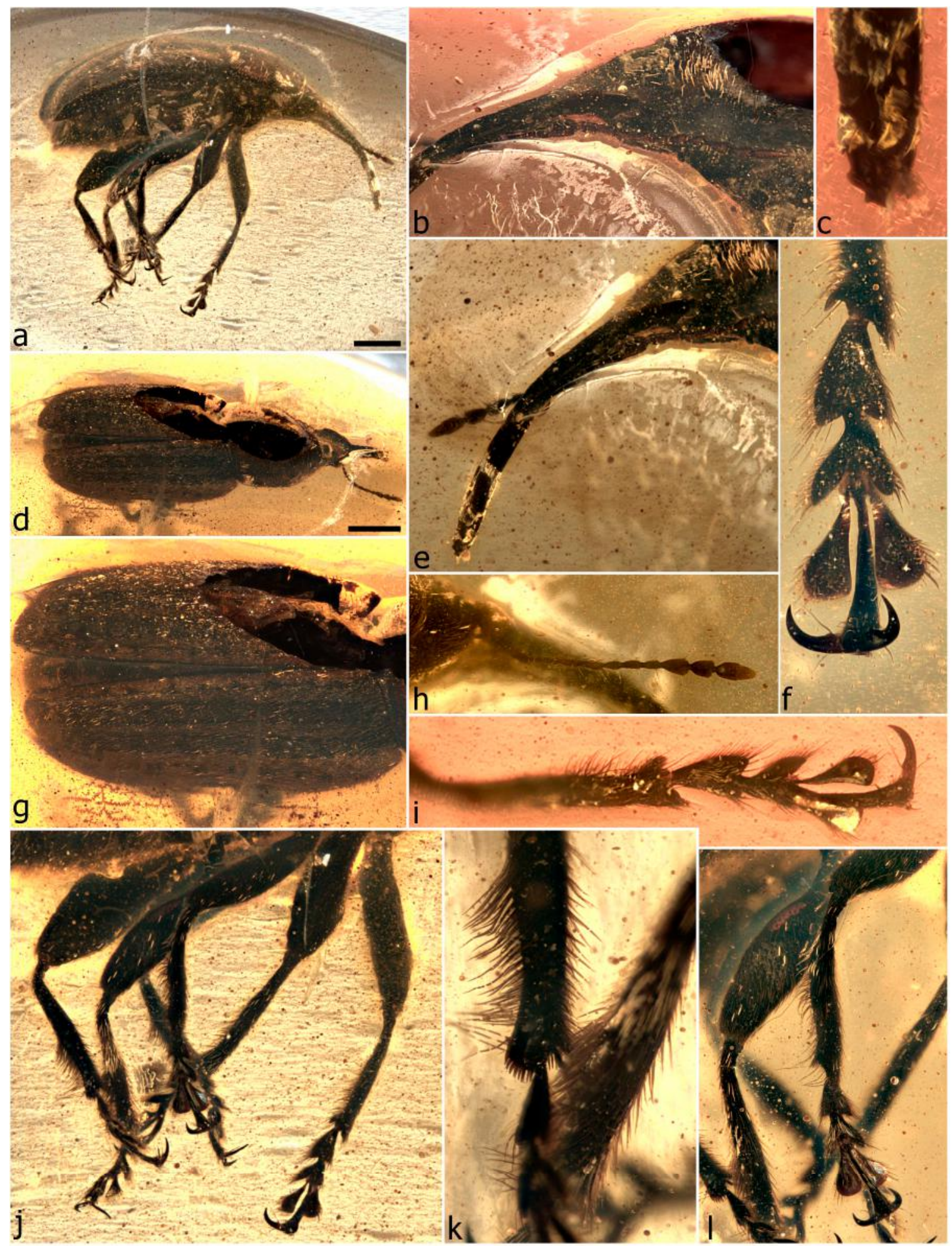

Figure 43. Opeatorhynchus comans sp. n., holotype. Habitus, lateral (a); head and prothorax, left lateral (b); mandibles, dorsal (c); habitus, dorsal (d); head and antenna, left lateral (e); protarsus, dorsal (f); elytra, dorsal (g); right antenna (h); left protibibia and -tarsus (i); legs, lateral (j); metatibia, showing dense setae in emargination of outer side (k); middle leg, dorsal (1). Scale bars: $1.0 \mathrm{~mm}(\mathrm{a}, \mathrm{d})$.

Material examined. Holotype (NIGP154217) (probably a male): extremely well preserved and well visible specimen, largely intact but with left side of pronotum, anterior half of left elytron, scutellar shield and part of left protarsal claw partly cut away during preparation, subsequently infilled with 
resin (see Section 2.2), left side partly obscured by fracture planes and large flattish murky bubble; in irregular amber block $8.2 \times 7.3 \times 4.0 \mathrm{~mm}$, with large flat and large curved face and five smaller flat faces; amber clear yellow with diffuse tiny particles; with several large fractures connected to specimen.

Derivation of name. The species is named for its hairy appearance, the name being the Latin participle comans (covered with hair).

Remarks. This species is distinctive among those of Cetionyx and Burmocorynus, also with broad tarsi and shaggy legs, in having the distal half of the outer sides of the meso- and metatibiae emarginate and lined with dense long thick setae and in also having a shorter rostrum. The specimen was submitted for CT scanning, but the resulting images and video are not too clear (Figure 42, Video S4).

Genus Echogomphus Clarke \& Oberprieler, gen. $\mathbf{n}$.

Type species: Echogomphus viridescens Clarke \& Oberprieler, sp. $\mathrm{n}$.

Description. Size. Length $5.5 \mathrm{~mm}$, width $1.22 \mathrm{~mm}$. Large, densely setose, with scattered iridescent green setae everywhere. Head elongate, subporrect, only slightly bulging ventrally, not constricted behind eyes. Eyes flattened, elongate, protruding, coarsely facetted, dorsally separated by approximately width of rostrum anteriorly but further separated posteriorly; forehead flat, without tubercles between eyes. Rostrum long, terete (apex cut off), weakly downcurved; antennal insertions lateral, inserted in about posterior third of rostrum; without scrobes behind them, in front of them laterally with a few long erect setae. Apparently a single long gular suture present (not clearly discernible). Antennae geniculate, very long and thin; scapes reaching anterior margin of eye in repose, cylindrical, apically only slightly inflated, shorter than funicles; funicles 7-segmented, segment 1 short, obconical, ca. $0.33 \times$ as long as 2,2 long, others progressively shorter towards club; clubs ill-defined, long, loosely 4-segmented, apical segment about as long as 3, acute, broadly inserted, others slightly expanding apicad. Mouthparts not visible. Thorax. Prothorax slightly proclinate, with anterior lateral margins oblique in lateral view. Pronotum slightly convex, laterally rounded, without tooth, posterior corners distinctly angulate, fitting closely onto elytra; surface finely punctate, densely setose, setae reclinate, directed caudad; notosternal sutures closed, vertical, abrupty deflected anteriad. Prosternum moderately long; procoxal cavities medially confluent, in middle of prothorax. Scutellar shield not visible. Mesocoxal cavities laterally not discernible. Metanepisterna distinct, densely setose. Mesoventrite short, anteriorly sloping. Metaventrite longer, shape not discernible. Elytra elongate, basally extended over pronotum; humeri concavely produced, posteriorly declivous, lateral margin sinuate to roundly emarginate in middle; apically individually rounded, exposing broad pygidium; surface punctostriate, without scutellary striole; interstriae broad, flat, rugose, setose, setae short, thin, reclinate, directed caudad. Legs. Procoxae rather short (not protruding), possibly slightly separated; meso- and metacoxae small, globular, separated. Trochanters short, oblique. Femora long, inflated at about middle, outside rounded, inside excavate in distal half, receiving tibiae in repose, walls of groove at apex roundly flatly extended. Tibiae substraight, compressed, distally slightly expanded, outer edge rounded, with dense long stiff setae in distal half, apex obliquely truncate; protibiae with 2 short spurs, meso- and metatibiae at outer edge emarginate in apical third with row of long setae, at inner apical angle with sharp inner spike and 1 outer spur at base of spike, mesotibial spike straight, smooth, metatibial spike flattened, curved at apex and with brush of long setae on underside. Tarsi with tarsite 1 elongate $(2.0 \times$ longer than 2), 1 and 2 excised, 3 deeply bilobed, lobes strongly pedunculate (all but 1 of 12 lobes broken off!), 5 long, apically expanded; claws divaricate, basally angulate with ventrobasal seta. Abdomen with ventrites broad, subequal in length except 4 shorter, 5 ca. $2.0 \times$ longer than 4 , broadly subtruncate at apex; broad pygidium exposed, without median groove.

Derivation of name. The name of the genus is composed of the Greek verb echo (to have) and noun gomphos (G: gomphou), a peg or nail, in reference to the stout spike at the apex of the tibiae; its gender is masculine.

Remarks. This is a seemingly isolated genus, unique in the group of Mesophyletidae with non-dentate tarsal claws in having a large exposed pygidium and further distinguishable from all other Burmese amber weevils by the combination of its size, iridescent green setae and long apical 
spike on the inner angle of the meso- and metatibiae. Whereas the smooth, straight mesotibial spike appears as if it may represent the inner, fixed and enlarged spur, the setiferous nature of the larger, curved metatibial spike suggests that it may be a secondary outgrowth of the tibial apex, equivalent to the mucro in some Curculionidae. A specimen of another, seemingly related species that we received too late for inclusion in this paper has a similar but much longer metatibial spike (ca. $0.25 \times$ as long as metatibia). Similarly modified meso- and metatibial spurs occur in Elwoodius, but the metatibial one without setae. Echogomphus also has a unique tarsal structure, with elongate, flattened, apically emarginate tarsites 1 and 2 together with the strongly pedunculate but relatively short lobes of tarsites 3 and very long tarsites 5 . It seems most closely related to Opeatorhynchus, with which it shares confluent procoxal cavities and similarly emarginate outer sides of the meso- and metatibiae lined with dense setae (a similar setation occurs in Cetionyx but the tibiae are not or only indistinctly emarginate). However, better-preserved additional specimens are required to assess its affinities in Mesophyletidae. Echogomphus contains a single known species, but a specimen of an undescribed species known to us may also belong in it as well; it lacks iridescent green setae but possesses an extraordinarily long apical spike perpendicular to the tibial axis and also with a setal brush on the ventral side, as occurs in Echogomphus viridescens.

Echogomphus viridescens Clarke \& Oberprieler, sp. n. (Figures 44 and 45)

Description. Size. Length $5.5 \mathrm{~mm}$, width $1.22 \mathrm{~mm}$. Body blackish, concolorous, tarsi slightly paler, translucent. Head subporrect, elongate, not expanded dorsally, slightly bulging ventrally; not constricted behind eyes dorsally or laterally; distance between eyes at base of rostrum approximately one rostral width, expanding in width posteriorly. Eyes bulbous, flatly elongately protuberant; coarsely facetted. Rostrum at least as long as pronotum; antennal insertions in basal third. Antennae. Scapes elongate, apically slightly oblique; funicles with segments very sparsely setose, segment 1 flask-shaped, expanding distad, 2-7 elongate, progressively shorter; clubs densely, shortly setose, segments obconical, 1 and 2 subequal, apically more than $2.0 \times$ wider than at base, 3 shorter than 2, 4 elongate, acutely pointed, much narrower than and distinctly articulating with 3 . Thorax. Pronotum densely setose, setae directed caudad; seemingly with slight change in contour anterolaterally. Prosternum and hypomeron very short, seemingly much less than half procoxal length. Elytra densely setose, whitish and brown setae interspersed with iridescent green setae; striae linear, thin; interstriae broad, flat; laterally with clear marginal groove, gradually widening anteriad to form distinct lateral carina extending to humeri; anterior marginal notch present just before humeri. Legs densely setose, increasingly so distally. Tibiae apically with coarse fringing setae; protibiae with 2 short spurs and tiny burr on outer side of apex; meso- and metatibiae apically with shortly rounded outer flanges, metatibiae with setae in outer apical emargination denser and longer than on mesotibiae, tarsal articulation surfaces concavely truncate, inside with at least 1 (meta-) or 2 (mesotibiae) thicker setae, spike unarticulated, directed diagonally to tibial axis, on mesotibiae straight but bent at apex, on metatibiae subflattened and with dense long setal brush on underside, outer spur much smaller and directed distad. Tarsi elongate, flattened but not laterally expanded; tarsite 1 ventrally with dense, long setae, on protarsi longer and broader than on meso- and metatarsi, tarsite $2 \mathrm{ca} .0 .33 \times$ as long as 1 , ventrally with dense, long setae, on protarsi slightly longer and broader than on meso- and metatarsi, more flattened, ventrally with dense pad-like setae, tarsite 3 with lobes shortly and abruptly pedunculate, slightly more than $2.0 \times$ longer than 5 , very narrow basally (threadlike peduncle) then abruptly elongately lobate, tarsite 5 subequal in length to $1+2$ (slightly less in metatarsi), curved, not flattened, with longer setae dorso-apically, setose ventrally. Abdomen. Ventrites densely setose; 1 slightly shorter than 2, 2 slightly longer than 3, 4 shorter than 3, 5 nearly $2.0 \times$ longer than 4 , apically subtruncate to broadly rounded. 

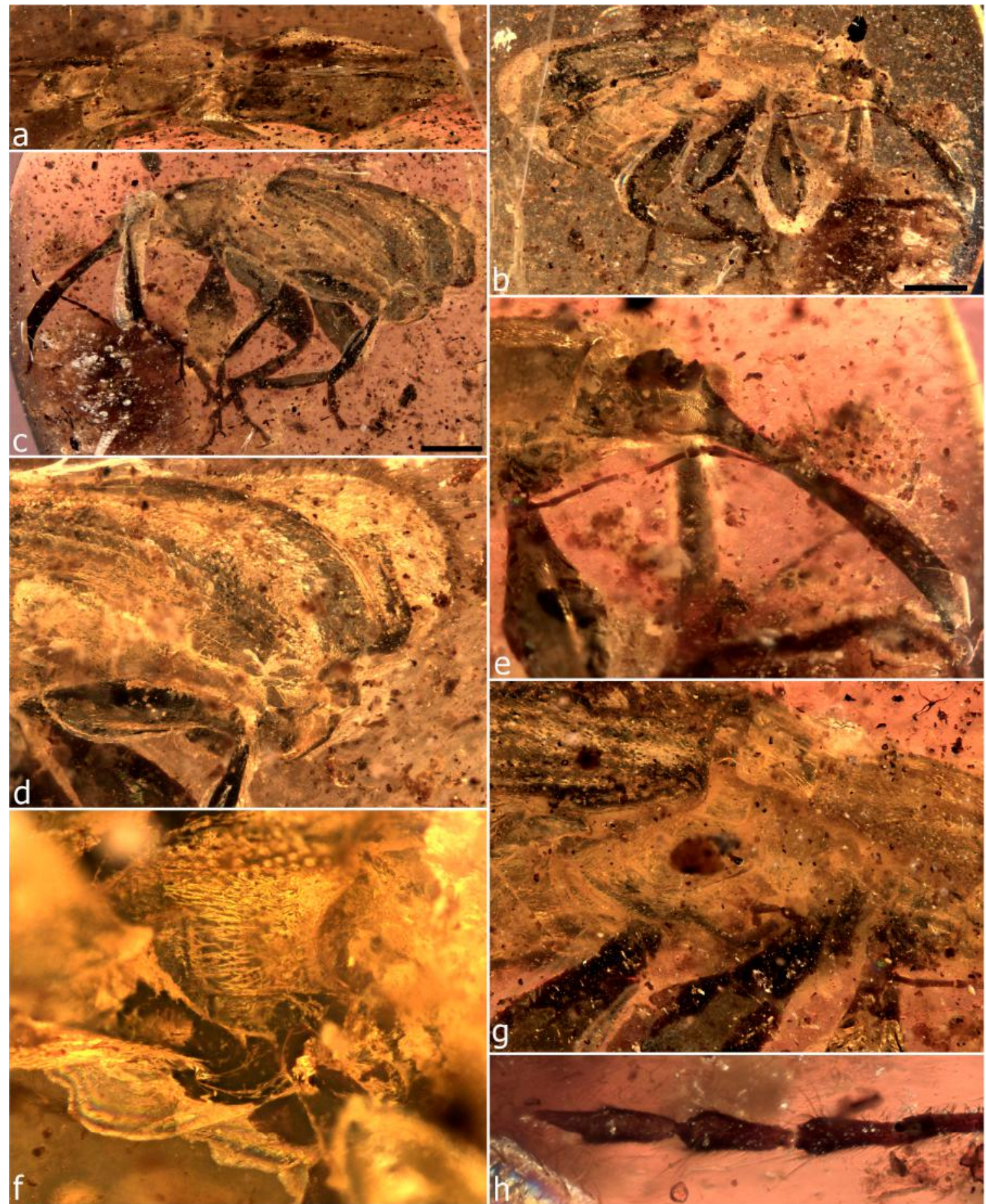

Figure 44. Echogomphus viridescens sp. n., holotype. Habitus, dorsal, showing effects of lateral distortion (a); habitus, right lateral (b); habitus, left lateral (c); apices of elytra and detail of pygidium, laterocaudad (d); head and antenna, right lateral (e); prothorax, showing notosternal suture (f); prothorax and elytral humerus, right lateral (g); antennal club (h). Scale bars: $1.0 \mathrm{~mm}(\mathrm{~b}, \mathrm{c})$. 


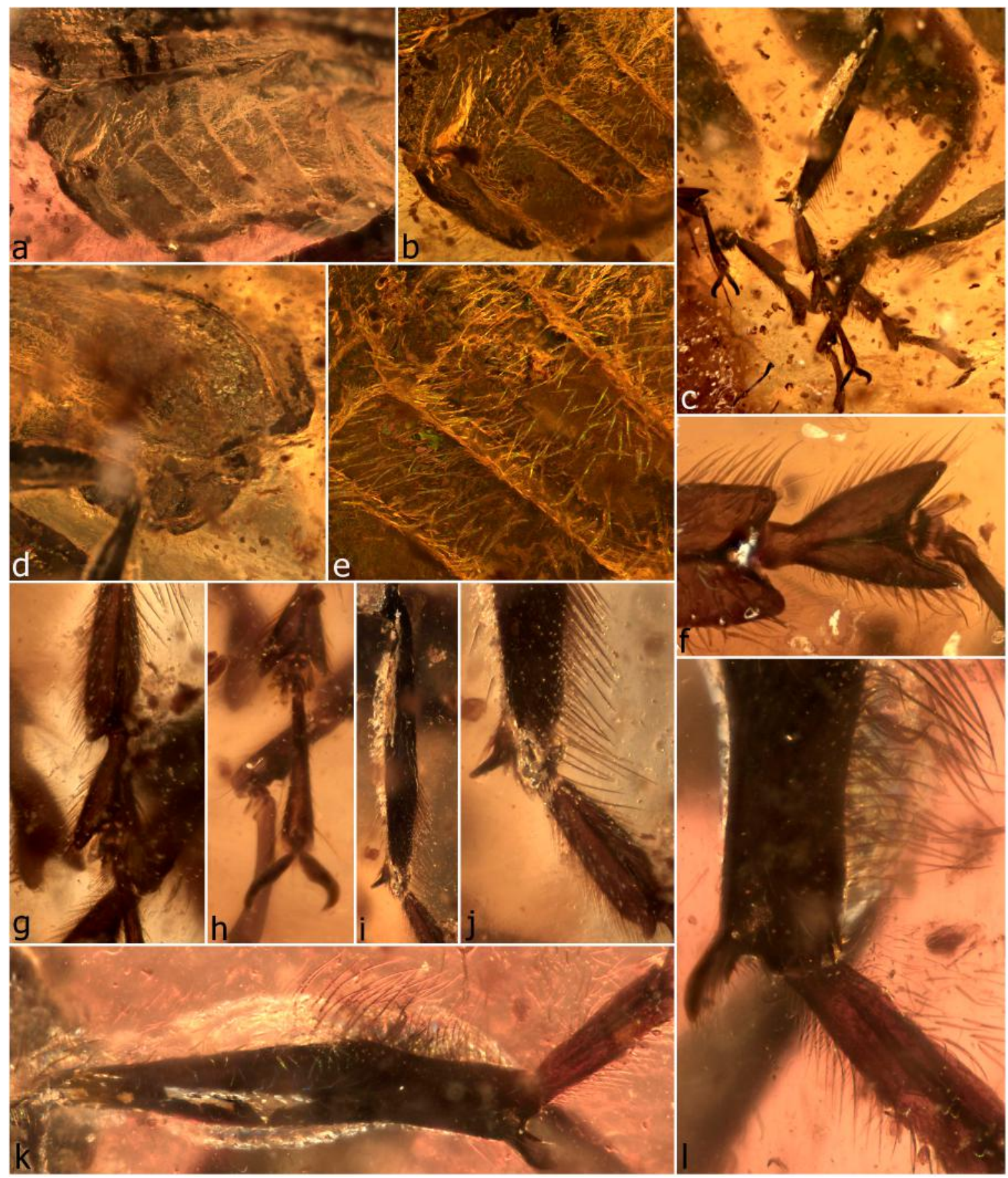

Figure 45. Echogomphus viridescens sp. n., holotype. Ventrites, ventrolateral (a); detail of ventrites, ventrolateral (b); legs (c); apex of elytra and pygidium, ventrolateral (d); detail of ventrites and iridescent setae (e); apex of tarsite 1, tarsites 2 and 3 and base of 5 , showing broken peduncle of 3 , dorsal (f); left mesotarsites 1 and 2, dorsal (g); left mesotarsal claws, dorsal (h); left mesotibia showing apical spur (i); same, apical part (j); left metatibia showing larger apical spike and smaller spur (k); detail of metatibial spike and spur (1).

Material examined. Holotype (NIGP154218): moderately well preserved but somewhat damaged and heavily distorted specimen, with body, rostrum and legs compressed and right elytron displaced, not well visible (width measurement probably not accurate), most of body covered with layer of air partly obscuring surface details and most ventral details of head and thorax invisible or not properly interpretable, right antenna severed between funicular segments 2 and 3 and 5 and 6, left antenna apparently missing except for possibly funicle segment 7 and club near block surface at left of rostrum, 
onychium of right protarsus missing and that of left metatarsus separated from tarsus, all tarsite 3 lobes missing except inner one of right mesotarsus, apical part of rostrum cut away with amber; in irregular cabochon $17.0 \times 11.9 \times 3.0 \mathrm{~mm}$, with flat top and one end obliquely cut to expose dorsum of specimen; amber clear yellow-brown with dense diffuse particles and few larger loose masses of organic material, with one large fracture behind posterior end of specimen.

Derivation of name. The species is named for its scattered iridescent green setae, which appear to be unique among the more primitive weevil families.

Remarks. This species has several unusual features of the legs, the most notable being the pair of indistinct short spurs of the protibiae contrasted with only one such spur and a conspicuous large spike on the meso- and metatibiae (on the latter broad, flat and ventrally lined with setae), and a small outer apical bur on the protibiae. The antennal clubs are also distinctively long and loosely articulated, with the long narrow fourth segment distinctly articulating with the third. The holotype was submitted for CT scanning, but the contrast between the specimen and the amber was too low to permit any meaningful visualisation of the specimen.

Genus Cyrtocis Clarke \& Oberprieler, gen. $\mathbf{n}$.

Type species: Cyrtocis gibbus Clarke \& Oberprieler, sp. n.

Description. Size. Length $2.92 \mathrm{~mm}$, width $0.93 \mathrm{~mm}$. Head elongate, subconical, dorsally slightly convex, ventrally bulging. Eyes large, elongate, strongly (possibly flatly) protruding, coarsely facetted, dorsally separated by nearly width of rostrum anteriorly but further separated posteriorly; forehead flat, without tubercles between anterior margin of eyes. Rostrum ca. $2.0 \times$ longer than pronotum, slender, subcylindrical, downcurved; antennal insertions lateral (possibly lateroventral), with scrobes behind them, in front of them laterally without long erect setae. Apparently a single long gular suture present (not clearly discernible). Antennae geniculate, long; scapes elongate, cylindrical, apically slightly inflated, about as long as funicle segments 1-5; funicles 7-segmented, segment 1 broader than others, $2-5$ subequal, elongate, apically widened, $6-7$ subequal, shorter, thinner, apically oblique; clubs large, loosely articulated, subcompressed, 4-segmented, segments apically strongly oblique, 4 flattened, acute, about as long as 3. Mouthparts. Labrum absent. Mandibles small, exodont, articulation probably horizontal. Maxillary and labial palps 3-segmented. Thorax. Prothorax proclinate, with anterior lateral margins oblique in lateral view. Pronotum slightly convex, laterally nearly straight, without tooth, posterior corners truncate, fitting closely to elytra; surface densely, coarsely punctate, tuberculate, sparsely setose, setae reclinate, directed anteromesad; notosternal sutures closed, abruptly curved anteriad. Prosternum moderately long; procoxal cavities seemingly medially confluent, in middle of prothorax. Scutellar shield densely setose. Mesocoxal cavities laterally closed by mesoand metaventrite. Metanepisterna distinct, sparsely setose. Mesoventrite short, anteriorly sloping. Metaventrite longer, posteriorly raised into transverse weals. Elytra elongate, basally concave to receive pronotum, with broadly rounded humeri, posteriorly very strongly, abruptly declivous (forming nearly right angle), with distinct hump or prominence separating disc from declivity; lateral margin weakly sinuate to roundly emarginate in middle, apically individually narrowly rounded, not exposing pygidium; sutural flanges narrow, seemingly equal; surface punctostriate, without scutellary striole, interstriae ill-defined, narrow, finely tuberculate, setose, setae long, thin, reclinate, directed caudad. Legs. Procoxae large, conical, medially contiguous; mesocoxae subglobular, prominent, narrowly separated; metacoxae flat, transversely elongate. Trochanters long, oblique. Femora long, subcylindrical, inflated in distal half, outside rounded, inside excavate in distal fifth to half, receiving tibiae in repose, walls of groove at apex flatly rounded, not extended. Tibiae straight, probably terete (heavily distorted), distally expanded, outer edge rounded, with dense long stiff setae in distal half, apex obliquely truncate, with 2 spurs. Tarsi about $0.75 \times$ as long as tibiae; moderately broad, flat; tarsite 1 apically subtruncate, 2 shorter, triangular, apically excised, 3 deeply bilobed, 5 long, apically expanded; claws divaricate, basally angulate with ventrobasal seta. Abdomen with ventrites 1 and 2 much longer than 3, 3 slightly longer than 4,5 as long as 3, apically narrowly rounded. 
Derivation of name. The name of the genus is derived from the Greek adjective kyrtos (humped) and noun kis (G: kios) (weevil or beetle); its gender is masculine.

Remarks. Cyrtocis is most similar to Electrocis but larger and with protruding eyes, broader tarsi (with broader lobes of tarsite 3) and stouter antennae with a shorter and inflated funicle segment 1 and apically oblique club segments. It also differs from the latter genus in having exodont mandibles with horizontal or oblique articulations (non-exodont and vertical in Electrocis) and different ventrites. A proper interpretation of further seemingly distinct characters will require better-preserved specimens and structures, including possibly partly elongate trochanters.

Cyrtocis gibbus Clarke \& Oberprieler, sp. n. (Figure 46)

Description. Size. Length $2.92 \mathrm{~mm}$, width $0.93 \mathrm{~mm}$. Head. Head dorsally densely, coarsely punctate, sparsely and shortly setose. Eyes elongate-oval, weakly protruding. Rostrum long, dorsally and ventrally with dense long curved setae in basal half; antennal insertions median. Antennae. Scapes slender, not apically clavate, gradually widening. Mouthparts. Mandibles small, with 2 small sharp teeth on outer side. Maxillary palps with segments progressively narrower toward apex, with terminal segment elongate, slender, much narrower than penultimate segment. Labial palps short, stout, segments subequal in width. Thorax. Pronotum elongate, laterally weakly rounded, nearly straight; pronotum rugose. Scutellar shield elongate, prominent. Elytra rugose, sparsely covered with short, blunt, recumbent reddish setae, weakly punctostriate, surface coarsely punctostriate, striae wider than interstriae, punctures large, deep, well defined; with single large hump at top of declivity; sides with marginal groove distinct, gradually widening anteriad, with anterior marginal notch; apices very narrowly rounded, almost spine-like. Hindwings seemingly fully developed. Legs. Procoxae elongate, very prominent, contiguous. Femora long, slender, subcylindrical, inside notched before apex (in lateral view), apical excavation extending to distal half on profemora, distal fifth on mesoand metafemora. Tibiae straight, with long stiff setae in distal half, apex with long, coarse fringing setae; protibiae with small, indistinct spurs; meso- and metatibiae with larger and prominent spurs, robust and slightly curved on metatibae. Tarsi long, robust, protarsi seemingly with much thicker, denser setal pads; tarsite 3 deeply, broadly bilobed. Abdomen. Tergites VII and VIII densely setose, setae long. Ventrites densely, coarsely punctate, setose, setae laterally very long.

Material examined. Holotype (NIGP154219): moderately well preserved, largely intact and well visible specimen, partly decomposed and distorted, with several artefactual cuticular protrusions usually associated with bubbles erupted from specimen (e.g., two large humps on rostrum, these possibly real in part, numerous small tubercle-like protrusions on right elytron and tarsi), legs largely compressed or depressed, missing left protarsus, left wing partly extended; in irregular 7-sided block $4.0 \times 3.5 \times 0.9 \mathrm{~mm}$; amber clear yellow with large oblique fracture above weevil pronotum, posteriorly and ventrally with numerous bubbles largely obscuring those sides, otherwise with minimal impurities and an insect wing below legs, several bubbles exposed during block preparation infilled with resin (see Section 2.2).

Derivation of name. The species is named for its conspicuously humped elytra, the Latin adjective gibbus meaning humped.

Remarks. Distinctive characteristics of this species include the elytral hump at the top of the declivity (though this appears partly exaggerated by a cuticular eruption), the strongly acute elytral apices, straight-sided pronotum and distinctive rugose sculpture. The first three features and several others may have been affected by an overall compression and distortion that is most obvious in dorsal view (the holotype seems disproportionately narrow), and additional specimens are needed to confirm them. The specimen may be a male (the apical part of what appears to be an aedeagus is visible in the abdominal apex) and is overall rather obscured by numerous close and large bubbles. Because of this it was submitted for CT scanning, but the contrast between the specimen and the amber was too low to permit any meaningful visualisation of the specimen. 


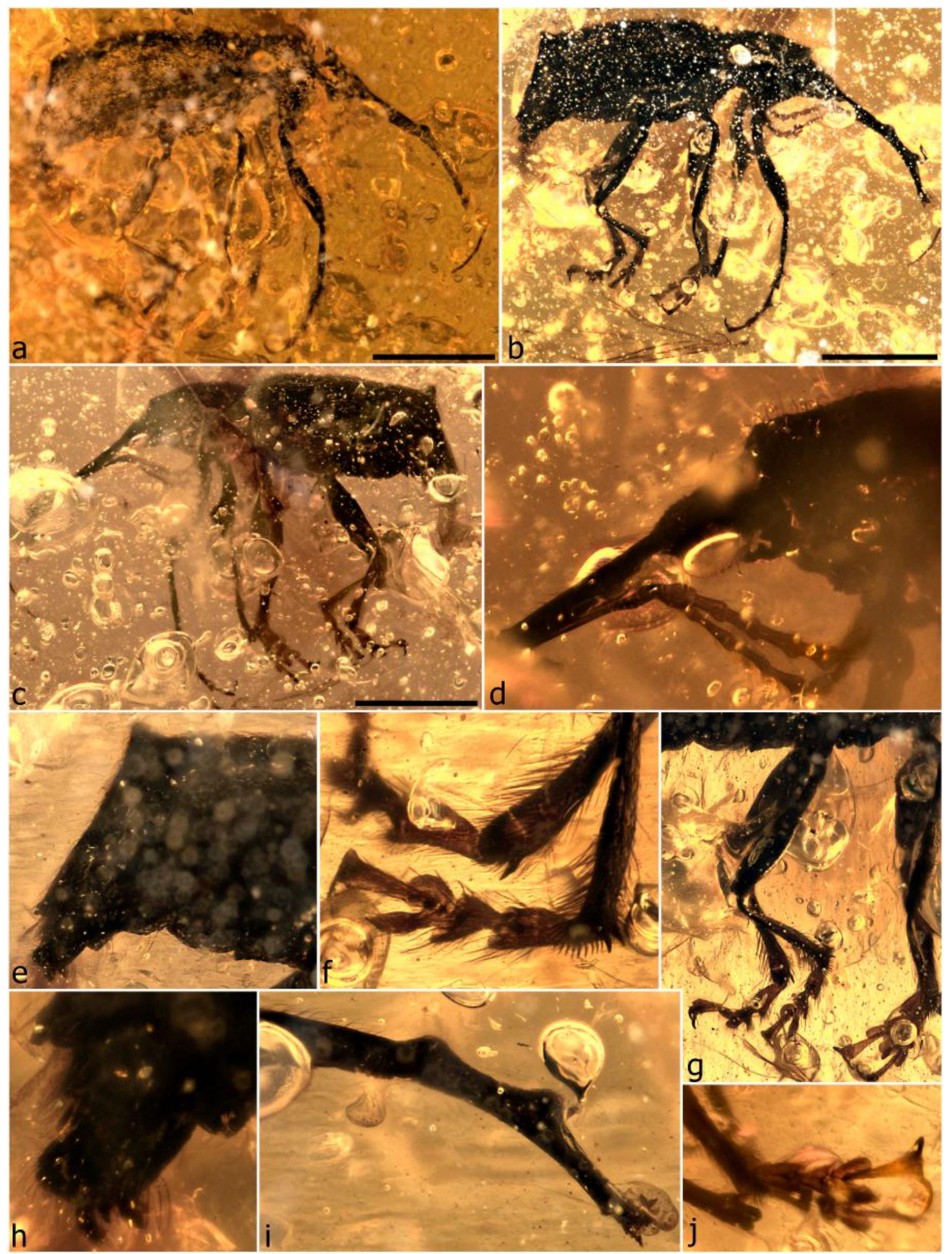

Figure 46. Cyrtocis gibbus sp. n., holotype. Habitus, right lateral (a); habitus, right lateral (different lighting) (b); habitus, left lateral (c); head, prothorax, and antenna, left lateral (d); posterior part of abdomen, right lateral (e); metatibiae and -tarsi (f); hindlegs, right (g); apex of abdomen, right lateral (h); rostrum, right lateral (i); mesotarsus, left (j). Scale bars: $1.0 \mathrm{~mm}(\mathrm{a}-\mathrm{c})$. 
Genus Ocriocis Clarke \& Oberprieler, gen. n.

Type species: Ocriocis binodosus Clarke \& Oberprieler, sp. n.

Description. Size. Length $1.97 \mathrm{~mm}$, width $0.78 \mathrm{~mm}$. Head elongate, subconical, dorsally slightly convex, ventrally bulging. Eyes large, round, strongly (possibly flatly) protruding, coarsely facetted, dorsally separated by nearly width of rostrum anteriorly but further separated posteriorly; forehead flat, without tubercles between anterior margin of eyes. Rostrum ca. $1.25 \times$ longer than pronotum, slender, subcylindrical, downcurved; antennal insertions lateral, with scrobes behind them, in front of them laterally with long erect setae. Apparently a single long gular suture present. Antennae geniculate, long; scapes elongate, cylindrical, apically slightly inflated, longer than funicle; funicles 7-segmented, very slender, segment 1 broader than others, $2-4$ subequal, elongate, apically widened, $5-7$ subequal, shorter, broader, apically truncate; clubs large, loosely articulated, subcompressed, 4-segmented, segments apically straight, segment 4 flattened, acute, slightly shorter than 3. Mouthparts. Labrum absent. Mandibles small, exodont, articulation probably oblique. Thorax. Prothorax seemingly proclinate, with anterior lateral margins oblique in lateral view. Pronotum slightly convex, laterally broadly rounded, without tooth, posterior corners truncate, fitting closely onto elytra; surface coarsely tuberculate, sparsely setose, setae reclinate, directed anteromesad; notosternal sutures closed, abruptly curved anteriad. Prosternum moderately long; procoxal cavities medially confluent, in middle of prothorax. Scutellar shield densely setose. Mesocoxal cavities closed laterally by mesoand metaventrite. Metanepisterna distinct, sparsely setose. Mesoventrite short, anteriorly sloping. Metaventrite longer, flat or slightly convex. Elytra elongate, basally extended over pronotum, with broadly rounded humeri, posteriorly strongly, abruptly declivous, probably with hump or prominence on side of disc of each elytron separating disc from declivity; lateral margin weakly sinuate to roundly emarginate in middle; apically conjointly rounded, apices broad, not exposing pygidium; sutural flanges narrow, equal; surface punctostriate, without scutellary striole, interstriae distinct, broadly convex, tuberculate, setose, setae long, thin, suberect, directed caudad. Legs. Procoxae large, conical, medially contiguous; mesocoxae subglobular, prominent, narrowly separated; metacoxae flat, transversely elongate. Trochanters short, oblique. Femora long, subcylindrical, inflated in distal half, outside rounded, profemora inside excavate in distal quarter, receiving tibiae in repose, walls of groove at apex flatly rounded, not extended, other femora not ventrally excavate apically. Tibiae substraight, flattened, distally expanded, outer edge costate (protibiae) or tuberculate (meso- and metatibiae), with dense long stiff setae in distal half, apex obliquely truncate, with 2 spurs. Tarsi almost as long as tibiae, moderately broad, flat; tarsite 1 apically subtruncate, 2 shorter, triangular, apically excised, 3 deeply bilobed, 5 long, apically expanded; claws divaricate, basally angulate with ventrobasal seta. Abdomen with ventrites 1 and 2 longer than 3, 3 slightly shorter than 4,5 nearly as long as $3+4$, apically very broadly rounded.

Derivation of name. The name of the genus is derived from the Greek nouns okris (G: okrios), (roughness) and kis (G: kios) (weevil or beetle), in reference to the granulose and generally rough surface of the weevil; its gender is masculine.

Remarks. This genus is unique in the group of genera with non-dentate tarsal claws in having a row of distinct, widely spaced oval slightly pointed carinulae on the outer edges of the meso- and metatibiae (Figure 47g) but a costate edge on the protibiae, as well as a low hump at the top of each elytral declivity and distinctive antennae, with very slender funicles but short, broad, subcompressed clubs with shortly obconical segments. In the non-serrate/crenulate cuticular projections on the tibiae it is similar to Debbia and Hukawngius, but in these genera the projections are differently shaped and in the former seemingly occurring only on the protibiae and in the latter not forming a row in dorsal view. Hukawngius also has dentate tarsal claws. Ocriocis also shares a similar tarsal structure and long rostrum with Debbia and Cyrtocis (tarsites 1 apically subtruncate, 2 distinctly excised, 3 deeply broadly bilobed). From Cyrtocis it can also be distinguished by the lateral row of long erect setae in front of the antennal insertions. 
Ocriocis binodosus Clarke \& Oberprieler, sp. n. (Figure 47)

Description. Size. Length $1.97 \mathrm{~mm}$, width $0.78 \mathrm{~mm}$. Antennae. Club segments shortly obconical, broad basally, segment 4 broadly inserted into 3. Mouthparts. Mandibles on outer side with 2 small broadly rounded teeth, on inner side with 2 large acute teeth, distal part slender, apex forming $\mathrm{T}$, with small rounded inner and outer apical tooth. Elytra. Surface tuberculate on disc, more granulose on declivity. Legs. Protibiae carinate on outer edge, meso- and metatibae with evenly widely spaced, subflat tubercles, roundly pointed at apex. Tibial spurs short, thin, indistinct on protibiae. Tarsi with tarsites 1 longer than 2, subequal in width, 3 broadly lobate. Abdomen. Tergite VII (or VIII?) broadly convex, posteriorly densely setose, setae long, subequal in length to apical setae of ventrite 5 .

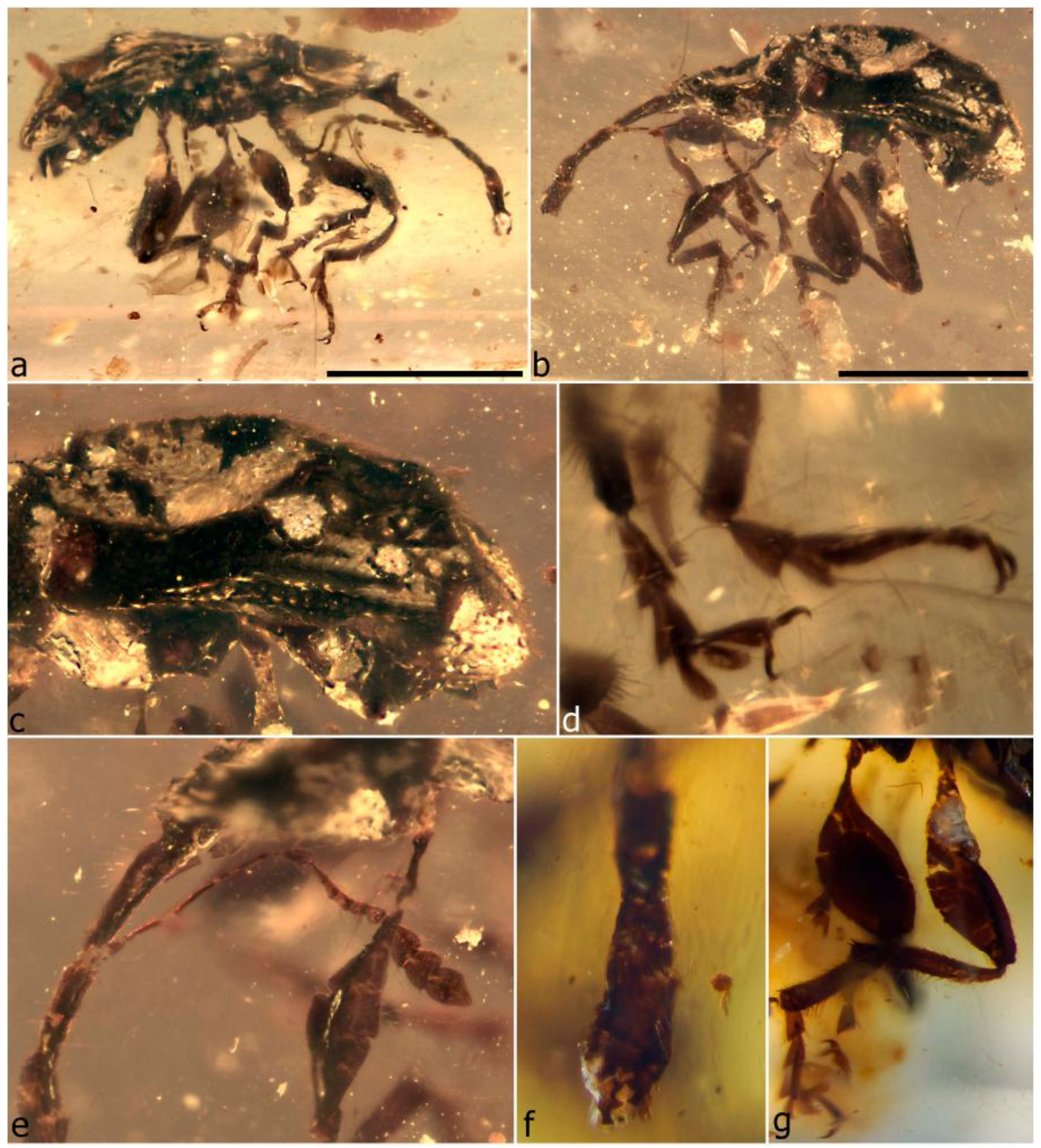

Figure 47. Ocriocis binodosus. Habitus, right lateral (a); habitus, left lateral (b); elytra, left lateral (c); protarsi (d); rostrum and left antenna, left lateral (e); apex of rostrum and mandibles, dorsal (f); middle and hindlegs, showing spurs and carinulae $(\mathrm{g})$. Scale bars: $1.0 \mathrm{~mm}(\mathrm{a}, \mathrm{b})$.

Material examined. Holotype (NIGP154220): poorly preserved, heavily distorted (crumpled) and somewhat decomposed specimen, with head retracted into prothorax, rostrum and antennae 
fragmented, right middle leg and hindlegs with tarsites 3-5 separated (some missing), right wing exposed, fragmented, surface details largely unobstructed except for fragmented coating of whitish debris; near centre of cuboid, $3.2 \times 2.1 \times 1.8 \mathrm{~mm}$; amber clear yellow, with gritty particles not obscuring specimen.

Derivation of name. The species is named after the pair of humps on the top of its elytral declivity, the name being a Latin adjective.

Remarks. The poorly preserved holotype nevertheless preserves sufficient structural details to reveal the specimen as being generically distinct from all others in our sample. Additional specimens assignable to this genus should also be identifiable to species, as details of the elytra, ventrites, legs, antennae and mandibles of $O$. binodosus are variably well preserved.

Genus Electrocis Clarke \& Oberprieler, gen. n.

Type species: Electrocis dentitibialis Clarke \& Oberprieler, sp. n.

Description. Size. Length $2.16 \mathrm{~mm}$, width $0.91 \mathrm{~mm}$. Head long, porrect, broadening posteriad, not constricted behind eyes. Eyes elongate, subflattened (not strongly protruding), coarsely facetted, dorsally separated by twice basal width of rostrum anteriorly but further separated posteriorly; forehead flat, without pair of tubercles between anterior margin of eyes. Rostrum ca. $1.5 \times$ longer than pronotum, slender, subcylindrical, weakly curved; antennal insertions lateral or possibly lateroventral, with scrobes behind them, in front of them laterally without any erect setae. Gular suture present, apparently long. Antennae geniculate, long; scapes elongate, cylindrical, apically clavate, longer than funicles; funicles 7-segmented, segments 1-3 elongate, others shorter, obconical; clubs short, loosely articulated, 4 -segmented, segment 4 acute, longer than 3. Mouthparts. Labrum absent. Mandibles small, vertical, slightly scoop-like, non-exodont but with 2 upturned apical teeth, articulation plane vertical. Thorax. Prothorax not proclinate, with anterior lateral margins vertical in lateral view, narrow, elongate, coarsely punctate. Pronotum strongly convex, laterally rounded, without tooth, posterior corners obsolete, fitting closely onto elytra; sparsely setose, setae erect, directed anteromesad; notosternal sutures closed, vertical above coxal cavities. Prosternum moderately long; procoxal cavities medially confluent, in about middle of prothorax. Scutellar shield densely setose. Mesocoxal cavities closed. Metanepisterna distinct, sparsely setose. Mesoventrite short, anteriorly sloping. Metaventrite longer, raised into subglobular weals. Elytra elongate, weakly extended over pronotum, with broadly rounded humeri, posteriorly steeply declivous, lateral margin slightly sinuate to roundly emarginate in middle, apically individually rounded, not exposing pygidium; sutural flanges not visible; surface coarsely punctostriate, punctures large, open, without scutellary striole, interstriae convex, finely tuberculate, very sparsely setose, setae short, thin, reclinate, directed caudad, interstriae without dense patches of coloured setae. Legs. Procoxae, prominent, medially contiguous at least at base; mesocoxae subglobular, narrowly separated; metacoxae flat, shortly transversely elongate. Trochanters short, oblique. Femora long, slender, subcylindrical, inflated in distal half, dorsally rounded, ventrally excavate in distal quarter, receiving tibiae in repose, walls of groove at apex flatly rounded. Tibiae substraight, compressed, distally expanded, outer edge costate, very sparsely setose, inner edge dentate; apex obliquely truncate, with dentate mucro at inner apex, with 2 spurs. Tarsi nearly as long as tibiae, slender; tarsites 1-2 subcylindrical, apically subtruncate, 2 nearly half length of 1, 3 deeply bilobed, lobes short, digitate, 5 elongate, length subequal to 1-3; claws robust, divergent, very slightly basally angulate, with ventrobasal seta. Abdomen with ventrites 1 and 2 very elongate, fused, subflatly aligned, with suture less distinct than others, subequal in length, each longer than $3+4,3$ and 4 subequal, each less than half of 1 or 2 .

Derivation of name. The name of the genus is derived from the Greek nouns elektron (G: elektrou) (amber) and kis (G: kios) (weevil or beetle); its gender is masculine.

Remarks. Seemingly an isolated genus, Electrocis is distinguishable from all other genera with non-dentate tarsal claws by its combination of non-exodont, vertically articulating mandibles, ventrally dentate and mucronate tibiae (with modified translucent setae in ventral preapical emargination), the elongate, strongly porrect head with vertical (not proclinate) anterior prothoracic margin and 
elongate prosternum and the slender tarsi with narrow digitate lobes of tarsites 3 (only tarsus of left hindleg preserved). These characters also distinguish it from the other genera with very long and subflatly aligned ventrites 1 and 2 (Burmorhinus and Rhadinomycter).

Electrocis dentitibialis Clarke \& Oberprieler, sp. n. (Figure 48)

Description. Size. Length $2.16 \mathrm{~mm}$, width $0.91 \mathrm{~mm}$. Body and legs black. Head. Dorsal outline of head in lateral view nearly continuous with rostrum (without distinct sinus); distance between eyes increasing to ca. 3.5 times rostral width at posterior margin of eyes; ventrally moderately bulging. Eyes lateral, longer than wide. Rostrum evenly weakly curved; antennal insertions median or slightly antemedian; scrobes reaching eye. Antennae. Scapes reaching just below front margin of eye, apically oblique; funicles with segment 1 ca. $1.5 \times$ longer than 2 , slightly broader, $2-5$ slightly expanding distally, 4 and 5 more abruptly so, 2 and 3 subequal in length, 4 ca. half as long as 3, 5-7 subequal, slightly shorter than 4; clubs with segments 1 and 2 subequal, obconical, 1 subconvex apically, 2 flat apically, 3 shorter than 2, slightly narrower, 4 acute, broadly inserted into 3 , about $1.5 \times$ longer than 3 . Mouthparts. Mandibles with 2 apicovertically orientated cusps. Thorax. Pronotum narrower than elytra, widest just before middle, gradually narrowing anteriad and posteriad; coarsely punctate. Prosternum elongate, about half as long as procoxae, anterior margin straight, prosternal process narrowly pointed; hypomeron about $1.25 \times$ longer than prosternum. Setae on scutellar shield pale or whitish. Metaventrite narrowly concave between weals. Elytra seemingly fused along suture and to thorax and abdomen; bases obtusely angulate, weakly sinuate; humeri narrowly rounded, with subserrate edges ( 3 teeth visible on left, 2 on right), margins indistinct from sides of thorax and ventrites 1 and 2, without marginal groove, seemingly without anterior marginal notch. Legs. Procoxae subconical; mesocoxae narrowly separated, moderately projecting, subglobular; metacoxae broadly separated. Femora slender, widening gradually distad, preapically swollen, abruptly constricted before apex, sparsely covered in whitish setae. Tibiae subequal in length, subequal in width, widest at ca. middle, gradually narrowed towards base and apex, on inner edges with ca. 8 denticles, in weak emargination distal third with ca. 1-4 coarse modified setae; apical edges with coarse fringing setae lining edges of weakly developed inner and outer flanges, on meso- and metatibiae fringing setae extending partly along outer apical edge of tibia. Tarsi (metatarsus) elongate, nearly as long as tibia; tarsite 1 ca. $2.0 \times$ longer than 2, lobes of 3 distinctly concave along inner margins, broadly connected basally. Abdomen. Ventrites 3-5 at higher level than 1-2, somewhat recessed into elytra (perhaps in part depression artefact); 3 and 4 subequal in length; 5 longer than $3+4$, apically rounded; sutures between 2 and 5 distinct, deeply grooved.

Material examined. Holotype (NIGP154221): very well preserved, largely undistorted specimen but with surface details partly obscured by surface debris and tiny bubbles, antennae intact but anterior, middle and right metatarsi missing tarsites 3-5 (only left metatarsus intact), left side of rostral apex (including left mandible) and parts of tarsi of anterior and middle legs cut away with amber during block preparation, other tarsites apparently severed prior to fossilisation; in irregular wedge with two large curved faces and three smaller edge faces, $3.4 \times 2.4 \times 1.0 \mathrm{~mm}$; amber imperfectly clear yellow-brown with greenish hue (under scope light), with dense granular impurities mainly below specimen, with small oblique fracture partly obscuring left ventral side.

Derivation of name. The name of the species is an adjective derived from the Latin nouns dens (G: dentis) (tooth) and tibia (G: tibiae) (shin).

Remarks. This species is distinctive in its black, heavily punctate integument. It is one of only a few probably flightless species of Burmese amber weevils, characterised by minimally tightly closed elytra but seemingly fused along the suture and to the thorax and ventrites 1 and 2 . In several respects this species resembles those of the next group of genera, especially Burmorhinus georgei, which also has two spurs and a mucro, and all these species share subcylindrical, apically expanded then constricted femora with retractable tibiae and slender tarsi, especially the lobes of tarsites 3 , and very long, flatly aligned ventrites 1 and 2 followed by very short ventrites $3-5$. 


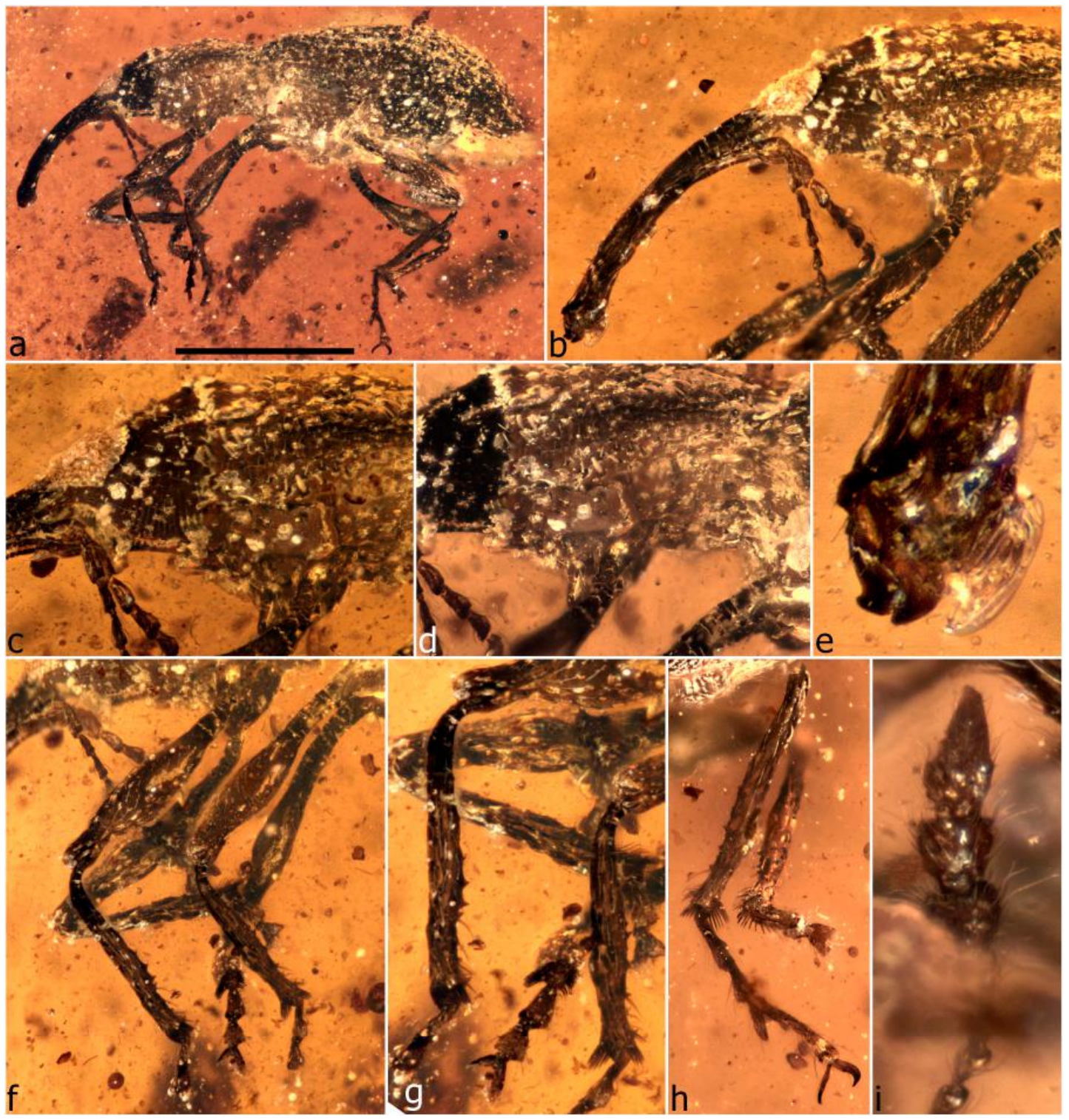

Figure 48. Electrocis dentitibialis sp. n., holotype. Habitus, left lateral (a); head and prothorax, left lateral (b); same, detail (c-d); apex of rostrum, left lateral, showing inner face of right mandible with two blunt apical cusps (left mandible cut away) (e); fore and middle legs (f); pro- and mesotibiae (g); hindlegs, showing complete left metatarsus (h); antennal club (i). Scale bars: 0.5 mm (a).

Genus Debbia Clarke \& Oberprieler, gen. $\mathbf{n}$.

Type species: Debbia gracilirostris Clarke \& Oberprieler, sp. $\mathrm{n}$.

Description. Size. Length $2.58 \mathrm{~mm}$, width $1.13 \mathrm{~mm}$. Head short, subspherical, slightly flattened. Eyes small, conically protuberant, forward-facing, coarsely facetted, dorsally separated by slightly more than width of rostrum anteriorly but further separated posteriorly; forehead flatly convex, without tubercles between eyes. Rostrum about $1.75 \times$ longer than pronotum, very thin, subcylindrical, distinctly curved; antennal insertions lateral, median, with scrobes behind them, in front of them laterally with a few long erect setae. Single gular suture present. Antennae geniculate, long; scapes elongate, slender, cylindrical, apically slightly inflated, about as long as funicle, not reaching eye; funicles thin, 7-segmented, segment 1 about as long as 2, wider, others progressively shorter towards club; clubs thin, large, loosely articulated, 4-segmented, segment 4 about as long as 3, acute. Mouthparts. Labrum absent. Mandibles small, flat, exodont, articulation oblique. Thorax. Prothorax 
slightly proclinate, with anterior lateral margins oblique in lateral view. Pronotum convex, laterally rounded, without tooth, posterior corners rounded, fitting closely onto elytra; surface punctate, densely setose, setae reclinate, directed anteromesad; notosternal sutures closed, abruptly curved anteriad. Prosternum moderately long; procoxal cavities medially confluent, in middle of prothorax. Scutellar shield prominent. Mesocoxal cavities laterally closed. Metanepisterna distinct, densely setose. Mesoventrite short, anteriorly sloping. Metaventrite longer, raised into strong transverse weals. Elytra elongate, basally obtusely straight, with weakly rounded humeri, posteriorly declivous, lateral margin weakly sinuate in middle; apically individually rounded, not exposing pygidium; surface weakly punctostriate, without scutellary striole, interstriae narrow, setose, setae long, thin, reclinate, directed caudad. Legs. Procoxae large and conical, prominent, medially contiguous; mesocoxae subglobular, narrowly separated; metacoxae flat, transversely elongate. Trochanters short, oblique. Femora long, strongly inflated in distal half, outside with thin black carina along most of length. Tibiae long, slender, subterete, outer edge rounded, on protibia with sparse subevenly spaced tubercles, apex obliquely truncate, with 2 spurs (visible on left pro- and mesotibia). Tarsi about $0.75 \times$ as long as tibiae; tarsite 1 subtriangulate, 2 shorter, apically excised, 3 deeply bilobed, lobes pedunculate, 5 very long and slender, apically expanded; claws divaricate, basally angulate with ventrobasal seta. Abdomen with ventrites 1 and 2 subequal, 3 and 4 slightly shorter, 5 subtriangular; ovipositor with long slender gonocoxites, each with a small elongate apical stylus.

Derivation of name. The genus is cordially named for our colleague Debbie Jennings, in recognition of all her help with and dedication to the study of these weevil fossils, in particular her superb photographs of them; the name of the genus is feminine.

Remarks. Among the genera with basally angulate claws, Debbia is distinctive in having conically protruding, widely separated eyes, long slender tibiae and tarsi, the latter with excised second tarsites, and small rounded tubercles along the outer edge of the protibiae. It is also one of the few genera in this group characterised by the type of exodont mandibles that is typical of the majority of Mesophyletinae, being flattened with large inner and outer teeth and horizontal in repose but opening into a vertical position via oblique articulation sockets. This mandible type seems to be shared with Cyrtocis and Ocriocis, which also have similar tarsi, but better-preserved specimens of these genera are needed to further understand their possible affinities.

Debbia gracilirostris Clarke \& Oberprieler, sp. n. (Figures 49 and 50, Video S5)

Description. Size. Length $2.58 \mathrm{~mm}$, width $1.13 \mathrm{~mm}$. Head sparsely, shallowly punctosetose; punctures minute, sparse, denser between eyes. Rostrum slightly widened before ape; dorsally with pair of fine grooves extending between base and apex; with elongately strigulose sculpture; scrobes extending to front of eyes. Antennae. Scapes apically subtruncate (slightly oblique); funicles with segment 1 subfusiform, wider than 2, 2-4 elongate, slightly expanded apically, with sparse long setae, 5-7 thinner, progressively shorter, 7 subglobular; clubs with segments 1 and 2 distinctly obconical, densely setose, with numerous longer setae, 2 ca. $0.67 \times$ as long as 1, 3 slightly shorter, 4 slightly longer than 3, broadly inserted into 3. Mouthparts. Mandibles individually subsymmetrical; with at least 3 teeth on inner and outer edges, 2 larger blunt teeth basally (also seemingly third large tooth at base of inner edge), apical part of mandible slender, with smaller blunt inner and outer apical teeth forming weak T. Maxillary palps projecting. Labial palps apically projected (2 segments visible); apical segment narrower and subequal in length to penultimate one, with minute tufted apical setae. Thorax. Pronotum densely setose, setae directed anteromesad, punctate, punctures coarser than on head; narrowed but not constricted anteriorly or posteriorly. Elytra densely setose; striae ca. $2.0 \times$ wider than interstriae, coarsely punctate, punctures large; laterally with distinct marginal groove, slightly increasing in width anteriad, with distinct anterior marginal notch. Legs. Femora sparsely setose, setae long, whitish; profemora on inside slightly notched before apex (in lateral view). Tibiae slender, slightly bent inwards near apex, densely setose with longer setae in distal half, setae whitish; apically with tarsal articulation surfaces concavely oblique, with short, indistinct flanges lined with long coarse loose fringing setae, outer edge apically with several elongate slender setae, spurs short, 
narrow, indistinct; protibiae with outer edge sparsely tuberculate for most of length, tubercles minute but distinct, subconical, apically rounded, widely and subevenly spaced; meso- and metatibiae shorter, probably without tubercles along outer edge, mesotibiae apically on outside with short row of slightly less coarse setae continuous with outer apical fringing setae. Tarsi densely, shortly setose dorsally and ventrally, with relatively short apicolateral setae; tarsite 3 lobes about half as long as 5, 5 very long, slightly shorter than 1-3, very slender basally. Abdomen. Ventrites 1 and 2 subequal in length, 2-4 progressively slightly shorter, 5 longer than 4 .

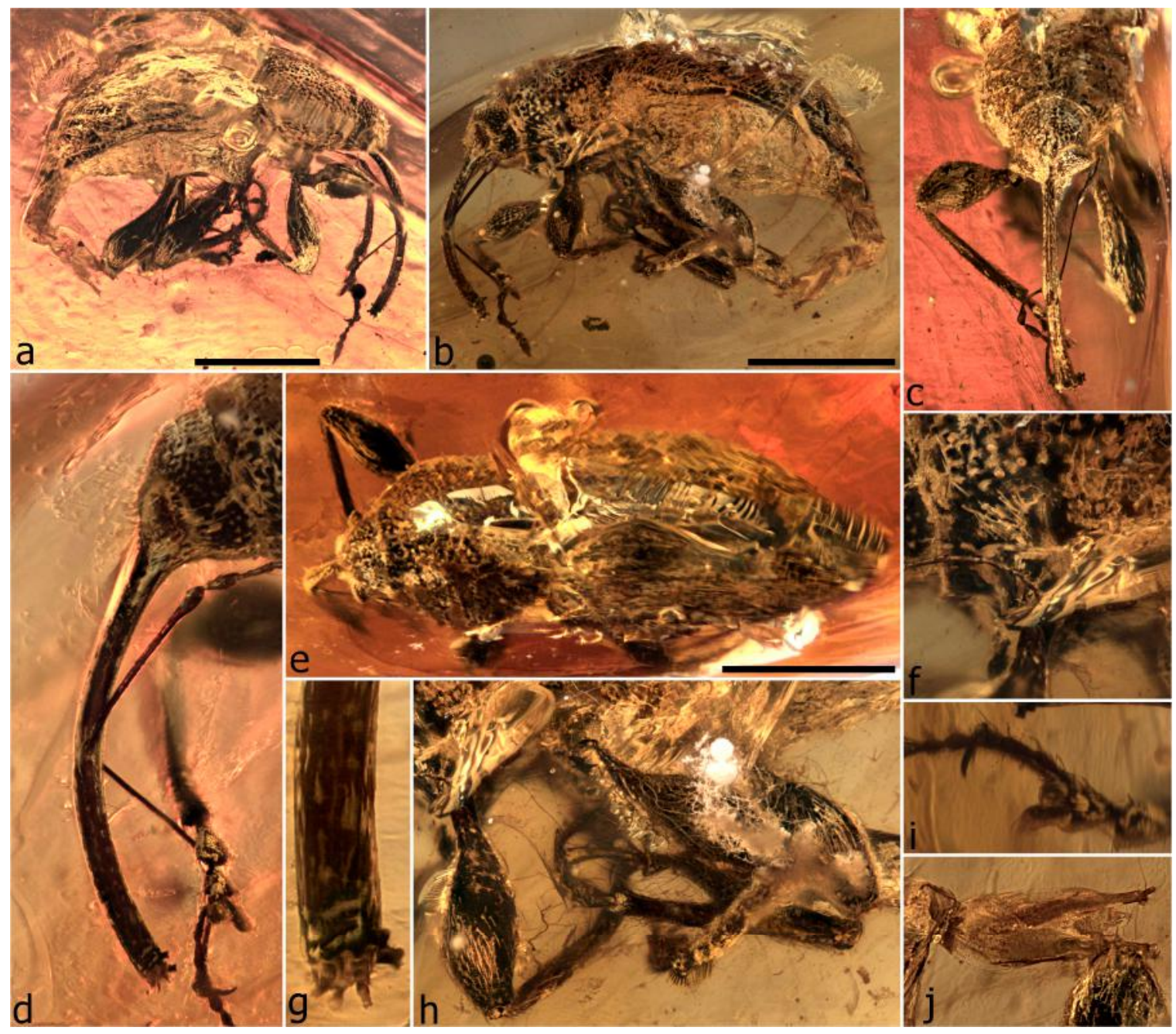

Figure 49. Debbia gracilirostris sp. n., holotype. Habitus, right lateral (a); habitus, left lateral (b); head, frontal (c); head and left protarsus, left lateral (d); habitus, dorsal (e); prothorax, showing notosternal suture, left lateral (f); apex of rostrum showing mandibles and maxillary palps, left lateral (g); legs, left lateral (h); right protarsus (i); ovipositor (j). Scale bars: $1.0 \mathrm{~mm}(\mathrm{a}, \mathrm{b}, \mathrm{e})$.

Material examined. Holotype (NIGP154222), female: well preserved, intact but poorly visible specimen, much of body surface obscured by whitish coating (seemingly mixed fungal hyphae, debris and air), rostrum and appendages well visible, with ovipositor fully extruded; in cuboid, $5.5 \times 5.1$ $\times 1.1 \mathrm{~mm}$, with one large face rounded to edge; amber clear yellow with several curved flow bands parallel to curved block face, with several small fractures in vicinity of and partly obscuring surface of specimen.

Derivation of name. The species is named for its long and slender rostrum, the name being a Latin adjective. 


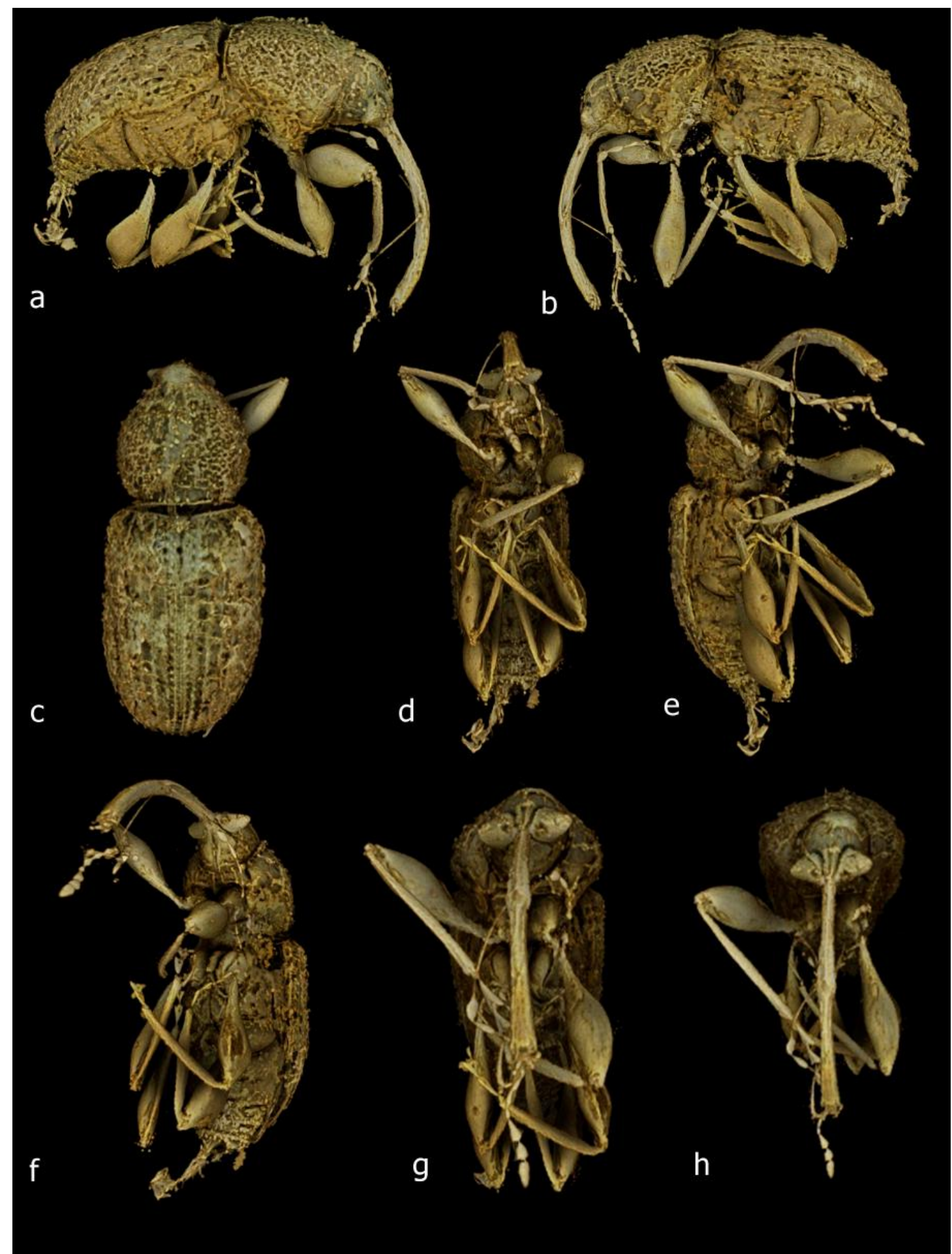

Figure 50. Debbia gracilirostris sp. n., holotype. Habitus images extracted from a micro-CT scanning reconstruction (see also Video S5). Right lateral (a); left lateral (b); dorsal (c); ventral (d); ventrolateral right (e); ventrolateral left (f); frontoventral (g); frontal (h).

Remarks. This species is characterised by the long, slender, curved, cylindrical rostrum with distinctive, symmetrically guitar-shaped mandibles. The general symmetry of the mandibles, with similarly sized teeth on both edges, is unusual in Mesophyletidae; normally either the inner or the outer teeth are significantly larger than those on the opposite edge. This difference may reflect a differentiation in specific details of mandible function among such taxa. The mandibles of Debbia are 
also extraordinary in having a very slender apical part in front of the teeth; this again may reflect a functional aspect of the mandible form and is comparable with the apically similarly slender mandibles of several other unrelated species (e.g., Bowangius cyclops) but contrasted with those mandibles with a robust anvil- or T-shaped apex, in which the apical part is often thick and the teeth can sometimes be as large as or larger than the basal ones. We are aware of one other undescribed species likely related to D. gracilirostris, of general similarity and with similarly guitar-shaped mandibles but a shorter rostrum and without the conical eyes that are so distinctive of $D$. gracilirostris.

The holotype was submitted for CT scanning, with astonishing results (Figure 50, Video S5) that demonstrate the inherent variability in the success of this imaging technique among samples. Much of the surface of the specimen (especially dorsally) is obscured by seemingly dense hyphal growths and other debris, and many ventral structures are also nearly entirely obscured from view under a light microscope. These surfaces were rendered very clear with CT scanning, the confluent procoxal cavities, narrowly separated mesocoxal cavities and distinctly punctostriate elytra being well visible.

Genus Burmorhinus Legalov, 2018

Burmorhinus Legalov, 2018: 13 [56] (type species, by original designation: Burmorhinus georgei Legalov, 2018)

Redescription. Size. Length $2.45-2.94 \mathrm{~mm}$, width $1.0-1.05 \mathrm{~mm}$. Head short, subglobulartransverse, strongly convex dorsally, not constricted behind eyes. Eyes large, weakly protruding, coarsely facetted, dorsally separated by basal width of rostrum anteriorly, similarly or further separated posteriorly; forehead concave or flat, without paired tubercles between anterior margin of eyes. Rostrum about as long as pronotum, stout, compressed behind antennal insertions, dorsoventrally flattened in front of them, strongly downcurved; antennal insertions lateral, in apical quarter (possibly a male trait), with scrobes behind them extending obliquely ventrad to below eye, in front of them laterally with a few long erect setae. Single long gular suture indicated. Antennae geniculate, long; scapes elongate, cylindrical, apically only slightly inflated, about as long as funicle segments 1-4, reaching front margin of eye; funicles 7-segmented, segments 1-4 progressively shorter towards club, 5-7 subglobular; clubs long, loosely 3-segmented but with weakly set-off segment 4, segments 1 and 2 obconical. Mouthparts. Labrum absent. Mandibles small to large, flat, horizontal, non-exodont, with single large inner tooth, articulation plane horizontal. Thorax. Prothorax slightly proclinate, with anterior lateral margins sinuate in lateral view, drawn out into distinct or weak ocular lobe. Pronotum slightly convex, laterally rounded, without tooth, posterior corners rounded and obsolete or angulate and slightly extended, fitting closely onto elytra; surface coarsely punctorugose, sparsely setose, setae recurved, multidirectional or directed anteromesad, not forming coloured patches; notosternal sutures closed, obliquely vertical. Prosternum with precoxal channel; procoxal cavities medially confluent, closer to posterior margin of hypomeron. Scutellar shield densely setose. Mesocoxal cavities closed laterally. Mesoventrite short, anteriorly sloping. Metaventrite about 3 times longer, flatly concave. Metanepisterna distinct, possibly fused to metaventrite, setose. Elytra elongate, narrow, basally extended over pronotum, with narrowly rounded humeri, posteriorly declivous, lateral margin nearly straight or weakly sinuate, apically conjointly rounded, not exposing pygidium; sutural flanges narrow, subequal; surface punctostriate, without scutellary striole, interstriae convex, subcostate, setose, setae long, thin, recurved, directed caudad, interstriae without dense patches of coloured setae. Legs. Procoxae large and subconical to subglobular, prominent, medially contiguous; mesocoxae globular, narrowly separated; metacoxae flat, transversely elongate, widely separated by broadly rounded process of ventrite 1 . Trochanters short, oblique. Femora long, subcylindrical, slightly inflated in middle, outside rounded, inside excavate in distal quarter to half, receiving tibiae in repose, walls of groove at apex flatly, roundly extended, shearing against basal part of tibia. Tibiae straight, subcylindirical to subcompressed, distally expanded, outer edge rounded to subcostate, densely setose, with longer stiff setae in distal half, apex obliquely truncate to subconcave, with 2 spurs and with or without a small mucro. Tarsi almost as long as or slightly longer than tibiae, narrow; tarsite 1 apically subtruncate to slightly rounded or apicolaterally roundly lobate, 2 shorter, apically truncate to 
slightly rounded or excised, 3 deeply but shortly bilobed, lobes narrow, 5 very long, slender, apically expanded; claws divergent or divergent-divaricate, basally angulate with ventrobasal seta. Abdomen with ventrites 1 and 2 elongate, fused (with suture less distinct than others), subflatly aligned, each about as long as $3+4,3-4$ subequal, 5 longer, apically broadly rounded.

Remarks. This genus was described in the family Curculionidae based on its geniculate antennae, uncinate tibiae, elongate ventrite 1 fused with 2 and the ventrites lying in one plane [56], but none of these characters are exclusive to this family. Three imaginal characters are generally considered to be synapomorphies of Curculionidae (e.g., [57]), and the states of two of them can be readily assessed in the holotypes of B. georgei and B. setosus. Although their antennae are clearly geniculate, the geniculation is of the 'open' type as in Mesophyletidae and Nanophyinae, not the 'closed' one of Curculionidae, and although the socket of the scapes is more narrowly encircling the base of the pedicel than it is in other Mesophyletidae, it is distinctly obliquely apically positioned, not ventrally, and the socket is clearly visible in apical view. Also contradicting a placement in Curculionidae are the antennal clubs of Burmorhinus, which are loosely 3(4)-segmented in B. setosus and also so indicated in B. georgei, the holotype preserving only segment 1 of one club but this with a distinctly setose apical surface and narrow articulation stem, sufficient evidence that its clubs are loose as well, not tightly compact as in Curculionidae. The third synapomorphy of Curculionidae, a pair of radial sclerites in the hindwing, cannot be assessed in Burmorhinus as the hindwings are not visible. The original placement of Burmorhinus in the curculionid subfamily Erirhininae [56] is also untenable, as two of the four characters on which it was based (scrobes directed towards the eye, tibiae with two apical spurs) occur widely in Curculionidae and also in Mesophyletidae and the other two (apex of the rostrum "with setae", tibial uncus "displaced" onto the inner apical angle) are misinterpretations. The rostrum of neither B. georgei nor B. setosus has an apicolateral setiferous groove as is characteristic of erirhinines [39], only a line of sparse setae as occurs in this position in many Mesophyletidae, and their tibiae do not have an uncus (only a small mucro in B. georgei). The purported affiliation of Burmorhinus with the erirhinine tribe Arthrostenini is also invalid, as its procoxae are in fact contiguous and it lacks scale-like setae, as occur in many genera related to Arthrostenus Schoenherr. Its strongly carinate and grooved, apically flattened rostrum and its long, flattened mandibles also do not accord with Arthrostenini.

Burmorhinus unequivocally agrees with Mesophyletidae in nearly all its characters except for the weak prosternal channel, but it shares the latter with Rhadinomycter (and also with Palaeocryptorhynchus if this belongs in the same family). Burmorhinus and Rhadinomycter are also unique in Mesophyletidae in having flattened, horizontal, non-exodont and horizontally articulating mandibles. Burmorhinus differs from Rhadinomycter in having two tibial spurs (one in Rhadinomycter), 3-segmented clubs and long setae on the body (Figure 51). From Palaeocryptorhynchus it is easily distinguishable by the lack of scales and of a receptacle on the mesoventrite for receiving the apex of the rostrum.

\section{Burmorhinus georgei Legalov, 2018}

\section{Burmorhinus georgei Legalov, 2018: 14 [56]}

Redescription. Size. Length $2.94 \mathrm{~mm}$, width $1.0 \mathrm{~mm}$. Body elongate, slender; integument uniformly black, vestiture pale, brown and whitish, setae slender, acuminate. Head short, globular, dorsal outline in lateral view from base of rostrum continuing evenly between eyes; dorsally bulging somewhat over eyes; densely setose, setae fine, directed anteriad, coarser and longer on rostrum; forehead in middle with oval impression. Eyes large, rounded, flattened, positioned ventrolaterally (not visible in dorsal view), dorsally separated by basal width of rostrum anteriorly, further separated posteriorly. Rostrum densely setose, setae long, distinctly more curved and thicker than on head; from base to antennal insertions slightly compressed but gradually increasing in width, dorsally with strong median, paramedian and dorsolateral carinate ridges and deep intervening setose grooves; from antennal insertions to apex depressed; median and paramedian grooves and carinae abruptly ending at elongate subtrapezoidal smooth plateau (corresponding to the frons) in front of antennal insertions, this connected distally to distinct epistome, marked at each anterior corner by closely spaced pair of 
thick curved macrosetae; dorsolateral grooves reaching slightly beyond antennal insertions; laterally with indistinct setose scrobe-like groove reaching front of eye; antennal insertions in apical quarter, behind them with true lateroventral scrobes, separated from lateral setose groove by carina, reaching below eyes; in front of (and below) them with narrow groove reaching mandibular articulations (these lateral, horizontal), with 2 thick curved macrosetae near apex, at least one other smaller seta further back and 2 elongate macrosetae at antennal insertions; ventrally on each side with very long, thick curved macroseta behind hypostomal area. Antennae. Scapes apically oblique, with numerous sparse setae, articulation socket with pedicel very narrow; funicles with segment 1 bent at base, elongate, only slightly wider than others, $2-4$ similar, elongate-cylindrical, 2 ca. $0.67 \times$ as long as 1 , others progressively shorter towards club, $5-7$ subequal, subglobular; clubs with segment 1 obconical, ca. $2.0 \times$ broader than last funicle segment (other club segments missing). Mouthparts. Mandibles symmetrical, long and narrow, apically strongly curved, outside with small rounded subflat projection with notch in front, inside with very large tooth at about middle, on left bicuspid, on right simple. Maxillary palps not clearly visible (only apical ovoid segment). Labium distinct, apicomedially with long narrow projection with group of ca. 4 setae at apex; palps 3-segmented, segments progressively narrower distad, segment 1 longer than 2 and with long thick macroseta, 2 short, globular, 3 slender, slightly longer and ca. half as wide as 2 . Thorax. Pronotum elongate, slightly narrower than elytra; densely coarsely punctate, with edges of rostral channel terminating posteriorly in a rounded tooth. Pronotum sparsely setose, setae multidirectional; sides substraight, weakly curved; base broadly convex, without marginal ridge; posterior corners rounded and obsolete. Scutellum with whitish setae. Metaventrite flatly concave, coarsely sparsely punctate, somewhat prominent posterolaterally but not raised into weals. Elytra narrowly elongate, sparsely setose, setae mainly brown; striae and interstriae subequal in width; interstriae raised, punctorugose, more densely setose than striae; bases weakly concave; humeri narrowly rounded, tightly fitting with pronotal corners; sides straight, parallel-sided, marginal groove indistinct, very narrow, subequal for entire length, with broad shallow anterior notch. Legs. Procoxae strongly projecting, subconical; mesocoxae prominent; metacoxae only weakly transverse, not prominent. Femora constricted preapically, outside at apex shallowly (profemora) to deeply truncately emarginate, without distinct comb of curved setae, inside excavate in apical half (profemora) or quarter (meso- and metafemora) to receive tibiae. Tibiae abruptly curved basally, subcompressed, substraight, outside edge subcostate, with dense long curved thick whitish setae, other setae slender, straight; apically with distinct, well developed apical flanges lined with coarse fringing setae, on meso- and metatibiae these extending shortly along distal outer margin, with short dentate mucro on inner apical side and 2 slender spurs, increasing in length from pro- to metatibiae. Tarsi progressively longer from fore- to hindlegs, nearly as long as tibiae, densely setose ventrally, less so dorsally, seemingly progressively narrower from fore- to hindlegs; tarsites 1-2 apically subtruncate to slightly rounded, 1 elongate, widening apically, 2 similar, shorter, ca. half as long as 1, very slightly wider, 3 with short digitate slightly compressed lobes broadly connected basally and not concave along inner edge, cryptotarsite globular, prominent, 5 about as long as or shorter than $1+2$; claws divergent-divaricate. Abdomen. Ventrites 1 and 2 large, flatly aligned, coarsely deeply sparsely punctate, elongate, subequal in length, each slightly longer than $3+4 ; 3-5$ stepped, at slightly higher level, 1 with very broadly convex intercoxal projection; 3 and 4 subequal in length, sparsely setose, 5 slightly longer than 4 , very densely setose, apically broadly rounded.

Material examined. Holotype (ISEA no. MA 2017/1): excellently preserved and well visible specimen, with diffuse whitish coating over most of surface but surface still well visible, left eye distorted, globular (right eye flattened), missing club and last five funicle segments of left antenna, last 2 or 3 club segments of right antenna, claw segment of left middle leg and claws of left metatarsus; re-prepared from much larger discoidal amber piece from which the original description was prepared, now in elongate rectangular cuboid, $3.9 \times 1.2 \times 1.1-2.1 \mathrm{~mm}$; amber clear yellow with diffuse gritty particles and few larger masses of organic material near right side of specimen, without fractures or other obscurities. 


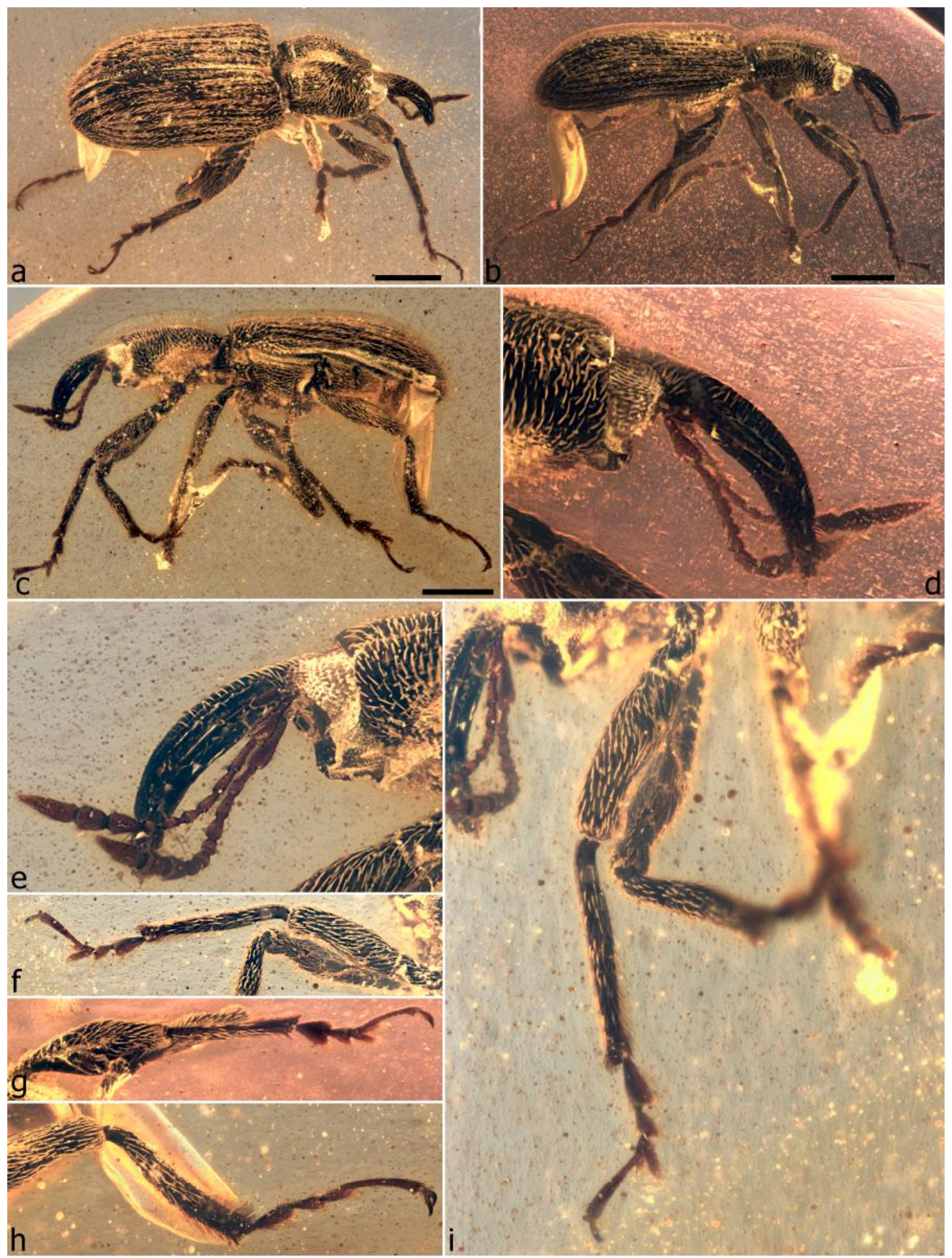

Figure 51. Burmorhinus setosus sp. n., holotype. Habitus, dorsolateral (a); habitus, right lateral (b); habitus, left lateral (c); head, antennae, and prothorax, right lateral (d); same, left lateral (e); forelegs, left (f); mesotibia (g); left metatibia (h); forelegs (i). Scale bars: $0.5 \mathrm{~mm}(\mathrm{a}-\mathrm{c})$.

Remarks. This distinctive species is readily distinguishable from B. setosus by its long narrow form, the multidirectional setae on the pronotum, the long dense setae on the interstriae and tarsites 5 being shorter than $1-3$, as well as the inner apical tooth on the tibiae. In details, particularly of the rostrum, it displays numerous differences from B. setosus, most notably the deep grooves on the rostrum with long curved setae and thick intervening carinae. The holotype is likely to be a male due to its preapically inserted antennae. 
Burmorhinus setosus Clarke \& Oberprieler, sp. n. (Figure 51)

Description. Size. Length $2.45 \mathrm{~mm}$, width $1.05 \mathrm{~mm}$. Body black, concolorous, rostrum slightly paler; with whitish golden vestiture on body and legs, setae generally tapering at both ends. Head short, dorsal outline continuing evenly from base of rostrum to between eyes; forehead flat, densely setose, setae fine, directed anteriad, on rostrum and head subequal; ventrally bulging. Eyes lateral, large, subglobular, subhemispherical, slightly longer than deep; dorsally separated by about half basal rostral width anteriorly, narrowing between eyes and further separated posteriorly. Rostrum sparsely setose, setae short, curved, subequal to setae on head; stout, subcylindrical to subcompressed from base to antennal insertions, dorsally with median ridge with minute impunctate asetose groove in middle, with 2 other low paramedian carinae, these effaced or confused distad from antennal insertions; grooves between carinae shallow, lined with setae directed anteromesad (basally) or mesad (further from head); from antennal insertions to apex slightly depressed, slightly expanding apicad; median and paramedian grooves and carinae abruptly ending at narrow ogival plateau in front of antennal insertions, this connected distally to distinct epistome, marked by 2 elongate macrosetae along oblique edges; dorsolateral grooves reaching slightly beyond antennal insertions; antennal insertions in apical quarter, marked dorsally by distinct tubercles, behind them with deep lateroventral scrobes reaching eyes, in front of (and below) them with narrow groove reaching mandibular articulations (these lateral, horizontal), with 2 thick curved macrosetae near apex and at least 2 other smaller setae at antennal insertions; ventrally on each side with very long thick curved macroseta behind hypostomal area. Antennae dark brown, concolorous; scapes apically oblique, asetose, articulation socket with pedical very narrow; funicles with segment 1 bent at base, elongate, subequal in length to $2+3$, distinctly broadened in apical half and ca. $2.0 \times$ wider than others, $2-5$ similar, elongate-cylindrical, increasingly obconical and progressively shorter towards club, 6-7 subequal, subglobular; clubs with segments 1 and 2 subequal in length and width, 1 distinctly obconical, ca. $2.5 \times$ broader than last funicle segment, 2 subcylindrical, both apically with dense ring of short modified setae, $3+4$ subfusiform, elongate, slightly longer and narrower than $1+2$, indistinctly separated, 4 acute. Mouthparts. Mandibles symmetrical, small, broad at base, apically narrowly pointed, outside with weak notch just before base, inside on each side with at least one acute tooth Maxillary palps short, 3-segmented, apical segment apically rounded, subequal in length to 2 , slightly narrower. Labial palps very slender, widely separated (not properly visible). Thorax. Prothorax not or slightly proclinate (area unclear), with anterior lateral margins seemingly drawn out into broad, weak ocular lobe, about as long as broad, distinctly narrower than elytra at base, distinctly punctosetose. Pronotum sparsely evenly setose, setae directed anteromesad, overall forming wavy pattern; sides broadly rounded; base distinctly sinuate, closely fitting to elytra, posterior angles acute, slightly extended. Scutellar shield tiny, prominent, longer than wide, with whitish setae. Metaventrite more finely punctosetose than dorsal side, raised into transverse weals. Elytra broadly elongate, sparsely setose, setae golden brown; punctostriate, striae asetose, punctures large; interstriae ca. $2.0 \times$ broader than striae, broadly convex, interstriae 7 and 8 densely setose, basally confluent forming flatly produced humeri; bases broadly obtuse, weakly sinuate, humeri flatly produced, then sharply inflexed; sides slightly sinuate, marginal groove distinct, densely setose, subequal in width for entire length, with narrow anterior marginal notch; apices with small lobe before suture; sutural flanges narrow, equal. Hindwings fully developed. Legs robust. Procoxae globular, moderately projecting. Femora constricted preapically, at outside at most weakly emarginate, with comb of curved setae; inside excavate in apical one third or more to receive tibiae. Tibiae abruptly curved basally, subcylindrical, outside rounded, with short sparse recurved setae, inside with longer, denser setae in distal third; apically with well-developed flanges lined with coarse fringing setae, on meso- and metatibae these extending shortly along distal outer margin and associated with patch of longer oblique setae on outer side, without mucro on inner apical side; with 2 short narrow acute spurs. Tarsi progressively longer from fore- to hindlegs, of foreleg slightly shorter, of middle and hindlegs slightly longer than tibiae, densely setose ventrally, less so dorsally; tarsite 1 elongate, broad, subtriangular, apicolaterally roundly lobate, 2 shorter, ca. half as long as and much 
narrower than 1, apically excised, 3 deeply lobate, lobes elongate-ovoid, subparallel-sided, slightly depressed, broadly connected basally and distinctly concave along inner edge, cryptotarsite narrow, indistinct, recessed into base of 3, 5 elongate, much longer than 1+2; claws divergent. Abdomen. Ventrites 1 and 2 large, subflatly aligned, finely sparsely punctosetose, elongate, subequal in length; each slightly longer than $3+4,3-5$ stepped, at slightly higher level, 1 with very broadly convex intercoxal projection; 3 and 4 subequal in length, sparsely setose, 5 longer than 4 (not properly visible), apically broadly rounded.

Material examined. Holotype (NIGP154223): very well preserved, intact and well visible specimen, dorsal surface unobstructed, ventral surface less visible due to gritty haze near specimen, also with some distortion of (mainly ventral) head and prothorax (with crack or wrinkle on left side of pronotum), with left wing partly extended; in irregular 6-sided prism, $4.0 \times 3.9 \times 3.5 \mathrm{~mm}$, with dorsum of weevil parallel to large curved face; amber hazy yellow-brown with darker halo around specimen, with diffuse microscopic particles, without fractures, bubbles, or debris.

Derivation of name. The species is named for its conspicuous covering of setae, the name being an adjective.

Remarks. This species is similar to B. georgei but distinguishable from the latter by its broader body, uniformly short whitish-golden setae, lack of a tibial mucro, small tibial spurs and the different dimensions of the tarsites, 1 being long and broad, 2 much shorter and narrower and 5 as long as 1-3. The condition and visibility of the prosternum is unfortunately poor due to it being depressed and obscured by some fine debris. The sides of the rostral channel have been somewhat flattened (pushed in), but the anterior lateral margin of the prothorax on both sides is traceable as a continuous edge from the front to the coxae. Although it is clear that the specimen has a prosternal channel, it is less certain whether it also has ocular lobes as occur in B. georgei and Rhadinomycter perplexus, because the flattening of the channel has obscured the curvature of the correct area (and also because these lobes were likely broadly rounded as they are in $R$. perplexus). Although the eyes seem somewhat bulging (they are, however, more dorsally positioned than in B. georgei, with a narrow flat space between them), the head is also distorted ventrally, likely accentuating the protrusion of the eyes. The holotype seemingly also represents a male.

Genus Rhadinomycter Clarke \& Oberprieler, gen. $\mathbf{n}$.

Type species: Rhadinomycter perplexus Clarke \& Oberprieler, sp. $\mathrm{n}$.

Description. Size. Length $2.45 \mathrm{~mm}$, width $0.78 \mathrm{~mm}$. Head short, subglobular-compressed, strongly convex dorsally and ventrally, not constricted behind eyes. Eyes large, weakly protruding, coarsely facetted, dorsally separated by about width of rostrum basally, anteriorly further separated posteriorly; forehead flatly convex, without paired tubercles between anterior margin of eyes. Rostrum slightly longer than pronotum, slender, strongly compressed to antennal insertions (partly a distortion), broader, slightly depressed to apex, weakly downcurved; antennal insertions lateral, in apical quarter to third (possibly a male trait; see also Remarks for R. perplexus), with scrobes behind them extending toward eye, in front of them laterally with a few long erect setae. Gular suture not discernible (ventral side of head not visible). Antennae geniculate, long; scapes elongate, cylindrical, apically slightly evenly expanded, about as long as funicles, not reaching eyes, articulation socket of funicle segment 1 apicoventral; funicles 7-segmented, segments 1-5 progressively shorter towards club, 6-7 subglobular; clubs short, loose, 4-segmented. Mouthparts. Labrum absent. Mandibles long (but partly concealed in dorsal view), flat, horizontal, non-exodont, articulation plane horizontal. Thorax. Prothorax not proclinate, with anterior lateral margins sinuate in lateral view, drawn out into broadly rounded ocular lobe. Pronotum strongly convex, laterally roundly subvertical, without tooth, posterior corners rounded and obsolete, tightly fitting onto elytra; surface coarsely densely punctate, sparsely setose, setae short, diverse, not forming dense coloured patches; notosternal sutures apparently absent. Prosternum with channel for reception of rostrum; procoxal cavities medially confluent, closer to hind margin of hypomeron. Scutellar shield densely setose. Mesocoxal cavities closed laterally. Metanepisterna not discernible (obstructed). Mesoventrite short, anteriorly sloping, with spiniform 
projection between coxae. Metaventrite about 3 times longer than mesoventrite, flatly concave. Elytra elongate, narrow, basally extended over base of pronotum, with narrowly rounded humeri, posteriorly weakly declivous, lateral margin substraight, apically conjointly rounded, not exposing pygidium; sutural flanges not visible; surface very coarsely punctostriate, without scutellary striole, punctures large, open, interstriae flat, narrower than striae, sparsely setose, setae short, diverse, indistinct, not forming dense coloured patches. Legs. Procoxae large, prominent, medially contiguous; mesocoxae elongate, narrowly globular, widely separated; metacoxae elongately globular, widely separated by broadly rounded process of ventrite 1 . Trochanters short, oblique. Femora long, subcylindrical, outside rounded, inside excavate in distal half (profemora) to quarter (meso- and metafemora), receiving tibiae in repose, walls of groove at apex flatly, roundly extended, shearing against basal part of tibia. Tibiae substraight, compressed, distally expanded, outer edge subcostate, smooth, sparsely setose, with longer stiff setae in distal half, apex obliquely truncate, with 1 fixed spur. Tarsi shorter than tibiae, narrow, subflat; tarsite 1 apically truncate, 2 shorter, subquadrate, apically truncate, 3 shortly bilobed, lobes digitate, narrow, 5 slender, apically expanded; claws divergent-divaricate, simple, with ventrobasal seta. Abdomen with ventrites 1 and 2 very elongate, fused (suture less distinct than others), subflatly aligned, each about as long as $3-5,3$ slightly longer than 4,5 subequal to $3+4$, apically broadly rounded.

Derivation of name. The genus is named for its slender shape, the name derived from the Greek adjective rhadinos (slender) and noun mykter (G: mykteros) (nose, beak) and being masculine in gender.

Remarks. This genus is most similar to Burmorhinus, sharing the characters of a prosternal channel for reception of the rostrum and postocular lobes, but it can be readily distinguished by the distinctly 4-segmented clubs and single spur on the tibiae. Other differences from Burmorhinus include the rostrum being slightly longer than the pronotum, the scrobes extending towards the eyes, the shorter and more distinctly 4 -segmented clubs, the flat narrow interstriae, the short, diverse, indistinct elytral setae and the more elongate, narrowly globular mesocoxae. Rhadinomycter is unique among Burmese amber weevils as known in being the only species in which the articulation socket of the scape with the pedicel is apicoventrally located (but still of the 'open' type of geniculation) and in having a long acute process on the mesoventrite projecting forwards from the base of the intercoxal process.

Rhadinomycter perplexus Clarke \& Oberprieler, sp. n. (Figure 52)

Decription. Size. Length $2.45 \mathrm{~mm}$, width $0.78 \mathrm{~mm}$. Narrow, slightly depressed, coarsely punctate. Head short, globular, subcompressed (partly distorted); dorsal outline in lateral view forming sinus at base of rostrum, dorsally convex but not bulging over eyes; forehead strongly narrowly convex; sparsely finely setose, setae directed anteriad; ventral outline of head in lateral view forming strong angle at base of rostrum. Eyes ventrolateral, subcircular in outline. Rostrum sparsely, shortly setose, setae indistinct dorsally, with median, paramedian and dorsolateral carinae and deep intervening setose grooves; from antennal insertions to apex somewhat depressed, median and paramedian grooves and carinae ending at elongate trapezoidal smooth plateau (frons) in front of antennal insertions, this connected to a distinctly narrower, long and apically subemarginate epistome with close pair of curved macrosetae at each anterior corner, junction of frons and epistome laterally marked by pair of long thick curved macrosetae, further back with additional erect macroseta set in groove; laterally in front of antennal insertions with narrow groove reaching mandibular articulation (these lateral, horizontal), with single thick curved macroseta in near apex, 2 smaller setae further back (one near antennal insertions); ventrally on each side with very long thick curved macroseta behind hypostomal area. Antennae. Scapes slender, apically rounded in dorsal view, articulation socket with funicle segment 1 very narrow, not visible in dorsal view, slightly visible in apical view; funicles with segment 1 bent at base, elongate-obconical, slightly wider than others, $2-5$ obconical, narrower, progressively shorter towards club, 2 ca. $0.67 \times$ as long as 1,6 and 7 subequal, subglobular, slightly broader than 5 ; clubs with segments 1-2 subequal in length, apically subangulately rounded, 1 obconical, longer than wide, ca. $2.0 \times$ broader than 4 , apical width ca. $3.0 \times$ basal width, 2 subquadrate, basal width ca. $2.0 \times$ broader than that of 1, 3 much narrower than 2, more broadly inserted into it than 2 is into 1, 4 ca. 
half as long as 3, distinctly narrower, apically subsubtruncate. Mouthparts. Mandibles symmetrical, elongate, apically strongly curved, ca. half their length or more concealed by elongate epistome (mandibles not well visible on outside and inside; appearing very short, curved). Thorax. Prothorax elongate, ca $2.0 \times$ longer than wide, with larger prothoracic volume, evenly curved from pronotal disc to sides; densely, coarsely punctate, punctures deep, irregularly distributed; with edges of rostral channel not terminating posteriorly in a tooth. Pronotum sparsely setose, setae stout, erect (some thickened, club-like); sides substraight, subparallel, gently curved anteriad; base broadly convex, without marginal ridge; posterior corners rounded, indistinct. Scutellar shield recessed a little beneath elytral surface, setae pale. Metaventrite broadly concave, seemingly wider posteriorly, narrowing anteriorly towards mesocoxae; coarsely punctate. Elytra narrowly elongate, subflat, seemingly fused at suture and to thorax and abdomen; sparsely setose, some setae almost clubbed, others curved or erect; striae distinct, much wider than interstriae anteriorly, punctures very large, deep, decreasing in size caudad, intervals between punctures flat, much less than puncture diameter; interstriae not raised (including sutural interstria), less distinct than striae anteriorly (broader, more distinct in posterior third); elytral bases strongly concave; sides straight, subparallel for most of length, marginal groove and anterior marginal notch absent. Legs. Procoxae prominent, subflatly conical, meso- and metacoxae weakly prominent, slightly elongate, metacoxae not transverse. Femora constricted preapically, outside at apex weakly emarginate, without distinct comb of curved setae; inside excavate in apical quarter to receive tibiae. Tibiae abruptly curved basally, subcompressed, sparsely setose, with erect setae; outside edge subcostate, with sparse curved pale setae, other setae slender, straight; apically with tarsal articulation surfaces suboblique (pro- and mesotibiae) or distinctly oblique (metatibiae), with distinct, well developed apical flanges lined with coarse fringing setae; with single slender tibial spur, shorter on protibiae, much longer on meso- and metatibiae; mucro absent; metatibiae slender basally, unevenly expanded distad, outer edge upturned in distal half, apically expanded, with edge of outer apical flange elongate, this and smaller inner flange lined with coarse fringing setae. Tarsi progressively longer and narrower from fore- to hindlegs, nearly as long as tibiae, densely setose ventrally, less so dorsally; tarsites 1 obconical, ca. $1.5 \times$ longer than 2 , apically truncate, 2 constricted basally, then subquadrate, wider than 1 , apically truncate, 3 elongately lobate, not pedunculate, wider than 2, of anterior and middle legs subequal in length, of hindlegs distinctly shorter than these, lobes of 3 very short, less half as long as 5, 5 slender, gradually expanding distad, distinctly curved, longer than 1-2. Abdomen. Ventrites flat, coarsely punctate, 1 and 2 very elongate, 2 slightly longer than 1 , $3-5$ extremely short, 3 about third as long as 2, 4 slightly shorter than 3; sutures between 2 and 5 very deep, straight or subarcuate.

Material examined. Holotype (NIGP154224): well preserved, mostly undistorted and largely intact specimen, with head, rostrum and anterior prothorax somewhat compressed, rostrum partly obscured by fractures and compression, legs well visible, club, most of pedicel and funicle segments 2-7 of right antenna cut away with amber; in flat 7-sided block, $5.3 \times 2.5 \times 1.2 \mathrm{~mm}$; amber clear yellow with murky patches, bubbles, and debris variously obscuring right-ventral views and apex of abdomen.

Derivation of name. The species is named for its perplexing characters, in particular the prosternal channel and the long, retractable legs (tibiae).

Remarks. This distinctive, possibly flightless species is characterised by a coarse, dense punctation, a dorsal sinus separating the rostrum from the head and a compressed prothorax. The apex of the rostrum has an extended epistome that conceals much longer mandibles than can be seen apically in dorsal view. In lateral view the articulation sockets are set much further back from the dorsal apex, such that much of the length of the mandibles is concealed in dorsal view. In the holotype the head and rostrum have been stretched asymmetrically so that the eye and antennal insertion on the left side are positioned further anteriorly than those on the right side. 


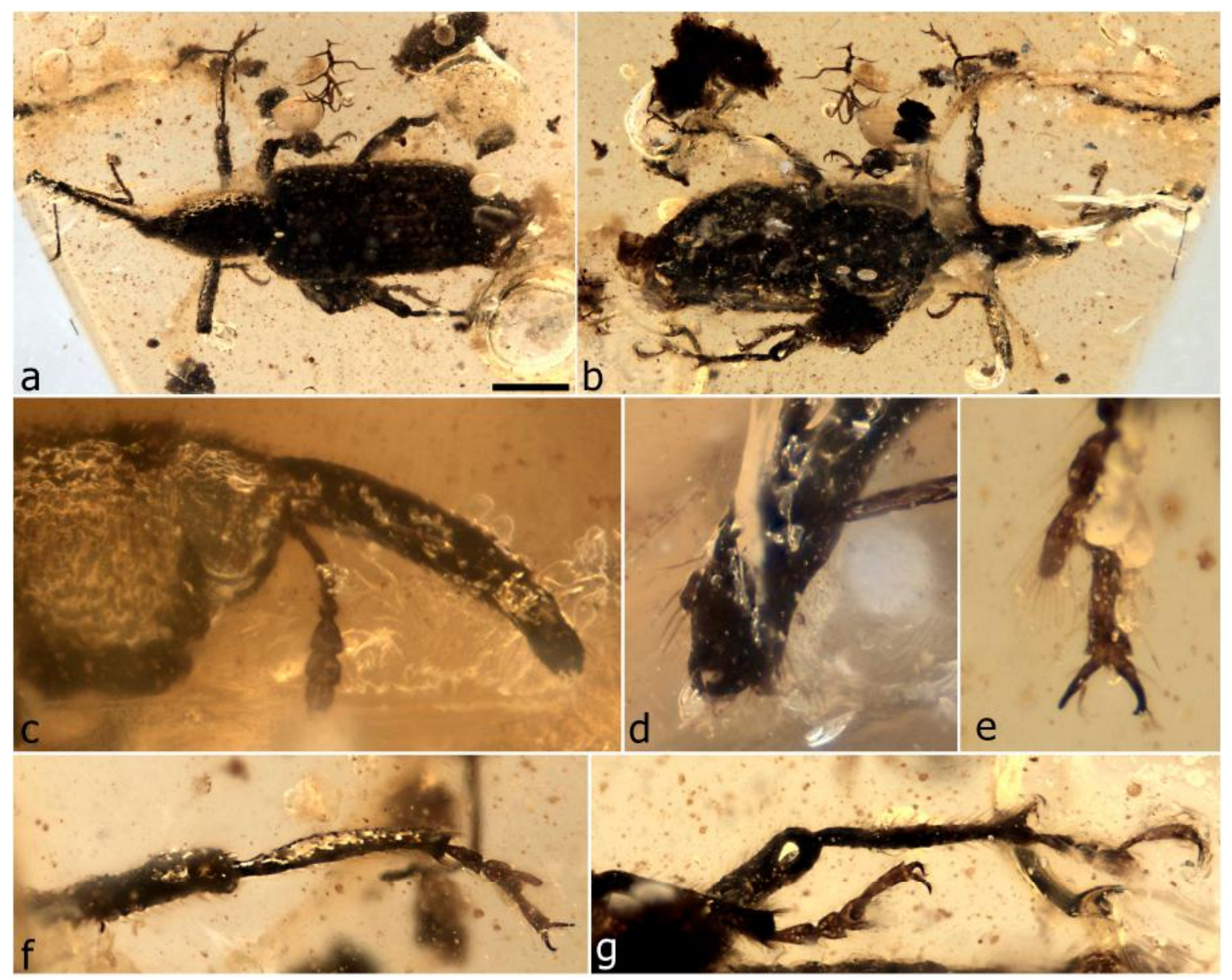

Figure 52. Rhadinomycter perplexus sp. n., holotype. Habitus, dorsal (rostrum appearing longer in this image due to a visual artifact caused by the angle of the block surface) (a); habitus, ventral (b); head and prothorax, right lateral (c); apex of rostrum and mandibles, dorsolateral (d); protarsus, dorsal (e); front leg (f); left meso-and metatibia (g). Scale bars: $1.0 \mathrm{~mm}(\mathrm{a})$.

Genus Gnomus Clarke \& Oberprieler, gen. n.

Type species: Gnomus brevis Clarke \& Oberprieler, sp. $\mathrm{n}$.

Description. Size. Length 2.1-2.7 mm, width $0.9 \mathrm{~mm}$ or more. Body short, compact; sparsely setose. Head shortly conical, not constricted behind eyes. Eyes elongate, flat, not strongly protruding, coarsely facetted, dorsally separated by width of rostrum, without tubercles between them, forehead flat. Rostrum about as long as pronotum, stout, slightly to strongly curved; antennal insertions lateral, behind middle of rostral length. Gular suture not discernible. Antennae geniculate; scapes straight, cylindrical, apically slightly inflated; funicles slightly longer than scape, 7-segmented; clubs elongate, broad, loosely articulated, 4-segmented, segment 4 about as long as 3, broad to narrow. Mouthparts. Labrum absent. Thorax. Prothorax not proclinate, with anterior lateral margins vertical in lateral view. Pronotum short, convex, laterally rounded, without tooth, posterior corners rounded, not fitting closely onto elytra; notosternal sutures closed; procoxal cavities medially confluent. Scutellar shield transverse. Mesocoxal cavities laterally closed (by meso- and metaventrite). Metanepisternal sutures distinct. Elytra shortly elongate, with broadly rounded humeri, posteriorly strongly declivous, apically individually rounded, not exposing pygidium (last tergite extruded, triangular, slightly convex, but fitting under elytra); sutural flanges unknown; surface punctostriate, without scutellary striole. Legs. Procoxae short, prominent; mesocoxae subglobular, slightly projecting, metacoxae transverse. Trochanters short, oblique. Femora short, flatly subcylindrical, inflated in distal half, unarmed, outside rounded. Tibiae short, robust, outer edge rounded, distally setose, apically with 2 
spurs. Tarsi almost as long as tibiae; tarsite 1 elongate, apically truncate, 2 shorter, triangular, apically truncate, 3 bilobed, lobes narrow to digitate, 5 slightly shorter than $1+2$; claws divaricate, basally swollen, with ventrobasal seta. Abdomen with ventrites subequal, 1-4 progressively slightly shorter, 5 about as long as 4 .

Derivation of name. The genus is named for its small, gnome-like appearance, from the Neo-Latin noun gnomus, meaning a dwarf; the gender of the name is masculine.

Remarks. Gnomus is largely a form genus, aggregating three species of similarly short and compact shape with non-dentate tarsal claws. The single specimens of all three species are poorly preserved (visible) and thus cannot be definitely assessed as being congeneric, but there are no sufficient discernible character differences between them to justify the erection of different genera for them. We selected the best-preserved specimen as the type species (Figure 53). We submitted the holotype of G. spinipes for CT scanning, but the density difference between the specimen and the surrounding amber was too small to allow the generation of suitable CT images. If further similar specimens are discovered, it may be possible to describe this genus more accurately and assess its proper species composition. Gnomus is similar in shape to the smaller Cretocar luzzii Gratshev \& Zherikhin, 2000, described from the slightly younger New Jersey amber, and a careful comparison of these genera is warranted.

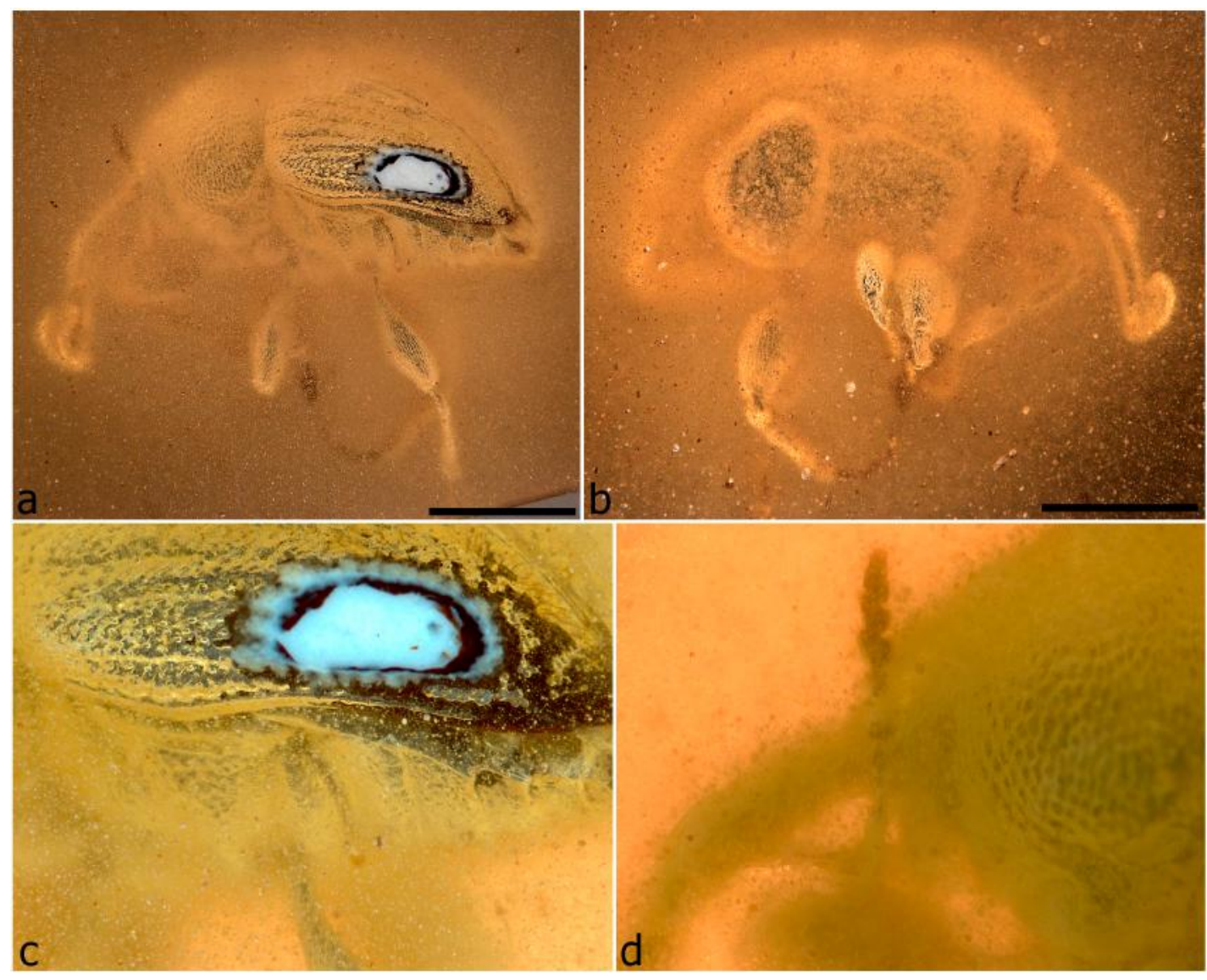

Figure 53. Gnomus brevis sp. n., holotype. Habitus, left lateral (a); habitus, right lateral (b); left elytron, left lateral (c); head, antenna and eye, left lateral (d). Scale bars: $1.0 \mathrm{~mm}(\mathrm{a}, \mathrm{b})$.

\section{Gnomus brevis Clarke \& Oberprieler, sp. n. (Figure 53)}

Description. Size. Length $2.72 \mathrm{~mm}$, width ca. $1.4 \mathrm{~mm}$. Antennae. Funicles with segments short, transverse but not clearly discernible; clubs flattened, apical segment bluntly triangular. Thorax. Pronotum with surface shallowly tuberculate, probably sparsely setose but setae indiscernible. Elytra posteriorly strongly evenly declivous, lateral margins bisinuate, emarginate over metacoxae; striae 
narrow, probably sparsely setose. Legs. Tibiae slightly flattened, spurs small (1 visible on metatibiae, possibly 2 on all tibiae). Tarsi with lobes of tarsite 3 narrow but not digitate. Abdomen with last tergite extruded, triangular, slightly convex, fitting under elytra (not espoused as pygidium), ventites subequal, 1-4 progressively slightly shorter, 5 about as long as 4 , sides flat, high, fitting under elytra.

Material examined. Holotype (NIGP154225): well preserved, intact specimen, not compressed or distorted but poorly visible due to cloudiness of amber, with large flat bubble on right side and smaller one at tip of rostrum, thin silvery layer of air over part of surface, left elytron cut into at side; in centre of thin rectangular cuboid ca. $6.0 \times 43 \times 1.8 \mathrm{~mm}$; amber densely packed with many minute impurities, giving it an opaque look.

Derivation of name. The genus is named for its short body, brevis being a Latin adjective.

Remarks. This is the best-preserved of the three species assigned to Gnomus. It differs from G. spinipes mainly in its more strongly curved rostrum and from Gnomus sp. in having normal tibial spurs.

Gnomus spinipes Clarke \& Oberprieler, sp. n. (Figure 54a-e)

Description. Size. Length $2.1 \mathrm{~mm}$, width not measurable. Head. Rostrum long, slender, slightly downcurved; antennal insertions median. Antennae. Scapes elongate slender, apically weakly expanded; funicles with segment 1 broader than others, 2-7 slightly progressively shorter towards clubs, 7 distinctly broader than 6; clubs with segments 1-3 subequal, obconical, progressively slightly longer apicad, 4 broadly inserted into 3, flattened, shorter than 3. Mouthparts. Not visible. Thorax. Prothorax not properly visible. Scutellum short, transverse. Elytra sparsely setose, setae short recurved, pale; strongly declivous, with very narrow marginal ridge subequal in width for entire length. Legs. Tibiae with stiff, suberect setae in distal half, spurs normal, paired, on metatibiae unequal and with long thicker fringing seta adjacent to inner spur. Tarsi with tarsite 1 apically subtruncate, 2 weakly excised, 3 with short lobes, ca. half as long as 5, digitate; claws angulate. Abdomen. Ventrites shortly, sparsely, finely setose; setae pale. Ventrite 5 broadly rounded apically.

Material examined. Holotype (NIGP154226): intact but poorly preserved and poorly visible specimen, compressed and pulled away from amber, leaving an impressed surface around most of specimen; in cuboid $5.5 \times 5.2 \times 2.5 \mathrm{~mm}$; amber clear yellow with diffuse small debris particles and bubbles.

Derivation of name. The species is named for its spiny legs, especially the tibiae; the name is a noun in apposition.

Remarks. This species is only very poorly characterisable, because the single specimen has retracted from the surface of the amber, resulting in a large silvery halo around the body and rostrum that obscures most of its features. Its assignment to Gnomus is therefore only tentative. It differs from Gnomus sp. in having two normal, distadly directed spurs and the tibiae with suberect, stiff setae. From G. brevis it is distinguishable by the digitate (finger-like) lobes of tarsites 3 .

Gnomus sp. (Figure 54f-h)

Material examined. One specimen (NIGP156990); length $2.08 \mathrm{~mm}$, width not measurable: intact but very poorly preserved, heavily distorted, partly decomposed and poorly visible, compressed and crumpled, covered with irregular bubbles; in slab with one rounded face, $5.3 \times 4.5 \times 1.7 \mathrm{~mm}$; amber clear yellow, with large ovoid fracture near head, without any debris obscuring specimen.

Remarks. This specimen is the only one we have seen other than the Nemonychidae and Palaeocryptorhynchus burmanus that may not belong in Mesophyletidae. However, because of its poor preservation (strongly crumpled and partially obscured by bubbles) we do not name and describe a species for it here. Its critical observable characters include subbasally inserted antennae with evidently 5- or possibly 6-segmented funicles, short scapes (not determinable whether the antennae are nonor subgeniculate) and 4-segmented clubs and seemingly subvertical, exodont but apically pointed mandibles with 2 outer recurved teeth and no inner teeth (a unique mandible structure among known Burmese amber weevils). Thoracic details are well discernible; the notosternal sutures are open and 
the mesocoxal cavities laterally open as well. Ventrites 1 and 2 are fused and the others seemingly free, and a pygidium is indicated but the area is too crumpled to clearly assess this (the apex may just be distended).

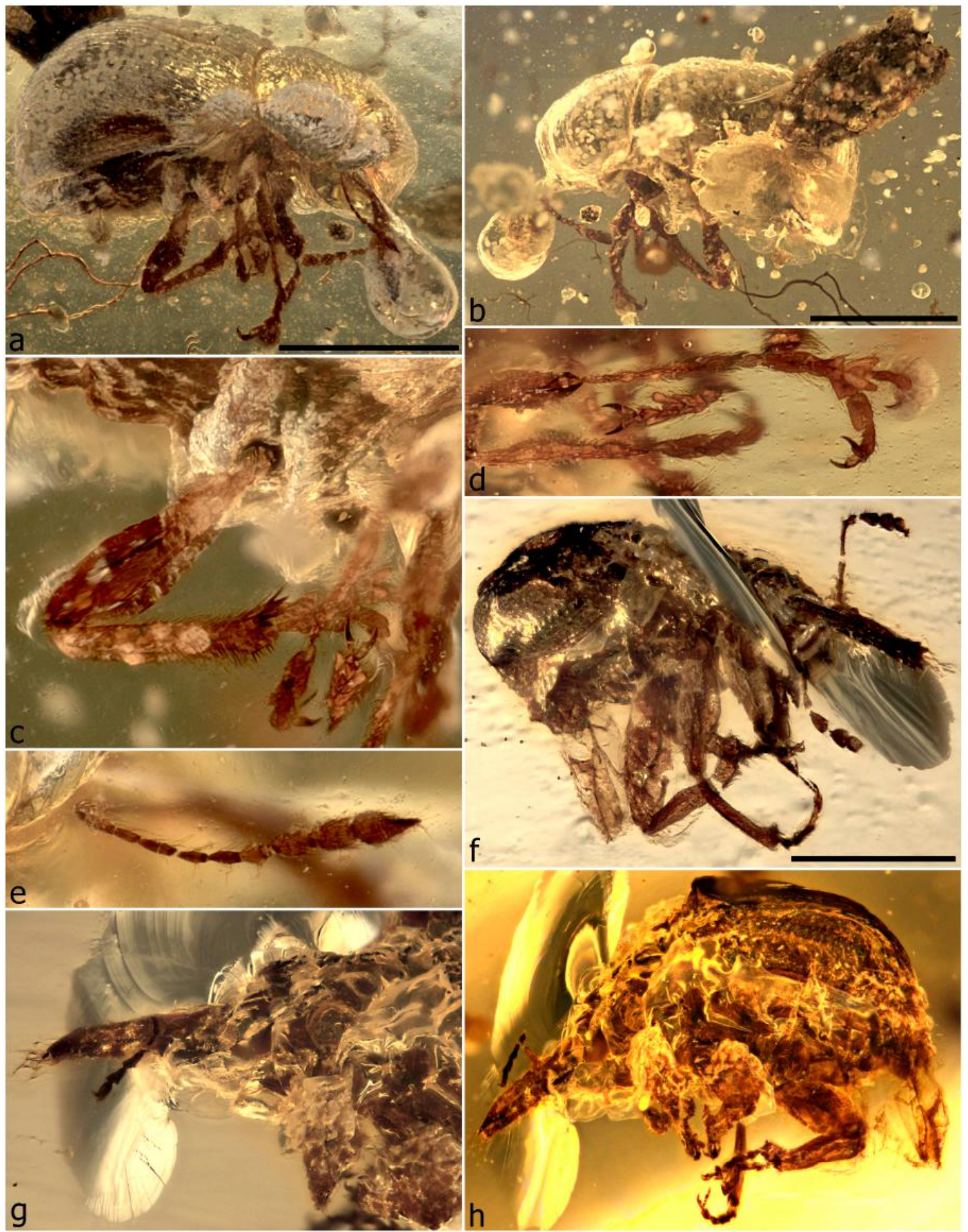

Figure 54. Gnomus spinipes sp. n., holotype (a-e) and Gnomus sp. (f-h). Habitus, left lateral (a); habitus, right lateral (b); right hindleg (c); protibia and tarsi (d); right antenna (e). Habitus, right caudolateral (f); head and rostrum, left lateral (g); habitus, left lateral (h). Scale bars: $1.0 \mathrm{~mm}(\mathrm{a}, \mathrm{b}, \mathrm{f})$.

The legs are relatively well preserved and the tarsi are distinctive, with digitate lobes of tarsites 3 and angulate claws. The claws, however, are unusual in that the triangular inner tooth is situated at the middle of the elongate claw rather than at the base, and the claws lack a ventrobasal seta. The 
4-segmented clubs, fused ventrites 1 and 2, laterally open pro- and mesocoxal cavities and subbasally inserted antennae are characters of Mesophyletidae, in particular of some genera of Aepyceratinae. However, the other antennal characters and the lack of ventrobasal claw setae do not agree with most Mesophyletidae (although ventrobasal setae are apparently absent in some species). Although the specimen is thus distinctive from other Mesophyletidae, we retain it in Gnomus for now, pending better-preserved material becoming available. It was submitted for CT scanning, but this produced no useful images to permit a better assessment of its characters.

This species is distinctive among Burmese amber weevils in having a pale reddish-brown cuticle (not so apparent under LED lighting) with a colourful metallic sheen (on elytra, seemingly other regions) and tibiae with divergent spurs, one of which is normal and directed distad and the other one is fixed and perpendicular to the tibial axis. Divergent spurs are so far otherwise known from one or two species related to Compsopsarus, of which we received specimens from the AMNH but which require further preparation to adequately describe and classify.

Genus Hukawngius Clarke \& Oberprieler, gen. $\mathbf{n}$.

Type species: Hukawngius crassipes Clarke \& Oberprieler, sp. n.

Description. Size. Length $3.8 \mathrm{~mm}$, width $5.0 \mathrm{~mm}$. Head short, conical. Eyes lateral, slightly protruding, coarsely facetted, dorsally narrowly separated, by less than width of rostrum at base, forehead without tubercles. Rostrum slightly longer than pronotum, stout, cylindrical; antennal insertions lateral, behind them with faint scrobes extending to eye, in front of them without lateral row of setae. Long single gular suture indicated. Antennae geniculate; scapes cylindrical apically inflated; funicles slightly longer than scape, 7-segmented; clubs loosely articulated, 4-segmented Mouthparts. Labrum absent. Mandibles exodont, with 2 teeth on outside, anterior one forming short flat $\mathrm{Y}$ with sharp apical tooth, articulation plane horizontal. Thorax. Prothorax proclinate, with anterior lateral margins oblique in lateral view. Pronotum laterally rounded, without tooth, posterior corners angulate but not produced to fit closely onto elytra; surface sparsely setose; notosternal sutures closed. Prosternum moderately long; procoxal cavities medially confluent, close to posterior margin of hypomeron. Scutellar shield transverse. Mesocoxal cavities laterally closed (by mesoand metaventrite). Metanepisternal sutures distinct. Mesoventrite very short, anteriorly strongly sloping. Metaventrite longer, convex, without transverse weals before metacoxae. Elytra with well-developed, broadly rounded humeri, posteriorly steeply declivous, apically individually rounded, not exposing pygidium; sutural flanges not visible; surface punctostriate, without scutellary striole, sparsely irregularly setose. Legs. Procoxae elongate, prominent, medially contiguous; mesocoxae subglobular, narrowly separated; metacoxae flat, transversely elongate. Trochanters short, oblique. Femora subcylindrical, strongly inflated in distal half, unarmed, outside rounded. Tibiae straight, subcylindrical, as long as femora, outside rounded, apex obliquely truncate in pro- and mesotibiae, truncate in metatibiae, with 2 spurs. Tarsi robust, $0.67 \times$ as long as tibia; tarsite 1 apically truncate, 2 apically slightly excised, 3 deeply bilobed, 5 as long as $1+2$; claws divaricate, strongly dentate with ventrobasal seta at apex of tooth. Abdomen with ventrites 1 to 2 broad and long, subequal in length, 3 and 4 each slightly shorter than 2,5 as long as 4 , wide.

Derivation of name. The genus is named after the Hukawng Valley in Myanmar, in which the amber mines are located; the gender of the name is masculine.

Remarks. Hukwangius is distinguishable from all other mesophyletid genera with dentate claws by the lack of any ridge or crest on the outside of the tibiae (with or without serrulation/crenulation). From Anchineus (which may or may not have serrulate tibiae; the legs in the holotype are distorted) it differs by its much larger size, its longer, thinner antennae, exodont horizontal mandibles, cylindrical tibiae and broadly lobed tarsites 3 (Figure 55). In the shape of its eyes it is similar to Aphelonyssus latus, but the latter is much smaller and has the tibiae and also the femora finely crenulate on the outside. 


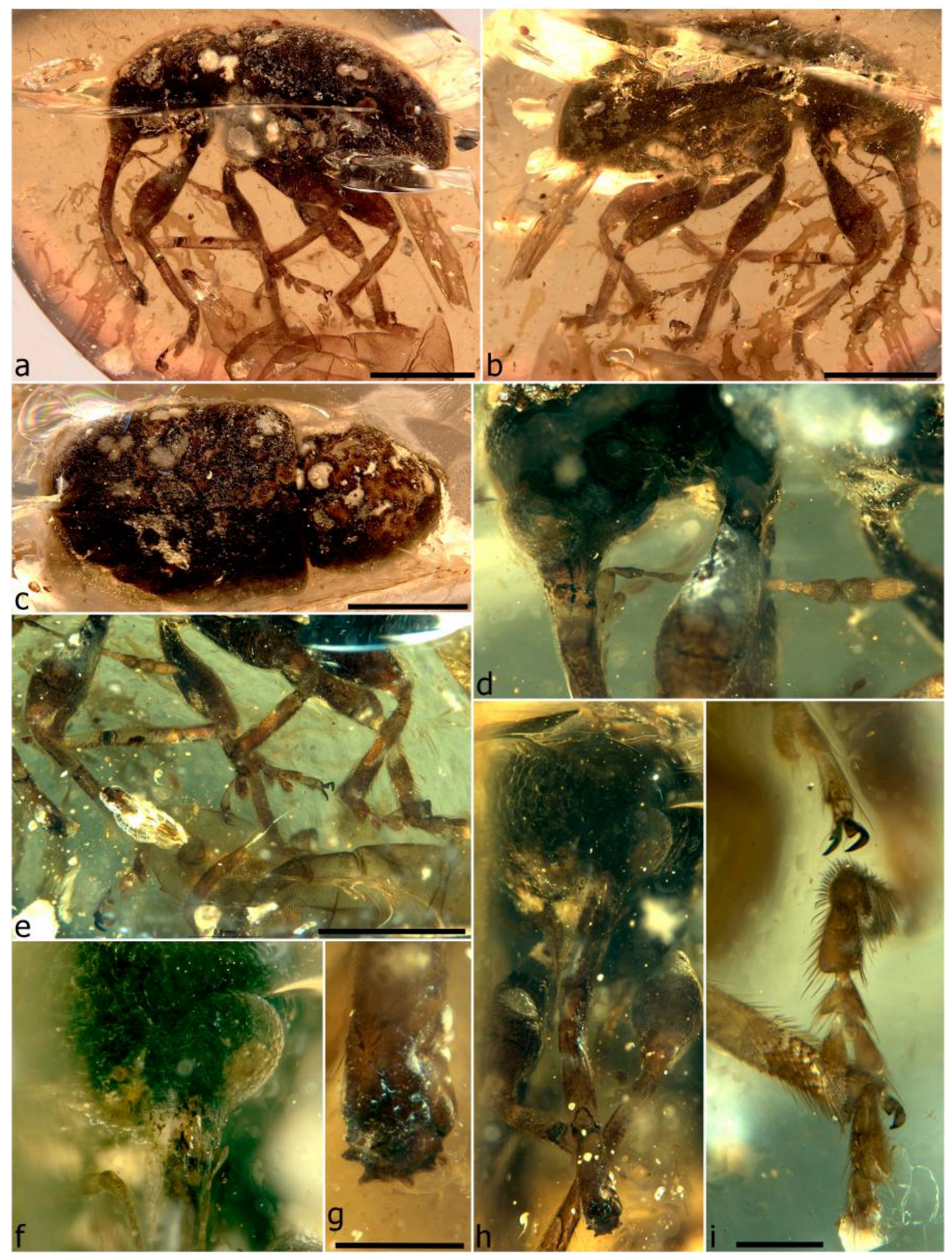

Figure 55. Hukawngius crassipes sp. n., holotype. Habitus, left lateral (a); habitus, right lateral (b); habitus, dorsal (c); head and antenna, left lateral (d); legs (e); eyes, frontal (f); apex of rostrum and mandibles, dorsal (g); head, frontal (h); tarsi, ventral (i). Scale bars: $1.0 \mathrm{~mm}(\mathrm{a}-\mathrm{c}, \mathrm{e}) ; 0.2 \mathrm{~mm}(\mathrm{~g}, \mathrm{i})$. 
Hukawngius crassipes Clarke \& Oberprieler, sp. n. (Figure 55)

Description. Size. Length $3.79 \mathrm{~mm}$, width $5.0 \mathrm{~mm}$. Head slightly constricted behind. Eyes large, hemispherical, dorsally close together. Rostrum strongly curved, dorsally forming slight sinus with head in profile; antennal insertions in basal third of rostral length. Antennae long; scapes slightly curved, thin proximally but gradually inflated towards apex; funicles with segment 1 spindle-shaped, 2 slightly shorter, others progressively shorter towards club; clubs long, apical segment about as long as 3, slightly flattened. Thorax. Pronotum broadly parabolic; convex, surface sculpture not discernible (decomposed, with large white spots), setae pale, thin, acute, dorsally directed anteriad, laterally directed anteromesad; notosternal sutures with upright stem, then abruptly bent and curved anteriad. Scutellar shield slightly rounded, short, setose. Elytra short, broad; striae indistinct, broad, setae pale, thin, acute, recurved caudad. Legs. Femora short, robust, faintly sinuate, thickest in about distal third. Tibiae stout, outside with a few small, low denticles visible in lateral view but not in a row in dorsal view, with dense setae in apical half, spurs small, pale, flat (best visible on left mesotibia in apical view from right side, also on protibia). Tarsi with tarsite 1 moderately elongate, apically broadening, 2 broader and shorter, 3 with lobes shortly pedunculate, 5 basally thin, strongly broadening apicad; claws very wide, ventral tooth almost right-angled. Abdomen as for genus.

Material examined. Holotype (NIGP156991): relatively well preserved, intact specimen, not compressed or distorted, with surface of pronotum and part of left elytron somewhat damaged; in centre of irregular rounded block ca. $7.5 \times 5.0 \times 3.5 \mathrm{~mm}$; amber clear with few impurities but with flat vertical film along left side of specimen and horizontal crack around specimen.

Derivation of name. The species is named for its stout legs, from the Latin adjective crassus (stout) and noun pes (a foot); the name is a noun in apposition.

Remarks. This species is seemingly isolated in the group with dentate tarsal claws and geniculate antennae in the form of the legs, with cylindrical (rounded) tibiae and low tubercles not arranged in a row on the outside. Uniquely for this group, it also has the antennae inserted in the basal third of the rostral length and large hemispherical eyes only very narrowly separated dorsally.

Genus Mekorhamphus Poinar, Brown \& Legalov, 2016

Mekorhamphus Poinar, Brown \& Legalov, 2016: 158 [54] (type species, by original designation:

Mekorhamphus gyralommus Poinar, Brown \& Legalov, 2016)

Description. Size. Length 2.84-3.18 mm, width 0.95-1.81 mm. Body and appendages black. Head short to shortly elongate, strongly constricted and dorsoventrally bulging behind eyes. Eyes large, strongly protruding, coarsely facetted, dorsally separated by about basal width of rostrum anteriorly but further separated posteriorly; forehead with a pair of elongate carinate tubercles between eyes. Rostrum longer than pronotum to nearly as long as body, slender, cylindrical, strongly curved; antennal insertions lateral, with scrobes behind them reaching slightly below eye, in front of them laterally with a few long erect setae in apical quarter or more. Gular suture not clearly discernible. Antennae geniculate, long; scapes long, slender, cylindrical, apically clavate, about as long as funicle, reaching below eyes; funicles 7 -segmented, segments $2-5$ subequal in shape, long, slender, apically slightly widened, 6-7 stouter, shorter; clubs large, much broader than funicles, loosely articulated, 4-segmented, segment 4 acute, subflattened, about as long as 3. Mouthparts. Labrum absent. Mandibles small, exodont, articulation horizontal to possibly oblique. Thorax. Prothorax proclinate, often strongly so, with anterior lateral margins oblique in lateral view. Pronotum convex, laterally rounded, with or without tooth, posterior corners distinct, angulate, fitting closely onto elytra; surface coarsely punctorugose, densely setose, setae reclinate, directed anteromesad, mixed brown and coloured; notosternal sutures closed, vertical then abruptly curved anteriad, this part distinctly sulciform (a narrow groove). Prosternum moderately long; procoxal cavities medially confluent, usually closer to posterior margin of hypomeron. Scutellar shield densely setose. Mesocoxal cavities laterally closed. Metanepisterna distinct, densely setose. Mesoventrite short, anteriorly sloping. Metaventrite longer, convex, raised into distinct transverse weals. Elytra broad, basally shortly broadly lobed over pronotum, with rounded humeri, lateral margin strongly sinuate to roundly emarginate in middle; 
posteriorly declivous, apically individually to nearly conjointly rounded, not exposing pygidium; sutural flanges narrow, subequal; surface punctostriate, without scutellary striole, interstriae flat, low, finely rugose, densely setose, setae mainly short (sometimes distinctly longer), mixed brown and coloured, thin, reclinate, directed caudad, interstriae without dense patches of coloured setae. Legs. Procoxae large, prominent, medially contiguous; mesocoxae subglobular, narrowly separated; metacoxae flat, transversely elongate. Trochanters short, oblique. Femora long, subcylindrical, inflated in distal half, outside rounded (profemora) or crenulate in distal half to third (meso-, metafemora). Tibiae compressed, outer edge carinate (protibiae; crenulate in M. gracilipes and M. tenuicornis) or crenulate (meso- and metatibiae), with longer denser setae in distal half, apex obliquely truncate, with 2 spurs; metatibiae dorsally notched at apex (except $M$. beatae). Tarsi almost as long as tibiae; flattened, densely setose; tarsite 1 elongate-triangular, apically excised, 2 shorter, triangular, apically deeply excised, 3 deeply bilobed, lobes pedunculate, inner margin sometimes concave at base, 5 long, slender, apically slightly expanded; claws divaricate, dentate with ventrobasal seta. Abdomen with ventrites 1 and 2 slightly longer than 3, 3 and 4 subequal, sutures between 2 and 5 distinctly grooved.

Derivation of name. The name of the genus is improperly formed and latinised; formed for a "prolonged rostrum" as stated it should have been Mecinorhamphus, as the Greek adjective for prolonged is mekynos (mekos is a noun and means length) and the Greek letter and sound $k$ should have been latinised to $c$ (as the Greek ending -os of rhamphos has been to the Latin -us). An unfortunate concoction but nonetheless nomenclaturally valid.

Remarks. Mekorhamphus was placed in its own tribe, Mekorhamphini, based on its horizontally moving exodont mandibles, 3-segmented maxillary palps, postmedially inserted antennae, elongate prosternum, contiguous procoxal cavities, distinct elytral striae, free ventrites, trochanters separating femora from coxae and first tarsites narrow and weakly extended. Only a few of these characters are correct as given (palps, procoxal cavities, striae); others cannot be compared in the other tribes from which Mekorhamphini were distinguished, because the characters cannot be properly seen in the other specimens, as we could observe, or are imprecisely defined (elongate prosternum, first tarsites). The genus was erected for a single species, $M$. gyralommus, and diagnosed by several characters, most of these being characteristic of all the species now known. Mekorhamphus is a character-rich genus distinguishable from all other Burmese amber weevils by the combination of the carinate tubercles between the eyes, crenulate meso- and metatibiae (sometimes also protibiae, e.g., M. gracilipes), broad, excised tarsites 1 and 2 (the latter more deeply so), strongly pedunculate lobes of tarsites 3 , curved ventrites (one or more) and deeply grooved sutures between ventrites 2 and 5 . The carinate tubercles between the eyes were not described for $M$. gyralommus, but they are present in this species too, just not distinctly visible because they are obscured by setal tufts and only discernible in direct dorsal or frontal views (e.g., Figure 56b,c,f-h and Figure 57f). Mekorhamphus is the only genus of Mesophyletidae that lacks an externally distinct gular suture as we could observe, this seemingly obliterated by the coarse punctorugose sculpturing of the venter. The deeply sulciform horizontal portion of the notosternal sutures and the coarse, dense, deep punctation of particularly the ventral side of the thorax are also characteristic of the genus. The lateral pronotal teeth (one on each side), as described for M. gyralommus, and the long fifth ventrite do not occur in all species of the genus but also in two Myanmarus species (though much more pronounced in Myanmarus dentifer). In most species, including M. gyralommus, the metatibiae (sometimes also the mesotibiae) are distinctly apically excised or notched on the outer side, whereas in other species it appears that the apex of the metatibia is instead strongly obliquely truncate, although compression may obscure the visibility of this character. 


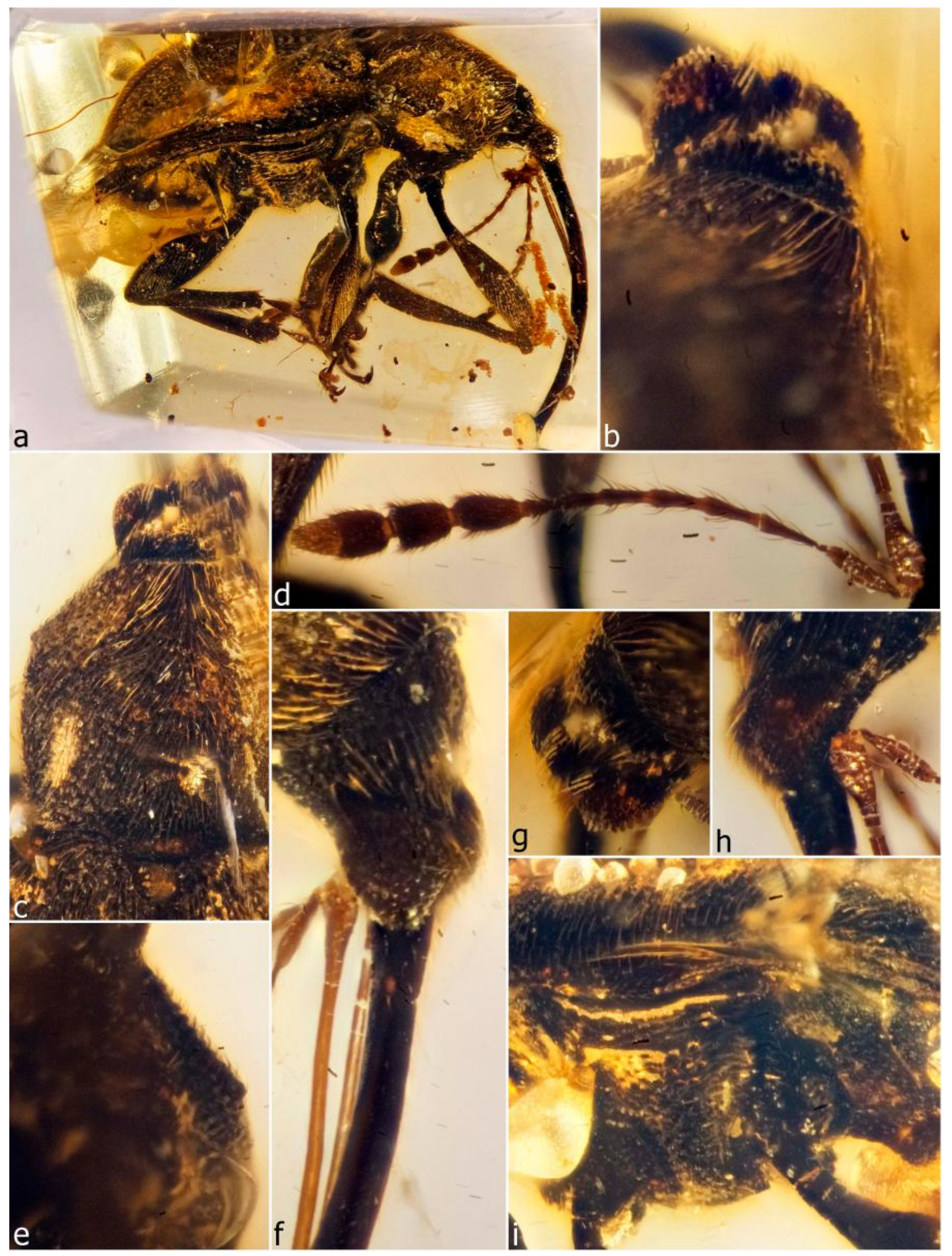

Figure 56. Mekorhamphus gyralommus. Habitus, right lateral (a); head showing tubercles and setal tufts between eyes, dorsoposterior (b); pronotum showing lateral denticle, dorsal (c); left funicle and club, left lateral (d); detail of pronotal denticle, dorsal (e); head, right dorsolateral (f); head, showing detail of tubercles and setal tufts, dorsolateral (g); eyes, left lateral (h); metathorax, left lateral (i). 


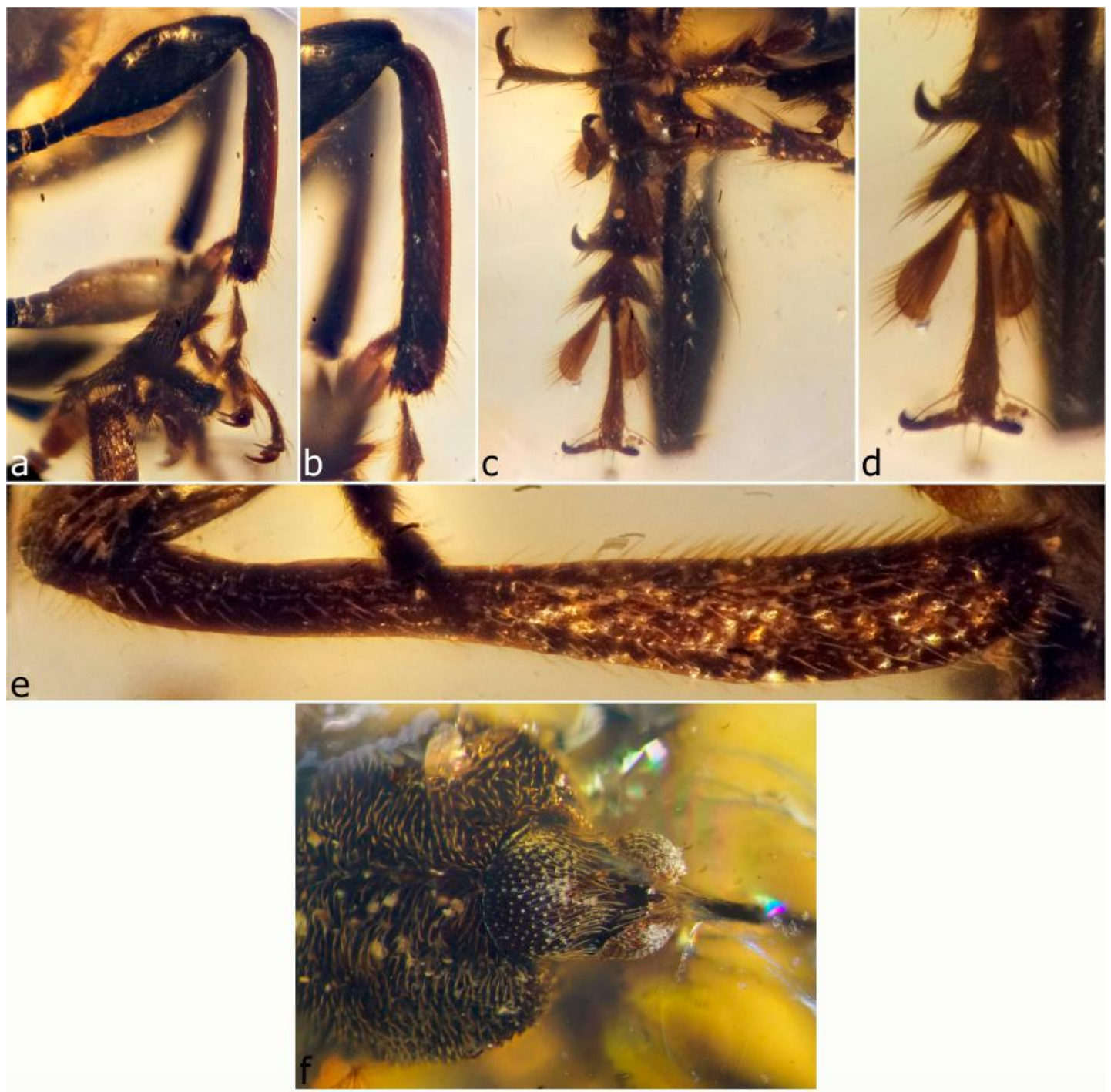

Figure 57. Mekorhamphus gyralommus. Left hindleg, outer side (a); detail of left metatibia, outer side (b); tarsi, dorsal (c); detail of tarsus, dorsal (d); right protibia, inner side (e); Mekorhamphus gyralommus, holotype, head, dorsal view (f).

We recognise five species in Mekorhamphus, four of them here described. We include one other specimen in the genus, but we do not describe and name the species as the specimen is so poorly preserved that it is virtually impossible to adequately compare it with or distinguish it from other species, both the ones here described and possible future ones. Another congeneric specimen, received from the FMNH but too late to be prepared for inclusion in this paper, has a shorter, straighter rostrum and may represent another undescribed species or the male of one of the described ones, in which case substantial sexual dimorphism in rostrum length is indicated to occur in Mekorhamphus.

Mekorhamphus gyralommus Poinar, Brown \& Legalov, 2016 (Figures 56 and 57)

Mekorhamphus gyralommus Poinar, Brown \& Legalov, 2016: 158 [54]

Redescription. Size. Length 2.84-3.06 mm, width 1.42-1.54 mm. Body coarsely punctate, densely setose; setae short, subrecurved; sparser ventrally. Head shortly elongate, narrow; coarsely densely punctorugose, setose; with tubercles tracking inner margin of eyes, somewhat concealed by tufts of dense long curved whitish setae converging at base of rostrum and continuing along rostrum in grooves and thinning toward antennal insertions; forehead (between tubercles) grooved; ventrally coarsely punctorugose, no gular suture discernible. Eyes without interfacettal setae; slightly elongate. Rostrum about as long as elytra, strongly downcurved; dorsally with median, paramedian and dorsolateral 
irregular carinae extending to apex, and with deep intervening setose grooves in basal half reaching antennal insertions; antennal insertions slightly postmedian, in front of them with 5 short widely spaced setae in lateral groove. Antennae. Scapes apically distinctly oblique; funicles with segment 1 elongate, widening distad, slightly wider than rest of funicle, 2 slightly obconical, slightly shorter, 3-6 subcylindrical, slightly broader apically, 7 obconical; clubs about as long as funicle segments 3-7, segments 1 and 2 obconical, 1 apically rounded, 2 slightly broader, apically flattened, shorter than 1, 3 shorter, 4 subequal in length to 3 , slightly paler, narrowly rounded, broadly inserted into 3. Mouthparts. Mandibles small, with 3 teeth on outside, 2 short triangular teeth basally, at least 1 large tooth on inside, apex forming $\mathrm{V}$ with apical-most inner and outer teeth, articulation oblique. Thorax. Prothorax proclinate, slightly narrower than elytra, coarsely punctate. Pronotum laterally with distinct but small denticle in apical third, base sinuate, closely fitting to elytra, posterior corners acutely angulate; with vestiture of mixed whitish and brownish setae. Prosternum short, ca. half as long as procoxae, anteriorly sloping, anterior margin substraight, prosternal process short, pointed; procoxal cavities slightly closer to posterior margin of hypomeron, this deeply, narrowly emarginate medially and with broad triangular hypomeral process. Scutellar shield elongately trapezoidal, covered with short whitish setae. Elytra with striae and interstriae subequal in width at least basally; strial punctures deep but narrow; interstriae prominent, more so basally, 1 (sutural) distinctly raised, lined with brownish setae, 8 more prominent than others, subcarinate, forming lateral margin visible in dorsal view, 9 subcarinate in basal third of length, becoming obsolete before about middle; elytral bases strongly sinuate; sides with distinct setose marginal groove, widening anteriad, with distinct anterior marginal notch; apices when fully closed weakly triangularly emarginate, nearly conjointly rounded; vestiture of largely whitish setae but mixed with some brownish setae. Legs long, slender; densely setose, covered with short subappressed golden or whitish setae, densest on femora; forelegs longer than middle legs, these slightly longer than hindlegs. Procoxae subconical. Protibiae swollen distally, outer edge carinate, broadly curved in distal half, inner edge straight with row of short oblique setae in distal half, apically without fringing setae, with 2 short spurs; mesotibiae apically abruptly curved inwards; metatibiae straight, shorter than mesotibiae, meso- and metatibae with outer edge finely carinate-crenulate, straight, notched at apex, inner and outer apical flanges with long coarse fringing setae, with 2 spurs, outer one on metatibiae robust, curved, inner one tiny, less than half length of larger spur. Tarsi at least half as long as tibiae (protarsi half, mesotarsi ca. $0.75 \times$ ), mesotarsi shorter and narrower than protarsi, ventrally with dense setal pads; tarsite $1 \mathrm{ca}$. twice longer than 2 , 3 strongly pedunculate, lobes elongate, ca. $0.5-0.75 \times$ as long as 5,5 slender, gradually expanding apicad. Abdomen. Ventrites subflatly aligned; densely setose, setae whitish; 1 and 2 subequal in length, 3 and $4 \mathrm{ca}$. half as long, subequal in length; sutures between 1 and 2 less distinctly grooved than between 2 and 5, sutures broadly curved, then kinked just before margin.

Material examined. Holotype (ISEA no. MA 2015/1), length $2.84 \mathrm{~mm}$, width $1.42 \mathrm{~mm}$ : well preserved specimen, visible from all sides, slightly depressed, with eyes partly compressed, elytra and thoracic venter with fragmented debris coating, right mesotarsus missing, right protarsus, right metatarsus and left mesotarsus missing tarsites 3-5 (latter claw segment in amber), left metatarsus missing lobes of tarsite 3 and claws; re-prepared from slightly larger cuboid amber piece from which original description was prepared, now at one end of cuboid $7.8 \times 4.3 \times 3.3 \mathrm{~mm}$; amber clear yellow with few large impurities, with two large discoidal fracture planes around specimen. Other material. One (probably female) specimen (GPIH no. 4987; coll. Gröhn no. 11145), length 3.06 mm, width 1.32 $\mathrm{mm}$ : near-perfectly preserved, intact and well-visible; re-prepared from ca. $20.0 \times 14.0 \mathrm{~mm}$ amber cabochon, now in irregular wedge, $5.5 \times 2.7 \times 2.5 \mathrm{~mm}$, with one curved face; amber clear yellow with few organic impurities, some larger scattered masses to left of specimen, with large bubble emanating from and obscuring apical ventrites and small bubble at apex of rostrum partly cut away and exposing mandibles (both infilled with resin; see Section 2.2), with numerous other smaller bubbles emanating from specimen and several small fractures on left and dorsal sides of specimen. 
Remarks. This species is distinguishable from all other Mekorhamphus species by the tufts of long setae between the eyes and the consequently indistinct tubercles, in concert with the slightly elongate head and eyes. It was described as having slightly curved protibiae with a small mucro; the protibiae are in fact distinctly curved ('machete'-shaped) and no mucro is evident in either of the specimens we examined. In the holotype there is a slight notch at the outer angle of the right protibia, with a coarser seta, but this is not matched on the other protibia and there is no mucro on the inner angle. We examined a second, very similar but slightly larger, evidently conspecific specimen that is much better preserved than the holotype and differs mainly in having a longer rostrum and some details that appear related to distortion in the holotype. Of particular importance in matching the two specimens is the form of the head and tubercles, the straight inner protibial edge lined with oblique setae and the curved outer edge of the protibiae. Mekorhamphus poinari has similarly modified but differently shaped protibiae and also anterolateral pronotal teeth, but its eyes are rounder, the tubercles between the eyes more conical and the metatibial spurs diminished and projecting distad (possibly fixed, the inner one much smaller).

Mekorhamphus beatae Clarke \& Oberprieler, sp. n. (Figures 58 and 59)

Description. Size. Length 3.01-3.31 mm, width $1.59 \mathrm{~mm}$ or more. Body coarsely, densely punctate; densely setose. Head grooved around lower sides of eyes. Eyes large, globular, facing forward, dorsally separated by about basal width of rostrum or less; forehead raised into 2 short, flat and blunt, keel-like longitudinal tubercles between eyes, distinctly grooved between them. Rostrum ca. $2.4 \times$ longer than pronotum; antennal insertions in ca. middle of rostral length, behind them with scrobes reaching base of eye, in front of them with lateral row of ca. 5 long, erect setae. Antennae very long; scapes slightly longer than funicle, terete, thin, apically oblique; funicles with segment 1 elongate, cylindrical, 2 subequal in length but slightly narrower proximally, 3-5 similar but progressively shorter, 6 and 7 slightly thicker, shorter; clubs slightly flattened, especially segment 4 , much broader than funicles, segments 1-3 obconical, 2 shorter and wider, 4 distinct but fitting closely onto 3, flat. Mouthparts. Mandibles narrow, strongly exodont, outer edge with 3 large blunt teeth, middle one directed obliquely down, apical one forming broad sharp $\mathrm{V}$ with opposing inner one, the latter double ( 2 above each other), inner edge with 2 or 3 teeth, basal one(s) large. Labial palps long, 2-segmented Thorax. Pronotum broadly ogival, strongly convex, laterally rounded, without lateral tooth, posterior corners extended, fitting closely onto elytra, densely coarsely punctate-tuberculate, setae arising from punctures raised on small low tubercles, pale. Prosternum moderately long, strongly declivous, anterior margin broadly emarginate; procoxal cavities in about middle of prothorax. Scutellar shield small, prominent. Elytra shortly elongate, posteriorly gently declivous, punctostriate but striae indistinct; densely setose, setae directed mesocaudad to caudad; sides without carinate interstria 8 , with setose marginal groove gradually widening anteriad, anterior marginal notch present; bases weakly sinuate, slightly extended over pronotum, apically individually rounded but closely fitting. Legs long, slender. Procoxae subconical; mesocoxae globular, subflat, narrowly separated. Femora inflated, slightly compressed, almost straight, outside with crenulate carina in distal $40 \%$ of length, weaker on profemora. Tibiae substraight, slightly curved inwards at apex, outer side carinate (protibiae) or carinate-crenulate (meso- and metatibiae); apically truncate, with tarsal articulation surfaces oblique, with long coarse fringing setae, with 1 (protibiae) or 2 long stout spurs (meso- and metatibiae, on latter unequal, inner one larger). Tarsi ventrally with dense setal pads; tarsite 1 slightly longer than 2, 3 with pedunculate lobes ca. half as long as 5, 5 as long as $1+2$, broadening distad. Abdomen. Ventrites stepped, densely setose, 3-4 with setae ca. $2.0 \times$ longer than those on 1-2, 1-2 subflatly aligned, subequal in length, 3-5 at slightly higher levels, $3-4$ very short, subequal in length, ca. half as long as 2, 4 shorter than 3, 5 seemingly shorter than 4, retracted; suture between 1 and 2 slightly curved, between 2 and 3 slightly sinuate, between 3 and 4 distinctly sinuate, between 4 and 5 seemingly weakly sinuate, between 2 and 5 forming deep groove, with broad gap between ventrites 2 and 3 and 3 and 4 near middle. 


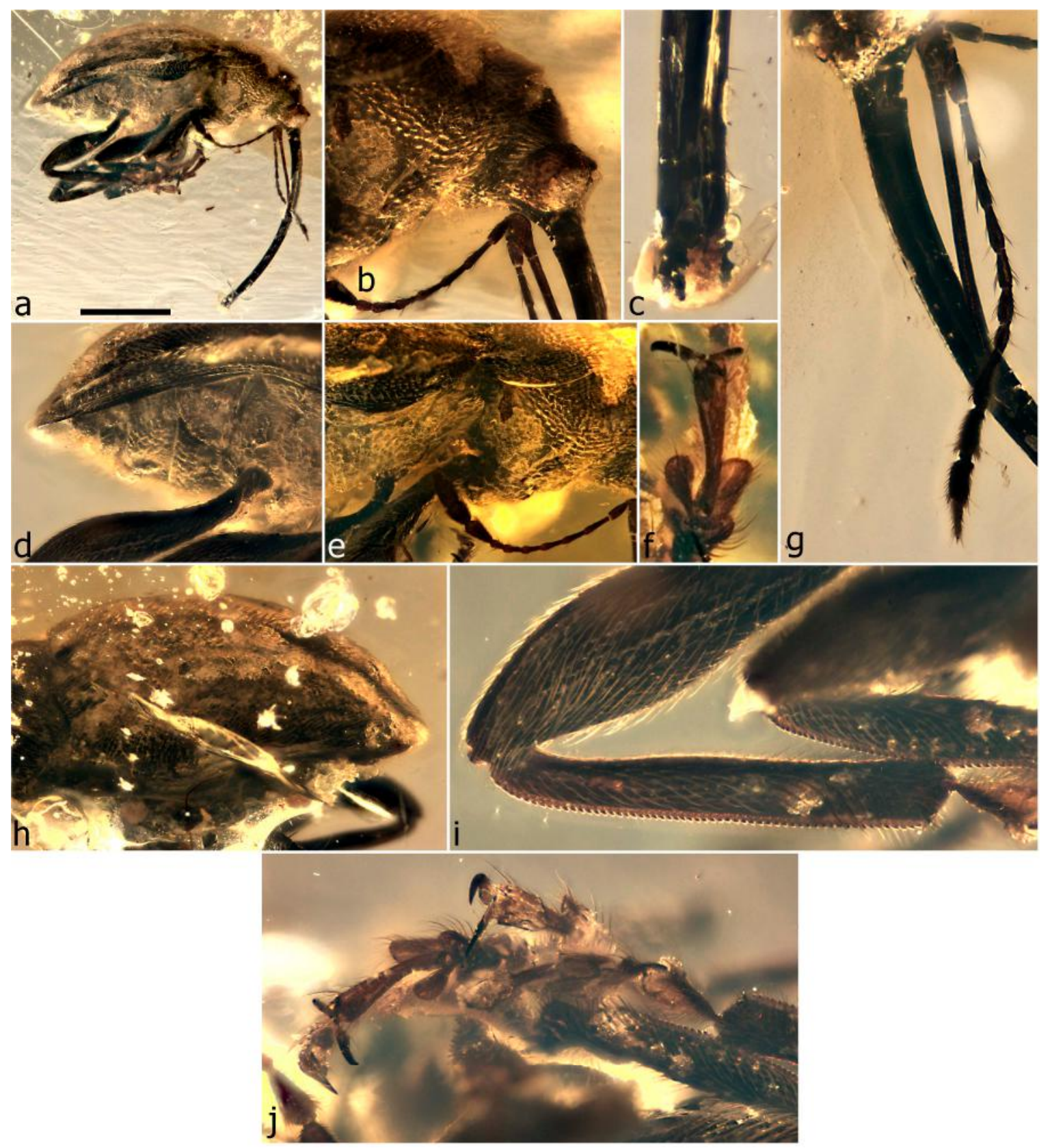

Figure 58. Mekorhamphus beatae sp. n., holotype. Habitus, right lateral (a); head and prothorax, right lateral (b); apex of rostrum and mandibles, dorsal (c); ventrites, right lateral (d); prothorax and anterior pterothorax, right lateral (e); tarsites 2-5, dorsal (f); left antenna, left lateral (g); elytra, left lateral (h); right metatibia (outer side) showing crenulation (i); tarsi (j). Scale bars: $1.0 \mathrm{~mm}$ (a).

Material examined. Holotype (NIGP156992; Figure 58), length $3.01 \mathrm{~mm}$, width $1.59 \mathrm{~mm}$ : exceptionally well preserved, nearly intact specimen, missing only claws of right hindleg, well visible (including mandibles) except from left side, surface details generally obscured by mostly even film of whitish debris; near edge of subovoid slab, $5.8 \times 3.2 \times 3.0 \mathrm{~mm}$; amber clear yellow without impurities, with numerous bubbles and few small fractures on left and partly obscuring that side of specimen. Paratype (in private collection of Wei Ma, China; Figure 59), length $3.31 \mathrm{~mm}$, width not measurable due to curvature of amber block: very well preserved, intact specimen, not compressed or distorted, well visible from both left and right but not from other sides due to shape of amber block; at an angle in centre of lenticular block with flat surface on left side of specimen, $16.1 \times 10.3 \times 6.3 \mathrm{~mm}$; amber clear 
but with layer of sparse bubbles along right side of specimen, also other impurities but not obscuring specimen (which will be almost perfectly and totally visible if amber is cut down).

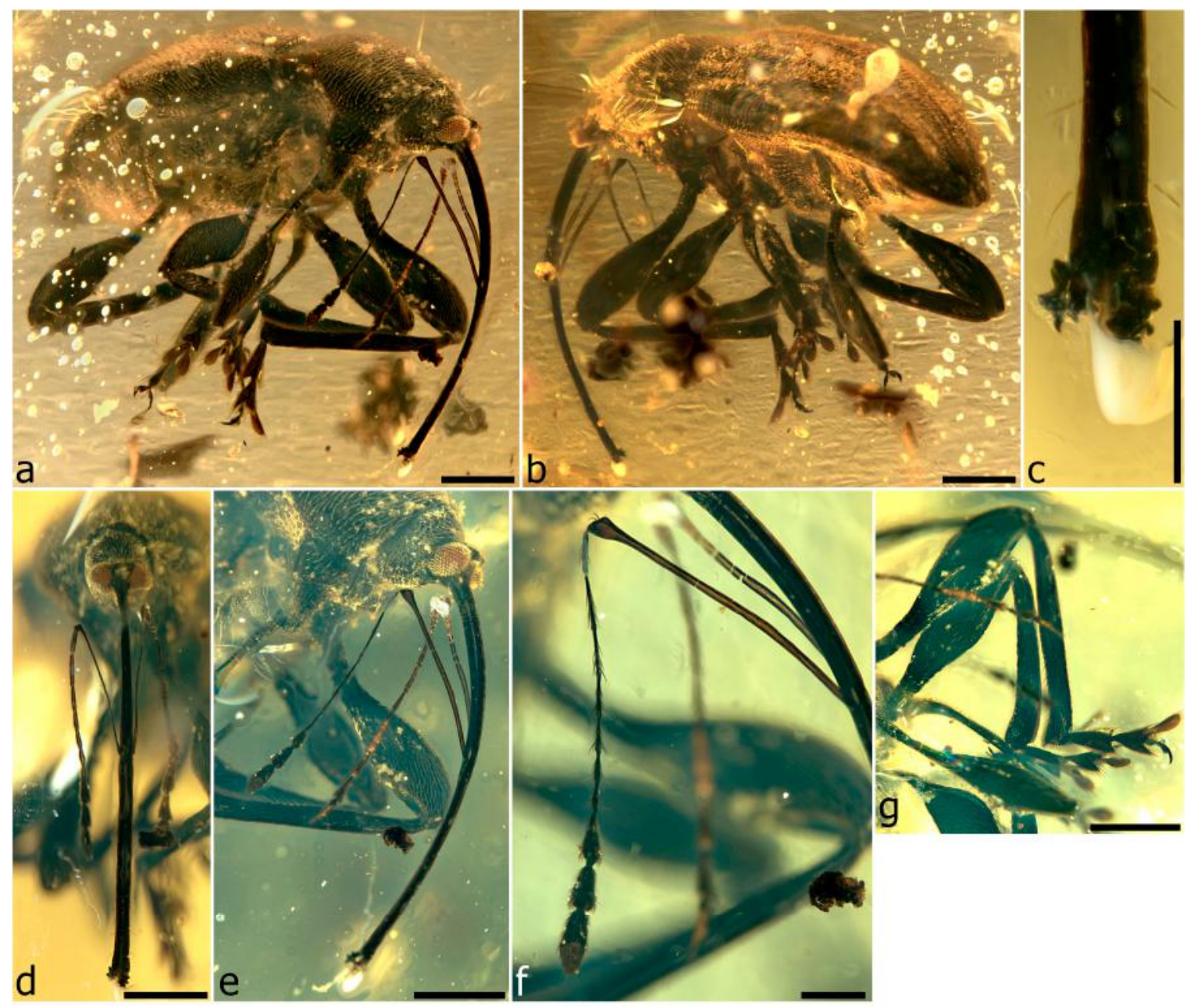

Figure 59. Mekorhamphus beatae sp. n., paratype. Habitus, right lateral (a); habitus, left lateral (b); apex of rostrum and mandibles (c); head and antennae, frontal (d); head and prothorax, right lateral (e); right antenna, lateral (f); anterior legs (g). Scale bars: $0.5 \mathrm{~mm}(\mathrm{a}, \mathrm{b}, \mathrm{d}, \mathrm{e}, \mathrm{g}) ; 0.2 \mathrm{~mm}(\mathrm{c}, \mathrm{f})$.

Derivation of name. This striking species is cordially named after Beate Oberprieler, wife of the senior author, in grateful recognition of her sacrifice of so many family hours and use of the family dinner table for our study of these fossils. The name also recalls the beauty and exceptional preservation of the specimens, the Latin adjective beatus meaning happy, fortunate, blessed.

Remarks. This species differs from M. gyralommus and M. poinari in having a laterally smooth prothorax, without any dentiform processes, and in a much longer and thinner rostrum. It differs from M. gracilipes in its shorter, stouter tarsi, dorsally carinate protibiae, less strongly curved ventrites and apically truncate metatibiae (not or weakly notched), and from $M$. tenuicornis it is distinguishable by its uniformly short elytral vestiture and dorsally carinate protibiae. The two specimens are virtually identical except that the paratype is slightly larger, and the very long, thin rostrum indicates both to be females. The holotype was submitted for CT scanning, but the contrast between the specimen and the amber was too low to permit any meaningful visualisation of the specimen.

Mekorhamphus gracilipes Clarke \& Oberprieler, sp. n. (Figures 60 and 61)

Description. Size. Length $2.85-3.2 \mathrm{~mm}$, width $1.5-1.8 \mathrm{~mm}$. Entire body coarsely and densely punctate. Eyes large, globular, lateral, separated dorsally by about a basal rostral width. Rostrum ca. $2 \times$ longer than pronotum (cut away apically); antennal insertions median, behind them with scrobes 
reaching eye, in apical quarter with lateral row of ca. 5 long, erect setae. Antennae very long, thin; scapes long, slightly longer than funicles, thin, apically oblique, reaching below eye; funicles with segment 1 slender, cylindrical, 2 subequal in length but slightly narrower proximally, 3-5 similar but progressively shorter, 6 and 7 slightly thicker, shorter; clubs slightly flattened, especially segment 4 , segments 1-3 obconical, subequal in length; 4 broadly inserted into and slightly shorter than 3 , apically narrowly rounded. Mouthparts (not preserved, cut away with amber). Thorax. Prothorax strongly proclinate. Pronotum broadly ogival, densely and coarsely punctate, laterally without tooth, sparsely setose, posterior angles acute, fitting closely to elytra. Prosternum long, anterior margin broadly arcuate, prosternal process short, pointed; procoxal cavities medially confluent, closer to posterior hypomeral margin. Scutellar shield narrowly roundedly triangular, raised, densely setose. Elytra short and broad, with well-developed, broadly rounded humeri, posteriorly gently declivous, apically individually rounded, surface indistinctly punctostriate, densely covered with long, recumbent setae; sides lacking any keel, margin with anterior marginal notch. Legs long, slender. Procoxae subconical; mesocoxae narrowly separated. Femora long, slightly compressed. Tibiae long and slender, pro- and metatibiae longer than mesotibiae; nearly straight, slightly widening distad, pro- and mesotibiae not bent inward apically, outer side crenulate, outer edge of metatibiae (and possibly mesotibiae, apices obscured or slightly distorted) distinctly emarginate apically; apex of pro- and mesotibiae obliquely truncate, of metatibiae squarely truncate, all with 2 long, sharp, slightly curved, equal spurs; apical edges with coarse fringing setae, tarsal articulation surfaces oblique. Tarsi shorter than tibiae; tarsite 1 longer and narrower than 2, 3 with lobes pedunculate, each ca. half as long as 5, 5 subequal to or slightly shorter than $1+2$ on pro- and mesotarsi, longer than $1+2$ on metatarsi. Abdomen. Ventrites subflatly aligned, curved (especially 2-4), 1 and 2 subequal in length, 3 half as long as 2, 4 slightly shorter than 3 , 2-5 with long erect setae, 5 broad, slightly shorter than 4 ; sutures distinctly curved, between ventrites 1 and 2 very slightly curved at middle but laterally kinked (deflected posterodorsally), between 2 and 5 strongly arcuate, forming broad gap at middle (gap narrow between ventrites 1 and 2).

Material examined. Holotype (NIGP156993; Figure 60), length $3.18 \mathrm{~mm}$, width $1.81 \mathrm{~mm}$ : exceptionally well preserved, nearly intact and well visible specimen, slightly depressed and distorted (prothorax, and right protibia bent inwards apically), with apical part of rostrum cut away with amber, with fragmented coating of whitish debris; in cuboid $7.2 \times 4.3 \times 3.5 \mathrm{~mm}$, with one rounded face; amber clear yellow, with faint flow bands, few impurities, with several smaller subcircular fractures around and partly obscuring specimen. Paratype (NIGP156994; Figure 61), length $2.85 \mathrm{~mm}$, width ca. $1.52 \mathrm{~mm}$ : reasonably well preserved specimen, not distorted but legs somewhat compressed, head, tip of rostrum and outside of left elytron cut off; in left side of irregular block with rectangular front surface $2.7 \times 2.3 \mathrm{~mm}$ and tapering towards back, $4.0 \mathrm{~mm}$ long; amber clear but with curved layer of flow lines with bubbles along right side and small horizontal crack at back of specimen, also large bubble below right profemur.

Derivation of name. The species is named for its long, slender legs, especially the tarsi.

Remarks. Mekorhamphus gracilipes also differs from M. gyralommus and M. poinari in having a laterally smooth prothorax, without any dentiform processes. It is very similar to $M$. beatae, differing in the dorsally rounded profemora, longer thinner tarsi, finer tibial crenulation, distinctly apically notched metatibiae, flatly aligned and distinctly curved ventrites (especially 3 and 4) and short but distinctly visible ventrite 5 . It is similar to $M$. tenuicornis in having long slender legs and distinctly apically notched metatibiae (also with long thick spurs), but it differs in having the pronotal setae not inserted on small tubercles and dense long recumbent setae on the elytra, as well as apically less strongly excised tarsites 2 . The two specimens available for study are virtually identical, differing in no significant characters. 


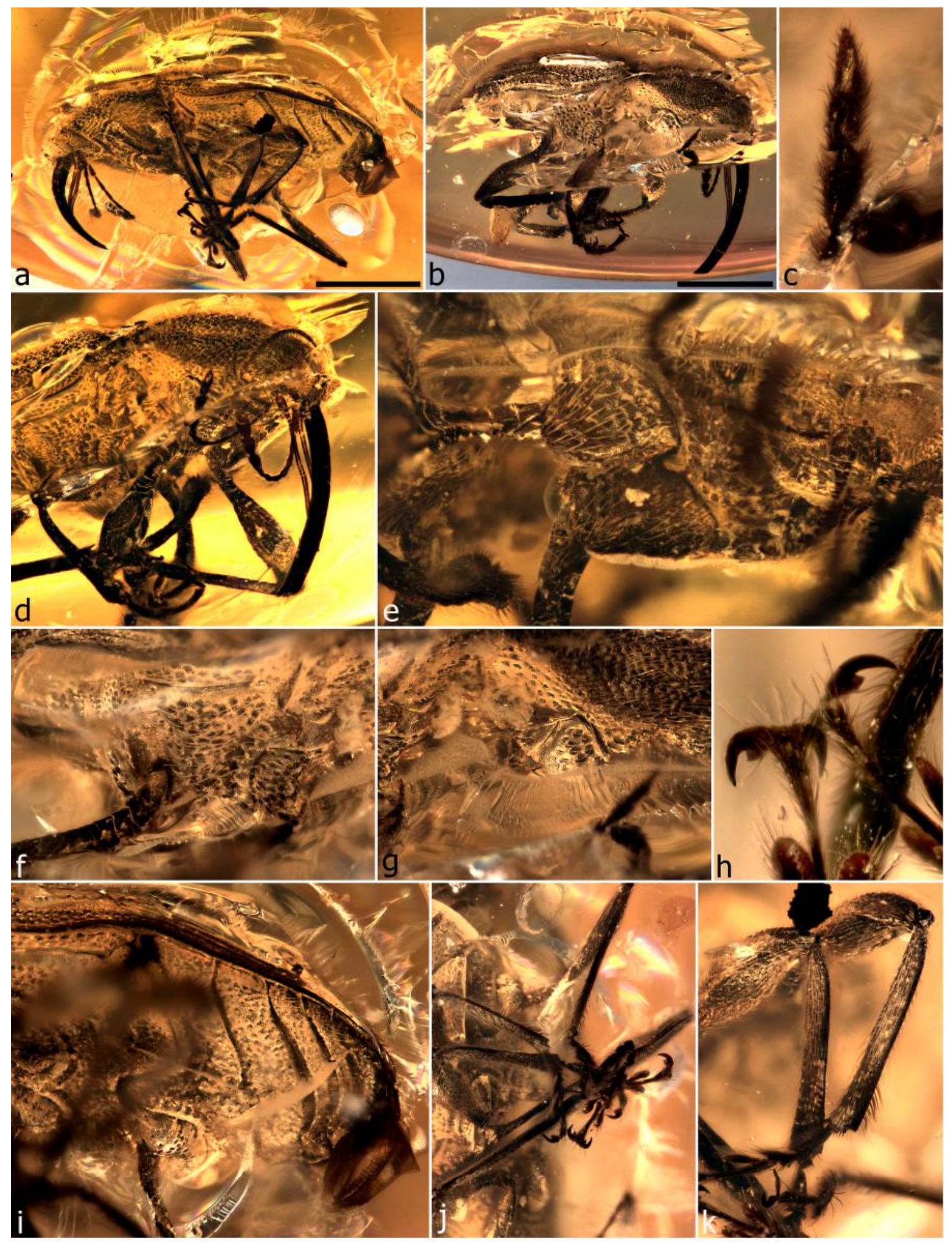

Figure 60. Mekorhamphus gracilipes sp. n., holotype. Habitus, left ventrolateral (a); habitus, right lateral (b); detail of antennal club (c); head and thorax, oblique frontal (d); prothorax and coxae, ventrolateral (e); metathorax, lateral (f); prothorax showing notosternal suture (g); tarsal claws (h); ventrites, ventrolateral (i); legs (j); meso- and metatibiae, outer sides (k). Scale bars: $1.0 \mathrm{~mm}(\mathrm{a}, \mathrm{b})$. 

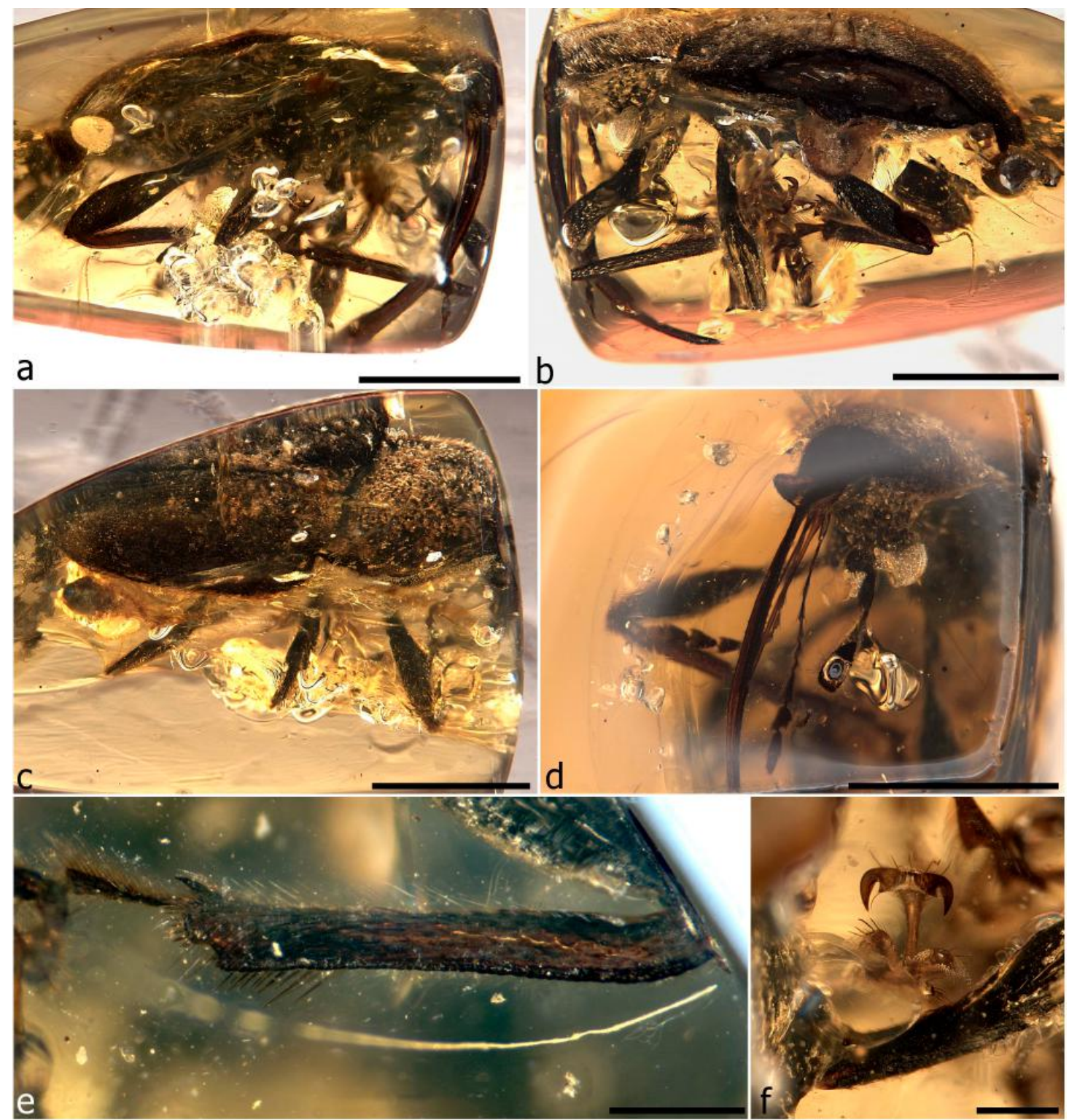

Figure 61. Mekorhamphus gracillipes sp. n., paratype. Habitus, right lateral (a); habitus, left lateral (b); habitus, dorsal (c); head and antennae, frontolateral (d); right metatibia showing subdued crenulation (e); claw, apical (f). Scale bars: $1.0 \mathrm{~mm}(\mathbf{a}-\mathbf{d}) ; 0.2 \mathrm{~mm}(\mathrm{e}, \mathrm{f})$.

Mekorhamphus tenuicornis Clarke \& Oberprieler, sp. n. (Figure 62)

Description. Size. Length $2.85 \mathrm{~mm}$, width $0.95 \mathrm{~mm}$. Head subglobular. Eyes dorsally narrowly separated. Rostrum longer than pronotum; antennal insertions in middle of rostral length, behind them with long narrow scrobes extending to eye, in apical quarter with lateral row of few long, erect setae. No gular suture visible. Antennae. Scapes apically abruptly clavate, strongly oblique; funicles slightly longer than scape, segments elongate, thin, 6 and 7 somewhat shorter and broader; clubs flattened, with segment 4 distinct. Mouthparts. Mandibles with 3 triangular teeth on outside and narrow apical point. Thorax. Prothorax strongly proclinate. Pronotum elongate, laterally without tooth, posterior angles acute, fitting onto elytra; sparsely setose, setae inserted on small tubercles, moderately long, thin, dark brown. Prosternum with position of procoxal cavities not discernible. Scutellar shield small, transverse (obscured). Metaventrite convex. Elytra elongate, with well-developed, broadly rounded humeri, anterior bases lobed, enclosing scutellar shield, posteriorly gently declivous, apically individually rounded; surface coarsely punctostriate but striae faint, interstriae narrow, roundly subcarinate, with 
sparsely vestiture of long, thin, dark brown, suberect setae directed caudad. Legs. Procoxae elongate, somewhat flattened, narrowly separated. Femora long, straight, slightly compressed, outside rounded (profemora) or crenulate in distal quarter of length (meso-, probably metafemora) Tibiae long, straight, outer edge crenulate, apex obliquely truncate, with 2 long, sharp spurs; metatibiae apically distinctly emarginate on outside. Tarsi nearly as long as tibiae; tarsites with long erect stiff setae, 1 longer than 2 , 2 apically bilobed (deeply excised), 3 deeply bilobed, lobes pedunculate, 5 as long as $1+2$. Abdomen with ventrites 1 to 2 subequal in length, 3 and 4 each half as long as 2, 5 not clearly discernible, apparently shortly triangular.

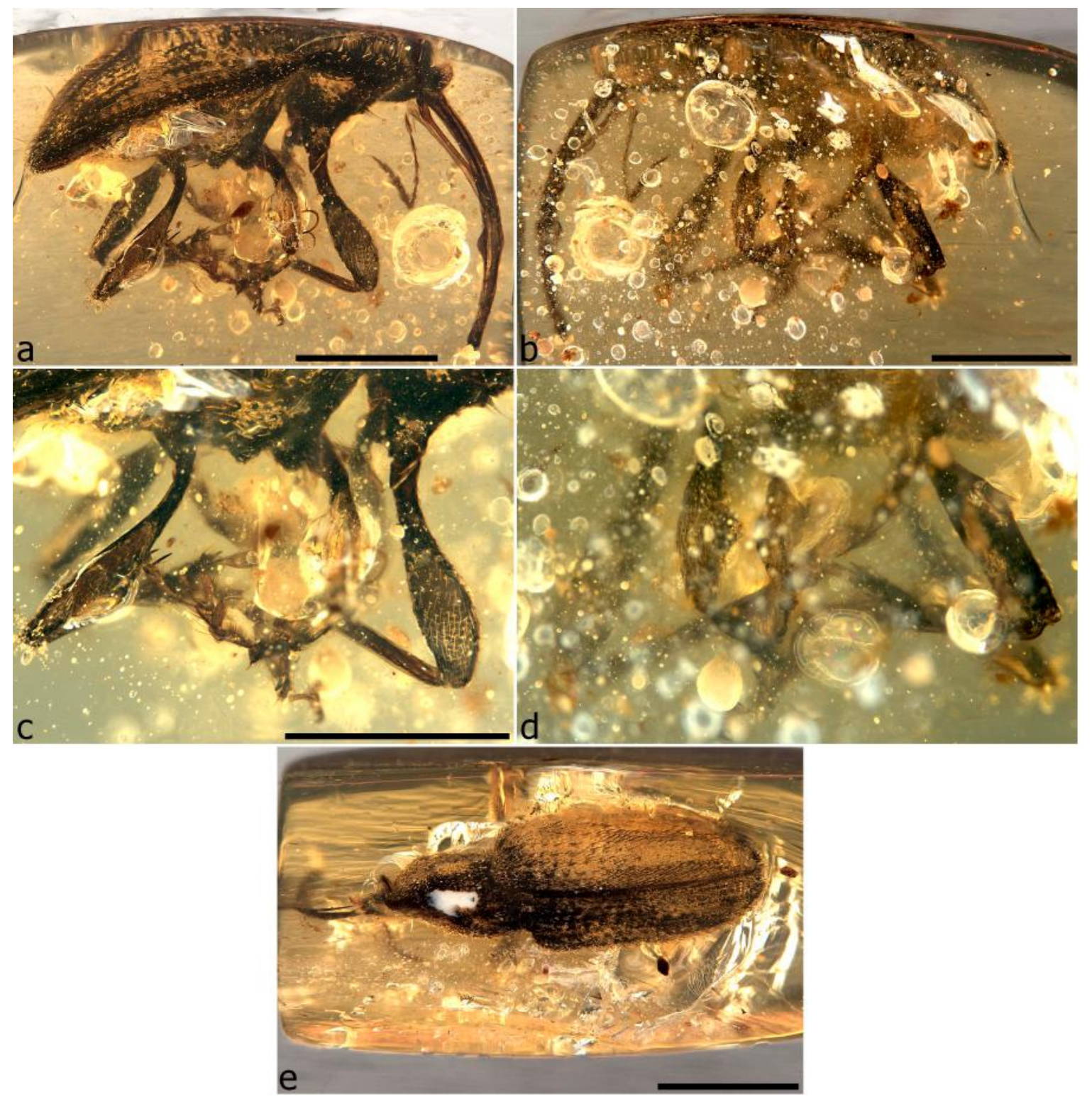

Figure 62. Mekorhamphus tenuicornis sp. n., holotype. Habitus, right lateral (a); habitus, left lateral (b); legs, right lateral (c); legs, left lateral (d); habitus, dorsal (e). Scale bars: $1.0 \mathrm{~mm}(\mathrm{a}-\mathrm{c}, \mathrm{e})$.

Material examined. Holotype (NIGP156995): reasonably well-preserved specimen, slightly distorted in dorsal view, with legs and rostrum compressed, pronotum dorsally slightly cut into; in middle but close to dorsal surface of rectangular cuboid $4.3 \times 3.0 \times 2.0 \mathrm{~mm}$; amber clear but with many subparallel vertical flow lines on right and vertical layer of dense bubbles and impurities of varying sizes on left side of specimen, largely obscuring it. 
Derivation of name. This species is named for its narrow antennae, the name being a Latin adjective.

Remarks. The species differs from M. gyralommus and M. poinari in having no lateral pronotal denticles and from M. gracilipes (both specimens) and M. beatae in the elytra being sparsely covered in long, thin, dark, suberect setae directed caudad and the bilobed (very deeply excised) tarsites 2 . It is further distinct from $M$. beatae in the apically emarginate metatibiae with long thick spurs and from $M$. gracilipes in the distinctly crenulate tibiae, much slenderer funicles, with segments 6 and 7 slightly broader, and the differently shaped ventrites.

Mekorhamphus poinari Clarke \& Oberprieler, sp. n. (Figure 63)

Description. Size. Length $2.94 \mathrm{~mm}$, width $1.45 \mathrm{~mm}$. Entire body coarsely and densely punctate. Head. Forehead with pair of flat and blunt, slightly oblique, keel-like tubercles between eyes. Eyes large, convex, semicircular, separated dorsally by about basal rostral width, very slightly further separated posteriorly. Rostrum ca. $1.5 \times$ longer than pronotum; moderately curved; antennal insertions median, behind them with scrobes reaching base of eye, in front of them with long fine erect setae. Antenna. Scapes elongate, longer than funicle, reaching to below eye, apically oblique; funicles with segment 1 subequal in length to 2, 2 slightly shorter than 1, longer than 3, 3 longer than 4 ; clubs with segment 4 broadly inserted onto 3, narrowly rounded apically (other funicle segments and rest of club not visible). Mouthparts. Mandibles on outer side with 3 teeth, on inside with at least 2, articulation plane oblique. Maxillary palps projecting slightly obliquely forwards, 3-segmented, basal segments shorter, broader, than elongate, tapering apical segment. Thorax. Prothorax strongly proclinate. Pronotum broadly roundly subquadrate, narrowed anterolaterally, with small dentiform process at anterior half, with slight but weakly concave anteromedial collar; densely setose, setae mostly whitish mixed with fewer blackish setae; posterior corners distinctly angulate; notosternal sutures vertical, then abruptly angulated anteriad. Prosternum short, about half as long as procoxae, anterior margin emarginate, prosternal process short, acute; hypomeron ca. half as long as prosternum. Scutellar shield prominent, covered in light setae. Metaventrite short, ca. half as long as mesocoxa. Elytra punctostriate, densely setose, setae largely whitish; bases subsinuate, humeri broadly rounded; apices individually rounded, meeting almost evenly at suture. Legs long, slender, densely setose. Procoxae conical; mesocoxae narrowly separated, very large, subglobular, apparently longer than wide, longer than metaventrite. Femora with outer edges obscured. Tibiae long, slender, on outer edge carinate-crenulate; apically with tarsal articulation surfaces suboblique, with coarse fringing setae, few short dorso-apical setae and 2 spurs; protibiae somewhat slightly abruptly expanded apicad, outer edge in apical half slightly convexly produced, with matching slight broad concavity lined with dense oblique setae; mesotibiae straight; metatibiae slightly expanded apically, covered with long setae, outer side apically emarginate (also on mesotibiae) and with fine fringing setae lining apical edges; with 2 spurs, outer one more distinct. Tarsi with tarsite 1 apically excised, 2 shorter and wider than 1, deeply excised, 3 pedunculate, ca. $0.5-0.67 \times$ as long as 5,5 about as long at $1+2$, longer on hindlegs. Abdomen. Ventrites setose, seemingly partly curved; 1 and 2 subequal, 1 somewhat inflated, 2-5 subflatly aligned, $3 \mathrm{ca}$. half as long as 2, 4 shorter than 3, 5 subequal in length to 4 , thin and broadly rounded apically; sutures between 3 and 5 distinctly grooved.

Material examined. Holotype (NIGP157009), probably male: well preserved, moderately well visible specimen, with fragmented coating of debris over particularly dorsal side, missing claw segment of right protarsus and tarsites 3-5 of right mesotarsus, right fore- and middle legs partly cut away with amber at femorotibial joints, antennal clubs and most of funicles not visible; in angulate cuboid, $4.2 \times 3.3 \times 2.5 \mathrm{~mm}$; amber clear yellow, somewhat hazy, with many impurities and bubbles obscuring clear view of specimen, one bubble near head and few on right side exposed and later infilled with resin (see Section 2.2), with large fracture running transversely-obliquely through block, intersecting specimen at pronotal-elytral juncture.

Derivation of name. This species is named after George Poinar Jr., in recognition of his wide-reaching contributions to the study of amber fossils, especially the biota preserved in Burmese 
amber, and for facilitating the study of type material housed in his collection (PACO), which greatly enhanced and enriched our work.

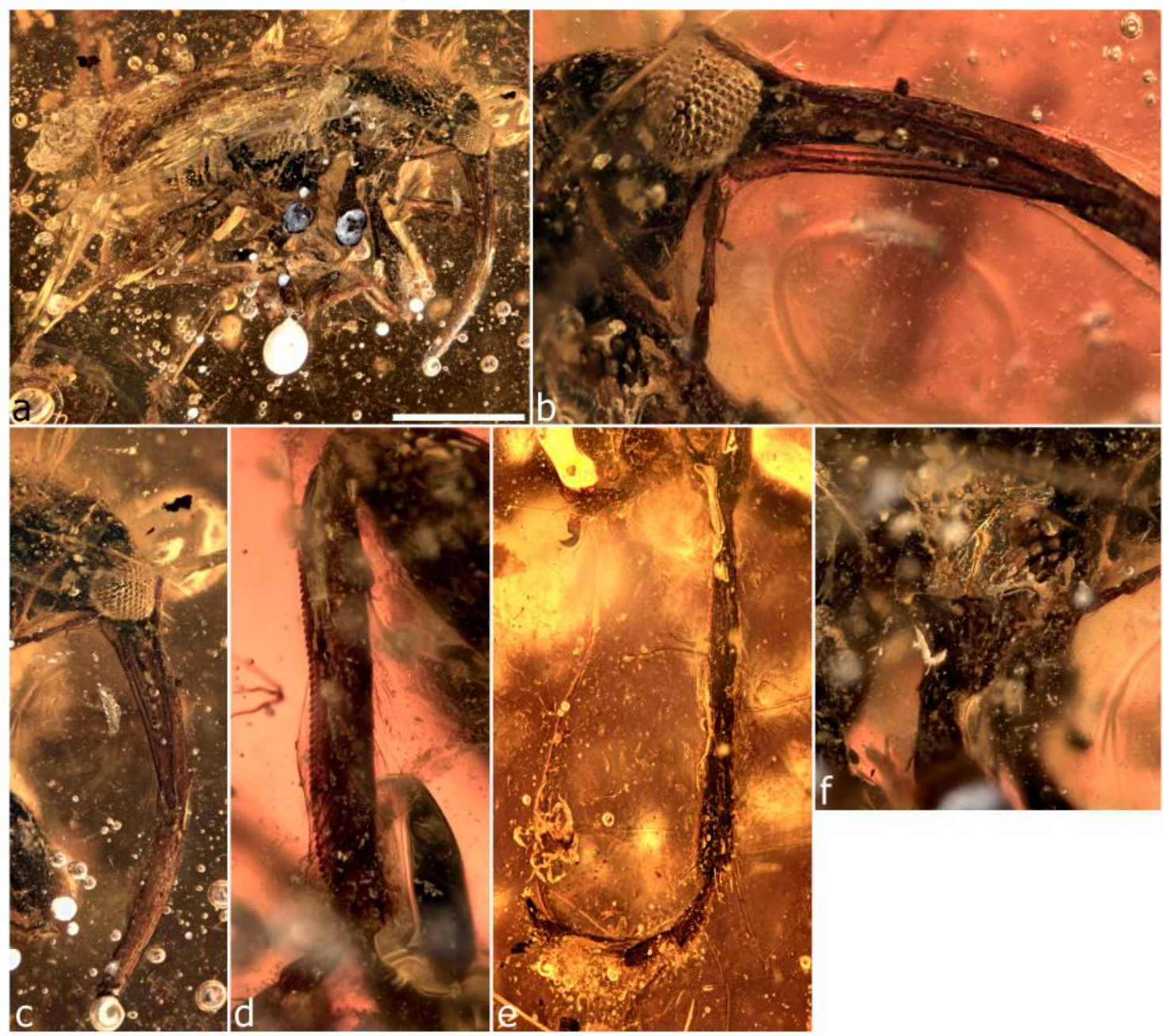

Figure 63. Mekorhamphus poinari sp. n., holotype. Habitus, right lateral (a); detail of head, right lateral (b); head, right lateral (c); right metatibia (d); left mesotibia and -tarsus, dorsal (e); prothorax showing notosternal suture, right lateral (f). Scale bar: $1.0 \mathrm{~mm}(\mathrm{a})$.

Remarks. This is the only other Mekorhamphus species in our sample with a small, flat, dentiform process on each side of the pronotum, as it occurs in M. gyralommus. It differs from this species in its rounder, hemispherical eyes with prominent tubercles between them, the less convex (hunched) elytra, the apically flatly enlarged protibiae curved shortly inwards at the apex, the large mesocoxae, leaving the disc of the metaventrite between them and the metacoxae very short, and the very short ventrite 5 (about as long as 4). Based on the length and thickness of the rostrum, the holotype appears to be a male.

\section{Mekorhamphus sp. (Figure 64)}

Material examined. One specimen (NIGP157010): badly distorted and compressed, black with milky greenish film around appendages; in centre of subcubic block of ca. $3 \mathrm{~mm}$ side length with rounded edges and convex dorsal side; amber clear without bubbles or impurities.

Remarks. This specimen appears similar to M. gyralommus in shape and the slightly sinuate and apparently distally widened protibiae, but the tubercles on its forehead are larger (though strongly compressed). It may represent a different species but is so poorly preserved that it cannot be properly 
diagnosed and compared with other Mekorhamphus species, and we therefore do not describe and name it.

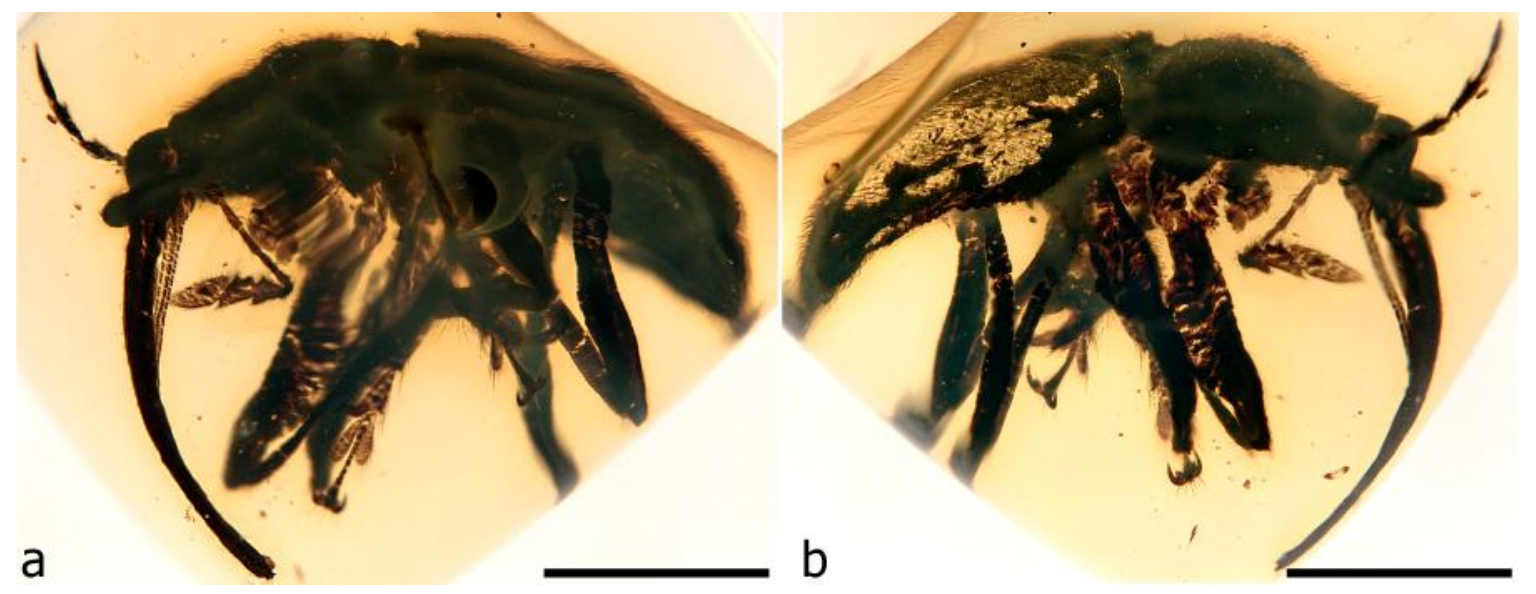

Figure 64. Mekorhamphus sp. Habitus, left lateral (a); habitus, right lateral (b). Scale bars: 1.0 mm (a,b).

Genus Compsopsarus Clarke \& Oberprieler, gen. $\mathbf{n}$.

Type species: Compsopsarus reneae Clarke \& Oberprieler, sp. n.

Description. Size. Length 2.30-2.39 mm, width 0.62-1.05 mm. Head short, subspherical, dorsally and ventrally bulging. Eyes large, strongly and vertically flatly protruding, coarsely facetted, dorsally separated by ca. basal width of rostrum; forehead with pair of transverse, thick, carinate tubercles between eyes, without any tufts or patches of coloured setae above eyes. Rostrum about as long as pronotum, short, subcylindrical, curved; antennal insertions lateral, with deep scrobes behind and in front of them, in front of them laterally with a few long erect setae. Antennae geniculate, long; scapes long, subcylindrical, apically gradually inflated, slightly shorter than funicle; funicles 7-segmented, segments 2 and 3 slender obconical, others subglobular, broader; clubs seemingly 4-segmented, loosely articulated but segments close, segment 4 hardly distinguishable from 3, marked mainly by ring of setae. Mouthparts. Labrum absent. Mandibles small, scoop-like, vertical, non-exodont, endodont, articulation horizontal. Maxillary and labial palps long, slender, 3-segmented. Thorax. Prothorax proclinate, with anterior lateral margins oblique in lateral view. Pronotum strongly convex, collared anteriorly, laterally rounded, without tooth, posterior corners angulate, fitting closely onto elytra; surface finely densely punctate, densely setose, setae reclinate, directed anteromesad, disc with 3 pairs of patches of dense whitish setae, a small one at middle on either side of midline, another anterolaterally between midline and sides and one near middle of sides, anteriorly in shallow collared groove with most setae whitish; notosternal sutures closed, horizontal portion not visible. Prosternum short; procoxal cavities medially confluent, closer to anterior margin of prosternum. Scutellar shield prominently raised above elytral surface, densely setose. Mesoventrite short, anteriorly sloping. Mesocoxal cavities laterally closed by processes of meso- and metaventrite. Metaventrite longer, slightly convex, raised into weak transverse weals. Metanepisterna distinct, densely setose. Elytra elongate, basally extended over pronotum, with indistinctly rounded humeri, posteriorly declivous, lateral margin weakly sinuate; apically individually rounded, exposing pygidium; surface punctostriate, without scutellary striole, interstriae subflat, finely punctate, densely setose, setae short, thin, subrecurved, directed caudad, with at least 16 patches of whitish setae on interstriae (Figure 65). Legs. Procoxae large and conical, prominent, medially contiguous; mesocoxae globular, less prominent, narrowly separated; metacoxae flat, transversely elongate. Trochanters short, oblique. Femora long, strongly inflated in distal half, outside rounded. Tibiae compressed, apically expanded, outer edge costate, with dense long stiff setae in distal half, apex obliquely truncate, with 2 spurs. Tarsi shorter than tibiae, very slender; tarsite 1 apically excised, 2 shorter, broader, triangular, apically excised, 3 deeply bilobed, lobes pedunculate, 5 about as long as $1+2$, apically expanded; claws divaricate, 
dentate (or possibly bifid; tooth distinctly curved inwards), ventrobasal seta not visible. Abdomen with ventrite 1 longer than 2, 3-4 subequal, 5 slightly shorter than $3+4$, apically subtruncate; apical tergite exposed as vertical pygidium, densely setose.

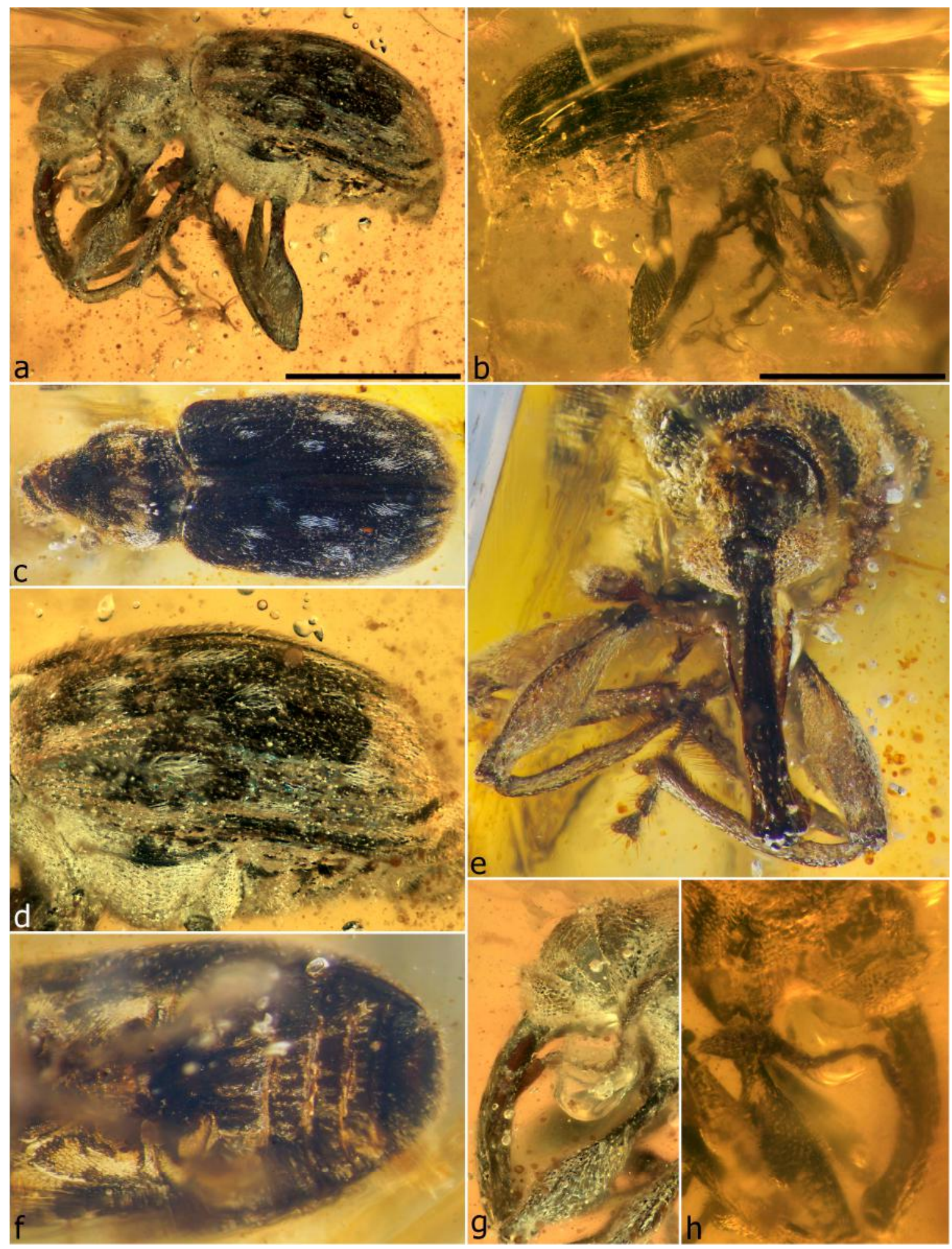

Figure 65. Compsopsarus reneae sp. n., holotype. Habitus, left lateral (a); habitus, right lateral (b); habitus, dorsal (c); elytra, left lateral (d); head, dorsal (e); ventrites, ventral (f); head and antenna, left lateral (g); same, right lateral (h). Scale bars: $1.0 \mathrm{~mm}(\mathrm{a}, \mathrm{b})$. 
Derivation of name. The name of the genus is formed from the Greek adjectives kompsos (elegant, pretty; Latin: compsus) and psaros (speckled, dappled, like a starling), in reference to the pleasing pattern of spots on the elytra of the type species, and it is masculine in gender.

Remarks. This extraordinary genus differs from all other Burmese amber weevils with geniculate antennae in having a pair of tubercles between the eyes, non-exodont, scoop-like vertical mandibles moving horizontally and an exposed flat (not cupulate) pygidium. It agrees with Mekorhamphus in the pair of tubercles between the eyes, but the form of the tubercles is different. It also differs from this genus in the lack of crenulation on the outside edge of the tibiae, the antennal scapes not reaching the eyes (separated by slightly more than length of funicle segment 1 ) and the slender tarsites 1 and 2 . It agrees superficially with Nugatorhinus in having patches of whitish setae on the pronotum and elytra, but the setae in the patches are sparser and less distinct from other vestiture setae. Nugatorhinus also has tubercle-like structures between the eyes, but these are again different from those of Compsopsarus. A particularly unusual feature of this genus is the form of the claws, which seem intermediate between the dentate and bifid conditions, with the tooth flattened but curved inwards and situated slightly on the inner edge, similar to the structure of the claws of Calyptocis. We are aware of one other undescribed species of this genus, which lacks the setal patches and has more strongly punctostriate elytra, as well as two other similar specimens for which further study (block preparation) is required to ascertain their affinity.

Compsopsarus reneae Clarke \& Oberprieler, sp. n. (Figures 65 and 66)

Description. Size. Length $2.30 \mathrm{~mm}$, width $1.05 \mathrm{~mm}$. Body small, compact, convex. Head seemingly weekly constricted behind eyes (eyes prominent, cuticle not constricted); with carinate tubercles between eyes converging posteriorly; distinctly, densely punctate. Eyes bulbous, somewhat protruding laterally, vertically subcompressed, slightly slanting backwards, with dense long interfacettal setae on top. Rostrum gradually widening and deepening distad, at mandibular articulations ca. wider than at base (possibly compression artefact); dorso-apically with oblique grooves delimiting narrow epistome; setose, setae small, appressed; antennal insertions slightly in front of middle. Scrobes strongly delimited, not quite reaching eyes. Mandibular sockets lateral, deep and thick. Antennae concolorous, club slightly darker; scapes elongate, not reaching eye (scape plus funicle segment 1 reaching eye), apically truncate; funicles with segment 1 elongate-ovoid, about $0.2 \times$ legth of scape, 2 narrower, elongate obconical, 3-4 similar, progressively shorter, 5-7 subglobular, subequal; clubs densely, shortly setose, with whorls of numerous elongate slender setae; articulations between segments very broad, segments 1-2 subequal in length, 1 obconical, apically flat, 2 subconcave apically, 3 and 4 subfusiform, narrowing distad, 4 indistinct from 3 in most views. Mouthparts. Mandibles asymmetrical, right-superior; right mandible with 3 teeth on inside, basal tooth small, rounded, apical tooth curved inwards, with subequal subapical tooth; left mandible somewhat smaller, with apical teeth smaller, closer. Thorax. Prothorax only slightly narrower than elytra at humeri. Pronotum distinctly impressed anteriorly; sparsely setose, setae pale brown, with 3 denser patches of whitish setae, one paramedian in front of base, one at middle of side and one anterolaterally; base sinuate, closely fitting with elytra; posterior angles tightly fitting onto humeri. Mesepimera flush dorsally with posterolateral prothoracic margin and elytral margin. Metaventrite coarsely, densely punctosetose; setae densest posterolaterally; longer than mesocoxae. Elytra broadly transversely convex; finely, shallowly punctate; weakly punctostriate, striae indistinct from flat interstriae; humeri rounded, not projecting; sides weakly sinuate, flush with ventrites, with indistinct minutely punctosetose marginal groove, without anterior marginal notch. Legs. Tibiae distinctly (protibiae) or slightly (mesotibiae) curved or straight (metatibiae); apically with long coarse fringing setae interrupted dorsally, much thicker on metatibiae, with several elongate slender dorso-apical setae; on outer side of meso- and metatibiae with 2 rows of coarse setae in distal third. Protarsi distinctly longer than mesotarsi; tarsites 1 and 2 apically expanded, excised, protarsite 1 ca. $2.0 \times$ longer than meso- and metatarsites 1,2 shorter than 1 , lobes of 3 ca. $0.67 \times$ as long as 5; claws with inner tooth distinctly curved inward. Abdomen. Apical (exposed) tergite darkly pigmented, vertical. Ventrites distinctly stepped, each progressively 
higher, 1-2 more flatly aligned than others, densely setose; sutures straight/arcuate, intersegmental membranes visible between all ventrites, more protruding between ventrites 2 and 4 .

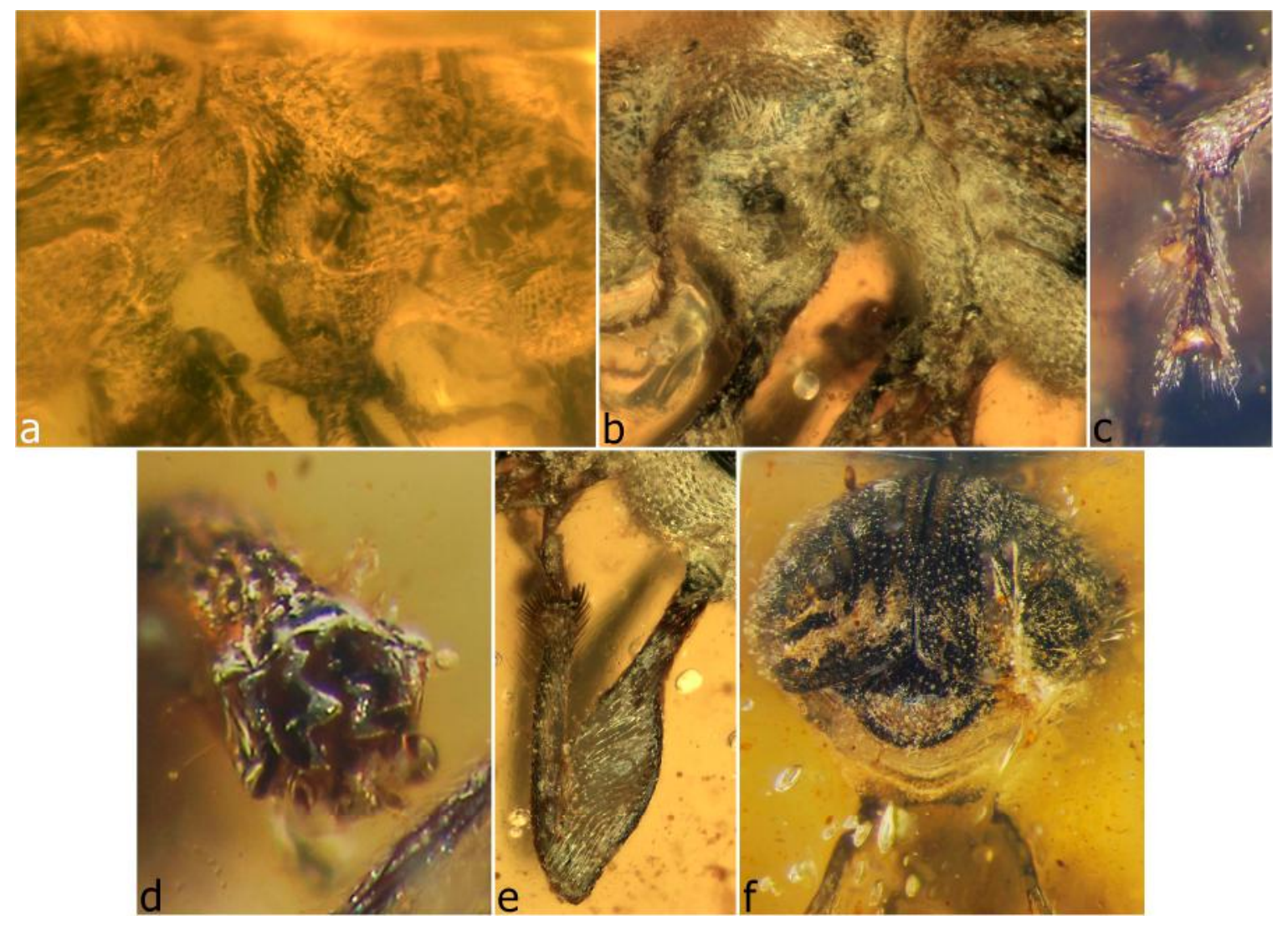

Figure 66. Compsopsarus reneae sp. n., holotype. Thorax, right lateral (a); thorax, left lateral (b); tarsites 1 and 2 (c); mandibles, apical (d); left hind leg (e); abdomen, showing pygidium, caudal.

Material examined. Holotype (NIGP157011): very well preserved, minimally distorted specimen, with left pro- and mesotarsi missing tarsites 3-5, other appendages intact, body surface largely visible but with fragmented surface coating of whitish material and/or minute bubbles; in irregular cuboid $3.0 \times 2.2 \times 1.5 \mathrm{~mm}$; amber clear yellow with longitudinal fractures along right elytron and over right side of prothorax and head of specimen, partly obscuring that side, otherwise clear with minimal impurities.

Derivation of name. This attractive species is named after Renee Berentsen, partner of the first author, in recognition of all her tireless support and patience during our study of these fossils.

Remarks. This species can be readily distinguished from all other Burmese amber weevils by the generally dense coat of setae obscuring the elytral striae, the diffuse setal patches on the elytra and distinct dense vestiture on the ventrites. It also has long, dense interfacettal setae on the top of the eyes, a feature unique in our sample, and long dense setae in the apical half of the tibiae forming two subaligned rows on the outer side, as well as elongate coarse apical fringing setae. The holotype was submitted for CT scanning, but the contrast between the specimen and the amber was too low to permit any meaningful visualisation of the specimen.

\section{Compsopsarus sp. (Figure 67)}

Material examined. One specimen (NIGP157012): very poorly preserved, compressed and distorted but intact; in middle of flat rectangular cuboid $4.7 \times 4.6 \times 1.5 \mathrm{~mm}$; amber clear with many sparsely distributed pieces of debris but no cracks or flow lines.

Remarks. This heavily distorted specimen is not definitely assignable to any genus as here described. It agrees with Compsopsarus reneae in having a short rostrum, non-crenulate tibiae and 
seemingly an exposed pygidium, but it differs in not having interfacettal setae or setal patches on the elytra and its tarsites 1 and 2 being shorter and thicker. From Mekorhamphus it differs mainly by its shorter rostrum, short and broad funicles and clubs, lack of tibial crenulations and narrow tarsi with tarsites 1 apically truncate and 2 only weakly excised. We tentatively place this specimen in Compsopsarus as it does not reveal sufficient characters on which to base a different genus. Better-preserved specimens are needed to assess its taxonomic affinities. It is too poorly preserved to be properly diagnosed and compared with other similar species, and we therefore do not describe or name it.

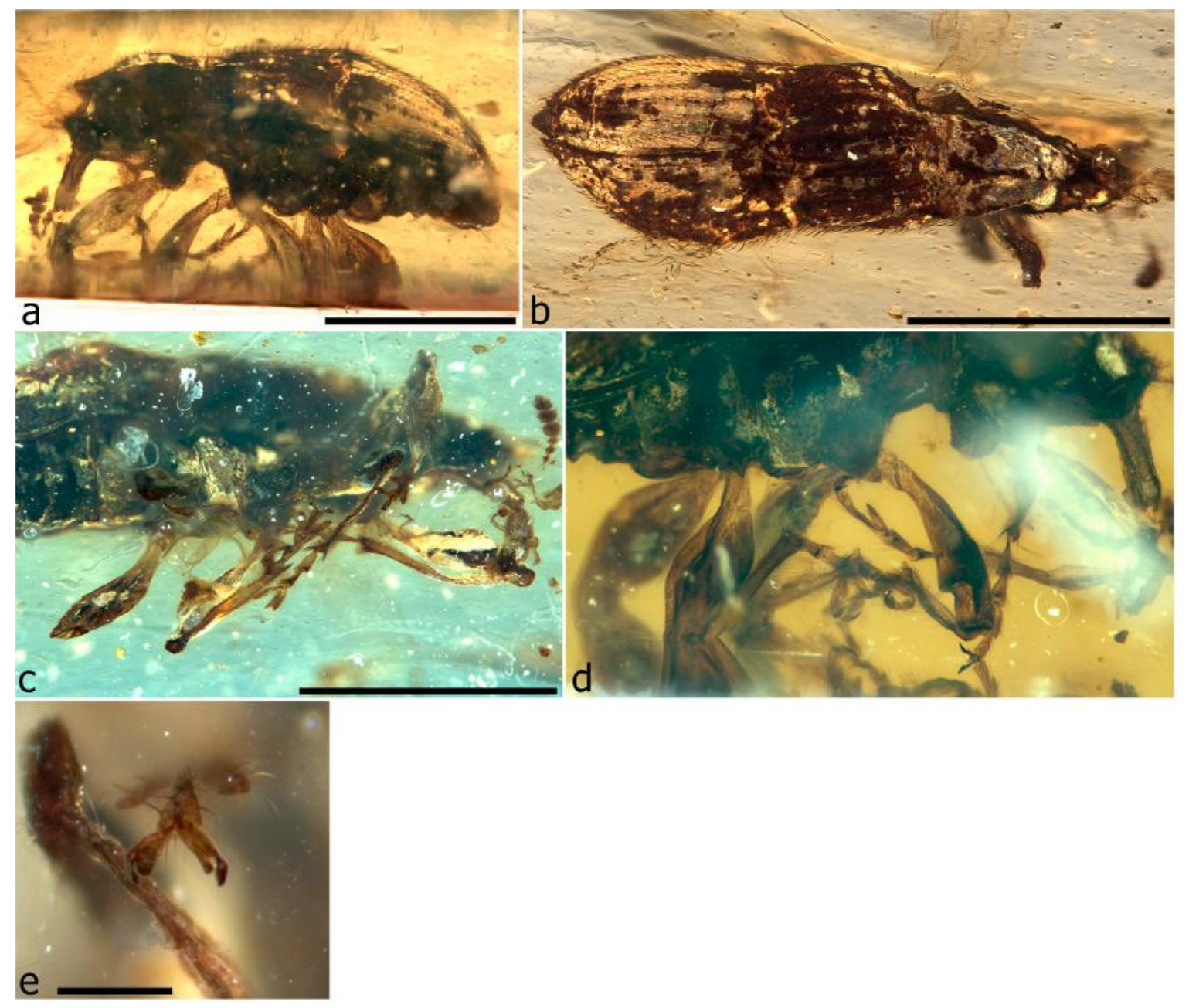

Figure 67. Compsopsarus sp. Habitus, left lateral (a); habitus, dorsal (b); legs and ventrites, ventral (c); same, right lateral (d); claw, apical (e). Scale bars: $1.0 \mathrm{~mm}(\mathrm{a}-\mathrm{c}) ; 0.1 \mathrm{~mm}(\mathrm{e})$.

Genus Myanmarus Clarke \& Oberprieler, gen. $\mathbf{n}$.

Type species: Myanmarus caviventris Clarke \& Oberprieler, sp. n.

Description. Size. Length 2.5-2.75 mm, width 1.2-1.4 mm. Body black, appendages distinctly paler. Head long, strongly constricted and dorsoventrally bulging behind eyes. Eyes large, strongly laterally protruding, coarsely facetted, dorsally separated by about half basal width of rostrum in anterior half, much further separated posteriorly; forehead thinly linearly grooved, without pair of tubercles between anterior margin of eyes. Rostrum about $1.25 \times$ longer than pronotum, slender, subcylindrical, moderately curved; antennal insertions lateral, behind them with scrobes reaching eye, in front of them lateroventrally with or without a few long erect setae. Single long gular suture present. Antennae geniculate, long; scapes elongate, cylindrical, apically clavate, about $4 \times$ longer than 
funicle segment 1 ; funicles 7 -segmented, much longer than scape, segments 2-7 progressively slightly decreasing in length; clubs large, loosely articulated, 4-segmented, segment 4 acute, about as long as 3 . Mouthparts. Labrum absent. Mandibles small, exodont, articulation horizontal. Thorax. Prothorax proclinate, with anterior lateral margins oblique in lateral view. Pronotum slightly convex, laterally rounded, with or without tooth, posterior corners angulate, fitting closely onto elytra; surface coarsely rugose, densely setose, setae reclinate, directed anteromesad, some scattered whitish setae; notosternal sutures closed, vertical, bent or curved anteriad. Prosternum moderately short; procoxal cavities in middle of prothorax or closer to front of prosternum. Scutellar shield densely setose, anterior margin flush with basal elytral margins. Mesocoxal cavities laterally closed (by meso- and metaventrite). Metanepisterna distinct, densely finely setose. Mesoventrite short, anteriorly sloping. Metaventrite longer, slightly convex. Elytra elongate, basally extended over pronotum, with broadly rounded humeri, posteriorly declivous, lateral margin strongly sinuate to roundly emarginate in middle; apically individually rounded, not exposing pygidium; sutural flanges not visible; surface seemingly not or very weakly punctostriate, without scutellary striole, interstriae indistinct from striae, surface rugose, setose, setae long, thin, reclinate, directed caudad, with scattered whitish setae seemingly not arranged into a pattern. Legs. Procoxae subconical, large, prominent, medially contiguous; mesocoxae large, subglobular, narrowly separated; metacoxae flat, transversely elongate. Trochanters short, oblique. Femora long, subcylindrical, inflated in distal half, outside rounded (profemora) or subcrenulate along distal third (meso- and metafemora), unarmed. Tibiae straight, compressed, narrowing in apical quarter, outer edge carinate-crenulate to apex (protibiae) or attenuating before apex (meso- and metatibiae) and dorsal edge continued as small apical lobe; with dense long stiff setae in distal half, apices obliquely truncate, with 2 spurs. Tarsi almost as long as tibiae; tarsite 1 elongate, apically expanded, 2 shorter, subtriangular, apically subacute, 3 deeply bilobed, lobes pedunculate or not, 5 long, apically expanded; claws divaricate, dentate with ventrobasal seta at apex of tooth. Abdomen mostly with ventrites variously impressed to grooved, 1 and 2 fused, at about same level, with suture less distinct than others, subequal in length, 3-5 more distinctly stepped, sutures straight, 4 shorter than 3, 5 longer than 4 , with distinct medial concavity.

Derivation of name. The genus is named after Myanmar, the literary name of the country of origin of the Burmese amber, in which the specimen is preserved; the gender of the name is masculine.

Remarks. Myanmarus is characterised by its darkly pigmented body with pale to very pale legs and antennae (most distinct in M. caviventris and M. dentifer), indistinct elytral striae, crenulate-serrulate tibiae and concave ventrites (one or more). Among the genera with crenulate tibiae it differs from Mekorhamphus in the lack of tubercles between the eyes and the structure of the tarsi (only weakly excised tarsites 2 and broad but not pedunculate lobes of tarsites 3) and agrees with this genus in the scapes reaching below the eyes. From Elwoodius it is most easily distinguished by the protruding but not conical eyes, the form of the tibial crenulation (pectinate in the metatibiae of Eldoodius) and the non-modified tibial spurs. With Leptopezus it agrees well in the form of the head and eyes and particularly in the structure of the metatibiae, but in Myanmarus the eyes are not depressed and the tarsi much broader and Leptopezus has unmodified ventrites. From other genera of Mesophyletiniae with dentate tarsal claws it can be distinguished by its crenulate tibiae and impressed ventrites. It differs from Habropezus also in its narrower body, crenulate tibiae and more strongly constricted head and from Mesophyletis also in having two subequal spurs on the tibiae, no pygidium and a strongly constricted head. It is also similar to Bowangius but larger and hairier and with the tibiae crenulate, not serrulate. The genus is represented by four species.

Myanmarus caviventris Clarke \& Oberprieler, sp. n. (Figures 68 and 69, Video S6)

Description. Size. Length $2.74 \mathrm{~mm}$, width $1.20 \mathrm{~mm}$. Body black, densely setose, setae mainly black but with areas of whitish setae on head, pronotum and elytra; legs and antennae distinctly paler than body (and translucent). Head more highly convex dorsally than ventrally, coarsely punctate; shortly setose, some setae whitish; ventrally more evenly continuous with base of rostrum. Eyes slanting backwards, in dorsal view subtriangular; without interfacettal setae. Rostrum dorsally with 
weak median, paramedian and dorsolateral carinae and grooves reaching antennal insertions, these median, without scrobes in front of them, apically effaced (rostrum smoothly cylindrical in distal half); with few long erect setae on ventrolateral side. Mouthparts. Mandibles with 2 small pointed teeth on outer side, apex truncate, forming T. Antennae. Scapes long, slender, reaching behind front margin of eyes, apically truncate; funicles with segments with regular whorls of long setae, otherwise sparsely setose, segment 1 about as long as $2+3,2-5$ similarly elongately obconical, progressively shorter towards club, 6-7 similarly ovoid, 6 longer than 5, 7 shorter and narrower than 6; clubs with segments 1-2 apically oblique, 1 elongate, obconical, 2 slightly broader and longer than 1, 3 and 4 subequal in length to 2, 4 narrowly inserted into 3, distinctly articulating with 3. Thorax. Prothorax strongly proclinate. Pronotum laterally without teeth; with scattered whitish setae; rugose. Prosternum very short, forming thin strip in front of procoxae, prosternal process small, pointed; procoxal cavities closer to prosternal margin. Scutellar shield transverse, not raised above elytral bases, anterior margin continuous with elytral basal margin. Meso- and metathorax with scattered whitish setae; metaventrite with posterior edge on either side with row of sparse, stiff whitish setae (appearing reddish under some lighting) reaching over metacoxae. Elytra punctostriate, punctures deep but indistinct, striae and interstriae indistinct; lateral margin with marginal groove subequal in width for entire length, with anterior marginal notch; surface coarsely sculptured, sparsely setose, setae dark, fine, some diffuse whitish thicker longer setae on humeri and sides, denser on posterior third. Legs pale translucent yellowish. Femora on outer side rounded (profemora) or subcrenulate along distal third (meso- and metafemora); profemora longer than others. Tibiae flattened, substraight (metatibiae) or abruptly slightly curved inwards in apical quarter (pro- and mesotibiae), apically with small (indistinct) inner and outer flanges; protibiae ventrally with long elongate setae along distal half, increasing in density in slight apical emargination, tarsal articulation surfaces subtruncate; meso- and metatibiae with apical edges lined with coarse fringing setae, dorso-apically with several very long setae, tarsal articulation surfaces suboblique. Tarsi ca. $0.67 \times$ as long as tibiae, ventrally densely setose, mesotarsi slightly shorter than protarsi; tarsite 1 elongate, apically expanded, subtruncate, on meso- and metatarsi slightly shorter than on protarsi, 2 ca. $0.67 \times$ as long as 1 , subtriangular, apically excised, with very long, thick dorso-apical setae, 3 deeply bilobed, lobes pedunculate, ca. half as long as 5, 5 elongate, slender. Abdomen. Apical tergites seemingly horizontally exposed (extruded). Ventrites slightly stepped; setose, with scattered white setae intermixed with darker setae; $1-3$ subequal in length, 4 shorter than 3, 5 longer than 4, with distinct medial concavity, setose on either side of concavity but not inside it; sutures straight. Ovipositor with long hemisternites, each bearing elongate spically setose stylus.

Material examined. Holotype (NIGP157013), female: exceptionally well preserved, intact specimen with ovipositor extruded (connected to abdomen), largely undistorted, not compressed but surface details somewhat obscured by fine film of debris; in wedge $6.1 \times 3.2 \times 2.2 \mathrm{~mm}$, with one large curved and large flat face and smaller edge faces exposing dorsal side and head; amber clear yellow, with large fracture plane obscuring left side and other inclusions partly obscuring rostral apex.

Derivation of name. The species is named for the peculiar large cavity on ventritre 5 ; the name being an adjective.

Remarks. This species has distinctive setal patterns on the elytra, with whitish setae intermixed with darker ones, as well as a line of thick whitish setae on the posterior edge of the metaventrite. In appearance it resembles $M$. dentifer but is distinguishable from the latter by the lack of the anterolateral tooth on the sides of the pronotum and the normal short spurs. It can be distinguished from $M$. robustus, also lacking pronotal teeth, in the concavity of ventrite 5, the longer slender tibiae and the metatibiae being emarginate on the outside before the apex. The holotype was submitted for CT scanning (Figure 69, Video S6), with good results, Figure 69 in particular revealing more distinct striae on the elytra and providing a clear view of ventral structures. 


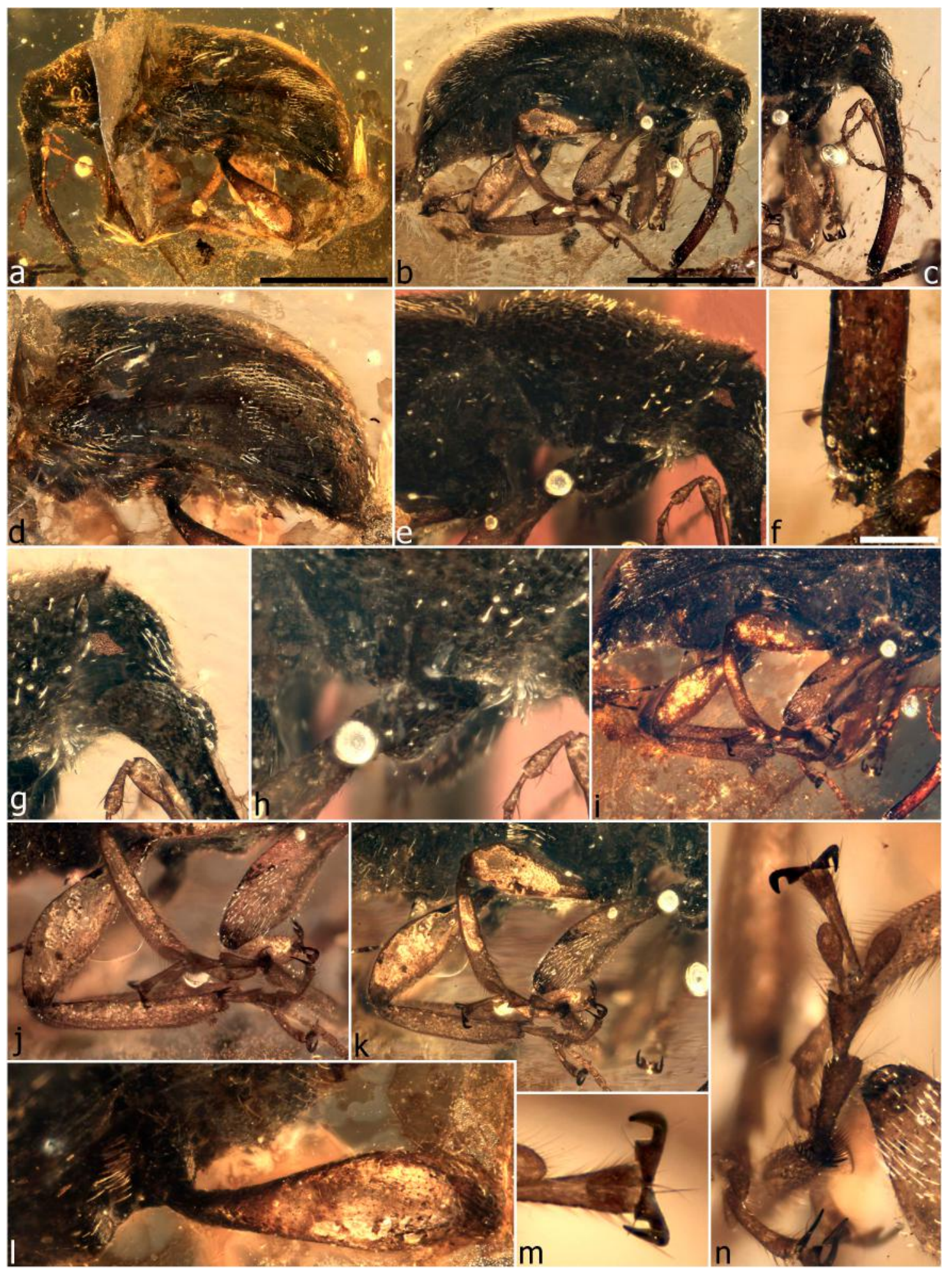

Figure 68. Myanmarus caviventris sp. n., holotype. Habitus, left lateral (a); habitus, right lateral (b); head and antennae, right lateral (c); elytra, left lateral (d); head and prothorax, right lateral (e); apex of rostrum and right mandible, dorsal (f); head, right lateral (g); prothorax showing notosternal suture, right lateral (h); abdomen showing ventrites, and legs, right lateral (i); legs, right lateral (j); same (k); left metacoxa and -femur, showing dense line of lighter setae on posterior metaventral margin (l); tarsal claw, ventral (m); protarsus, ventral (n). Scale bars: $1.0 \mathrm{~mm}(\mathrm{a}, \mathrm{b}) ; 0.1 \mathrm{~mm}(\mathrm{f})$. 


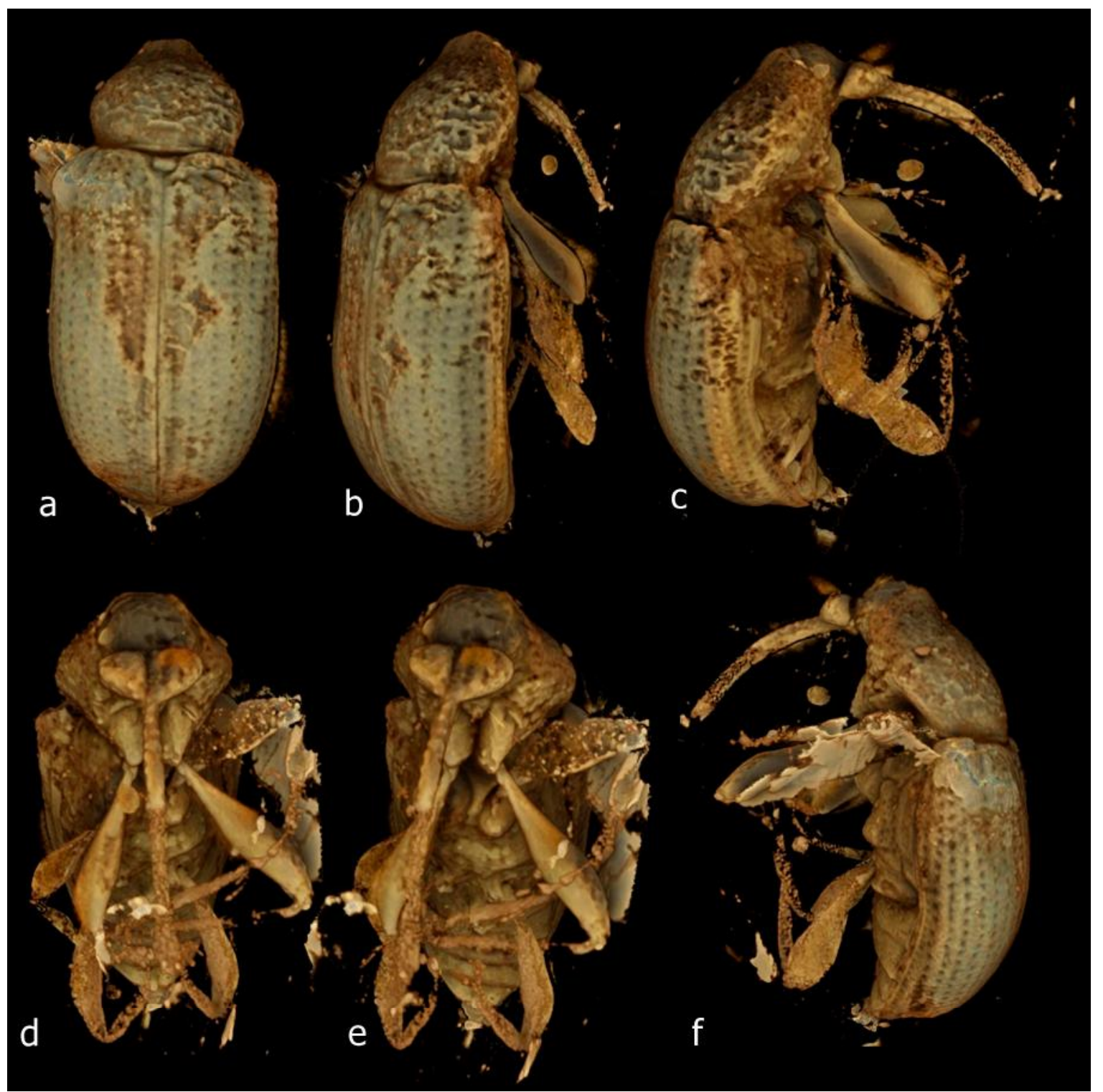

Figure 69. Myanmarus caviventris sp. n., holotype. Habitus images extracted from a micro-CT scanning reconstruction (see also Video S6). Dorsal, revealing punctate stria not clearly visible under light microscopy (a); dorsal oblique (b); right lateral (c); ventral (d); ventral (e); left lateral (f).

\section{Myanmarus robustus Clarke \& Oberprieler, sp. n. (Figure 70)}

Description. Size. Length $2.5 \mathrm{~mm}$, width $1.2 \mathrm{~mm}$. Head shortly subconical, strongly constricted behind eyes. Eyes large, compressed, protruding, triangular in dorsal view, coarsely facetted, dorsally separated by less than width of rostrum at base. Rostrum slightly longer than pronotum, thin, cylindrical, slightly downcurved; antennal insertions in middle of rostral length, behind them with scrobes indicated, extending to eye, no lateral row of setae in front of them visible. No gular suture visible. Antennae Scapes long, straight, thin, apically abruptly clavate; funicles slightly longer than scape, segment 1 elongate, not inflated, 2 slightly shorter than 1, 3-5 elongate, thin, 6 and 7 shorter and slightly thicker; clubs long, flattened, segment 4 distinct, long, acute. Mouthparts. Mandibles flatly scoop-shaped with seemingly 3 large inner teeth ( 2 dorsally, 1 apically) and 2 low outer ones, apical one forming weak oblique T with inner one, articulation plane oblique. Maxillary palps apparently 3-segmented. Thorax. Pronotum elongate, laterally rounded, without tooth, strongly convex, surface moderately densely setose, setae short, thin, acute, directed anteromesad. Prosternum moderately 
long; procoxal cavities in about middle of prothorax. Scutellar shield indiscernible. Elytra elongate, with weak, broadly rounded humeri, posteriorly strongly evenly declivous; surface punctostriate but striae indistinct, densely setose, setae moderately long, thin, acute, directed caudad, odd interstriae slightly elevated (artefact?). Legs. Procoxae elongate. Tibiae short, slightly flattened, outer edge faintly crenulate/serrulate (visible on mesotibia in ventral view, also on protibia proximally), apex obliquely truncate, with 2 spurs (visible on protibiae). Tarsi stout, slightly shorter than tibiae; tarsite 1 long, narrow, apically slightly excised, 2 apically excised, 3 shortly bilobed, lobes not pedunculate, 5 as long as 1; claws divaricate, dentate with ventrobasal seta at apex of tooth. Abdomen with ventrites flat but seemingly not impressed, 1 to 2 subequal in length, about $2 \times$ longer than 3 and 4, 5 apparently as long as 4 .

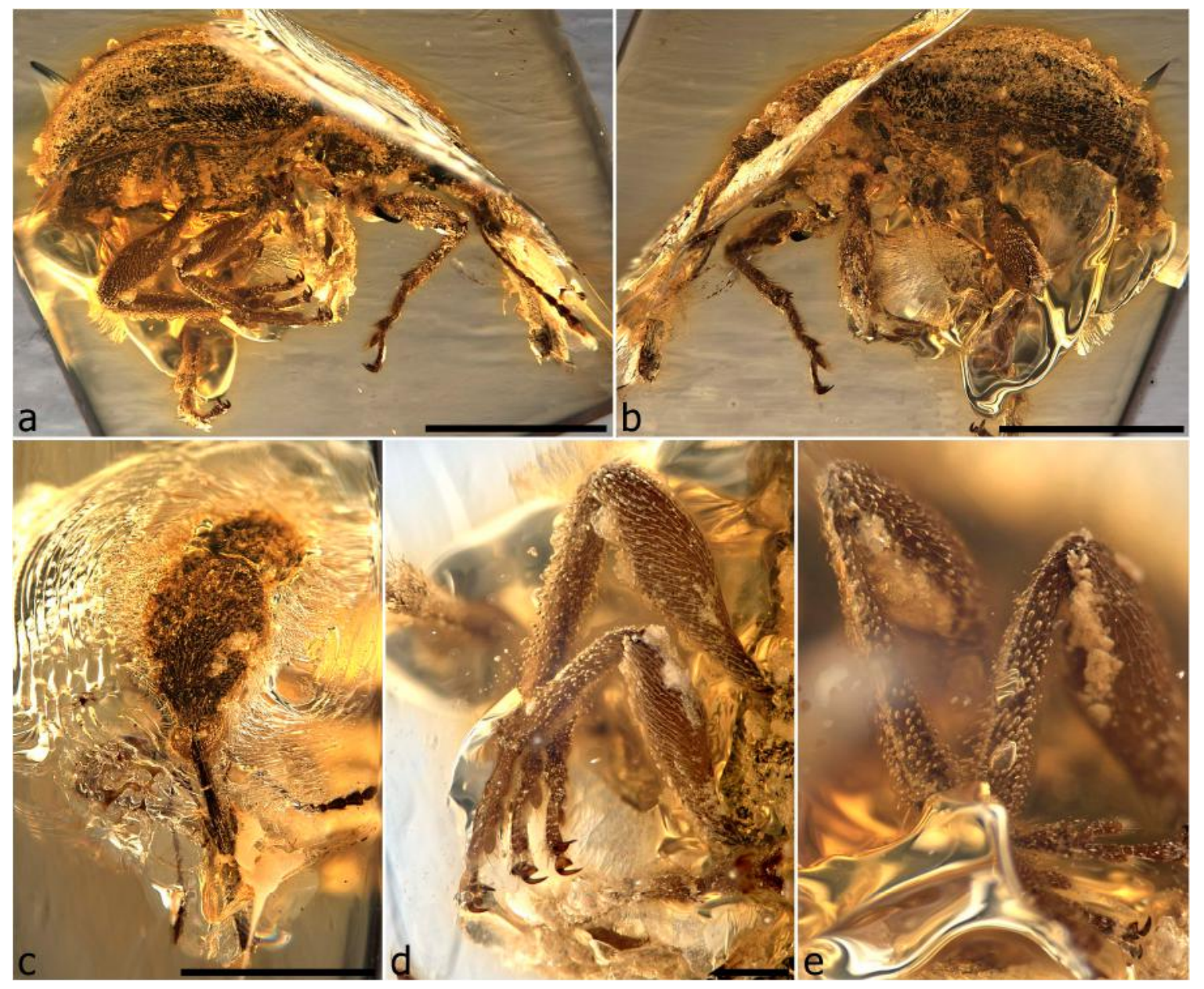

Figure 70. Myanmarus robustus sp. n., holotype. Habitus, right lateral (a); habitus, left lateral (b); head and prothorax, dorsal (c); legs, ventrolateral (d); tibiae (e). Scale bars: $1.0 \mathrm{~mm}(\mathrm{a}-\mathrm{c}) ; 0.2 \mathrm{~mm}(\mathrm{~d})$.

Material examined. Holotype (NIGP157014): well preserved, intact specimen, not compressed or distorted, mostly well visible except for left side of rostrum, pronotum, and legs posteriorly; obliquely transverse in rectangular cuboid $4.6 \times 3.3 \times 2.2 \mathrm{~mm}$; amber clear except for large reflective thin film of flow lines over rostrum, pronotum and basal part of elytra, with shallow crack along side of right elytron, transverse crack across elytral declivity and large, irregular, clear bubble beneath left side of crack enveloping middle and hindlegs, few other impurities.

Derivation of name. The species is named for its robust appearance, the name being an adjective.

Remarks. This species is similar to M. caviventris in lacking a distinct lateral prothoracic tooth, but it differs from that species in having whitish elytral setae, ventrite 5 without a concavity, the outer side of the meso- and metatibiae straight, not emarginate before the apex, and the outer side of the 
metafemora carinate (not crenulate) in the distal third. From $M$. dentifer and $M$. diversiunguis it is most readily distinguishable in not having a lateral tooth on the sides of the prothorax and from the latter also in having normal, dentate protarsal claws.

Myanmarus dentifer Clarke \& Oberprieler, sp. n. (Figure 71)

Description. Size. Length $2.7 \mathrm{~mm}$, width $1.03 \mathrm{~mm}$. Head subglobular, small, narrow, strongly constricted behind eyes. Eyes large, subglobular, protruding, slanting towards back; dorsally broadly triangularly separated. Rostrum longer than pronotum, robust, slightly curved; antennal insertions in middle of rostral length, behind them with distinct narrow scrobes extending to eye, in front of them without lateral row of setae. Antennae. Scapes long, straight, thin, apically slightly clavate, not quite reaching eye in repose; funicles slightly longer than scape, segment 1 slightly inflated in middle, spindle-shaped, 2 as long as 1 but narrower, others narrower but progressively shorter towards club; clubs long, loosely articulated, flattened, segment 4 distinct, as long as 3. Mouthparts. Mandibles (widely opened) scoop-shaped with 3 large inner teeth ( 2 dorsally, 1 apically) and 2 low outer ones, apical one forming weak oblique $\mathrm{T}$ with inner one, articulation plane horizontal. Thorax. Prothorax strongly proclinate. Pronotum elongate, laterally with sharp, black, flat tooth just anteriorly of middle; densely setose, setae pale, long, narrow, directed anteromesad, sculpture not discernible; notosternal sutures sharply bent anteriad. Prosternum moderately long; procoxal cavities in about middle of prothorax. Scutellar shield weakly visible, round, slightly concave. Mesocoxal cavities laterally closed (by meso- and metaventrite). Metanepisternal sutures distinct. Mesoventrite short, anteriorly strongly sloping. Metaventrite longer, raised into oblique weals before metacoxae. Elytra short and broad, with weakly developed, broadly rounded humeri, posteriorly strongly declivous; surface indistinctly punctostriate, sparsely covered with thin, sharp setae directed caudad. Legs. Procoxae elongate, prominent. Femora straight, subcylindrical, metafemora more flattened (possibly an artefact). Tibiae long, flattened, outer edge crenulate (appearing serrulate in lateral view), apex obliquely truncate, with 2 slightly flattened spurs, the inner one larger on the metatibiae. Tarsi with tarsites 1 and 2 narrow, elongate, subtruncate, 5 shorter than $1+2$; claws divaricate, strongly dentate. Abdomen with ventrites 1 to 2 subequal in length, 3, 4 and 5 about half as long, 1-3 with broad, deep median groove, its posterior angles on each ventrite strongly elevated into blunt, setose tubercles.

Material examined. Holotype (NIGP157015): eell preserved, intact specimen with slightly compressed tibiae, well visible from all sides, right metatarsus cut off except claws; at an angle in left side of irregular block $4.0 \times 4.0 \times 2.7$; amber clear with several small dispersed impurities and larger irregular brown film below front legs and tip of rostrum.

Derivation of name. The species is named for the distinct teeth on the sides of the prothorax; the name is a noun in apposition.

Remarks. This species is distinctive in its medially conspicuously grooved ventrites 1 to 3 , which apparently is not an artefact as all three ventrites are posteriorly extended into blunt tubercles next to the groove. It also has a distinctly laterally toothed prothorax, which otherwise only occurs in $M$. diversiunguis (but the tooth smaller), from which it also differs in having normally dentate protarsal claws (not bifid plus dentate). The lateral prothoracic teeth readily distinguish $M$. dentifer from $M$. caviventris and $M$. robustus. 


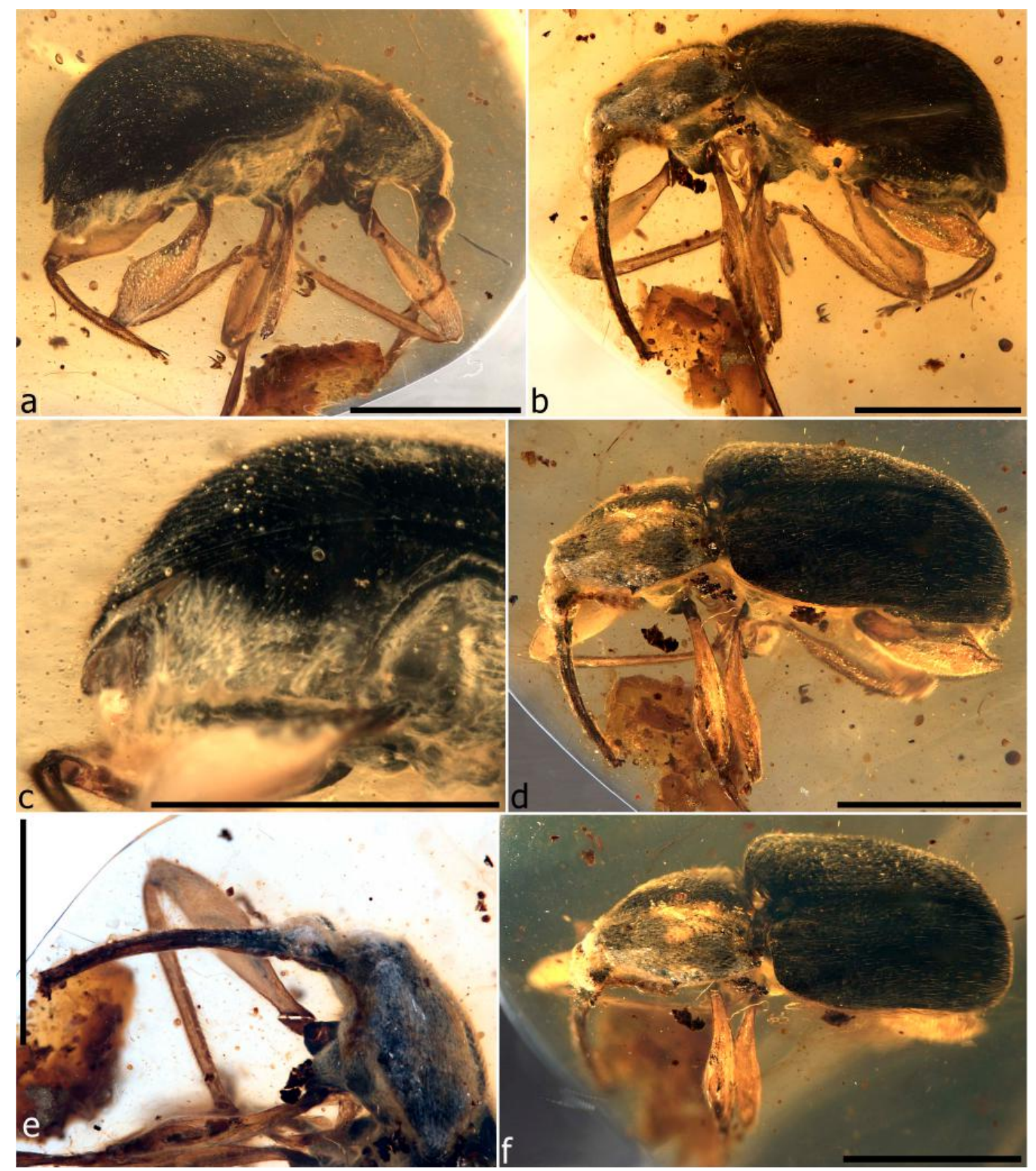

Figure 71. Myanmarus dentifer sp. n., holotype. Habitus, right lateral (a); habitus, left lateral (b); ventrites, ventral oblique (c); habitus, lateral oblique (d); head and prothorax, left lateral (e); habitus, dorsal oblique (f). Scale bars: $1.0 \mathrm{~mm}(\mathrm{a}-\mathrm{f})$.

\section{Myanmarus diversiunguis Clarke \& Oberprieler, sp. n. (Figure 72)}

Description. Size. Length $2.75 \mathrm{~mm}$, width $1.38 \mathrm{~mm}$. Head short, strongly constricted behind eyes. Eyes large, slightly elongate, protruding, dorsally narrowly separated along entire length, forehead very narrow, lower than dorsal margin of eyes, without tubercles. Rostrum slightly longer than pronotum, stout, slightly curved, subcylindrical; antennal insertions median, behind them with short scrobes extending to eye, in front of them with lateral row of ca. 5 long, erect setae in apical quarter of rostrum. No gular suture visible. Antennae. Scapes long, straight, thin, apically abruptly clavate; funicles slightly longer than scape, segment 1 inflated, others much narrower, elongate, progressively shorter towards club; clubs long, loosely articulated, flattened, segment 4 distinct, almost as long as 3. Mouthparts. Mandibles flatly scoop-shaped with 2 (possibly 3) large inner teeth 
(1-2 dorsally, 1 apically) and 2 low outer ones, apical one forming weak oblique $\mathrm{T}$ with inner one, articulation plane oblique. Maxillae and labium indiscernible. Thorax. Prothorax strongly proclinate. Pronotum broadly roundly trapezoidal, laterally with small tooth; sparsely setose, setae pale, long, thin, directed anteromesad; notosternal sutures closed. Prosternum and hypomeron both short, about equal in length; procoxal cavities medially confluent, in middle of prothorax. Scutellar shield shortly transverse, rounded, faintly setose. Mesocoxal cavities laterally closed (by meso- and metaventrite). Metanepisternal sutures distinct. Mesoventrite short, anteriorly strongly sloping. Metaventrite longer, convex, with thick transverse weal before metacoxae. Elytra short and broad, with well-developed, broadly rounded humeri, posteriorly gently declivous, apically individually rounded, not exposing pygidium; sutural flanges not visible; surface coarsely punctostriate, without scutellary striole, sparsely covered with longish setae. Legs. Procoxae elongate, prominent, medially contiguous; mesocoxae subglobular, narrowly separated; metacoxae flat, transversely elongate. Trochanters short, oblique. Femora short, slightly compressed, pro- and mesofemora slightly inflated, metafemora strongly so, unarmed. Tibiae long, straight, compressed, outer edge crenulate, apex obliquely truncate, with 2 strong sharp spurs. Tarsi ca. half as long as tibiae; tarsite 1 elongate, on protarsi longer, on mesoand metatarsi shorter than $2+3$, apically slightly excised, 2 shorter than 1 , narrowly triangular, shallowly excised, 3 deeply bilobed, lobes short, 5 as long as 1, apically broadened; claws divaricate, on protarsi deeply bifid as well as dentate, with ventrobasal seta, on other tarsi only dentate. Abdomen with ventrites 1-3 broadly shallowly longitudinally impressed, posterior angles of impression on each ventrite elevated into blunt tubercle, 1 to 2 subequal in length, 3 and 4 slightly shorter, 5 not discernible.

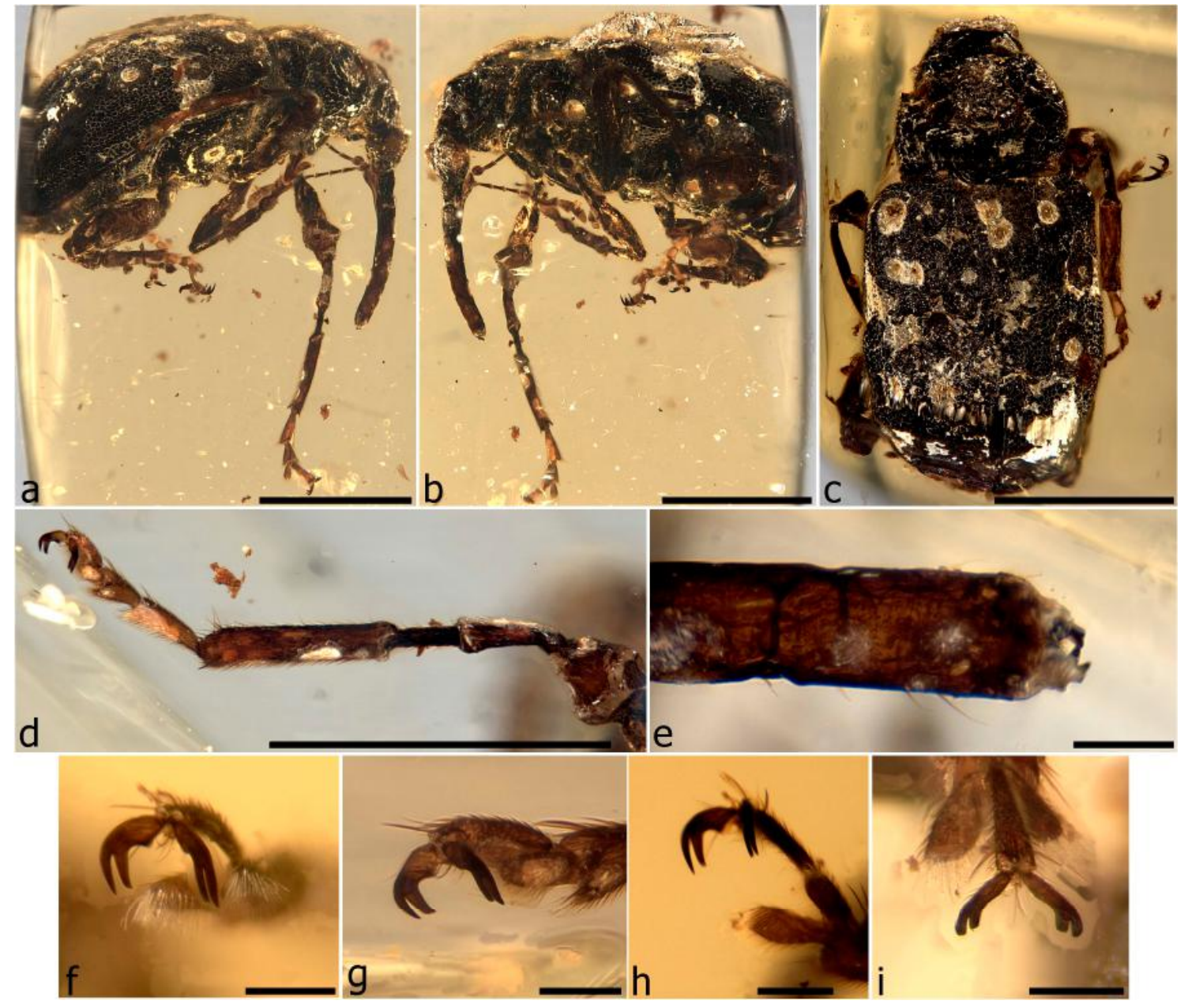

Figure 72. Myanmarus diversiunguis sp. n., holotype. Habitus, right lateral (a); left lateral (b); dorsal (c); protibia and tarsus (d); mandibles (e); protarsal claws (f-i). Scale bars: $1.0 \mathrm{~mm}(\mathrm{a}-\mathrm{d}) ; 0.1 \mathrm{~mm}(\mathrm{e}-\mathrm{i})$. 
Material examined. Holotype (NIGP157016): not too well preserved but intact, slightly crumpled, dark specimen, with left front leg stretched out ventrad, surface of elytra with some pale spots, apex of left elytron slightly cut, otherwise well visible; in upper left part of rectangular cuboid $4.3 \times 3.0 \times$ 3.0-3.2 mm; amber clear with very few impurities, small crack and brown film next to left elytron.

Derivation of name. The species is named for its diverse tarsal claws, being normally dentate on the meso- and metatarsi but extraordinarily dentate as well as bifid on the protarsi. The name is an adjective.

Remarks. This species is one the most extraordinary of all Burmese amber weevils (as of weevils in general) in having the claws of its front tarsi distinctly bifid (with an inner long secondary claw) as well as dentate (with a shorter basal tooth, carrying a ventrobasal seta). This aptly demonstrates that the bifid and dentate conditions of the tarsal claws are not homologous and need to be distinguished. The prothorax of the holotype is somewhat distorted and the lateral teeth are not equal, the left one exaggerated due to a linear oblique depression in front of it, but as there is a small tooth in the same position on the undistorted right side of the prothorax, these teeth appear to be a real character of the species. The species also differs from all other Myanmarus species in its broadly impressed ventrites.

Genus Mesophyletis Poinar, 2006

Mesophyletis Poinar, 2006: 879 [29] (type species, subsequent designation (Poinar, 2008): Mesophyletis calhouni Poinar, 2006)

Redescription. Size. Length 2.12-2.82 mm, width 1.15-1.56 mm. Head short, transverse, constricted behind eyes, strongly domed dorsally, less convex ventrally. Eyes large, subelongate, protruding, coarsely facetted, dorsally separated by about basal width of rostrum; forehead grooved, without tubercles above eyes. Rostrum about as long as pronotum, subcylindrical, weakly downcurved; antennal insertions median, with scrobes behind them reaching eye, in front of them laterally with row of several of long erect fine setae. Single long gular suture present. Antennae geniculate, long; scapes elongate, cylindrical, apically inflated, shorter than funicle; funicles 7-segmented, segment 1 slightly longer and much broader than 2, 2-5 subequal, elongate-obconical, 6-7 similarly shortly ovoid, broader than 5, progressively shorter; clubs long, loosely articulated, 4-segmented, segment 4 broadly rounded, about as long as 3. Mouthparts. Labrum absent. Mandibles small, flat, exodont, articulation oblique. Maxillary and labial palps 3-segmented, both projecting obliquely forwards. Thorax. Prothorax strongly proclinate, with anterior lateral margins oblique in lateral view. Pronotum convex, laterally rounded, without tooth, posterior corners angulate, fitting closely onto elytra; surface coarsely tuberculate, sparsely finely setose, setae arising from minute punctures on top of tubercles, reclinate, directed anteromesad; notosternal sutures closed, vertical then abruptly deflected anteriorly. Prosternum short; procoxal cavities medially confluent, closer to anterior margin of prosternum. Scutellar shield asetose (or very sparsely setose), raised above elytral surface. Mesocoxal cavities laterally closed. Metanepisterna distinct, sparsely setose. Mesoventrite short, anteriorly sloping. Metaventrite longer, raised into transverse weals. Elytra elongate, basally extended over pronotum, with broadly rounded humeri, posteriorly declivous, lateral margin strongly sinuate to roundly emarginate in middle, apically individually rounded; sutural flanges not visible (elytra closed); surface weakly to distinctly punctostriate, without scutellary striole, interstriae tuberculate, setose, setae short, thin, reclinate, directed caudad. Legs. Procoxae large and conical, prominent, medially contiguous; mesocoxae subglobular, narrowly separated; metacoxae flat, transversely elongate. Trochanters short, oblique. Femora long, subcylindrical, inflated in distal half, unarmed, outer side serrulate in apical third to half (distinctly so on meso- and metafemora). Tibiae elongate straight, slender, compressed; outer edges serrulate, with dense long stiff fine setae in distal half of meso- and metatibiae, apically emarginate; apex subtruncate, with single strong apparently fixed inner spine and smaller free spur on pro- and mesotibiae, with 2 strong spurs on metatibiae, inner one fixed, broadened and flattened or slender and conical-rounded. Tarsi (as in M. calhouni; all missing from undescribed sp.) with tarsite 1 apically weakly excised, 2 shorter, subtriangular, apically excised, 3 deeply bilobed, lobes strongly pedunculate, 5 long, very slender, apically expanded; claws 
divaricate, dentate, probably with ventrobasal seta. Abdomen. Ventrites subflatly aligned, sutures straight; ventrites 1 and 2 subequal in length, 3 and 4 subequal, shorter than 2, 5 subequal in length to $3+4$, broadly rounded.

Remarks. As the single type specimen of Mesophyletis calhouni is unavailable for study (see Section 2.1 above), this redescription is partly based on another evidently congeneric specimen we received from the FMNH but too late to fully include in this paper. It unfortunately lacks all its tarsi, and therefore the structure of the claws of the genus cannot be confirmed. In Mesophyletis calhouni the tarsi are very slender and the lobes of tarsites 3 are pedunculate. In the original description [29] the claws are reported as being bifid on the pro- and mesotarsi and "appendiculate (laminate)" on the metatarsi [29], which would be a very unusual condition in Mesophyletidae (different claws are otherwise present only in Myanmarus diversiunguis). The metatarsal claws as illustrated by Poinar [29] appear typically dentate (assuming the teeth carry a ventrobasal seta), but whether those of the mesotarsi are truly bifid (the secondary tooth attached on the inside rather than the ventral side of the primary one) is not clear in the photo (Figure 4 in [29]). In a later diagnosis of a tribe Mesophyletini [53], the claws are described as "widely divergent, with large tooth at base", which would accord with all claws being dentate. Confusion also surrounds the structure of the tibial spurs as reported in the literature [29,53]. In the original description [29] the metatibiae were described as "serrulate with 2 broad symmetrical spines at apex", with Figure 2 clearly showing the serrulation but only a single thick, curved and pointed spine (it is unclear from Figure 2 whether this is homologous with a spur). However, in the later paper [53] the apex of the metatibiae was described as "with two apical spurs" and so illustrated in Figure 10 (one spur very short, appearing to be broken off). From Figure 1 of the original description [29] and Figure 9 of the later paper [53] it is evident that both Figures 2 and 10 do depict metatibiae but that Figure 2 shows the left one (the inner side) and Figure 10 the right one (the outer side). As the spurs or spines must be identical on the two metatibiae, neither description in the literature can be correct. The only possible way to resolve this discrepancy is to assume that the metatibial spurs of Mesophyletis calhouni are constructed as they are in Elwoodius conicops, i.e., the inner one broad, flat and apparently fixed (as visible in Figure 2 in [29], obscuring the smaller outer one) and the outer one normal, slender and pointed (as visible in Figure 10 in [53], the broad inner one either broken off or only its apex visible due to the viewing angle). This metatibial spur configuration is also largely in agreement with our Mesophyletis specimen, which has two shorter robust but also unequal spurs on the metatibiae, with the inner one also fixed (but narrowly conical, not flattened). The pro- and mesotibiae of our specimen, however, have a small, slender free outer spur and an enlarged, apparently fixed but elongate, straight and narrowly conical inner spur that is directed distad, thus not agreeing with the pro- and mesotibial spurs of E. conicops (see under that species) but consistent with the original description of M. calhouni, which describes the proand mestotibiae as "bearing well-developed spine at apex". Other key observable characters of our specimen in agreement with M. calhouni are the large protruding eyes (recorded and drawn as round for M. calhouni but not so appearing in the published photo), relatively short curved rostrum with strongly exodont mandibles opening into a vertical position, serrate tibiae (recorded as "denticles absent" on the protibiae, although these also are easily overlooked - the denticles are less than half the size of the mesotibial ones in our specimen), sublevelled ventrites and likely the exposed tergites VII and VIII. The structure of the exposed abdominal apex is not clear in the photograph of M. calhouni but may be similar to that of the exposed tergite VIII in some Bowangius specimens. Mesophyletis is distinguishable from all other Burmese amber weevils by the above-listed characters, except that it apparently shares its metatibial spur structure with Elwoodius conicops, in which the inner, larger, fixed spur is flattened and asymmetrical on the metatibiae (Figure 91g). The large apical setiferous spike of Echogomphus viridescens (Figure 45l) is probably not homologous with a spur; see under this species. Fixed inner spurs of the metatibiae (and sometimes mesotibiae) also occur in some Bowangius species, but these are not much larger than the outer spurs but also apically slightly bent. Mesophyletis 
is easily distinguishable from Elwoodius by its normal eyes, these not being elongate-conical, and by the different spur configuration on the pro- and mesotibiae.

Mesophyletis was originally placed in a monotypic subfamily (Mesophyletinae, in a family 'Eccoptarthridae') and later as a tribe Mesophyletini in Carinae of a family 'Ithyceridae' [53], but several of its alleged diagnostic characters (e.g., absence of striae, exposed pygidium, swollen trochanters, bifid pro- and mesotarsal claws, procoxae separated by a keel-like prosternum) are probably not valid as described and require re-examination. In Burmese amber weevils it is sometimes easy to confuse basal breaks or cracks in the femora as the trochanterofemoral joint, perhaps giving the appearance of an enlarged trochanter; in all Mesophyletidae we examined (except Aepyceratus, in which the trochanters are sublobate) the trochanters are small and strongly oblique. Separation of the procoxal cavities in our sample of Mesophyletinae only occurs in some genera with simple or basally angulate claws (and not by a "keel-like" prosternum); all those in the group with dentate claws (in which Mesophyletis belongs) have the procoxae contiguous at least at the base and their cavities confluent. Mesophyletis is quite similar to various other mesophyletine genera, in particular Bowangius (and Anchineus), of which most species seem to have an exposed apical tergite (which may be a sexual trait) and several have a fused inner spur on the metatibiae, but it differs from Bowangius in having a subequal pair of spurs on each leg, subflatly aligned ventrites, more typically broader mandibles and slender tarsi.

\section{Mesophyletis calhouni Poinar, 2006}

Mesophyletis calhouni Poinar, 2006: 880 [29]

Material (not examined). Holotype, "body" length $2.8 \mathrm{~mm}$ (seemingly excluding rostrum, but not SL), $2.20 \mathrm{~mm}$, width $1.21 \mathrm{~mm}$; not studied, originally in amber collection of Ron Buckley, Sumter Ridge, Florence, KY, but sold to Deniz Eren in Turkey, where it is evidently not available for scientific study.

Remarks. As we were unable to study the holotype of this important species, despite repeated requests to its current owner (Deniz Eren, Turkey) to borrow the specimen, we are unable to provide a revised description or diagnosis of the species. According to the original description [29], the species is distinctive in having bicoloured elytra with areas of "castaneous colored squamae" and an "elliptical castaneous spot", also in having no striae, no serration on the protibiae and two broad symmetrical spurs on the metatibiae. Among our sample of Burmese amber weevils, several species have vestiture patterns generally involving patches or defined areas of paler setae, but all have the body cuticle unicolorous (or at least none have different regions of distinctly different colours as described for M. calhouni). In some specimens (e.g., Compsopsarus reneae), however, a distinct paler 'squamous' type pattern can be observed, created by a localised thin air layer seemingly divided into irregular cells forming a pattern. In our undescribed species of Mesophyletis the body cuticle is entirely black, the elytra are distinctly striate, the protibiae finely serrulate and the metatibial spurs unequal. According to Figure 2 in the original description [29], another distinctive feature of M. calhouni is the apical structure of the metatibiae (also indicated to be the same on the other tibia in Figure 1 in [29]), in which the inner edge appears to form a low rounded carina. Among our sample of specimens this character is otherwise present only in Bowangius cyclops (also on both metatibiae; see under that species), which also has an exposed tergite VIII (appearing similar to the apex of the abdomen in M. calhouni and other Bowangius species) and round hemispherical eyes. Bowangius cyclops can be distinguished from $M$. calhouni by the distinctly striate elytra, more robust tarsi with broad lobes of tarsites 3 and shorter tarsites 5 (only the metatarsal claw is preserved in B. cyclops, similar to that of M. calhouni in being dentate) and the distinctly thicker segment 4 of the funicles.

Genus Euryepomus Clarke \& Oberprieler, gen. n.

Type species: Euryepomus lophomerus Clarke \& Oberprieler, sp. n.

Description. Size. Length $2.8 \mathrm{~mm}$, width ca. $1.4 \mathrm{~mm}$. Head short, subconical. Eyes small, hemispherical, coarsely facetted, without tubercles between them. Rostrum about as long as pronotum, stout, subcylindrical, curved; antennal insertions postmedian, behind them with scrobes not quite extending to eye, in front of them without lateral row of setae discernible. No gular suture discernible. 
Antennae geniculate, long; scapes relatively short, cylindrical, apically well clavate; funicles slightly longer than scape, 7-segmented, segment 1 elongate, 2 shorter, thinner, 3-7 very shorter; clubs loosely articulated, 4-segmented. Mouthparts. Labrum absent. Mandibles flat, exodont, curved down, articulation oblique. Maxillae and labium not discernible. Thorax. Prothorax strongly proclinate, with anterior lateral margins oblique in lateral view. Pronotum elongate, slightly convex, laterally rounded, without tooth, posterior corners rounded, fitting closely onto elytra; surface densely setose; notosternal sutures closed, upright then curved anteriad. Prosternum moderately long; procoxal cavities medially confluent. Mesocoxal cavities laterally closed (by meso- and metaventrite). Metanepisternal sutures distinct. Mesoventrite short, anteriorly strongly sloping. Metaventrite longer, slightly convex. Elytra broad, with prominent, broadly rounded, flattened humeri, apex obscured, probably individually rounded, not exposing pygidium; sutural flanges not visible; surface punctostriate, without scutellary striole, densely setose. Legs. Procoxae large, prominent, medially contiguous; mesocoxae subglobular, narrowly separated; metacoxae flat, transversely elongate. Trochanters short, oblique. Femora short, subcylindrical to slightly flattened, distally inflated, unarmed. Tibiae long, flattened, outer edge carinate, not crenulate, apex obliquely truncate, with 2 small spurs. Tarsi with tarsite 1 long, narrow, 2 shorter, triangular, 3 deeply bilobed, 5 as long as $1+2$; claws divaricate, dentate with ventrobasal seta at apex of tooth. Abdomen with ventrites 1 and 2 fused, elongate.

Derivation of name. The genus is named for its broad, sharp shoulders, the name derived from the Greek adjective eurys (broad) and noun epomis (G: epomidos), the point of the shoulder, but being masculine in gender.

Remarks. Euryepomus belongs in the group of genera with carinate, crenulate or serrulate tibiae and subglobular eyes and is therefore most similar to Mesophyletis, Mekorhamphus and Myanmarus. From Mekorhamphus it is distinguishable by the lack of dorsal tubercles between the eyes, from Myanmarus by not having the ventrites impressed and from Mesophyletis by having carinate tibiae, free spurs and tarsites 3 with short, digitate lobes, the last having serrulate tibiae, one spur fixed and enlarged and tarsites 3 with long, pedunculate lobes.

Euryepomus lophomerus Clarke \& Oberprieler, sp. n. (Figure 73)

Description. Size. Length $2.85 \mathrm{~mm}$, width ca. $1.4 \mathrm{~mm}$. Head strongly constricted behind eyes. Eyes dorsally separated anteriorly by less that width of rostrum but posteriorly by more (forehead triangular). Rostrum slightly longer than pronotum, dorsoventrally flattened (possibly a compression artefact); antennal insertions just behind middle of rostral length. Antennae. Scapes thin, not reaching eye in repose, apical club about twice as thick as shaft; funicles with segment 1 spindle-shaped, 2 shorter, thinner, 3-7 submoniliform; clubs long, slightly flattened, apical segment distinct, as long as segment 3, flattened. Mouthparts. Mandibles with 3 inner (dorsal) teeth, basal one broad and blunt, median one long and acute, apical one forming short, narrow, downcurved $\mathrm{T}$ at apex with corresponding inner one, outer (ventral) side with at least one small median tooth. Thorax. Pronotum slightly longer than broad; setae fine, long, sharp, suberect, directed anteriad. Prosternum moderately long; procoxal cavities in middle of prothorax. Scutellar shield small, transverse, slightly raised. Elytra with humeri laterally flattened, slightly explanate with short thick black carina; posteriorly gently declivous, lateral margin sinuate; punctures indistinct, setae long, straight, suberect, directed caudad. Legs. Profemora with outer edge rounded, non-carinate, meso- and metafemora with distinct black carina in distal half. Tibiae somewhat flattened, densely setose, spurs slender, small. Tarsi slightly longer than half of tibial length; tarsite 1 apically truncate, 2 apically slightly excised, 3 with lobes digitate, 5 very narrow between lobes of 3 but broadening distad. Abdomen with ventrites 1 and 2 each almost twice as longas $3+4,5$ as long as 4 .

Material examined. Holotype (NIGP157017): well preserved, intact specimen, with rostrum slightly distorted, surface of pronotum party obscured by thin layer of small bubbles, otherwise well visible; slightly diagonally placed in centre of rectangular cuboid $4.4 \times 3.2 \times 2.05-2.25 \mathrm{~mm}$; amber clear but with many impurities, especially on left side and around back of specimen, at back and 
below specimen with dense layer of flow lines obscuring caudal view, along left side also with narrow horizontal crack.

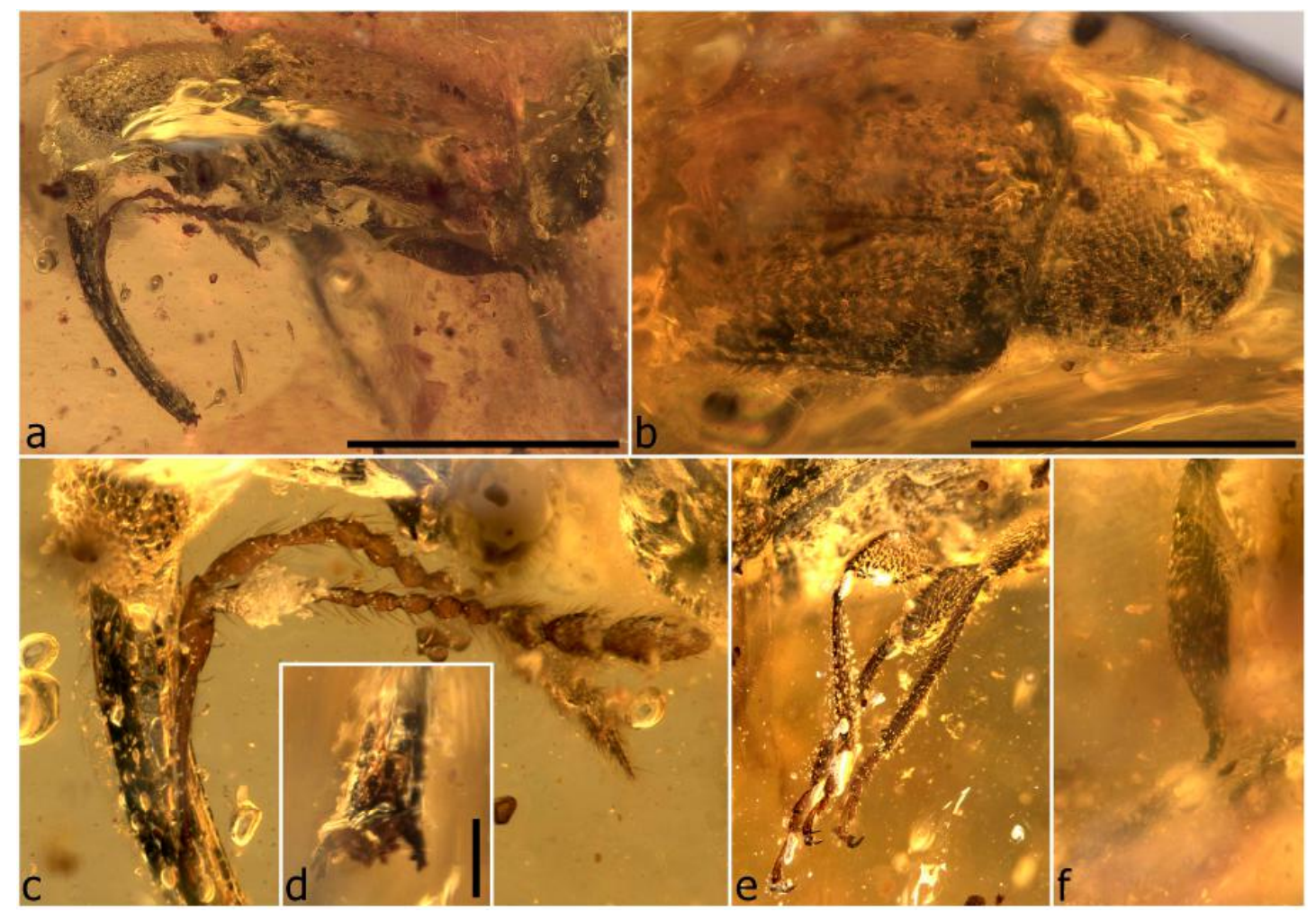

Figure 73. Euryepomus lophomerus sp. n., holotype. Habitus, left lateral (a); habitus, dorsal (b); eyes and antennae, left lateral (c); apex of rostrum and mandibles, apical (d); legs (e); left hindleg (f). Scale bars: $1.0 \mathrm{~mm}(\mathrm{a}, \mathrm{b}) ; 0.1 \mathrm{~mm}(\mathrm{~d})$.

Derivation of name. The name of the species is a latinised adjective formed from the Greek nouns lophos (G: lophou), a crest or ridge, and meros (G: mereos), a thigh, for the distinct black ridge on the meso- and metafemora of the species.

Remarks. The single specimen of this species known thus far resembles that of Mesophyletis calhouni as illustrated by Poinar [29] in size and shape, but it differs mainly in its legs, the tibiae not being crenulate on the outside (only carinate) and with very small, normal spurs, the meso- and metafemora having a distinct, black carina in the distal half of the outer (dorsal) side, the lobes of tarsites 3 being narrow, digitate, not pedunculate, (all) the tarsal claws dentate and the ventrites slightly stepped (not flatly aligned).

Genus Periosocerus Clarke \& Oberprieler, gen. $\mathbf{n}$.

Type species: Periosocerus deplanatus Clarke \& Oberprieler, sp. n.

Description. Size. Length 2.6-2.7 mm, width 1.35-1.42 mm. Head porrect, short, subconical, constricted behind eyes. Eyes large, strongly protruding laterally, facing forward or evenly semicircular in outline, coarsely facetted, without interfacettal setae, separated dorsally by about width of rostrum, without tubercles between them. Rostrum stout, subcylindrical but compressed; antennal insertions lateral, in apical third of rostral length, behind them with scrobes extending to eye, in front of them scrobes shortly extending, ventral margin with row of 6-7 long, erect setae. Gular suture single, long. Antennae geniculate, long, robust; scapes long, thick, cylindrical, apically gradually clavate; funicles as long as scape, 7-segmented, segment 1 long, 2-3 subequal but thinner, 4-5 shorter, 6 and 7 asymmetrical, all sparsely stiffly setose; clubs long, robust, loosely articulated, 4-segmented. Mouthparts. Labrum absent. Mandibles bluntly exodont, with 2 blunt upper teeth, articulation oblique. Maxillae exposed, palpiger about as wide as basal palp segment, palps 3-segmented, basal segment short, ca. 0.67 
$x$ as long and about as wide as 2, 3 fusiform, narrower than 2, about as long as 1 and 2, apically hyaline. Labium with palps inserted apically, porrect, 3-segmented, segment 1 apically oblique, with large seta, subequal in length to 3, 2 about $0.25 \times$ as long as 3, 3 fusiform, apically hyaline (or with sensilla). Thorax. Prothorax not proclinate, with anterior lateral margins vertical in lateral view; laterally strongly inflexed. Pronotum longer than broad, slightly convex, laterally rounded, without tooth, posterior corners shortly extended to fit closely onto elytra; surface setose; notosternal sutures closed, vertical at base, then bent anteriad onto prothoracic margin. Prosternum moderately long; procoxal cavities medially confluent, situated about their length away from anterior margin of prosternum. Mesocoxal cavities laterally closed (by meso- and metaventrite). Metanepisterna setose, metanepisternal suture distinct. Mesoventrite short, anteriorly strongly sloping. Metaventrite longer, about as long as metacoxa, slightly convex. Elytra elongate, with broadly rounded humeri, apically individually rounded, not exposing pygidium; sutural flanges invisible; surface punctostriate, without scutellary striole, densely setose, setae long, fine, sharply pointed, directed caudad. Legs. Procoxae large, prominent, medially contiguous; mesocoxae subglobular, narrowly separated; metacoxae flat, transversely elongate. Trochanters short, oblique, recessed into coxae. Femora long, subcylindrical, strongly inflated in distal half, unarmed. Tibiae long, flattened, outer edge rounded or crenulate, apex truncate, with 2 spurs. Tarsi robust; tarsite 1 broadly triangular, 2 triangular, 3 deeply bilobed but short, 5 as long as $1+2$, widening apicad; claws divaricate, dentate with ventrobasal seta at apex of tooth. Abdomen with ventrites 1 and 2 fused, slightly longer than 3 .

Derivation of name. The genus is named for its large, thick antennae, the name formed from the Greek adjective periosus (immense) and noun keras (G: keratos), a horn, and being masculine in gender.

Remarks. This genus is similar to Habropezus in its elongate, depressed eyes and elytral sculpture and vestiture but differs mainly in its much larger, thicker antennae. It also has a flatter body and a longer prosternum (the procoxae placed further back). From Mekorhamphus it is readily distinguishable by lacking tubercles between the eyes. It is represented by two species.

Periosocerus deplanatus Clarke \& Oberprieler, sp. n. (Figure 74)

Description. Size. Length $2.60 \mathrm{~mm}$, width $1.35 \mathrm{~mm}$. Head strongly constricted behind eyes, densely setose between eyes. Eyes elongate, compressed, in dorsal view strongly oblique, anteriorly separated by width of rostrum, forehead slightly impressed. Rostrum as long as pronotum, of even width throughout length, very slightly curved; dorsally sparsely setose, setae suberect, curved anteriad. Antennae. Funicles with segment 1 spindle-shaped, 2-3 almost as long but thinner, 4-5 shorter, 6-7 slightly longer than 4-5 but thicker; clubs slightly flattened, segments 1-3 asymmetrical, 4 bluntly triangular, about as long and almost as broad as 3. Mouthparts. Mandibles flat, with 2 blunt outer teeth, apical one forming square with inner apical one. Thorax. Pronotum slightly narrower than elytra, anteriorly not constricted, sides arcuate, widest across anterior third, basal margin arcuate, bent up, beaded, apical margin straight; surface shallowly rugose, densely setose, setae long, thin, sharp, directed mesad to anteromesad. Scutellar shield roundly subquadratic, flat, densely squamose. Elytra narrow, posteriorly sharply declivous, striae broad, shallow, punctures large, interstriae weakly convex, lateral margin faintly sinuate, with epipleural groove, anteriorly slight notched over head of metanepisternum. Legs. Procoxae in about middle of prosternal length. Femora rounded on outside. Tibiae straight, protibiae apically bent inwards, outer edge rounded, not crenulate, with long straight suberect setae in distal third. Tarsi almost as long as tibiae; tarsite 1 apically truncate, 2 apically strongly excised, 3 with lobes not pedunculate, 5 narrow. Abdomen with ventrites 1 and 2 slightly longer than 3, 4 slightly shorter than, 5 long, subtriangular.

Material examined. Holotype (NIGP157018): well preserved, intact specimen but strongly depressed, especially head and rostrum, left hindwing protruding at back; in centre of rectangular cuboid $5.4 \times 3.8 \times 2.75 \mathrm{~mm}$; amber very clear with almost no impurities except small bubble well above pronotum, narrow slanting film of minute bubbles along side of right elytron and large elongate milky bubble beneath side of left elytron. 
Derivation of name. The species is named for its flattened shape. Even though this is partly due to a compression artefact, the species appears to have been very flat in nature.

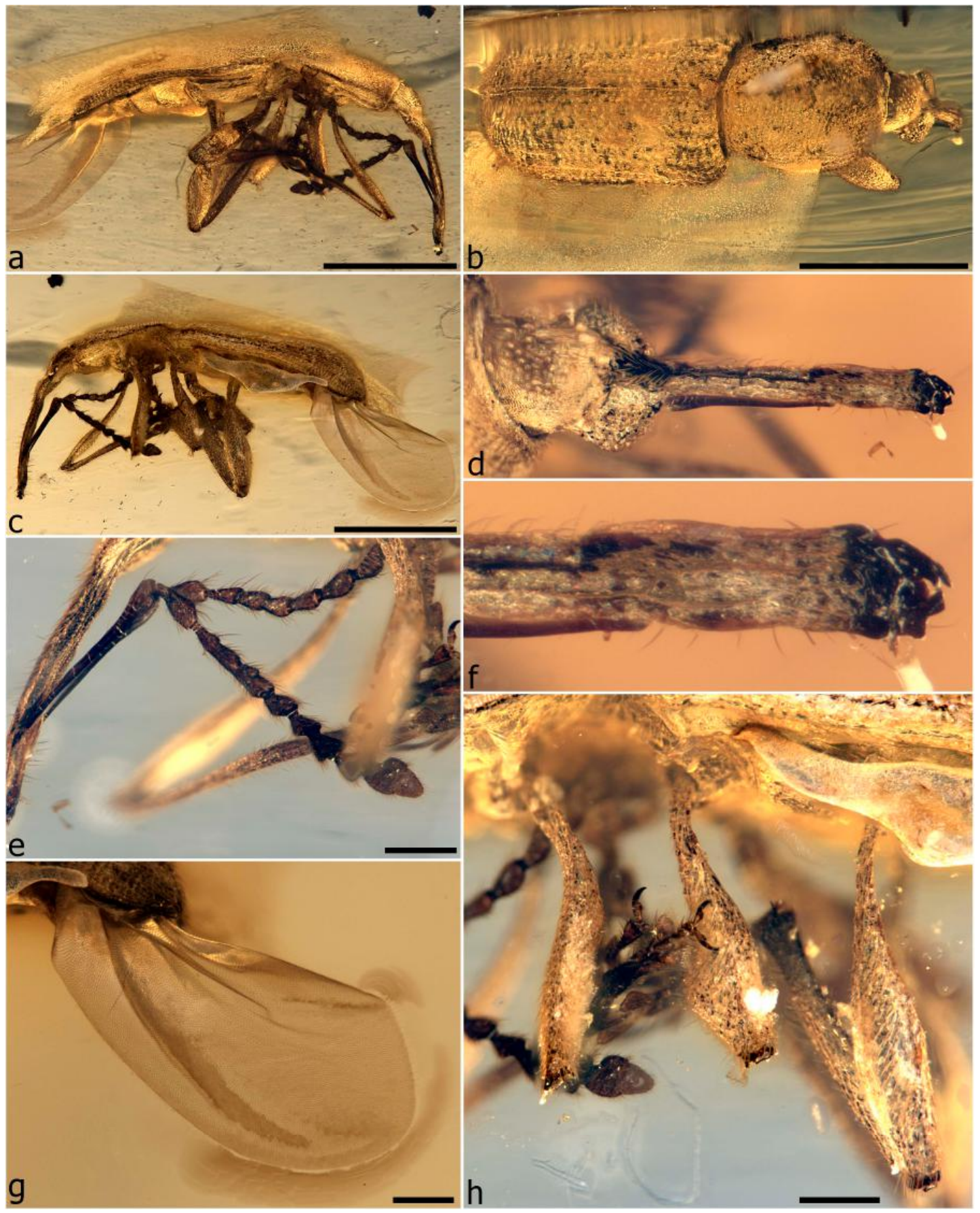

Figure 74. Periosocerus deplanatus sp. n., holotype. Habitus, right lateral (a); habitus, dorsal (b); habitus, left lateral (c); head, dorsal (d); left antenna (e); apical part of rostrum and mandibles (f); distal part of hindwing (g); left femora and tarsal claws (h). Scale bars: $1.0 \mathrm{~mm}(\mathrm{a}-\mathrm{c}) ; 0.2 \mathrm{~mm}(\mathrm{e}, \mathrm{g}, \mathrm{h})$.

Remarks. The species differs from P. crenulatus mainly in having the tibiae not crenulate on the outside, as well as by having longer tarsi but shorter antennal clubs. The single known specimen is strongly depressed, especially the head and rostrum, and does not allow a proper determination of all critical characters. 
Periosocerus crenulatus Clarke \& Oberprieler, sp. n. (Figures 75 and 76, Video S7)

Description. Size. Length $2.67 \mathrm{~mm}$, width $1.42 \mathrm{~mm}$. Head weakly constricted behind eyes, densely setose, finely punctorugose; ventrally moderately bulging. Eyes in dorsal view evenly semicircular, dorsally separated by basal width of rostrum anteriorly but further separated posteriorly. Rostrum ca. $0.67 \times$ as long as pronotum, dorsally with short recurved setae from base to antennal insertions; with median, paramedian and dorsolateral carinae extending to antennal insertions, all but dorsolateral ones partly confused beyond antennal insertions; dorso-apically with pair of stout curved setae on each side; ventrally on either side of postmentum with pair of thick setae, postmentum distinct, projecting somewhat obliquely, narrowing toward antennal insertions, apically (suture with prementum) truncate. Scrobes narrowly extending anteriad from antennal insertions to mandibular articulations, distal 2 lateral setae distinctly thicker than others. Antennae. Scapes about as long as funicle; funicles with segment 1 fusiform, $2.0 \times$ longer than 2, 2-4 elongate-obconical, subequal, 5 similar, ca. half as long as 4, 6-7 broader, distinctly obconical, apically oblique, seemingly more densely setose than 1-5 (like club segments); clubs with segments $1-2$ obconical, $2 \mathrm{ca}$. $0.67 \times$ as long as 1, apices of 1-3 distinctly oblique, $31.5 \times$ longer than 4, 4 acute, narrowly inserted into 3 . Mouthparts. Mandibles flat, outside and inside with 2 teeth, basal ones larger, apical ones smaller, those from opposite sides together forming apical Y. Maxillae with coarse seta on palpiger. Thorax. Pronotum slightly narrower than elytra, anteriorly slightly constricted; sides sinuate, straight in basal third, broadly convex anteriorly, in dorsal view seemingly tuberculate, almost toothed; base broadly convex in median half, slightly curved outwards to posterior angles, closely fitting onto elytra; coarsely punctorugose, setae directed anteriad and anteromesad. Prosternum elongate, about as long as procoxae, prosternal process short, pointed; hypomeron ca. $0.25 \times$ as long as prosternum. Scutellar shield distinct, level with elytra, densely setose. Elytra with interstriae weakly prominent, punctorugose, striae and interstriae more prominent laterally; bases weakly sinuate, closely fitting over pronotum; lateral margin sinuate with distinct marginal groove, slightly widening anteriorly. Legs. Procoxae close to posterior hypomeral margin. Femora on outside rounded (profemora) or crenulate (meso- and metafemora); mesofemora strongly notched before apex, with curved, blunt, posteriadly projecting tooth on anterior edge of inner side. Tibiae with long suberect setae, denser longer setae in apical half; outer edge sparsely serrulate (protibiae) or crenulate with curved, pointed and closely spaced teeth (meso- and metatibae); apically somewhat expanded, apex with short narrow flange lined with coarse fringing setae, dorso-apically with stronger, coarser, spur-like seta (less distinct from other fringing setae on metatibiae) and slender elongate setae; with 2 elongate unequal spurs. Tarsi ca. half as long as tibiae; tarsite 1 apically subtruncate, $2 \mathrm{ca}$. half as long as 1, apically strongly excised, 3 with lobes subpedunculate, ca. half as long as 5, somewhat recessed into apex of 2, 5 long, very slender. Abdomen. Ventrites densely setose, setae much finer than dorsal setae; sutures substraight or arcuate, 1 and 2 subflatly alligned, lower than others, subequal in length, 3-4 progressively shorter, 5 longer than 4 .

Material examined. Holotype (NIGP157019): well preserved specimen, not distorted or compressed, well visible (especially ventrally), with fragmented coating of whitish debris, with femorotibial joints of right legs and left hindleg, distal half of left mesotibia and right elytral apex and half of ventrite 5 cut away with amber, other structures intact with all mouthpart structures clearly visible, tarsi bunched beneath specimen (poorly visible); in triangular prism $5.1 \times 3.2 \times 2.5 \mathrm{~mm}$ with one long edge rounded off; amber clear yellow, with one large bubble above pronotum and several other smaller bubbles and few tiny fractures close to dorsal surface of specimen.

Derivation of name. The species is named for its crenulate tibiae, the name being a Latin adjective.

Remarks. Periosocerus crenulatus differs from P. deplanatus mainly in having the tibiae serrulate to crenulate on the outside and by having shorter tarsi but longer antennal clubs. An exceptional feature of the single known specimen is the astonishing preservation and unobstructed view of the mouthparts. The specimen was submitted for CT scanning, but the resulting images are not too clear (Figure 76, Video S7). 

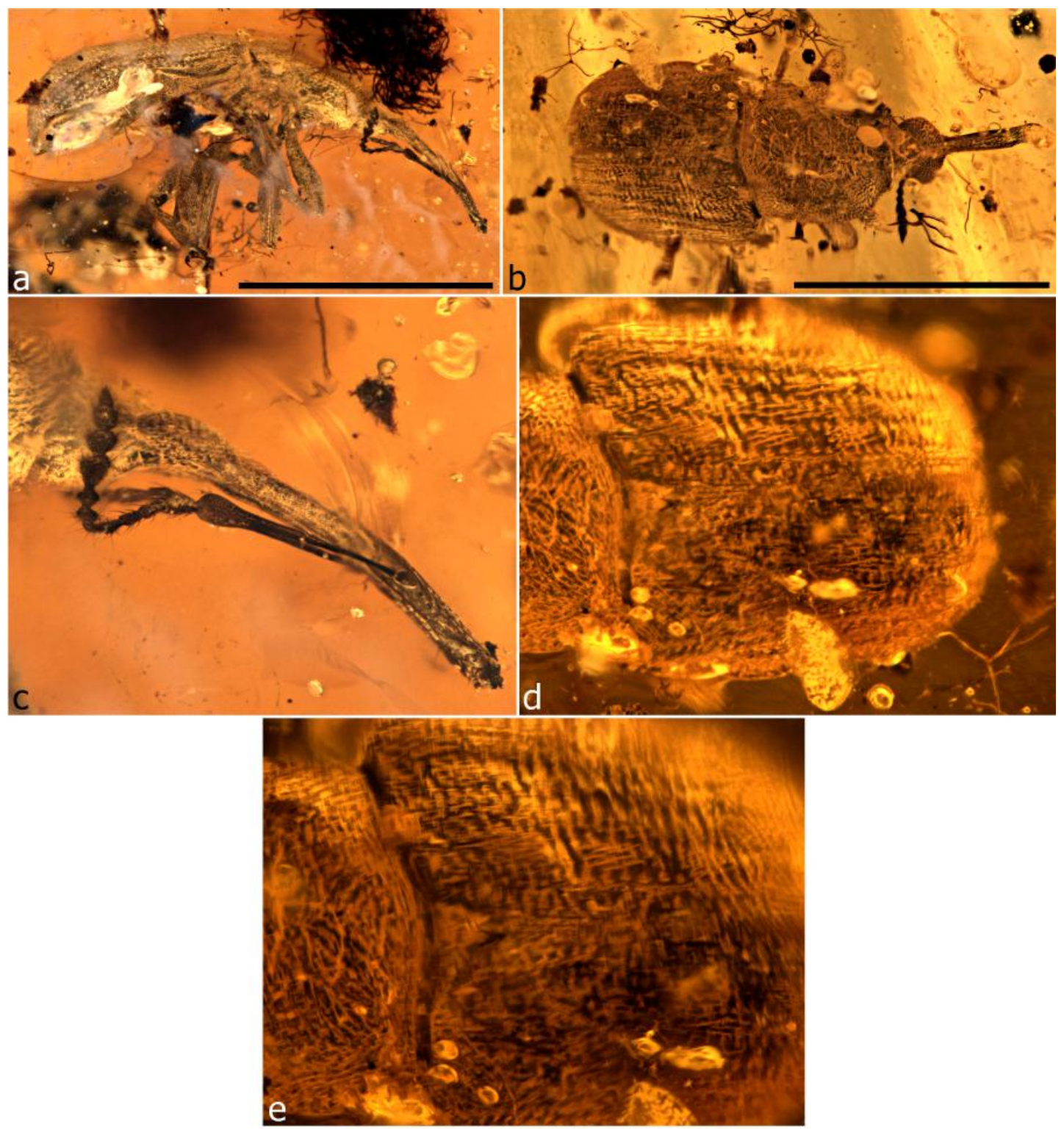

Figure 75. Periosocerus crenulatus sp. n., holotype. Habitus, right lateral (a); dorsal oblique (b); head and antenna, right lateral (c); elytra, dorsal oblique (d); same, detail (e). Scale bars: $1.0 \mathrm{~mm}(\mathrm{a}, \mathrm{b})$.

Genus Habropezus Poinar, Brown \& Legalov, 2016

Habropezus Poinar, Brown \& Legalov, 2016: 160 [54] (type species, by original designation:

Habropezus plaisiommus Poinar, Brown \& Legalov, 2016)

Redescription. Size. Length $1.74-3.0 \mathrm{~mm}$, width $0.68-1.2 \mathrm{~mm}$. Head short, subconical, moderately constricted behind eyes, bulging dorsally, more strongly ventrally. Eyes large, elongate-compressed, strongly protruding, moderately coarsely facetted, without interfacettal setae, dorsally separated by about width of rostrum anteriorly but further separated posteriorly; forehead flat, without tubercles above eyes. Rostrum about $1.5 \times$ longer than pronotum, subcylindrical, moderately curved; antennal insertions lateral, with scrobes behind them reaching eye, in front of them with or without (H. kimpulleni) row of sparse erect setae. Gular suture single, from base of head to underside of rostrum. Antennae geniculate, long; scapes elongate, cylindrical, apically only slightly inflated, almost as long as funicle; funicles 7-segmented, segment 1 subequal in length to and wider than 2, others thinner and progressively shorter towards club; clubs elongate, loosely articulated, 4-segmented, segment 4 acute, flattened, about as long as 3, broadly inserted into 3 in 
dorsal view, much more narrowly in lateral view (at least in H. tenuicornis). Mouthparts. Labrum absent. Mandibles small, exodont, articulation oblique. Maxillae and labium not clearly visible. Thorax. Prothorax slightly to strongly proclinate, with anterior lateral margins oblique in lateral view. Pronotum convex, laterally rounded, without tooth, posterior corners subacute, fitting closely onto elytra; surface coarsely punctorugose to closely tuberculate, sparsely to densely finely setose, setae reclinate, directed anteromesad; notosternal sutures closed, vertical then abruptly deflected anteriorly. Prosternum short; procoxal cavities medially confluent, closer to anterior prosternal margin. Scutellar shield densely setose, raised above elytral surface. Mesocoxal cavities laterally closed (by meso- and metaventrite). Metanepisterna distinct, setose. Mesoventrite short, anteriorly sloping. Metaventrite longer, raised into transverse weals before metacoxae. Elytra elongate, basally concave to receive basal pronotal margin, with broadly rounded humeri, posteriorly declivous, lateral margin strongly sinuate to roundly emarginate in middle, apically weakly individually to conjointly rounded, not exposing pygidium; sutural flanges narrow, equal; surface punctostriate, without scutellary striole, interstriae coarsely tuberculate, sparsely setose, setae long, thin, reclinate, directed caudad. Legs. Procoxae large, prominent, medially contiguous; mesocoxae subglobular to conical, projecting, narrowly separated; metacoxae flat, transversely elongate. Trochanters short, oblique. Femora long, subcylindrical, inflated in distal half, unarmed, meso- and metafemora on outside carinate to serrulate in distal third. Tibiae elongate, straight, slender, compressed, outer edges serrulate, with dense long stiff setae in distal half, apex subtruncate, with 2 spurs. Tarsi more than half length of tibiae; tarsite 1 apically subtruncate, 2 shorter, subtriangular, apically subtruncate, 3 deeply bilobed, 5 long, slender, apically expanded; claws divaricate, dentate with ventrobasal seta on proximal face of tooth. Abdomen. Tergite VII flat, apically sharply rimmed, fitting tightly onto caudal edge of ventrite 5. Ventrites 1 and 2 longer than 3 , 1-4 progressively shorter, 5 shorter or slightly longer than 4 , apically broadly rounded, flat.

Remarks. Along with Mekorhamphus, this genus was placed in a tribe Mekorhamphini based on several alleged characters, including its horizontally moving exodont mandibles, an elongate procoxal prosternum, contiguous procoxal cavities and swollen trochanters, and distinguished from the tribes Anchineini and Mesophyletini based on combinations of these. Our examination of the remarkably well preserved and largely unobstructed holotype of $H$. plaisiommus revealed that the original description is somewhat unclear on the ventral prothoracic details, describing the prosternum as elongate and almost equal in length to the procoxal cavities, whereas the hypomeron ("postcoxal portion") is stated as being short, this seemingly indicating a placement of the procoxal cavities closer to the posterior than the anterior prothoracic margin. However, the prosternum is in fact shorter than the hypomeron, and thus the procoxal cavities are more anteriorly positioned. The original description also mentions a fused labrum, mandibles probably with teeth on the external margins and moving horizontally, antennal scrobes directed toward the eyes and free ventrites. We found no evidence of a labrum (fused or otherwise; the apical part of the rostrum forms a truncate margin), the first two ventrites to be fused, only the last three free (as in other Mesophyletidae), but the mandibular dentition to be correct as stated. The rostrum in the holotype of H. plaisiommus is depressed, resulting in the antennal insertions being pushed to the ventral side (an artefact), obscuring the scrobes and leaving the mandibular articulation plane unverifiable. The antennal insertions would have naturally been in a lateral position, as they are in all other Mesophyletidae, and the mandibular articulation plane could have been horizontal or oblique given the clearly visible, typically flat structure and overlapping configuration of the mandibles in their repose position. The displacement of the ventrites (sunken) prevents an assessment of the exposure and structure of tergite VIII, which in several species of the very similar genus Bowangius is carinate along the upper edge and apically sharply flanged. This structure is seemingly absent or different in most Habropezus species (in H. kimpulleni tergite VII abuts directly onto ventrite 5), but more material is required to confirm this, especially if the condition present in our Bowangius specimens is a character of the male. Most of the above-mentioned details were only visible at magnifications greater than $100 \times$, as is the serrulation of the tibiae, a critical feature not mentioned in the original description. 


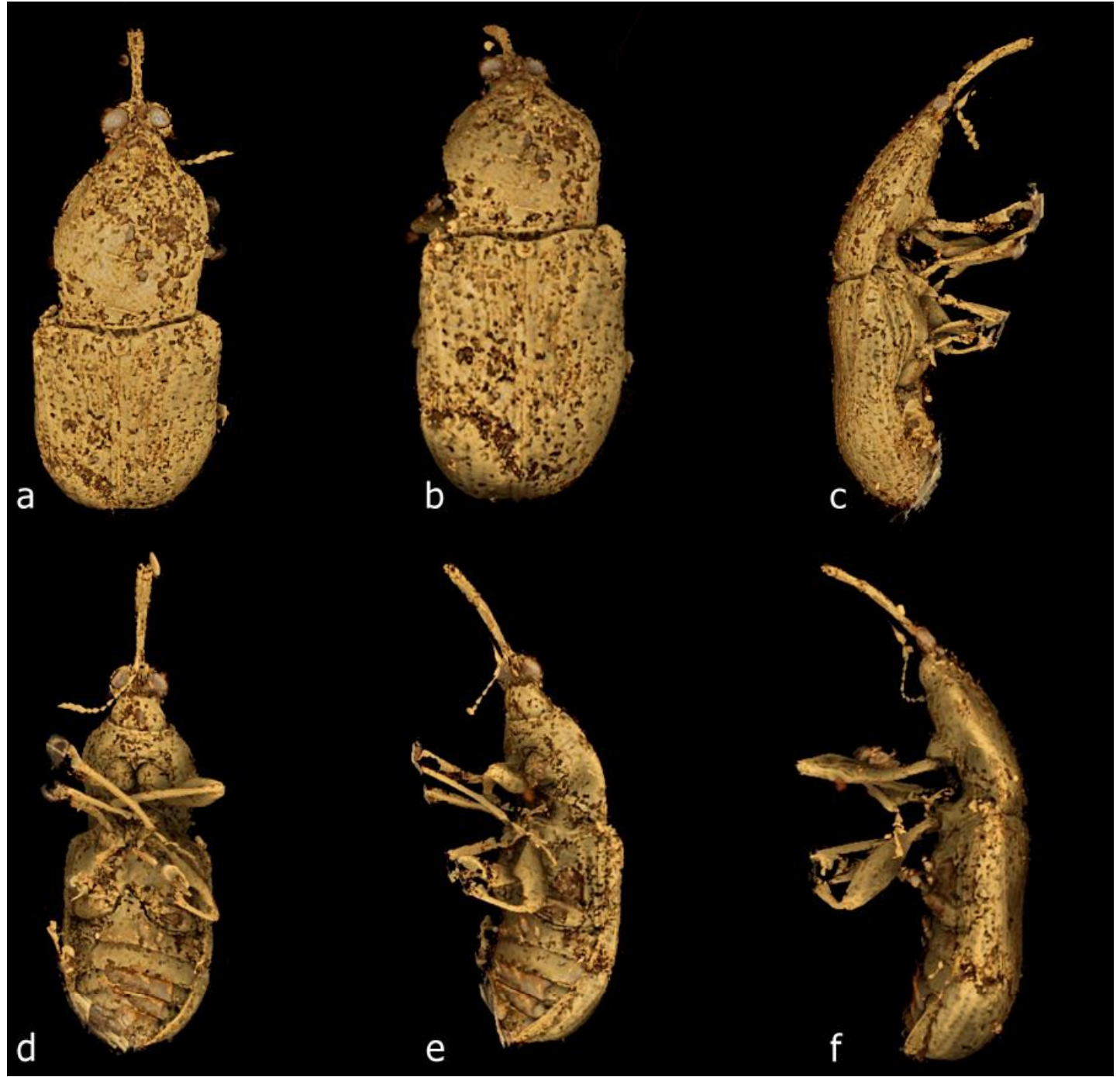

Figure 76. Periosocerus crenulatus sp. n., holotype. Habitus images extracted from a micro-CT scanning reconstruction (see also Video S7). Dorsal oblique (a); dorsal (b); right lateral (c); ventral (d); ventral oblique (e); left lateral (f).

Habropezus is difficult to distinguish from several other genera, seemingly forming a group of closely related taxa including Bowangius, Euryepomus, Leptopezus, Mesophyletis and Periosocerus. Among its most important diagnostic characters are the compressed eyes and posteriorly widening, flattened forehead, which distinguish it from all other genera with serrulate or crenulate tibiae except Periosocerus, from which it differs in its serrulate tibiae, distinctly punctostriate elytra with raised interstriae, distinct humeri, higher body with shorter prosternum and the proclinate prothorax. Habropezus currently contains four species, a pair of larger ones without lateral setae on the rostrum (H. kimpulleni) or with only fine, indistinct ones (H. plaisiommus) and a pair of smaller ones with long and very distinct such setae (H. tenuicornis and $H$. incoxatirostris).

Habropezus plaisiommus Poinar, Brown \& Legalov, 2016

Habropezus plaisiommus Poinar, Brown \& Legalov, 2016: 160 [54]

Redescription. Size. Length $3.0 \mathrm{~mm}$ (excl. rostrum, not SL). Small, uniformly black but with legs paler, dark brown; coarsely punctate, sparsely setose. Head setose. Eyes strongly, flatly protuberant. Rostrum apically slightly expanded, dorso-apically grooved, with at least 2 long setae at sides; antennal insertions slightly antemedian. Antennae. Scapes extending to near front margin of eye; funicles with segments 2-7 subequal in width, apically expanded; clubs ca. $2.0 \times$ wider than funicle, segment 1 
slightly longer and about as wide as 2, obconical, basal width less than that of 2, 3 slightly shorter than 4 . Mouthparts. Mandibles with 2 large teeth on inner and outer edges; apically forming broad V, slightly emarginate, with apical outer tooth much larger than middle outer one but middle inner tooth much larger than apical inner tooth; articulation probably oblique (rostrum depressed). Thorax. Prothorax strongly proclinate. Pronotum sparsely, coarsely punctate, punctures distinct, setae fine, recurved; sides weakly curved; base slightly sinuate, fitting closely onto elytra. Prosternum short, anterior margin broadly emarginate, prosternal process short, pointed; hypomeron longer than prosternum. Scutellar shield subcircular, slightly convex. Mesocoxal cavities narrowly separated. Elytra evenly rugosely sculptured between punctures; punctures on interstriae finer than in striae; interstriae prominent, raised above striae, setose, setae arising from prominences; bases weakly sinuate, extended over pronotum; humeri slightly flatly projecting; sides weakly sinuate, without any lateral carina, margin pre-apically with row of 3-4 small teeth along edge; with marginal groove subequal in width for entire length, with anterior marginal notch. Hindwings present (wing visible beneath slightly parted elytra). Legs long, very slender, similarly setose. Femora very slender basally, inflated in distal half, with subappressed fine recurved whitish setae; outside slightly (profemora) to more distinctly (mesoand metafemora) serrulate in distal third. Tibiae with outer edges (protibiae) carinate in proximal third to half and sparsely serrulate in distal half (gap of 2-4 teeth between teeth), or (meso- and metatibiae) closely serrulate for entire length, with teeth curved, pointed; apically with shortly and broadly rounded outer flanges and slender fringing setae; dorso-apically with several very long fine setae; ventrally with 2 long dark spurs; protibiae ca. $1.25 \times$ longer than others; metatibiae without inner apical flanges. Tarsi distinctly elongate-slender, progressively shorter from fore- to hindlegs; tarsite 1 elongate, ca. $2.0 \times$ longer than 2 , slightly expanded apically, 2 slightly wider, of metatarsi with dorso-apical setae denser and longer than others, 3 with lobes slightly wider apically than basally, slightly less than half length of claw segment, with inner edges of lobes distinctly continuous basally, of metatarsi narrower than other legs; claws with strong triangularly acute basal tooth. Abdomen. Ventrites sparsely setose, distinctly sparsely punctate (punctures similar to dorsal punctures, finer), rugosely microsculptured; $1-2$ subflatly aligned, $2-5$ stepped, 5 slightly longer than 4 , apically rounded; sutures deeply grooved, straight.

Material examined. Holotype (PACO, with curatorial \#Bu-C-48A): excellently preserved, intact, well visible and minimally distorted specimen (rostrum depressed), with several bubbles emanating from body, including large one from abdominal apex and from rupture of ventral side of right profemur; situated close to large curved face of irregular cuboid; amber clear yellow-brown with flow band above top left side of specimen and few impurities, but numerous large bubbles (see also [54]). Paratype (PACO, with curatorial \#Bu-C-48B): heavily distorted and decomposed, poorly visible specimen, with head and prothorax crumpled and ruptured, most legs missing or not properly visible (left legs) or missing parts, antennae largely missing; in irregular cuboid with one end rounded; amber clear yellow, largely free of impurities, with large mass (interpreted a braconid wasp cocoon [54]) adjacent to left side. This specimen is not conspecific with Habropezus plaisiommus (see Genus and species incertae sedis below).

Remarks. This species is most similar to H. kimpulleni, agreeing in mandibular structure and dentition, apparently not having an apicolateral row of erect setae on the rostrum, which occurs in the other two species, and in having a similar tarsal configuration. It differs from H. kimpulleni in its long, slender, straight, serrulate tibiae (apically notched and crenulate in H. kimpulleni). From H. tenuicornis and $H$. incoxatirostris it differs in its rostrum not having apicolateral setae and in its regularly and closely serrulate tibiae.

Habropezus kimpulleni Clarke \& Oberprieler, sp. n. (Figure 77)

Description. Size. Length $2.78 \mathrm{~mm}$, width $1.2 \mathrm{~mm}$. Head short, subconical, strongly constricted behind eyes. Eyes large, forehead between them triangular, flat. Rostrum relatively thick, slightly curved; antennal insertions in basal 2/5 of rostral length, in front of them without lateral row of setae. Antennae long; scapes long, thin; funicles longer than scape, segment 1 inflated (as thick as 
club of scape), 2-7 thinner, also long but gradually shortening towards club; clubs almost as long as funicle, slightly flattened, segment 1 as long and broad as 2, both obconical, segment 4 as long as 3 , broadly inserted into 3, flat, acute. Mouthparts. Mandibles with 3 teeth on inner (dorsal) side, basal 2 large and acute, apical one smaller (and double on right mandible, with another tooth projecting obliquely ventrad from it), with 2 teeth on outer (ventral) side, basal one also larger but blunt, inner and outer apical teeth together forming broad sharp T; articulation oblique. Thorax. Prothorax strongly proclinate. Pronotum elongate, slightly convex, laterally strongly rounded, posterior margin bisinuate, distinctly rimmed; surface densely bluntly tuberculate, sparsely setose, setae long, thin, recumbent. Scutellar shield short, broad, covered with long setae directed caudad. Mesepimera large. Metanepisternal sutures distinct. Elytra with almost angular humeri, posteriorly gently declivous, apically weakly individually rounded; striae indistinct. Legs. Femora subcylindrical, profemora on outside rounded but meso- and metafemora finely crenulate in distal third. Tibiae flattened, outer edge distinctly crenulate, meso- and metatibiae apically excised on outside, apex obliquely truncate, with 2 large spurs. Tarsi almost as long as tibiae; tarsite 1 elongate, narrow, 2 shorter, narrowly triangular, 3 with lobes not pedunculate, 5 as long as $1+2$. Abdomen. Ttergite VII strongly sclerotised, finely punctate. Ventrites 1 and 2 slightly longer than $3+4,3$ slightly longer than 4,5 short, apically broadly rounded.

Material examined. Holotype (NIGP157020): extremely well preserved, intact specimen, not compressed or distorted, very well visible from all sides; in centre of rectangular cuboid $5.5 \times 3.1 \times$ $2.6 \mathrm{~mm}$; amber very clear with almost no impurities except large brown film diagonally above head pronotum, white bubble below prosternum, large, irregular clear bubble below right side of abdomen, and clear bubble above elytral declivity.

Derivation of name. The species is cordially named after our colleague Kimberi Pullen for his longstanding and able assistance with weevil research and curation of the ANIC weevil collection, especially during the compilation of the catalogue of Australian weevils [58].

Remarks. This species is most similar to H. plaisiommus, the rostrum also without a distal row of erect lateral setae and the mandibles with a similar dentition, but it differs from the latter in its broader antennal clubs and several leg characters, the tibiae crenulate throughout their length (not carinate or serrulate), the meso- and metatibiae apically notched on the outside, tarsites 1 shorter (less than $2.0 \times$ longer than 2) and the lobes of tarsites 3 less than half as long as tarsites 5. From H. tenuicornis and $H$. incoxatirostris it is most readily distinguishable by its rostrum not having an apicolateral row of sparse erect setae and its crenulate tibiae and longer tarsi.

Habropezus tenuicornis Clarke \& Oberprieler, sp. n. (Figure 78)

Description. Size. Length $1.83 \mathrm{~mm}$, width $0.9 \mathrm{~mm}$. Head porrect, weakly constricted behind eyes. Eyes elongate, in dorsal view hemispherical, laterally protruding. Rostrum dorsally with 2 subparallel grooves along entire length; antennal insertions median, in front of them with ca. 6 long curved setae in groove reaching apex of rostrum; dorso-apically with 2 long setae at sides. Antennae. Scapes not quite reaching front margin of eye, shorter than funicles (ca. as long as first 5 funicle segments), apically truncate; funicles ca. $0.33 \times$ as long as scapes, segments $1-4$ subequal in width, 1 oval, longer than 2, 2-6 similarly narrow basally, apically expanded and rounded, 2-6 subequal in length, 6 slightly narrower than 5, $7 \mathrm{ca} .0 .67 \times$ as long as and slightly narrower than 6; clubs very long (almost as long as funicles), thin, segments $1-3$ obconical, progressively shorter distally, 4 acute, tapering to a point, shorter than 3. Mouthparts. Mandibles seemingly exodont (not entirely visible), articulation oblique. Thorax. Prothorax slightly proclinate, narrower than elytra. Pronotum weakly collared anteriorly, widest at about middle; punctate, sparsely setose; base weakly sinuate and posterior corners distinctly angulate, fitting closely to elytra. Elytra densely setose; apically almost conjointly rounded. Hindwings present (partially extended). Scutellar shield slightly prominent. Legs and setae pale, spurs and fringing setae of tibiae dark. Procoxae conical, strongly projecting, others not visible. Femora narrow basally, moderately inflated apically; outside rounded (profemora) or serrulate (metafemora; mesofemora not properly visible). Tibiae long, slender, flattened, sparsely serrulate on 
outside, setose with stiff sparse longer setae in distal half; apically with tarsal articulation surfaces suboblique, with short narrow flanges lined with coarse fringing setae, with spurs large, distinct, subequal. Tarsi ca. $0.67 \times$ as long as tibiae, slender; tarsite 1 narrower and ca. $2.0 \times$ longer than 2 , 3 lobate, not pedunculate, lobes short, finger-like, broad at base, slightly wider distally, ca. half as long as 5. Abdomen not visible.

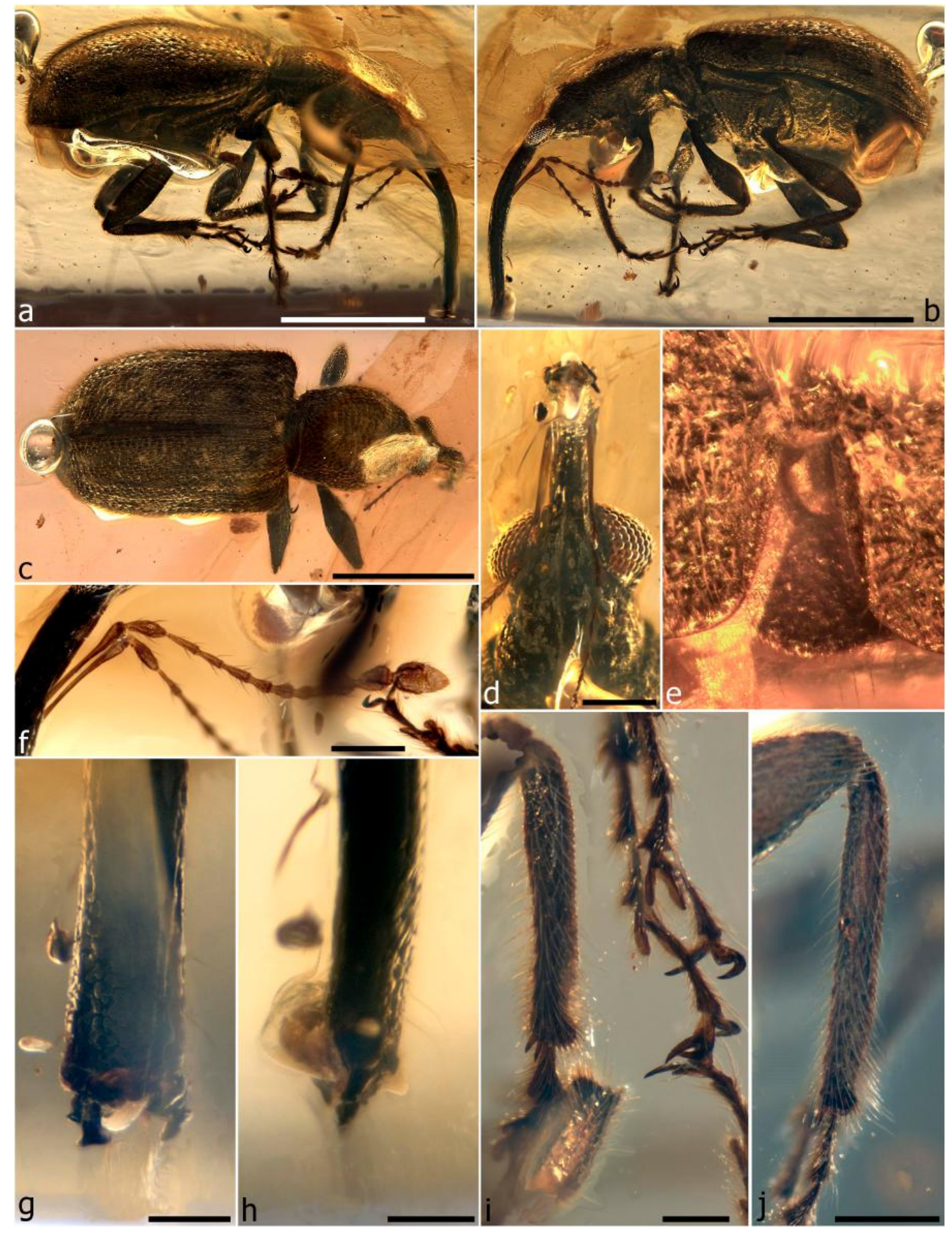

Figure 77. Habropezus kimpulleni sp. n., holotype. Habitus, right lateral (a); habitus, left lateral (b); habitus, dorsal (c); head, ventral (d); elytra and apical tergite, apical (e); antennae (f); rostrum apex and mandibles, dorsolateral (g); same, right lateral (h); tarsi and left mesotibia (i); left metatibia (j). Scale bars: $1.0 \mathrm{~mm}(\mathbf{a}-\mathbf{c}) ; 0.2 \mathrm{~mm}(\mathrm{~d}, \mathrm{f}, \mathrm{j}) ; 0.1 \mathrm{~mm}(\mathrm{~g}-\mathrm{i})$. 


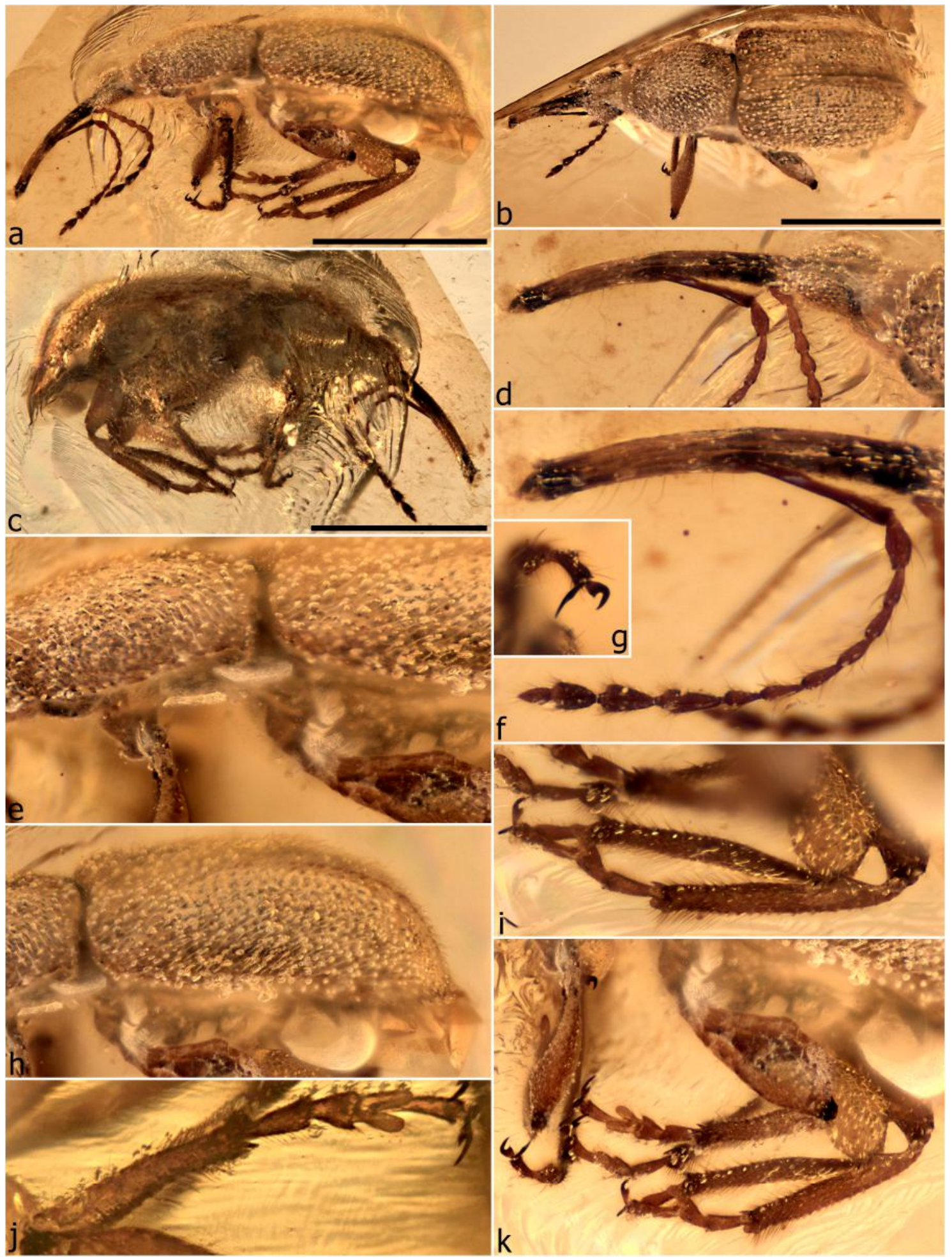

Figure 78. Habropezus tenuicornis sp. n., holotype. Habitus, left lateral (a); habitus, dorsal (b); habitus, right lateral, showing fracture plan obscuring right side (c); head (d); prothorax and humeral region of elytra (e); rostrum and antenna (f); left protarsal claw (g); elytra, left lateral (h); metatibiae (i); tibia and tarsus, ventral (j); legs (k). Scale bars: $1.0 \mathrm{~mm}(\mathrm{a}-\mathrm{c})$.

Material examined. Holotype (NIGP157021), male: well preserved, intact but poorly visible specimen, not distorted or compressed but body nearly entirely covered by thin cloudy whitish substance and tiny bubbles, right side of prothorax and elytra concealed by fracture and flow band, 
head, rostrum and appendages well visible; in irregular triangular prismoid (with sixth face) $7.5 \times 5.1$ $\times 3.0 \mathrm{~mm}$; amber clear yellow, without debris, other fractures or bubbles.

Derivation of name. The species is named for its very slender antennae, from the Latin adjective tenuis (slender) and noun cornu (G: cornus), the name being an adjective.

Remarks. This species differs from H. plaisiommus and H. kimpulleni in its smaller size, slightly shorter rostrum, thicker tibiae with indistinct serration, thicker tarsi with broader lobes of tarsites 3 and in having, like H. incoxatirostris, an apicolateral row of sparse erect setae on the rostrum and the outside of the meso- and metatibiae adorned with a row of smaller, widely separated denticles. From the last species it differs mainly in its evenly curved rostrum and serrulate tibiae. The holotype was submitted for CT scanning as much of its surface is obscured, but the contrast between the specimen and the amber was too low to permit any meaningful visualisation of the specimen.

Habropezus ncoxatirostris Clarke \& Oberprieler, sp. n. (Figure 79)

Description. Size. Length $1.73 \mathrm{~mm}$, width $0.68 \mathrm{~mm}$. Body setae long, suberect. Head indicated to be constricted behind eyes and moderately bulging, impunctate. Eyes coarsely facetted. Rostrum distinctly kinked (bent at ca. $40^{\circ}$ ) at antennal insertions (probably partly a distortion); dorsally with grooves and carinae indicated; antennal insertions median, in front of them with lateral row of ca. 10 elongate slender setae in groove. Antennae. Scapes slender, shorter than funicles, gradually expanding apicad, not quite reaching eye, apex slightly oblique; funicles longer than scapes, segment 1 ca. $2.0 \times$ longer than 2 , broader than others, $2-6$ subequal, 7 ca. $0.67 \times$ as long as 6 ; clubs long, distinctly broader than funicles, segments $1-2$ subequal, obconical with rounded apices, $3 \mathrm{ca}$. $0.67 \times$ as long as 2, 4 broadly inserted, elongate-acute, slightly narrower and distinct from 3. Mouthparts. Mandibles with 2 teeth on outside and inside edges (at apices forming medially notched ' $\mathrm{T}$ '), basal inner tooth much larger, triangular. Maxillary palps visible but not clear. Thorax. Prothorax slightly proclinate. Pronotum narrower than elytra, punctorugose, sparsely setose, setae long, at apices of prominences; widest in front of middle, sides strongly narrowing anteriad and posteriad, laterally margined (but not carinate). Prosternum very short, ca. $0.33 \times$ as long as procoxae, prosternal process short, angulate; procoxal cavities closer to prosternal margin; hypomeron longer than prosternum. Scutellar shield recessed into elytral bases, anterior margin concavely continuous with elytral basal margins. Elytra coarsely rugose, punctostriate; striae much broader than interstriae, punctures indistinct; interstriae prominent, subcarinate in anterior third, less distinct from striae posteriorly, seemingly with line of setae in striae and on interstriae, setae situated on cuticular prominences; sides with 2 macrosetae in basal third, with distinct punctosetose marginal groove subequal in width for entire length, with anterior marginal notch; bases weakly sinuate; humeri subflat; apically individually rounded, outer edges lined with minute teeth. Hindwings present. Legs. Procoxae conical; mesocoxae subglobular, weakly projecting, separated by unconnected processes of meso- and metaventrite. Femora subcylindrical, inflated in distal half, outside seemingly rounded. Tibiae with outer side costate, without teeth (protibiae) or subserrulate, with sparse fine denticles only (meso- and metatibiae); apically with short flanges lined with coarse fringing setae, dorso-apically with elongate slender setae; spurs small, indistinct, unequal, inner one slightly smaller on pro- and metatibiae but distinctly on metatibiae. Tarsi slender, nearly as long as tibiae, tarsites 1 and 2 gradually expanding apicad, 1 ca. 1.5 $\times$ longer than 2, 2 slightly wider, 3 strongly lobate, lobes elongate-oval, ca. half as long as 5 (shorter on protarsi), with inner margins concave, 5 extremely slender, clearly articulating with cryptotarsite; claws with basal tooth small, with wide arcuate gap between outer claw and inner edge of tooth. Abdomen, Ventrites seemingly stepped, sparsely setose, with scattered longer setae; ventrite 1 slightly longer than 2, 3 half as long as 2, 4 longer than 3,5 short, ca. half as long as 4; sutures between ventrites deeply grooved, subarcuate. 


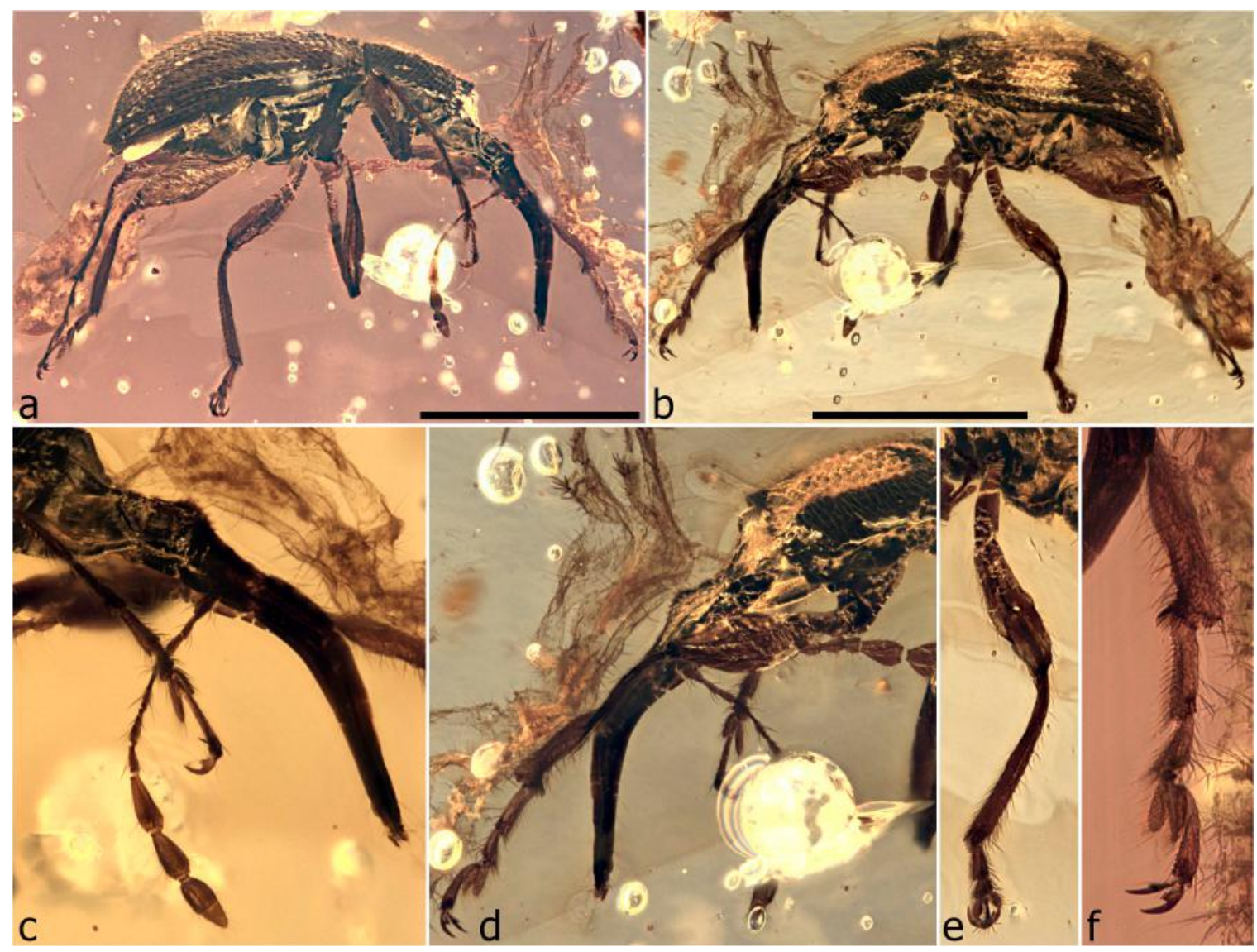

Figure 79. Habropezus incoxatirostris sp. n., holotype. Habitus, right lateral (a); habitus, left lateral (b); head, antenna and protibia and tarsus, right lateral (c); same, left lateral (d); left middle leg (e); left protibia and tarsus (f). Scale bars: $1.0 \mathrm{~mm}(\mathrm{a}, \mathrm{b})$.

Material examined. Holotype (NIGP157022): poorly preserved, somewhat decomposed (mainly legs) and heavily distorted (crumpled) but largely intact specimen, with left protarsal claw and most of tarsite 3 cut away with amber and right mesotibia severed (prior to preservation) and missing, both hindwings partly extended, head, rostrum and eyes, pro- and pterothorax, legs, and ventrites heavily distorted (compressed, crumpled); in subcuboidal block, $5.3 \times 2.6 \times 1.9 \mathrm{~mm}$, with one large curved side; amber clear yellow, with minor debris particles and another arthropod inclusion in front of head and rostrum, with large white spherule anteriorly and large mite posteriorly on left side obscuring left aspect of metatibiae.

Derivation of name. The species is named for its kinked rostrum, from the Latin adjective incoxatus (bent down).

Remarks. This species agrees with $H$. tenuicornis in having an apicolateral row of sparse erect setae on the rostrum and the outside of the meso- and metatibiae adorned with a row or smaller, widely separated denticles, which are apparently formed by the edges of setal sockets rather than being distinct curved teeth. From H. tenuicornis it differs in having broader antennal clubs (much broader than the funicles) and longer tarsi. It is also distinctive in its coarse pronotal and elytral sculpturing and the distinct striae, as well as by the rostrum being bent in the middle, at least some of these features possibly accentuated by distortion. 
Genus Leptopezus Clarke \& Oberprieler, gen. n.

Type species: Leptopezus rastellipes Clarke \& Oberprieler, sp. n.

Description. Size. Length 2.12-2.82 mm, width 1.15-1.56 mm. Head short, transverse, constricted behind eyes, weakly convex dorsally, more strongly bulging ventrally. Eyes large, elongate, slightly depressed and protruding, coarsely facetted, without interfacettal setae, dorsally separated by about width of rostrum; forehead grooved, without tubercles above eyes. Rostrum ca. $1.25 \times$ longer than pronotum, subcylindrical, downcurved; antennal insertions lateral, with scrobes behind them reaching eye, in front of them laterally with row of long erect setae. Single long gular suture present. Antennae geniculate, long; scapes elongate, cylindrical, apically inflated, almost as long as funicle; funicles 7-segmented, segment 1 subequal in length to and wider than 2, 2-3 subequal, elongate, subcylindrical, 4-7 progressively shorter towards club; clubs short, loosely articulated, 4-segmented, segment 4 broadly rounded, subequal in length to 3 . Mouthparts. Labrum absent. Mandibles small, flat, exodont, articulation oblique. Maxillary and labial palps 3-segmented, both projecting obliquely forwards. Thorax. Prothorax proclinate, with anterior lateral margins oblique in lateral view. Pronotum convex, laterally rounded and without tooth, posterior corners produced to fit closely onto elytra; surface coarsely punctorugose, sparsely to densely finely setose, setae reclinate, directed anteromesad; notosternal sutures closed, vertical then abruptly bent anteriad. Prosternum moderately long; procoxal cavities medially confluent, in middle of prothorax. Scutellar shield densely setose, raised above elytral surface. Mesocoxal cavities laterally closed. Metanepisterna distinct, setose. Mesoventrite short, anteriorly sloping. Metaventrite longer, raised into transverse weals in front of metaxcoxae. Elytra elongate, basally extended over pronotum, with broadly rounded humeri, posteriorly declivous, lateral margin strongly sinuate to roundly emarginate in middle, apically individually rounded, not exposing pygidium; sutural flanges narrow; surface punctostriate, without scutellary striole, interstriae rugose, setose, setae short, thin, reclinate, directed caudad. Legs. Procoxae large and conical, prominent, medially contiguous; mesocoxae subglobular, narrowly separated; metacoxae flat, transversely elongate. Trochanters short, oblique. Femora long, subcylindrical, inflated in distal half, unarmed, profemora on outside rounded, meso- and metafemora serrulate in apical third. Tibiae elongate, straight, slender, compressed, outer edges serrulate (protibiae) or carinate-crenulate (mesoand metatibiae), with dense long stiff setae in distal half, of meso- and metatibiae apically emarginate; apex subtruncate, with 2 strong spurs. Tarsi more than half as long as tibiae; tarsite 1 apically subtruncate, 2 shorter, subtriangular, apically excised, 3 deeply bilobed (not or subpedunculate), 5 long, very slender, apically expanded; claws divaricate, dentate with ventrobasal seta on proximal face of tooth. Abdomen with ventrites 1 and 2 longer than 3, 1-4 progressively shorter, 5 not discernible.

Derivation of name. The genus is named for its very slender tarsi, especially the long, thin onychia, the name composed from the Greek adjective leptos, thin, and noun peza, a foot, and being masculine in gender.

Remarks. This genus is similar to Habropezus but differs in the more robust body form, more strongly globular and protruding eyes, different elytral sculpturing and the strongly crenulate and distinctly apically emarginate outsides of the meso- and metatibae. It is also similar to Myanmarus but has unmodified ventrites, and from Mekorhamphus it can be distinguished by the lack of tubercles between the eyes. It is represented by two species.

Leptopezus rastellipes Clarke \& Oberprieler, sp. n. (Figure 80)

Description. Size. Length $2.82 \mathrm{~mm}$, width $1.56 \mathrm{~mm}$. Robust, short; weakly sclerotised, legs paler, rostrum darker. Head widening posteriorly; dorsally setose, setae whitish, directed anteromesad. Eyes strongly protuberant, roundly triangular, slanting backwards. Rostrum very long and thin, ca. $1.25 \times$ longer than pronotum, strongly downcurved, subcylindrical, gradually narrowing before slightly expanding at apex; dorsally with median, paramedian and dorsolateral carinae extending to antennal insertions, all but dorsolateral ones somewhat obsolete or confused beyond antennal insertions; dorso-apically with 2 erect setae in short oblique sulcus bordering epistome; antennal insertions median, in dorsal view marked by weak protuberances, behind them with deep scrobes 
reaching eye, in front of them with ca. 10 widely spaced erect setae placed in groove extending to mandibular articulation. Antennae. Scapes extending to front margin of eye, apically slightly inflated; funicles with segments 1-3 subequal in length, segment 1 ovoid, ca. $2.0 \times$ wider than 2, 2-3 subcylindrical, subequal, 4-7 progressively shorter, 4-6 similar to 3, more obconical, 7 subglobular; clubs short, about as long as funicle segments $3-7$, segments 1-3 successively slightly shorter, 2 slightly wider than 1, 4 flat, broadly inserted into 3. Mouthparts. Mandibles with 4 teeth on outside, 2 very small basal denticles, larger ones at middle and apex, inside edge with 3 large teeth, apical teeth on each side long, slender, curved, forming short apical Y. Maxillae with galea subequal in length to palp, with apical brush; apical palp segment roundly conical, apically setose (or hyaline), penultimate segment subequal, basal segment (?) slightly shorter and narrower than penultimate one. Labial palps with last segment slender, cylindrical, twice longer than wide, apically hyaline (or microsetose). Thorax. Pronotum narrower than elytra; weakly collared anterolaterally, sides curved, basally slightly constricted; basal margin broadly curved, corners quadrately rounded; punctures strongly delimited. Prosternum short, prosternal process short, pointed. Scutellar shield slightly longer than wide. Metaventrite and metanepisterna coarsely punctate, punctures ca. $2.0 \times$ diameter of elytral punctures. Elytra sparsely setose, setae very fine; interstriae flat, finely microsculptured; sides with distinct marginal groove, slightly thicker in anterior half, setose, with anterior marginal notch; bases nearly straight. Hindwings present, fully developed. Legs sparsely setose. Femora on outside rounded (profemora) or subcrenulate in distal third (meso- and metafemora). Tibae sparsely shortly setose, outer edge serrulate (protibiae) or sharply carinate-crenulate (meso- and metatibiae), ventrally in apical half with longer oblique setae; apically with short, narrow outer flanges lined with coarse long fringing setae, dorso-apically with several elongate slender setae, with 2 subequal apical spurs; protibiae very slender, much longer than mesotibiae, teeth along outer edge oblique, broadly spaced (about one tooth apart); meso- and metatibiae dorsally carinate-crenulate, teeth overlapping (difficult to distinguish), more densely setose in outer preapical emargination. Tarsi very long and slender, dorsally densely setose, ventrally with short dense setae; tarsite 1 elongate, ca. $2.0 \times$ longer than 2, slightly widening apicad, 2 ca. half as long as 1, very slightly wider, dorso-apically with distinctly longer setae, 3 strongly lobate, lobes subpedunculate, short and flimsy, ca. half as long as 5, 5 elongate, longer than 1-2, extremely slender, gradually widening apicad; claws long and sharp, basal tooth strongly pointed. Abdomen. Ventrites finely punctate finely setose; $2-5$ slightly stepped, sutures straight.

Material examined. Holotype (NIGP157023), probably female: well preserved (including mouthparts and rostrum) teneral specimen (weakly pigmented, internal structures visible), not distorted or compressed but partially damaged, with terminal ventrites and most of left elytron severed in amber block (but missing) and left eye and pro- and mesofemora ruptured, onychium and part of tarsite 3 lobes of right metatarsus cut away with amber, otherwise intact and well visible from all sides (except ventral prothorax) with surface unobstructed by debris, right wing partially extended; in irregular cuboid $8.0 \times 3.0 \times 3.2 \mathrm{~mm}$ with four flat sides, one large flat face and large curved flat face; amber clear yellow with several flow bands with diffuse particles and three small fractures near specimen, with line of small bubbles emanating from near left humerus.

Derivation of name. The species is named for its large, sharp, rake-like tarsal claws, from the Latin nouns rastellus (G: rastelli), a little rake, and pes (G: pedis), a foot; the name is a noun in apposition.

Remarks. This distinctive species is characterised by its long thin legs with strongly serrulate protibiae but distinctly crenulate meso- and metatibiae. It is most easily distinguishable from L. barbatus by the slender inconspicuous setae in front of the antennal insertions and the broad interstriae with distinct but thin and shallow striae. The holotype is a very teneral specimen, probably a female because of its long slender rostrum. The metendosternite is visible, distinctly Y-shaped and indicated to have either a short stalk or no stalk at all and anterior arms. 


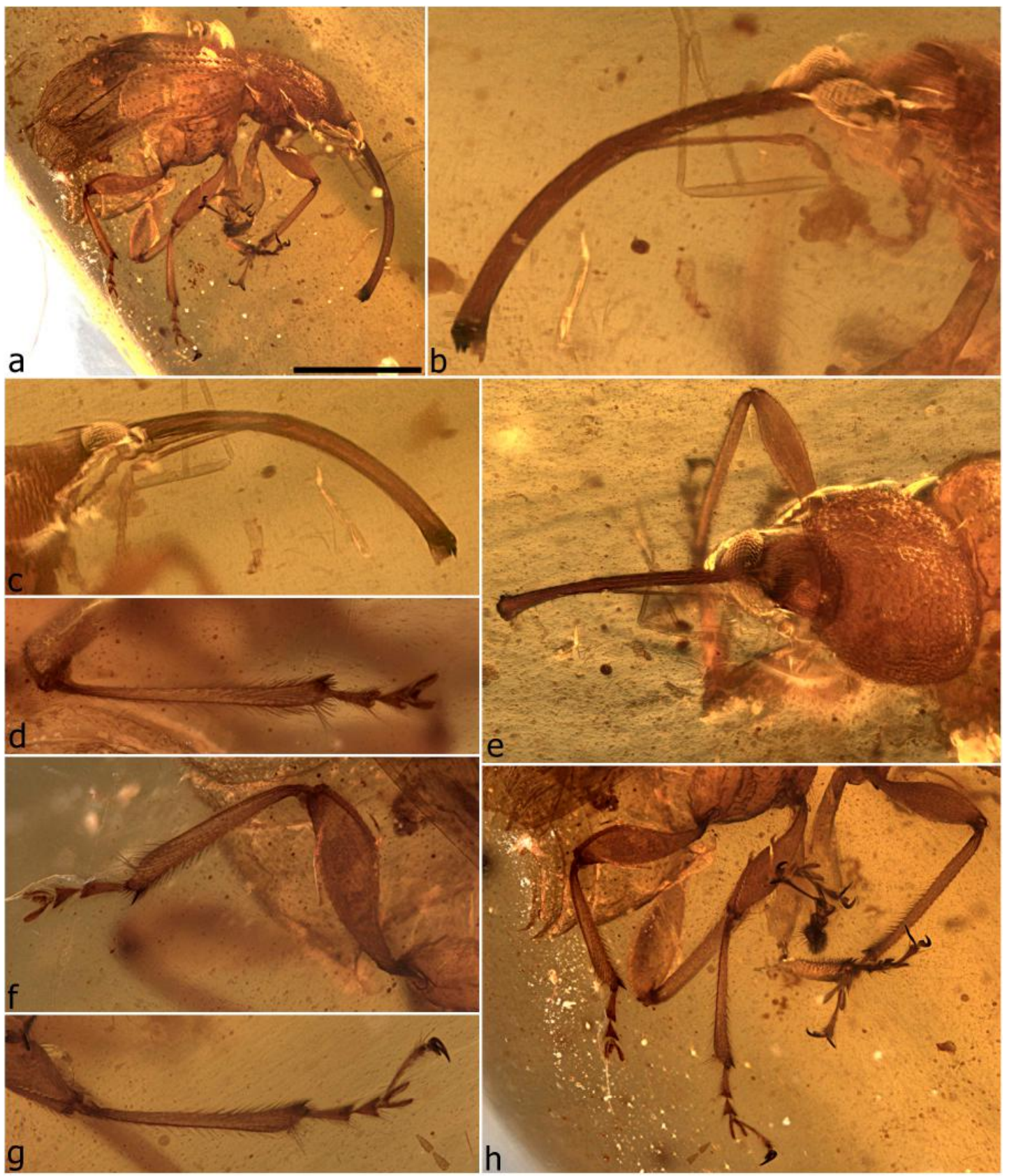

Figure 80. Leptopezus rastellipes sp. n., holotype. Habitus, right lateral (a); head and antenna, left lateral (b); same, right lateral (c); right metatibia and tarsus (d); head and pronotum, dorsal (e); right hindleg, outer side (f); right middle leg (g); legs (h). Scale bars: $1.0 \mathrm{~mm}$ (a).

\section{Leptopezus barbatus Clarke \& Oberprieler, sp. n. (Figure 81)}

Description. Size. Length $2.12 \mathrm{~mm}$, width $1.15 \mathrm{~mm}$. Eyes slightly protruding, slanting backwards, forehead triangular. Rostrum slightly longer than pronotum, downcurved, thick at base, gradually narrowing and widening distad; antennal insertions in middle of rostral length, in front of them with lateral row of 7-8 long, erect setae curved anteriad. Antennae. Scapes straight, narrowly cylindrical, apically strongly clavate, reaching below eye; funicles not clearly visible; clubs long, segment 1 longer than 2, 1 and 2 widening apicad, 4 as long and broad as 3, flattened. Mouthparts. Mandibles not clearly discernible. Thorax. Pronotum elongate, laterally weakly curved; convex, densely setose, setae pale, long directed anteromesad, sculpture not discernible. Scutellar shield small, transverse, slightly rounded. Meso- and metaventrite distorted. Elytra short, broad, at base slightly 
sinuate, closely fitting onto prothorax, with broadly rounded, flattened humeri, posteriorly strongly declivous, apically individually rounded, not exposing pygidium; sutural flanges not visible; surface indistinctly punctostriate, densely setose, setae short, sharp, suberect, directed caudad. Legs. Coxae largely obscured, procoxae apparently contiguous, close to posterior hypomeral margin. Femora long, subcompressed, slightly inflated in middle, profemora on outside slightly carinate, mesoand metafemora distinctly carinate in distal half or more. Tibiae long, straight, compressed, outer edge faintly crenulate in meso- and metatibiae (in protibia not properly visible), metatibiae abruptly narrowed at apex; mesotibiae bent inwards at apex; tibiotarsal articulation surfaces (i.e., at apex of tibia) subtruncate to at most weakly oblique, spurs equal, protibiae apparently with single spur. Tarsi almost as long as tibiae; tarsite 1 elongate, narrow, ca. $2.0 \times$ longer than 2, 2 shorter, apically deeply excised in protarsi, truncate in meso- and metatarsi, 3 deeply bilobed, lobes subpedunculate, 5 slightly longer than $1+2$. Abdomen. Tergite VII domed, apical margin truncate-excised, slightly exposing VIII, this tightly fitting onto apical margin of ventrite 5 . Ventrites not clear, 1 and 2 indicated to be longer than others.

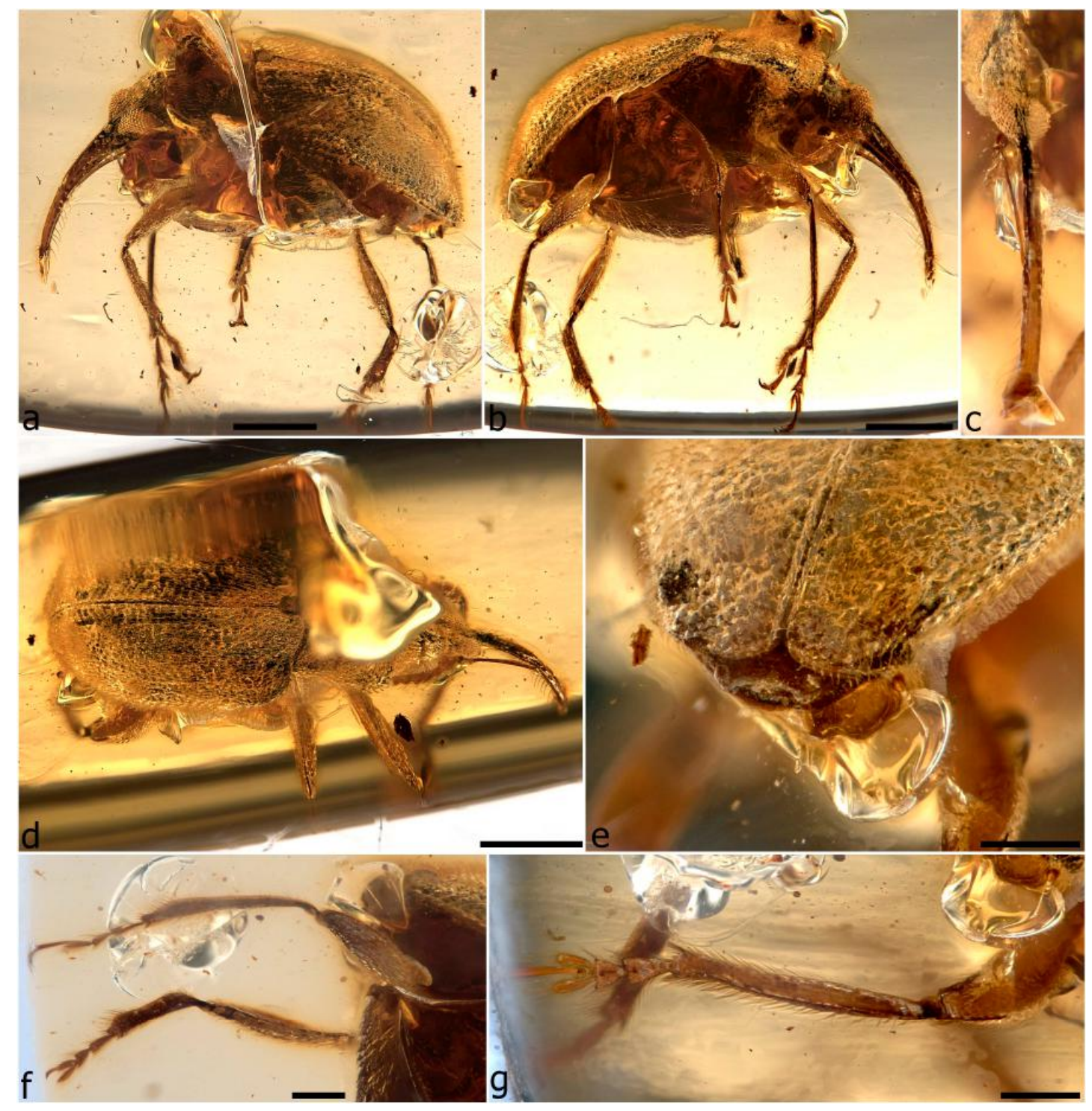

Figure 81. Leptopezus barbatus sp. n., holotype. Habitus, left lateral (a); habitus, right lateral (b); head, dorsal (c); habitus, dorsal (d); apices of elytra showing exposed tergite (e); hindlegs, lateral (f); right hindleg, posterior $(\mathrm{g})$. Scale bars: $0.5 \mathrm{~mm}(\mathrm{a}, \mathrm{b}, \mathrm{d}) ; 0.2 \mathrm{~mm}(\mathrm{e}-\mathrm{g})$. 
Material examined. Holotype (NIGP157024): not well preserved but intact specimen, body and rostrum depressed, legs compressed, mostly well visible except for underside (including head) and left side; at slight angle in centre of rectangular cuboid $3.9 \times 3.53 \times 1.7 \mathrm{~mm}$; amber very clear with no impurities except large clear bubble between hindlegs, but large, irregular, dark bubble on pronotum, extending dorsad to edge of amber block and ventrad down left side of specimen, also with irregular dark layer of air on underside between legs, with small cracks between femora.

Derivation of name. The species is named for the distinct lateral rows of sparse, stiff, erect setae on the rostrum in front of the antennal insertions, giving it a bearded (barbatus in Latin) appearance; the name is a Latin adjective.

Remarks. This species is readily characterised by the conspicuous lateral row of long, erect, curved setae in the apical half of the rostrum. Whereas this row of setae occurs in many mesophyletids, it it usually fairly indistinct (as it also is in L. rastellipes). From the latter species L. barbatus further differs in having very indistinct interstriae (properly discernible only laterally), the shorter rostrum and the carinate (not crenulate) outer edge of the metafemora.

Genus Anchineus Poinar \& Brown, 2009

Anchineus Poinar \& Brown, 2009: 264 [59] (type species, by original designation: Anchineus dolichobothris Poinar \& Brown, 2009)

Redescription. Size. Length ca. $1.6 \mathrm{~mm}$, width $0.85 \mathrm{~mm}$. Head convex dorsally, more so ventrally. Eyes small, elongate, protruding, facing forwards, coarsely facetted, dorsally separated by ca. width of rostrum anteriorly; forehead flat, without tubercles. Rostrum slightly longer than pronotum, cylindrical, moderately curved; antennal insertions lateral, slightly postmedian, with scrobes behind them not reaching eye, also with scrobes in front of them indicated, laterally without long erect setae. Single long gular suture indicated (not clearly discernible). Antennae geniculate, long; scape, funicle segments 1 and 2 and club segments 3 and 4 distinctly paler than rest of antenna; scapes elongate, slender, subcylindrical, apically only slightly inflated, shorter than funicle; funicles 7-segmented, segment 1 about as long as 2, much broader, others narrower, 2 elongate slender, cylindrical, ca. $2.0 \times$ longer than 3, narrower, 3-7 progressively slightly shorter towards club; clubs large, loosely articulated, 4-segmented, segment 4 acute, about as long as and broadly inserted into 3 . Mouthparts. Labrum absent. Mandibles small, flat, vertical, exodont, articulation apparently vertical. Maxillae with galea pointed, densely setose apically and along inner side; palps 3-segmented, projecting obliquely from rostral apex, apical segment ca. half as long as penultimate segment. Labial palps slender, 3-segmented, directed forward. Thorax. Prothorax transverse, strongly proclinate, with anterior lateral margins oblique in lateral view. Pronotum slightly narrowed anteriorly, nearly as wide as elytra at base, without lateral tooth, posterior corners not extended, fitting closely onto elytra; surface sparsely setose, setae reclinate, directed anteromesad; notosternal sutures closed. Prosternum moderately long; procoxal cavities probably medially confluent. Mesoventrite short, anteriorly sloping. Metaventrite longer. Elytra elongate, basally lobed over base of pronotum, with indistinct rounded humeri, posteriorly declivous, lateral margin strongly sinuate to roundly emarginate in middle, apically conjointly rounded, probably not exposing pygidium; sutural flanges narrow, equal; surface punctostriate, without scutellary striole, interstriae flat, finely granulate interspersed with tubercles, sparsely setose, setae short, thin, reclinate, directed caudad. Legs. Procoxae conical, prominent, probably medially contiguous; mesocoxae subglobular, moderately projecting, narrowly separated; metacoxae flat, transversely elongate. Trochanters short, oblique. Femora long, subcylindrical, inflated in distal half, narrowed before apex, outside rounded. Tibiae substraight, compressed, slender, outer edges carinate, serrulate on protibiae (probably others also), with denser longer setae in distal half, apex obliquely truncate, with 2 spurs. Tarsi almost as long as tibiae; tarsite 1 apically subtruncate, 2 shorter, subtriangular, apically weakly excised, 3 deeply bilobed, lobes digitate, 5 long, apically expanded; claws divaricate, dentate with ventrobasal seta. Abdomen. Tergite VIII with curved line where elytral apices fit, with apex fitting evenly into concave margin of ventrite 5 . Ventrite 1 longer than 2, 2-4 subequal, 5 slightly longer than 3 , apically broadly rounded. 
Remarks. This genus was originally placed in Curculionidae based on its geniculate antennae, well-developed scrobes, an upper position of the rostrum and small trochanters [59]. Although these characters are correct as given, the antennal geniculation in Anchineus is of the open type as in all other Mesophyletidae and the genus does not have compact clubs, as occur in "the great majority of taxa" in Curculionidae. Several unusual differentiating characters as given in the original description are seemingly unique to Anchineus, but some of them are misinterpretations that have not been corrected in subsequent publications, as follows.

Scrobes extending in front of the antennal insertions. These were described as "foveiform scrobes" with depressions for the reception of the club, and our examination of the holotype revealed them to be real. Although many other genera of Burmese amber weevils also have the scrobes seemingly extending in front of the antennal insertions (though rarely as distinctly as behind them), none of these have such foveiform impressions as evident in Anchineus.

Vertical mandibles. Our examination of the holotype also revealed that the original description of the mandibles as "laterally flattened and would have moved vertically" is correct. Assuming a flattened form, the vertical position of the mandibles is relatively clear from the photographs of the rostrum apex in lateral view (Figures 6 and 7 in [59]), but these do not resolve the distinction between rostrum and mandible nor show the position of the articulation sockets. We can corroborate both the flattened (though slightly scoop-shaped) form and the vertical position (in repose!) of the mandibles as originally figured and also that the movement plane at a minimum would have been very strongly oblique (subvertical), as the articulation sockets are not visible in lateral view and the rostrum is not distorted at the apex. However, the authors compared the vertical position of the mandibles of Anchineus with that of Mesophyletis. In the figures of the latter genus (Figures 1 and 3 in [29]), the right mandible is shown in the vertical open position typical of most Mesophyletinae, which is not the same as the position when the mandibles are closed. The mandibles of Anchineus and Mesophyletis are thus not comparable, as the repose position is vertical in the former but horizontal in the latter and the articulation sockets are vertical in the former but oblique in the latter.

Tibiae with three apical spurs. We could discern in the holotype the tibial part described as "bearing 3 apical spurs" [59] and illustrated in Figure 6 of [53] (incorrectly labelled as the mesotibia ) for the only tibia on which there appear to be three spurs (the right metatibia); the other tibiae cannot be viewed from a comparable angle, e.g., Figures 5 and 7 [53], and show only one or two spurs. Under high magnification (ca. $120 \times$ with a Leica M165C microscope) we could determine that the supposed third spur on the right metatibia is actually a narrow piece of debris, texturally different from the two real spurs. Anchineus therefore has only two tibial spurs, like all other Burmese amber weevils (in fact all weevils, unless one or both are lost).

Apex of tarsites 5 with "unguitractor plate". The tarsus of the holotype that shows the supposed "unguitractor plate" (Figure 9 in [59]) with an apically lobed fifth segment is the only tarsus so appearing in the specimen, and this appearance is a simple artefact of depression of the segment; the lobes identified in the figure are actually the apices of the fifth segment appearing thicker and drawn out due to the compression. We have seen a similar artefact in some other specimens. Furthermore, an unguitractor plate does not occur in any extant weevils.

Procoxae separated by narrow prosternal process. We could not achieve a clear view of the ventral prothorax in the holotype because this area is heavily distorted (crumpled), but the procoxal cavities are indicated to be confluent and without a narrow process (at least without one that contacts the hypomeral process). All comparable Mesophyletidae we examined also have the procoxal cavities confluent.

Pygidium "probably slightly exposed". Our examination of the holotype did not reveal a true pygidium, i.e., a permanently exposed, vertically orientated tergite VII (or even VIII) when the elytra are closed and the abdomen is in its normal resting position (as is present in Calyptocis, Acalyptopygus, Echogomphus and Compsopsarus), but in Anchineus the apex of the abdomen may have been exposed 
in a way similar as that in genera such as Bowangius, in which tergite VIII is carinate and in repose orientated subvertically.

Anchineus is similar to Bowangius but differs in having the mandibles articulating in a vertical position and a trapezoidal pronotum (wider at the base, although some distortion apparent). It also differs in having digitate lobes of tarsites 3, postmedially inserted antennae and the scapes in repose terminating well in front of the eyes (possibly a male trait). Although much of the head of the holotype of A. dolichotbothris is obscured from view, the somewhat forward-facing eyes and flat forehead are also distinctly different from those of Bowangius. Apparently its protibiae but not its meso- and metatibiae are serrulate; if the latter indeed lack this serrulation (not due to decomposition or wear in life), this would be another critical difference from Bowangius.

Anchineus dolichobothris Poinar \& Brown, 2009

Anchineus dolichobothris Poinar \& Brown, 2009: 266 [59]

Redescription. Size. Length $1.6 \mathrm{~mm}$ ("body", seemingly excluding rostrum, not SL). Head probably short. Eyes black. Rostrum moderately curved; scrobes extending somewhat dorsolaterally to just before anterior margin of eye; distally of insertions laterally weakly concave, seemingly with weak depressions (Figure 1 inset [59]); with few short setae dorsally near apex and ventrally, without elongate setae. Antennae. Scapes not reaching eye, articulation with funicle segment 1 suboblique; funicles with segment 1 with bend just distally of condyle, expanding apicad, 3 slightly longer than 4 , 4-7 subequal; clubs with segments 1-2 shortly obconical, subequal in length, 1 slightly narrower at base and apex; 3 and 4 subequal in length, weakly differentiated. Mouthparts. Mandibles without subapical teeth along external edge, with a rounded blunt tooth at outer apex, a rounded apical tooth at inner apex (these ones projecting forwards) and larger rounded basal tooth along inner edge (Figures 6 and 7 [59]). Thorax. Prothorax strongly proclinate, with anterior lateral margins oblique in lateral view. Pronotum slightly narrowed anteriorly, basal margin broadly sinuate. Scutellar shield triangular. Elytra metallic black, shiny, seemingly glabrous but sparsely and shortly setose (Figure 5 [59]), more densely so apically; sides with distinct marginal groove, subequal in width along entire length, with anterior marginal notch before humeri; striae narrow, linear, with small indistinct punctures; interstriae broad, more than $3.0 \times$ wider than striae, micropunctate. Legs. Metacoxae strongly narrowed laterad. Protibiae long, slender, slightly thicker in middle, shortly sparsely setose, longer and denser ventrally in apical third, outer edge carinate, sparsely serrulate from about middle to just before apex, teeth widely irregularly spaced (width of several teeth), slightly elongately concave on inner edge before apex, lined with short oblique setae, apically weakly flanged, with sparse coarse fringing setae; mesotibiae widening at about basal third, then subequal, outer edge with irregularly longer setae in distal half, longer than short oblique setae along inside, inner edge in distal third curved slightly inwards, apex with larger flanges, lined with coarse fringing setae; metatibiae with setae in apical third longer than those of mesotibiae, forming loose patch; apically with long coarse fringing setae. Tarsi short, protarsi slightly more than half as long as protibia, mesotarsi only slightly shorter than protarsi; tarsite $1 \mathrm{ca}$. $1.5 \times$ longer than 2, expanding apicad, 3 distinctly bilobed, lobes digitate (tubular; rounded apically), slightly widening apicad, ca. $0.67 \times$ as long as 5 , with inner sides distinctly concave in basal half, 5 expanding distad, curved; claws dentate, with basal tooth large and flat. Abdomen. Tergites VII and VIII probably partly exposed, subequal in length, VII with pale area on either side of midline (possibly wing binding patch). Ventrite 5 apically strongly concavely curved upwards beneath elytral apices.

Material examined. Holotype (PACO, 'accession' \#B-C-41): poorly preserved, heavily distorted and somewhat decomposed specimen, surface details largely unobstructed, head retracted into prothorax, this crumpled, pterothorax and abdomen sunken into body cavity, elytra pushed inwards with left partially overlapping right, exposing abdominal apex, tarsites 3-5 of left metatarsus missing; at one end of irregular rectangular cuboid; amber clear brown, with several small impurities and bubbles; with another coleopteran inclusion at opposite end of block, partially cut away during preparation (see also [59]). 
Remarks. This species is distinguishable from all other known Burmese amber weevils by the combination of its very small size, glabrous-appearing and slightly metallic black elytra with deep narrow striae and the digitate lobes of tarsites 3. From Bowangius glabratus, also with metallic and seemingly glabrous elytra, it most readily differs by its smaller size and narrow lobes of tarsites 3 .

Genus Bowangius Clarke \& Oberprieler, gen. n.

Type species: Bowangius cyclops Clarke \& Oberprieler, sp. $\mathrm{n}$.

Description. Size. Length $1.86-2.87 \mathrm{~mm}$, width $0.59-1.3 \mathrm{~mm}$. Body small, elongate, sparsely setose, Head elongate, convex dorsally, more strongly bulging ventrally, constricted behind eyes. Eyes large, round to elongate, strongly protruding, coarsely facetted, dorsally separated by nearly width of rostrum throughout; forehead flat, without tubercles between eyes. Rostrum as long as or slightly longer than pronotum, subcylindrical, weakly downcurved; antennal insertions lateral, with scrobes behind them and in front, in front of them laterally with a few long erect (usually indistinct) setae (absent in B. glabratus). Single long gular suture present. Antennae geniculate, long; scapes elongate, cylindrical, apically inflated; funicles 7-segmented, segment 1 broad, 2-5 narrower, progressively shorter towards club, 6-7 broader, subglobular; clubs large, loosely articulated, 4-segmented, segment 4 acute, about as long as 3 . Mouthparts. Labrum absent. Mandibles small, exodont, articulation oblique. Thorax. Prothorax weakly to strongly proclinate, with anterior lateral margins oblique in lateral view. Pronotum slightly convex, laterally rounded, without tooth, posterior corners not extended, fitting closely onto elytra; surface coarsely punctate, sparsely setose, setae reclinate, directed anteromesad; notosternal sutures closed, vertical then curved anteriad. Prosternum moderately long; procoxal cavities medially confluent, in middle of prothorax. Scutellar shield densely setose. Mesocoxal cavities closed by meso- and metaventrites. Mesoventrite short, anteriorly sloping. Metaventrite longer, raised into transverse weals in front of metacoxae. Metanepisterna distinct, sparsely setose. Elytra elongate, basally closely fitting to pronotum, with broadly rounded flatly produced humeri, posteriorly declivous, lateral margin strongly sinuate to roundly emarginate in middle, apically individually rounded, not exposing pygidium; sutural flanges narrow, equal; surface punctostriate, without scutellary striole, interstriae convex, finely tuberculate, setose, setae long, thin, reclinate, directed caudad. Legs. Procoxae large, prominent, medially contiguous; mesocoxae subglobular, narrowly separated; metacoxae very large, flat, transversely elongate. Trochanters short, oblique. Femora long, subcylindrical, inflated in distal half, outside rounded or carinate in distal half to third. Tibiae straight, compressed, outer edge serrulate, teeth sharp, pointed, separate at their bases, with sparse long stiff setae in distal half, apex obliquely truncate, with 2 spurs. Tarsi shorter than tibiae; tarsite 1 apically excised to subtruncate, 2 shorter, triangular, apically excised or subtruncate, 3 deeply bilobed, lobes not or subpedunculate, 5 long, apically expanded; claws divaricate, dentate with ventrobasal seta at apex of tooth. Abdomen. Tergite VIII sometimes (apparently in males) exposed, with tranverse carinate ridge along upper edge and sharp apical flange. Ventrites 1 and 2 slightly longer than 3, 3 slightly longer than 4,5 as long as 3, apically broadly rounded.

Derivation of name. The genus is cordially named for Professor Bo Wang, of the Nanjing Institute of Geology and Palaeontology, for making these many interesting amber fossils available to us for study. The gender of the name is masculine.

Remarks. This genus is difficult to distinguish from Habropezus, being generally similar in shape and sculpture and also having serrulate tibiae, but it has different, more globular eyes (strongly so, subhemispherical in B. cyclops and Bowangius sp. 1) and a narrower grooved forehead, shorter stouter antennae and different, seemingly more specialised mandibles with a slenderer apical ' $\mathrm{T}$ '. The eyes of B. tanaops and B. zhenuai are somewhat flattened in comparison with those of B. cyclops and in this sense are more in agreement with Habropezus than with B. cyclops; however, the forehead is broad between the eyes and posteriorly widening in Habropezus, whereas in Bowangius it is very narrow, at most as broad as the base of the rostrum, and not widening posteriorly. Another distinctive character of Bowangius is the exposed and carinate tergite VIII in some specimens (apparently males; they also have a shorter rostrum), although this character may also be present in Anchineus. From this genus 
Bowangius can be distinguished by its more distinctly exodont mandibles and their horizontal repose position. Bowangius is represented by up to eight species as known, although the specimens of two of the species that we do not describe are not preserved adequately enough to ascertain whether they represent different species (and even belong in Bowangius).

Bowangius cyclops Clarke \& Oberprieler, sp. n. (Figure 82)

Description. Size. Length $2.05 \mathrm{~mm}$, width $0.76 \mathrm{~mm}$. Head. Head punctate, punctures finer than on prothorax; densely setose behind and between eyes. Eyes large, subglobular, dorsally separated by ca. half width of rostrum. Rostrum ca. $1.25 \times$ longer than pronotum, weakly downcurved; antennal insertions in middle of rostral length, behind them with scrobes extending to front of eye; apex produced into narrowly rounded lobe. Antennae. Scapes about as long as funicles, reaching to just below eye; funicles with segment 1 slightly longer than 2, 3 elongate-obconical, shorter than 2, 4 shorter, distinct, ca. $2.0 \times$ broader than long, 5 similar to 3, shorter, 6-7 subglobular, 7 slightly longer, broader than 6; clubs with segments 1-2 subequal, obconical, 3 slightly shorter, 4 subequal in length to 3, narrowly acute apically. Mouthparts. Mandibles slender, abruptly curved from base, outside with small bluntly rounded tooth in middle and smaller pointed tooth at apex, inside with larger sharper curved tooth (ca. $3.0 \times$ longer than outer middle tooth) in middle and smaller pointed tooth at apex; apically subemarginate, with inner and outer angles formed by apical teeth. Thorax. Prothorax strongly proclinate. Pronotum densely punctate. Prosternum short, subequal in length to hypomeron. Scutellar shield elongate-quadratic, densely setose, slightly lower than elytra. Elytra with bases sinuate, formed by swellings at base of interstriae $2-5$, sharply carinate and extended over base of pronotum; humeri flatly concavely extended; sides lacking any keel (carinate interstriae), with marginal groove irregularly lined with setae, with anteromarginal notch; apices rounded; striae and interstriae irregularly setose. Legs long, slender. Procoxae subconical, contiguous; mesocoxae bulbous, prominent, possibly slightly elongate; metacoxae prominent. Protibiae long and slender, nearly straight, not or only weakly widening distally, apically roundly truncate, spurs slender; mesotibiae long and slender, nearly straight, only slightly widening apicad, outer edge narrowing before apex, spurs short, robust; metatibiae with rounded flange in apical third, with one large flat apparently fixed spur and one normal narrower spur; tarsal articulation surfaces oblique, apically with coarse fringing setae. Tarsi at least half as long as tibiae; tarsite 1 large, subtriangular, apically excised, 2 wider than and ca. half as long as 1, apically excised, 3-4 not preserved, 5 shorter than $1+2$, slightly curved (basal teeth possibly asymmetrical on metatarsal claws). Abdomen. Tergite VIII exposed, concave, forming small apical setose flange, delimited on upperside by arcuate carina. Ventrites setose; $1-2$ subequal in length, subflatly aligned, 3-5 stepped, successively higher, 3-4 successively shorter, 5 very broadly rounded, subequal in length to 3; sutures straight, not forming broad gaps.

Material examined. Holotype (NIGP157025): very well preserved, minimally distorted and compressed specimen with anterolateral thoracic and elytral structures somewhat obscured (most significantly on left side), body covered by fragmented coating of whitish debris or secretions, otherwise well visible, with rostrum, antennae and left legs slightly compressed/decomposed, mandibles well-preserved, fully opened and clearly visible, left metatarsus, tarsites 3-5 of left pro- and mesotarsi and right fore-, middle and hindlegs missing (inner lobe of tarsite 3 of right protarsus still attached and claw segment of evidently the right metatarsus in vicinity of this leg); in narrow elongate cuboid, $2.7 \times 2.0 \times 1.6 \mathrm{~mm}$ ); amber clear, with minimal impurities; with several dark flat flow lines and shearing planes parallel to specimen.

Derivation of name. The species is named for its large round eyes, from the Greek nouns kyklos (G: kyklou), meaning circle, and ops (G: opos), meaning eye.

Remarks. This distinctive species is distinguished from all other Bowangius species by its large globular (almost hemispherical) eyes, flatly concavely extended humeri, short inner flange on the apical third of the metatibiae and more elongate and slightly depressed body. It shares with B. tanaops and B. zhenuai an exposed tergite VIII, with a broad carina at the base and a thick apical rim. Bowangius cyclops is also similar to A. dolichobothris in its antennae, the scape being relatively short and both it 
and funicle segments 1 and 2 being pale, but it differs in the more elongate pronotum, coarsely rugose and densely setose elytra and strongly exodont mandibles.

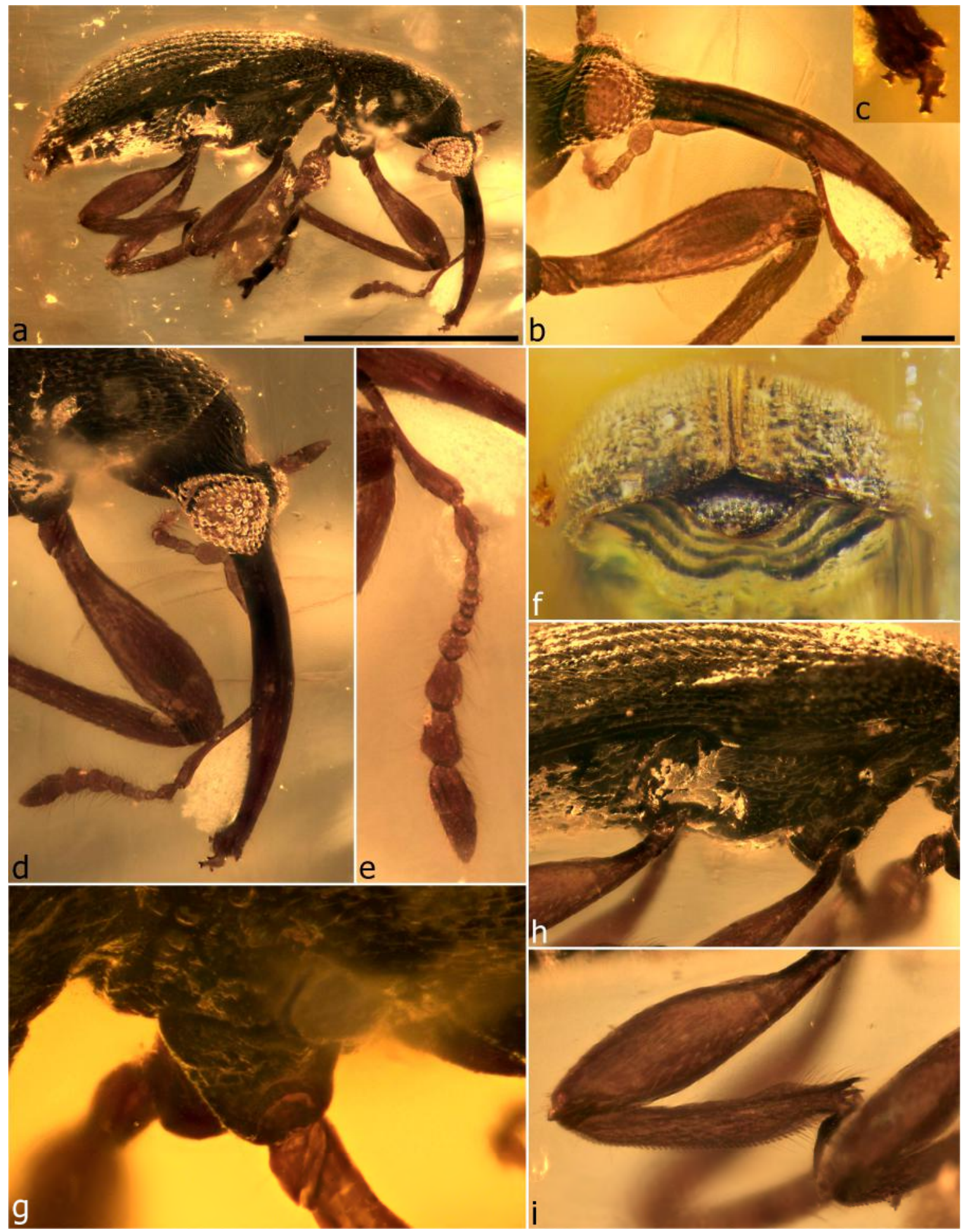

Figure 82. Bowangius cyclops sp. n., holotype. Habitus, right lateral (a); head and rostrum, right lateral (b); mandibles, right lateral (c); prothorax and head, right lateral (d); right antenna, right lateral (e); abdomen and elytra, caudal (f); detail of notosternal suture, right lateral (g); elytra, pterothorax and ventrite 1, right lateral (h); right hindleg (i). Scale bars: $1.0 \mathrm{~mm}$ (a); $0.2 \mathrm{~mm}(\mathrm{~b})$. 
Bowangius sp. 1 (Figure 83)

Material examined. One specimen (in private collection of Mr. Huijun Huang, China), $2.12 \mathrm{~mm}$ long: intact, pale yellowish-brown (teneral), extremely well preserved, not distorted, well visible from both lateral sides but not from dorsal and ventral sides due to shape of amber block; in left corner of large flat ellipsoid $20.2 \times 15 \times 5.7 \mathrm{~mm}$; amber clear but with many impurities away from specimen, also containing a large leaf, probably of a fern.

Remarks. This specimen is exceptionally well preserved and shows many structures and characters in extreme detail and clarity, but due to its position and orientation in the flat lenticular amber piece its dorsal and right side are partly obscured, and other aspects are distorted due to the curvature of the amber surface. It would be perfectly and totally visible if it were cut out of the amber block in a cuboid aligned with its sides. It is very similar to B. cyclops in size and nearly all discernible characters, differing only in having a longer, thinner rostrum, the outside of the femora finely carinate in the distal half, tarsites 2 apically truncate (excised in B. cyclops) and tergite VIII not exposed beyond VII. The longer rostrum and hidden tergite VIII suggest that the specimen is a female, and if the carination of the femora and the shape of the tarsites are also subject to sexual dimorphism, this specimen may well be the female of B. cyclops. Because of this and because the specimen is housed in a private collection and its accessibility to science therefore not assured, we prefer not to describe it as another species.

\section{Bowangius sp. 2 (Figure 84)}

Material examined. One specimen (in private collection of Mr. Huijun Huang, China), $2.8 \mathrm{~mm}$ long, ca. $1.3 \mathrm{~mm}$ wide: extremely well preserved, intact with extended ovipositor, not distorted, superbly visible from left side and largely from right and ventral side but not from dorsal side due to shape of amber block; slightly off centre to left in irregular flat ellipsoid $15 \times 11 \times 7.1 \mathrm{~mm}$; amber very clear but with many impurities, in particular a layer of sparse small bubbles along left side of specimen, also a large, elongate, clear bubble beneath rostrum and dark structure (possibly a flower) between legs on right side.

Remarks. This specimen is very well preserved and shows a large suite of characters, including an extended ovipositor, but for proper scientific study it needs to be cut out of the large, cabochon-shaped amber block so that its critical structures can be properly assessed. It is similar to B. cyclops in having large, subglobular eyes, but it is slightly larger, has a higher body, thinner rostrum, more strongly clavate scapes, longer funicular segments, the outer side of the meso- and metafemora distally carinate (not rounded) and tarsites 2 apically truncate (not excised). Its most valuable feature in evidence is the extruded ovipositor, showing long, slender, weak gonocoxites with thin dorsal and ventral sclerotised baculi (rods) and a long subapical stylus with an apical tuft of setae. We do not describe this species as the specimen is housed in a private collection, in which accessibility of a holotype to science cannot be guaranteed.

\section{Bowangius sp. 3 (Figure 85).}

Material examined. One specimen (NIGP157026), $1.89 \mathrm{~mm}$ long, $0.59 \mathrm{~mm}$ wide: poorly preserved but intact, body and especially rostrum and legs compressed and slightly distorted, reasonably well visible from all sides; in centre of rectangular cuboid $4.45 \times 3.86 \times 1.62 \mathrm{~mm}$; amber clear but with many small impurities not obstructing view of specimen significantly.

Remarks. This distorted and inadequately preserved specimen appears to belong in Bowangius mainly due to its globular eyes (similar to those of B. cyclops) and serrulate meso- and metatibiae (the protibiae being carinate only), but it displays too few unequivocal characters for a definite assignment to this genus and a comparison with its species. We therefore do not describe and name it as another species here. 


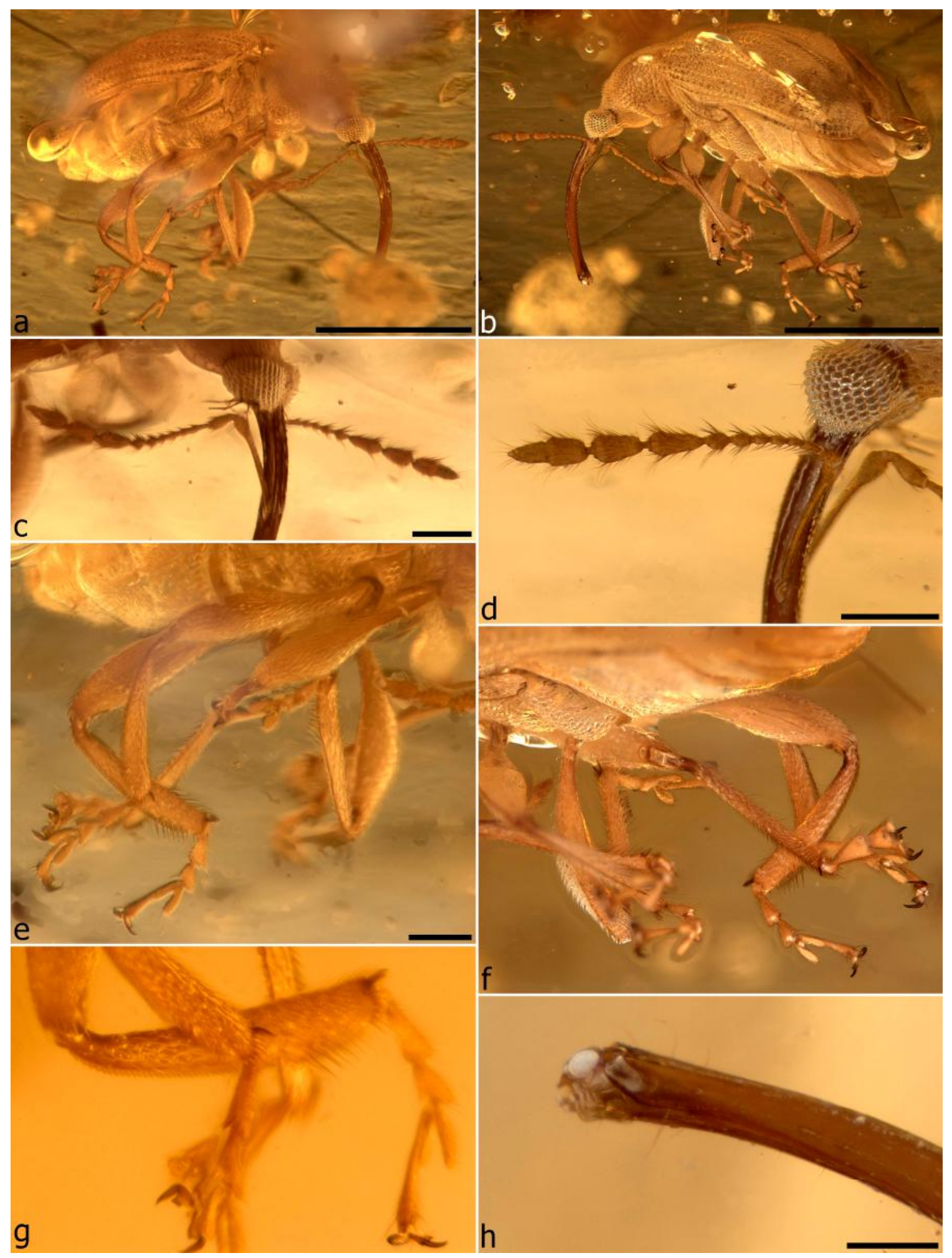

Figure 83. Bowangius sp. 1, Habitus, right lateral (a); habitus, left lateral (b); head and antennae, right lateral (c); eye, antenna and base of rostrum, left lateral (d); legs, right lateral (e); legs, left lateral (f); detail of metatibia and tarsi, right lateral (g); detail of rostrum apex showing mandibular articulation socket (h). Scale bars: $1.0 \mathrm{~mm}(\mathrm{a}, \mathrm{b}) ; 0.2 \mathrm{~mm}(\mathrm{c}-\mathrm{e}) ; 0.1 \mathrm{~mm}(\mathrm{~h})$. 


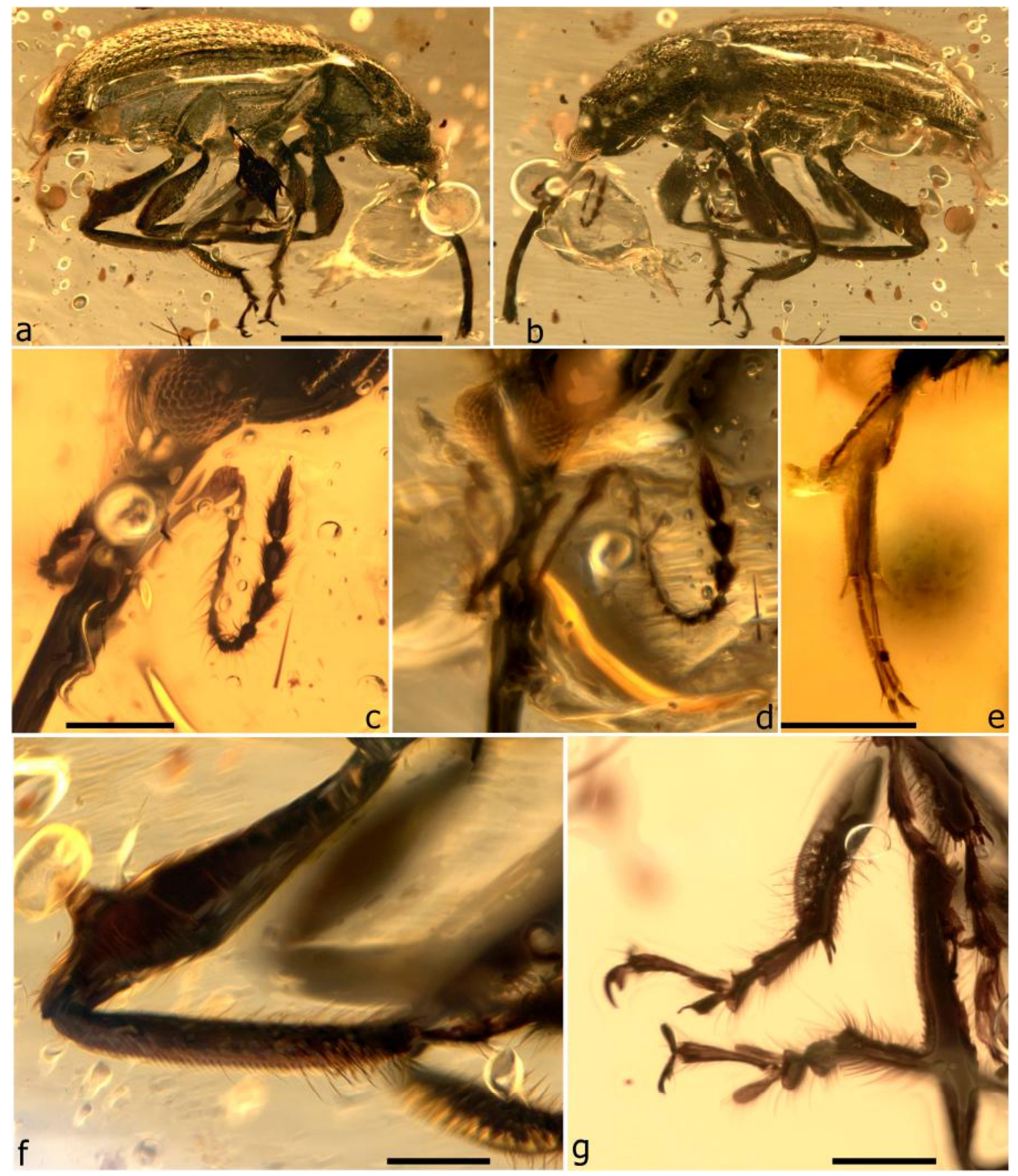

Figure 84. Bowangius sp. 2. Habitus, right lateral (a); left lateral (b); head and antenna, left lateral (c); same (d); ovipositor (e); left hindleg, posterior (f); tarsi (g). Scale bars: $1.0 \mathrm{~mm}(\mathrm{a}, \mathrm{b})$; $0.2 \mathrm{~mm}(\mathrm{c}, \mathrm{e}-\mathrm{g})$. 


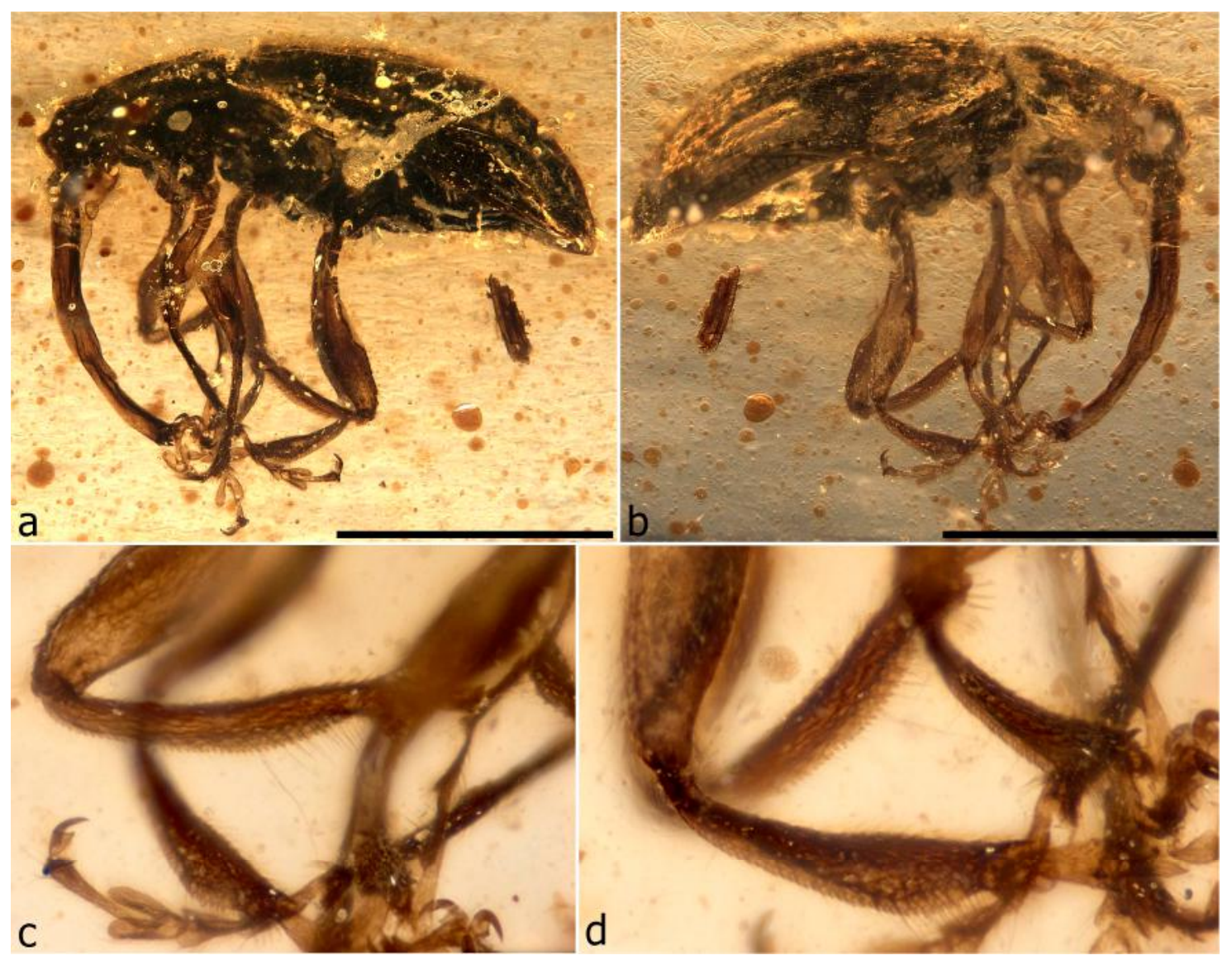

Figure 85. Bowangius sp. 3. Habitus, left lateral (a); habitus, right lateral (b); legs (c); legs, showing detail of metatibial serrulation (d). Scale bars: $1.0 \mathrm{~mm}(\mathrm{a}, \mathrm{b})$.

Bowangius tanaops Clarke \& Oberprieler, sp. n. (Figure 86)

Description. Size. Length $1.93 \mathrm{~mm}$, width $0.7 \mathrm{~mm}$. Head weakly constricted behind eyes; forehead flat. Eyes slightly depressed, somewhat elongate, dorsally separated by about basal width of rostrum. Rostrum ca. $1.25 \times$ longer than pronotum; weakly curved; dorsally with distinct median, paramedian and dorsolateral carinae and intervening grooves from base to antennal insertions, grooves linearly setose at least to antennal insertions, carinae and grooves confusedly continued to near apex; dorso-apically subtruncate, with few setae, epistome distinct, V-shaped, delimited by grooves; antennal insertions median, behind them with deep scrobes reaching front of eye, in front of them continuing narrowly to mandibular articulation; rostrum basally on ventral side without paramedian tubercles. Mandibular articulations oblique, angled upward. Antennae paler than rostrum; scapes apically oblique, reaching just below front margin of eye; funicles with segment 1 broader than others, 2 elongate, fusiform, shorter than 1, 2-7 progressively shorter towards club, 6-7 subglobular, subequal, broader than 2-5; clubs with segments 1-2 subequal in length, apically oblique, anterior sides somewhat produced to rounded point, 3 narrower, slightly shorter than 2, 4 slightly more than half length of 3, seemingly flattened. Mouthparts. Mandibles on outside with 2 subequal teeth. Maxillary palps obliquely projecting from apex of rostrum, 3-segmented; terminal segment narrower than penultimate, hyalinae, apically with slender seta. Labial palps projecting forwards. Thorax. Prothorax weakly proclinate; moderately roundly inflexed laterally, lateroventrally less punctorugose than pronotum. Pronotum elongate, longer than wide, narrowing anteriad from about distal third, slightly emarginate behind middle, base broadly convex in middle, tightly fitting to elytra, posterior angles acutely angulate; surface evenly contoured, punctorugose, setose, setae uniformly whitish, indistinct, short, largely directed mesad to anteromesad. Prosternum short, less than half as long as procoxae, anterior 
margin broadly arcuate, prosternal process short, narrow, pointed; procoxal cavities close to posterior hypomeral margin, hypomeron ca. half as long as prosternum. Scutellar shield subeven with elytra, with anterior edge subcontinuous with elytral bases. Metaventrite coarsely punctate. Elytra with bases bisinuate, weakly extended over pronotum, humeri broadly rounded, slightly flatly or concavely produced, formed by confluent interstriae 6 and 7, tightly fitting onto pronotum, outer apical edges smooth (not toothed), lateral margins with punctosetose marginal groove gradually increasing in width anteriad, with distinct anterior marginal notch; surface rugose, sparsely setose, punctures restricted to striae, striae and interstriae subequal in width, stria 5 somewhat deeper basally than others, interstriae prominent, somewhat raised, distinct also on declivity. Hindwings present. Legs darkly coloured as body. Procoxae conical, contiguous; mesocoxae roundly conical, prominent; metacoxae large, broadly transverse. Femora rounded on outside, without carina or teeth. Tibiae on outer side carinate-serrulate along entire length, teeth distinctly curved, separated, less distinct on protibiae; protibiae slightly longer than meso- and metatibiae, with more prominent inner apical flange, meso- and metatibiae slightly curved inwardly near apex; apically indistinctly flanged, with coarse, sparse fringing setae and elongate dorso-apical setae, with 2 apical spurs, one fixed and larger on meso- and metatibiae. Tarsi ca. $0.75 \times$ as long as tibiae; tarsites $1-2$ apically expanded, 1 ca. $2.0 \times$ longer than 2 , very slender basally, apically subtruncate, 2 more shortly triangular, apically excised, 3 with lobes weakly pedunculate, subovoid, very narrow basally, weakly concave along inner margins, ca. half as long as 5, cryptotarsites distinct, 5 extremely slender basally, slightly flattened. Abdomen. Tergite VII strongly sclerotised, distinctly vertically margined laterally (but not apically), moderately densely punctosetose, laterally with distinct (wing binding?) patches on either side of base; tergite VIII divided by arcuate carina into basal and apical parts, with apical part subconcave, vertical, densely punctosetose, apically delimited by marginal ridge, then inflexed (appearing as sixth ventrite as seen). Ventrites sparsely setose; 1-2 subequal in length, subflatly aligned, with narrow suture, $3-5$ slightly stepped, separated by more distinct, straight to arcuate sutures, 3 slightly shorter than 2, 4 slightly shorter than 3, 5 about as long as 3, apically broadly rounded, with distinct lip.

Material examined. Holotype (NIGP157027): exceptionally well preserved specimen, well visible from all sides, missing tarsus of right hindleg, otherwise intact, with abdominal apex (tergites VII and VIII) distended, completely exposed; in triangular slab with longest edge face curved, $3.9 \times 3.1 \times$ $1.7 \mathrm{~mm}$; amber clear yellow with several transverse fractures over dorsal side of specimen, one large one above pronotum, with several large bubbles in vicinity of specimen, partly obscuring ventral proand mesothorax.

Derivation of name. The species is named for its elongate eyes, from the Greek adjective tanaos, meaning elongate, and the Greek noun ops (G: opos), meaning eye.

Remarks. This species is distinguishable from B. cyclops by its more elongate, slightly depressed eyes, its ventrally strongly bulging head, at most slightly flattened humeri, lack of flanges along the inner edge of the metatibiae and the basally narrower elytra (across humeri). Although the holotype appears relatively slender compared with congeners, it is slightly distorted (compressed), as particularly evident in the preservation of the ventrites and possibly also in the extended apical tergites (VII and VIII), which are protruding and well visible. From B. zhenuai it is distinguishable by the narrower body, curved rostrum, more posteriorly positioned procoxae and more distinct and anteromesadly directed pronotal setae (this last feature shared with B. cyclops). The holotype was submitted for CT scanning, but the contrast between the specimen and the amber was too low to permit any meaningful visualisation of the specimen.

Bowangius zhenuai Clarke \& Oberprieler, sp. n. (Figure 87)

Description. Size. Length $1.86 \mathrm{~mm}$, width $0.78 \mathrm{~mm}$. Head slightly constricted behind eyes; interocular area narrow, dorsally maximally slightly less than basal width of rostrum, forehead flat. Eyes somewhat depressed, elongate. Rostrum slightly longer than head + pronotum; substraight; dorsally with distinct median, paramedian and dorsolateral carinae and intervening setose grooves from base to antennal insertions, carinae and grooves confusedly continued to near apex; antennal 
insertions median, behind them with deep scrobes extending to front of eye, in front of them with similar groove and with row of short slender indistinct setae; rostrum basally on ventral side in front of eyes with raised paramedian line of curved tubercles with a short seta between tubercles. Antennae. Scapes apically oblique, reaching well below front margin of eye, shorter than funicles; funicles with segment 1 broader than others, 2-5 elongate, slender, progressively shorter towards club, 6-7 broader, 6 expanded apically, slightly broader than 7, 7 subglobular; clubs with segments 1-2 subequal, distinctly obconical, apically suboblique, 2 basally wider than 1,3 ca. half as long as 2, 4 broadly inserted, flattened. Mouthparts. Mandibles on outside with 2 small subequal denticles, on inside with 3 (or 4) teeth, mesal 2 larger, largest with subemarginate apex (sub-bicuspid), apical part elongate, slender, apex narrowly T-shaped; articulations oblique, also upwardly oblique. Thorax. Prothorax strongly proclinate. Pronotum widest at about middle, gradually narrowing anteriad and posteriad, base weakly convex in middle, tightly fitting onto elytra, posterior angles roundly angulate (not acute); surface punctorugose, sparsely shortly setose, setae pale whitish, indistinct, short, largely directed anteriad. Prosternum very short, ca. $0.2 \times$ as long as procoxae, anterior margin distinctly narrowly emarginated, prosternal process short, broadly triangular; procoxal cavities closer to anterior prosternal margin, hypomeron ca. $3.0 \times$ longer than prosternum. Scutellar shield narrower transverse, densely setose. Metaventrite finely, sparsely punctate. Elytra with bases bisinuate, closely fitting, shortly extended over pronotum, humeri broadly rounded, somewhat flatly produced, formed by confluent interstriae 6 and 7, outer apical edges smooth, not toothed, lateral margins with punctosetose marginal groove increasing in width anteriad, with distinct anterior marginal notch; surface with strial punctures very small, fine, striae as broad as or broader than interstriae, interstriae prominent, interstria 6 obsolete before humeri, 6 and 7 confluent near humeri, interstriae much less distinct on declivity, sparsely shortly setose, setae pale, whitish. Hindwings present. Legs. Legs much paler than body. Procoxae subconical; mesocoxae nearly as prominent as procoxae; metacoxae large, strongly transverse, ovoid. Femora on outside rounded, without carina or teeth. Tibiae on outer side carinate-serrulate along entire length, teeth distinctly curved, approximate on mesotibiae (appearing crenulate due to viewing angle), less distinct on protibiae; protibiae longer than meso- and metatibiae, the latter straight (not distinctly curved inwardly near apex); apically with coarse elongate fringing setae and elongate dorso-apical setae, with 2 subequal apical spurs, strong and curved on meso- and metatibiae, inner spur on metatibiae shorter, apparently fixed, more curved than outer spur. Tarsi ca. half (protarsi) to $0.75 \times$ (meso- and metatarsi) as long as tibiae, protarsi slightly longer than others; tarsites 1-2 apically expanded, 1 ca. $2.0 \times$ longer than 2, very slender basally, apically weakly excised, 2 more triangular, apically excised, dorso-apically with several elongate black setae, 3 with lobes weakly pedunculate, subovoid, distinctly concave along inner margins, slightly more than half as long as 5 , cryptotarsite distinct, 5 extremely slender basally, slightly flattened. Abdomen. Tergite VII setose at least apically, distinctly edged laterally; tergite VIII flattened, divided by concavely arcuate carina into basal and apical parts, with apical part flatly concave, densely, finely setose. Ventrites 1-2 subequal in length, subflatly aligned with narrow suture, 3-5 slightly stepped, separated by more distinct, straight to arcuate sutures, 3 shorter than 2, 4 shorter than 3, 5 subequal in length to 3, apically broadly rounded, with distinct lip.

Material examined. Holotype (NIGP169513): exceptionally well preserved, intact specimen, not distorted or compressed, well visible from all sides, with right hindwing partly extended, abdominal apex (tergites VII and VIII) partly distended and visible; in trapezoidal block $4.0 \times 2.0 \times 1.4 \mathrm{~mm}$ with all faces flat; amber clear yellow with darker flow bands, with diffuse minute particles and with few minor cracks around side of specimen.

Derivation of name. The species is named after Zhenua Liu, currently a Ph.D. student at the ANIC, for his assistance with obtaining specimens for this study and for his stimulating discussions about and his work on the beetle fauna preserved in Burmese amber.

Remarks. This species is also readily distinguishable from $B$. cyclops by its elongate, slightly depressed eyes and the lack of diagnostic characters of that species. It is most similar to $B$. tanaops, from 
which it differs in its straighter rostrum, row of flat tubercles on either side of the gular suture and distinctly anteriadly directed, fine pronotal setae. It is also much broader, with distinct and broadly rounded humeri and more coarsely punctostriate elytra, the procoxae situated closer to the anterior prosternal margin and the mesotibiae straight, with both spurs free.

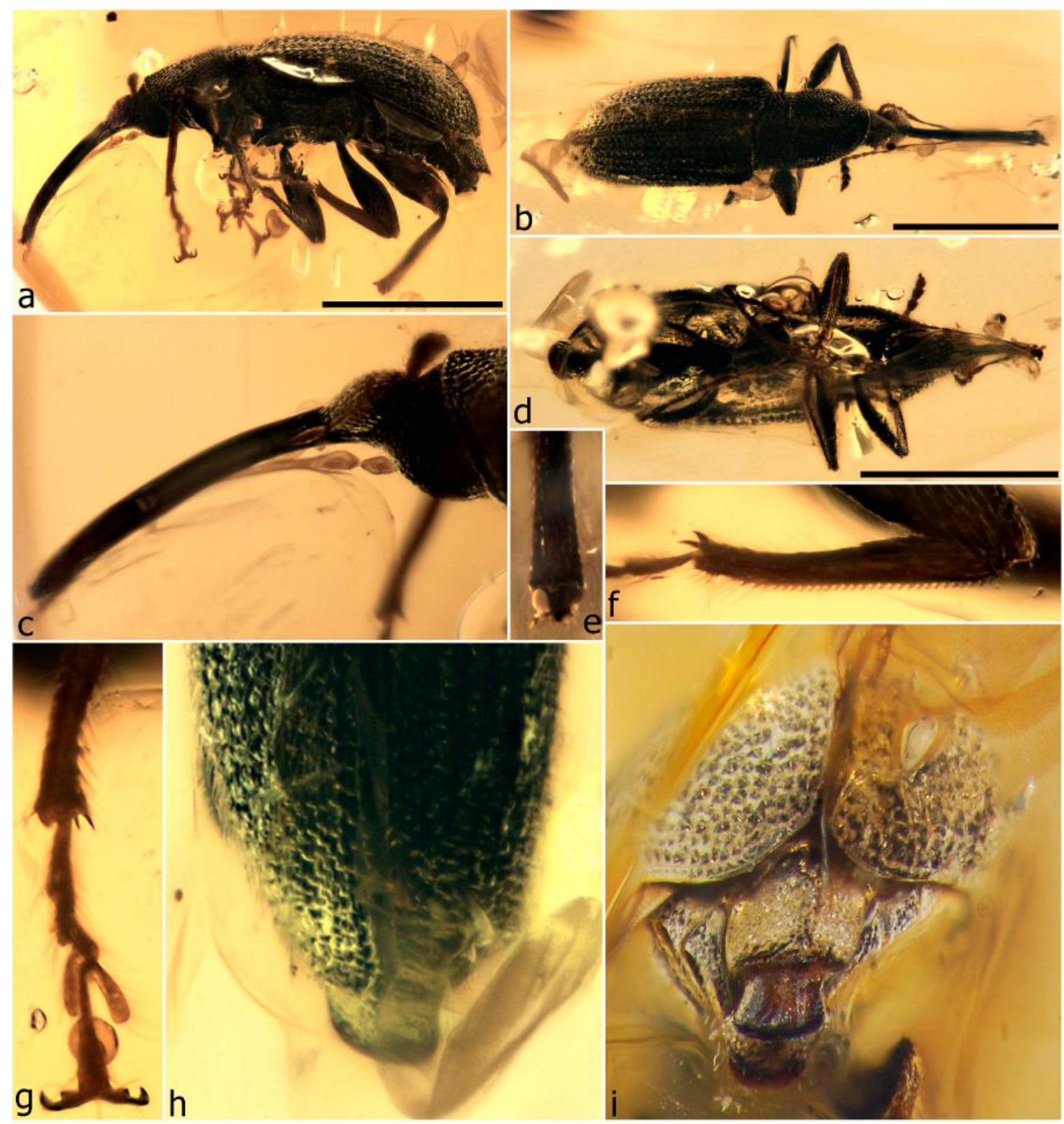

Figure 86. Bowangius tanaops sp. n., holotype. Habitus, left lateral (a); habitus, dorsal (b); head, left lateral (c); habitus, ventral (d); apex of rostrum and mouthparts, dorsal (e); left metatibia (f); left protarsus (g); apical half of elytra and exposed tergite VII, dorsal (h); apex of abdomen and elytra, caudal (i). Scale bars: $1.0 \mathrm{~mm}(\mathrm{a}, \mathrm{b}, \mathrm{d})$. 


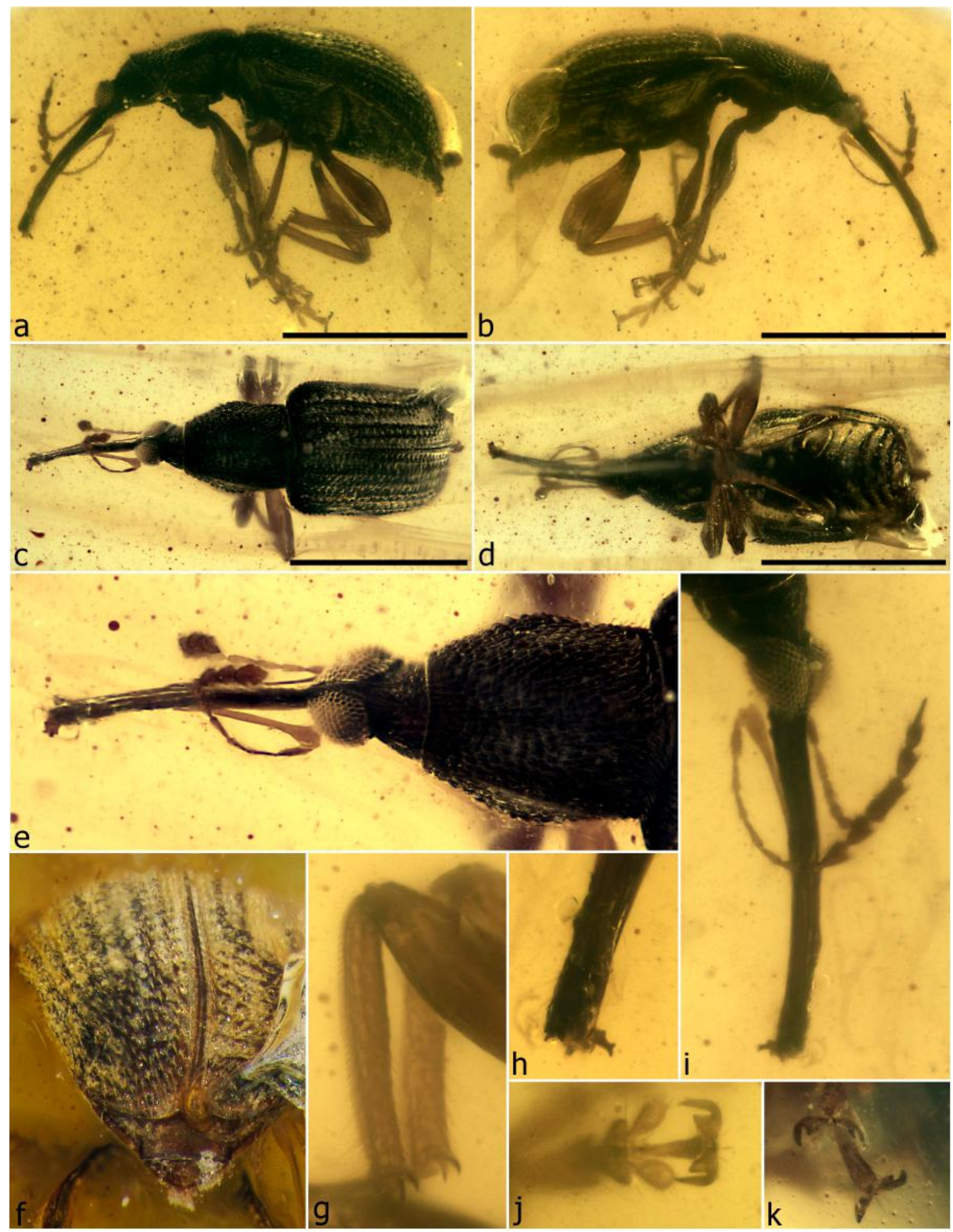

Figure 87. Bowangius zhenuai sp. n., holotype. Habitus, left (a); habitus, right (b); habitus, dorsal (c); habitus, ventral (d); head and pronotum, dorsal (e); apex of elytra and abdomen, caudal (f); metatibiae (g); apex of rostrum and mandibles, left (h); head and rostrum, oblique right (i); tarsus (j); tarsal claws (k). Scale bars: $1.0 \mathrm{~mm}(\mathrm{a}-\mathrm{d})$. 
Bowangius glabratus Clarke \& Oberprieler, sp. n. (Figure 88)

Description. Size. Length $2.86 \mathrm{~mm}$, width unmeasurable. Body seemingly robust, probably broad, integument uniformly metallic black, vestiture short, pale. Head short, probably globular, dorsally somewhat bulging; densely setose, setae fine, directed anteriad, not continuing onto rostrum; forehead in middle narrow, setose. Eyes large, probably slightly elongate, dorsally separated by about basal width of rostrum or less. Rostrum asetose, dorsally with median, paramedian and dorsolateral ridges and intervening grooves; antennal insertions in middle of rostrum length, behind them with scrobes extending to eye, in front with narrow grooves reaching mandibular articulations, without row of setae in groove. Antennae. Scapes elongate, apically strongly clavate, oblique; apical articulation socket very narrow; funicles with segment 1 elongate, only slightly wider than others; $2-5$ similar, elongate-cylindrical, slender; 6-7 shorter, thicker, 7 shorter than 6; clubs with segment 1 obconical, shorter, narrower than 2, 2-3 subequal, 3 somewhat rounder, 4 conical, broadly inserted onto 3, apically acute. Mouthparts. Mandibles symmetrical, short and broad, apically forming strongly notched V, outside with 2 small pointed teeth, one at base and one in middle, inside with very large tooth in about middle, adjacent to apical inner tooth of V. Maxillary palps short, 3-segmented, narrowing apicad. Thorax. Prothorax probably proclinate. Pronotum with posterior corners angulate, closely fitting onto elytra; sparsely setose, setae directed anteromesad, fine, short and pale. Elytra with humeri narrowly rounded, tightly fitting to pronotal corners, marginal groove distinct, narrow, subequal for entire length, with broad anterior marginal notch; surface nearly smooth, sparsely setose, interstriae much broader than striae, flatly convex, setae short, fine. Legs. Femora on outside rounded (profemora) or serrulate in apical third (meso- and metafemora). Tibiae slightly curved, compressed; protibiae longer than others, carinate and sparsely setose on outside, meso- and metatibiae on outside serrulate, with dense long setae in apical quarter; apically with distinct well-developed flanges lined with coarse fringing setae, with 2 short slender spurs. Tarsi with tarsite 1 apically slightly excised, 2 excised, about as wide as 1, 3 with short ovoid lobes, broadly connected basally and concave along inner edges; 5 slightly shorter than $1+2$; claws divaricate, with triangular basal tooth. Abdomen. Ventrites flatly aligned, finely sparsely punctate; $1-2$ fused, $3-4$ progressively shorter, 5 about as long as 3 , apically broadly rounded.

Material examined. Holotype (NIGP169514): reasonably well preserved, largely intact but heavily distorted specimen (compressed and crumpled), well visible from all sides (including mandibles and appendages), appendages severed as follows: scape of right antenna broken in several places and funicle between segments 2 and 3, right profemora from trochanter and protarsites 1 and 2 and 4 and 5 and outer claw, left protarsites and right mesotarsites 4 and 5, right metatarsites 1 and 2 and left metatarsus from tibia, also missing claws; in subtrapezoidal slab $5.6 \times 3.3 \times 0.9-1.1 \mathrm{~mm}$, with three flat edges and rounded edge in front of rostrum; amber clear brownish-yellow, hazy, with diffuse microscopic particles, without any bubbles or cracks.

Derivation of name. This species is named for its glabrous, black appearance, the name being a Latin adjective.

Remarks. This species can be distinguished from all other known Bowangius species by the combination of its larger size, glossy elytra without sculpture and with extremely fine short vestiture (the elytra appearing nearly glabrous) and its carinate protibiae. The combination of carinate protibiae (without teeth) and serrulate meso- and metatibiae is rare, otherwise occurring in our sample only in Louwiocis megalops, Habropezus incoxatirostris and Bowangius sp. 3, possibly also in Mesophyletis calhouni (described as smaller denticles on the mesotibiae and none on the protibiae [29]). Despite the distorted condition of the holotype, B. glabratus is not or hardly decomposed and perfectly visible from all sides, allowing confirmation of its uniqueness among our sample of Burmese amber weevils. We tentatively assign this large specimen to Bowangius, but additional better-preserved specimens are needed to confirm this placement. 


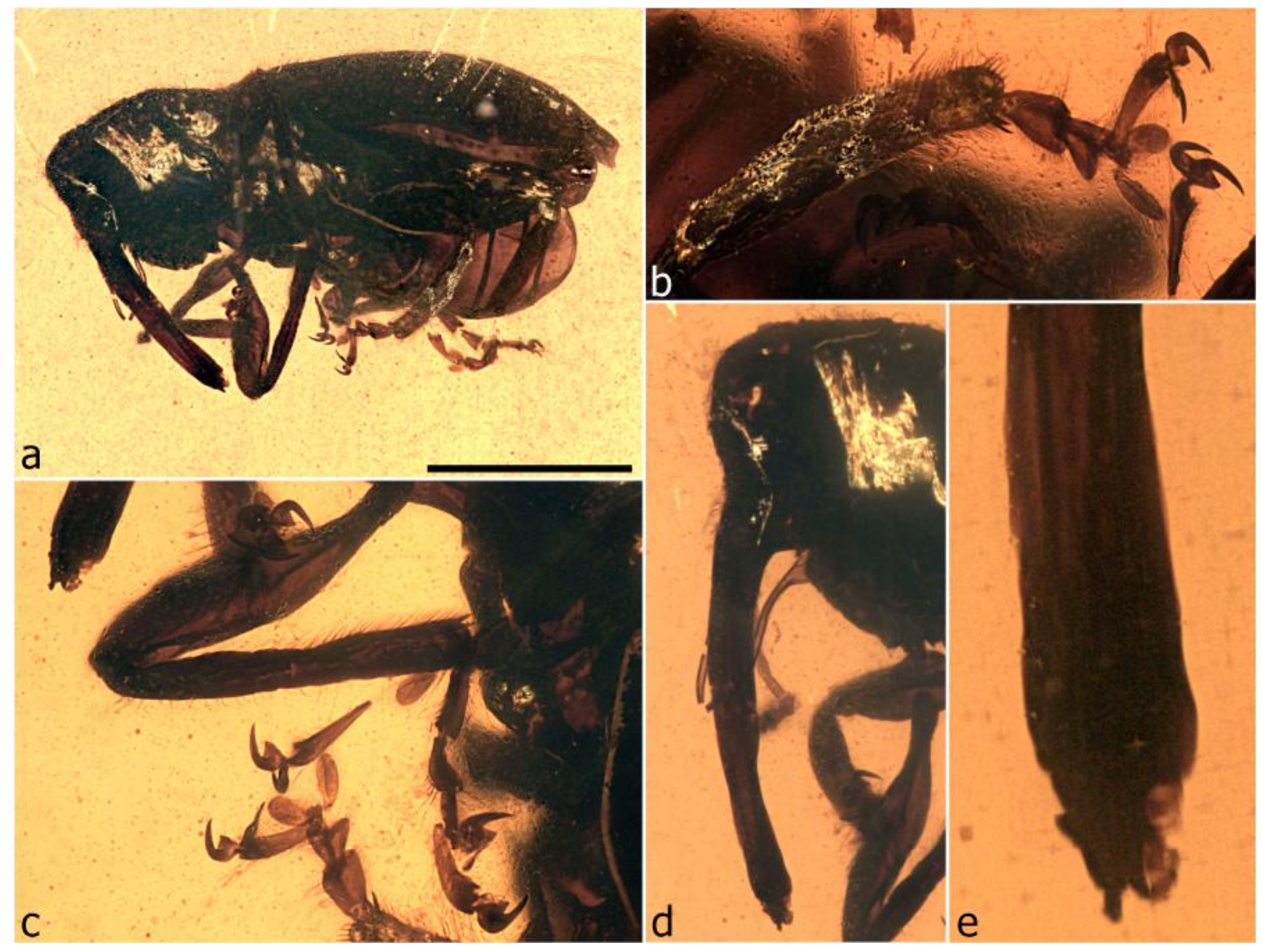

Figure 88. Bowangius glabratus sp. n., holotype. Habitus, left lateral (a); left metatibia (b); protibia and tarsi (c); head and rostrum, left lateral (d); apical part of rostrum, left lateral (e). Scale bar: $1.0 \mathrm{~mm}$ (a).

\section{Bowangius sp. 4 (Figure 89)}

Material examined. One specimen (NIGP169515), female; length $2.62 \mathrm{~mm}$, width not measurable: reasonably well preserved, intact but heavily distorted (compressed and crumpled), well visible from all sides (including mandibles and appendages); in cuboid $3.1 \times 2.8 \times 1.9 \mathrm{~mm}$; amber clear yellowish-green, without any bubbles or cracks or debris.

Remarks. While well visible, the specimen had decayed somewhat and is crumpled and collapsed, with key areas of the thorax crushed and associated characters rendered invisible or uninterpretable. Important among these are the basal leg segments, abdominal ventrites and pterothoracic sclerites. However, the mouthparts and many other important details of the legs are visible. On the characters that can be assessed reliably, it appears to belong in Bowangius. Its most charactertistic features are the sparse, semi-appressed short body setae and the crenulate-serrulate tibiae. The extruded ovipositor reveals elongate, apically obliquely pointed gonocoxites, each subapically with a tubular truncate stylus with few short setae.

Genus Louwiocis Clarke \& Oberprieler, gen. $\mathbf{n}$.

Type species: Louwiocis megalops Clarke \& Oberprieler, sp. n.

Description. Size. Length $2.2 \mathrm{~mm}$, width $1.2 \mathrm{~mm}$. Head large, bulbous, faintly constricted behind eyes. Eyes large, vertically elongate, anterior and posterior margins almost straight; hardly prominent, coarsely facetted; dorsally separated by basal width of rostrum, without tubercles between them. Rostrum as long as pronotum, stout, cylindrical, inserted in middle of head and dorsally forming deep acute sinus with head; antennal insertions lateral, behind them with scrobes extending to eye, in front of them with lateral row of setae. Gular suture seemingly single, long. Antennae geniculate; scapes relatively short, straight, cylindrical, apically clavate; funicles slightly longer 
than scape, 7-segmented, segment 1 elongate, 2 subequal but thinner, rest progressively shorter towards club; clubs loosely articulated, 4-segmented, apical segment distinct. Mouthparts. Labrum absent. Mandibles flat, exodont, vertical in open position, inner (dorsal) side with 2 large teeth and smaller apical one forming short thick $\mathrm{V}$ with opposing outer tooth, outer (ventral) side with 2 other much smaller and lower teeth; articulation plane oblique. Maxillary palps 3-segmented. Thorax. Prothorax proclinate, with anterior lateral margins oblique in lateral view. Pronotum roundly trapezoidal, laterally rounded, without tooth, posterior corners produced to fit closely onto elytra; surface sparsely setose, setae directed anteromesad; notosternal sutures closed, upright above procoxal cavity, then curved anteriad. Prosternum seemingly short, reduced (not clearly visible); procoxal cavities medially confluent, close to anterior border of prosternum. Scutellar shield distinct. Mesocoxal cavities laterally closed (by meso- and metaventrite). Metanepisternal sutures distinct. Mesoventrite short, anteriorly strongly sloping. Metaventrite longer, flat with slight transverse weals before metacoxae. Elytra elongate, with well-developed, broadly rounded humeri, posteriorly gently declivous, apically individually rounded but almost subtruncate together, not exposing pygidium; sutural flanges not visible; surface punctostriate, without scutellary striole, sparsely setose. Legs. Procoxae elongate, prominent, medially contiguous; mesocoxae subglobular, narrowly separated; metacoxae flat, transversely elongate. Trochanters short, oblique. Femora subcylindrical, inflated in distal half, unarmed, meso- and metafemora on outside with crenulate carina in distal third to half. Tibiae long, straight, outer edge carinate or serrulate, apex with 1 (protibiae) or 2 (meso- and metatibiae) spurs; meso- and metatibiae with row of sparse, long erect setae on inside in distal half. Tarsi longer than half length of tibiae; tarsite 1 elongate, 2 triangular, 3 deeply bilobed, 5 as long as 1 ; claws divaricate, dentate with ventrobasal seta at apex of tooth. Abdomen with ventrites 1-2 fused, subequal in length, 3-4 each slightly shorter than 2,5 as long as 4 .

Derivation of name. The genus is cordially named after the late Schalk Louw (1952-2018) in recognition of his work on the weevil fauna of southern Africa; the name is composed of his surname and the Greek noun kis (G: kios) (weevil or beetle) and is masculine in gender.

Remarks. On its dentate claws, exodont mandibles and serrulate tibial edges, Louwiocis relates to the group of genera including Mekorhamphus, Mesophyletis, Myanmarus, Habropezus, Bowangius, Anchineus and Elwoodius. It differs from these in its vertically elongate, hardly protruding eyes. From Aphelonyssus it differs additionally in its much larger eyes, more distinct elytral striae longer body setae, apically bent mesotibiae and longer first and truncate second tarsites. It includes a single species among the material available for study.

Louwiocis megalops Clarke \& Oberprieler, sp. n. (Figure 90)

Description. Size. Length $2.18 \mathrm{~mm}$, width $1.2 \mathrm{~mm}$. Eyes large, vertically subrectangular (anterior and posterior margins straight), hardly protruding. Rostrum slightly curved; antennal insertions in middle of rostral length, in front of them with lateral row of ca. 5 long, erect setae. Antennae long; scapes thin, apically slightly clavate; funicles with segment 1 elongate, slightly inflated, 2 as long as 1 but narrower, others also narrow, progressively becoming shorter towards club; clubs long, flattened, segment 4 distinct, shorter and narrower than 3, flat. Mouthparts. Mandibles flat, with 2 large recurved teeth on inner (dorsal) side, smaller one at apex forming short $\mathrm{V}$ with similar one on outer (ventral) side, this with 2 much smaller teeth. Thorax. Pronotum strongly convex, surface rugulose, sparsely setose, setae fine, pale. Scutellar shield elongate, posteriorly rounded, slightly raised, setose. Elytra with surface sparsely setose, setae short, yellowish, suberect, slanting caudad. Legs. Femora long, medially inflated; profemora on outside rounded, meso- and metafemora with crenulate carina in distal half. Tibiae long, flattened, outer edge finely serrulate (faintly carinate on protibiae), apex obliquely truncate, extended shortly inwards, mesotibiae bent inwards at apex; protibial spur short, cylindrical, meso- and metatibial spurs equal, free, slightly curved and flattened. Tarsi with tarsite 1 long, narrow, apically truncate, 2 half as long, apically truncate, 3 with lobes not pedunculate. Abdomen as for genus. 
Material examined. Holotype (NIGP169516): well preserved, intact specimen, not compressed or distorted, right middle leg outstretched ventrad, right front leg broken off at trochanter, well visible from all sides except posterior right; in dorsal half of flat rectangular cuboid $4.2 \times 3.65 \times 1.2 \mathrm{~mm}$; amber very clear without any impurities except two small elongate clear bubbles over right metathorax and larger flat clear bubble over posterior side of right elytron.

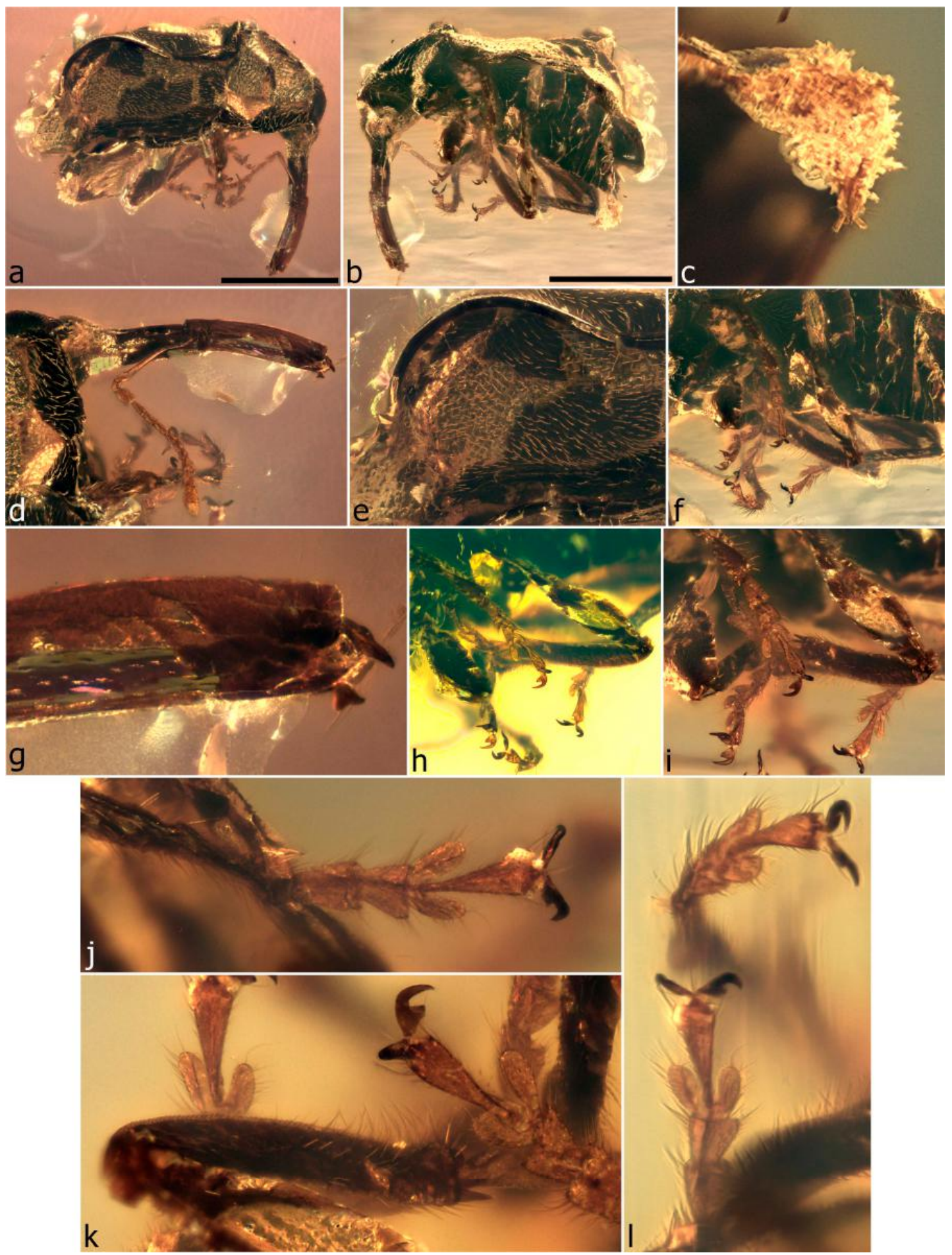

Figure 89. Bowangius sp. Habitus, right lateral (a); habitus, left lateral (b); ovipositor (c); head and antenna, right lateral (d); right elytral surface, right lateral (e); legs and ventrites (f); rostral apex and mandibles, right lateral (g); legs, left lateral (h); same, showing crenulation of metatibia and spurs (i);

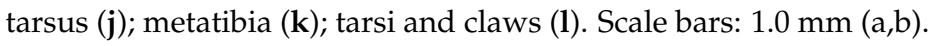




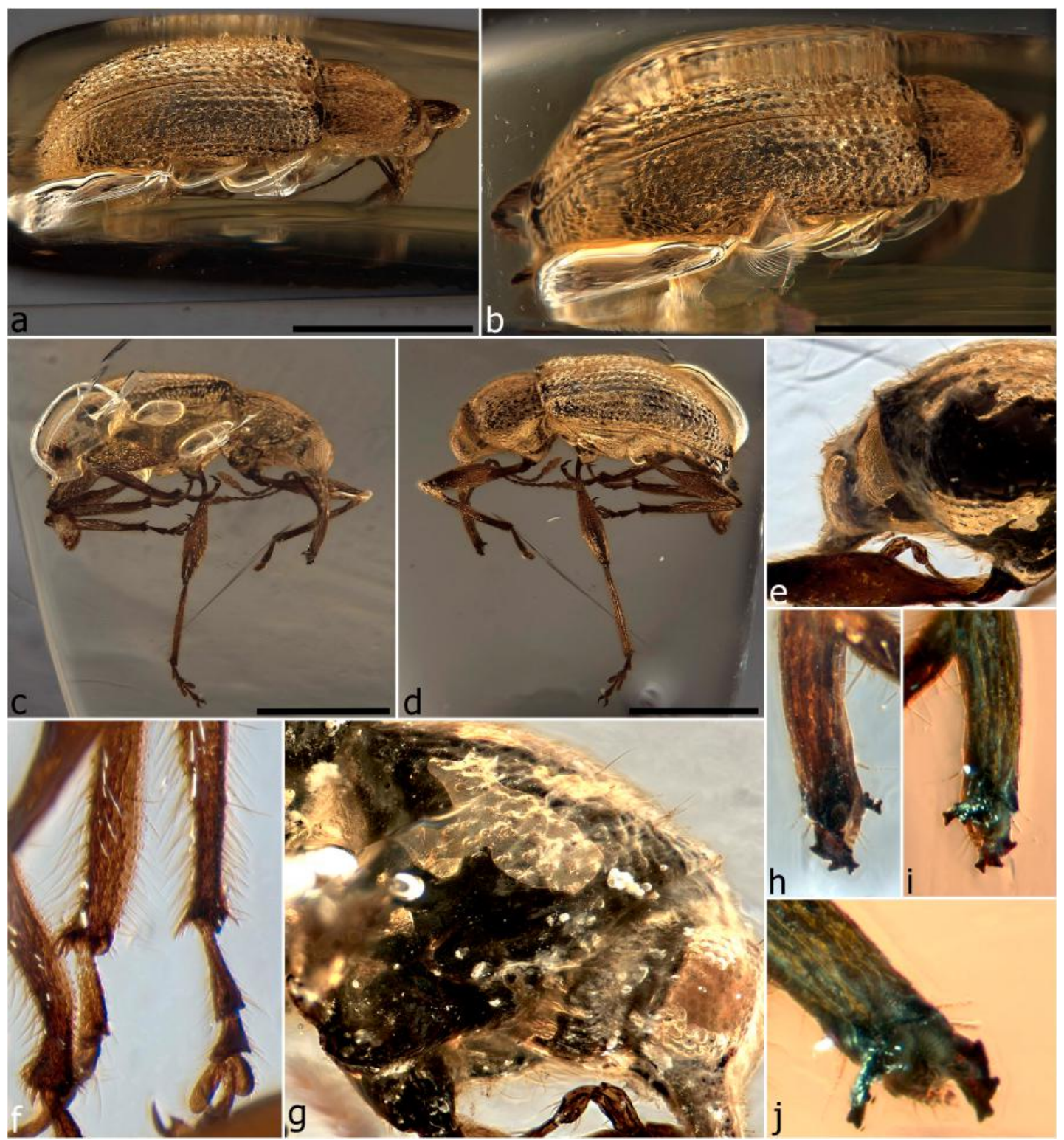

Figure 90. Louwiocis megalops sp. n., holotype. Habitus, dorsal oblique (a); detail of elytra, dorsal oblique (b); habitus, right lateral (c); habitus, left lateral (d); head and prothorax, left lateral (e); tibiae (f); head and thorax, right lateral (g); apex of rostrum and mandibles, left lateral (h); same, right oblique (i); same, frontal (j). Scale bars: $1.0 \mathrm{~mm}(\mathrm{a}-\mathrm{d})$.

Derivation of name. The species is named for its large, subrectangular, hardly protruding eyes, the name formed from the Greek adjective megas (large) and noun ops (eye) and being a noun in apposition.

Remarks. The vertically elongate, almost straight-sided eyes distinguish this species from all other Burmese amber weevils as studied. In the holotype the mandibles are very well preserved and visible in their vertical, open position.

Genus Elwoodius Clarke \& Oberprieler, gen. n.

Type species: Elwoodius conicops Clarke \& Oberprieler, sp. n.

Description. Size. Length $3.8 \mathrm{~mm}$, width $2 \mathrm{~mm}$. Head short, subconical. Eyes large, conical, strongly protruding, coarsely facetted, dorsally separated by basal width of rostrum, without tubercles between them, forehead slightly impressed. Rostrum relatively short, as long as pronotum, stout, cylindrical; antennal insertions lateral, behind them with scrobes extending to eye, in front of them 
with lateral row of erect setae. Gular suture single, from base of head to underside of rostrum. Antennae geniculate; scapes long, cylindrical, apically clavate; funicles slightly longer than scape, 7-segmented, segment 1 elongate, thick, rest thinner, subequal in length but progressively shortened; clubs long, loosely articulated, 4-segmented. Mouthparts. Labrum absent. Mandibles small, very narrow, flat, exodont, outside with 3 teeth, basal and median one large, triangular, apical one smaller, narrower, forming small $\mathrm{T}$ with similar inner tooth; articulation oblique. Maxillary palps long, 3-segmented. Thorax. Prothorax strongly proclinate, with anterior lateral margins oblique in lateral view. Pronotum broader than long, laterally rounded, without tooth, posterior corners angled, fitting closely onto elytra, surface sparsely setose; notosternal sutures closed. Prosternum short; procoxal cavities medially confluent, close to anterior margin of prosternum. Scutellar shield short, broad, slightly convex. Mesocoxal cavities laterally closed (by meso- and metaventrite). Metanepisternal sutures distinct. Mesoventrite short, anteriorly strongly sloping. Metaventrite longer, raised into narrow transverse weals before metacoxae. Elytra elongate, with weakly, broadly rounded humeri, posteriorly gently declivous, apically individually angled, not exposing pygidium; sutural flanges narrow, equal; surface finely punctostriate, without scutellary striole, very sparsely irregularly setose, setae directed caudad. Hindwings present. Legs. Procoxae large, prominent, close to anterior margin of prosternum, medially contiguous; mesocoxae subglobular, narrowly separated; metacoxae flat, transversely elongate. Trochanters short, oblique. Femora subcylindrical, inflated in distal half, unarmed, on outside with crenulate carina. Tibiae flattened, outer edge serrulate (protibiae) to pectinate (meso- and metatibiae), apex with 2 spurs, inner one on meso- and metatibiae fixed and modified. Tarsi almost as long as tibiae; tarsite 1 elongate, triangular, 2 triangular, 3 deeply bilobed; claws divaricate, dentate with ventrobasal seta at apex of tooth. Abdomen. Last tergite (seemingly VII) apically with sharply rimmed setiferous cavity. Ventrites 1-2 fused, equal in length, each slightly longer than 3-4, 5 long, subtriangular, all with long erect setae.

Derivation of name. The genus is respectfully named after the late Elwood C. Zimmerman (1912-2004), in recognition of his huge contributions to the study of the weevil faunas of the Pacific region and Australia; the name is masculine in gender.

Remarks. Elwoodius is readily distinguishable from all other mesophyletid genera by its extraordinary narrowly conical, laterally protruding eyes and the flattened meso- and metatibaie with their pectinate outer edges and modified inner spurs. Another unusual feature is the setose apical cavity of the last tergite, which appears unique not only among the Burmese amber weevils but among weevils in general. Only a single species is included in Elwoodius thus far.

Elwoodius conicops Clarke \& Oberprieler, sp. n. (Figure 91)

Description. Size. Length $3.79 \mathrm{~mm}$, width $1.9 \mathrm{~mm}$. Head strongly constricted behind eyes, vertex abruptly higher than forehead. Eyes strongly elongate-conical, about $2 \times$ wider than long, protruding laterad as well as above forehead. Rostrum slightly curved, basally extending smoothly onto forehead; antennal insertions in apical third of rostral length, in front of them with lateral row of 6-7 long, erect setae. Antennae long; scapes thin, apically abruptly shortly clavate; funicles with segment 1 slightly spindle-shaped, 2-5 slightly shorter, much thinner but thickening apicad, 6-7 shorter and thicker; clubs long, slightly flattened, terminal segment basally as broad as segment 3 , slightly shorter, bluntly triangular. Mouthparts. Mandibles narrow, curved, outer teeth low but acute, apex narrow, acute. Thorax. Pronotum broadly roundly trapezoidal, slightly convex; surface very sparsely setose, setae (discernible laterally) very fine, pale, sharp, directed mesad to anteromesad. Prosternum deeply roundly emarginate (allowing head and rostrum to flex down onto procoxae). Elytra with fine, moderately long, sharply pointed white setae, arising both from strial punctures and on interstriae. Legs. Procoxae long, contiguous throughout their length, anteriorly slightly compressed and angled apart (seemingly to receive rostrum when flexed down). Femora long, strongly inflated distally, thickest in about distal quarter, outside with crenulate carina in distal 0.4 of length. Tibiae slightly curved inwards at apex, outer edge serrulate on protibiae, pectinate on meso- and metatibiae; apex truncate, spurs on protibiae small, thin, narrow equal, on meso- and metatibiae unequal, the 
inner one fixed (fused), on mesotibiae subcylindrical and curved inwards, on metatibiae broad and flat. Tarsi with tarsite 1 narrowly triangular, apically excised, 2 shorter, triangular with thin base, apically excised, 3 deeply bilobed but short, lobes not pedunculate, 5 slightly shorter than $1+2$. Abdomen with ventrites in about middle of length with irregular transverse band of long, erect silvery white setae of varying lengths.

Material examined. Holotype (ANIC 25-073777): very well preserved, intact specimen, not compressed or distorted, both hindwings extruded posteriorly, right elytron slightly cut laterally, well visible from all sides; in centre of rectangular cuboid $5.15 \times 4.1-3.7 \times 3.2 \mathrm{~mm}$ with convex dorsal surface; amber very clear with few scattered impurities and a number of small clear bubbles over pronotum, a sinuate layer of flow lines above eyes and faint fault layer on inside of left legs to edge of amber block, also fine cracks above dorsum of specimen.

Derivation of name. The species is named for its pronounced conical eyes, from the Greek nouns konos, meaning cone, and ops, meaning eye; the name is a noun in apposition.

Remarks. This is one of the most peculiar species of Buremese amber weevils, immediately recognisable by its large conical eyes and its pectinate meso- and metatibiae with enlarged, fixed inner spurs. Although clearly a mesophyletid (one of the few specimens with the long single gular suture of the group well visible), it approaches the habitus of the family Curculionidae in having its anterior prosternal margin deeply emarginate and its procoxae anteriorly narrowed and splayed, evidently allowing the head and rostrum to flex down and rest on the procoxae. This condition may be interpreted as a morphological precursor to the short prosternal channel of Burmorhinus.

Genus Aphelonyssus Clarke \& Oberprieler, gen. $\mathbf{n}$.

Type species: Aphelonyssus latus Clarke \& Oberprieler, sp. n.

Description. Size. Length $2.4 \mathrm{~mm}$, width $1.2 \mathrm{~mm}$. Head short, subglobular, very faintly constricted behind eyes. Eyes relatively small, flatly hemispherical, coarsely facetted, dorsally separated by width of rostrum, without tubercles between them, placed anteriorly on head (Figure 92e,f). Rostrum shorter than pronotum, stout, cylindrical, only very slightly curved; antennal insertions lateral, behind them with deep scrobes extending to eye, in front of them with lateral row of few long, erect setae. Gular suture single, long but indistinct posteriorly. Antennae geniculate; scapes short, straight, cylindrical, apically clavate; funicles slightly longer than scape, 7-segmented, segment 1 elongate, 3-7 thinner and gradually shorter towards club; clubs loosely articulated, 4-segmented but segment 4 not well distinct from 3. Mouthparts. Labrum, mandibles, maxillae and labium unknown (apex of rostrum of single specimen cut off). Thorax. Prothorax strongly proclinate, with anterior lateral margins oblique in lateral view (Figure 92a). Pronotum roundly ogival, laterally rounded, slightly explanate, without tooth, posterior corners angled, fitting closely onto elytra; notosternal sutures closed. Prosternum long, strongly declivous, anteriorly deeply roundly emarginate, surface moderately densely setose, setae suberect, directed anteriad; procoxal cavities medially confluent, close to posterior margin of hypomeron. Scutellar shield short, broad, rounded. Mesocoxal cavities laterally closed (by meso- and metaventrite). Metanepisternal sutures distinct. Mesoventrite short, anteriorly sloping. Metaventrite longer, very weakly convex, with distinct discrimen. Elytra shortly elongate, with weakly, broadly rounded humeri, posteriorly gently declivous, apically individually rounded, not exposing pygidium; sutural flanges narrow, equal; surface coarsely punctostriate, without scutellary striole; sparsely setose, setae short, suberect, directed caudad. Legs. Procoxae short, subglobular, slightly prominent, medially contiguous; mesocoxae globular, narrowly separated; metacoxae flat, transversely elongate. Trochanters short, oblique. Femora short, strongly inflated in distal half, subcylindrical to subcompressed, unarmed, meso- and metafemora with outer edge faintly serrulate in distal third. Tibiae short, straight, meso- and metatibiae with outer edge finely serrulate, apex with 2 spurs (at least on metatibiae). Tarsi slightly shorter than tibiae; tarsites 1 and 2 triangular, apically excised, 3 deeply bilobed, 5 as long as than $1+2$; claws divaricate, dentate with ventrobasal seta at apex of tooth. Abdomen with ventrites 1 and 2 fused, subequal, 2 slightly longer than 3, 3 slightly longer than 4,5 as long as 4 , crescentic. 
Derivation of name. The genus is named for its simple, smooth surface and stout, almost straight rostrum, the name derived from the Greek adjective aphelos (even, smooth) and verb nysso (to pierce) and being masculine in gender.

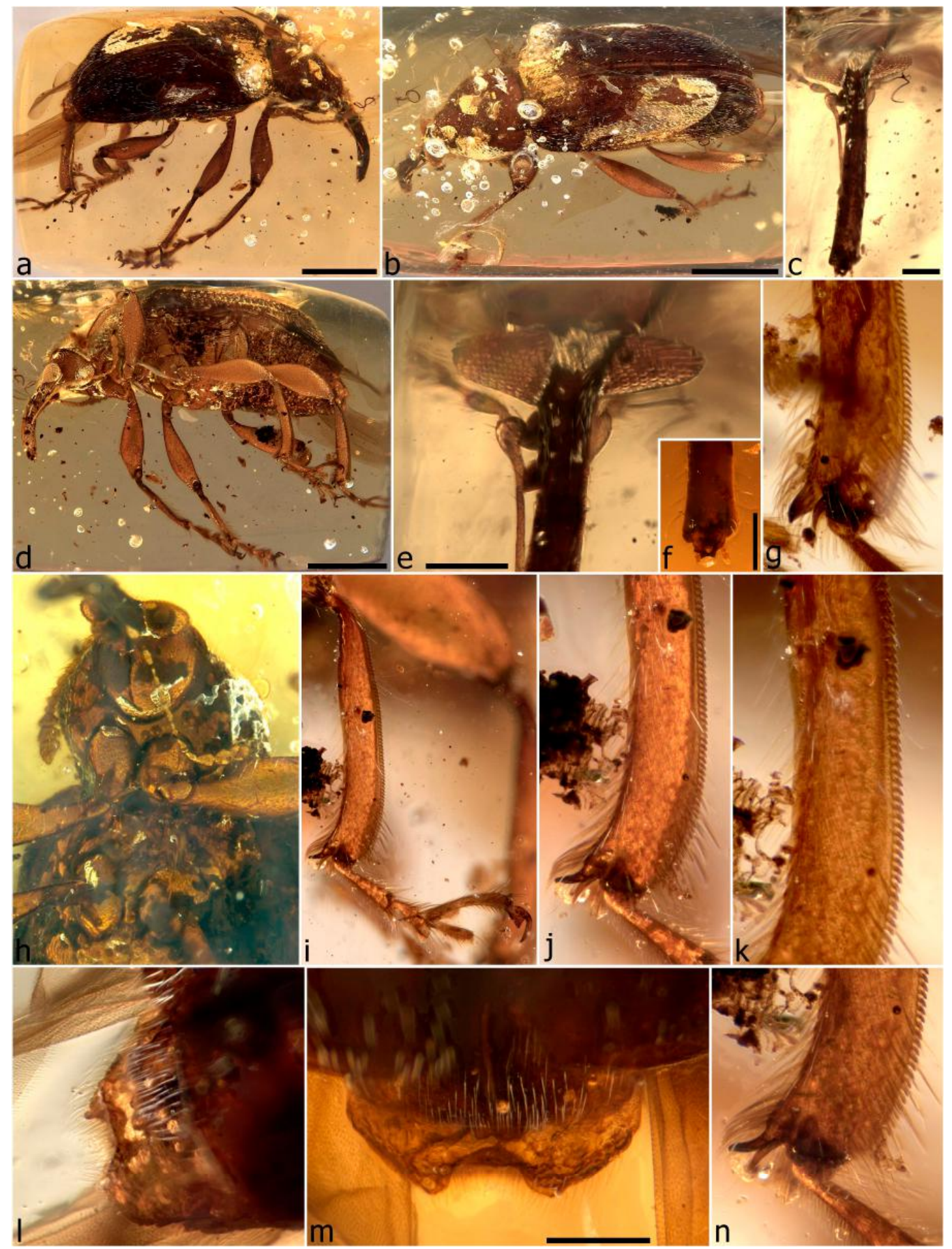

Figure 91. Elwoodius conicops sp. n., holotype. Habitus, right lateral (a); habitus, dorsal oblique (b); head and rostrum (c); habitus, left lateral (d); head (e); apex of rostrum and mandibles, dorsal (f); left metatibia (g); head and thorax, ventral (h); mesotibiae and tarsus (i); mesotibiae showing spurs (j); mesotibiae, detail of dorsal pectination (k); tergite VII, dorsal oblique (1); tergite VII, dorsal (m); mesotibial spurs (n). Scale bars: $1.0 \mathrm{~mm}(\mathrm{a}, \mathrm{b}, \mathrm{d}) ; 0.2 \mathrm{~mm}(\mathrm{c}, \mathrm{e}, \mathrm{f}, \mathrm{m})$. 


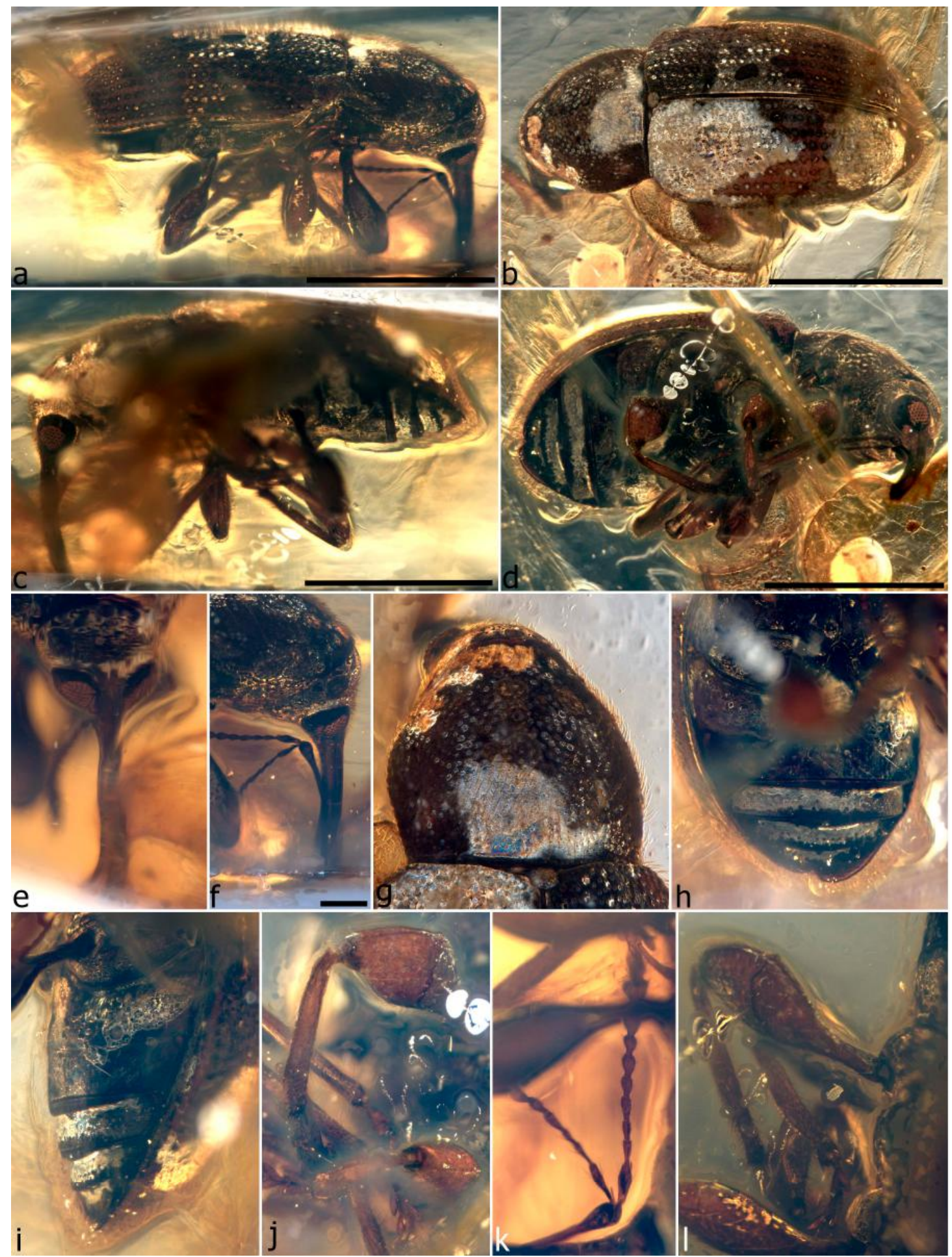

Figure 92. Aphelonyssus latus sp. n., holotype. Habitus, right lateral (a); habitus, dorsal (b); habitus, left lateral (c); habitus, ventral oblique (d); head and eyes, dorsal (e); prothorax and head, right lateral (f); pronotum, dorsal (g); ventrites (h); ventrites, left lateral (i); meso- and metafemora and metatibia (j); right antenna (k); right metafemur and tibia (1). Scale bars: $0.5 \mathrm{~mm}(\mathrm{a}-\mathrm{d}) ; 0.2 \mathrm{~mm}(\mathrm{f})$.

Remarks. Due to its serrulate femora and tibiae, this genus belongs in the Mekorhamphus-Mesophyletis-Habropezus-Bowangius group, but its non-dentate head and prothorax and round, anteriorly placed (forward-facing) eyes set it apart from all these genera. Its broad, smooth shape (Figure 92) is also atypical of Mesophyletidae, although shared by Elwoodius, which has very 
different (conical) eyes and legs. Thus far it appears to be an isolated genus in the family, containing a single species.

Aphelonyssus latus Clarke \& Oberprieler, sp. n. (Figure 92)

Description. Size. Length $2.35 \mathrm{~mm}$, width $1.2 \mathrm{~mm}$. Eyes large, circular in outline, flat, only slightly protruding, facing forwards, forehead impressed. Rostrum slightly curved; antennal insertions in middle of rostral length. Antennae long; scapes apically abruptly clavate; funicles with segment 1 as long as $2+3$, thinly spindle-shaped, 2-3 thinner, 4-7 progressively thickening; clubs short, about 2 $\times$ thicker than funicle segment 7 , segments laterally rounded, segment 4 short, not well distinct from 3, flattened, apically broadly rounded. Thorax. Pronotum slightly broader than long, slightly convex, base straight; surface shallowly coarsely punctate, setae fine, short, stiff, suberect; procoxal cavities placed about their length from anterior margin. Elytra broad; surface with strial punctures large, shallow, setae short, fine, acute, brown. Legs. Profemora subcylindrical, outer edge rounded, mesoand metafemora compressed, outer edge serrulate in distal third (visible in caudal view). Tibiae slightly flattened, broadening distad, metatibiae apically bent inwards, apex truncate, spurs thin but quite long (only discernible on metatibiae). Tarsi with tarsite 1 apically excised, corners rounded, 2 shorter, apically deeply excised with corners rounded, appearing almost bilobed, 3 with lobes subpedunculate. Abdomen as for genus.

Material examined. Holotype (NIGP169517): very well preserved, intact specimen, not compressed or distorted, with tip of rostrum cut off, left elytron and part of pronotum with patches of silvery film, well visible from all sides except middle of left side; slightly angled in centre of rectangular cuboid $4.4 \times 3.8 \times 1.6 \mathrm{~mm}$; amber very clear without impurities but with four large interconnected clear bubbles with brown walls on left anterior side of specimen, extending into a diagonal brown flow line on underside across left front leg and similar subparallel one further back (not obscuring specimen).

Derivation of name. The species is named for its broad shape, especially of the elytra, the name being the Latin adjective latus.

Remarks. This species has a characteristic look due to its broad, flattish, smooth shape and small, flat, forward-facing eyes, appearing more curculionid- than mesophyletid-like. However, its loosely articulated antennal clubs, serrulate meso- and metafemora and -tibiae and indicated long single gular suture show that it belongs in the latter family. Unfortunately the rostrum of the holotype is cut away at the apex and the mandibles are not preserved.

\section{Incertae sedis}

Tribe Palaeocryptorhynchini Poinar \& Legalov, 2015

Paleocryptorhynchini [sic] Poinar \& Legalov, 2015: 562 [53] (type genus, by original designation: Palaeocryptorhynchus Poinar, 2009 (misspelled as Paleocryptorhynchus))

Remarks. The original spelling of the name, Paleocryptorhynchini, is incorrect as the original spelling of its type genus is Palaeocryptorhynchus, not Paleocryptorhynchus as cited when the tribe was described [53]. This mistake has been perpetuated in later literature. Given the uncertainty regarding the relationships and the family-group assignment of the single genus and species placed in this tribe (see below), it is a rather redundant taxon.

Genus Palaeocryptorhynchus Poinar, 2009

Palaeocryptorhynus Poinar, 2009: 587 [60] (multiple original spelling; rejected by Legalov, 2010) [61] Palaeocryptorhynchus Poinar, 2009: 588 [60] (multiple original spelling; accepted by Legalov, 2010 [61], though misspelled as Paleocryptorhynchus) (type species, by original designation: Palaeocryptorhynchus burmanus Poinar, 2009)

Redescription. Size. Length $6.7 \mathrm{~mm}$, width ca. $2.1 \mathrm{~mm}$. Head short, subspherical, dorsally strongly domed, distinctly sculptured and squamose. Eyes ventrally positioned, subflat, dorsally (near base of rostrum) separated by about half basal width of rostrum; forehead convex between 
eyes. Rostrum slightly longer than pronotum, slender, weakly curved, broad basally, covered with suberect scales directed posteriad, in repose retracted in prosternal channel and mesothoracic receptacle. Antennae, antennal insertions and mouthparts not visible. Thorax. Prothorax tightly fitting onto elytra and pterothorax; proclinate, anterior lateral margins drawn out into strong narrowly rounded ocular lobes partly covering eyes when rostrum in repose; sides weakly convex, abruptly constricted in anterior third, more strongly rounded just before base. Pronotum slightly narrower than elytra, widest basally; distinctly collared in anterior third, extending over head; densely squamose, scales directed mesad and anteromesad, appressed to integument, differently coloured; basal margin strongly bisinuate, medially broadly subangularly rounded, fitting into broad emargination in base of elytra, concavely curved laterad to sides, posterior corners rounded, not acute; notosternal sutures obsolete or obscured by rounded, flattened scales. Prosternum forming deep channel for reception of rostrum, with carinate edges terminating posteriorly as small denticles between procoxae, these marking posterolateral corners of a concave plate partly extending between procoxae. Scutellar shield slightly raised above elytral surface. Mesoventrite with curved receptacle for apex of rostrum in repose, situated between procoxae and partly between mesocoxae. Elytra elongate, basally lobed over base of pronotum, with broadly rounded humeri, posteriorly declivous, lateral margin substraight to weakly emarginate in middle, apically strongly pointed, subconjointly rounded, not exposing pygidium; surface distinctly punctostriate, without scutellary striole, strial punctures large, seemingly without setae, squamose; interstriae 7-9 confluent at humerus. Legs long, slender. Pro- and mesocoxae conical, strongly protruding, broadly separated. Trochanters short, oblique. Femora long, subcylindrical, outside rounded, armed, inside with large flattened triangular tooth near middle, inside excavate in distal half, receiving tibiae in repose, walls of groove at apex flatly and roundly extended. Tibiae sinuate, subcompressed, outer edge rounded, apically extended into long curved uncus-like tooth; apex obliquely truncate, without spurs. Tarsi very long, almost as long as tibiae; tarsite 1 subcylindrical, apically rounded, ventrally densely setose, 2 shorter, subtriangular, apically subtruncate, 3 strongly lobate, 4 (cryptotarsite) distinct; claws divergent, simple, without distinct basal angle or tooth. Abdomen not visible.

Remarks. The name of the genus was spelled in two ways in the original paper, as "Palaeocryptorhynus gen. nov." in the genus heading on page 587 and as Palaeocryptorhynchus in the title, in the discussion (page 588) and in combination with the species name [60]. Legalov [61] selected the latter spelling as the valid one, though inadvertently and also misspelling it as Paleocryptorhynchus (as he did in later papers).

The taxonomic position of this genus remains enigmatic and uncertain. Its assignment to the family Curculionidae [60] appears cogent based on characters such as the deflexed rostrum retracting into a channel between the proxocae, the vestiture of scales and the long tibial unci. However, a prosternal rostral channel also occurs in the mesophyletid genera Burmorhinus and Rhadinomycter (albeit not posteriorly closed by a receptacle), and as the antennae of Palaeocryptorhynchus are hidden, it is unknown whether their clubs are also compact like those of Curculionidae. Furthermore, its subfamilial and tribal placement in Curculionidae is problematic. It was originally assigned to the erstwhile subfamily Cryptorhynchinae (sensu lato), based on its deep narrow rostral channel, sharply demarcated mesosternal receptacle and long tibial unci [60], but it was subsequently placed in the subfamily Erirhininae based on its allegedly subapically inserted antennae and relatively prominent eyes [53] (given that a mesosternal receptacle also occurs in the erirhinine genus Aonychus Schoenherr). This placement is, however, unconvincing for several reasons. Firstly, our examination of the type specimen of $P$. burmanus did not reveal any evidence of the position of the antennal insertions; the structure indicated as such by Legalov and Poinar (Figure 11 in [53]) is the left posterior angle of the prosternal channel (also visible in ventral view in Figure 6 in [60]), and all extant erirhinine genera with a rostral channel (Afghanocryptus Voss, Aonychus, Arthrostenus, Desmidophorus Dejean, Ocladius Schoenherr, Tadius Pascoe) have medially inserted antennae (which is also the common position in Cryptorhynchini). Secondly, the only such erirhinine genus with prominent eyes is Arthrostenus, 
but this has a very weak rostral channel without any posterior receptacle. Thirdly, the tibiae of $P$. burmanus have a fairly long, curved uncus (directed more or less along the tibial axis), whereas the tibiae of all these erirhinine genera have a mucro (inserted at the inner angle of the tibial apex and directed perpendicular to the tibial axis). There is therefore no character in evidence to support the placement of Palaeocryptorhynchus in Erirhininae. Its mesosternal receptacle, the long unci and also its general habitus (the tightly retractable rostrum and legs) are in much greater agreement with Cryptorhynchini, as originally concluded by its author [60]. An assignment to this tribe is, however, also problematic, because this is indicated to be much too young (50-60 Ma), and even the larger CCCMS clade, in which the tribe belongs, is estimated to be only ca. 75 million years old [6]. Additionally, the erirhinine taxa as compared above are seemingly too young to be in contention as possible relatives of Palaeocryptorhynchus. This, together with the fact that no further such specimen has been reported from Burmese amber, places doubt on its origin and age. The amber piece is said to have been obtained from the Noije Bum mine in the Hukawng Valley in Myanmar [60], and in our exposure to UV light it fluoresced in the same way as the other Burmese amber weevil specimens we studied in PACO, suggesting that it is of the same origin and age as these. If this is true, the specimen may not, after all, be a representative of the family Curculionidae. Its identity can probably only be clarified if more specimens are found and reveal critical structures such as the antennae and mouthparts. For the time being, this taxon should be treated as incertae sedis and not be used to infer ages and other evolutionary scenarios in Curculionoidea.

\section{Palaeocryptorhynchus burmanus Poinar, 2009}

Palaeocryptorhynchus burmanus Poinar, 2009: 588 [60]

Redescription. Size. Length $6.7 \mathrm{~mm}$, width ca. $2.1 \mathrm{~mm}$. Head strongly directed posteroventrad, bulging slightly over eyes, with thin shiny groove separating eyes from head. Eyes weakly flatly protruding, separated by about half basal width of rostrum. Rostrum narrowing to about middle, then expanding to apex; antennal insertions not visible. Antennae not visible. Thorax. Pronotum as long as wide, covered in flat scales, mixed circular and ovoid in shape, paler near midline, distinctly darker either side of midline forming oblique separated broad bands in posterior two-thirds; with low indistinct median ridge extending from base to about posterior two-thirds, slightly narrowly beaded at base and contacting scutellar shield; prothoracic ocular lobes not densely setose. Scutellar shield oblong, (probably) setose. Elytra with 10 strongly carinate interstriae; interstria 3 strongly protuberant in basal fifth, forming elongate prominence raised higher than level of other interstriae. Legs. Profemora seemingly with long flange in basal third of inner edge fitting into groove on outer face of mesofemora (possibly an artefact of leg distortion); tibiae slightly shorter than femora. Tarsi with tarsite 1 more than twice longer than 2, not apicolaterally lobed, 2 subtriangular, narrow basally, apically expanded, subtruncate, 3 with lobes short, semicircularly expanded (not pedunculate), 5 elongate, more than twice longer than tarsite 3 lobes, slender at base, somewhat expanding apically, sparsely setose. Abdomen not visible.

Material examined. Holotype (PACO, with curatorial \#B-C-42): exceptionally well-preserved, seemingly intact specimen, not compressed or distorted except for collapsed ventrites (not visible), well visible from all except right side, with mite attached to left side of first ventrite; in irregular block with two flat sides, one flat edge, and two rounded sides, orientated with sides parallel to flat faces; amber clear dark brown, with flow band adjacent to and largely obscuring right side of specimen, with another insect inclusion near pronotum and few bubbles emanating from abdomen.

Remarks. Our redescription of this species (and genus) is based largely on the original description [60], updated where applicable to include other characters (or terminology) consistently evaluated and used in our study. The antennal insertions, if subapical as suggested [53], would seem more likely to be positioned further distally on the rostrum than indicated in the figure, more in the vicinity of the maximal width of the spatulate apical part. Some other details mentioned in previous descriptions are also at odds with our examination of the specimen and need further clarification, such as the supposed two groups of setae and the uncus/mucro on the tibiae, the structure of the ventrites 
and the presence (or absence) of deciduous mandibular cusps. We could not see any of these features, although it is possible that examination of the specimen immersed in a liquid could render some of them visible. The original description mentions black and whitish scales in P. burmanus; we add here that these scales are also iridescent greenish. The peculiar flange of the profemora, seemingly locking onto the mesofemora when the legs are retracted, is also a most unusual character, seemingly not reported for any extant weevil. From our examination of the specimen it is not clear whether this is a real feature or a distortion artefact. Unfortunately the right side of the specimen is not visible to further assess this. The study of this enigmatic specimen would benefit from trimming down the amber block as much as possible, so as to allow a clearer view of all its features, and CT scanning may also be able to reveal further taxonomically critical characters (e.g., the antennae or the presence of sclerolepidia).

\section{Genus and species incertae sedis}

Diagnosis. Head. Rostrum longer than pronotum. Antennae. Scapes elongate, slender, apically swollen, not reaching anterior margin of eye. Mouthparts. Mandibles small, exodont (single tooth visible). Thorax. Pronotal vestiture comprising dense, mixed brown and whitish setae, forming loose clumps (but not seemingly part of a pattern). Elytra punctostriate; marginal groove present; vestiture as on pronotum; apically steeply declivous. Legs very slender; protibiae not serrulate along distal edge; tarsi narrow, tarsite 1 of meso- and metatarsi seemingly shorter than 2 (left hindleg), tarsite 3 lobes elongate, subpedunculate; claws divaricate, basally angulate with ventrobasal seta. Abdomen. Ventrites slightly stepped, 1-3 progressively shorter, 3 and 4 subequal, 5 subequal to 4 .

Material Examined. See Material Examined section under Habropezus plaisiommus above.

Remarks. The type series of Habropezus plaisiommus includes a single paratype specimen. Our examination of it revealed that it is not conspecific with the holotype and belongs in a different genus. While enough details could be discerned in the specimen to conclude this much, it is so poorly preserved (distorted, quite decomposed and missing critical structures) and insufficiently visible that it is impossible to confidently place it in one of the genera treated here. Most of the legs are either missing, not visible or missing parts, the antennae are largely missing, the head and prothorax are crumpled and the ventral side and elytra are poorly visible. Nevertheless, the combination of observable characters suggests that this specimen may represent a different, as yet unknown genus. Though unlikely, further trimming of the amber block may still reveal further details, enable a generic assignment and clarify some details seemingly unusual as we observed (e.g., narrow tarsi with tarsites 1 shorter than 2).

\section{Taxa excluded from Curculionoidea or from Burmese amber}

Subfamily Palaeotylinae Poinar, Vega \& Legalov, 2018

Palaeotylinae Poinar, Vega \& Legalov, 2018: 2 [62] (type genus: Palaeotylus Poinar, Vega \& Legalov, 2018)

Genus Palaeotylus Poinar, Vega \& Legalov, 2018

Palaeotylus Poinar, Vega \& Legalov, 2018: 2 [62] (type species, by original designation: Palaeotylus femoralis Poinar, Vega \& Legalov, 2018)

Palaeotylus femoralis Poinar, Vega \& Legalov, 2018

Palaeotylus femoralis Poinar, Vega \& Legalov, 2018: 2 [62]

Remarks. This genus and species was very recently described and assigned to a new family taxon of Platypodinae, described as a subfamily Palaeotylinae (treating the platypodines as a family distinct from Curculionidae, contrary to the common current classification). The placement of the genus in Platypodinae was based on it having femoral "mycangia", elongate tarsi, a broad head (as broad as the pronotum) and tibiae without outer denticles and spurs, although the authors noted that it differs from platypodines in several critical characters, having six-segmented funicles, loosely three-segmented clubs, coarsely facetted eyes, the tibiae with apical teeth, tarsites 1 shorter than $2-4$ combined, the mesoand metatarsi with tarsites 2 and 3 bilobed and the pronotum without mycangia [62]. In Platypodinae the funicles are usually four-segmented (rarely two-, three- or five-segmented), the clubs are lenticular 
one-segmented, the tarsites are all cylindrical, tarsites 1 are longer than 2-5 together and mycangia occur on the pronotum, never on the femora. In addition, some of the structures of Palaeotylus femoralis seem to be misinterpreted in the description: The very loose, stalked club segments appear natural in the photograph in Figure 2, not damaged and in reality compact as in the "reconstruction" presented in Figure 3, and the tarsi appear to be four-segmented (Figures 6 and 8) rather than five-segmented as drawn (Figures 7 and 9). Further, weevils (including Platypodinae) have no "cerci" on the abdomen nor a segmented, cylindrical spiculum ventrale projecting from it. On the basis of the characters presented in the description of Palaeotylus femoralis, the specimen cannot be accepted as belonging in Platypodinae (or in Curculionoidea). Careful re-examination, and probably trimming of its amber block, are required to assess its real taxonomic affinities and classification.

Representatives of Platypodinae (of "tesserocerine affinities") have been reported from Burmese amber in the literature before [63], but no such specimens have been described and this record remains unconfirmed. The photographs of one of them as we have seen (courtesy of Anthony Cognato) reveal that it is not a platypodine either but one of the curious bostrichoids that have been known from Burmese amber for some time and are currently under study. Very similar (possibly conspecific) specimens examined by us have a large free labrum, flabellate three-segmented antennal clubs, large posteriorly open procoxal cavities, flattened protruding metacoxae, large unequal tibial spurs (the larger one serrate), pentamerous tarsi with cylindrical segments on all legs (formula 5-5-5) and five free ventrites, all characters that are incompatible with Curculionoidea including Platypodinae. A similar species was recently described in Bostrichidae as Poinarius burmaensis Legalov [64].

The occurrence of Platypodinae in Burmese amber is also highly unlikely because no authentic specimens have been reported among the several thousand beetles known from this amber by now and because of the indicated age of the subfamily (ca. $75 \mathrm{Ma}$, [6]), which is too young for Burmese amber.

\section{Subfamily Scolytinae}

Two inclusions in Burmese amber have been placed in this subfamily. The first, named Cryphalites rugosissimus, was the first beetle described from this amber [28], but it was later recognised as being misidentified and tentatively assigned to the family Colydiidae [23], now classified as a subfamily of Zopheridae. A colour photograph of the specimen published [23] clearly shows that it is not a scolytine. The second scolytine described from Burmese amber is Microborus inertus, as discussed below.

Genus Microborus Blandford, 1897

Microborus Blandford, 1897: 879 [65] (type species, by monotypy: Microborus boops Blandford, 1897)

Remarks. This small genus is extant mainly in the Neotropical region, with eight species, but it has recently also been confirmed from Africa, with two species in Cameroon and one in Madagascar [66]. It is currently placed in the tribe Hexacolini but appears to occupy a more isolated position in Scolytinae [66]. It was recorded from Burmese amber with the species B. inertus Cognato \& Grimaldi, forcing the conclusion that it was once more widely distributed and has remained morphologically conserved (unchanged) for 100 million years [67]). However, recent dated estimates of weevil phylogeny have found much younger ages for the subfamily Scolytinae, between $82 \mathrm{Ma}$ [14] and an early Cenozoic age [6], making this scenario unlikely and casting doubt on the origin and age of the M. inertus specimen (see below).

\section{Microborus inertus Cognato \& Grimaldi, 2009}

Microborus inertus Cognato \& Grimaldi, 2009: 95 [67]

Material examined. Holotype (AMNH JZC-Bu228): well preserved and mostly visible, intact specimen, with ventral side partially obscured by whitish emulsion-like substance; at one corner of subquadrangular slab $7.0 \times 9.0 \times 1.0 \mathrm{~mm}$; amber clear-yellowish with several fracture planes near specimen and with minor flow bands and impurities.

Remarks. This specimen was obtained from a large amount of unprocessed amber sent to the AMNH from Myanmar by a Canadian company, the locality given as the Tanai village in Kachin State [67], so not the mine at Noije Bum from which the date of Burmese amber has been obtained [20]. 
As we were able to borrow the specimen, we checked it under UV light and found the amber not to fluoresce like typical Burmese amber does (Figure 1m), confirming that it is not from the Noije Bum mine and evidently a different (younger) amber. The specimen also has a white, partially opaque layer between its pronotum and elytra and along its venter, similar to the characteristic Verlumung of Baltic amber (Figure 3d). This milky emulsion of minute bubbles, apparently caused by decomposition of gases and moisture, is typical of Baltic amber $[68,69]$ and does not evidently occur in Burmese amber (also not present in any of the specimens studied by us, although a pale translucent film occurs on the underside of the Habropezus tenuicornis holotype, Figure 78a,e,h). The nature and provenance of the amber enclosing the Microborus inertus specimen should be investigated using infrared light or nuclear magnetic resonance; Baltic amber has a characteristic infrared spectrum [69] and Burmese amber a characteristic NMR spectrum [70]. Pyrolysis gas chromatography can also be used to confirm Burmese amber [71]. The conclusion that the Microborus inertus specimen is not embedded in Burmese amber is further supported by the fact that, among the many tens of thousands of beetles that have now been recovered from Burmese amber, no further scolytines have been found. Age estimates of Scolytinae cannot therefore be based on this specimen and its alleged age. Further, the issue of compromised dates of Burmese amber inclusions is evidently not limited to the Microborus inertus specimen, as we have also found undescribed staphylinid inclusions in amber from the same source to glow in the same dull yellowish-green colour under UV light, not to fluoresce blue like Burmese amber does.

\section{Discussion}

Before this study the knowledge of the Burmese amber weevil fauna was based on isolated descriptions of only a few specimens (and the taxa mostly misclassified), which did not allow much interpretation of the peculiarities of the fauna. From our more comprehensive study of a much larger set of specimens and taxa, it is now possible to draw some first conclusions about the salient features and adaptations of the fauna and put it into an ecological and evolutionary context. Based on the additional specimens we have seen but are not describing here, there is no doubt that many more specimens and more taxa (genera and species) of this extraordinary fauna will be discovered in due course, which should allow refinement of the preliminary extrapolations presented here.

\subsection{Diversity of Burmese Amber Weevils}

By now about 110 weevil specimens appear known from Burmese amber. This includes the 12 specimens so far described, the 64 presented in this paper, another 18 we received late from the AMNH and the FMNH and another 14 we have seen on photographs in books [25,55] and on various internet sites (some no longer available there). Undoubtedly there are more specimens in private collections that have not been documented anywhere, and with more and more Burmese amber inclusions becoming available for sale, there is little doubt that this number will increase substantially. Even at this stage, the weevil fauna in Burmese amber emerges as one of the richest Mesozoic faunas known of this beetle group, rivalling that of the Upper Jurassic Karatau site in Kazakhstan, of which about the same number of specimens has been recorded in the literature but more apparently exist. It certainly far exceeds the latter fauna in terms of the preservation of morphological details, however.

As recognised in this study, the Burmese amber weevil fauna currently comprises 70 species classified in 36 genera and two families (Nemonychidae and Mesophyletidae) (see Appendix A). Only three species are assignable to the former family, the remainder all representing an evidently extinct family that appears to be as diverse, in taxa as in forms, as several of the smaller extant ones. The large number of species and the dearth of conspecific specimens is somewhat surprising. In consideration of preservation artefacts and of sexual differences as exhibited by extant weevils, we initially regarded several inclusions as conspecific with others, but after trimming the amber blocks and carefully studying the specimens under high magnification, it became apparent that they differ in characters that are species-specific in extant weevils and thus represent different species. It generally proved easier to recognise different species among these amber weevils than different genera. 
In size the Burmese amber weevil fauna ranges between 10 and $1.6 \mathrm{~mm}$ in body length (excluding the rostrum) as measured. A specimen pictured by Xia et al. [55], p. 115, is given as being $18 \mathrm{~mm}$ long, but this probably includes the rostrum, the body then being about $12 \mathrm{~mm}$ long, comparable with the largest ones we have examined. Most of the species range between 2 and $5 \mathrm{~mm}$ in size, but a few are larger (Calyptocis $5.6 \mathrm{~mm}$, Burmocorynus 6.15-6.7, Aepyceratus $6.9 \mathrm{~mm}$, Petalotarsus $4.1-7.25 \mathrm{~mm}$, Cetionyx 8.2-10 mm) and a few are smaller (Bowangius 2.8-1.9 mm, Gnomus 2.8-2.1 mm, Guillermorhinus $1.8 \mathrm{~mm}$, Anchineus $1.6 \mathrm{~mm}$ ).

In shape the Burmese amber weevils are relatively uniform. Most species have a high, loose body form with long legs and long to very long tarsi, but the smaller ones (Anchineus, Bowangius and Habropezus) have somewhat lower, narrower bodies. The only significant deviations from this body plan occur in Petalotarsus, and to some degree in Burmocorynus, whose species have flatter, more robust bodies with shorter and stouter legs, especially shorter and separated procoxae, and in Palaeocryptorhynchus, which has the withdrawn ('cryptic') body and appendages of certain extant Curculionidae. Nearly all species have a porrect head and a long, slender rostrum, which often reaches two-thirds of the body length (up to $0.82 \%$ in Mekorhamphus beatae), translating into $1.7-2.7 \mathrm{~mm}$ in length in Mekorhamphus and 5.3-7.2 mm in Cetionyx. The antennae of species with such long rostrums are invariably geniculate, often very long and slender as well. Shorter rostrums (about as long as the pronotum) occur in relatively few species, nearly always in conjunction with non-geniculate antennae. Except for Palaeocryptorhynchus, the vestiture of all species consists only of setae, never of scales. The eyes are mostly large to very large, strongly protruding and coarsely facetted.

\subsection{Specialised Features}

The most noticeable feature of the Burmese amber weevil fauna is the preponderance of geniculate antennae. Of the 70 species recognised here, only 12 have antennae that are not distinctly geniculate (although then subgeniculate, with an elongate scape, in all but the three species of Nemonychidae). This makes the Mesophyletidae the third group of weevils with geniculate antennae, the others being the extant Curculionidae and Nanophyinae (Brentidae). As shown in the chapter on morphology above, the geniculate antenna of Mesophyletidae is of the 'open' type as it is in Nanophyinae, not of the 'closed' one as occurs in Curculionidae. The geniculate antenna is concomitant with the long rostrum in these weevils, the scape folding back into a long narrow scrobe along the sides of the rostrum, behind the antennal insertions. This modification of the antenna enables especially females to insert their entire rostrum into plant tissues, past the antennal insertions, and reach deep-lying plant organs for oviposition [2]. The larger mesophyletids such as Cetionyx would thus have been able to drill oviposition holes to about $7 \mathrm{~mm}$ in depth. The mesophyletid ovipositors that are exposed (in Bowangius sp. 2 and sp. 4, Debbia gracilirostris) are correspondingly thin and elongate, evidently likewise adapted to be inserted into long and narrow holes for laying eggs. This adaptation indicates that these mesophyletids were highly specialised herbivores, likely ovule or seed predators, on a par with extant curculionid tribes such as Anthonomini, Curculionini and others.

Another striking feature of Mesophyletidae are the mostly strongly exodont, flat mandibles. These resemble those of Rhynchitinae but differ foremost in having two large inner (dorsal) teeth in addition to the outer ones and the apex narrowly T- or Y-shaped (see chapter on morphology). They also have a very different, oblique articulation plane and appear to have opened from a more or less horizontal position into a vertical one, then projecting forwards from the rostrum (not sideways as in Rhynchitinae). This motion would have given them a sawing or rasping rather than a biting action and enabled them to cut a $\wedge$ - or $\cap$-shaped hole into plant tissues, of the same width as the rostrum diameter. By analogy with the oblique mandibles of Ergania (Figure 4j,n) and Pimelata Pascoe (Curculionini), the Allocorynini (Belidae) and the seed-feeding species of Antliarhinus (Brentidae) and the vertical mandibles of other Curculionini, it appears that such mandibles are more effective and efficient in drilling deep holes with long thin rostrums, especially into harder or tougher plant tissues (such as nuts in several Curculionini and cycad sporophylls and seeds in Allocorynini and Antliarhinus), as the 
hole does not have to be larger than the diameter of the rostrum. Together with the long rostrum, these unique exodont mandibles suggest that many Mesophyletidae were similarly adapted to pierce inner plant organs, such as ovules and seeds, and that they were in fact more specialised piercers than extant Rhynchitinae, which mostly pierce or cut terminal shoots and flower or fruit buds [52].

The third outstanding characteristic of the Burmese amber weevils are the long legs and especially the long tarsi with their sharp claws. In the Mesophyletidae the tibiae are often flattened and externally strengthened by a crenulate or serrulate carina, the spurs are generally large and sometimes fused to the apex of the tibia, the tarsi are large, flat and very flexible (tarsites 1 and 2 apically deeply excised to bilobed) and the claws are widely divaricate and mostly strongly and sharply dentate. These features suggest that the weevils were well adapted to an arboreal life, able to tightly grip onto smooth plant surfaces such as leaves or climb among flimsy plant parts during feeding and oviposition. Their loose body form, with the elytra not tightly locked together at the apex (individually rounded, the sutural flanges narrow and equal) and to the pygidium (which is sometimes exposed), indicates that they were able fliers and probably quick to take to flight. Somewhat in contrast to this is the more robust and stockier shape of Petalotarsus. Its more compact, flatter body, with a shorter thicker rostrum, shorter, separated procoxae, shorter legs and broader tarsi, suggests a more sedentary lifestyle and, at least in P. oxycorynoides, an ability to squeeze into tight spaces, such as between leaf sheaths or under bark. Other body shapes, such as the short compact one of Gnomus, indicate yet different lifestyles.

Also outstanding among the characters of the Mesophyletidae are the large, protruding and coarsely facetted eyes. In comparison, similar-sized extant Rhynchitinae have much less protruding and more finely facetted eyes, as have various curculionid tribes of similar size and body shape (e.g., Acalyptini, Ceutorhynchni, Curculionini, Eugnomini, Storeini). Whereas the large size and subglobular to conical shape of the mesophyletid eyes indicate that they were able to see well, the large facets suggest that the eyes may have been adapted to conditions of low light, such as in dense canopy or lower vegetation strata in thick forests. Similarly coarse eyes occur among extant weevils in many Nemonychidae, in some Caridae (Carodes and an undescribed genus) and in particular in the curculionine tribes Ochyromerini and Rhamphini, all of which are arboreal groups. Similar but much smaller eyes occur in several weevil taxa inhabiting leaf litter, especially Phrynixini, which also appear to be adapted to see in relative darkness. As Nemonychidae, Caridae, Ochyromerini and Rhamphini are generally active during the day, as far as known, the large and coarsely facetted eyes of Mesophyletidae do not necessarily suggest a nocturnal life style, although this cannot be excluded.

\subsection{Host Associations}

The resin that formed the Burmese amber has been attributed to araucarioid trees similar to the extant genus Agathis [70], but no specific araucariaceous taxon has yet been described from Burmese amber. Conifers identified in the amber thus far are two fragments of leafy shoots assigned to the extant monotypic genus Metasequioa (Cupressaceae) [24], some wood fragments with araucarioid pitting [70], and some araucarioid or podocarpoid leaves and a cone [25]. Other plant groups identified in Burmese amber include marchantiophytes (liverworts), bryophytes (mosses), pteridophytes (ferns) and twelve species of angiosperms, most of them flowers that cannot or only tentatively be placed in extant families; for a list see [26]. It is the last group that is of particular interest for the weevils preserved in Burmese amber.

The three nemonychid species thus far found in Burmese amber, Burmonyx zigrasi, Burmomacer kirejtshuki and Guillermorhinus longitarsis, all assignable to the now predominantly southern-hemisphere subfamily Rhinorhynchinae, are likely to have lived in association with conifers and particularly with Araucariaceae, as the extant Rhinorhynchinae in Australia and South America do [42,45]. No extant nemonychid is known to live on Cupressaceae [44]. The larvae of Burmonyx, Burmomacer and Guillermorhinus can be assumed to have also developed in the microstrobili of their hosts, feeding on pollen, as most extant Nemonychidae do (except the small angiosperm-associated tribe Rhynchitomacrini and genus Nemonyx). In view of the large amount of Burmese amber that has been 
mined and the tens of thousands of beetles that have been found in it, it is surprising that only three nemonychids have been discovered in this amber so far.

The other Burmese amber weevils, the Mesophyletidae, were most probably associated with the early angiosperms that appear to have been quite diverse in Burmese amber. Among the twelve angiosperm species described, the two grasses, Programinis burmitis and P. laminatus [72], are unlikely to have served as mesophyletid hosts, as grass-adapted taxa among modern Curculionidae are usually elongate and conspicuously striped or spotted and not shaped like mesophyletids, although some mesophyletids may have inhabited the inflorescences of Programinis (which were, however, very small [72]). Also by analogy with modern curculionids, the staminate flowers of Palaeoanthella huangii and Cascolaurus burmitis were probably less attractive to mesophyletids due to the more ephemeral and less nutritious nature of such flowers. The pistillate and bisexual flowers, however, containing nutritious ovules, would have been much more suitable to sustain developing mesophyletid larvae, and the long thin rostrums with exodont mandibles of most adult weevils appear eminently suited to piercing the calyx and ovules of these flowers. The pistillate flowers of Lachnociona terriae and the bisexual ones of Antiquifloris latifibris, Tropidogyne pikei and T. pentaptera were about $5 \mathrm{~mm}$ long and wide and their ovules thus in easy reach of the rostrums of the larger mesophyletids such as Mekorhamphus, whose rostrums measure 1.7-2.7 mm in length, whereas the smaller $(0.8-2.1 \mathrm{~mm}$ diameter) bisexual flowers and calyces of Eoëpigynia burmensis, Jamesrosea burmensis, Micropetasos burmensis and Endobeuthos paleosum could have served as brood sites for the larvae of the smaller mesophyletids such as Anchineus and Bowangius (ca. $2 \mathrm{~mm}$ body length). Especially the deep calyces and hypanthia of the Eoëpigynia, Lachnociona and Tropidogyne flowers appear like ideal brood sites for weevils, and it is very unlikely that they would not have been utilised as such by mesophyletids. If the largest known mesophyletids (Burmocorynus and Cetionyx) also developed in flowers or fruits, as seems likely given their long rostrums, even larger flowers can be expected to have occurred among the angiosperms of the Burmese amber flora.

The angiosperms described from Burmese amber all appear to represent basal family group taxa, a few tentatively assignable to extant families but several not. Four have been interpreted as magnoliids, Antiquifloris latifibris as an extinct lineage [73] and the other three as Laurales, Jamesrosea burmensis as the sister taxon of Atherospermataceae and Gomortegaceae [74], Palaeoanthella huangii with possible affinities to Monimiaceae [75] and Cascolaurus burmitis as a basal lineage of Lauraceae resembling the extant genus Litsea [76]. The other taxa have been assigned to the core eudicot clade [77], Micropetasos burmensis with no affinity to any modern family [78] but Lachnociona terriae near the rosid families Brunelliaceae and Cunoniaceae [79], Tropidogyne pikei and T. pentaptera as related to Cunoniaceae, with similarity to the genus Ceratopetalum [80,81], Eoëpigynia burmensis in the asteroid family Cornaceae sensu lato, with similarities to the genus Cornus [82], and Endobeuthos paleosum with similarities to Dilleniaceae [83]. Programinis has been identified as a grass-like monocot of an early bambusoid type, originally only assigned to the order Poales [72] but subsequently to Poaceae [84].

\subsection{Evolutionary Significance}

The dominant component of the Burmese amber weevil fauna is represented by a diverse but distinct family-group taxon, whose characters do not accord with those of any of the eight extant families (after [6]) and which thus needs to be treated as a separate, ninth family of weevils, the Mesophyletidae. In its characters it displays strong affinities to the 'middle group' of weevil families (Belidae, Attelabidae, Caridae), being quite different from the more basal families Cimberididae, Nemonychidae and Anthribidae and also from the more derived Brentidae and Curculionidae. It appears related to Attelabidae, sharing the characteristic long single gular suture of this family, but it differs in many other characters (absence of scutellary strioles, typically geniculate antennae, flat exodont oblique mandibles, dentate tarsal claws and covered pygidium) and cannot be accommodated in Attelabidae without a significant widening of the concept of the latter. The antennae, mandibles 
and tarsal claws also differentiate the Mesophyletidae from the small southern family Caridae, which furthermore has ventrally inserted antennae and a short gular suture.

The long thin rostrum, the exodont oblique mandibles, the large eyes and the broad dentate tarsal claws indicate that most mesophyletids were specialised phytophages, evidently adapted to an arboreal life as flower or seed predators of the early angiosperms that began to diversify in the conifer forests of the middle Cretaceous. As many of the flowers thus far discovered in Burmese amber are assigned to the basal magnoliid clade and as extant magnoliids are largely pollinated by weevils [85], it seems likely that mesophyletid weevils may have also played a role in the pollination of the early, Cretaceous representatives of this plant group. The weevil pollinators of extant magnoliids belong to the curculionid tribes Ochyromerini and Storeini sensu lato, the former pollinating members of the Annonaceae and seemingly Magnoliaceae and Schizandraceae and the latter pollinating species of Eupomatiaceae, Myristicaceae and Winteraceae [85]. Possibly nursery pollination mutualisms as exist between extant Storeini and their hosts species of Eupomatia and Myristica may also have already developed between mesophyletids and their hosts in the middle Cretaceous.

Poinar recently presented evidence that the flora preserved in Burmese amber has strong connections to Gondwana [86], both regarding the araucariaceous trees that may have produced the resin that formed the amber and several of the angiosperms whose flowers are preserved in it (affiliated with Gondwanan families such as Cunoniaceae, Monimiaceae and Dilleniaceae). Also some insects appear to show such connections to the extant Gondwanan fauna. The underlying reason for this connection given is the geological origin of the West Burma Block, which was originally attached to eastern Gondwana (north-western Australia) and rafted to its current location in South-East Asia later, possibly during the Upper Jurassic, although the angiosperm fossils with proposed Gondwanan affinities in Burmese amber suggest that it could not have occurred before the Lower Cretaceous [86]. However, recent interpretations of tectonic evidence indicate that the West Burma block was already attached to Asia by the Upper Triassic [87-89]. The weevils in Burmese amber provide no specific support for a Gondwanan origin of the biota preserved in this amber. The three species of Nemonychidae are readily assignable to the subfamily Rhinorhynchinae, which presently occurs in Australia and the Southern Pacific region (New Caledonia and New Zealand) as well as in South America [45]. Fossils assignable to this subfamily have been recorded from the Upper-Jurassic Talbragar Fish Bed in Australia [90], indicating that it has been present in Eastern Gondwana for at least $150 \mathrm{Ma}$. It is mainly associated with Araucariaceae, on whose pollen the larvae feed. This plant family is today largely restricted to the Southern Hemisphere but had an almost worldwide distribution in the Mesozoic [91-93], and Rhinorhynchinae can therefore also be expected to have occurred quite widely in the Northern Hemisphere in the past, including in South-East Asia, without any specific Gondwanan affinity. Furthermore, results from pyrolysis gas-chromatography and mass spectrometry suggest that Burmese amber may be derived from conifers of the northern family Pinaceae rather than Araucariaceae [94], which would make a Gondwana connection for Rhinorhynchinae even less likely and also account for their scarcity in this amber. The biogeographical affinities of the family Mesophyletidae are more difficult to assess, as no extant representatives remain. Its closest affinities are with the extant families Attelabidae and Caridae. Attelabidae are represented in Australia with only three genera [58], in New Caledonia with only one species [95], in New Zealand with none and in South America with only the genus Minurus Waterhouse outside of the tropical areas, and the family is therefore evidently not of Gondwanan origin. By contrast, the small family Caridae is restricted to Australia, New Guinea and southern South America and seemingly of Gondwanan origin as, despite various claims in the literature, no authentic fossils of it are known from the Northern Hemisphere [16]. The relationships of Mesophyletidae to these two families are in need of further study, but if inclusions in other Cretaceous ambers (in Europe and North America) can be assigned to Mesophyletidae, this family may have a Laurasian or Pangaean rather than Gondwanan origin.

Given the taxic and morphological diversity of Mesophyletidae as currently evident, this family appears to represent the first (earliest) diversification of weevils on angiosperms. Its extent 
over time and space is still unclear, but it may be represented in other Cretaceous ambers and sedimentary Lagerstätten as well and have prevailed for some time during the Upper Cretaceous. When it disappeared is also unknown, but it seems to have become extinct by the Cenozoic era, its ecological niche on later angiosperms filled by later diversifications of 'flower weevils' of Brentidae and Curculionidae and of rhynchitine Attelabidae. Along with the numerous other curious beetles and other insects preserved in Burmese amber, the mesophyletids evidently represent the unique weevil fauna of an extinct ecosystem. Judging by the frequency with which new specimens are discovered in Burmese amber, its known diversity stands to increase and its relationships and evolutionary history will become increasingly better understood over time.

\section{Conclusions}

Our study has revealed the existence of a remarkable diversity of weevils in the middle Cretaceous, both in numbers of genera and species and in specialised morphological structures that rival, and in some instances exceed, those present in extant weevils. These specialisations indicate that the weevils were as highly adapted to their hosts (evidently early angiosperms, as preserved in Burmese amber) as modern weevils are to theirs and that they likely occupied similar niches as flower or seed predators, perhaps as wood-borers and with other lifestyles as well. Noticeably absent from Burmese amber are short-snouted leaf-feeders and trunk-borers, as represented by the subfamilies Entiminae and Scolytinae among extant weevils, suggesting that these niches were either not present in this mid-Cretaceous ecosystem or not exploitable by mesophyletids. Their diversity nonetheless shows that weevils had evolved manifold shapes and sizes and morphological adaptations 100 million years ago, when the angiosperm-dominated ecosystems of today started to emerge [96]. With this diversity the Burmese amber weevils fill a large and important lacuna in the fossil history of weevils, given the severe paucity of weevil fossils known from the Cretaceous period.

Our study also highlights the difficulties encountered in the study of weevil fossils, in which critical structures and characters are often not preserved or are distorted or obscured by other inclusions or amber impurities. Three approaches have to be taken to mitigate or surmount this problem: specimen preparation, examination of larger numbers of specimens and careful comparison with extant weevils and their characters. Study of specimens in large and unsuitably shaped amber pieces is generally a futile exercise, as critical characters (even well-preserved ones) can usually not be observed accurately and are easily misinterpreted. For scientific study it is imperative to cut the amber block as close to the specimen as possible and into a cuboid or similar shape that allows undistorted views of the characters, and the size, shape and characteristics of the block should also be provided in descriptions so as to aid interpretation of the specimen and of structures that are obscured or distorted by the amber. The description of taxa based on single specimens is an equally precarious undertaking, as no fossil has all structures preserved adequately, and interpretations of apparent characters are not infrequently proved wrong by their comparison in other specimens. As an example, the failure to discern a gular suture in a specimen does not necessarily mean that it is absent, as another similar specimen may show it up very clearly. Accurate interpretation of characters of fossils requires careful comparison of equivalent features in extant weevils and a general familiarity with extant weevils and their salient characters. As we have shown, characters such as geniculate antennae, exodont mandibles, crenulate tibiae and 'toothed' claws are not identical (homologous) in extant weevils, and classifications of fossils based on crude similarities in such features are usually mistaken.

As a result of these shortcomings, the identification and classification of Burmese amber weevils in the literature is nearly always incorrect or at least severely compromised. The eleven species so far described (not counting Microborus inertus) have been classified in four families, Nemonychidae, Belidae, Caridae (as 'Ithyceridae') and Curculionidae. Only two of these assignments, of Burmonyx and Burmomacer to Nemonychidae, proved to be correct. Although some misclassification of fossils is to be expected given their imperfect preservation, the lack of proper peer review evidently also plays a role in this. Many papers describing Burmese amber weevils have clearly not been scrutinised by 
competent reviewers, and we are also aware of cases of reviewer critiques having been disregarded by journal editors. As a consequence, the descriptions and classifications of Burmese amber weevils (as of other weevil fossils) are largely unreliable and should not be accepted at face value in the construction of phylogenetic and evolutionary scenarios unless or until they have been vetted by suitable peers. This is all the more important for fossils to be used in calibrating phylogenetic estimates and inferring lineage ages; these have to be rigorously assessed for both their identity and their age, using specific criteria such as those set out by Parham et al. [97]. If either their provenance or their identity is not unequivocally demonstrated in the description and has not been vetted by peer review, they should not be used to calibrate phylogenetic trees and infer lineage ages, much less to construct evolutionary scenarios.

Supplementary Materials: The following are available online at https://zenodo.org/record/2526793\# .XCNDQ8QRWU1. Video S1: Video clip showing a 3D micro-CT scanning reconstruction of the holotype of Calyptocis brevirostris; Video S2: Video clip showing a 3D micro-CT scanning reconstruction of the holotype of Cetionyx batiatus; Video S3: Video clip showing a 3D micro-CT scanning reconstruction of the holotype of Petalotarsus oxycorynoides; Video S4: Video clip showing a 3D micro-CT scanning reconstruction of the holotype of Opeatorhynchus comans; Video S5: Video clip showing a 3D micro-CT scanning reconstruction of the holotype of Debbia gracilirostris; Video S6: Video clip showing a 3D micro-CT scanning reconstruction of the holotype of Myanmarus caviventris; Video S7: Video clip showing a 3D micro-CT scanning reconstruction of the holotype of Periosocerus crenulatus.

Author Contributions: D.J.C. and R.G.O. conceived and carried out the study and wrote the paper (Conceptualization; Writing-original draft); A.L. composed the CT images (Methodology) and D.D.M. contributed to writing the paper and acquired financial support for the project leading to this publication (Writing-original draft; funding acquisition).

Funding: D.J.C.'s research was supported by the US National Science Foundation grant \#DEB1355169 (to Duane McKenna), and the Strategic Priority Research Program (B) of the Chinese Academy of Sciences (grant XDB26000000 to Bo Wang) supported the acquisition of specimens.

Acknowledgments: We are greatly indebted to Bo Wang (NIGP) for kindly making the vast majority of the specimens available for this study for a considerable period of time. We sincerely thank Steve Davis (AMNH), Carsten Gröhn (GPIH) and Marek Wanat (University of Wroclav), Dong Ren (CNUB) Shuhei Yamamoto (FMNH), and Yu-Lingzi Zhou (ANIC) for contributing other specimens, Andrei Legalov (ISEA) for loaning type specimens in his care, David Grimaldi for loaning the types of Burmonyx zigrasi and Microborus inertus and George Poinar Jr. for allowing access to type specimens of described species maintained at Oregon State University. We are grateful to Debbie Jennings (ANIC) for the majority of the photography used in our study, to Chenyang Cai (NIGP) for photographs of Nugatorhinus chenyangi and for assisting in the description of this species, to Steve Davis and Chris Marshall for hosting D.J.C. during visits to AMNH and Oregon State University, respectively, to Corrie Morreau (FMNH) for access to her microscope for photography of specimens, to Michael Turner (ANU) for CT scanning work, to Cristian Beza-Beza (University of Memphis) for help with UV photography and to Adam Ślipiński, Yu-Lingzi Zhou and Zhenua Liu (ANIC) for stimulating discussions about the beetle fauna preserved in Burmese amber.

Conflicts of Interest: The authors declare no conflict of interest.

Appendix A Checklist and Classification of Burmese Amber Weevils

Family Nemonychidae

Subfamily Rhinorhynchinae

Genus Burmonyx Davis \& Engel, 2014

Burmonyx zigrasi Davis \& Engel, 2014

GenusGenus Guillermorhinus Clarke \& Oberprieler, gen. n. Guillermorhinus longitarsis Clarke \& Oberprieler, sp. n.

Genus Burmomacer Legalov, 2018

Burmomacer kirejtshuki Legalov, 2018

Family Mesophyletidae stat. $\mathbf{n}$.

Subfamily Aepyceratinae 
Genus Aepyceratus Poinar, Brown \& Legalov, 2017 Aepyceratus hyperochus Poinar, Brown \& Legalov, 2017

Genus Platychirus Clarke \& Oberprieler, gen. n. Platychirus beloides Clarke \& Oberprieler, sp. n.

Genus Rhynchitomimus Clarke \& Oberprieler, gen. n. Rhynchitomimus chalybeus Clarke \& Oberprieler, sp. n.

Genus Nugatorhinus Clarke \& Oberprieler, gen. $\mathbf{n}$. Nugatorhinus albomaculatus Clarke \& Oberprieler, sp. n. Nugatorhinus chenyangi Clarke \& Oberprieler, sp. n.

Genus Calyptocis Clarke \& Oberprieler, gen. n. Calyptocis brevirostris Clarke \& Oberprieler, sp. n.

Genus Acalyptopygus Clarke \& Oberprieler, gen. n. Acalyptopygus astriatus Clarke \& Oberprieler, sp. n. Acalyptopygus brevicornis Clarke \& Oberprieler, sp. n. Acalyptopygus elongatus Clarke \& Oberprieler, sp. n. Acalyptopygus lingziae Clarke \& Oberprieler, sp. n.

\section{Subfamily Mesophyletinae}

Genus Cetionyx Clarke \& Oberprieler, gen. $\mathbf{n}$. Cetionyx batiatus Clarke \& Oberprieler, sp. $\mathrm{n}$. Cetionyx terebrans Clarke \& Oberprieler, sp. $\mathrm{n}$. Cetionyx ursinus Clarke \& Oberprieler, sp. n.

Genus Burmocorynus Legalov, 2018

Burmocorynus jarzembowskii Legalov, 2018 Burmocorynus longus Clarke \& Oberprieler, sp. n.

Genus Petalotarsus Clarke \& Oberprieler, gen. $\mathbf{n}$. Petalotarsus curculionoides Clarke \& Oberprieler, sp. n. Petalotarsus cylindricus Clarke \& Oberprieler, sp. n. Petalotarsus oxycorynoides Clarke \& Oberprieler, sp. n. Petalotarsus sp.

Genus Opeatorhynchus Clarke \& Oberprieler, gen. n. Opeatorhynchus comans Clarke \& Oberprieler, sp. n.

Genus Echogomphus Clarke \& Oberprieler, gen. $\mathbf{n}$.

Echogomphus viridescens Clarke \& Oberprieler, sp. n.

Genus Cyrtocis Clarke \& Oberprieler, gen. $\mathbf{n}$.

Cyrtocis gibbus Clarke \& Oberprieler, sp. n.

Genus Ocriocis Clarke \& Oberprieler, gen. n.

Ocriocis binodosus Clarke \& Oberprieler, sp. n.

Genus Electrocis Clarke \& Oberprieler, gen. n.

Electrocis dentitibialis Clarke \& Oberprieler, sp. n.

Genus Debbia Clarke \& Oberprieler, gen. n.

Debbia gracilirostris Clarke \& Oberprieler, sp. n.

Genus Burmorhinus Legalov, 2018

Burmorhinus georgei Legalov, 2018

Burmorhinus setosus Clarke \& Oberprieler, sp. n. 
Genus Rhadinomycter Clarke \& Oberprieler, gen. $\mathbf{n}$.

Rhadinomycter perplexus Clarke \& Oberprieler, sp. n.

Genus Gnomus Clarke \& Oberprieler, gen. n.

Gnomus brevis Clarke \& Oberprieler, sp. n.

Gnomus sp.

Gnomus spinipes Clarke \& Oberprieler, sp. n.

Genus Hukawngius Clarke \& Oberprieler, gen. $\mathbf{n}$.

Hukawngius crassipes Clarke \& Oberprieler, sp. $\mathrm{n}$.

Genus Mekorhamphus Poinar, Brown \& Legalov, 2016

Mekorhamphus beatae Clarke \& Oberprieler, sp. $\mathrm{n}$.

Mekorhamphus gracilipes Clarke \& Oberprieler, sp. n.

Mekorhamphus gyralommus Poinar, Brown \& Legalov, 2016

Mekorhamphus poinari Clarke \& Oberprieler, sp. n.

Mekorhamphus tenuicornis Clarke \& Oberprieler, sp. n.

Mekorhamphus sp.

Genus Compsopsarus Clarke \& Oberprieler, gen. $\mathbf{n}$.

Compsopsarus reneae Clarke \& Oberprieler, sp. n.

Compsopsarus sp.

Genus Myanmarus Clarke \& Oberprieler, gen. $\mathbf{n}$.

Myanmarus caviventris Clarke \& Oberprieler, sp. n.

Myanmarus dentifer Clarke \& Oberprieler, sp. n.

Myanmarus diversiunguis Clarke \& Oberprieler, sp. n.

Myanmarus robustus Clarke \& Oberprieler, sp. n.

Genus Mesophyletis Poinar, 2006

Mesophyletis calhouni Poinar, 2006

Genus Euryepomus Clarke \& Oberprieler, gen. n.

Euryepomus lophomerus Clarke \& Oberprieler, sp. n.

Genus Periosocerus Clarke \& Oberprieler, gen. n.

Periosocerus crenulatus Clarke \& Oberprieler, sp. n.

Periosocerus deplanatus Clarke \& Oberprieler, sp. n.

Genus Habropezus Poinar, Brown \& Legalov, 2016

Habropezus incoxatirostris Clarke \& Oberprieler, sp. n.

Habropezus kimpulleni Clarke \& Oberprieler, sp. n.

Habropezus plaisiommus Poinar, Brown \& Legalov, 2016

Habropezus tenuicornis Clarke \& Oberprieler, sp. n.

Genus Leptopezus Clarke \& Oberprieler, gen. n.

Leptopezus barbatus Clarke \& Oberprieler, sp. n.

Leptopezus rastellipes Clarke \& Oberprieler, sp. n.

Genus Anchineus Poinar \& Brown, 2009

Anchineus dolichobothris Poinar \& Brown, 2009

Genus Bowangius Clarke \& Oberprieler, gen. n.

Bowangius cyclops Clarke \& Oberprieler, sp. $\mathrm{n}$.

Bowangius glabratus Clarke \& Oberprieler, sp. n.

Bowangius tanaops Clarke \& Oberprieler, sp. $\mathrm{n}$.

Bowangius zhenuai Clarke \& Oberprieler, sp. n. 
Bowangius sp. 1
Bowangius sp. 2
Bowangius sp. 3
Bowangius sp. 4

Genus Louwiocis Clarke \& Oberprieler, gen. $\mathbf{n}$.

Louwiocis megalops Clarke \& Oberprieler, sp. n.

Genus Elwoodius Clarke \& Oberprieler, gen. n.

Elwoodius conicops Clarke \& Oberprieler, sp. n.

Genus Aphelonyssus Clarke \& Oberprieler, gen. $\mathbf{n}$.

Aphelonyssus latus Clarke \& Oberprieler, sp. $\mathrm{n}$.

Incertae sedis

Genus Palaeocryptorhynchus Poinar, 2009

Palaeocryptorhynchus burmanus Poinar, 2009

Genus and species incertae sedis

Taxa excluded from Curculionoidea or from Burmese amber

Genus Palaeotylus Poinar, Vega \& Legalov, 2018

Palaeotylus femoralis Poinar, Vega \& Legalov, 2018

Genus Microborus Blandford, 1897

Microborus inertus Cognato \& Grimaldi, 2009

\section{References}

1. Kuschel, G. A phylogenetic classification of Curculionoidea to families and subfamilies. Mem. Entomol. Soc. Wash. 1995, 14, 5-33.

2. Oberprieler, R.G.; Marvaldi, A.E.; Anderson, R.S. Weevils, weevils, weevils everywhere. Zootaxa 2007, 1668, 491-520.

3. Holloway, B.A. Anthribidae (Insecta: Coleoptera). Fauna N. Z. 1982, 3, 1-264.

4. Zimmerman, E.C. Australian Weevils (Coleoptera: Curculionoidea). Vol. 1. Orthoceri. Anthribidae to Attelabidae. The Primitive Weevils; CSIRO: Melbourne, Australia, 1994.

5. Marvaldi, A.E.; Sequeira, A.S.; O'Brien, C.W.; Farrell, B.D. Molecular and morphological phylogenetics of weevils (Coleoptera, Curculionoidea): do niche shifts accompany diversification? Syst. Biol. 2002, 51, 761-785. [CrossRef] [PubMed]

6. Shin, S.; Clarke, D.J.; Lemmon, A.R.; Moriarty-Lemmon, E.; Aitken, A.L.; Haddad, S.; Farrell, B.D.; Marvaldi, A.E.; Oberprieler, R.G.; McKenna, D.D. Phylogenomic data yield new and robust insights into the phylogeny and evolution of weevils. Mol. Biol. Evol. 2017, 35, 823-836. [CrossRef] [PubMed]

7. Anderson, R.S. Weevils and plants: phylogenetic versus ecological mediation of evolution of host plant associations in Curculionidae (Curculioninae). Mem. Entomol. Soc. Can. 1993, 165, 197-232. [CrossRef]

8. Thompson, R.T. Observations on the morphology and classification of weevils (Coleoptera: Curculionoidea) with a key to the major groups. J. Nat. Hist. 1992, 26, 835-891. [CrossRef]

9. Alonso-Zarazaga, M.A.; Lyal, C.H.C. A World Catalogue of Families and Genera of Curculionoidea (Insecta: Coleoptera) (excepting Scolytidae and Platypodidae); Entomopraxis: Barcelona, Spain, 1999; 315p, ISBN 84-605-9994-9.

10. Alonso-Zarazaga, M.A.; Lyal, C.H.C. A catalogue of family and genus group names in Scolytinae and Platypodinae with nomenclatural remarks (Coleoptera: Curculionidae). Zootaxa 2009, 2258, 1-134.

11. Bouchard, P.; Bousquet, Y.; Davies, A.E.; Alonso-Zarazaga, M.A.; Lawrence, J.F.; Lyal, C.H.C.; Newton, A.F.; Reid, C.A.M.; Schmitt, M.; Ślipiński, S.A.; Smith, A.B.T. Family-group names in Coleoptera (Insecta). ZooKeys 2011, 88, 1-972. [CrossRef]

12. Marvaldi, A.E.; Morrone, J.J. Phylogenetic systematics of weevils (Coleoptera: Curculionoidea): a reappraisal based on larval and adult morphology. Insect Syst. Evol. 2000, 31, 43-58. 
13. McKenna, D.M.; Sequeira, A.S.; Marvaldi, A.E.; Farrell, B.D. Temporal lags and overlap in the diversification of weevils and flowering plants. Proc. Nat. Acad. Sci. USA 2009, 106, 7083-7088. [CrossRef] [PubMed]

14. Gunter, N.L.; Oberprieler, R.G.; Cameron, S.L. Molecular phylogenetics of Australian weevils (Coleoptera: Curculionoidea): exploring relationships in a hyperdiverse lineage through comparison of independent analyses. Aust. Entomol. 2016, 55, 217-233. [CrossRef]

15. McKenna, D.D. Temporal lags and overlap in the diversification of weevils and flowering plants: recent advances and prospects for additional resolution. Am. Entomol. 2011, 57, 54-55. [CrossRef]

16. Oberprieler, R.G.; Anderson, R.S.; Marvaldi, A.E. 3 Curculionoidea Latreille, 1820: Introduction, Phylogeny. In Handbook of Zoology. Arthropoda: Insecta. Coleoptera, Beetles. Volume 3: Morphology and Systematics (Phytophaga); Leschen, R.A.B., Beutel, R.G., Eds.; Walter de Gruyter: Berlin, Germany; Boston, MA, USA, 2014; pp. 285-300.

17. Franz, N.M.; Engel, M.S. Can higher-level phylogenies of weevils explain their evolutionary success? A critical review. Syst. Entomol. 2010, 35, 597-606. [CrossRef]

18. Johnson, A.J.; McKenna, D.D.; Jordal, B.H.; Cognato, A.I.; Smith, S.M.; Lemmon, A.R.; Lemmon, E.L.M.; Hulcr, J. Phylogenomics clarifies repeated evolutionary origins of inbreeding and fungus farming in bark beetles (Curculionidae, Scolytinae). Mol. Phylogenet. Evol. 2018, 127, 229-238. [CrossRef] [PubMed]

19. McKenna, D.D.; Clarke, D.J.; Anderson, R.; Astrin, J.J.; Brown, S.; Chamorro, L.; Davis, S.R.; de Medeiros, B.; del Rio, M.G.; Haran, J.; et al. Morphological and molecular perspectives on the phylogeny, evolution and classification of weevils (Coleoptera: Curculionoidea): Proceedings from the 2016 International Weevil Meeting. Diversity 2018, 10, 64. [CrossRef]

20. Shi, G.; Grimaldi, D.A.; Harlow, G.E.; Wang, J.; Wang, J.; Yang, M.; Lei, W.; Li, Q.; Li, X. Age constraint on Burmese amber based on U-Pb dating of zircons. Cretac. Res. 2012, 37, 155-163. [CrossRef]

21. Chhibber, H.L. The Mineral Resources of Burma; Macmillan \& Co.: London, UK, 1934; 320p.

22. Sun, T.T.; Kleismantas, A.; Nyunt, T.T.; Zheng, M.R.; Krishnaswamy, M.; Ying, L.H. Burmese amber from Hti Lin. J. Gemmol. 2015, 34, 606-615. [CrossRef]

23. Ross, A.J.; York, P.V. A list of types and figured specimens of insects and other inclusions in Burmese amber. Bull. Nat. Hist. Mus. Geol. 2000, 56, 11-20.

24. Grimaldi, D.A.; Engel, M.S.; Nascimbene, P.C. Fossiliferous Cretaceous amber from Myanmar (Burma): Its rediscovery, biotic diversity, and paleontological significance. Am. Mus. Novit. 2002, 3361, 1-71. [CrossRef]

25. Zhang, W. Frozen Dimensions. The Fossil Insects and Other Invertebrates in Amber; Chongqin University Press: Chongqin, China, 2017; 698p.

26. Ross, A.J. Burmese (Myanmar) Amber Taxa, On-Line Checklist v. 2018.2. 2018. Available online: http:/ / www. nms.ac.uk/explore/stories/natural-world/burmese-amber (accessed on 3 November 2018).

27. Ross, A.; Mellish, C.; York, P.; Crighton, B. Chapter 12. Burmese Amber. In Biodiversity of Fossils in Amber from the Major World Deposits; Penney, D., Ed.; Siri Scientific Press: Castleton, UK, 2010; pp. 208-235.

28. Cockerell, T.D.A. Arthropods in Burmese amber. Am. J. Sci. 1917, 44, 360-368. [CrossRef]

29. Poinar, G., Jr. Mesophyletis calhouni (Mesophyletinae), a new genus, species and subfamily of Early Cretaceous weevils (Coleoptera: Curculionoidea: Eccoptarthridae) in Burmese amber. Proc. Entomol. Soc. Wash. 2006, 108, 878-884.

30. McKenna, D.D.; Wild, A.L.; Kanda, K.; Bellamy, C.L.; Beutel, R.G.; Caterino, M.S.; Farnum, C.W.; Hawks, D.C.; Ivie, M.A.; Jameson, M.L.; et al. The beetle tree of life reveals that Coleoptera survived end-Permian mass extinction to diversify during the Cretaceous terrestrial revolution. Syst. Entomol. 2015, 40, 835-880. [CrossRef]

31. Jordal, B.H.; Cognato, A.I. Molecular phylogeny of bark and ambrosia beetles reveals multiple origins of fungus farming during periods of global warming. BMC Evol. Biol. 2012, 12, 1-10. [CrossRef] [PubMed]

32. Gohli, J.; Kirkendall, L.R.; Smith, S.M.; Cognato, A.I.; Hulcr, J.; Jordal, B.H. Biological factors contributing to bark and ambrosia beetle species diversification. Evolution 2017, 71, 1258-1272. [CrossRef] [PubMed]

33. Xing, L.; McKellar, R.C.; Xu, X.; Li, G.; Bai, M.; Persons, W.S.; Miyashita, T.; Benton, M.J.; Zhang, J.; Wolfe, A.P.; et al. A feathered dinosaur tail with primitive plumage trapped in mid-Cretaceous amber. Curr. Biol. 2016, 26, 3352-3360. [CrossRef] [PubMed]

34. Xing, L.; Sames, B.; McKellar, R.C.; Xi, D.; Bai, M.; \& Wan, X. A gigantic marine ostracod (Crustacea: Myodocopa) trapped in mid-Cretaceous Burmese amber. Sci. Rep. 2018, 8, 1365. [CrossRef] 
35. Bisulca, C.; Nascimbene, P.C.; Elkin, L.; Grimaldi, D.A. Variation in the deterioration of fossil resins and implications for the conservation of fossils in amber. Am. Mus. Novit. 2012, 3734, 1-19. [CrossRef]

36. Nascimbene, P.; Silverstein, H. The preparation of fragile Cretaceous ambers for conservation and study of organismal inclusions. In Studies on Fossils in Amber, with Particular Reference to the Cretaceous of New Jersey; Grimaldi, D., Ed.; Backhuis Publishers: Leiden, The Netherlands, 2000; pp. 93-102.

37. Azar, D.; Perrichot, V.; Néraudeau, D.; Nel, A. New psychodids from the Cretaceous ambers of Lebanon and France, with a discussion of Eophlebotomus connectens Cockerell, 1920 (Diptera, Psychodidae). Ann. Entomol. Soc. Am. 2003, 96, 117-126. [CrossRef]

38. Limaye, A. Drishti: a volume exploration and presentation tool. In Developments in X-Ray Tomography VIII; Stock, S.R., Ed.; SPIE: Bellingham, WA, USA, 2012; Volume 8506. [CrossRef]

39. Oberprieler, R.G. 3.7.1 Brachycerinae Billberg, 1820. In Handbook of Zoology. Arthropoda: Insecta. Coleoptera, Beetles. Volume 3: Morphology and Systematics (Phytophaga); Leschen, R.A.B., Beutel, R.G., Eds.; Walter de Gruyter: Berlin, Germany; Boston, MA, USA, 2014; pp. 424-451.

40. Riedel, A.; dos Santos Rolo, T.; Cecilia, A.; van de Kamp, T. Sayrevilleinae Legalov, a newly recognised subfamily of fossil weevils (Coleoptera, Curculionoidea, Attelabidae) and the use of synchrotron microtomography to examine inclusions in amber. Zool. J. Linn. Soc. 2012, 165, 773-794. [CrossRef]

41. Oberprieler, R.G.; Thompson, R.T.; Peterson, M. Darwin's forgotten weevil. Zootaxa 2010, 2675, $33-46$.

42. Kuschel, G. Nemonychidae of Australia, New Guinea and New Caledonia. In Australian Weevils (Coleoptera: Curculionoidea). Vol. 1. Orthoceri: Anthribidae to Attelabidae: The Primitive Weevils; Zimmerman, E.C., Ed.; CSIRO: Melbourne, Australia, 1994; pp. 563-637.

43. Oberprieler, R.G.; Scholtz, C.H. The genus Urodontidius Louw (Anthribidae: Urodontinae) rediscovered and its biological secrets revealed: a tribute to Schalk Louw. Diversity 2018, 10, 92. [CrossRef]

44. Anderson, R.S.; Oberprieler, R.G.; Marvaldi, A.E. 3.1 Nemonychidae Bedel, 1882. In Handbook of Zoology. Arthropoda: Insecta. Coleoptera, Beetles. Volume 3: Morphology and Systematics (Phytophaga); Leschen, R.A.B., Beutel, R.G., Eds.; Walter de Gruyter: Berlin, Germany; Boston, MA, USA, 2014; pp. 301-309.

45. Kuschel, G.; Leschen, R. Phylogeny and taxonomy of the Rhinorhynchinae (Coleoptera: Nemonychidae). Invertebr. Syst. 2011, 24, 573-615.

46. Legalov, A.A. Two new weevil tribes (Coleoptera: Curculionidae) from Burmese amber. Hist. Biol. 2018. [CrossRef]

47. Legalov, A.A.; Azar, D.; Kirejtshuk, A.G. A new weevil (Coleoptera; Nemonychidae; Oropsini trib. nov.) from Lower Cretaceous Lebanese amber. Cretac. Res. 2017, 70, 111-116. [CrossRef]

48. Peris, D.; Davis, S.R.; Engel, M.S.; Delclòs, X. An evolutionary history embedded in amber: Reflection of the Mesozoic shift in weevil-dominated (Coleoptera: Curculionoidea) faunas. Zool. J. Linn. Soc. 2014, 171, 534-553. [CrossRef]

49. Davis, S.R.; Engel, M.S. A new nemonychid weevil from Burmese amber (Coleoptera: Curculionoidea). ZooKeys 2014, 405, 127-138. [CrossRef]

50. Poinar, G., Jr. Type genus for Mesophyletinae, a subfamily of Early Cretaceous weevils (Coleoptera: Curculionoidea: Eccoptarthridae) in Burmese amber. Proc. Entomol. Soc. Wash. 2008, 110, 262. [CrossRef]

51. Poinar, G.O., Jr.; Bown, A.E.; Legalov, A.A. A new weevil. Aepyceratus hyperochus gen. et sp. nov., Aepyceratinae subfam. nov., (Coleoptera: Nemonychidae) in Burmese amber. Cretac. Res. 2017, 77, 75-78. [CrossRef]

52. Riedel, A. 3.4 Attelabidae Billberg, 1820. In Handbook of Zoology. Arthropoda: Insecta. Coleoptera, Beetles. Volume 3: Morphology and Systematics (Phytophaga); Leschen, R.A.B., Beutel, R.G., Eds.; Walter de Gruyter: Berlin, Germany; Boston, MA, USA, 2014; pp. 328-355.

53. Legalov, A.A.; Poinar, G., Jr. New tribes of the superfamily Curculionoidea (Coleoptera) in Burmese amber. Hist. Biol. 2015, 27, 558-564. [CrossRef]

54. Poinar, G.O., Jr.; Bown, A.E.; Legalov, A.A. A new weevil tribe, Mekorhamphini trib. nov. (Coleoptera, Ithyceridae) with two new genera in Burmese amber. Ukrainian J. Ecol. 2016, 6, 157-164. [CrossRef]

55. Xia, F.; Yang, G.; Zhang, Q.; Shi, G.; Wang, B. Burmese Amber: Lives through Time and Space; Science Press: Beijing, China, 2015; 197p.

56. Legalov, A.A. A new weevil, Burmorhinus georgei gen. et sp. nov. (Coleoptera; Curculionidae) from the Cretaceous Burmese amber. Cretac. Res. 2018, 84, 13-17. [CrossRef] 
57. Oberprieler, R.G. 3.7 Curculionidae Latreille, 1802. In Handbook of Zoology. Arthropoda: Insecta. Coleoptera, Beetles. Volume 3: Morphology and Systematics (Phytophaga); Leschen, R.A.B., Beutel, R.G., Eds.; Walter de Gruyter: Berlin, Germany; Boston, MA, USA, 2014; pp. 423-424.

58. Pullen, K.R.; Jennings, D.; Oberprieler, R.G. Annotated catalogue of Australian weevils (Coleoptera: Curculionoidea). Zootaxa Monogr. 2014, 1-481.

59. Poinar, G., Jr.; Bown, A.E. Anchineus dolichobothris, a new genus, species and family of Early Cretaceous weevils (Curculionidae: Coleoptera) in Burmese amber. Proc. Entomol. Soc. Wash. 2009, 111, 263-270. [CrossRef]

60. Poinar, G., Jr. Palaeocryptorhynchus burmanus, a new genus and species of Early Cretaceous weevils (Coleoptera: Curculionidae) in Burmese amber. Cretac. Res. 2009, 30, 587-591. [CrossRef]

61. Legalov, A.A. Checklist of Mesozoic Curculionoidea (Coleoptera) with description of new taxa. Balt. J. Coleopterol. 2010, 10, 71-101.

62. Poinar, G.O., Jr.; Vega, F.E.; Legalov, A.A. New subfamily of ambrosia beetles (Coleoptera: Platypodidae) from mid-Cretaceous Burmese amber. Hist. Biol. 2018, 1-6. [CrossRef]

63. Jordal, B.H. Molecular phylogeny and biogeography of the weevil subfamily Platypodinae reveals evolutionarily conserved range patterns. Mol. Phylogenet. Evol. 2015, 92, 294-307. [CrossRef] [PubMed]

64. Legalov, A.A. New auger beetle (Coleoptera; Bostrichidae) from mid-Cretaceous Burmese amber. Cretac. Res. 2018, 92, 210-213. [CrossRef]

65. Blandford, W.F.H. Insecta. Coleoptera. Rhynchophora. Scolytidae. [Cont.]. Biol. Centrali-Am. 1897, 4, 169-176.

66. Jordal, B. Ancient diversity of Afrotropical Microborus: three endemic species-not one widespread. ZooKeys 2017, 710, 33-42. [CrossRef] [PubMed]

67. Cognato, A.I.; Grimaldi, D. 100 million years of morphological conservation in bark beetles (Coleoptera: Curculionidae: Scolytinae). Syst. Entomol. 2009, 34, 93-100. [CrossRef]

68. Hoffeins, C. On Baltic amber inclusions treated in an autoclave. Polish J. Entomol. 2012, 81, 165-183. [CrossRef]

69. Weitschat, W.; Wichard, W. Atlas of Plants and Animals in Baltic Amber; Verlag Dr. Friedrich Pfeil: München, Germany, 2002; 256p.

70. Poinar, G., Jr.; Lambert, J.B.; Wu, Y. Araucarian source of fossiliferous Burmese amber: spectroscopic and anatomical evidence. J. Bot. Res. Inst. Tex. 2007, 1, 449-455.

71. Zherikhin, V.V.; Ross, A.J. A review of the history, geology and age of Burmese amber (Burmite). Bull. Nat. Hist. Mus. Geol. 2000, 56, 3-10.

72. Poinar, G.O., Jr. Programinis burmitis gen. et sp. nov. and P. laminatus sp. nov., Early Cretaceous grass-like monocots in Burmese amber. Aust. Syst. Bot. 2004, 17, 497-504. [CrossRef]

73. Poinar, G.O., Jr.; Buckley, R.; Chen, H. A primitive mid-Cretaceous angiosperm flower, Antiquifloris latifibris gen. \& sp. nov., in Myanmar amber. J. Bot. Res. Inst. Tex. 2016, 10, 155-162.

74. Crepet, W.L.; Nixon, K.C.; Grimaldi, D.; Riccio, M. A mosaic Lauralean flower from the Early Cretaceous of Myanmar. Am. J. Bot. 2016, 103, 290-297. [CrossRef]

75. Poinar, G.O., Jr.; Chambers, K.L. Palaeoanthella huangii gen. and sp. nov., an Early Cretaceous flower (Angiospermae) in Burmese amber. SIDA Contrib. Bot. 2005, 21, 2087-2092.

76. Poinar, G.O., Jr. A mid-Cretaceous Lauraceae flower, Cascolaurus burmitis gen. et sp. nov., in Myanmar amber. Cretac. Res. 2017, 71, 96-101. [CrossRef]

77. The Angiosperm Phylogeny Group. An update of the Angiosperm Phylogeny Group classification for the orders and families of flowering plants: APG IV. Bot. J. Linn. Soc. 2016, 181, 1-20. [CrossRef]

78. Poinar, G.O., Jr.; Chambers, K.L.; Wunderlich, J. Micropetasos, a new genus of Angiosperms from mid-Cretaceous Burmese amber. J. Bot. Res. Inst. Tex. 2013, 7, 745-750.

79. Poinar, G.O., Jr.; Chambers, K.; Buckley, R. An Early Cretaceous angiosperm fossil of possible significance in rosid floral diversification. J. Bot. Res. Inst. Tex. 2008, 2, 1183-1192.

80. Chambers, K.L.; Poinar, G.O., Jr.; Buckley, R.T. Tropidogyne, a new genus of Early Cretaceous eudicots (Angiospermae) from Burmese amber. Novon 2010, 20, 23-29. [CrossRef]

81. Poinar, G.O., Jr.; Chambers, K.L. Tropidogyne pentaptera, sp. nov., a new mid-Cretaceous fossil angiosperm flower in Burmese amber. Palaeodiversity 2017, 10, 135-140. [CrossRef]

82. Poinar, G.O., Jr.; Chambers, K.L.; Buckley, R. Eoëpigynia burmensis gen. and sp. nov., an Early Cretaceous eudicot flower (Angiospermae) in Burmese amber. J. Bot. Res. Inst. Tex. 2007, 1, 91-96. 
83. Poinar, G.O., Jr.; Chambers, K.L. Endobeuthos paleosum gen. et sp. nov., fossil flowers of uncertain affinity from mid-Cretaceous Myanmar amber. J. Bot. Res. Inst. Tex. 2018, 12, 133-139.

84. Poinar, G., Jr. Silica bodies in the Early Cretaceous Programinis laminatus (Angiospermae: Poales). Palaeodiversity 2011, 4, 1-6.

85. Caldara, R.; Franz, N.M.; Oberprieler, R.G. 3.7.10 Curculioninae Latreille, 1802. In Handbook of Zoology. Arthropoda: Insecta. Coleoptera, Beetles. Volume 3: Morphology and Systematics (Phytophaga); Leschen, R.A.B., Beutel, R.G., Eds.; Walter de Gruyter: Berlin, Germany; Boston, MA, USA, 2014; pp. 589-628.

86. Poinar, G.O., Jr. Burmese amber: evidence of Gondwanan origin and Cretaceous dispersion. Hist. Biol. 2018. [CrossRef]

87. Metcalf, I. Gondwana dispersion and Asian accretion: tectonic and palaeogeographic evolution of eastern Tethys. J. Asian Earth Sci. 2013, 66, 1-33. [CrossRef]

88. Metcalfe, I. Tectonic evolution of Sundaland. Bull. Geol. Soc. Malaysia 2017, 63, 27-60.

89. Sevastjanova, I.; Hall, R.; Rittner, M.; Paw, S.M.T.L.; Naing, T.T.; Alderton, D.H.; Comfort, D. Myanmar and Asia united, Australia left behind long ago. Gondwana Res. 2016, 32, 24-40. [CrossRef]

90. Oberprieler, R.G.; Oberprieler, S.K. Talbragarus averyi gen. et sp. n., the first Jurassic weevil from the southern hemisphere (Coleoptera: Curculionoidea: Nemonychidae). Zootaxa 2012, 3478, 256-266.

91. Stockey, R.A. Mesozoic Araucariaceae: morphology and systematic relationships. J. Plant Res. 1994, 107, 493-502. [CrossRef]

92. Kershaw, P.; Wagstaff, B. The southern conifer family Araucariaceae: history, status and value for paleoenvironmental reconstruction. Annu. Rev. Ecol. Syst. 2001, 32, 397-414. [CrossRef]

93. Sequeira, A.S.; Farrell, B.D. Evolutionary origins of Gondwanan interactions: how old are Araucaria beetle herbivores? Biol. J. Linn. Soc. 2001, 74, 459-474. [CrossRef]

94. Dutta, S.; Mallick, M.; Kumar, K.; Mann, U.; Greenwood, P.F. Terpenoid composition and botanical affinity of Cretaceous resins from India and Myanmar. Int. J. Coal Geol. 2011, 85, 49-55. [CrossRef]

95. Kuschel, G. Curculionoidea (weevils) of New Caledonia and Vanuatu: basal families and some Curculionidae. In Zoologia Neocaledonica 6. Biodiversity Studies in New Caledonia; Grandcolas, P., Ed.; Mémoires du Muséum National d'Histoire Naturelle: Paris, France, 2008; Volume 197, pp. 99-249.

96. Magallón, S.; Gómez-Acevedo, S.; Sánchez-Reyes, L.L.; Hernández-Hernández, T. A metacalibrated time-tree documents the early rise of flowering plant phylogenetic diversity. New Phytol. 2015, 207, 437-453. [CrossRef]

97. Parham, J.F.; Donoghue, P.C.J.; Bell, C.J.; Calway, T.D.; Head, J.J.; Holroyd, P.A.; Inoue, J.G.; Irmis, R.B.; Joyce, W.G.; Ksepka, D.T.; et al. Best practices for justifying fossil calibrations. Syst. Biol. 2012, 61, 346-359. [CrossRef] [PubMed]

(C) 2018 by the authors. Licensee MDPI, Basel, Switzerland. This article is an open access article distributed under the terms and conditions of the Creative Commons Attribution (CC BY) license (http:/ / creativecommons.org/licenses/by/4.0/). 